

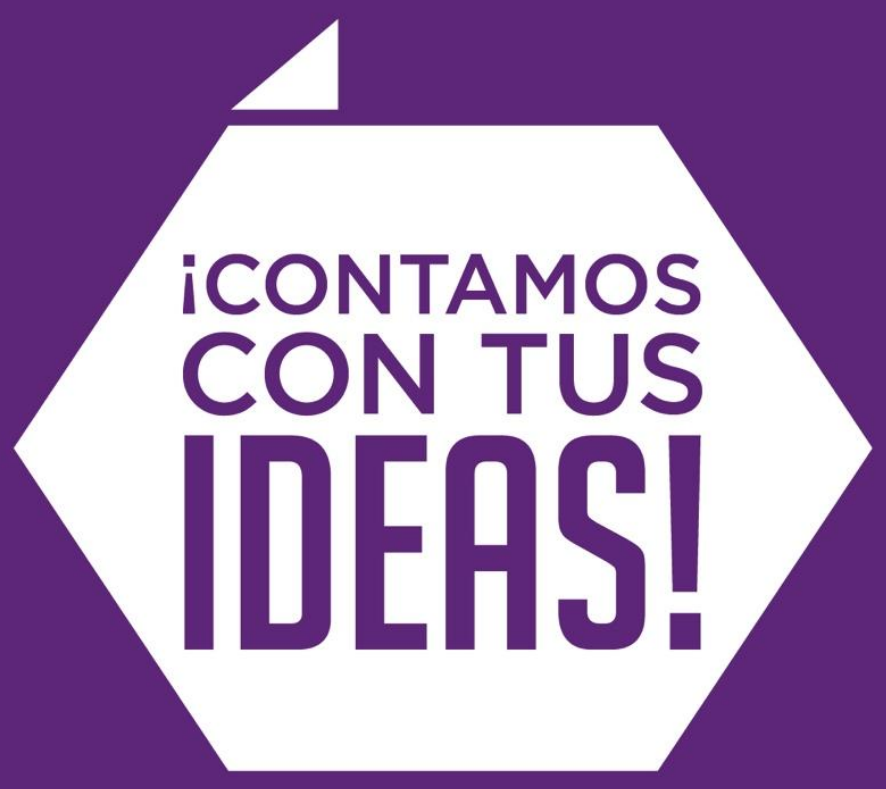

Estamos construyendo

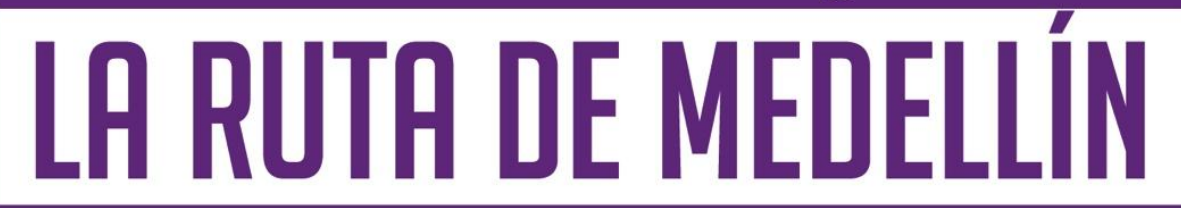

Plan de Desarrollo Medellín cuenta con vos 2016-2019

\section{FEDERICO GUTIÉRREZ}

Alcalde de Medellín

Documento final anteproyecto

Febrero 29 de 2016

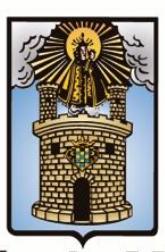

Alcaldía de Medellín cuenta con vos 


\section{• CONGLOMERADO PÚBLICO DE MEDELLÍN •}

\section{GABINETE MUNICIPAL 2016 - 2019}

\section{FEDERICO GUTIÉRREZ ZULUAGA}

Alcalde de Medellín

MARGARITA MARÍA GÓMEZ MARÍN

Primera Dama

\author{
LUIS SANTIAGO GÓMEZ BARRERA \\ Secretario de Gobierno y Gestión del \\ Gabinete
}

\section{FELIPE VÉLEZ ROA}

Director Administrativo de Planeación

MANUEL VILLA MEJÍA

Secretario Privado

GUSTAVO ALBERTO VILLEGAS RESTREPO

Secretario de Seguridad

VERÓNICA DE VIVERO ACEVEDO

Secretaria General

ORLANDO DE JESÚS URIBE VILLA

Secretario de Hacienda

MARÍA FERNANDA GALEANO ROJO

Secretaria de Desarrollo Económico

NATALIA ANDREA RAMÍREZ ÁNGEL

Secretaria de Gestión Humana y Servicio a

la Ciudadanía

JOSÉ NICOLÁS RÍOS CORREA

Secretario de Suministros y Servicios

LUIS GUILLERMO PATIÑO ARISTIZÁBAL

Secretario de Educación

LUZ MARINA LÓPEZ OROZCO

Secretaria de Infraestructura Física
JUAN ESTEBAN MARTÍNEZ RUIZ

Secretario de Movilidad

\section{LUIS BERNARDO VÉLEZ MONTOYA}

Secretario de Inclusión Social, Familia

y Derechos Humanos

\section{ANDRÉS FELIPE BEDOYA RENDÓN}

Secretario de Participación Ciudadana

ÓSCAR GUILLERMO HOYOS GIRALDO

Secretario de Medio Ambiente

CLAUDIA HELENA ARENAS PAJÓN

Secretaria de Salud

AMALIA LONDOÑO DUQUE

Secretaria de Cultura Ciudadana

JUANA BOTERO PIEDRAHITA

Secretaria de Juventud

JOHN JAIRO VELÁSQUEZ BEDOYA

Secretario de Evaluación y Control

\section{GLORIA LUZ GÓMEZ OCHOA}

Secretaria de las Mujeres

JOSÉ NICOLÁS DUQUE OSSA

Secretario de Gestión y Control

Territorial

ISOLDA MARÍA VÉLEZ HOLGUÍN

Secretaria de Comunicaciones

CAMILO ZAPATA WILLS

Director de Gestión del Riesgo de

Desastres 
ANDREA GONZÁLEZ OSPINA

Gerente de Corregimientos
PILAR VELILLA MORENO

Gerente del Centro

\section{ENTE DESCENTRALIZADO ADSCRITO}

DAVID MORA GÓMEZ

Director INDER

MIGUEL SILVA MOYANO

Director Agencia de Educación Superior

de Medellín - SAPIENCIA

MARÍA VICTORIA MEJÍA

Rectora Instituto Tecnológico

Metropolitano - ITM

MAURICIO MORALES SALDARRIAGA

Rector Instituto Tecnológico Pascual

Bravo Institución Universitaria

BERNARDO ARTEAGA VELÁSQUEZ

Rector Colegio Mayor de Antioquia

HUMBERTO IGLESIAS GÓMEZ

Director General Instituto Social de

Vivienda y Hábitat de Medellín - ISVIMED

JESÚS ALBERTO SÁNCHEZ RESTREPO

Director Aeropuerto Olaya Herrera
LEOPOLDO GIRALDO VELÁSQUEZ

Gerente Hospital General

GLORIA INÉS PALOMINO

Directora Biblioteca Pública Piloto

MARTHA CECILIA CASTRILLÓN SUÁREZ

Directora de ESE Metrosalud

\section{JAIME BERMÚDEZ MESA}

Agencia para la Gestión del Paisaje, el Patrimonio y las Alianzas Publico

Privadas - APP

ADRIANA VALDERRAMA LÓPEZ

Directora Museo Casa de la Memoria

FABIO ANDRÉS GARCIA TRUJILLO

Administrador del Patrimonio

Escindido de Empresas Varias de

Medellín APEV

\section{ENTE DESCENTRALIZADO VINCULADO}

JORGE LONDOÑO DE LA CUESTA

Gerente Empresas Públicas de Medellín

WILLIAM DARÍO ÁLZATE FRANCO

Gerente de Metroparques

CLAUDIA PATRICIA RESTREPO MONTOYA

Gerente Metro de Medellín
OVIDIO ANTONIO BUITRAGO SIERRA

Gerente Terminales de Transporte

RICARDO MEDINA GIRALDO

Gerente Metroplus 
CÉSAR AUGUSTO HERNÁNDEZ CORREA

Gerente Empresa de Desarrollo Urbano

DAVID VIEIRA MEJÍA

Gerente Empresa de Seguridad Urbana
JUAN DAVID PÉREZ ORTIZ

Gerente Plaza Mayor Medellín

Convenciones y Exposiciones

CARLOS MARIO RAMÍREZ RAMÍREZ

Gerente de Savia Salud EPS

\section{ENTE DESCENTRALIZADO INDIRECTO}

ANDRÉS FELIPE ROLDÁN GIRALDO

Director Parque Explora

MARIO ALBERTO ZAPATA VANEGAS

Director Ejecutivo Corporación Hospital

Infantil Concejo de Medellín

MARÍA CLAUDIA DE LA OSSA

Directora Corporación Cuenca Verde

BEATRIZ ELENA ARAQUE TOBÓN

Directora Parque Arví

DIANA MILENA ARANGO

Directora Jardín Botánico

SERGIO ARTURO ESCOBAR SOLÓRZANO

Gerente Agencia de Cooperación e

Inversión de Medellín y el Área

Metropolitana
ALEJANDRO FRANCO RESTREPO

Director Corporación Ruta N

CRISTIAN DANIEL CARTAGENA GONZÁLEZ

Gerente de TeleMedellín

ANA MARÍA GALLEGO MARTÍNEZ

Gerente General Fundación Medellín

Convention and Vistors Bureau

MABEL LÓPEZ SEGURA

Gerente de Teleantioquia

ALVARO SIERRA JONES

Director Ferrocarril de Antioquia

MARÍA LILIANA GALLEGO

Directora Créame

DAVID BOCANUMET TRUJILLO

Presidente Fondo de Garantías

\section{ENTIDAD ADMINISTRATIVA}

\section{EUGENIO PRIETO SOTO}

Director Área Metropolitana del Valle de

Aburrá

\section{ENTES DE CONTROL}

GUILLERMO DURÁN URIBE

Personero Municipal de Medellín
PATRICIA BONILLA SANDOVAL

Contralora Municipal de Medellín 


\author{
FELIPE VÉLEZ ROA \\ Director Plan de Desarrollo Municipal \\ Director Departamento Administrativo de Planeación \\ JULIANA MORENO BOTERO \\ Coordinadora General del Plan de Desarrollo Municipal \\ Subdirectora de Planeación Social y Económica
}

EQUIPO PLAN DE DESARROLLO

PILAR DE CONSOLIDACIÓN

Daniela Sánchez Zapata

Juan Alberto Landinez Osorio

Ana María Hernández Maya

Diana Rojas Giraldo

Juan Esteban Rivillas López

Juan Diego Lopera

Rodrigo Toro Londoño

Luz Stella Barco Ruiz

Mauricio Ocampo

TATIANA GARCIA ECHEVERRY

Subdirectora Información y Evaluación

Estratégica

Enrique Tintinago

Juan Carlos Anadon Freiwald

Natalia Muñoz Carmona

Yury Elizabeth Restrepo Bueno

Eddy Patricia Trujillo García

Isabel Cristina Grajales Atehortua

María Camila Mejía Peláez

Charle Augusto Londoño Henao

Giovanny Areiza Madrid

Giovanny Bello Álvarez

Valentina Franco Manchola

Sergio Alberto Zapata Betancur

Jimer Jader Yepes Rojas

Carlota Ramírez García

Nora Elena Jimenez Gómez
CLAUDIA GARCÍA LOBO GUERRERO

Subdirectora de Planeación Territorial

y Estratégica de Ciudad

Dora Patricia Ortiz Gómez

María Victoria Naranjo Jaramillo

Carlos Alberto Bohórquez Gutiérrez

Mario Augusto Flórez Arroyave

Margarita María Ortiz Arroyave

Olga Lucía Balbin Medina

ORLANDO DE JESÚS URIBE VILLA

Secretario de Hacienda

CATALINA NARANJO AGUIRRE

Subsecretaria de Presupuesto y

Gestión Financiera

Claudia Hincapie Gallego

Miriam Gómez Amaya

JAIME BERMUDEZ MESA

Director - Agencia para la gestión del paisaje, el patrimonio y las alianzas

público privadas - APP 


\section{PILAR DE COMUNICACIONES}

Juliana Arizmendi González

Fredy Zuluaga Hoyos

Andrea Lopera Álvarez

Laura Pérez

Juan José Ramírez Muñoz

Laura Durango

ISOLDA MARÍA VÉLEZ HOLGUIN

Secretaria de Comunicaciones

\section{FEDERICO VILLEGAS}

Subsecretario de Comunicación Estratégica

Paula Bustamante Jaramillo
ALEJANDRO FRANCO RESTREPO

Director Ruta N

Paola Pollmeier

Angélica Cervera Aguirre

Andrés Henao Álvarez

\section{PILAR DE PARTICIPACIÓN}

Mary Luz Aguirre

Paula Londoño Hincapie

Diana Marcela Londoño

Soledad Montoya

Zulema Atehortua

Ana Cristina Caro

Claudia Gómez Londoño

Manuela Arboleda

Jasmid Emilse Fernández Sánchez

Mercedes Hoyos Rojas

Juan Fernando Lopera González

MARGARITA GÓMEZ MARÍN

Primera Dama

Carolina Hernández

Laura Escovar

Eliana Uribe
ANDRES BEDOYA RENDÓN

Secretario de Participación Ciudadana

JUANA BOTERO PIEDRAHITA

Secretaria de Juventud

GLORIA LUZ GÓMEZ OCHOA

Secretaria de Mujeres

LUIS GUILLERMO PATIÑO ARISTIZABAL

Secretario de Educación

LUIS BERNARDO VÉLEZ MONTOYA

Secretario de Inclusión Social, Familia y

Derechos Humanos

AMALIA LONDOÑO DUQUE

Secretaria de Cultura Ciudadana

CLAUDIA HELENA ARENAS PAJÓN

Secretaria de Salud 


\section{DIMENSIONES ESTRATÉGICAS}

\section{DIMENSIÓN 1}

Manuel Villa Mejía

Secretario Privado - Articulador

Duber Avendaño Rua

Alba Lucía González Ramírez

Enlace DAP

\section{DIMENSIÓN 2}

\section{Gustavo Villegas Restrepo}

Secretario de Seguridad - Articulador

Camilo Arango Osorno

Carlos Mario Sierra Londoño

Enlace DAP

\section{DIMENSIÓN 3}

Luis Bernardo Vélez Montoya

Secretario de Inclusión Social, Familia y

Derechos Humanos - Articulador

Adis Cristina Villera Monterrosa

Mary Luz Duque Estrada

Enlace DAP

\section{DIMENSIÓN 4}

Luis Guillermo Patiño Aristizabal

Secretario de Educación - Articulador
Tatiana Mora

Rodrigo Loaiza García

Enlace DAP

\section{DIMENSIÓN 5}

Juan Esteban Martínez Ruiz

Secretario de Movilidad - Articulador

\section{Donald Calle Guerra}

Jaime Humberto Pizarro Arteaga

Enlace DAP

\section{DIMENSIÓN 6}

Oscar Hoyos Giraldo

Secretario de Medio

Ambiente -Articulador

Diana Frankel Gallo

Nelson Valderrama Cuartas

Enlace DAP

\section{DIMENSIÓN 7}

Oscar Hoyos Giraldo

Secretario de Medio

Ambiente -Articulador

Diana Frankel Gallo

Nelson Valderrama Cuartas

Enlace DAP

El proceso de elaboración del anteproyecto del Plan de Desarrollo "Medellín cuenta con vos" fue un proceso de construcción colectiva y de co - creación por parte de todas las entidades del conglomerado público de Medellín (secretarías, direcciones y equipos de trabajo) quienes con su esfuerzo y dedicación hicieron que hoy la finalización de esta primera etapa de construcción sea una realidad para la ciudad. 
El Consejo Territorial de Planeación es un órgano consultivo de carácter colegiado que se constituye como un espacio fundamental para la participación en el proceso de planeación de la ciudad. Con la entrega del anteproyecto del Plan de Desarrollo 2016-2019, "Medellín cuenta con vos", la cual se hace por parte de la Administración Municipal, dan inicio a su primera tarea al recibir, estudiar y hacer aportes respectivos al mismo.

Desde la Administración Municipal reiteramos nuestro interés de trabajar en equipo con el CTP, por el bienestar y desarrollo de la ciudad en la construcción de la ruta que guiará a Medellín en los próximos 4 años.

A continuación presentamos los miembros del Consejo de Planeación Territorial

DIEGO FABIÁN BARRIOS LOAIZA, Junta Administradora Local Zona 1.

FRANCIA CATALINA OSORIO PABÓN

Junta Administradora Local zona 2.

CLAUDIA ELENA TIRADO VÉLEZ

Junta Administradora Local Zona 3

MARÍA FARITH BEDOYA CARRILLO

Junta Administradora Local Zona 4

SEBASTIÁN MONTOYA MAYA

Junta Administradora Local Zona 5

FERNANDO MOREIRA VELASCO

Junta Administradora Local Zona 6

ALEXIS MEJÍA ECHEVERRY

Junta Administradora Local corregimientos

CARLOS HUMBERTO GARCÍA VELÁSQUEZ

Juntas de Acción Comunal

JUAN SEBASTIÁN JARAMILLO SEPÚLVEDA

ONG's del sector social

JUAN DAVID BOTERO AGUDELO

Sector industria

MANUEL JOSÉ VALLEJO RENDÓN

Gremio de la construcción
JUAN CARLOS RESTREPO

Comercio

ANDRÉS EMIRO DÍEZ RESTREPO

Asociaciones de profesionales

WALTER DAVID NAVARRO GIRALDO

Trabajadores sindicalizados

ALEJANDRO ZAPATA ARANGO

ONG'S ecológicas

JUAN LUIS MEJÍA ARANGO

Universidades

MIRIAM MONTES TAMAYO

Colegios

MARÍA DEL PILAR NORIEGA

Centros de investigación

CARLOS ALBERTO VÉLEZ ESCOBAR

Organizaciones culturales

JAIME EDUARDO ECHEVERRI

CHAVARRIAGA

Gremios económicos

VICENTE ANTONIO SUESCÚN PARRA

Economía solidaria 


\section{CONSEJO TERRITORIAL DE PLANEACIÓN}

STELLA RESTREPO OSORIO

Organizaciones de mujeres

MARCO ANDRÉS JARAMILLO ORTIZ

Consejo Consultivo LGBTI

SANTIAGO BETANCUR FLÓREZ

Juventud

NÉSTOR LAGOS HERNÁNDEZ

Indígenas

JOHN JAIRO FLÓREZ JIMÉNEZ

Adulto mayor

DANIEL CARVALHO MEJÍA

Concejo de Medellín
CARLOS MARIO MONTOYA

Gobernación de Antioquia

BEATRIZ ELENA QUESADA CUESTA

Mujeres

MARÍA ISELA QUINTERO VALENCIA

Víctimas

WILLIAN ALBERTO ÁLVAREZ PÉREZ

Área Metropolitana Valle de Aburrá 


\section{CONCEJO DE MEDELLÍN}

Para la Administración Municipal es de gran importancia contar dentro de la construcción del Plan de Desarrollo 2016-2019, "Medellín cuenta con vos" con el Concejo Municipal, quienes cumplen un rol fundamental para la ciudad. Es por esto, que faltando dos meses para radicar nuestro proyecto de acuerdo en dicha corporación, hacemos entrega del anteproyecto del Plan de Desarrollo para que les sirva a cada uno de los concejales y concejalas como insumo de estudio y preparación para los debates próximos a realizar.

Desde la Administración Municipal reiteramos nuestro interés de trabajar en equipo con el Concejo Municipal, por el bienestar y desarrollo de la ciudad en la construcción de la ruta que guiará a Medellín en los próximos 4 años.

A continuación presentamos los miembros del honorable Concejo de Medellín

\section{DANIELA MATURANA AGUDELO}

Presidente Concejo de Medellín

NATALY VÉLEZ LOPERA

Vicepresidente Primera

BERNARDO ALEJANDRO GUERRA HOYOS

Vicepresidente Segundo

\section{CONCEJALES}

Álvaro Múnera Builes

Aura Marleny Arcila Giraldo

Carlos Alberto Zuluaga Díaz

Daniel Carvalho Mejía

Fabio Humberto Rivera Rivera

Jaime Alberto Mejía Alvarán

Jaime Roberto Cuartas Ochoa

Jesús Anibal Echeverry Jiménez

John Jaime Moncada Ospina
Luz María Munera Medina

Manuel Alejandro Moreno Zapata

María Paulina Aguinaga Lezcano

Norman Harry Posada

Ramón Emilio Acevedo Carmona

Ricardo León Yepes Pérez

Robert Bohorquez Álvarez

Santiago Jaramillo Botero

Simón Molina Gómez 


\section{- TABLA DE CONTENIDO •}

\section{$\triangle$ PRESENTACIÓN}

$\triangle$ INTRODUCCIÓN

\section{GENERALIDADES}

- Fundamentos

- Construcción participativa y democrática del anteproyecto del Plan Desarrollo 2016 - 2019: Medellín cuenta con vos

- Enfoques

- Diagnóstico General

- Objetivo superior

42 PARTE ESTRATÉGICA -Indicadores generales

\section{Dimensión transversal $\quad$ Creemos en la cultura ciudadana}
A Diagnóstico
A Presentación
$\therefore$ Retos
$\therefore$ Programas
$\Delta$ Proyectos

\section{Dimensión estratégica Recuperando la seguridad y la} convivencia ciudadana

$$
\begin{aligned}
& \text { a Diagnóstico } \\
& \text { a Presentación } \\
& \text { a Retos } \\
& \text { a Programas } \\
& \text { a Proyectos }
\end{aligned}
$$

\section{Dimensión estratégica Un nuevo modelo de equidad social}
a Diagnóstico
A Presentación
$\triangle$ Retos
$\Delta$ Programas
$\therefore$ Proyectos

Dimensión estratégica

a Diagnóstico
Educación con calidad para el desarrollo y la competitividad 


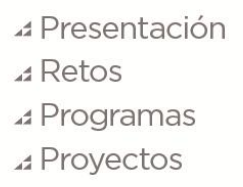

$\triangle$ Diagnóstico

a Presentación

$\Delta$ Retos

$\triangle$ Programas

a Proyectos

\section{PARTE FINANCIERA}

$\triangle 3$ - Plan financiero

- Plan plurianual de inversiones

DOCUMENTOS COMPLEMENTARIOS

44 - Diagnóstico de Infancia

4 BIBLIOGRAFÍA

4 LISTADO DE GRÁFICOS, MAPAS Y TABLAS

$\triangle$ CRÉDITOS DE FOTOGRAFÍA 


\section{a iLO CONSTRUIMOS CON TODOS!}

\section{•PRESENTACIÓN •}

M e inicié en la vida pública durante mi época universitaria, hace diecisiete años, en 1999, pertenecí al Consejo Municipal de Juventud y en representación de los jóvenes hice parte del Consejo Territorial de Planeación, el organismo que acompaña y orienta la construcción del Plan de Desarrollo Municipal. Fui el secretario de esta instancia de participación ciudadana y creo que fue en gran parte por esa experiencia donde me enamoré de mi ciudad, conocí hasta su último rincón y desde ese entonces tengo como premisa trabajar por Medellín.

Hoy como alcalde, estoy a cargo del proceso de construcción del Plan de Desarrollo 2016-2019, Medellín cuenta con vos. Una labor que, por primera vez, ha sido producto de un ejercicio democrático y participativo, pues nunca antes se habían escuchado las necesidades e ideas de los ciudadanos previo a la construcción del anteproyecto.

Decidimos hacerlo así porque en nuestra concepción, la política se hace de cara al ciudadano, ellos son nuestros aliados y quienes mejor conocen las necesidades de las dieciseis comunas y los cinco corregimientos de Medellín. Son ellos los que a diario enfrentan los problemas de seguridad, los que viven en asentamientos irregulares sin acceso a servicios públicos, los que no encuentran garantías para estudiar, trabajar y tener mejores condiciones de vida. Y podría seguir enumerando razones por las que su aporte al Plan de Desarrollo es fundamental.

Para escuchar a la ciudadanía programamos 14 encuentros ciudadanos con habitantes de
Federico Gutiérrez

Alcalde de Medellín

todas las comunas y corregimientos de Medellín, reuniones con los gremios, con el cuerpo consular y otros sectores organizados para que nos dieran aportes desde su visión de desarrollo para Medellín. Hicimos también un gran encuentro con niños donde nos contaron los grandes sueños que tienen para esta ciudad que todos queremos y que para mi ha sido un día inolvidable no solo en mi ejercicio como alcalde si no en mi trayectoria como servidor público.

Pusimos a disposición de los ciudadanos canales alternativos de escucha, orejas andantes, una orecápsula, un stand interactivo, la plataforma www.mimedellin.org y aprovechamos las redes sociales usando la etiqueta \#LaRutadeMedellín, todo con el propósito de que la comunidad contara sus necesidades e ideas. Es decir que quien quiso aportar para la construcción del plan de desarrollo de Medellín lo pudo hacer porque este gobierno municipal dispuso todos los medios para ello.

El resultado de ese ejercicio ha sido muy positivo, porque el anteproyecto que presentamos recoge el verdadero sentir de los habitantes de Medellín. En él están consignadas las voces de miles de niños, jóvenes, adultos y adultos mayores que soñamos con una ciudad mejor; una ciudad en la que las oportunidades no sean un favor sino una obligación y el compromiso de sus gobernantes.

Cuando termine mi período como Alcalde de 
Medellín, no quiero que me recuerden por grandes obras de cemento. Quiero que me recuerden como el Alcalde que le devolvió la confianza a los medellinenses, el que propició un cambio sin precedentes, una transformación cultural desde el papel que tenemos como ciudadanos; y también como el alcalde que hizo obras pensando en el bienestar de las comunidades.
Quiero presentarles a continuación el anteproyecto que todos construimos y darles infinitas gracias por acompañarme en este primer gran ejercicio de gobierno que es la base para los próximos cuatro años, un proyecto de ciudad en el que todos creemos.

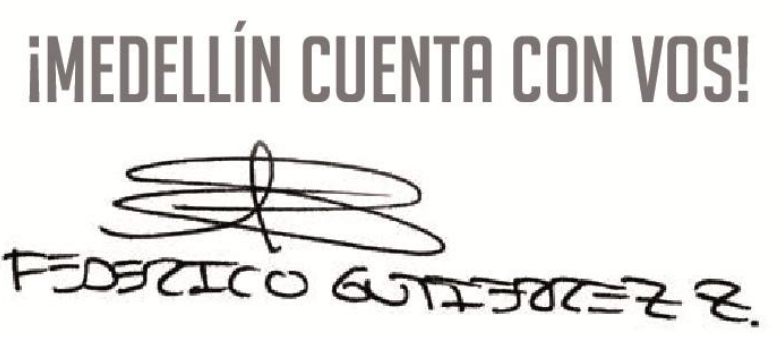




\section{- INTRODUCCIÓN・}

El anteproyecto que conocerán a continuación del Plan de Desarrollo 2016-2019, Medellín cuenta con vos, es producto de un ejercicio de construcción colectiva con los ciudadanos, los gremios y sectores más representativos de la sociedad medellinense, las juntas y organizaciones sociales de cada comuna y corregimiento de la ciudad, los servidores públicos del Municipio de Medellín, y el nuevo gabinete municipal.

En el presente documento se describe la propuesta de ciudad que soñamos para el periodo 2016-2019, considerando como esencia conceptual de dicho plan su enfoque hacia el desarrollo integral del Municipio de Medellín, entendiendo desarrollo integral como "un proceso de transformación multidimensional, sistemático, sostenible e incluyente que se genera para lograr el bienestar de la población en armonía y equilibrio con lo ambiental (natural y construido), lo sociocultural, lo económico y lo político administrativo en un territorio determinado (...) y teniendo en cuenta un contexto global" (Departamento Nacional de Planeación, 2011).

Cabe resaltar que la construcción y formulación de este Plan de Desarrollo fue establecida por el Departamento Administrativo de Planeación Municipal, y regulada mediante el Decreto 0225 de 2016. Dicha metodología se estructuró basada en los lineamientos y normativas vigentes a nivel nacional, especialmente la Constitución Política de Colombia de 1991 y la Ley 152 de 1994, y por supuesto en la propuesta de gobierno de Federico Gutiérrez Zuluaga "Porque creemos en Medellín", presentada en calidad de candidato a la Alcaldía del municipio e inscrita ante la Registraduría Nacional del Estado Civil el 21 de julio 2015.

Es importante tener en cuenta que el Plan de Desarrollo 2016-2019, Medellín cuenta con vos, parte de un claro modelo viable, sostenible y sustentable de ciudad liderado por el Alcalde Federico Gutiérrez Zuluaga, convertido no solo en un sueño de todo un equipo de trabajo y de la ciudadanía en general, sino en un conjunto riguroso de estrategias cuyo objetivo es hacer de este sueño una realidad, con una orientación metodológica basada en resultados concretos en el territorio, y construido y ejecutado de manera democrática y participativa dentro del marco de la legalidad y la transparencia.

Con el enfoque destacado de desarrollo integral para el territorio, los niveles definidos para la estructura del plan fueron: 


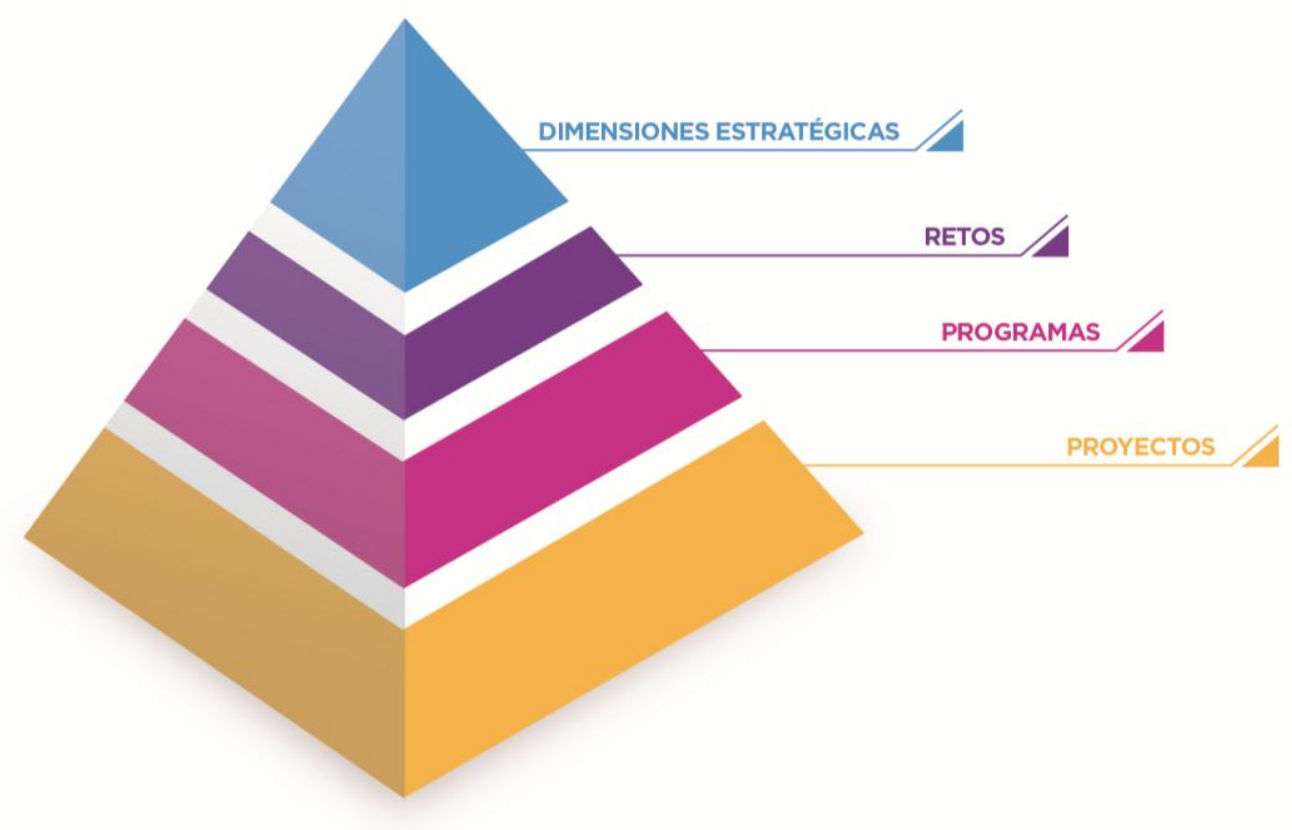

Fuente: Elaboración propia. Departamento Administrativo de Planeación, 2016.

El primer nivel: 'Dimensiones estratégicas', obedece a los ejes fundamentales de ciudad donde se enfocan los impactos considerables de este gobierno; el segundo nivel: 'retos', como la palabra lo dice son los grandes desafíos de ciudad dentro de cada una de estas temáticas; el tercer nivel: 'programas', son las agrupaciones de proyectos encaminados a resolver la misma problemática; y el último y cuarto nivel: 'proyectos', como la unidad básica de la gestión pública donde se describen el conjunto de acciones para satisfacer una necesidad puntual de la sociedad, tal y como lo establece la autoridad nacional en materia de planificación, el Departamento Nacional de Planeación - DNP.

Desde el discurso de posesión del Alcalde el 1 de enero de 2016, las palabras claves para describir las problemáticas que hoy vive la ciudad fueron tres: se necesita una Medellín legal, segura y equitativa, de ahí que el anteproyecto actual gire en torno a la solución de estos tres temas.

La primera dimensión de carácter transversal a todo el ejercicio de gobierno se llama Creemos en la cultura ciudadana. El interés del gobierno es propiciar que la ciudadanía sea corresponsable del desarrollo de la ciudad, empezando primero que todo por entender nuestro papel como ciudadanos, donde todas sus acciones con respecto a la salud, al cuidado del medio ambiente, a los valores, a la participación, la convivencia y en general todas su acciones cotidianas, impactan no solo en la familia sino también en la escuela, el trabajo y demas espacios de la sociedad. Para esto en la dimensión se describen las acciones que se 
desarrollarán en función de ese trabajo por el cambio en la cultura ciudadana, los medios por los cuales puede participar la ciudadanía y las diferentes acciones que como estado se harán para construir con todos los ciudadanos una ciudad mejor.

Con la dimensión Recuperando la seguridad y convivencia ciudadana, es claro que se debe atender una necesidad sentida por todos, mientras no recuperemos la seguridad no podemos disfrutar plenamente de nuestros derechos como ciudadanos. Paralelamente a la recuperación de la seguridad, desarrollamos estrategias para una sana convivencia ciudadana que propenda por una ciudad tolerante. Es por esto que se describen en esta dimensión todas las acciones en materia de planificación, infraestructura física y tecnológica en materia de seguridad de la ciudad y todas las iniciativas para el mejoramiento de la convivencia entre los ciudadanos, la recuperación de confianza en las instituciones que inciden en la construcción de paz desde nuestro territorio y la apuesta de reconstrucción del tejido social y del reto que significa el posacuerdo para nosotros como ciudad.

Atendiendo la problemática de la desigualdad, se construye la dimensión tres, como un nuevo modelo de equidad social para la ciudad de Medellín, ya que hoy se tienen muchos programas de atención e inclusión social, algunos que se deben revisar al interior, pues nos hemos vuelto receptores de población en condiciones vulnerables de otras municipios. Aquí, más que atender esta población y seguir teniéndola en estas condiciones, Medellín y todos debemos apostarle a que dicha población salga de su condición de vulnerabilidad y alcance condiciones normales de calidad de vida que le permitan más y mejores oportunidades de desarrollo. Es por esto que se describen todas las acciones en esta materia siempre desde el punto de vista de cómo mantenemos y mejoramos los programas y proyectos sociales que existen pero con un enfoque diferente donde se mejore la cobertura pero al mismo tiempo se migre de la vulnerabilidad a la prosperidad.

En la dimensión de educación de calidad para el desarrollo y la competitividad, si bien se reconocen los avances importantes de ciudad en esta materia, la preocupación hoy de la administración en sintonía con el gobierno nacional es la calidad educativa y el acceso a la eduación superior. Los esfuerzos se centran en procesos de formación de calidad con pertinencia a la oferta laboral de la ciudad, por esto en esta misma dimensión aparecen los programas para el desarrollo económico y la competitividad de la ciudad, visibilizando así la importancia de hacer concurrir el desarrollo de las capacidad humanas y las competencias laborales con las necesidades del mercado. No se puede dejar atrás el reconocimiento mundial como la ciudad mas innovadora en el 2013, y por esto se tiene una gran apuesta en esta materia sobretodo con un enfoque de innovación cercana al ciudadano tal y como es el modelo de administración de este gobierno. 
Medellín, como todas las grandes ciudades, no es ajena a la problemática en materia de movilidad, la dimensión para la movilidad sostenible le apunta a solucionar dicha problemática pero reconoce la importantancia del sistema de transporte público al interior de una ciudad como la nuestra, no solo para disminuir brechas sociales, pues no es justo que a quien tenga menos recursos le resulte más costoso moverse en el sistema de transporte público, sino para el aporte que le debemos hacer al medio ambiente y a la calidad del aire. Es así como todas las iniciativas de esta dimensión no solo son en materia de obras de infraestructura que solucionan deudas de muchos años con el sistema vial, sino que se tiene una mirada integral, desde la perspectiva de un verdadero sistema de transporte público integrado y la importancia del peatón y el uso de medios alternativos de transporte para la movilidad de la ciudad.

La transformación urbana en los últimos años ha hecho de Medellín un referente mundial en esta materia, no solo por grandes obras de infraestructura sino por la transformación social que esto ha traído consigo. Por eso la dimensión intervención integral en el territorio y recuperación del centro, es una apuesta desde intervenciones estratégicas en el territorio para lograr la equidad y el mejoramiento de las condiciones de vida de quienes habitan en esos espacios. Continuamos con la mirada de cómo llevar transformación y cambios sociales desde la ejecución de obras físicas que satisfagan necesidades y a la vez articulen los territorios al interior de la ciudad. Igualmente el centro de la ciudad se torna relevante desde la redacción de nuestro programa de gobierno, y es por esto que debemos priorizar transformaciones urbanas en nuestro centro, para devolverle la vida al corazón de la ciudad, para que vuelva a latir.

Por último y lo entendemos como un hecho histórico en la ciudad, tenemos una dimensión que se constituye como una apuesta de ciudad por el medio ambiente, hoy no podemos desconocer una realidad global, donde los recursos básicos para la vida tienden a desgastarse, deteriorarse y hasta desaparecer poniendo en riesgo la vida misma de los habitantes. Lo mas grave es que esto se debe a nuestras propias acciones del día a día. Por eso Medellín desde su Plan de Desarrollo le apuesta a una acción conjunta donde tanto el Estado como el ciudadano constribuyan en equipo a mitigar y reducir los impactos del cambio climático en la ciudad y el mundo.

Vale la pena resaltar cómo en todas las dimensiones no solo se describe el trabajo del Estado sino que se ven todas las iniciativas como un trabajo en equipo donde se debe contar con la corresponsabilidad de los ciudadanos del común, así como de los sectores representativos de la sociedad y diferentes entidades departamentales y nacionales que puedan aportar a la construcción de este sueño de ciudad.

Cabe resaltar que el anteproyecto que van a conocer es un ejercicio innovador no solo por su enfoque participativo en su construcción, sino 
también por la forma como se expresan las cosas que acá se consigan. Por primera vez conocerán explícitamente en el anteproyecto aspectos como:

- Identificación y descripción de grandes proyectos de ciudad en las diferentes temáticas.

- Marcas indicativas en cada uno de los proyectos dependiendo de los asuntos poblacionales que impacta o las grandes temáticas mundiales que contribuyen con su ejecución.

- Programa de ejecución del POT (por lo general no se entrega en el anteproyecto).

- Identificación de fuentes alternativas para la ejecución de un plan de desarrollo ambicioso en sus impactos.

Los invitamos entonces a conocer este gran sueño que acá describimos, partiendo de una ciudad que es resultado de muchas acciones previas. La invitación es a que volvamos a retomar nuestros roles dentro del territorio y cada uno desde sus capacidades contribuya para tener una Medellín mejor para todos. 


\section{- FUNDAMENTOS •}

Creemos en el potencial de Medellín y su gente. Es una declaración de esperanza y confianza para el presente y futuro de nuestra ciudad, esa que aún con sus preocupaciones cotidianas, tiene un inmenso deseo de convertirse en escenario de más y mejores oportunidades.

Medellín es una ciudad que se transforma constantemente. Las realidades de los habitantes y los territorios lo requieren. Hoy seguimos recorriendo el camino de la transformación y hemos construido una ruta para Medellín entre 2016 y 2019, generando oportunidades, superando problemáticas y emprendiendo nuevos retos.

\section{Visión del plan de desarrollo}

Nuestra visión de ciudad consiste en una Medellín más segura, más legal y más equitativa, en la que los ciudadanos recuperen la esperanza y la confianza en su administración y su ciudad, brindando una mejor calidad de vida para todos.

\section{Principios del Plan de Desarrollo}

Nuestros valores y nuestros principios son un punto de partida y prenda de garantía para el buen ejercicio de lo público, con la convicción de que como se hace campaña se gobierna. A continuación describimos nuestros principios entendiendo nuestra apuesta como un Gobierno de cara al ciudadano.

1. Se Gobierna con transparencia y honestidad.

2. El respeto de lo público en la transparencia y eficiencia como expresiones de legalidad.

3. Medellín responsable e incluyente desde la diversidad en la construcción de ciudad desde el territorio y con la comunidad.

4. La ciudad como lugar de encuentro para sus ciudadanos.

5. El Gobierno se ve y se siente cercano a la gente, siendo efectivo en sus acciones.

6. La seguridad no es de izquierda ni de derecha, es un derecho y hay que garantizarlo.

7. La ciudad sin miedo que se atreve a pasar de la esperanza a la confianza.

8. Con cultura ciudadana las personas se sientan dueñas y responsables con su ciudad. 
9. La educación, el deporte y la cultura como motores de la transformación social.

10. La dignidad de las personas, desde el valor que cada ciudadano tiene como ser humano. En el respeto a la vida, en la equidad y el bienestar de nuestros ciudadanos.

11. Diversidad de ideas y opiniones, pues la crítica es necesaria en las democracias cuando se hace con altura, respeto y argumentos.

12. La importancia del control político y la independencia de los poderes.

13. El crecimiento que se traduce en desarrollo, empleo, oportunidades laborales y mejores condiciones de vida para nuestros ciudadanos.

14. La ciudad responsable con su región y abierta al mundo.

15. Medellín con un proyecto y objetivo común: una ciudad debidamente planeada, amigable y responsable con sus habitantes y su entorno. 


\section{Construcción participativa y democrática del anteproyecto del \\ Plan de Desarrollo Municipal 2016 -2019

$\mathbf{E}$ I alcalde Federico Gutiérrez Zuluaga le apostó a un proceso diferente para la construcción del Plan de Desarrollo 2016-2019, Medellín cuenta con vos. Uno cuya principal característica fuera la participación de la ciudadanía desde sus territorios. Donde se impusiera esa inteligencia colectiva capaz de transformar vivencias y necesidades en ideas para la ciudad, y así llegar a soluciones y proyectos conjuntos entre la Administración Municipal y los habitantes.

El proceso no se hace así por simple capricho, sino por coherencia con los pilares de campaña del hoy Alcalde, quien siempre se ha identificado como un mandatario en la calle, un gobernante cercano a sus ciudadanos. Así las cosas, qué mejor manera de empezar el primer ejercicio de gobierno de la forma como gobernará estos cuatro años.

Este ejercicio no solo es para escuchar a los ciudadanos, sino también para concientizarlos sobre la importancia de pensarse como territorios, con sentido de pertenencia y compromiso por el espacio donde habitan. Así se podrán lograr acuerdos con el Estado e idear iniciativas que puedan ser incluidas en el Plan de Desarrollo, aportes que alimenten la ruta de la ciudad para los próximos cuatro años y que garanticen que esta sea coherente con las realidades de cada territorio. Todo en el marco de la legalidad, la seguridad y la equidad para los habitantes.

\section{Nuestros objetivos con esta metodología fueron:}

- Tener capacidad para responder al mandato popular, recogiendo las necesidades de la comunidad, volviéndolas de interés general y validándolas con los actores en territorio.

- Fortalecer la democracia y la participación activa, continua y permanente de la comunidad, que debe hacer parte de todos los momentos de la planeación (elaboración, aprobación del Plan, ejecución, seguimiento y evaluación). Su papel debe ser activo y continuo y debe reflejar una cultura de la planeación.

-El eje transversal del Plan es legalidad y transparencia en las decisiones públicas y para ello es vital el control ciudadano, político y fiscal sobre la gestión pública.

- Fomentar los procesos de inclusión social y respeto por las diferencias; la capacidad para articular los diferentes instrumentos de la planeación del desarrollo y su armonización con planes de mayor jerarquía territorial y la responsabilidad política de los mandatarios con relación al respeto y promoción de los derechos humanos. 
El Plan de Desarrollo Municipal es la carta de navegación de la Administración Municipal durante el periodo de gobierno. Es el resultado del mandato popular entregado por diferentes actores sociales y comunitarios que avalaron con sus votos el programa de gobierno del gobernante electo. Por eso la planeación del desarrollo territorial requiere de procesos de modernización estatal complementarios, de ahí la importancia de dicha metodología participativa. Partiendo de la premisa de que la planeación participativa tiene el potencial de generar lazos de confianza entre el Estado y la sociedad, que contribuyen al desarrollo integral, se planteó una estrategia general de participación ciudadana para la construcción del anteproyecto del Plan de Desarrollo 2016-2019, Medellín cuenta con vos, que está conformado por dos grandes componentes: uno territorial y otro digital, aunque los dos se complementan.

El componente territorial que se desarrolló en esta primera fase de construcción del anteproyecto, se considera uno de los

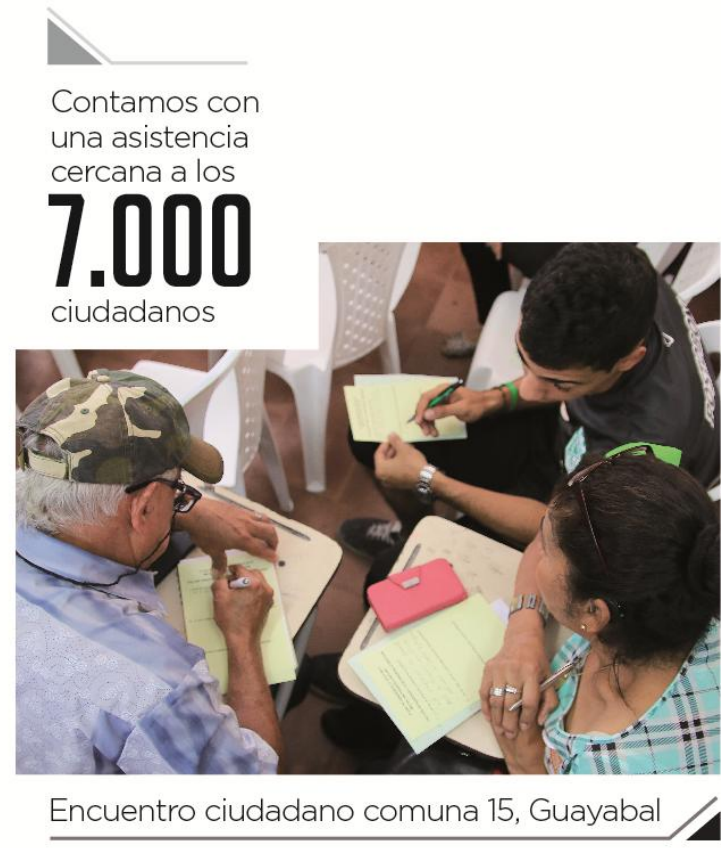

elementos innovadores en la formulación de los Planes de Desarrollo. Históricamente la discusión con las comunidades se daba en una etapa posterior a la presentación del anteproyecto al Consejo Territorial de Planeación, iniciativa que surgía desde el mismo Consejo Territorial o la Administración, y en el caso del Concejo Municipal cuando se radicaba en dicha instancia. Sin embargo, la actual Administración, reconociendo que quien más conoce su territorio es quien lo habita, llevó la discusión a las comunidades de manera previa a la presentación del anteproyecto. Por eso hoy se entrega un documento que en primera instancia contempla las propuestas, necesidades e iniciativas de la comunidad, que durante poco más de un mes, en un ejercicio que supera en asistencia los procesos de participación comunitaria de la ciudad, se reunió para construir su sueño de ciudad. Creemos en la oportunidad de la información y la oportunidad de las ideas. Por eso quisimos hacer el ejercicio en el momento oportuno.

La estrategia se lleva a cabo en dos momentos: uno denominado de escucha, que empezó el 29 de enero y concluyó el 25 de febrero, y otro de retroalimentación, que comienza en mayo y va hasta el mes de julio del presente año.

Fuimos a los 21 territorios: 16 comunas y 5 corregimientos, con 14 encuentros de co-creación ciudadana. Contamos con una asistencia cercana a los 7.000 ciudadanos que participaron de manera directa en la construcción de su Plan. 
En los encuentros los participantes se inscribían según sus intereses en cada una de las dimensiones definidas en el Plan: Creemos en la cultura ciudadana, Seguridad y convivencia ciudadana, Equidad social, Educación de calidad para el desarrollo, Movilidad sostenible y Medio ambiente y renovación urbana. Luego se pasaba a mesas de trabajo de acuerdo a la dimensión elegida, lideradas por secretarios de despacho que hacían las veces de articulador,

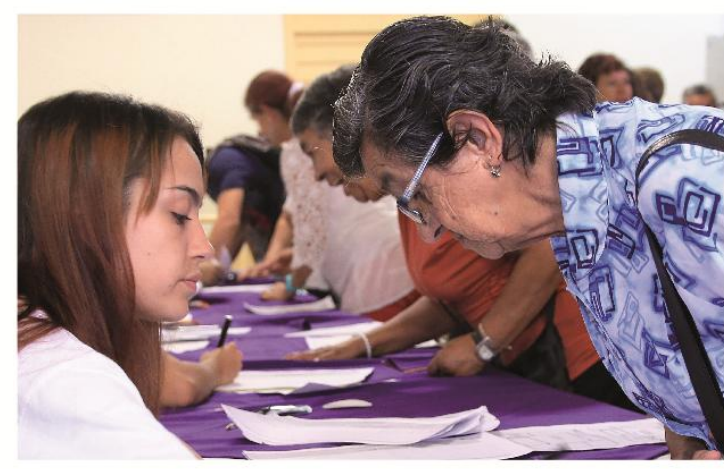

acompañados por integrantes del gabinete a los que misionalmente les correspondía dicha dimensión. En esas mesas todas las personas inscritas podían participar con sus ideas y propuestas.

LA CONVOCATORIA FUE ABIERTA, SE promocionó por todos los medios de comunicación (prensa, radio, televisión, medios digitales y redes sociales, entre otros) y se fortaleció mediante un trabajo conjunto con las secretarías misionales que tienen escenarios de participación. Especialmente se trabajó con las Secretarías de Participación Ciudadana, Inclusión Social y Familia, Juventud, Mujeres, Cultura, Salud y Educación.

Finalmente, después de una mesa de trabajo de dos horas, se elegía de manera democrática a uno de los participantes para que socializara lo trabajado en la dimensión durante la plenaria con el Alcalde junto a los demás participantes de las dimensiones. Allí el alcalde Federico Gutiérrez realizaba una introducción y hablaba de algunas de las ideas que se habían planteado en la discusión por dimensiones. Luego escuchaba y conversaba con cada uno de los voceros. Algunos de estos ejercicios se realizaron de manera virtual con el Alcalde cuando sus obligaciones no le permitían estar de manera presencial, siendo plenamente validados con la comunidad, pues se aprovecharon las nuevas tecnologías para fortalecer uno de nuestros pilares: estar cerca a la ciudadanía.

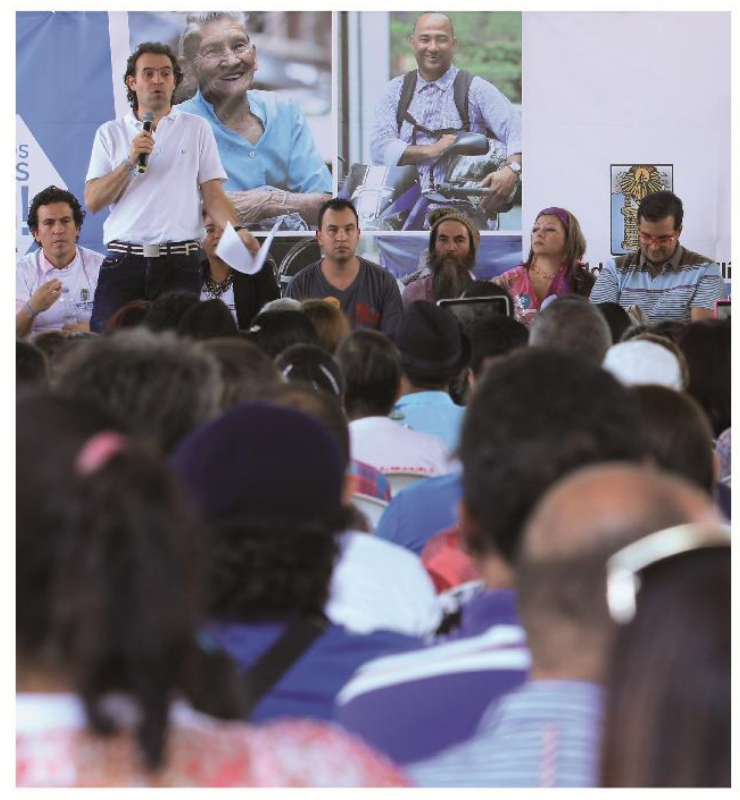

Se aprovecharon las nuevas tecnologías

PARA FORTALECER UNO

DE NUESTROS PILRRES:

ESTAR CERCA A LR CIUDADANÍA.

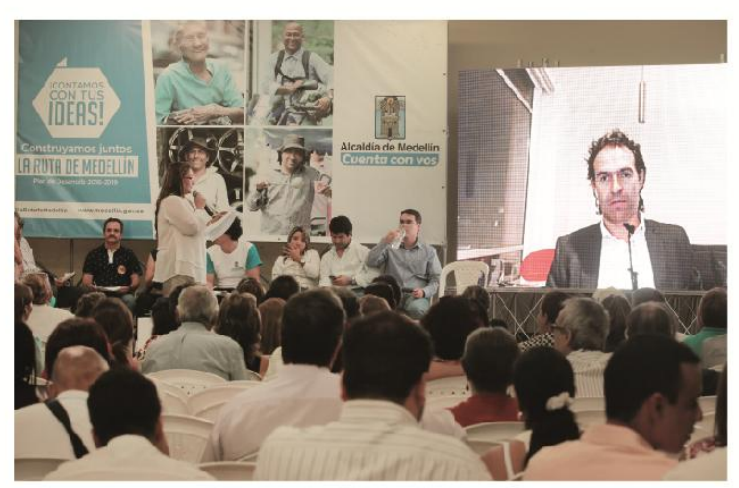




\section{PROGRRMACIÓN ENCUENTROS CIUDADANOS}

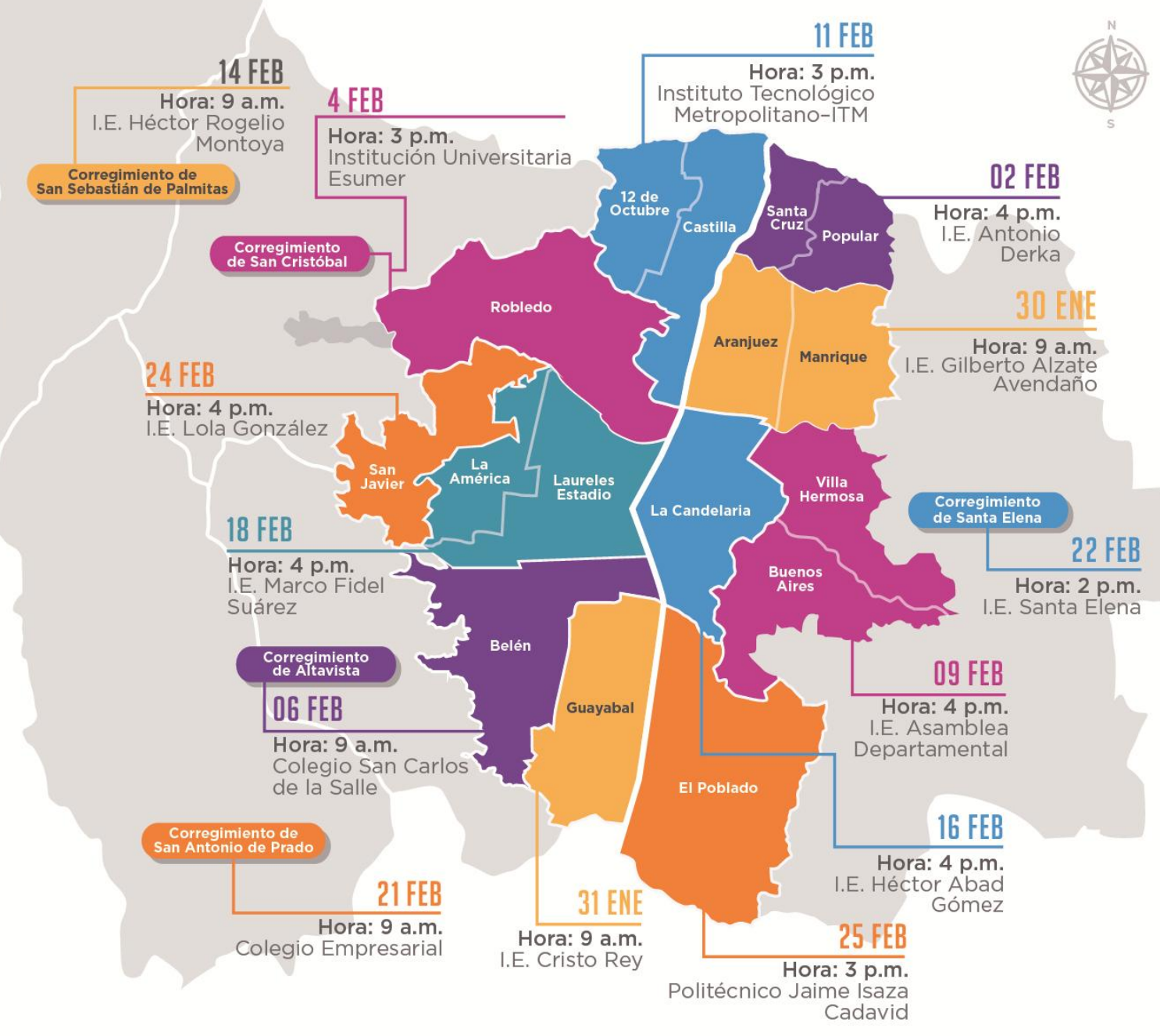


Dentro del componente territorial, hicimos más de 50 encuentros sectoriales, convocados por las dependencias y entes descentralizados. Ellos se reunieron con los sectores afines a su interés misional para escuchar sus ideas.
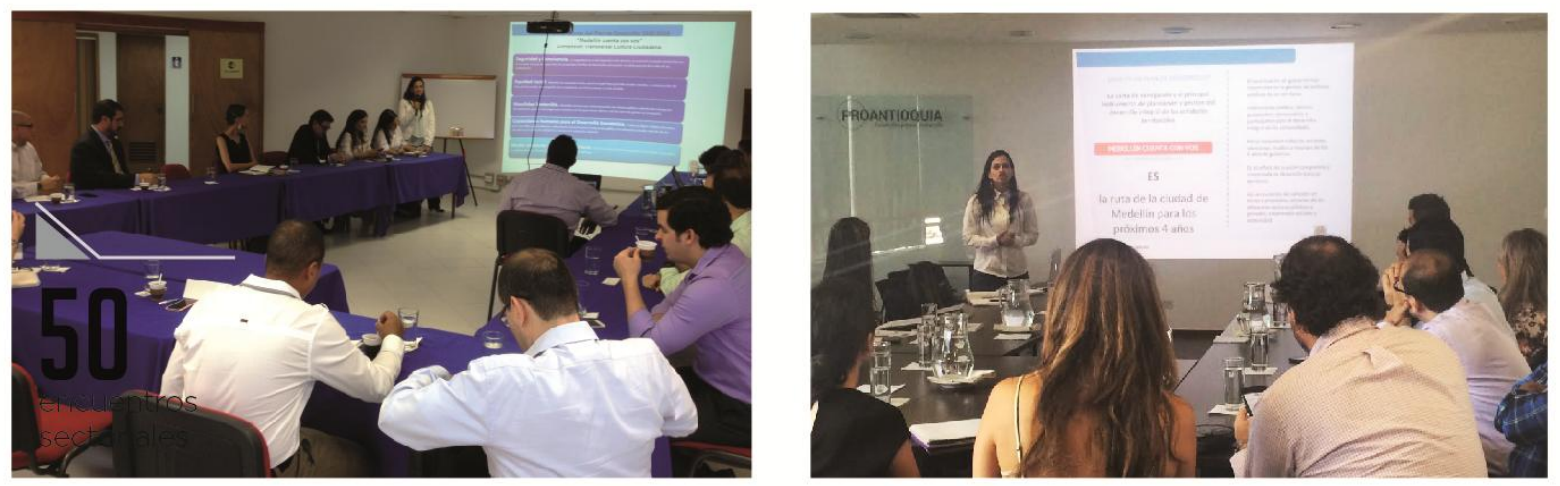

Encuentro sectorial Acopi

Encuentro sectorial Proantioquia

Adicionalmente, tuvimos otros espacios innovadores, como un encuentro con 240 niños de toda la ciudad, donde tanto ellos, como los adolescentes y las madres gestantes aportaron sus ideas. Allí quedó clara la importancia de escucharlos y no suponer qué es lo que sienten y quieren. Un evento que evidenció la claridad de los argumentos de los niños y la vehemencia con que defienden sus ideas.

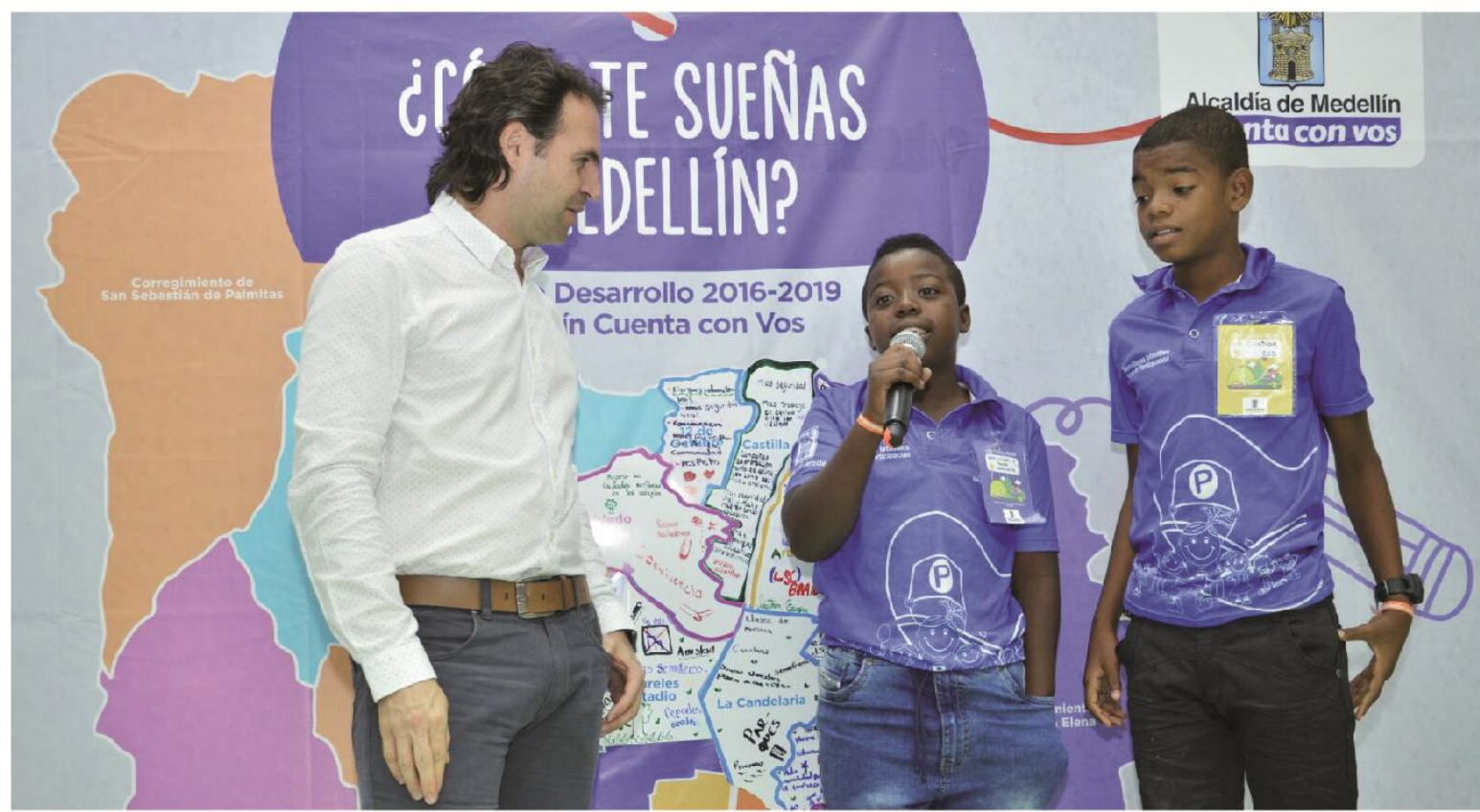

Encuentro con los niños 
Como se debe gobernar igual de bien en casa, desarrollamos una campaña de participación al interior del conglomerado público. El Alcalde, personalmente, por medio de un correo electrónico invitó a todos los funcionarios a participa y dispuso las herramientas digitales para captar sus ideas.

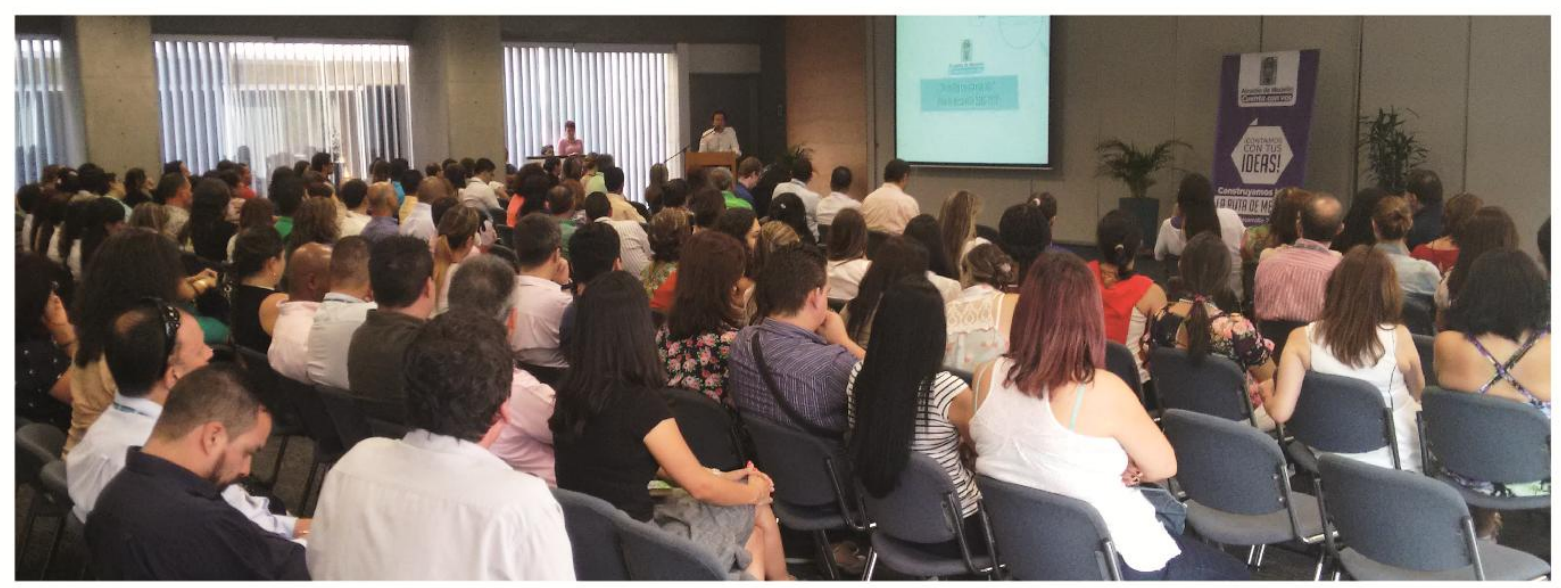

EL COMPONENTE DE PARTICIPACIÓN DIGITAL ES EL MÁS INNOVADOR DE TODOS, ya que por primera vez se dispuso una plataforma de participación digital para la participación alrededor del Plan de Desarrollo. La web www.mimedellin.org, de Ruta N, es un espacio para la co -creacion ciudadana que estimula la participación digital.

El 29 de enero, cuando se presentó la estrategia de participación, se pusieron al aire en la plataforma seis pulsos relacionados con las temáticas principales de las dimensiones. Hasta el 25 de febrero, que fue el último encuentro ciudadano, se habían recibido más de 10.000 ideas por este medio.

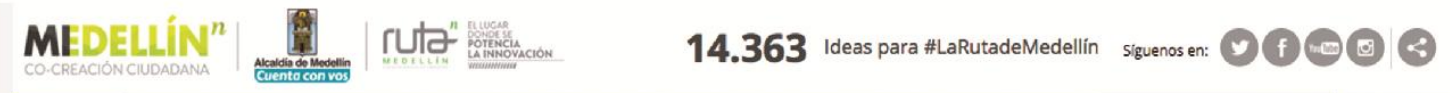

\begin{tabular}{|c|c|c|c|c|}
\hline OS & ESTADÍSTICAS & ENTÉRATE & NOSOTROS & INGRESAR \\
\hline
\end{tabular}

Pulsos

Pulsos IAPORTA TU IDEA AL PLAN DE DESARROLLO 2016 - 20191

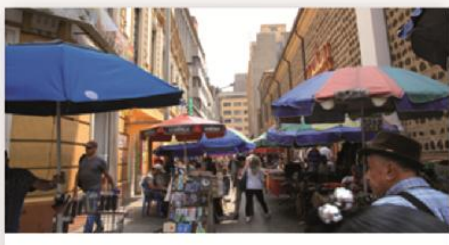

¿Cómo construimos el nuevo Centro de Medellin?

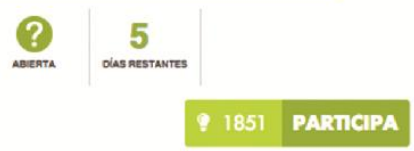

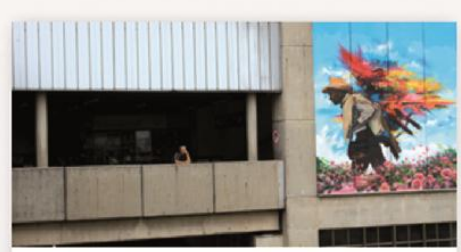

¿Cómo fortalecer la relación ciudadano gobierno para gestionar juntos la ciudad que soñamos?

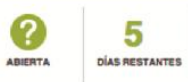

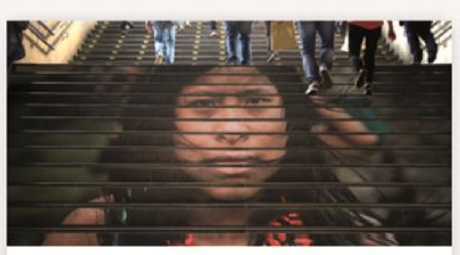

¿Qué acciones ciudadanas propones para mejorar la convivencia?

? 5 
Adicionalmente se hizo una activación y dinamización en redes sociales, donde con la etiqueta \#LaRutadeMedellín identificamos aquellas intervenciones, ideas, opiniones y demás referentes al Plan de Desarrollo. En total hemos logrado cerca de 300 aportes en redes sociales.

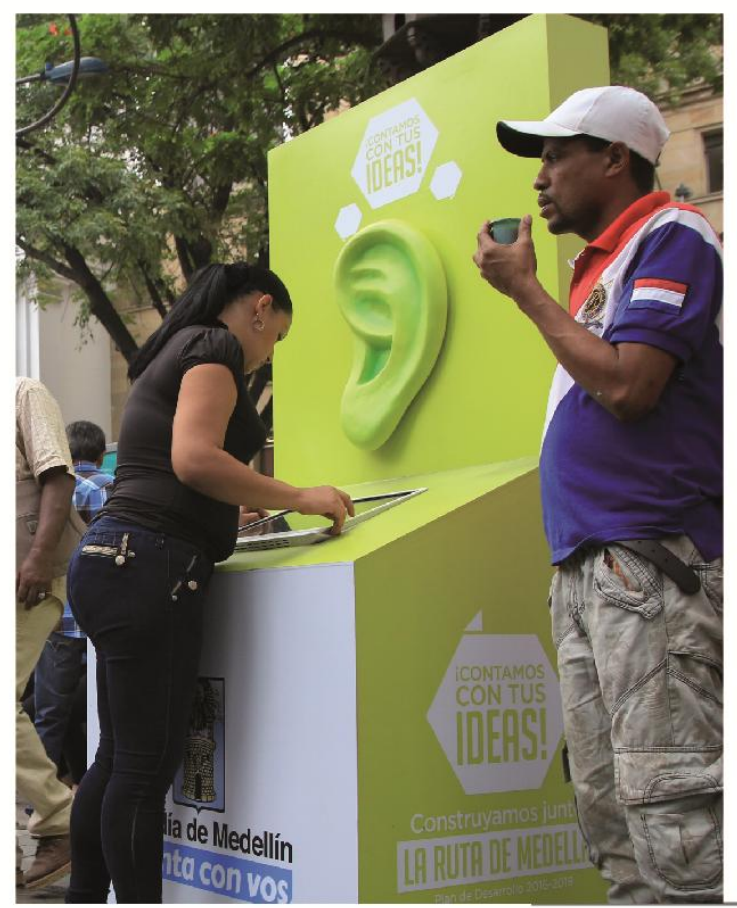

El campo digital es un escenario en el que la población joven está familiarizada con su lenguaje. Sin embargo, hay otra parte de la población que no. Para ello llevamos al territorio herramientas que capturaran de manera digital las ideas de las personas y luego nosotros las registramos en la plataforma Mi Medellín. Se trata de un par de orejas verdes que caminaron por toda la ciudad 'escuchando' ideas desde el primer momento. También tuvimos un stand interactivo que estuvo en diferentes sitios de la ciudad y una orecápsula. Con estas tres actividades conseguimos ideas que reposan en el gran contenedor, y muchas de las cuales están reflejadas en el presente anteproyecto.

Orecápsula
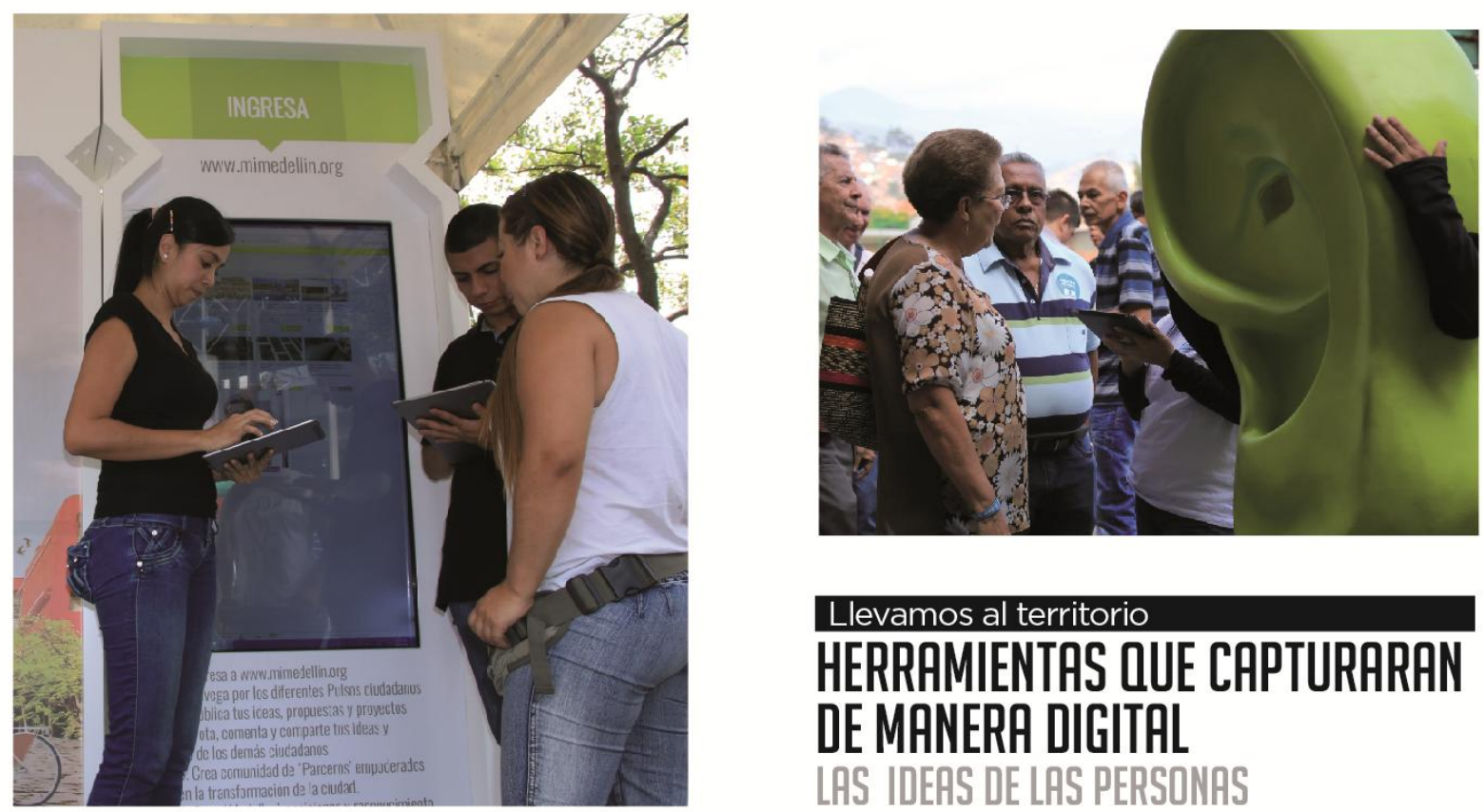

Llevamos al territorio

HERRAMIENTAS QUE CAPTURRRRN DE MANERA DIGITHL

LAS IDEAS DE LAS PERSONAS 
Es importante aclarar que se recibieron muchas propuestas por escrito que fueron entregadas puntualmente a algún secretario o al Alcalde en los encuentros territoriales, o radicadas en la Alcaldía. Todas fueron registradas en el gran contenedor de ideas para el Plan de Desarrollo.

Ahora la pregunta es: ¿qué se hace con todas esas ideas? El Departamento Administrativo de Planeación dispuso una instancia que llamamos laboratorio de ideas, donde todas las propuestas digitales que llegan por redes sociales o la plataforma www.mimedellin.org, reposan en un gran contenedor. Para las ideas que surgen en los 14 encuentros territoriales y en el encuentro de los niños, tenemos una plataforma para sistematizar las temáticas trabajadas y las ideas generadas. Cada encuentro está sistematizado por dimensión. Adicionalmente se registraron todas las ideas que llegaron por escrito por ciudadanos u organizaciones particulares, o las ideas que se consolidaban en las actas de las diferentes reuniones sectoriales. Todo en un contenedor de información que permite saber de dónde vino la idea. En un trabajo posterior se realizó un análisis puntual de cada una de ellas. Luego, en el laboratorio, se hará un análisis de tendencias para poder priorizar definitivamente las ideas que podrán convertirse en proyectos de inversión o acciones de estas iniciativas en el marco del Plan de Desarrollo.

Todo este ejercicio territorial y digital ha estado acompañado por una gran estrategia de comunicaciones con la que no solo se ha pretendido informar a la ciudadanía sobre las diferentes formas que tiene de participar, sino que ha tenido otro objetivo clave y es que la ciudadanía entienda qué es un plan de desarrollo y la importancia que tiene participar en su construcción, además que sienta que la ciudad entera está haciendo el ejercicio de planificación más importante y que todos estamos en el proceso de construcción de la ruta de Medellín para los próximos 4 años.

No solo la ciudad se ha vestido visual y auditivamente con el tema Plan de Desarrollo, sino que hemos tenido activaciones lúdicas en espacios públicos para que cualquier ciudadano que quiera saber conozca qué es un plan de desarrollo, la importancia que tiene y cómo puede participar.

Uno de los aspectos más importantes, además de escuchar, es contarle a la ciudadanía, independiente del medio utilizado, si sus ideas quedaron plasmadas en el Plan de Desarrollo, en dónde y de qué forma. Por eso entramos al segundo momento de la estrategia en los meses de mayo, junio y julio, cuando se tiene contemplada la fase de retroalimentación con la ciudadanía. En ese momento, a través de los medios de recolección de ideas, se evidenciará si la idea quedó dentro del Plan y de qué manera.

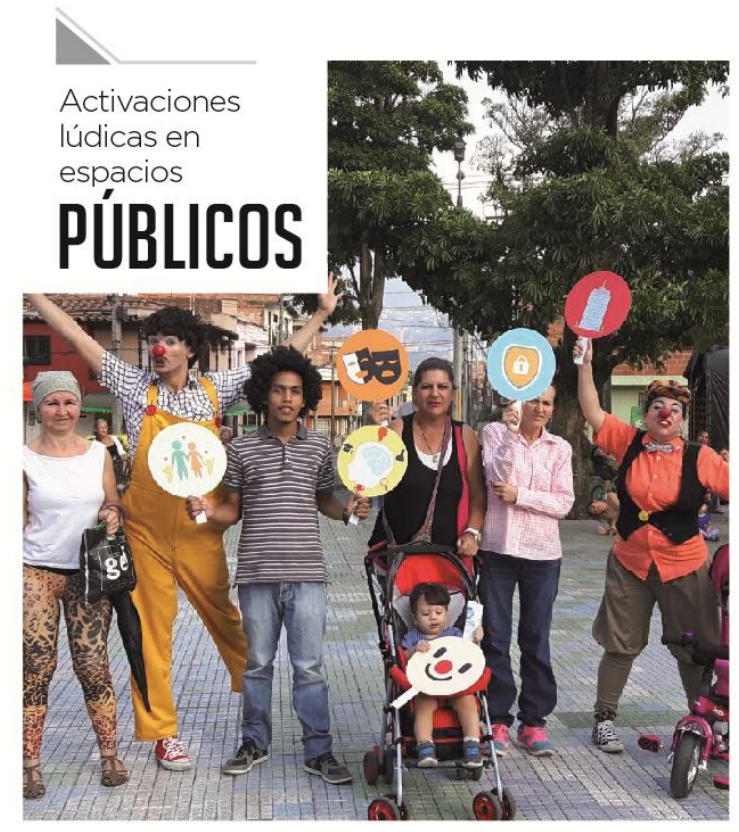




\section{Laboratorio de ideas para LA RUTH DE MEDELLÍN}

Lideramos la construcción del Plan de Desarrollo 2016-2019, Medellin cuenta con vos, con la participación de toda la ciudadanía.

O PARTCPACLON

La participación en territorio, Mi Medellín o por otros canales tiene el mismo peso.

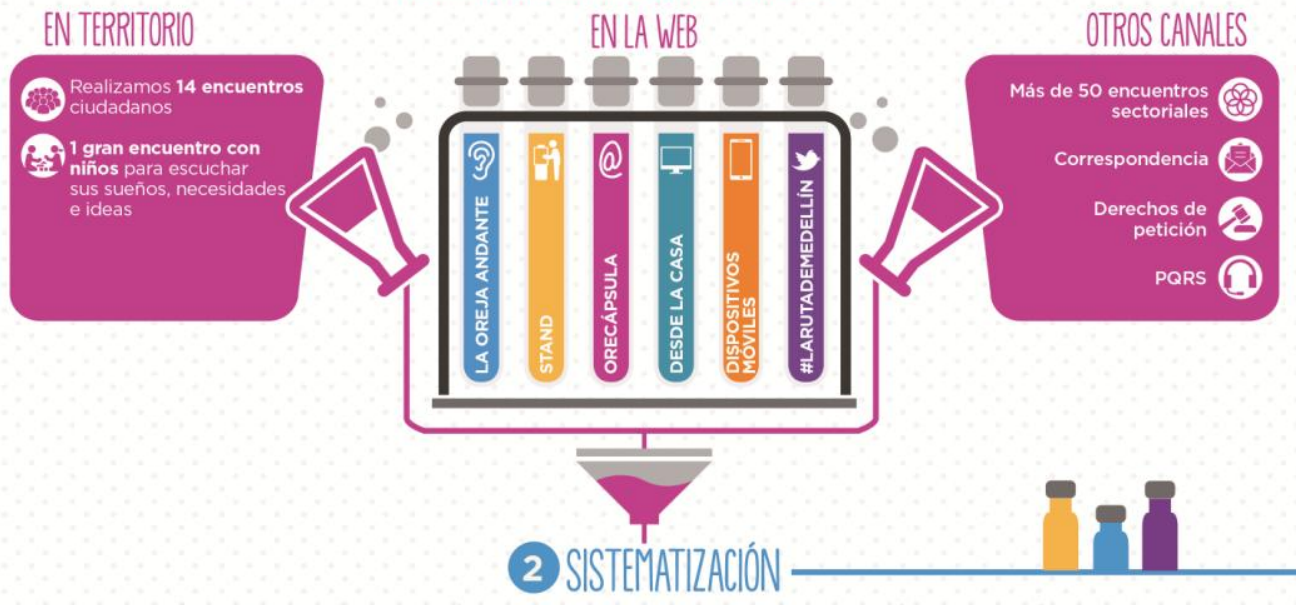

Las ideas que se reciben por todos los canales son sistematizadas, analizadas y priorizadas por el DEPARTAMENTO ADMINISTRATIVO DE PLANEACIÓN (DAP) de acuerdo con las 7 dimensiones del Plan de Desarrollo.
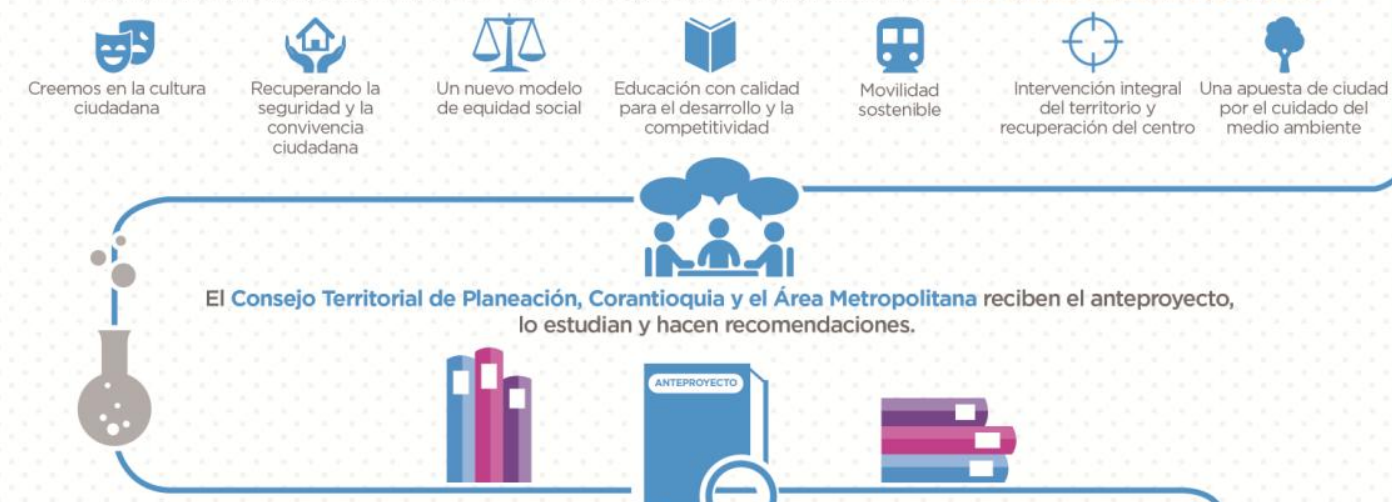

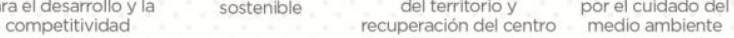
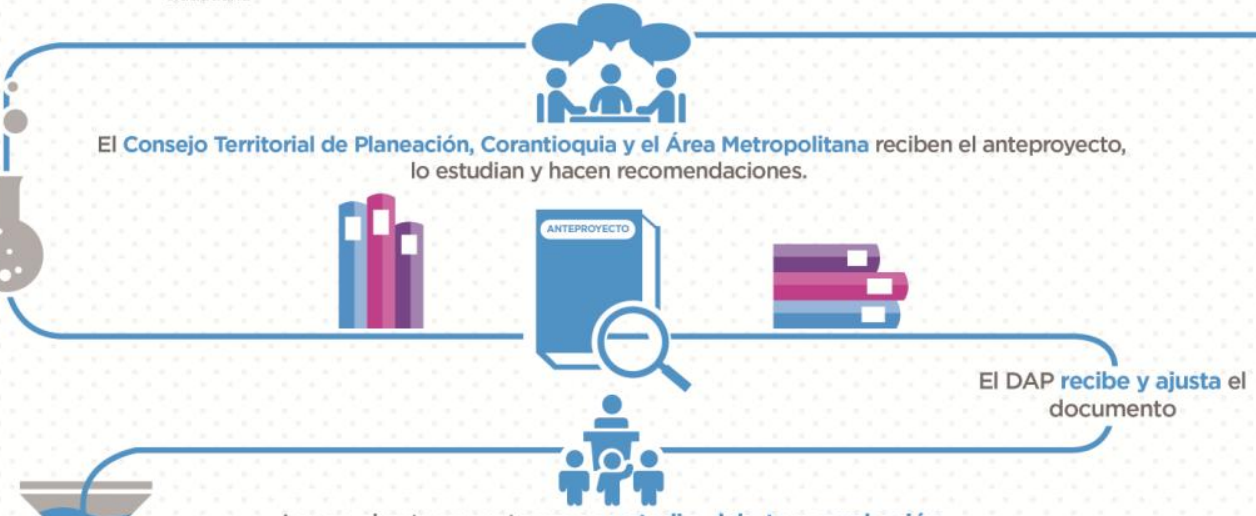

Luego el anteproyecto pasa a estudio, debate y aprobación por parte del Concejo Municipal

\section{RETROALLIENTACIÓN}

Al final socializamos el Plan de Desarrollo 2016-2019, Medellin cuenta con vos, con habitantes de las 16 comunas y los 5 corregimientos en los espacios de participación digital y por medio de los demás

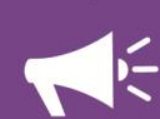

EN TERRITORIO

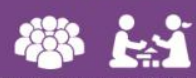
21 encuentros ciudadanos de socialización y plan ae desarrollo para los niños canales por los que recibimos ideas.

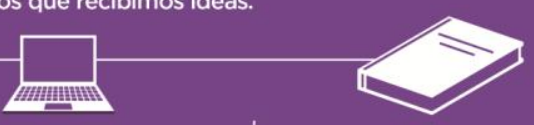

ENLA WEB

$@ \square \square$ v $\mathbf{f}$

\#LaRutadeMedellin www.medellin.gov.co www.mimedellin.org
OTROS CANALES

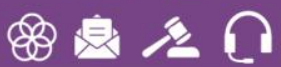

Encuentros sectoriales,

correspondencia, derechos 


\section{- ENFOQUES •}

El plan de desarrollo "Medellín cuenta con vos", tiene un enfoque claro hacia el desarrollo integral de la ciudadanía. Este plan de desarrollo quiere mostrar las cosas de una manera diferente e innovadora y es por eso que el enfoque del plan será marcado en los proyectos de manera específica, donde con "sellos de enfoque" podran identificar las acciones de gobierno hacia que poblaciones o temáticas van dirigidas. Se podrán entonces evidenciar uno por uno los proyectos del Plan de Desarrollo "Medellín cuenta con vos", con cada uno de los sellos de enfoques específicos respectivos. A continuación se describe cada uno de los enfoques

Un enfoque de derechos es fundamental para alcanzar el desarrollo integral tal y como se describió inicialmente. Este debe basarse en el esfuerzo para garantizar, promover y proteger a diferentes grupos poblacionales en situación de vulnerabilidad que afectan su calidad de vida, tales como las víctimas del conflicto armado. Más allá de programas que garanticen los derechos, se debe propender por otro tipo de modelo con programas que potencialicen las capacidades de las personas, y abran oportunidades que contribuyan al mejoramiento de su bienestar.

A través de este enfoque logramos hablar de inclusión, igualdad, equidad, universalidad, entre muchas otras categorías, que lo que nos indican es el interés de la administración por la búsqueda de la igualdad de oportunidades, para que con las capacidades individuales de las personas logremos desarrollo individual de los habitantes. Partimos también de un enfoque poblacional, donde es claro el reconocimiento de la pluralidad de la población en el municipio de Medellín, en los cuales cada uno desde su diferencia cultural, etaria, política, entre otras, tiene necesidades diferentes y es por esto que marcamos el enfoque atendiendo a la responsabilidad del estado de llegar con programas y proyectos pertinentes para dichas poblaciones.

El sello joven tiene como objetivo, de una parte, articular la oferta pública y por otra parte, busca reconocer y fortalecer los proyectos y programas que se ejecutan con y para los jóvenes, desde cada una de las instancias institucionales que desarrollan acciones con esta población, con el fin de incidir ən una adecuada lectura de los contextos y conceptos sobre ra juventud, así como en los enfoques y modelos de intervención.

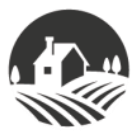

Tenemos que hablar también de un enfoque territorial, el cual pretende establecer políticas, programas y proyectos 
coherentes con las necesidades de los territorios y no simplemente quedarse en marcar los proyectos que están a las diferentes comunas; tal es el caso del territorio rural y el urbano donde cada uno tiene sus particularidades creando la necesidad de identificar los proyectos con enfoque rural por la importancia de sus territorios para el resto de la ciudad, sumándose a la búsqueda de mejorar las condiciones de bienestar para los mismos.

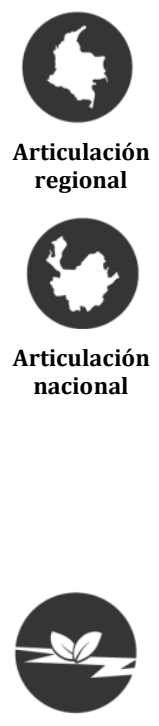

En la actualidad a nivel público se habla en sentido regional, nacional y global, no local. Se deben establecer y articular estrategias de desarrollo a través de proyectos regionales y nacionales, buscando desde lo local poder construir con nuestros vecinos $\mathrm{y} / \mathrm{o}$ otros territorios aliados para así mejorar las condiciones de todos colectivamente y aprender de las buenas prácticas de los demás, teniendo como resultado impactos mejores y más eficientes e los territorios.

La resiliencia es la capacidad de planeación estratégica que permite identificar y diseñar soluciones integrales desde múltiples aspectos como la seguridad y la convivencia; la cohesión social, la cultura ciudadana, la movilidad sostenible, la educación, la gestión del riesgo y del territorio, la gestión de la información y la sostenibilidad, entre otros. Este plan le apunta a que Medellín siga siendo una ciudad resiliente, plateándonos el reto de aumentar la capacidad que hasta ahora hemos tenido de sobreponernos a las dificultades y mantener tanto el optimismo como las acciones dirigidas a mejorar nuestro entorno de ciudad.

Al no ser ajena la problemática mundial del calentamiento global, la escasez del agua y otros asuntos que golpean fuertemente al medio ambiental y afectan la conservación de los recursos naturales, es por esto que Medellín al ser una de las ciudades más importantes del país, debe apostarle a enfrentar el cambio climático a través de estrategias de ciudad que permitan educar y concientizar a toda la ciudadanía acerca del cuidado de los recursos naturales para bienestar de todos, impactando de este modo la ciudad, el país, y del mundo entero.

Medellín no puede estar por fuera del marco de los objetivos de desarrollo sostenible, teniendo en cuenta la agenda 2030 de Desarrollo Sostenible, al igual que todos los estados miembros la ciudad le apuesta a finalizar la pobreza, a reducir las desigualdades e iniquidades y obviamente a la problemática mundial de cuidar el medio ambiente para mitigar y/o reducir el cambio climático.

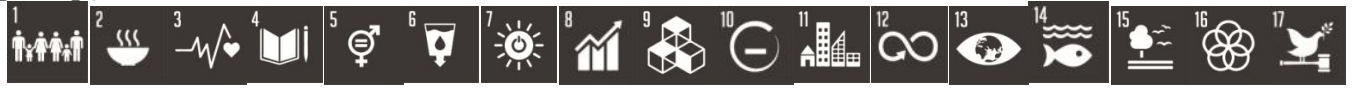

Objetivos de desarrollo sostenible 


\section{- DIAGNÓSTICO GENERAL・}

Medellín es una ciudad de 2'457.680 habitantes, la segunda más grande en población de Colombia. Cuenta con una extensión de 380 km2, de los cuales $105 \mathrm{~km} 2$ son de suelo urbano, $270 \mathrm{~km} 2$ de suelo rural y $5 \mathrm{~km} 2 \mathrm{de}$ suelo para extensión. Nuestra ciudad se ha venido constituyendo como un importante referente regional y global en la lucha por la superación de la pobreza y la reducción de la violencia, lo cual ha significado un destacable aumento en las oportunidades de mejorar las condiciones de vida y en mayores posibilidades de contribuir al desarrollo económico local y al bienestar de sus habitantes.

El Plan de Desarrollo Medellín cuenta con vos 2016-2019 se enmarca en un proceso mucho más amplio de surgimiento de nuevas transformaciones sociales, políticas, económicas y culturales que requieren de la acción institucional y del potencial de los ciudadanos para disminuir las persistentes brechas sociales y las desigualdades, pues creemos en la necesidad de construir una cultura ciudadana en donde las personas se sientan dueñas y responsables con su ciudad, apuntando a la construcción conjunta de una ciudad segura, legal y equitativa que tenga la capacidad de adaptarse a las necesidades de una ciudad dinámica y en permanente cambio.

Nuestra ciudad enfrenta problemáticas que requieren una mirada multidimensional para su abordaje, comprensión y resolución. Desde este Plan de Desarrollo proponemos gobernar desde lo simple, haciendo explícita la necesidad de generar apuestas sociales, económicas y culturales que permitan acercar los discursos y lógicas gubernamentales a la ciudadanía. Creemos firmemente en que la construcción de la cultura ciudadana parte de la recuperación de la confianza institucional a partir de una gestión transparente, eficiente y visible para la ciudadanía, que respeta lo público y que hace posible el fortalecimiento del gobierno local, promoviendo el empoderamiento de los ciudadanos como dueños y responsables de su ciudad.

No obstante, creemos que este ejercicio debe aparejarse al sentido de la corresponsabilidad ciudadana, pues es indispensable que los ciudadanos comiencen a transformar sus actitudes y comportamientos, que hagan posible el entendimiento mutuo y la convivencia pacífica, y que le apuesten a nuevas formas de relacionamiento con el otro, valorando el reconocimiento de las diferencias y garantizando la sujeción a las normas como pauta básica de la convivencia en sociedad. De igual manera, la promoción y garantía de la participación activa y decidida de la ciudadanía forma parte de esta estrategia administrativa, en la medida que favorece el diseño e implementación de políticas más incluyentes.

Creemos en el crecimiento que se traduce en desarrollo, educación, empleo, oportunidades laborales y mejores condiciones de vida para 
nuestros ciudadanos. Reconocemos las potencialidades y fortalezas que hacen posible el ejercicio de los procesos de planificación para el desarrollo humano integral de la población urbana y rural de Medellín, toda vez que para este gobierno no hay lugar a la improvisación, pues la planeación estratégica y participativa configura una de las bases fundamentales para la construcción de la ciudad que soñamos. Así mismo, el Plan de Desarrollo Medellín cuenta con vos cree que el respeto por la vida y la resolución pacífica de los conflictos son aspectos innegociables y fundamentales para la consolidación de la cultura ciudadana, una cultura edificada sobre la confianza, la honestidad, la solidaridad, el civismo, la legalidad y la paz, que ubica en un primer plano la dignidad humana y propende por una gestión transparente, eficiente y cercana a la ciudadanía y sus intereses. Esta debe ser la base sobre la que se construya la ciudad que queremos, una en la que la cultura de la legalidad venza, de una vez por todas, la cultura de la trampa; en la que lo público deje de ser visto como un negocio para pasar a ser considerado como un deber, un servicio y un compromiso de todos.

Una lectura cuidadosa de la realidad actual de nuestra ciudad permite reconocer los diferentes desafíos ante los que nos enfrentamos, y aunque la ciudad ha avanzado en materia de seguridad, educación y empleo, todavía queda mucho por hacer. Hoy somos la ciudad del país que más invierte en lo social, con una inversión per cápita de 1,95 millones de pesos, por encima de ciudades como Barranquilla, Cartagena y Bucaramanga con inversiones de 1,30, 1,22 y 1,18 millones de pesos, respectivamente. A pesar de ello, somos la ciudad colombiana con el más alto índice de GINI, pues tal y como lo expresa el mapa 1, para el año 2014 la ciudad ha registrado un incremento sostenido en los niveles de desigualdad al interior de sus comunas, registrando un coeficiente de 0.527 para el año 2014, comparado solamente con el total de la nación que registra un coeficiente de 0.539, resultado que ubica a Colombia en el puesto $14^{\circ}$ a nivel mundial de los países más desiguales y con mayor concentración de la riqueza, y que deja un importante reto sobre el escenario local para este Plan de Desarrollo en cuanto la reducción de la desigualdad 
Mapa 1: Coeficiente de GINI para la ciudad de Medellín

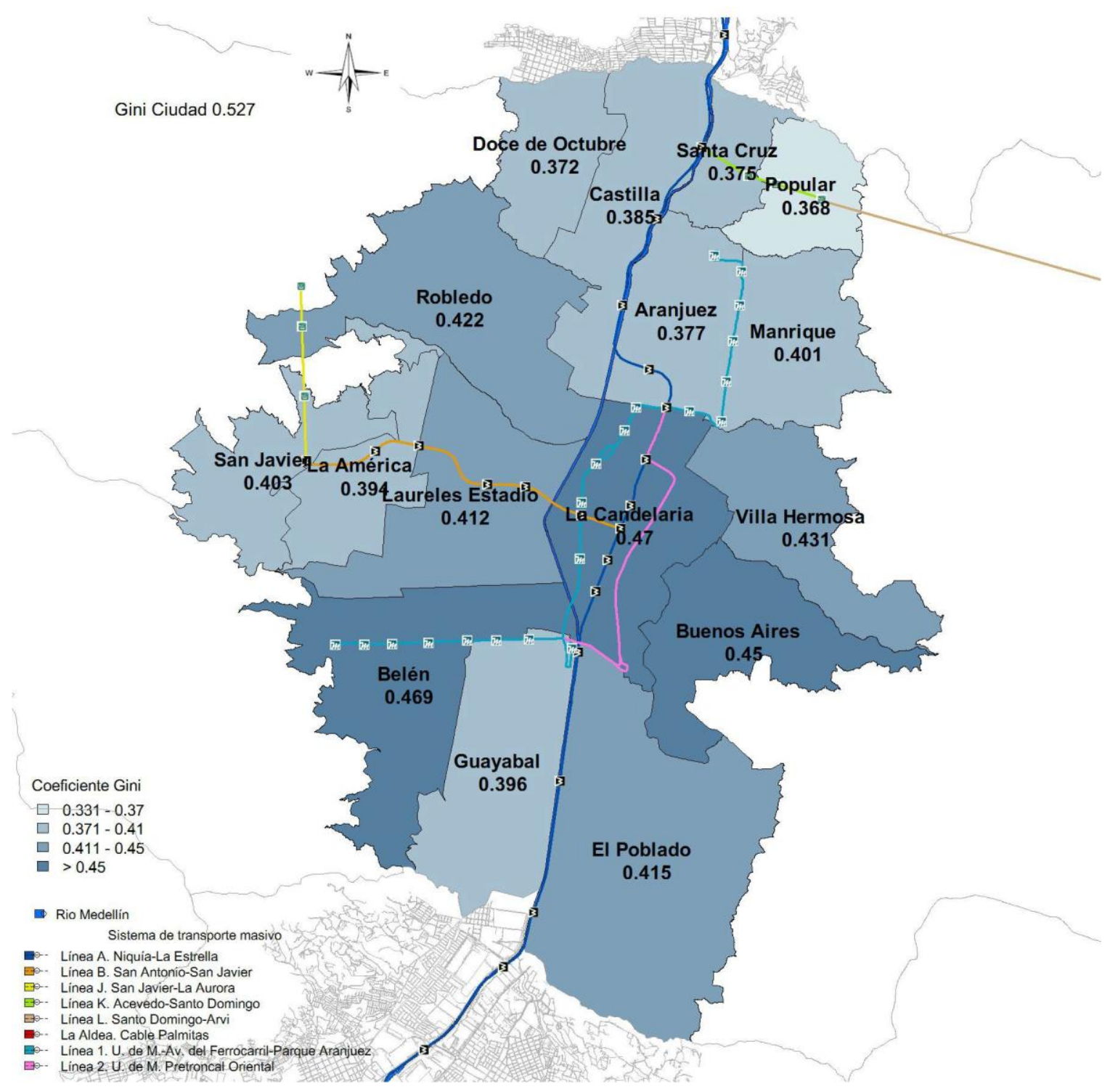

Fuente: Observatorio de Políticas Públicas de la Alcaldía de Medellín, 2014.

Por otra parte, existen brechas por cerrar en términos de desarrollo en el territorio rural y urbano de la ciudad, toda vez que coexisten diversas problemáticas asociadas al mejoramiento de la calidad de vida de sus habitantes. En ese sentido, las mediciones desarrolladas a partir del Índice Multidimensional de Condiciones de Vida (IMCV) arrojan desequilibrios importantes al interior de las comunas y corregimientos de Medellín.

El mapa 2 toma las cifras arrojadas por el IMCV para cada una de las comunas y corregimientos del municipio de Medellín. En este se observan resultados por encima de 70 puntos a comunas como Laureles-Estadio y El Poblado, y por debajo de 39 puntos a comunas como San Javier, Santa Cruz, Manrique, Villa Hermosa y Popular. De igual manera, en el ámbito 
rural y en sectores como los corregimientos de San Sebastián de Palmitas, Altavista y San Cristóbal se encuentran resultados por debajo de los 40 puntos, y sólo los corregimientos de San Antonio de Prado y Santa Elena consiguen acercarse a los 43 puntos, lo que permite leer un desafío central en ese camino hacia la equidad y hacia la reducción de las brechas sociales y económicas entre comunas y corregimientos, lo que sugiere que esta administración debe focalizar sus esfuerzos institucionales y presupuestales en impactar estos aspectos.

Mapa 2: Índice Multidimensional de condiciones de Vida.

Distribución por comunas y corregimientos en la ciudad de Medellín, 2014

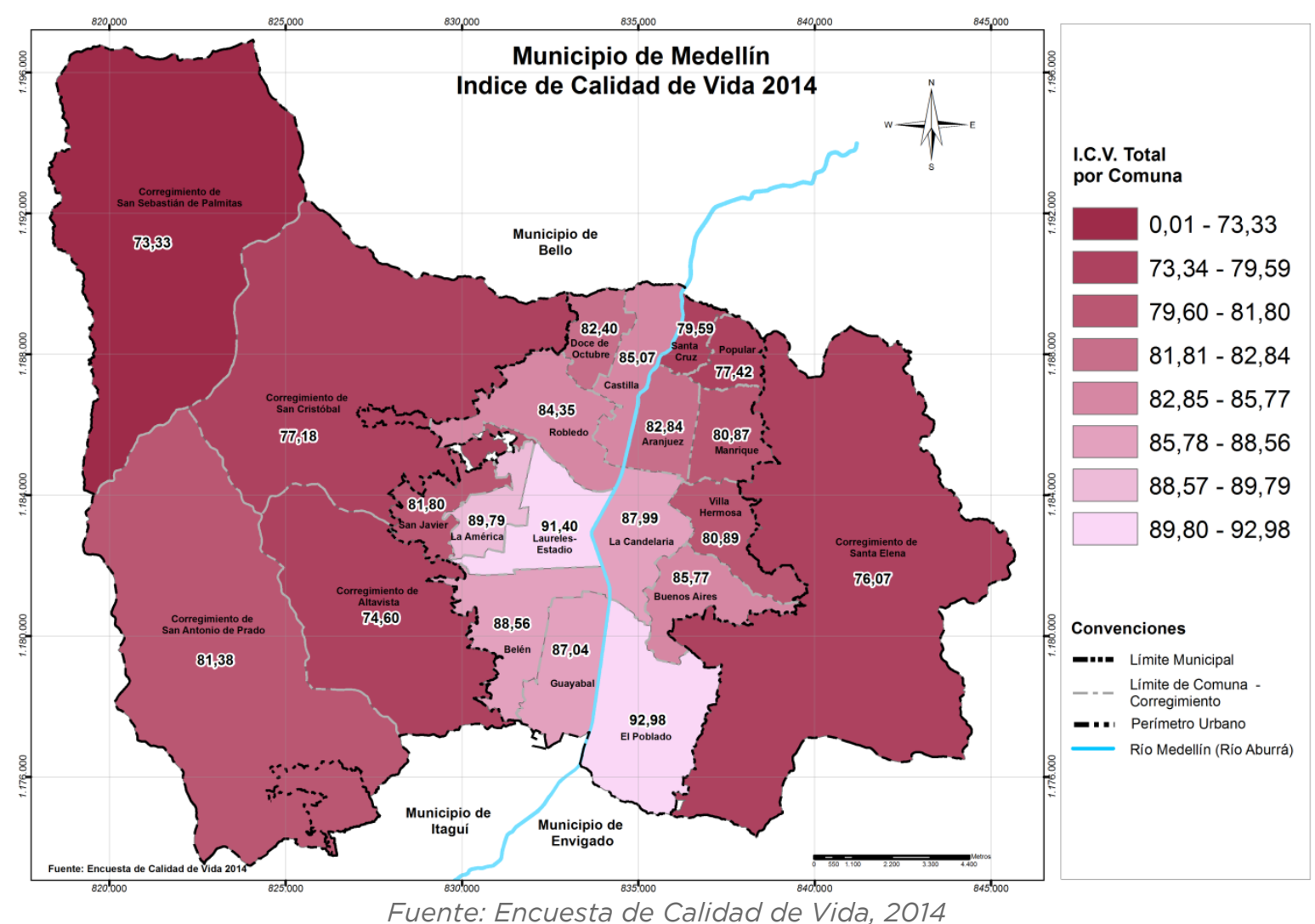

Creemos en el crecimiento que se traduce en desarrollo, educación, empleo, oportunidades laborales y mejores condiciones de vida para nuestros ciudadanos. Reconocemos las potencialidades y fortalezas que hacen posible el ejercicio de los procesos de planificación para el desarrollo humano integral de la población urbana y rural de Medellín, toda vez que para este gobierno no hay lugar a la improvisación, pues la planeación estratégica y participativa configura una de las bases fundamentales de esta apuesta por construir la ciudad que soñamos.

Así mismo, en este Plan de Desarrollo creemos que el respeto por la vida y la resolución pacífica de los conflictos son aspectos innegociables y fundamentales para la consolidación de la cultura ciudadana, una cultura edificada sobre la confianza, la honestidad, la solidaridad, el civismo, la 
legalidad y la paz, que ubica en un primer plano la dignidad humana y propende por una gestión transparente, eficiente y cercana a la ciudadanía y sus intereses. Esta debe ser la base sobre la que se construya la ciudad que queremos, una en la que la cultura de la legalidad venza, de una vez por todas, la cultura de la trampa; en la que lo público deje de ser visto como un negocio para pasar a ser considerado como un deber, un servicio y un compromiso de todos.

Nos encontramos ante una ciudad que se ha esforzado por dar continuidad a políticas públicas, programas y proyectos dirigidos a contrarrestar los fenómenos de pobreza extrema, violencia y delincuencia que obstaculizan el desarrollo humano integral de la población e impiden el crecimiento económico. No obstante, los problemas relacionados con la inseguridad constituyen una de las principales prioridades de este Plan de Desarrollo, pues creemos que la seguridad representa un pilar fundamental para la sociedad, una seguridad que no es de izquierda ni de derecha sino un derecho que hay que garantizar a la totalidad de la población. Y aunque Medellín ha registrado durante el año 2015 la tasa más baja de homicidios de los últimos 30 años, con 27 homicidios por cada 100 mil habitantes, creemos que la seguridad no se puede medir únicamente mediante un solo indicador, pues el crimen es plural. Deben considerarse otros delitos que tienen impacto en la ciudadanía y mantienen al habitante en una sensación de inseguridad e intranquilidad.

En este Plan de Desarrollo trabajamos de la mano de la ciudadanía por una Medellín sin miedo, y creemos que la ciudad debe ser un lugar para el encuentro y el goce efectivo de derechos, donde sus habitantes disfrutan y utilizan de manera adecuada el espacio público. Sin embargo, no desconocemos la realidad que se vive en las comunas y corregimientos de Medellín, cuyas problemáticas se asocian al control territorial y poblacional de organizaciones delincuenciales que repercuten en cifras significativas, y todavía preocupantes, en fenómenos como el hurto a personas y vehículos, cuyo aumento en 2014 fue de 12.533 casos reportados frente a los 11.658 casos reportados en 2013, lo que muestra un aumento del $8 \%$ y una grave situación de crecimiento de la criminalidad en la ciudad. Así mismo, tal y como se evidencia en el gráfico 2, el desplazamiento forzado intraurbano constituye uno de los delitos que más afecta la seguridad de la ciudad, pues en el año 2014 se registraron 1.774 casos ante la Personería de Medellín que significaron 5.395 víctimas. 
Gráfico 2: Casos reportados de desplazamiento forzado intraurbano en Medellín. Periodo 2007-2014

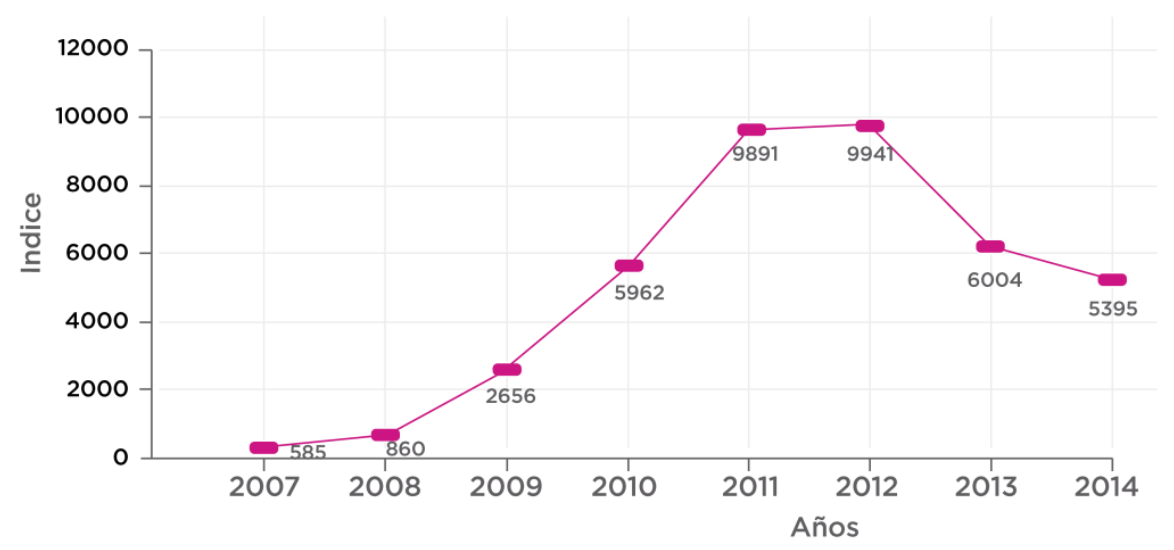

- Casos reportados de desplazamiento forzado intraurbano en Medellín.

Fuente: Personería de Medellín, 2015

Por tal razón, este plan diseña y articula una estrategia integral de seguridad y convivencia ciudadana que no se limita exclusivamente a los aspectos punitivos y policiales sino que se complementa con un amplio entramado de programas y proyectos dirigidos a la promoción de buenas prácticas ciudadanas sostenidas sobre la cultura de la legalidad, que propenden por el cuidado colectivo del espacio público y la protección de los Derechos Humanos, fortaleciendo la infraestructura institucional y garantizando el acceso a la justicia de toda la población. Este conjunto de estrategias multidimensionales e interrelacionadas inciden directamente en la percepción ciudadana de seguridad en la ciudad, cuyas variaciones al interior de las comunas y corregimientos exhiben, por un lado, niveles de sensación de seguridad por encima de 65 puntos en comunas como Popular, Manrique y Santa Cruz y, por otro, comunas con niveles por debajo de los 40 puntos como Laureles-Estadio y La Candelaria, cifras que permiten reconocer una problemática generalizada de inseguridad que impactan la percepción ciudadana en sectores que padecen el flagelo de la delincuencia, la extorsión y el homicidio. La acción interinstitucional y el acompañamiento permanente de la fuerza pública permitirán consolidar a Medellín como un territorio de paz, que garantiza el libre desarrollo, la movilidad y uso efectivo del espacio público, donde sus habitantes tramitan sus conflictos por medios no violentos y aportan de manera conjunta a la reconstrucción del tejido social y familiar. 


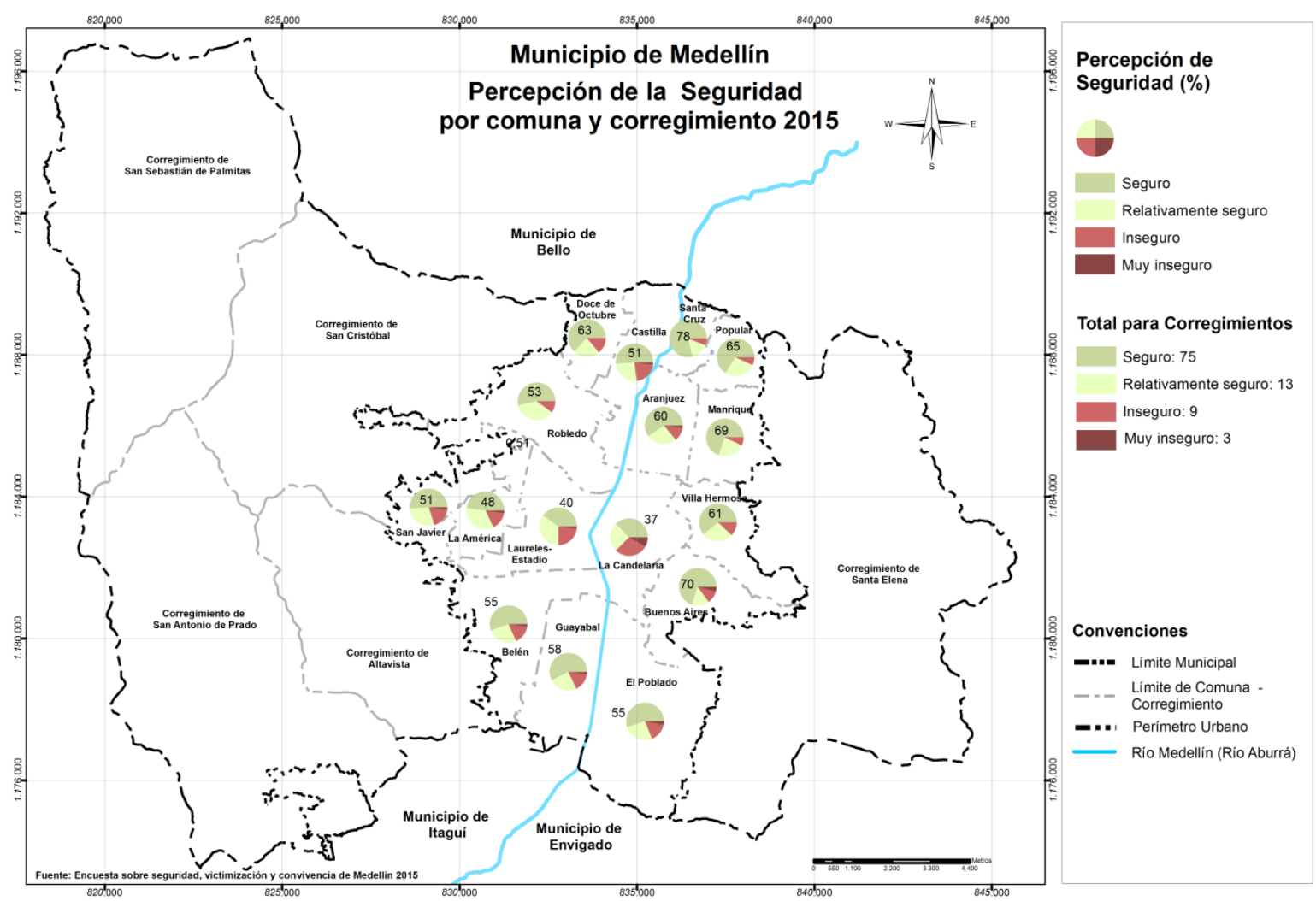

Fuente: Encuesta sobre seguridad, victimización y convivencia de Medellín, 2015

En este contexto, el liderazgo del Alcalde desempeña un papel central en esta estrategia de seguridad, pues frente a este adverso panorama de incremento de la delincuencia urbana y rural se ha propuesto liderar acciones como los Consejos de Seguridad que favorecen la cercanía con la ciudadanía y sus necesidades, lo que se traduce en una estrategia de articulación y respuesta ante la criminalidad y la violencia que se refleja en una política criminal concreta y efectiva.

La garantía de los derechos fundamentales a la educación y a la salud constituye un aspecto central de nuestra gestión hacia la Medellín equitativa y competitiva que pretendemos construir. El descenso en las cifras que arroja la tasa de deserción de personas en edad escolar en establecimientos oficiales, las cuales han pasado de un 4,11\% en 2004 al $3,11 \%$ del total de la población, permite reconocer y valorar el esfuerzo realizado por las antecedentes administraciones para garantizar la permanencia en el sistema educativo.

De igual forma, este gobierno municipal dirigirá todo su esfuerzo y capacidad institucional para garantizar y ampliar la cobertura educativa y la calidad en los niveles básico, medio y en la educación superior, en tanto los indicadores muestran la tasa de cobertura neta más alta de la última década en todos los niveles educativos, representada en más del $90 \%$ del total de la población. Además, la equidad social solo se hace 
efectiva en la medida en que la ciudadanía goza efectivamente del derecho a la salud y recibe condiciones dignas de prestación de los servicios sin ningún tipo de discriminación. Por tanto, motivamos a la ciudadanía a ejercer el control social y la veeduría al sistema municipal de salud, favoreciendo y promocionando la participación social y comunitaria en salud.

Potenciar la educación con calidad para el desarrollo es un objetivo prioritario, pues en este plan creemos que la educación es el valor máximo que tiene una sociedad para superar la pobreza y fortalecer el sistema productivo, lo que se traduce en un aumento de oportunidades de acceder al mercado laboral, contribuir al desarrollo económico local y mejorar las condiciones de vida de los ciudadanos. No obstante, tal y como lo señala nuestra administración, es necesario contribuir al mejoramiento de la calidad de los servicios y la infraestructura educativa, que permita garantizar, por un lado, el derecho fundamental a la educación, y por otro, conseguir los más altos estándares de calidad que permitan la articulación a procesos de investigación y desarrollo en ciencia y tecnología, que favorezcan la interconexión de Medellín como polo de innovación frente a las exigencias que el mercado internacional plantea, que posibilite ajustarse a los avances tecnológicos que requieren de personal cualificado y del desarrollo de procesos locales de generación de conocimiento.

La formación de capital humano cualificado y la generación de nuevos empleos impactan directamente el desarrollo de la industria local y el crecimiento empresarial, por ello el Plan desarrolla una variedad de programas dirigidos al fortalecimiento de la infraestructura comercial que garantiza la creación de empleos dignos y decentes para el beneficio de la población urbana y rural del municipio de Medellín. Aunado a esta estrategia de formación de habilidades y capacidades para el empleo digno, surge la necesidad de afrontar uno de los principales retos hacia el mejoramiento de la calidad de vida de los habitantes de nuestra ciudad, esto es, el acceso y cobertura efectiva de los servicios públicos domiciliarios.

A pesar de que existen cifras de cobertura y conexión a redes de energía que rondan el $100 \%$ del total de la población urbana y rural de nuestro municipio, los indicadores de conexión a redes de acueducto y alcantarillado para los habitantes de las diferentes comunas y corregimientos de Medellín expresan amplias brechas en las condiciones y oportunidades de cobertura y acceso a servicios públicos de calidad que propicien el bienestar colectivo de la población, mostrando cifras de $96,7 \%$ para la zona urbana y $88,1 \%$ para la zona rural en cobertura de servicios de acueducto, $91,6 \%$ y $66,1 \%$ de cobertura en alcantarillado y de $94,3 \%$ y $50,1 \%$ en la cobertura de aseo, respectivamente.

Lo anterior demuestra un avance destacable en las oportunidades de acceder a servicios públicos de calidad para el bienestar de la población urbana, pero además, la necesidad de garantizar el derecho al acceso de 
servicios públicos a los habitantes de las zonas rurales, mejorar las condiciones de prestación de los mismos y contribuir, de manera efectiva, al mejoramiento las condiciones de subsistencia en la totalidad del territorio.

Los procesos de renovación urbana y la consolidación de espacios para el disfrute y el encuentro de la ciudadanía precisan de una transformación efectiva del espacio público, que implica, necesariamente, desarrollar procesos de intervención hacia la consecución de un sistema de movilidad sostenible, entendido como un escenario en donde se articulan los diferentes medios de transporte propiciando el cuidado del medio ambiente. También, es indispensable consolidar el sistema integrado de transporte en toda la ciudad, pues creemos que la ciudad tiene grandes retos en materia de mejoramiento de la infraestructura para la movilidad, que permita optimizar y ampliar la malla vial y mejorar las condiciones de prestación del servicio de transporte masivo. Estas problemáticas en asuntos referidos al uso y accesibilidad al sistema de transporte público, a la necesidad de complementar la red de metrocables y tranvías, y a la promoción de medios de transporte no motorizados requieren de un plan integrado de movilidad sustentable, orientado al mejoramiento de la calidad de vida de todos los habitantes de la ciudad y al aprovechamiento del espacio público.

El Plan de Desarrollo 2016-2019, Medellín cuenta con vos, presenta a la ciudadanía la posibilidad de materializar la ciudad que soñamos. Una ciudad que reconoce como fundamento del orden social el respeto por la vida y el reconocimiento de la diversidad, que tramita sus conflictos por medios pacíficos y que hace posible el ejercicio de la ciudadanía desde la perspectiva de derechos en el marco de un escenario de corresponsabilidad, donde el Estado y sus ciudadanos se comprometen en un pacto común orientado al mejoramiento de la calidad de vida. Construir una Medellín segura, legal y equitativa es un compromiso de todos.

\section{- OBJETIVO SUPERIOR •}

Nuestro objetivo es hacer de Medellín una ciudad segura, equitativa y sostenible; que mejora las condiciones de vida y genera más y mejores oportunidades para la población urbana y rural, una ciudad que construye cultura ciudadana y recupera la confianza institucional a partirde una gestión eficiente y transparente para la ciudadanía, una ciudad donde la seguridad es un derecho, y la educación de calidad y pertinente sea la base para el desarrollo y la competitividad. 


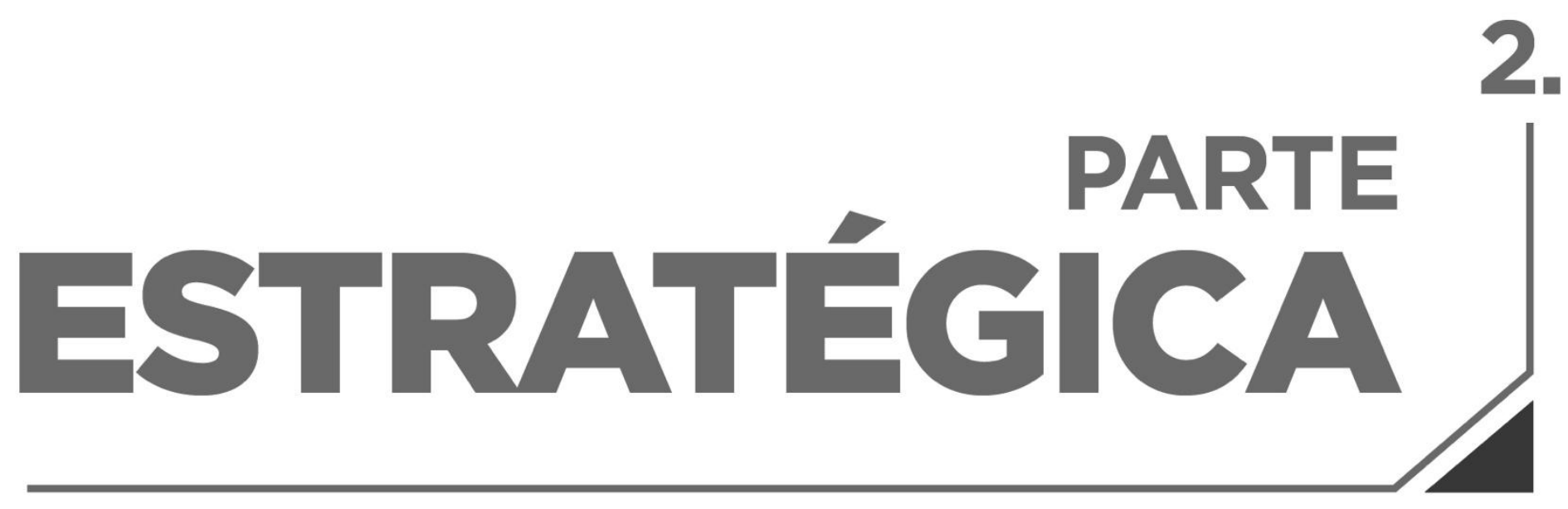




\section{- INDICADORES GENERALES •}

"El Producto Interno Bruto no tiene en cuenta la salud de nuestros hijos, la calidad de su educación, o la alegría de su juego, la belleza de nuestra poesía o la fortaleza de nuestros matrimonios; en fin, mide todo, excepto lo que hace que la vida valga la pena". Robert F. Kennedy, Universidad de Kansas 18 de marzo, 1968

A continuación se hace una presentación técnica de aquellos indicadores estratégicos que soportarán el ejercicio de seguimiento, diagnóstico y evaluación general de la evolución a través del tiempo de las condiciones de vida (ambientales, culturales, económicas y sociales, entre otras), bienestar, felicidad y desarrollo de la ciudad.

\section{Creemos en una ciudad feliz}

Índice de Felicidad Integral (IFI)

El Índice de Felicidad Integral (IFI) se plantea como un ejercicio alternativo dentro de los ya realizados en la ciudad para medir el desarrollo integral de su población, esta vez desde la medición sistémica de la experiencia de felicidad sentida por sus habitantes y de los mecanismos y acciones que despliega la ciudad para contribuir a dicha felicidad.

Lo anterior diferencia al IFI de otros índices que miden la felicidad que centran su atención exclusivamente en dimensiones subjetivas. El IFI hace hincapié tanto en la reproducción de la felicidad y satisfacción con la vida que es sentida e interpretada por las personas (con respecto a sus emociones, sensación subjetiva y respuesta ante el entorno), como en aquellas condiciones que la ciudad genera y dispone para que esta experiencia sea efectivamente posible. Esto implica reconocer la capacidad de felicidad de una población en un territorio, desde la correlación entre diferentes tipos de desarrollo: material, social, ambiental, y personal (psicológico, espiritual, y emocional), es decir, la importancia recíproca tanto de factores objetivos como subjetivos.

Gracias a este ejercicio Medellín conocerá qué tan feliz es su población y también cómo la ciudad se organiza para potenciar esta emoción. Además de contar con información estratégica para analizar la correspondencia entre la felicidad, el bienestar y la calidad de vida de sus habitantes.

\section{Aspectos conceptuales}

Las diferentes disciplinas que tienen como objeto al ser humano individual y en sociedad (psicología, antropología, sociología, entre otras), han estudiado la felicidad reconociendo de paso la dificultad de construir un concepto único de ella, ya que básicamente cada persona 
reconoce para sí los elementos y condiciones que le configuran: cada quien contiene una dimensión infinita de criterios que le llevan a experimentar la felicidad.

No obstante esta dificultad, Veenhoven (2001 y 2005) ha establecido que la felicidad puede ser entendida como el grado de emoción positiva con el cual una persona evalúa y considera la calidad total de su vida presente; en otras palabras, en qué manera aprecia la vida que lleva.

También García Martín (2002), plantea que es posible identificar tres posturas generales sobre la felicidad:

- Aquella que focaliza su atención en la valoración de la vida que las personas realizan -satisfacción con la vida-.

- La segunda, enfocada en el bienestar subjetivo y las emociones positivas y negativas -estado de ánimo-.

- Y la última, donde se aborda la felicidad como virtud (concentrándose principalmente en los aspectos morales, religiosos y filosóficos).

A diferencia de la calidad de vida objetiva que se remite a la satisfacción de las necesidades básicas y estándares de buena vida obtenidos por una persona (Veenhoven, 2000), y del bienestar como la satisfacción y tranquilidad que es experimentada en relación con sus condiciones de vida aptas -sean estas físicas, mentales y materiales- (Zapf, 1984), la felicidad implica una autoapreciación basada en criterios personales y subjetivos.

\section{Aspectos metodológicos}

Para la estructuración de este ejercicio se retomaron aportes de experiencias posicionadas mundialmente que han compartido el interés por medir y/o impulsar la felicidad:

* GNH - Gross National Happinnes (en español FIB - Felicidad Interior Bruta), este indicador se enfoca en la medición de la felicidad asumida como valor subjetivo, y en sintonía con la calidad de vida vista en términos holísticos.

* HPI - Happy Planet Index: es un indicador alternativo para la medición del desarrollo sobre la base de la expectativa de vida, la percepción subjetiva de felicidad y el impacto ambiental generado por la demanda humana.

* HCl - Happy City Index: es tanto un proyecto como un ejercicio de medición del progreso y la prosperidad en el siglo XXI. Parte de la premisa de que si bien la felicidad es subjetiva, es posible establecer condiciones para que las personas tengan la posibilidad de serlo. 
* Informe de Felicidad de España: estudio que analiza el nivel de felicidad de los españoles en comparación con otros países de Europa.

Dimensiones

Se tiene en cuenta para el diseño de este índice, la delimitación de sus dimensiones en clave de los factores de producción y factores intrínsecos, necesarios para que la felicidad pueda suscitarse:

Factores de producción

La viabilidad del ambiente: se refiere a condiciones de vida óptimas para que la persona logre ser feliz, sinónimo de calidad de vida y bienestar.

La viabilidad personal: es decir, qué tan preparada está una persona para enfrentar los retos de la vida, como la habilidad para disfrutar de la misma (sea esta física, mental y emocional).

Dimensiones Indice de Felicidad Integral IFI

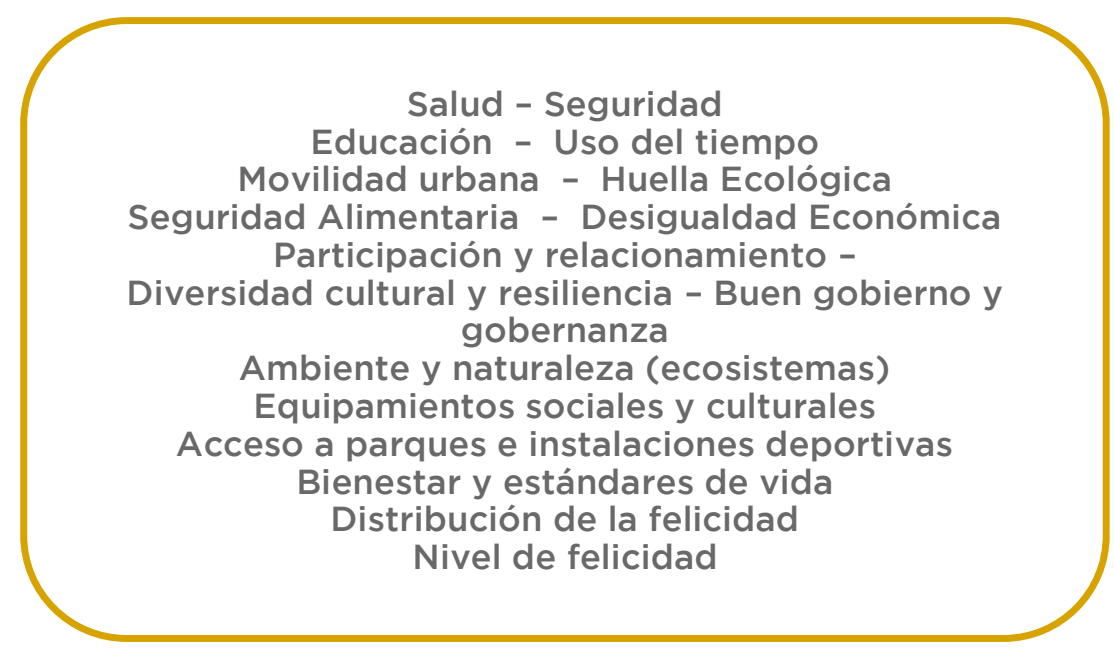

Creemos en el bienestar, igualdad y vida digna para la población

Índice Multidimensional de Condiciones de Vida (IMCV)

Es un indicador compuesto que permite medir la evolución de las condiciones de vida de la población de Medellín, e incorpora el concepto de la multidimensionalidad, el cual combina en una sola medida variables cuantitativas y cualitativas que en la teoría y en la práctica se han encontrado más relacionadas con el estándar de vida de la población y en

1 Teniendo como referentes las cuatro cualidades de vida (Veenhoven, 2005: 22) 
el de las dimensiones porque permite integrar características integrales, especialmente las relacionadas con el capital humano.

Su propósito es medir las condiciones de vida de la población a través de quince dimensiones: entorno y calidad de la vivienda, acceso a servicios públicos, medio ambiente, escolaridad, desescolarización, movilidad, capital físico del hogar, participación, libertad y seguridad, vulnerabilidad, salud, trabajo, recreación, percepción de la calidad de vida e ingresos.

Con este índice se da un paso adelante en la comprensión y en la medición de las dimensiones del bienestar, porque permite calificar los resultados de las políticas frente a criterios de desarrollo.

Gráfico 3. Índice Multidimensional de Condiciones de Vida, 2010-2014

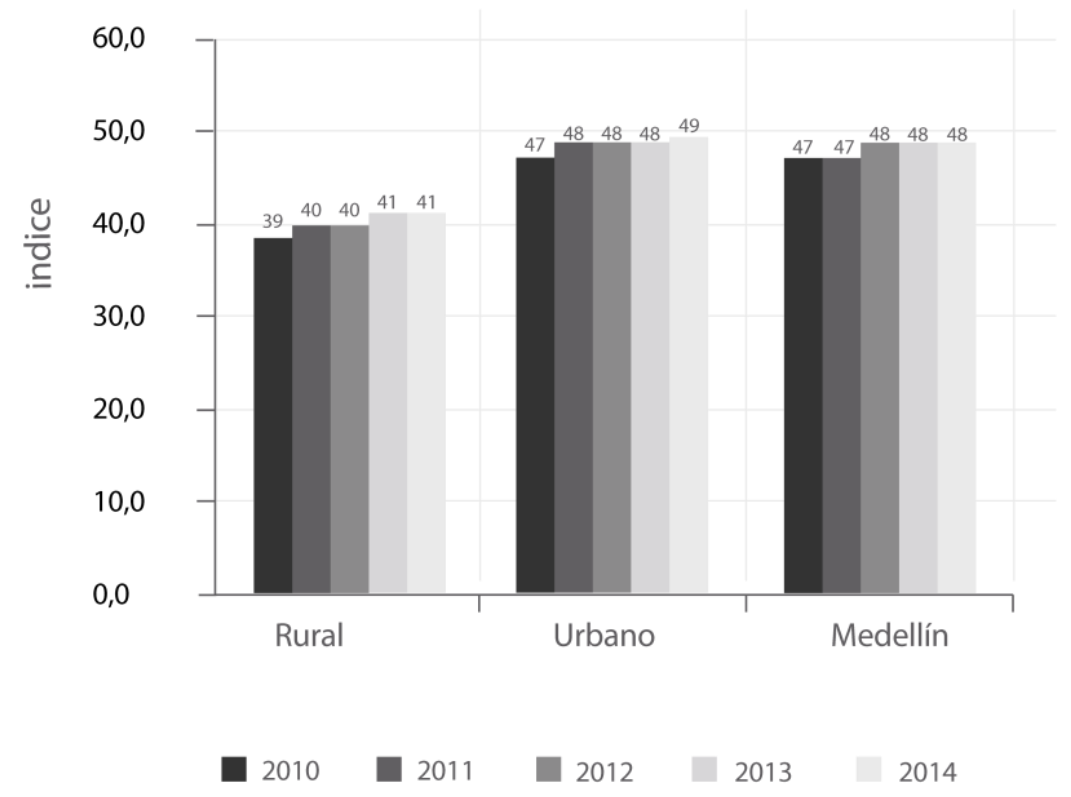

Fuente: Alcaldía de Medellín - Departamento Administrativo de Planeación, Subdirección de Información. Observaciones: Cifras con base en resultados de la Encuesta de Calidad de Vida.

Según los últimos datos disponibles para la ciudad, el comportamiento del IMCV entre 2010-2014 es creciente, tanto para el nivel urbano cuyo incremento fue de $2,5 \%$, como para el rural, que lo hizo en $2,8 \%$ (pasando de 38,6 a 41,0 y de 47,3 a 48,8 respectivamente).

A nivel de ciudad el IMCV subió en un 2,3\%, pasando de 46,7 a 48,1 en el período de tiempo referenciado, lo que implica un mejoramiento de los estándares de vida y la promoción de derechos. 


\section{Coeficiente de Gini}

El Gini es una medida de la concentración del ingreso entre las personas que habitan una ciudad, región o país, en un determinado período, el cual permite conocer qué tan desiguales pueden ser en términos de ingresos. En este indicador un valor de cero $(0)$ indica que todos los habitantes del territorio tienen los mismos ingresos (igualdad), mientras que cuando tiende a uno (1) muestra que los ingresos son detentados por unos cuantos habitantes (desigualdad).

Cabe recalcar que este coeficiente no mide el bienestar de una sociedad; tampoco permite, por sí solo, determinar la forma como está concentrado el ingreso; y no indica la diferencia entre mejores condiciones de vida en un territorio u otro. Focalizando su objeto de medición solo en la distribución de ingresos, aunque es insensible ante los cambios en la distribución de ingreso, es más sensible a aumentos en el ingreso de los individuos más pobres.

Gráfico 4. Coeficiente de Gini, Medellín-AM, 2002-2005 y 2008-2014

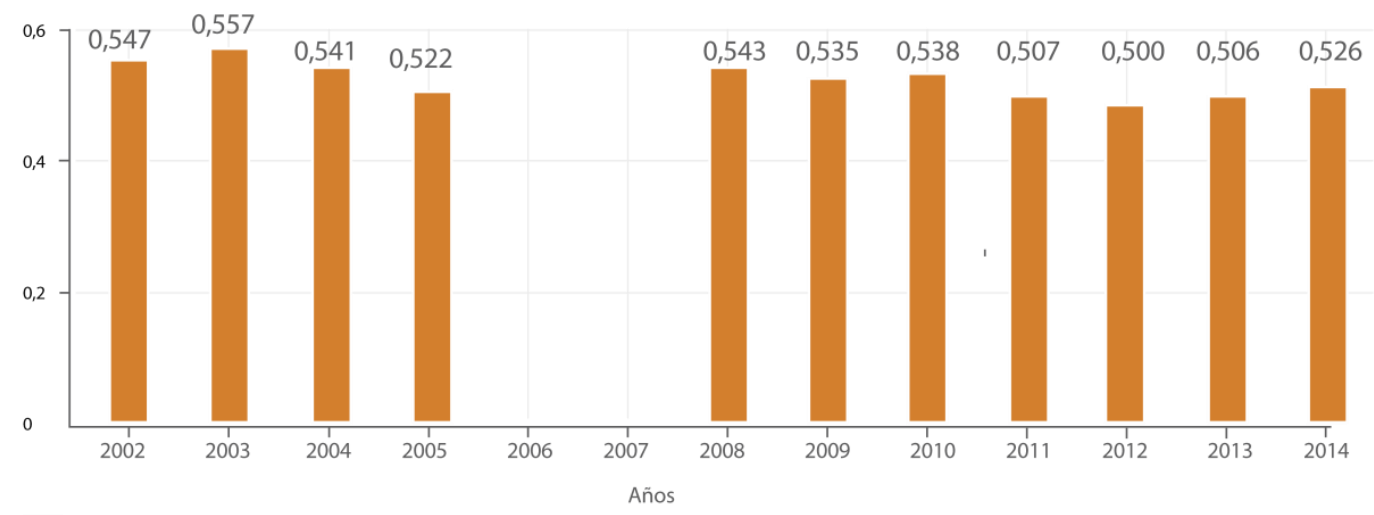

Coeficiente de Gin

Fuente: Departamento Administrativo Nacional de Estadística (DANE), con base a la Gran Encuesta Integrada de Hogares (GEIH).

Observación: El Área Metropolitana incluye los municipios de Barbosa, Bello, Caldas, Copacabana, Itagüí, La Estrella, Medellín y Sabaneta.

Este indicador evidencia una tendencia diversa, presentando incrementos y disminuciones a lo largo del período 2002-2014. Entre estos años el Coeficiente de Gini ha disminuido 4,0\%, aunque se evidencia un leve aumento entre 2013 y 2014 (del 3,8\%).

Indicadores de pobreza monetaria e Índice de Pobreza Multidimensional (IPM)

El cálculo de estos indicadores surge tanto de la necesidad de contar con una medida sobre la afectación de la pobreza en la ciudad, como de profundizar en análisis relacionados con las múltiples dimensiones de la pobreza diferentes a la variable de ingresos. 
En su conjunto, estos indicadores permiten aproximarse a la situación de pobreza que enfrenta la ciudad de forma objetiva (en cuanto las capacidades que tiene la ciudadanía para poder acceder a bienes y servicios según su nivel de ingresos), y subjetivamente (de acuerdo a las privaciones que pueda tener un hogar para acceder a educación, salud, vivienda, alimentos, servicios públicos).

La cuantificación de este índice se realiza a partir de cinco dimensiones: condiciones educativas del hogar (bajo logro educativo y analfabetismo); condiciones de la niñez y juventud (inasistencia escolar, rezago escolar, barreras de accesos a servicios para el cuidado de la primera infancia y trabajo infantil); trabajo (desempleo de larga duración y empleo informal); salud (sin aseguramiento en salud y barreras de acceso a servicios de salud); y acceso a servicios públicos domiciliarios y condiciones de la vivienda (sin acceso a fuente de agua mejorada, inadecuada eliminación de excretas, pisos inadecuados, paredes exteriores inadecuadas, hacinamiento crítico).

Gráfico 5. Indicadores de Pobreza monetaria extrema y moderada para Medellín-AM (2002-2005 y 2008-2014), e Índice de Pobreza Multidimensional (IPM) de Medellín, 2012-2014

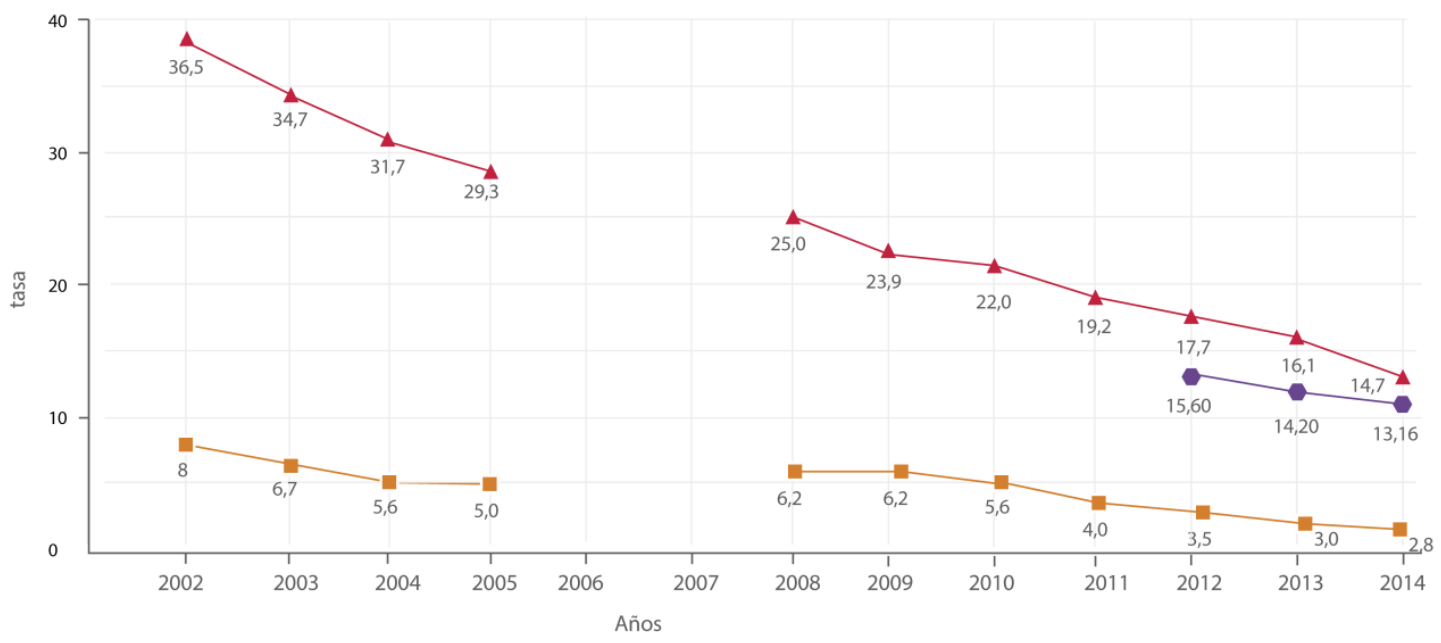

Pobreza Monetaria Extrema

- Indice de Pobreza Multidimensional

$\Delta$ Pobreza Monetaria Moderada

Fuente: Indicadores de pobreza extrema y moderada: Departamento Administrativo Nacional de Estadística (DANE), con base a la Gran Encuesta Integrada de Hogares (GEIH). Indice de Pobreza Multidimensional: Departamento Administrativo de Planeación de Medellín en base a la ECV y la GEIH.

Observación: El Área Metropolitana incluye los municipios de Barbosa, Bello, Caldas, Copacabana, Itagüí, La Estrella, Medellín y Sabaneta.

El indicador de pobreza extrema para Medellín y el Área Metropolitana muestra entre 2002 y 2014 una tendencia decreciente del porcentaje de población bajo esta condición (en 5,2 pp -puntos porcentuales-), 
pasando de 8,0 a 2,8. Tendencia compartida por el indicador de pobreza moderada que lo hizo en 21,8 pp (pasando de 36,5 a 14,7).

Estas cifras muestran una significativa disminución de la problemática de la pobreza, como del impacto de las políticas sociales orientadas a mejorar el bienestar e inclusión de la ciudadanía en las ganancias del crecimiento.

A su vez, el Índice de Pobreza Multidimensional (IPM) muestra entre 2012 y 2014 un aumento en el acceso a oportunidades de bienestar y desarrollo para la población de Medellín. En este período el índice disminuyó 2,4 pp (pasando de 15,6 a 13,2), lo que traduce durante este período que cerca de 48.500 personas superaron condiciones de este tipo de pobreza. 


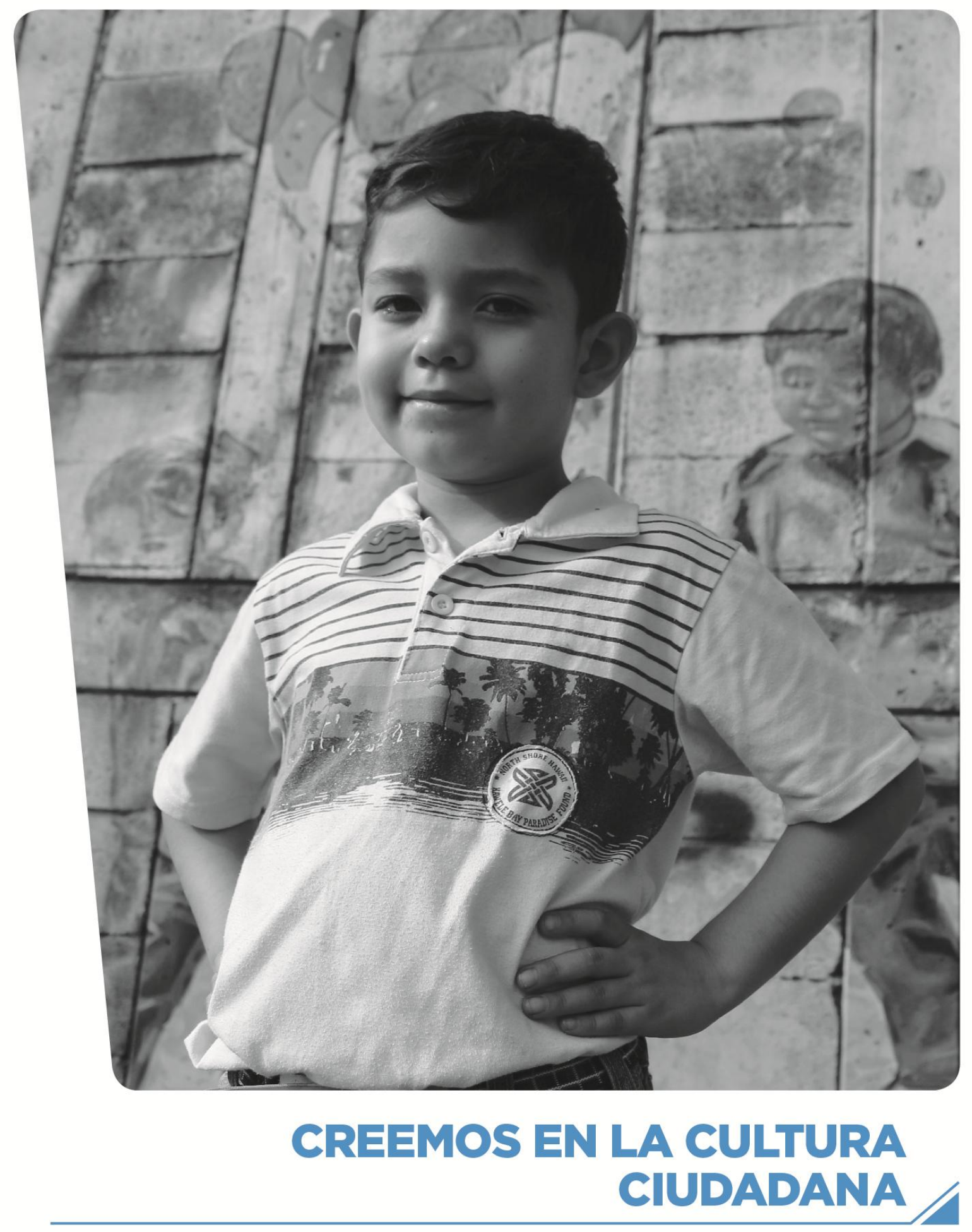




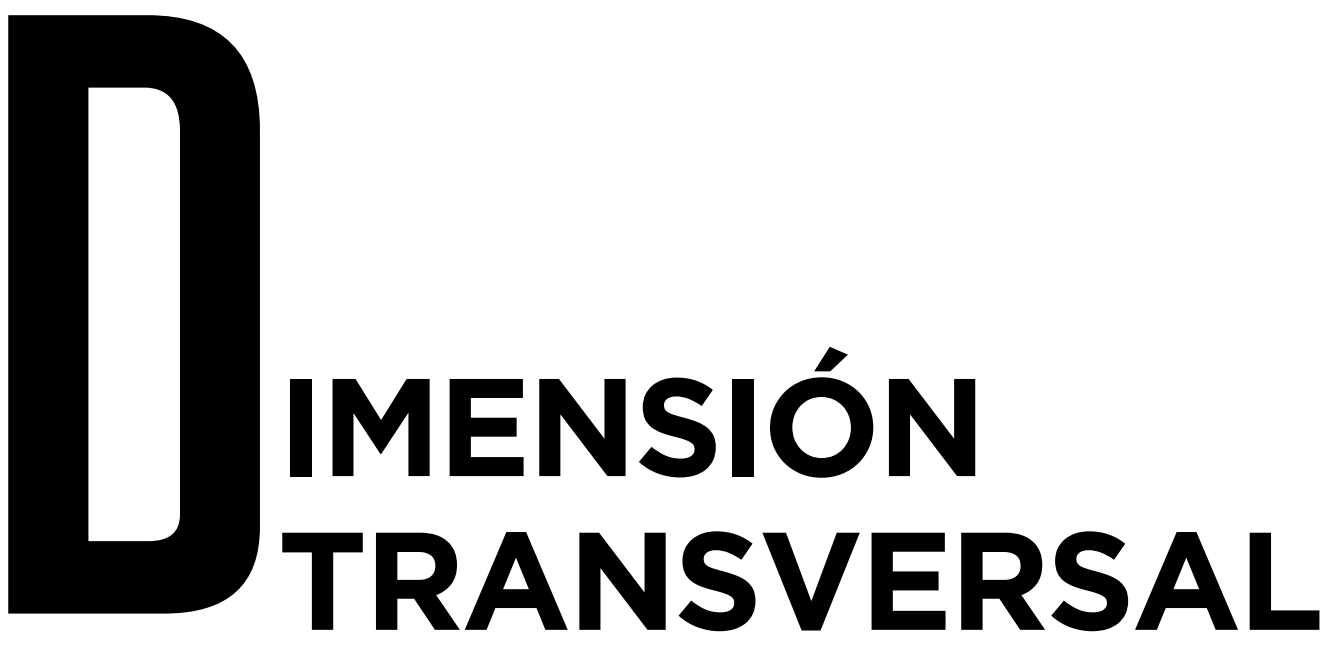

\section{Creemos en la cultura ciudadana}

Generar las condiciones para que el comportamiento ciudadano e institucional se regulen y transformen por las normas sociales positivas, la legalidad, la transparencia y la eficiencia en el uso de los recursos públicos. 


\section{- DIAGNÓSTICO •}

"Creemos en la Cultura Ciudadana" se constituye como el eje transversal del Plan de Desarrollo Medellín cuenta con vos 2016-2019, una apuesta hacia la trasformación de las prácticas ciudadanas que representa la base fundamental de los cambios que se requieren para construir la ciudad que soñamos. Conseguir tales transformaciones precisa de un proceso colectivo de generación y recuperación de la confianza, que logre garantizar el buen funcionamiento de una sociedad. Confiar en el otro contribuye a romper el círculo vicioso de justificación para infligir las normas "porque los demás las infringen". Por tal razón, nuestro programa de gobierno promociona e incentiva la formación de ciudadanos que actúan bajo acciones de convivencia y civismo en el marco de la ley.

Creemos que la confianza en las personas influye significativamente en el correcto funcionamiento de la vida social, la convivencia y la seguridad, ya que en la medida en que exista confianza será más fácil la solución de los problemas colectivos, dado que esta determina significativamente la disposición a cooperar entre las personas y los grupos sociales. Esta confianza es clave no sólo a nivel interpersonal sino a nivel institucional, toda vez que la ciudadanía se relaciona de una u otra forma con las estructuras y los organismos del Estado de Derecho. El Plan de Desarrollo prestará especial atención a estos dos tipos de confianza, ya que su comportamiento será un termómetro del impacto de los programas y proyectos desarrollados en esta dimensión.

Según la medición de confianza que propone la Encuesta de Cultura Ciudadana (ECC 2015) Medellín registró niveles de confianza interpersonal de 62\% para el año 2015 y de confianza institucional del $26 \%$ para el mismo año; es por esto que, los esfuerzos realizados a partir de esta dimensión se dirigen a elevar el nivel de confianza en ambos aspectos, de tal manera que sea el resultado de una administración competente, visible y eficaz que está comprometida con mejorar la calidad de vida de la población, fortaleciendo la cohesión y la interrelación efectiva entre los ciudadanos y las estructuras gubernamentales, influyendo directamente en el ejercicio políticoadministrativo eficiente y favoreciendo la gobernabilidad en el territorio.

Este ejercicio de confianza requiere del compromiso de todos los habitantes de la ciudad de Medellín de regir todas las prácticas ciudadanas bajo el marco legal y normativo, pues a partir de la sujeción a las leyes es posible contribuir a la cultura de la legalidad, la cual debe primar como pauta de consolidación de las relaciones humanas hacia comportamientos y prácticas orientadas al bienestar colectivo y al cuidado del entorno. El objetivo de erradicar las prácticas ilegales de las relaciones sociales, económicas, políticas y culturales viene de la mano de 
las transformaciones locales que favorecen mayores oportunidades para los ciudadanos, pues se ataca directamente un fuerte obstáculo para el desarrollo de actitudes pacíficas que son la base de la vida en sociedad.

Medellín es líder en urbanismo pedagógico, políticas culturales comunitarias y educativas para la diversidad étnica y poblacional, propiciando la formación ciudadana desde las expresiones artísticas particulares. No obstante, la ciudad debe enfrentar retos como la interacción de la cultura ciudadana como eje transversal a otros sectores (económico, político, social y ambiental) y la construcción de nuevas ruralidades, que implica expandir los efectos de las políticas públicas al escenario rural y se traducen en nuevas formas de comprender y habitar dichos territorios.

Tabla 1. Comparación de indicadores de cultura ciudadana en Medellín 2007 a 2015

\begin{tabular}{|c|c|c|c|c|c|c|c|}
\hline 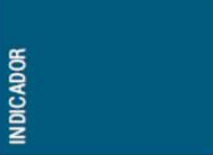 & 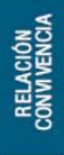 & 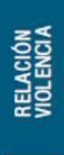 & $\begin{array}{l}\text { 올 } \\
\text { 정 }\end{array}$ & $\begin{array}{l}\text { 을 } \\
\text { ㅊ } \\
\text { ż } \\
\text { 팰 }\end{array}$ & 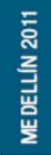 & 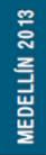 & 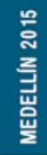 \\
\hline Pluralismo & $\uparrow$ & $\downarrow$ & $\begin{array}{l}\text { Personas que no manifiesta inconformidad en tener como } \\
\text { vecino a: enfermos de sida, personas de religión distinta, } \\
\text { personas de nacionalidad distinta, personas de región } \\
\text { distinta, personas de color distinto }\end{array}$ & & & & \\
\hline $\begin{array}{l}\text { Razones desobedecer } \\
\text { la ley }\end{array}$ & $\downarrow$ & $\uparrow$ & $\begin{array}{l}\text { Promedio de personas que justifica desobedecer la ley } \\
\text { por alguna de las } 10 \text { razones preguntadas (se excluye } \\
\text { desobediencia civil) }\end{array}$ & & & & \\
\hline Razones violencia & $\downarrow$ & $\uparrow$ & $\begin{array}{l}\text { Promedio de personas que justifica utilizar la violencia } \\
\text { por alguna de las } 10 \text { razones preguntadas (se excluye } \\
\text { desobediencia civil) }\end{array}$ & & & & \\
\hline Disposición a regular & $\uparrow$ & $\downarrow$ & $\begin{array}{l}\text { Personas que estarian dispuestas a llamle la atención a } \\
\text { otra persona si la vieran saltarse el turno de una fila o cola, } \\
\text { arrojar basuras a la calle, llegar tarde a una cita o reunión } \\
\text { de trabajo, comprar mercanclas de contrabando o piratas o } \\
\text { cruzar la calle por donde no se debe }\end{array}$ & & & & \\
\hline $\begin{array}{l}\text { Disposicion a ser } \\
\text { regulado }\end{array}$ & $\uparrow$ & - & $\begin{array}{l}\text { Personas que aceptarlan el llamado de atención en las } \\
\text { sigulentes situaclones: saltarse el tumn de una fila o cola, } \\
\text { arrojar basuras a la calle, llegar tarde a una cita o reunión } \\
\text { de trabajo, comprar mercanclas de contrabando o piratas, } \\
\text { cruzar la calle por donde no se debe }\end{array}$ & & & & \\
\hline $\begin{array}{l}\text { Confianza inter } \\
\text { personal }\end{array}$ & $\uparrow$ & $\downarrow$ & $\begin{array}{l}\text { Promedio de los promedios de las conflanzas interpersonal } \\
\text { (personas que por lo general conflan en vecinos, amigos, } \\
\text { parientes y compañeros de estudio y trabajo) }\end{array}$ & & & & \\
\hline $\begin{array}{l}\text { Confianza en institu- } \\
\text { ciones }\end{array}$ & $\uparrow$ & - & Promedio de las frecuencias de conflanza en instituciones & & & & \\
\hline Confianza en la policla & $\uparrow$ & $\downarrow$ & $\begin{array}{l}\text { Total de personas que manifiestan tener mucha y muchisi- } \\
\text { ma conflanza en la policia }\end{array}$ & & & & \\
\hline $\begin{array}{l}\text { Confianza en jueces y } \\
\text { organos judiciales }\end{array}$ & $\uparrow$ & $\downarrow$ & Total de personas que conflan en estas dos instituciones & & & & \\
\hline Acuerdos de calidad & $\uparrow$ & - & $\begin{array}{l}\text { Personas que manifiestan que en los acuerdos que hacen } \\
\text { estos siempre lo acordado queda claro entre las partes, } \\
\text { son libres y voluntarios y cada parte conflia en que la otra } \\
\text { va a cumplir }\end{array}$ & & & & \\
\hline Porte de armas & - & $\uparrow$ & $\begin{array}{l}\text { Personas que responde de acuerdo y completamente de } \\
\text { acuerdo a la pregunta: "Pensando en la inseguridad de } \\
\text { la ciudad, usted cree que lo mejor es tener un arma para } \\
\text { protegerse" }\end{array}$ & & & & \\
\hline Victimización & $\downarrow$ & - & $\begin{array}{l}\text { Personas que manifiestan haber sido victimas o vivir con } \\
\text { algulen que ha sido víctima de algún delito en la ciudad } \\
\text { durante el último año }\end{array}$ & & & & \\
\hline $\begin{array}{l}\text { Disposición a la justicia } \\
\text { por mano propia }\end{array}$ & $\downarrow$ & $\uparrow$ & $\begin{array}{l}\text { Personas que están de acuerdo o completamente de } \\
\text { acuerdo con alguna de las siguientes frases: "Cuando un } \\
\text { grupo de ciudadanos atrapa un ladrón que acaba de robar } \\
\text { deberían darle una golpiza", "Cuando los policlas atrapan a } \\
\text { delincuentes deberian matarlos" }\end{array}$ & & & & \\
\hline
\end{tabular}

Fuente: Encuesta de cultura ciudadana 2015. 


\section{- PRESENTACIÓN•}

La Dimensión 1 sobre "CREEMOS EN LA CULTURA CIUDADANA", como el eje transversal del Plan de Desarrollo Medellín cuenta con vos 20162019, y como apuesta hacia la trasformación de las prácticas ciudadanas que se requieren para construir la ciudad y la sociedad que soñamos, esta basada en lograr los retos que queremos para Medellín, en cuanto a la cultura ciudadana enmarcada en la recuperación de los valores, de la confianza y de entornos más seguros y amables con el medio ambiente; en tener un Medellín participativo, mediante la formación y promoción para la participación ciudadana y para la representación de la comunidad; en tener una ciudad bien administrada, donde se destaque la transparencia como modelo de gestión y un excelente manejo de las finanzas.

Para tener resultados más asertivos frente a este propósito, se contó desde el inicio con la participación de la comunidad de todas las comunas y corregimientos de Medellín, donde mediante las mesas coordinadas por la Alcaldía de Medellín y acompañadas por representantes del gabinete municipal, se conoció la percepción y las necesidades de la comunidad, sobre sus costumbres, el trato cotidiano con sus vecinos y con las organizaciones comunales que los representan y ante la Administración Municipal, entre otras.

A continuación se describen los indicadores de impacto asociados a esta dimensión:

Indicadores de impacto

\begin{tabular}{|l|c|c|c|c|}
\hline \multicolumn{1}{|c|}{ Nombre } & Unidad & Línea de Base & Meta 2019 & Responsable \\
\hline $\begin{array}{l}\text { Confianza interpersonal. } \\
\text { Confianza que los } \\
\begin{array}{l}\text { ciudadanos tienen en los } \\
\text { demás (ECC) }\end{array}\end{array}$ & Porcentaje & $62 \%(2015)$ & $70 \%$ & $\begin{array}{c}\text { Secretaría de } \\
\text { Cultura } \\
\text { Ciudadana }\end{array}$ \\
\hline $\begin{array}{l}\text { Confianza institucional. } \\
\text { Confianza de los ciudadanos } \\
\text { en las instituciones (ECC) }\end{array}$ & Porcentaje & $26 \%(2015)$ & $40 \%$ & $\begin{array}{c}\text { Secretaría de } \\
\text { Cultura } \\
\text { Ciudadana }\end{array}$ \\
\hline Índice de Cultura Ciudadana & Porcentaje & $\begin{array}{c}\text { Línea base ECC } \\
\text { 2015 } \\
\text { (ponderación) }\end{array}$ & P.D & $\begin{array}{c}\text { Departamento } \\
\text { Administrativo } \\
\text { de Planeación }\end{array}$ \\
\hline
\end{tabular}

En este sentido proponemos para Medellín bajo esta dimensión, los siguientes retos: 


\subsection{RETO:}

\section{CULTURA MEDELLÍN}

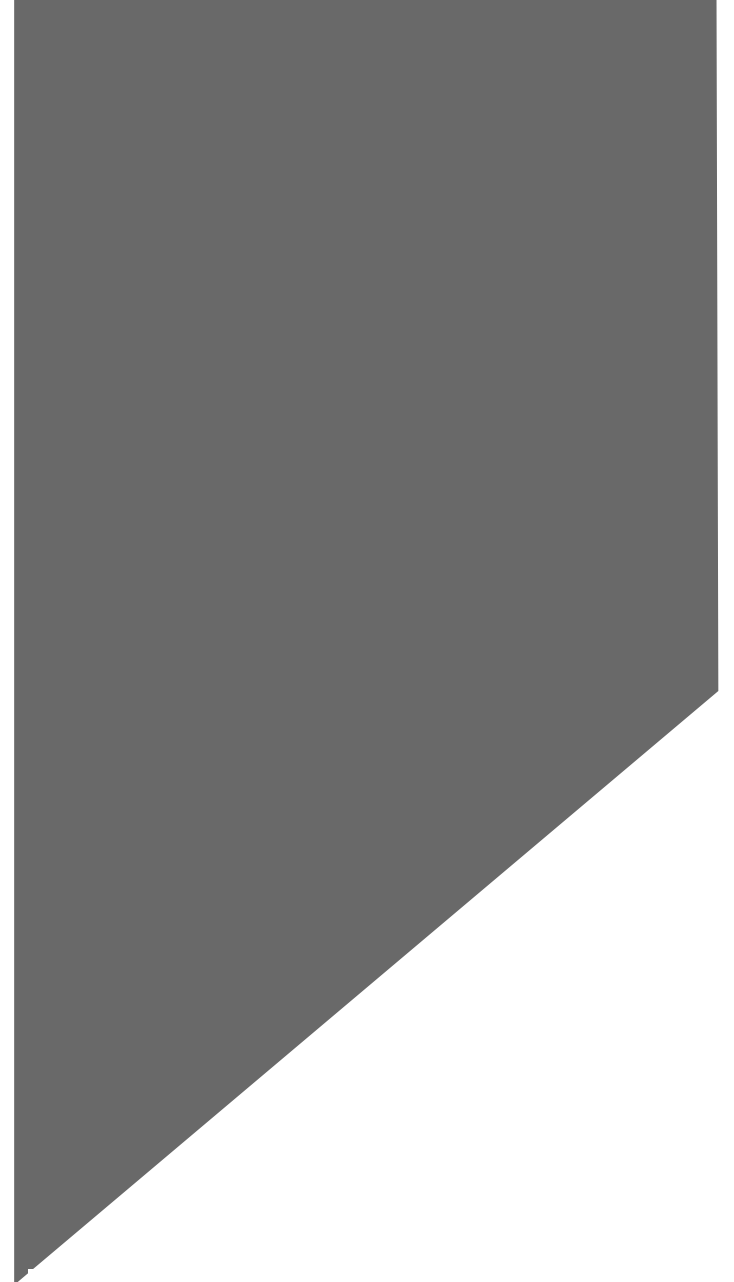

\section{OBJETIVO}

Formar a la ciudadanía para generar transformaciones en sus comportamientos y actitudes de tal manera que logren mejores actuaciones en la sociedad, generando en ellos una cultura permanente de corresponsabilidad con Medellín.

\section{PROGRAMAS:}

4 1.1.1. Recuperando la confianza

$\Delta$ 1.1.2. Formación ciudadana

$\Delta$ 1.1.3. Cultura de la legalidad

4 1.1.4. Cultura del cuidado para una Medellín saludable

4 1.1.5. Educación y buenas prácticas ambientales

$\Delta$ 1.1.6. Cultura D 


\subsection{Cultura Medellín}

El nivel de convivencia en una sociedad se determina por su capacidad para concertar y cumplir acuerdos, por la confianza de los ciudadanos entre sí y de los mismos hacia las instituciones. Medellín es reconocida internacionalmente como una ciudad amable y agradable, y cuenta además con unos niveles importantes de comportamiento cívico.

Creemos que es posible sembrar bases sólidas en el territorio urbano y rural de Medellín de un proyecto cultural de ciudad, fruto de una institucionalidad fortalecida y un sector de la cultura participante en la construcción de los procesos político-ciudadanos, donde la Secretaría de Cultura Ciudadana viene desarrollando su propósito de transformar dicha cultura ciudadana y ampliar el horizonte de las políticas culturales de la ciudad a partir de la concepción y práctica de los derechos culturales en los que, categorías como inclusión, territorio, economía, educación, participación ciudadana y ejercicio de la democracia han moldeado el proyecto de cultura ciudadana de la ciudad y su transformación política, urbana, social y ambiental, haciendo de la cultura fuente vital de educación ciudadana, convivencia, seguridad, gobernabilidad y sostenibilidad.

Con respecto a la norma legal y de acuerdo a la ECC, en Medellín el sentimiento positivo y muy positivo hacia las normas se encuentra en 93\% frente al 90\% a nivel nacional (2015). Sin embargo, la percepción positiva de la norma no es garantía de su cumplimiento, más bien lo contrario, se encuentra una relación entre la percepción positiva hacia la ley y la propensión a incumplirla por diversas razones (Justicia por mano propia $36 \%$, utilizar violencia por distintas razones $14 \%$, entre otras). Medellín, en comparación con ciudades como San Diego, Montevideo o Estocolmo tienen una percepción más positiva de la ley, sin embargo esta se incumple en mayor medida, lo que evidencia la necesidad de armonizar los comportamientos de los ciudadanos no solo por temor a la ley sino que en realidad apele a normas morales o culturales, en este sentido se identifican diversas oportunidades que deben ser abordadas de manera detallada, toda vez que según la ECC existen pocos ciudadanos dispuestos a ejercer control social corrigiendo a otro, al indagar por lo que hacen o hicieron los encuestados en situaciones adversas o conflictivas, el $84 \%$ de ellos respondió que no hizo nada (2015).

Preocupa que en Medellín la confianza interpersonal (personas que por lo general confían en vecinos, amigos, parientes, y compañeros de estudio y trabajo) se haya estancado desde el 2013 después de alcanzar un máximo del $65 \%$ en 2011 . El promedio de personas que confían en el otro ha disminuido para llegar a niveles cercanos del $60 \%$ en los últimos 4 años, es por esto que establecemos como un objetivo principal el elevar estas cifras. 
Así pues, vemos el reto que enfrenta Medellín para armonizar las normas legales, morales y culturales para un funcionamiento armónico de la sociedad donde la norma legal debería ser la última a la que acude la sociedad para solucionar sus conflictos, únicamente después que la moral y la social hayan fallado (Mockus, 2002).

Mapa 4. Percepción de confianza en las instituciones por comuna y corregimiento 2014

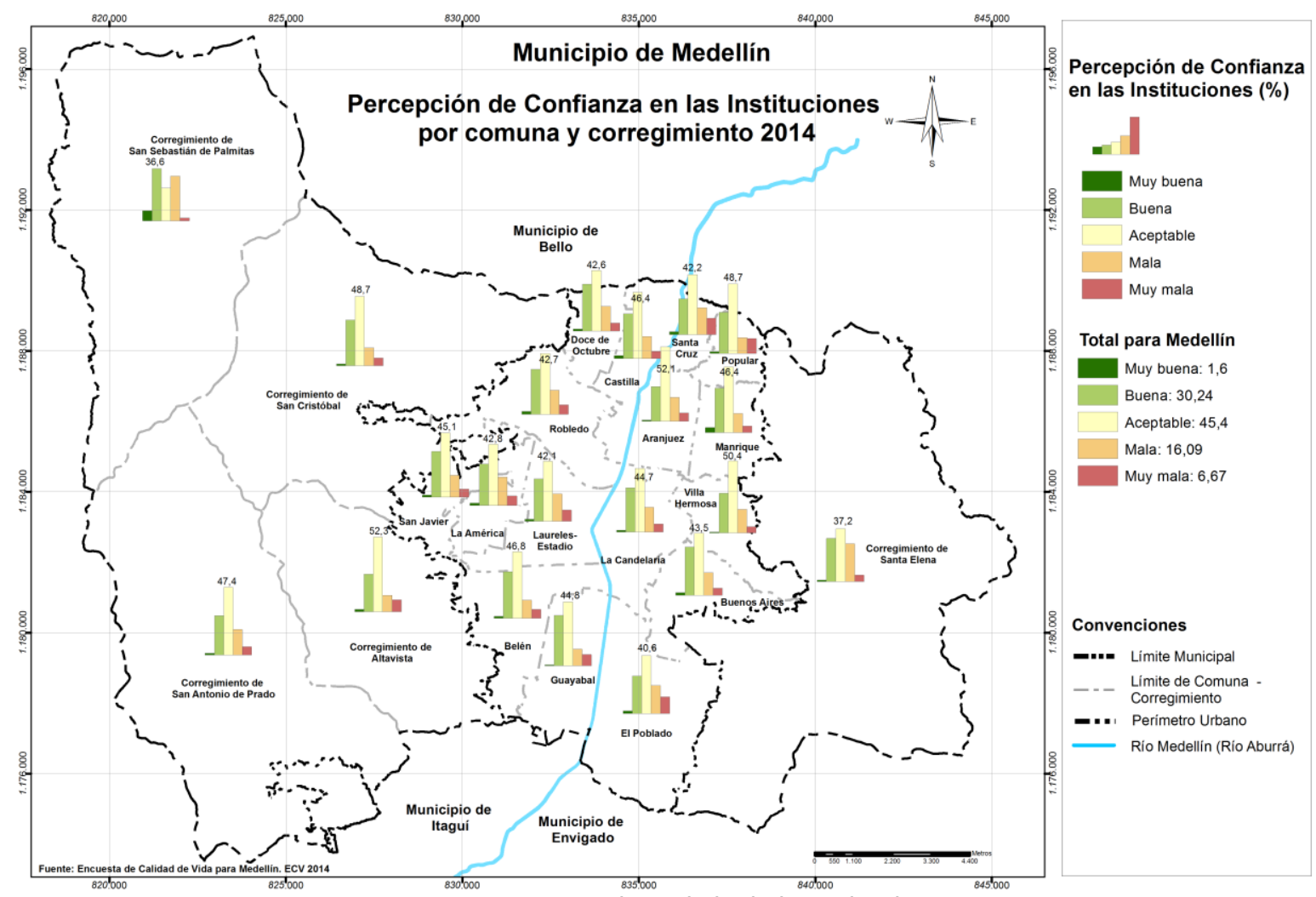

Fuente: Encuesta de calidad de vida de 2014

De igual manera, la disposición a convivir con la diversidad pasó del 73\% en 2009 al 57\% en 2015, mientras que la justificación a la desobediencia de la ley pasó del 18\% al 20\% y la justificación de la violencia pasó del 11\% al $14 \%$ en el mismo periodo. Sin embargo, la ciudad también presenta algunas fortalezas en cultura ciudadana, oportunidades para apalancar transformaciones por medio de la comunicación, la pedagogía y la reproducción de mensajes y comportamientos. Por otro lado, la disposición a regular a otras personas, el porcentaje de ciudadanos que le llamarían la atención a otra persona que incumple una norma, pasó del 54\% de los encuestados en 2009 al 55\% en 2015. Asimismo, en cómputo general, creció la confianza interpersonal, fundamental para la convivencia, la resolución de conflictos y la cooperación, pasando del $55 \%$ en 2009 al $62 \%$ en 2015. 
La ciudad cuenta entonces con retos en la forma de la justificación del incumplimiento y el uso de la violencia, el reconocimiento y el respeto de la diversidad, y la confianza institucional. Pero tiene fortalezas en la forma del capital social de sus habitantes, su disposición a regular y ser regulados, y en la oportunidad de sumarlos a procesos de transformación ciudadana desde la corresponsabilidad individual y colectiva.

A continuación se describe el indicador de resultado que se evaluará en este reto:

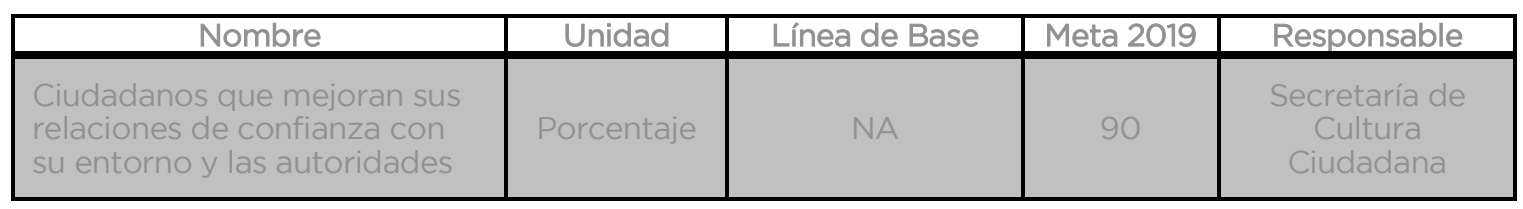

\subsubsection{PROGRAMA: RECUPERANDO LA CONFIANZA}

Medellín, una ciudad en constante transformación social, política, económica y cultural, es habitada por más de dos millones y medio de personas tan diversas como sus propios territorios, nombrados por el Estado como zonas - comunas. Sin embargo, esas clasificaciones son en muchos casos para asuntos de orden administrativo o de ordenamiento territorial, pues cada ciudadano se reconoce, interactúa y se establece desde otras comprensiones, desde unas dinámicas que suceden en los 240 barrios reconocidos.

Las transformaciones de la ciudad han sido de todo tipo, en el orden social hemos pasado de una ciudad habitada por la violencia a una ciudad habitada por la resiliencia; en el político, hemos dado cabida a nuevas formas de acción del Estado, que por más de tres planes de gobierno han privilegiado la educación y la cultura; en el orden económico, nos hemos enfocado en ser una ciudad de servicios; y en el cultural, estamos ya en la implementación de un segundo plan de desarrollo cultural, que recoge las fortalezas de la gobernanza de la cultura en Medellín, pero que de igual manera hace énfasis en tres enfoques para esta nueva ciudad transformada, los de derecho territorial y poblacional.

Así es como en esta ciudad transformada y habitada por ciudadanos tan diversos, cobran fuerza y pertinencia modelos de planificación y gestión de la cultura que permitan recoger y leer de manera permanente las necesidades de los que habitamos el territorio, que entren en diálogo con las distintas poblaciones y garanticen el cumplimiento de los derechos culturales bajo un esquema de gobernanza para un modelo de ciudad en el que se hace cada vez más necesaria una interrelación equilibrada entre actores públicos, privados y de la sociedad civil en favor del bienestar colectivo de las comunidades y de su desarrollo. 
Por eso hoy en Medellín se le apuesta a trabajar con la cultura ciudadana como una política pública, como una estrategia de gobierno, pero también como una práctica en la que todos sus habitantes sean corresponsables, buscando recuperar la confianza interpersonal e interinstitucional a través de la implementación de unos enfoques teóricos y marcos de análisis que permitan diseñar programas, proyectos, acciones e intervenciones que incidan en un tiempo, en la transformación de comportamientos de los ciudadanos a través de distintos mecanismos y estrategias que armonicen las normas legales, morales y culturales.

Se trabajará entonces en cultura ciudadana desde el marco de compresión de la autonomía de la cultura que ofrece la sociología cultural de Alexander Jeffrey, quien destaca la complejidad de la acción humana y lleva a comprender el campo simbólico de los grupos humanos como un elemento independiente de variables como la economía, la dominación o la estructura social. Es decir, se trabajará este programa comprendiendo la ciudad como un espacio habitado por la diversidad de sus poblaciones, lo que conlleva a tener en cuenta que coexisten infinidad de elementos culturales que los definen y los constituyen frente a otros en el campo de la cotidianidad y de las relaciones. Sin embargo, el bienestar colectivo será la mejor elección para lograr el bienestar individual y por ello la invitación sistemática desde este programa es a la transformación social de manera colectiva a través de la interculturalidad y participación en los asuntos públicos.

Es así como a través de los proyectos de cultura del sí, voluntariado, gobierno local y Medellín a pie se buscará fortalecer el tejido social, recuperar confianzas y llegar a consensos en torno a la transformación social de la ciudad, promover una movilización para que todos los ciudadanos se comprometan en una acción colectiva por el bien común que finalmente movilice los comportamientos de cada ciudadano a propósitos superiores de la ciudad, que una gran mayoría de ciudadanos quieran trabajar por lograr tener la mejor ciudad. En este sentido, mediante la cultura ciudadana este programa se pretenderá fortalecer en Medellín los valores democráticos, el pluralismo y la acción colectiva en el marco de una sociedad de derechos pero también de deberes.

De esta manera el Programa parte de que la confianza y los acuerdos serán dos indicadores importantes de la apuesta por la Cultura Ciudadana en Medellín que, como lo señala la Encuesta de Cultura Ciudadana, fomentarán la convivencia, mejorarán las capacidades de regulación, reducirán las creencias negativas del otro y permitirán la generación y difusión de nuevas normas sociales que promuevan la disminución de los comportamientos problemáticos para la ciudad. 
Indicadores de resultado

\begin{tabular}{|l|c|c|c|c|}
\hline \multicolumn{1}{|c|}{ Nombre } & Unidad & Línea de Base & Meta 2019 & Responsable \\
\hline $\begin{array}{l}\text { Percepción de cercanía del } \\
\text { Alcalde con la ciudadanía }\end{array}$ & Porcentaje & NA & 80 & $\begin{array}{c}\text { Secretaría } \\
\text { Privada }\end{array}$ \\
\hline $\begin{array}{l}\text { Personas que manifiestan no } \\
\text { tener inconformidad de tener } \\
\text { como vecino a poblaciones } \\
\text { vulnerables (ECC Pluralismo). }\end{array}$ & Porcentaje & $57(2015)$ & 70 & $\begin{array}{c}\text { Secretaría de } \\
\text { Cultura } \\
\text { Ciudadana }\end{array}$ \\
\hline
\end{tabular}

\subsubsection{Proyecto: Cultura del Sí}

Busca generar una afirmación constante del ciudadano frente a su papel y pertenencia a las instituciones. Por tanto, con este proyecto se pretende fortalecer los principios cívicos (confianza, pertenencia, legalidad y solidaridad) para solucionar o gestionar problemas públicos, involucrar a todos los ciudadanos en la resolución de dichos problemas y desarrollar la cultura del sí como un proyecto colectivo de ciudad que integre poblaciones y grupos sociales que anteriormente han estado excluidos de los procesos de toma de decisiones.

El proyecto se desarrollará en el marco de referencia de las concepciones concertadas en la Mesa de Cultura Ciudadana, en los acumulados 20072015 de las mediciones periódicas de los indicadores de cultura ciudadana, y en los retos y oportunidades que tiene el potencial de la cultura ciudadana como política cultural y su rol en la transformación de comportamientos colectivos.

Responsable: Secretaría de Cultura Ciudadana

Indicador de producto

\begin{tabular}{|c|c|}
\hline Nombre & Unidad \\
\hline Campañas de pedagogía ciudadana adelantadas & Número \\
\hline
\end{tabular}

\subsubsection{Proyecto: Fortalecer el voluntariado ciudadano}

Pretendemos movilizar en más ciudadanos y organizaciones el sentimiento y compromiso que los inspira a realizar acciones colectivas voluntarias, para trabajar de manera conjunta en la construcción de Medellín como proyecto de todos sus habitantes, fortaleciendo el voluntariado e incrementando acciones que sean promovidas con la ciudadanía en lugares cotidianos.

El proyecto se trabajará bajo el enfoque de cultura ciudadana que entiende la participación como el encuentro de agencias individuales que persiguen un objetivo común e involucra cualquier tipo de acción comunitaria o social que pretenda perseguir un propósito común de una sociedad. 
Indicador de producto

\begin{tabular}{|c|c|}
\hline \multicolumn{1}{|c|}{ Nombre } & Unidad \\
\hline Voluntarios certificados por la Alcaldía de Medellín & Número \\
\hline
\end{tabular}

1.1.1.3. Proyecto: Fortalecimiento del gobierno local y recuperación de confianza en la institucionalidad

Fortalecer el gobierno local y restablecer las relaciones de confianza con la ciudadanía, a través de un acompañamiento permanente en cada comuna y corregimiento, canalizando por intermedio del Comité Local de Gobierno los comentarios, inquietudes, quejas y propuestas provenientes de los ciudadanos, recogidas en su mayoría en los Consejos de Convivencia Ciudadana, en la atención directa a la comunidad y en la observación de necesidades o focos originadores de riesgo social, entre otros. Dicho acompañamiento contempla, de manera complementaria, la promoción y fomento de la participación ciudadana en la gestión del desarrollo territorial, el control, la corresponsabilidad y la autorregulación frente a las indisciplinas sociales, así como la resolución pacífica de conflictos y la prevención de la violencia interpersonal y cotidiana, bajo los lineamientos del Manual de Convivencia Ciudadana de Medellín, mediante estrategias y acciones pedagógicas que propicien la movilización ciudadana hacia el bienestar colectivo.

Responsable: Secretaría de Gobierno y Gestión del Gabinete Indicadores de producto:

\begin{tabular}{|l|c|}
\hline \multicolumn{1}{|c|}{ Nombre } & Unidad \\
\hline Comités Locales de Gobierno realizados & Número \\
\hline Concejos de Convivencia Ciudadanos realizados & Número \\
\hline
\end{tabular}

1.1.1.4. Proyecto: Gestión y articulación de gobierno

Gestores públicos en territorio atendiendo las necesidades de la comunidad y generando relaciones de confianza con la misma, con el fin que las inversiones se correspondan a las dinámicas propias de cada comuna y corregimiento.

Responsable: Secretaría de Gobierno y Gestión del Gabinete Indicadores de producto:

\begin{tabular}{|l|c|}
\hline \multicolumn{1}{|c|}{ Nombre } & Unidad \\
\hline Gestores públicos actuando en cada uno de los territorios & Número \\
\hline
\end{tabular}

\subsubsection{Proyecto: Movilización para la participación y la cultura ciudadana gracias a la comunicación}

Mediante este proyecto se definirán acciones estratégicas para la movilización a partir de la focalización de programas bandera en comunas y corregimientos, la ruta de campañas con enfoque sectorial y las plataformas especiales de participación que le permitan al ciudadano un voz a voz con la Administración Municipal. 
Responsable: Secretaría de Comunicaciones

Indicadores de producto:

\begin{tabular}{|l|c|}
\hline \multicolumn{1}{|c|}{ Nombre } & Unidad \\
\hline Herramientas de comunicación utilizadas para la movilización. & Número \\
\hline Estrategia de comunicación para la movilización diseñada y ejecutada & Porcentaje \\
\hline
\end{tabular}

\subsubsection{PROGRAMA: FORMACIÓN CIUDADANA}

Apostarle a la cultura ciudadana como política pública de Medellín es un reto que requiere abordar la ciudad desde una comprensión de su contexto, transitar por sus territorios y reconocer la diversidad que los habita para construir una hoja de ruta como el plan promotor de cultura ciudadana que guiará este propósito dentro del marco de referencia desde donde el Estado se entenderá como el ente que debe garantizar unos derechos a la ciudadanía y que para lograrlo lo hace a través de una estructura, unos lineamientos y estrategias que permiten el cumplimiento de su campo misional, y que para este programa específico lo hará a través de la formación ciudadana.

Esta formación ciudadana se desarrollará en los ámbitos de ser individual y colectivo, donde se privilegiarán las intervenciones en los escenarios de la familia y la juventud, la escuela y los ecosistemas culturales, en asuntos fundamentales como la cultura viva comunitaria, la actividad física y la recreación, la movilidad, la participación y la convivencia.

Este ejercicio de formación no pretende homogenizar a los ciudadanos de Medellín, busca que la ciudadanía reflexione sobre sus comportamientos e incorpore a través de distintos consensos otras formas de concebirse y relacionarse en las diferentes instancias y espacios sociales, la familia, la escuela, el espacio público, los equipamientos públicos, el barrio, la calle, etc.

Por ello más allá de mensajes persuasivos este programa busca sintonizar la apuesta pública con la teoría de las normas sociales, en la que una agenda de formación debe obedecer a una agenda de cambio cultural que no debe buscar transformar las convicciones o ideas que los ciudadanos tienen de sí mismos en Medellín, sino más bien transformar las ideas y representaciones que los ciudadanos tienen de otros ciudadanos; es decir en cada uno de los escenarios priorizados para la formación ciudadana de Medellín tener en cuenta la agenda de cambio cultural que plantea el investigador Henry Murrain, como unos espacios de coordinación y transformación de expectativas mutuas más que una agenda de transmisión de nuevas preferencias o valores en los ciudadanos.

Para abordar y desarrollar este programa se tendrá como referencia el informe del Banco Mundial 2015 "Mente, sociedad y conducta", que convoca a revisar los paradigmas más recientes de las ciencias sociales basados en la 
existencia de comportamientos automáticos, en la comprensión del funcionamiento de las normas sociales, en el fenómeno de la ignorancia pluralista y la conformidad del grupo.

Indicador de resultado

\begin{tabular}{|l|c|c|c|c|}
\hline \multicolumn{1}{|c|}{ Nombre } & Unidad & Línea de Base & Meta 2019 & Responsable \\
\hline $\begin{array}{l}\text { Personas que ante la palabra, } \\
\text { regla o norma, les despierta } \\
\text { un sentimiento positivo }\end{array}$ & Porcentaje & $92(2015)$ & 96 & $\begin{array}{c}\text { Secretaría de } \\
\text { Cultura } \\
\text { Ciudadana }\end{array}$ \\
\hline
\end{tabular}

\subsubsection{Proyecto: Implementar el plan promotor de cultura ciudadana}

Es un proyecto transversal y estructurante de todo el plan de desarrollo y busca conectar las acciones de gobierno con la transformación de la cultura ciudadana de la ciudad, como una política pública que dirija los esfuerzos y comprometa recursos y apuestas para construir y consolidar el programa de la legalidad.

Cabe destacar que el proyecto estará en consonancia con los principios y enfoques territoriales, poblacionales, de derechos y gobernanza del plan de desarrollo cultural, que comprende las diferentes dimensiones de la participación y el desarrollo de los ciudadanos.

Responsable: Secretaría de Cultura Ciudadana

Indicador de producto:

\begin{tabular}{|c|c|}
\hline \multicolumn{1}{|c|}{ Nombre } & Unidad \\
\hline Plan promotor de cultura ciudadana implementado & Porcentaje \\
\hline
\end{tabular}

\subsubsection{Proyecto: Creación de ecosistemas culturales}

Pretende evitar la desarticulación territorial de espacios y actividades culturales, integrando iniciativas con las decisiones políticas para conseguir transformaciones culturales. Así buscará que el gobierno local conecte sus decisiones con estos ecosistemas, desde una gestión que comprenda y actúe acogiendo las infraestructuras culturales, los lineamientos, las estrategias, los programas, los proyectos y las ofertas de cultura ciudadana, para que de manera amplia impacten diferentes ámbitos (legal, ético y cultural). En este sentido, se trabajará bajo las siguientes dimensiones de cultura ciudadana: acuerdos, tolerancia, participación comunitaria y confianza.

Responsable: Secretaría de Cultura Ciudadana

Indicadores de producto

\begin{tabular}{|l|c|}
\hline \multicolumn{1}{|c|}{ Nombre } & Unidad \\
\hline $\begin{array}{l}\text { Proyectos territoriales implementados que articulan acciones e iniciativas de zonas } \\
\text { o corregimientos en el marco de la cultura ciudadana }\end{array}$ & Número \\
\hline Eventos sobre diversidad e interculturalidad realizados & Número \\
\hline
\end{tabular}


1.1.2.3 Proyecto: Formación ciudadana para el fortalecimiento de la familia como entorno protector

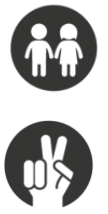
Teniendo en cuenta que una de las principales problemáticas sociales de nuestra ciudad es la violencia intrafamiliar, se busca con este proyecto promover el buen trato entre los miembros de la familia y evitar cualquier tipo de violencia dentro de la familia que afecte la dignidad humana de alguno de sus miembros, evitar la vulneración de sus derechos y buscar superar la situación de mal trato.

Responsable: Secretaría de Gobierno y Gestión del Gabinete Indicador de producto:

\begin{tabular}{|l|c|}
\hline \multicolumn{1}{|c|}{ Nombre } & Unidad \\
\hline Elaboración e implementación de un plan de formación ciudadana para el & Porcentaje \\
fortalecimiento de la familia como entorno protector
\end{tabular}

\subsubsection{Proyecto: Convivencia y cultura ciudadana juvenil}

Generar y acompañar estrategias de promoción, prevención, y garantía de los derechos y libertades de los jóvenes, y al tiempo fortalecer su desarrollo positivo en convivencia con los demás y su

P) entorno. Como estrategia de convivencia, acompañaremos a los procesos de barrismo y promoveremos el diálogo intergeneracional mediante estrategias formativas y fomento de encuentros ciudadanos.

En materia de cultura ciudadana, se propenderá por generar procesos para el desarrollo del ser joven que fomentan la confianza, la convivencia y la paz. Así, se fortalecerá la participación en espacios y prácticas culturales -Semana de la Juventud, Seminario de comunicación juvenil, jóvenes destacados, entre otros- que enriquezcan la vida personal y colectiva y permitan la proyección e integración de la población juvenil.

Responsable: Secretaría de Juventud

Indicadores de producto:

\begin{tabular}{|c|c|}
\hline \multicolumn{1}{|c|}{ Nombre } & Unidad \\
\hline Procesos de difusión, promoción e integración para la población joven realizados & Númeró \\
\hline Proyectos y programas identificados con sello joven & Porcentaje \\
\hline
\end{tabular}

\subsubsection{Proyecto: Cultura vial en mi barrio para la movilidad segura y ordenada}

Busca la formación ciudadana en torno al sentido más amplio de la movilidad y el espacio público, donde confluya un interés colectivo sobre el uso y la apropiación de los espacios públicos. Pretende articular de manera pertinente las comprensiones de la Alcaldía de Medellín, quien la entiende como "el derecho al espacio público es en última instancia el derecho a ejercer como ciudadano que tienen todos los que viven y que quieren vivir en las ciudades" (Borja\&Muxí, 2000) y también la de los ciudadanos, 
quienes exponen en la Encuesta de Cultura Ciudadana el desafío que se tiene de recuperar el espacio público en tres temas: invasión tanto por automóviles parqueados en las calles, como por las ventas ambulantes y por la expansión ilegítima de los establecimientos comerciales; seguridad vial; y uso democrático de los espacios (ECC, 2015).

Responsable: Secretaría de Movilidad

Indicadores de producto

\begin{tabular}{|l|c|}
\hline \multicolumn{1}{|c|}{ Nombre } & Unidad \\
\hline Campañas o acciones realizadas de cultura vial & Número \\
\hline Ciudadanos sensibilizados en educación vial para la movilidad segura & Número \\
\hline
\end{tabular}

\subsubsection{Proyecto: La cuadra y la vereda cuenta con vos}

Es un espacio para posibilitar la participación ciudadana desde lo micro, es decir acercar al ciudadano a la institucionalidad gubernamental, desde la cotidianidad que caracteriza la cuadra y la vereda, superando barreras limitantes para el acceso. La finalidad de este proyecto es la generación de confianzas y la construcción de tejido social, buscando acercar a la ciudadanía oportunidades para su desarrollo.

Con este proyecto queremos retomar una época en la que podíamos llegar a todos los ciudadanos, a todos los espacios sociales y comunitarios con el fin de incluir y propiciar la participación de la población en la gestión pública y el desarrollo de su territorio, la estrategia del sistema cuadral busca consolidar y activar nuevos escenarios de participación, fortalecer el tejido comunitario, construirlo de manera consciente, colectiva, participativa, transformadora, en comunicación abierta con el desarrollo comunal, que trabaja por el bienestar, la convivencia, la inclusión y la equidad de las familias, a través del conocimiento de sus problemas, apalancados en valores de vecindad solidaria y respeto por la diferencia.

Responsable: Secretaría de Participación Ciudadana

Indicador de producto

\begin{tabular}{|c|c|}
\hline \multicolumn{1}{|c|}{ Nombre } & Unidad \\
\hline $\begin{array}{l}\text { Cuadras de las comunas de Medellin con la estrategia "La cuadra cuenta con vos" } \\
\text { implementada }\end{array}$ & Número \\
\hline
\end{tabular}

\subsubsection{PROGRAMA: CULTURA DE LA LEGALIDAD}

El programa cultura de la legalidad se constituye como la apuesta dentro del plan de desarrollo para la formación de ciudadanía en ejes temáticos relacionados con la legalidad entendida como "la disposición de una sociedad en su conjunto a seguir las normas, tanto legales como sociales, que organizan sus interacciones y la ciudadanía. La legalidad responde a valores individuales, pero también al apego social a las normas, sobre todo respecto a la posibilidad de sanciones sociales ante conductas 
incumplidoras" buscando la armonización entre la ley, la moral y las normas sociales.

Formar ciudadanía para el ejercicio de una cultura de la legalidad es impartir a través de una pedagogía en las instituciones educativas, escuelas y universidades, no solo los conceptos que conciernen a las normas, sanciones y obligaciones, es contemplar de manera integral todas las acciones sociales y el conjunto de valores de los habitantes de la ciudad para la interrelación virtuosa de todos los grupos poblacionales en el marco normativo y social, que toma como base las instituciones educativas para la búsqueda de formación de estudiantes a ciudadanos con conocimiento pleno de las herramientas, medios, canales, instituciones públicas, derechos y deberes para la práctica de la legalidad en la cotidianidad, en la convivencia con el otro, generando igualdad y equidad.

El programa de cultura de la legalidad pretende a través de procesos de enseñanza aprendizaje, campañas y formación renovar y hacer mejores ciudadanos, modificar comportamientos y acentuar las actuaciones, el acatamiento voluntario de normas formales, a través de una puesta en común de mecanismos de regulación cultural que sea sistemático, continuo y que permita una cultura de la legalidad en todos los ámbitos de relacionamiento interpersonal e institucional, especialmente desde lo escolar, empresarial y comunitario.

Indicador de resultado

\begin{tabular}{|c|c|c|c|c|}
\hline Nombre & Unidad & Línea de Base & Meta 2019 & Responsable \\
\hline $\begin{array}{l}\text { Razones para desobedecer la } \\
\text { ley. Actitudes hacia el marco } \\
\text { normativo legal (ECC) }\end{array}$ & Porcentaje & $20(2015)$ & 15 & $\begin{array}{c}\text { Secretaría de } \\
\text { Cultura } \\
\text { Ciudadana }\end{array}$ \\
\hline
\end{tabular}

1.1.3.1 Proyecto: Difundir la cultura de legalidad en las escuelas y universidades

Fortalecer el desarrollo de competencias ciudadanas en estudiantes, padres de familia, docentes y directivos docentes que fomente la cultura de la legalidad y de la participación democrática tanto en el gobierno escolar como en la práctica democrática de la institución educativa. Comprende actividades de sensibilización-capacitación y jornadas (semana de la democracia) frente a la cultura democrática y de la legalidad, formación en competencias ciudadanas, acompañamiento al fortalecimiento participación en espacios de gobierno escolar, personeros y contralores estudiantiles, representación y consejos, liderazgo y democratización de la vida escolar.

Responsable: Secretaría de Educación 
Indicador de producto

\begin{tabular}{|l|c|}
\hline \multicolumn{1}{|c|}{ Nombre } & Unidad \\
\hline $\begin{array}{l}\text { Instituciones Educativas oficiales acompañadas en el fortalecimiento de la cultura } \\
\text { de la legalidad y de los distintos mecanismos de participación democrática en la } \\
\text { escuela. }\end{array}$ & Número \\
\hline
\end{tabular}

1.1.3.2 Proyecto: Inculcar la cultura de legalidad en el ambiente empresarial La cultura de la legalidad busca promover la igualdad en armonía entre el respeto a la ley, las convicciones morales y las tradiciones y convicciones culturales. Se busca fomentar la formalidad en las empresas, con el fin de que sean visibles para el Estado, otros empresarios y otras entidades, lo cual genera igualdad de condiciones e institucionalidad, que facilita el acceso a beneficios como líneas de crédito, apoyo técnico, capacitación, y otros incentivos que facilitan su sostenibilidad y competitividad en el mercado.

Responsable: Secretaría de Desarrollo Económico

Indicador de producto

\begin{tabular}{|l|c|}
\hline \multicolumn{1}{|c|}{ Nombre } & Unidad \\
\hline Jornadas de Formalización realizadas & Número \\
\hline
\end{tabular}

1.1.3.3 Proyecto: Héroes de la legalidad

Busca visibilizar e incentivar la legalidad, para promover prácticas y liderazgos con impacto social, y desmontar el errado imaginario de la legalidad. Este proyecto se trabajará bajo el enfoque de cultura ciudadana que permita movilizar otros comportamientos en el marco de las dimensiones de sistemas reguladores del comportamiento, cultura de la legalidad, cultura tributaria, ley moral y cultura, y satisfacción.

Responsable: Secretaría de Cultura Ciudadana

Indicador de producto

\begin{tabular}{|l|c|}
\hline \multicolumn{1}{|c|}{ Nombre } & Unidad \\
\hline $\begin{array}{l}\text { Eventos realizados para visibilizar los buenos comportamientos en relación con } \\
\text { las campañas pedagógicas }\end{array}$ & Número \\
\hline
\end{tabular}

\subsubsection{PROGRAMA: CULTURA DEL CUIDADO PARA UNA MEDELLÍN SALUDABLE}

La cultura puede entenderse como ideas, símbolos y comportamientos, hace referencia a los valores, creencias, normas y modos de vida que son aprendidos, asumidos y transmitidos por un determinado grupo y que guían sus pensamientos, decisiones, acciones o patrones de comunicación; la cultura es un sistema de símbolos compartidos que cambian a través del tiempo (Duque Páramo, María Claudia. Cultura y Salud: elementos para el estudio de la diversidad y las inequidades. Bogotá. 2007).

Por otra parte, el cuidado es entendido como las capacidades, decisiones y acciones que el individuo toma para proteger su salud, la de su familia, la 
comunidad $y$ el medio ambiente que lo rodea, es decir, las responsabilidades del ciudadano consigo mismo y con la comunidad, así como las responsabilidades del Estado al cual se pertenece. Surge desde el autocuidado, es decir, de todo lo que hacemos por nosotros mismos para establecer y mantener la salud, prevenir y manejar la enfermedad" (OMS, 1998). Involucra una condición dinámica que integra en diferentes momentos de su vida la capacidad para acumular aprendizajes, experiencias y autonomía para la toma de decisiones que permitan ganancias en salud.

La Cultura del cuidado se identifica como la intersección entre las acciones de cuidado que el individuo y la comunidad emprenden para mantener la salud y con las intervenciones del Estado, tanto de tipo prestacional (dirigidas al individuo) como colectivas (dirigidas a la comunidad) (Política de Atención Integral en Salud. MSPS. 2016).

Por lo anterior, es necesario desarrollar acciones de promoción de la salud y prevención de la enfermedad lideradas por el territorio de forma intersectorial para la construcción, la generación de condiciones, capacidades y medios necesarios para que los individuos, las familias y la comunidad en su conjunto logren construir, modificar, implementar y vivenciar la Cultura del cuidado a partir de la cual se intervengan los determinantes sociales, así como las condiciones de salud y bienestar.

El impacto positivo en la promoción de la salud, la prevención de la enfermedad, el tratamiento, curación y rehabilitación se hace posible en la medida en que se incrementen los niveles de autocuidado en los individuos, para que sus decisiones reduzcan las conductas riesgosas a la largo de su curso de vida y en los espacios cotidianos en los que se desenvuelve; el autocuidado no es solo una decisión y un objetivo personal, es además el desarrollo de intervenciones a la comunidad por parte del sistema - Estado, para que conjuntamente se construya la Cultura del cuidado.

Para la construcción de la Cultura del cuidado, la Secretaría de Salud, tendrán en cuenta las dimensiones del Plan Decenal de Salud Pública, el Curso de Vida, el enfoque diferencial y su accionar será a través de los entornos hogar, educativo, comunitario, y laboral-institucional, como aquellos espacios o lugares donde transcurre la vida de las personas, por ejemplo: hábitos alimentarios (dimensión de seguridad alimentaria y nutricional), en la primera infancia (curso de vida) en el entorno hogar. Adicionalmente, se proponen estrategias para fortalecer y promocionar la práctica de actividad física saludable, desarrollando en los ciudadanos una cultura de comportamientos saludables que impacten el cuidado propio y de los demás. 
Indicadores de resultado

\begin{tabular}{|c|c|c|c|c|}
\hline Nombre & Unidad & Línea de Base & Meta 2019 & Responsable \\
\hline $\begin{array}{l}\text { Comportamientos saludables } \\
\text { en salud bucal (Encuesta Steps) }\end{array}$ & Porcentaje & N/D & $\begin{array}{c}\text { Aumento del } \\
3 \% \\
\end{array}$ & $\begin{array}{l}\text { Secretaría de } \\
\text { Salud } \\
\end{array}$ \\
\hline $\begin{array}{l}\text { Prevalencia de Consumo de } \\
\text { número de porciones de frutas } \\
\text { y verduras en los siete días a la } \\
\text { semana (Encuesta Steps) }\end{array}$ & Promedio & N/D & $\begin{array}{c}\text { Incrementar } \\
\text { el consumo } \\
\text { diarios de } \\
\text { frutas y } \\
\text { verduras a } 3 \\
\text { porciones } \\
\text { diarias los } \\
\text { siete días a la } \\
\text { semana } \\
\end{array}$ & $\begin{array}{l}\text { Secretaría de } \\
\text { Salud }\end{array}$ \\
\hline $\begin{array}{l}\text { Promedio de edad e inicio de } \\
\text { consumo de tabaco en } \\
\text { población general (Encuesta } \\
\text { Steps) }\end{array}$ & $\begin{array}{l}\text { Promedio } \\
\text { años }\end{array}$ & 16 & 16 & $\begin{array}{l}\text { Secretaría de } \\
\text { Salud }\end{array}$ \\
\hline $\begin{array}{l}\text { Personas que perciben los } \\
\text { beneficios de la actividad física } \\
\text { saludable }\end{array}$ & Porcentaje & $\mathrm{O}$ & 70 & INDER \\
\hline $\begin{array}{l}\text { Planes para la gestión de } \\
\text { entornos saludables formulados } \\
\text { e implementados en las } \\
\text { entidades capacitadas. } \\
\end{array}$ & Número & 0 & 34 & INDER \\
\hline $\begin{array}{l}\text { Personas atendidas con } \\
\text { actividad física saludable }\end{array}$ & Número & 50.287 & 45.740 & INDER \\
\hline
\end{tabular}

\subsubsection{Proyecto: Cultura del cuidado en todos los entornos}

Desarrollar estrategias en el territorio para el empoderamiento y la promoción de elecciones positivas en salud que permitan la consolidación de una cultura saludable, basada en el cuidado propio y de los demás, en los diferentes entornos (Escuela, trabajo, hogar, espacio público, etc.)

Responsable: Secretaría de Salud

Indicadores de producto

\begin{tabular}{|l|c|}
\hline \multicolumn{1}{|c|}{ Nombre } & Unidad \\
\hline $\begin{array}{l}\text { Cobertura de actividades IEC en grupos de trabajadores del sector informal } \\
\text { en el entorno hogar }\end{array}$ & Porcentaje \\
\hline $\begin{array}{l}\text { Número de personas intervenidas para el cuidado en salud en el entorno público } \\
\text { y comunitario }\end{array}$ & Púmerontaje \\
\hline $\begin{array}{l}\text { Instituciones educativas que reciben acciones para promover la cultura del } \\
\text { cuidado en el entorno escolar }\end{array}$ & Porcentaje \\
\hline
\end{tabular}

\subsubsection{Proyecto: Fortalecimiento de la actividad física saludable}

Es una apuesta de ciudad para promover la práctica de actividad física y la adopción de estilos de vida saludables, a través de alternativas novedosas y llamativas, con una oferta permanente, la cual adopta las recomendaciones de la Organización Mundial de la Salud - OMS en cuanto a la frecuencia, duración e intensidad para obtener beneficios en salud. También vincula actividades 


\section{Creemos en la cultura Ciudadana}

complementarias y un componente pedagógico para la población desde los niños hasta el adulto mayor.

Responsable: INDER

Indicador de producto

\begin{tabular}{|l|c|}
\hline \multicolumn{1}{|c|}{ Nombre } & Unidad \\
\hline $\begin{array}{l}\text { Planes para la gestión de entornos saludables formulados e implementados en } \\
\text { las entidades capacitadas. }\end{array}$ & Número \\
\hline
\end{tabular}

\subsubsection{PROGRAMA: EDUCACIÓN Y BUENAS PRÁCTICAS AMBIENTALES}

De acuerdo con la política nacional de producción más limpia y los Decretos Municipales que nos obligan al cumplimiento de diferentes acciones, se pretende continuar con la sensibilización y capacitación de la comunidad, representada por diferentes sectores (empresa, establecimientos de comercio y servicio, hogares urbanos y rurales, unidades agrícolas, ejecución de obras públicas), en diferentes temáticas encaminadas al cuidado y uso racional de los recursos naturales.

Indicador de resultado

\begin{tabular}{|c|c|c|c|c|}
\hline Nombre & Unidad & Línea de Base & Meta 2019 & Responsable \\
\hline $\begin{array}{l}\text { Grupos atendidos en } \\
\text { educación y cultura ambiental }\end{array}$ & Número & 0 & 1.248 & $\begin{array}{c}\text { Secretaría de } \\
\text { Medio Ambiente }\end{array}$ \\
\hline
\end{tabular}

\subsubsection{Proyecto: Sensibilización sobre las buenas prácticas ambientales}

Dado que la competencia de medición, evaluación y control de temas de contaminación ambiental del aire y por ruido, son de la autoridad ambiental, las acciones que desde el municipio se pueden emprender en dicho sentido son de índole educativo-pedagógicas, educación no formal para el mejoramiento en estas prácticas ambientales.

Indicador de producto:

Responsable: Secretaría de Medio Ambiente

\begin{tabular}{|c|c|}
\hline \multicolumn{1}{|c|}{ Nombre } & Unidad \\
\hline Intervenciones en buenas prácticas ambientales realizadas & Número \\
\hline
\end{tabular}

1.1.5.2 Proyecto: Cultura, educación y promoción del medio ambiente Con este proyecto se pretende contribuir con la consolidación de una cultura ambiental en la ciudad de Medellín, mediante procesos educativos informales y campañas educativas que busquen la participación ciudadana a través de los espacios físicos de aulas, aulas granjas agroambientales e instituciones educativas, así como todas aquellas actividades que puedan desarrollarse en sus propios espacios de barrio y/o comuna, de tal forma que aporten a la concientización de la comunidad sobre la necesidad de recuperar, conservar y mantener los recursos naturales. Adicionalmente se busca 
como resultado de la estrategia pedagógica, especialmente en los temas de transformación de residuos orgánicos, obtener como producto final proyectos demostrativo-productivos como las ecohuertas, en sincronía con procesos de compostaje y/o lombricultivo.

Responsable: Secretaría de Medio Ambiente

Indicador de producto

\begin{tabular}{|c|c|}
\hline \multicolumn{1}{|c|}{ Nombre } & Unidad \\
\hline Campañas en educación y cultura ambiental realizadas & Número \\
\hline
\end{tabular}

1.1.5.3 Proyecto: Educación para la prevención del maltrato animal Gestores infantiles

Con este proyecto se busca promover estándares de bienestar en los animales domésticos de la ciudad, así como la educación, respeto, y buenas prácticas ambientales que incluyan a todos los seres vivos, como una forma de afianzar a Medellín como ciudad líder en protección animal, con énfasis en la población infantil en edad educativa, ya que es en la infancia donde se siembra y cultiva el amor y respeto por los seres vivos.

Responsable: Secretaría de Medio Ambiente

Indicador de producto

\begin{tabular}{|c|c|}
\hline \multicolumn{1}{|c|}{ Nombre } & Unidad \\
\hline Campañas de educación sobre el respeto animal, para prevenir el maltrato. & Número \\
\hline
\end{tabular}

\subsubsection{PROGRAMA: CULTURA D}

Establecer la política pública Cultura D, que propenda por el deporte, la actividad física y la recreación como herramientas sociales transformadoras y generadoras de oportunidades y permitan la construcción de un proyecto de vida digno, la inclusión social, la equidad, la participación, la cultura ciudadana y los entornos protectores.

Cultura D será el marco bajo el cual se creen y se direccionen los diferentes programas deportivos y recreativos de la ciudad de Medellín, así mismo trazará las alianzas entre los programas deportivos del departamento y el municipio en pro del desarrollo y potencialización de los deportistas y consolidará una ruta de trabajo de Medellín en materia de deporte en los próximo 15 años que ayude a posicionar la ciudad como un referente internacional en dicha materia.

Indicador de resultado

\begin{tabular}{|c|c|c|c|c|}
\hline Nombre & Unidad & Línea de Base & Meta 2019 & Responsable \\
\hline $\begin{array}{l}\text { Ciudadanos integrados a } \\
\text { través del deporte }\end{array}$ & Porcentaje & N/A & 70 & INDER \\
\hline
\end{tabular}




\section{Creemos en la cultura Ciudadana}

1.1.6.1 Proyecto: Adelantar procesos de formación, integración y conocimiento ciudadano a través de la actividad física, recreación y deporte

Este proyecto concibe el deporte, la actividad física y la recreación - como herramientas sociales transformadoras y, en articulación con ámbitos como el educativo y de seguridad, impulsadores de posibilidades alternativas para la construcción y fortalecimiento de la cultura ciudadana y en particular la cultura D.

Responsable: INDER

Indicador de producto:

\begin{tabular}{|c|c|}
\hline Nombre & Unidad \\
\hline Ciudadanos que mejoran sus competencias para la participación en el sector & Porcentaje \\
\hline
\end{tabular}

1.1.6.2 Proyecto: Fortalecimiento del deporte comunitario para la integración social

El deporte comunitario es un medio para fomentar espacios de integración, socialización y construcción de tejido colectivo a partir de intervenciones orientadas desde el contexto y las necesidades de cada comunidad. Además de la intervención pedagógica en diferentes entornos deportivos que se realiza desde Deporte y Convivencia.

Responsable: INDER

Indicadores de producto

\begin{tabular}{|l|c|}
\hline \multicolumn{1}{|c|}{ Nombre } & Unidad \\
\hline Población que participa en actividades deportivas comunitarias & Número \\
\hline $\begin{array}{l}\text { Estrategias pedagógicas implementadas a través del deporte para la } \\
\text { promoción de la convivencia y el buen uso del espacio público }\end{array}$ & Número \\
\hline
\end{tabular}




\subsection{RETO:}

\section{MEDELLIIN}

PARTICIPATIVA

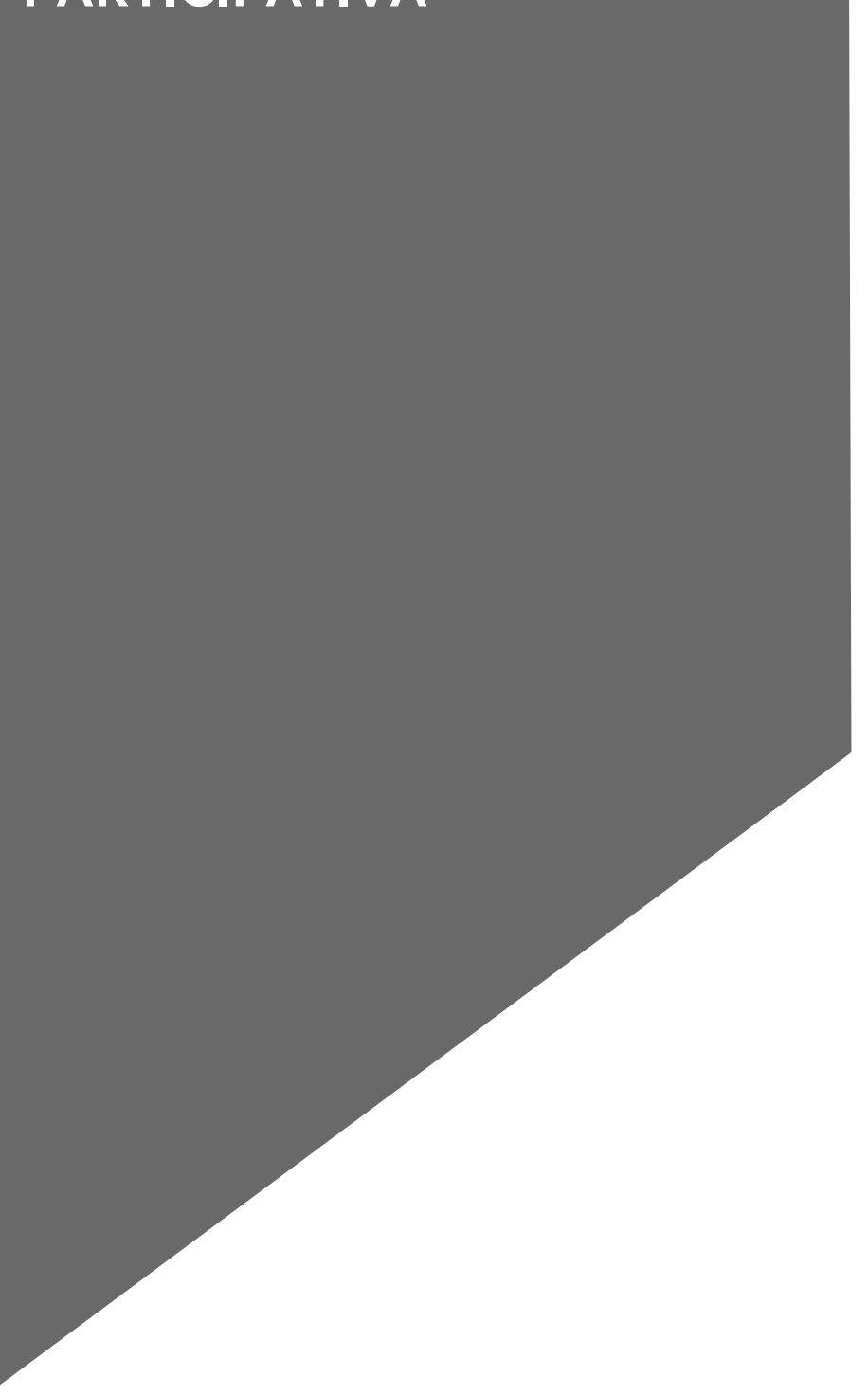

OBJETIVO

Fortalecer a la ciudadanía activa de manera inclusiva e incrementar la participación ciudadana para aumentar la incidencia en el desarrollo local sostenible y el control social.

\section{PROGRAMAS:}

1.2.1 Promoción de la organización, la movilización y la formación para la participación

1.2.2. Presupuesto participativo

1.2.3. Fortalecimiento estratégico de la planeación social y económica 


\subsection{Medellín participativa}

Entendemos la participación ciudadana como el encuentro de agencias individuales que persiguen un objetivo común. Según la ECC, no se han evidenciado cambios importantes en la participación en Medellín durante los últimos 8 años, salvo en la organización de eventos culturales, recreativos y deportivos y las actividades de voluntariado y obras comunitarias (2015).

Gráfica 6. Participación en espacios públicos durante el último año

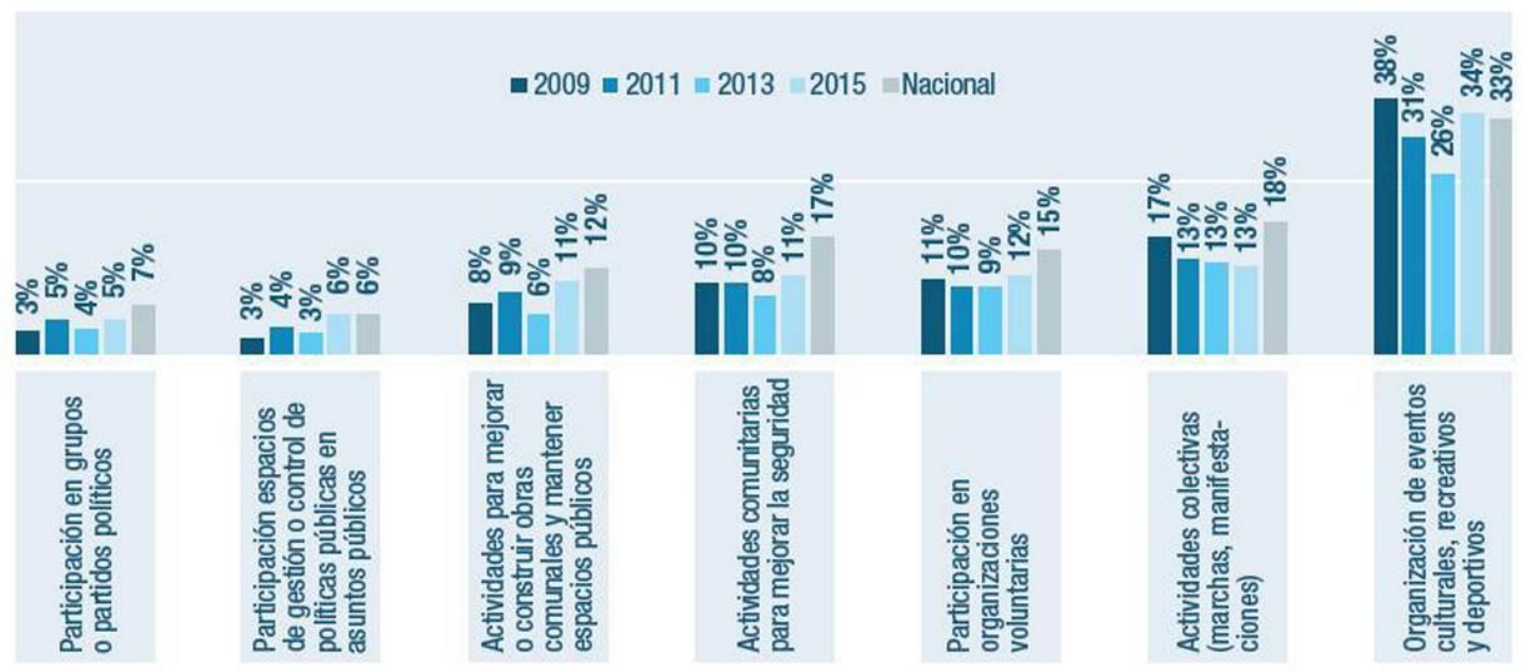

Fuente: Encuesta de cultura ciudadana 2015.

El grupo mayoritario de participación es masculino ( $57 \%$ hombres) y se concentra en estratos 2 y 3 (62\%). Los jóvenes entre 14 y 17 años tienen una participación significativamente menor (8,7\%), comparado con los distintos grupos de edad. De lo anterior, se infiere la necesidad de lograr una mayor participación femenina y de los jóvenes en los escenarios de construcción y discusión de agendas de desarrollo que aportan a la consolidación de una mejor sociedad, la cual, desde el territorio, reconoce sus potencialidades y limitaciones.

Por otra parte, desde esta dimensión se orienta el ejercicio de la planificación a la promoción de la participación de jóvenes entre 14 y 17 en escenarios de desarrollo local y política pública. Actualmente el Municipio de Medellín cuenta con una caracterización de 615 clubes juveniles que se encuentran en las diferentes Comunas, de estos el $54 \%$ se enfocan en desarrollar procesos artísticos y culturales, tal y como lo señala la Secretaría de Juventud (2015). Sin embargo entre grupos, clubes y organizaciones juveniles solo participan el 3\% del total de los jóvenes de la ciudad. 
Creemos en la necesidad de promover e incentivar la participación de otros estratos (1, 4, 5 y 6) para construir de una manera más integral la ciudad que queremos. No es desconocido que nuestra ciudad vive segmentada en diversas ciudades que no se conectan entre sí, que se desconocen entre sí y que se temen entre sí. La participación y la cultura son dos herramientas imprescindibles para trabajar en una ciudad "compartida", de todos, y para todos.

Otro elemento clave para Medellín en cuanto a participación es el Presupuesto Participativo. La lógica del proceso de Planeación Local (PL) y Presupuesto Participativo (PP) en Medellín es posibilitar la incidencia ciudadana sobre las decisiones de inversión pública, a partir de proyectos que las propias comunidades van generando e integrando a sus Planes de Desarrollo Local y deciden concertadamente para asignarles partidas presupuestales dentro del recurso económico asignado anualmente a este ejercicio participativo para cada comuna y corregimiento de la ciudad.

A continuación se describen los indicadores de resultados que se evaluarán en este reto:

\begin{tabular}{|l|c|c|c|c|}
\hline Nombre & Unidad & Línea de Base & Meta 2019 & Responsable \\
\hline $\begin{array}{l}\text { Ciudadanos que participan } \\
\text { activamente en escenarios de } \\
\text { incidencia en la planificación y } \\
\text { control social }\end{array}$ & numero & 0 & 650.000 & $\begin{array}{l}\text { Secretaria de } \\
\text { Participación } \\
\text { Ciudadana }\end{array}$ \\
\hline $\begin{array}{l}\text { Índice de } \\
\text { participación ciudadana en } \\
\text { Medellín }\end{array}$ & Porcentaje & 0 & 5 & $\begin{array}{l}\text { Secretaria de } \\
\text { Participación } \\
\text { Ciudadana }\end{array}$ \\
\hline $\begin{array}{l}\text { Planeación local y Presupuesto } \\
\text { Participativo como escenario } \\
\text { de pedagogía política para } \\
\text { incidir en la cultura } \\
\text { democrática }\end{array}$ & Porcentaje & 0 & 80 & $\begin{array}{l}\text { Secretaria de } \\
\text { Participación } \\
\text { Ciudadana }\end{array}$ \\
\hline
\end{tabular}

\subsubsection{PROGRAMA: PROMOCIÓN DE LA ORGANIZACIÓN, LA MOVILIZACIÓN Y LA FORMACIÓN PARA LA PARTICIPACIÓN}

Como instancias de planeación las Juntas Administradoras Locales son los auténticos representantes de las comunas y corregimientos ante las autoridades municipales y demás entes públicos y privados, razón por la cual su actuación está determinada por un cuerpo que se manifiesta en forma colectiva y no individual, refrendando sus actuaciones a través de resoluciones elaboradas en el marco de la Constitución Nacional, para lo 
cual recibirán la respectiva formación y el acompañamiento desde la institucionalidad, en pro de la profundización de la democracia participativa, apuntándole a la consolidación del Estado Social de Derecho.

En la tarea de fortalecer a la ciudadanía para el ejercicio de la participación se reconoce a las organizaciones comunales como actores esenciales para el desarrollo de la comunidad, en donde se promueven acciones de planeación, organización, dirección, evaluación y control; bajo los principios de responsabilidad, solidaridad y transparencia para el desarrollo de sus territorios, a través del fomento de estrategias de corresponsabilidad y la integración de esfuerzos públicos, privados y comunitarios que propenden por su autonomía y sostenibilidad.

Las organizaciones de la sociedad civil y las diversas redes sociales existentes en Medellín, han sido históricamente un bastión fundamental para la gestión social y política de la ciudad.

Con el aporte de cada una de ellas, se han construido y mantenido diversos espacios de participación y desarrollo, hoy se cuenta con una política pública resultado del consenso entre la Administración Municipal y las organizaciones, orientada a la construcción colectiva de herramientas para promover su desarrollo, fortalecimiento, acompañamiento, sostenibilidad y gestión.

Se busca mejorar la infraestructura física y tecnológica de los equipamientos sociales para constituirlos en ejes articuladores de la participación comunitaria en sus zonas de influencia, a través del mantenimiento, adecuación, dotación y gestión.

Este programa articula desde el Sistema de formación Ciudadana para la Participación la Escuela- Red de Formación Ciudadana, diversos procesos que se desarrollan en el territorio con el propósito de incidir eficaz y oportunamente sobre la construcción de lo público, desde acciones de formación ciudadana en el marco de una propuesta pedagógica que racionalice recursos y esfuerzos institucionales, con el propósito de desarrollar capacidades y habilidades para la promoción de una ciudadanía crítica, responsable y activa, la cualificación de la participación en el desarrollo local, el fortalecimiento de la convivencia y el control social de lo público.

Por lo mismo la promoción de más y mejores formas de participación ciudadana se constituyen en garante de mejores y más potentes democracias, consecuentemente la formación de niños y niñas en los Semilleros Infantiles para la Participación se convierte en una herramienta estratégica para lograr una ciudad que quiere ser ejemplo de participación.

El mejoramiento continuo de los procesos participativos implica la promoción de la investigación y la innovación a partir de la formulación de 
estrategias, herramientas y acciones para la gestión de la información y el conocimiento.

La participación democrática en la vida política, administrativa, económica, social y cultural, y en el control del poder político, es ahora un derecho que la Ley 1757 de 2015 busca proteger y garantizar; implicarse en este reto es hacerse parte de la construcción del presente y porvenir de un municipio comprometido con la trasformación de los imaginarios del bien egoísta, por el bien público y colectivo, para una sociedad más justa y equitativa.

La construcción de imaginarios democráticos en la participación y la construcción de sentidos colectivos ameritan relaciones solidarias con otros municipios y territorios y la escucha de enseñanzas y practicas participativas con las cuales intercambiar saberes, experiencias y motivaciones, los foros públicos, el trabajo en red, los intercambios y escenarios, serán el método para hacernos conscientes de que somos parte de una cosmovisión mayor a la de nuestro territorio municipal.

En materia de escenarios de participación el programa garantiza la articulación institucional como herramienta prioritaria para materializar la política pública de participación ciudadana acorde con las necesidades de los territorios, los grupos poblacionales y los sectores sociales. La conformación del Consejo y el Sistema Municipal de Participación Ciudadana, articulado al Sistema Municipal de Planeación.

Indicadores de resultado

\begin{tabular}{|l|l|c|c|c|}
\hline \multicolumn{1}{|c|}{ Nombre } & Unidad & Línea de Base & Meta 2019 & Responsable \\
\hline $\begin{array}{l}\text { JAL que inciden en el control } \\
\text { político y la gestión del } \\
\text { desarrollo territorial. }\end{array}$ & Número & ND & 21 & $\begin{array}{c}\text { Secretaria de } \\
\text { Participación } \\
\text { Ciudadana }\end{array}$ \\
\hline $\begin{array}{l}\text { Organizaciones comunales que } \\
\text { mejoran su funcionamiento } \\
\text { interno y de gestión }\end{array}$ & Numero & 271 & 320 & $\begin{array}{l}\text { Secretaria de } \\
\text { Participación } \\
\text { Ciudadana }\end{array}$ \\
\hline $\begin{array}{l}\text { Organizaciones y redes sociales } \\
\text { legitimadas }\end{array}$ & Número & ND & 200 & $\begin{array}{l}\text { Secretaria de } \\
\text { Participación } \\
\text { Ciudadana }\end{array}$ \\
\hline
\end{tabular}

\subsubsection{Proyecto: JAL ando con vos}

Este proyecto permite el acompañamiento técnico, político y administrativo a las Juntas Administradoras Locales para el ejercicio de sus funciones constitucionales, legales y normativas en pro de la profundización de la democracia participativa, apuntándole a la consolidación del Estado Social de Derecho.

En su función como instancias de planeación las Juntas Administradoras Locales serán protagonistas en los procesos de concertación y construcción del desarrollo social. 
Indicador de producto:

\begin{tabular}{|c|c|}
\hline \multicolumn{1}{|c|}{ Nombre } & Unidad \\
\hline $\begin{array}{l}\text { Planes de trabajo de las Juntas Administradoras Locales formulados e } \\
\text { implementados }\end{array}$ & Porcentaje \\
\hline
\end{tabular}

\subsubsection{Proyecto: Organismos comunales, integrales y modernos} Los organismos comunales (Juntas de Acción Comunal, Asocomunales, Juntas de Vivienda Comunitaria y la Federación de Organizaciones Comunales del Municipio de Medellín - Fedemedellín) son fundamentales para el desarrollo de las comunidades; su trabajo es un baluarte para los procesos de participación y gestión. Este proyecto busca promover y fortalecer los organismos comunales, reconocerlas como actores esenciales para el desarrollo de la comunidad, fomentar el liderazgo comunal, a través de estrategias que propendan por su autonomía y sostenibilidad, promover procesos de formación y cualificación personal y social, implementar políticas de estímulos, apoyar iniciativas y planes de trabajo, apoyar y financiar procesos de planeación participativa, fomentar la contratación social y la innovación social, realizar vigilancia, inspección y control, entre otras.

La Administración Municipal debe seguir acompañando a los organismos comunales para que asuman responsablemente las funciones contempladas en la Ley Comunal y participen activamente en el proceso de revisión de la misma, acorde con los retos del contexto nacional y local, en términos del aporte y la responsabilidad con lo público.

Responsable: Secretaría de Participación Ciudadana

Indicadores de producto

\begin{tabular}{|l|c|}
\hline \multicolumn{1}{|c|}{ Nombre } & Unidad \\
\hline $\begin{array}{l}\text { Planes de trabajo de las Juntas de acción Comunal formulados e } \\
\text { implementados }\end{array}$ & Porcentaje \\
\hline $\begin{array}{l}\text { Actuaciones de vigilancia inspección y control realizados a las Juntas de acción } \\
\text { comunal }\end{array}$ & Número \\
\hline
\end{tabular}

1.2.1.3 Proyecto: Red de formación e investigación para la participación ciudadana

Cualificar los procesos existentes de formación ciudadana y la creación de nuevos, tanto del quehacer institucional de las dependencias de la Alcaldía Municipal, como a nivel comunal y de otros actores del sector privado y académico, a través de una estrategia de acción pedagógica y política para la ciudad con el propósito de desarrollar capacidades y habilidades para la promoción de una ciudadanía crítica, responsable y activa, la cualificación de la participación en el desarrollo local, el fortalecimiento de la convivencia y el control social de lo público. 
Potenciar el desarrollo de los procesos de formación ciudadana para la participación democrática realizados con y por distintos grupos poblacionales, grupos organizados y sociedad civil en general, que se identifiquen con la construcción de lo público en los barrios y veredas de las comunas y corregimientos de Medellín, posibilitando la articulación entre la institucionalidad, las organizaciones comunales, la sociedad civil, los actores del mercado y la academia, permitiendo el reconocimiento de la pluralidad y la construcción de lo público de manera colectiva.

Indicadores de producto

Responsable: Secretaría de Participación Ciudadana

\begin{tabular}{|l|c|}
\hline \multicolumn{1}{|c|}{ Nombre } & Unidad \\
\hline Procesos y entidades articulados a la red de formación ciudadana & Número \\
\hline $\begin{array}{l}\text { Ciudadanos formados en el marco del sistema de formación para la } \\
\text { participación }\end{array}$ & Numero \\
\hline
\end{tabular}

1.2.1.4 Proyecto: Promoción y fortalecimiento de las organizaciones de la sociedad civil y las redes sociales

Promover el desarrollo, fortalecimiento y sostenibilidad de las organizaciones de la sociedad civil y las redes sociales de la ciudad de Medellín, a través de la implementación de estrategias de formación permanente para cualificar a sus integrantes, generación y ampliación de plataformas de participación para impulsar el reconocimiento y visibilización de las organizaciones y redes, posibilitando la incidencia política, generación de espacios técnicos interinstitucionales para la articulación y el trabajo en red de actores, esfuerzos, voluntades, conocimientos y recursos en torno a objetivos comunes y el acompañamiento y asistencia técnica para el desarrollo de las líneas de acción de la política pública de las organizaciones de la sociedad civil.

Los Centros de Desarrollo Social, antes Centros de Integración Barrial, serán espacios de encuentro para la participación, la convivencia, la autogestión e integración comunitaria, en torno a las organizaciones.

Responsable: Secretaría de Participación Ciudadana

Indicador de producto

\begin{tabular}{|c|c|}
\hline Nombre & Unidad \\
\hline Organizaciones y redes sociales Promovidas y fortalecidas & Porcentaje \\
\hline
\end{tabular}

1.2.1.5 Proyecto: Infraestructura física y tecnológica para la participación Mejoramiento de los equipamientos sociales con el fin de constituirlos en ejes articuladores de la participación comunitaria en sus zonas de influencia a través del mantenimiento, adecuación y dotación de sedes sociales y la gestión de equipamientos comunitarios. 
La organización social y comunitaria requiere condiciones mínimas para el encuentro y la gestión del desarrollo, a pesar de que en los últimos años esta ciudad ha ido construyendo espacios colectivos para el encuentro ciudadano es importante revisar las condiciones y necesidades de barrios y veredas que aún no cuentan con espacios y dotaciones mínimas para el desarrollo de su trabajo. Es necesario hacer un diagnóstico de los espacios comunitarios de la ciudad y construir un plan de gerenciamiento y sostenibilidad de los mismos.

Responsable: Secretaría de Participación Ciudadana

Indicadores de producto

\begin{tabular}{|l|c|}
\hline \multicolumn{1}{|c|}{ Nombre } & Unidad \\
\hline Equipamientos sociales que mejoran sus condiciones físicas & Número \\
\hline Telecentros comunitarios creados y fortalecidos & Numero \\
\hline
\end{tabular}

\subsubsection{Proyecto: Vos sos participación - promoción y garantía del derecho a la participación}

La participación ciudadana es la estrategia más potente de la democracia, por tanto es trascendente posicionarla como un ejercicio que promueve el debate de ideas, la generación de propuestas, la conciliación de agendas, las alianzas, la reconciliación, la convivencia, el empoderamiento y la incidencia en el desarrollo de la ciudad que compartimos.

Desarrollo de líneas de actuación en el marco del concepto de movilización social, como la información, la comunicación, el diálogo ciudadano, la dinamización y articulación de escenarios, instancias, organizaciones de la sociedad civil, sectores públicos y privados, como condiciones fundamentales para garantizar el derecho a la participación en la vida política, administrativa, económica, social y cultural de la ciudad. Se llevarán a cabo campañas de movilización social para promover la participación y la cultura democrática, el conocimiento y apropiación de los mecanismos de participación ciudadana y comunitaria, instancias de participación, escenarios, niveles, normatividad, creación e implementación del Consejo Municipal de Participación y el Sistema Municipal de Participación Ciudadana en el marco de la Ley Estatutaria 1757 de 2015, como pilares y referentes para direccionar, planear el desarrollo y articular todas las políticas públicas de participación existentes, consejos locales de participación, sistemas locales de participación, sistema municipal de planeación y otras instancias de participación.

Indicadores de producto

Responsable: Secretaría de Participación Ciudadana

\begin{tabular}{|l|c|}
\hline \multicolumn{1}{|c|}{ Nombre } & Unidad \\
\hline Agenda de participación formulada e implementada & Porcentaje \\
\hline $\begin{array}{l}\text { Instancias de participación ciudadana articuladas a través del Sistema } \\
\text { Municipal de Participación }\end{array}$ & Número \\
\hline
\end{tabular}


Creemos en la cultura Ciudadana

1.2.1.7 Proyecto: Fortalecimiento a la participación formal para la juventud

Desde el fomento de la vivencia de los jóvenes en su territorio, se promoverá el fortalecimiento y apoyo a las organizaciones, grupos, clubes y procesos juveniles, pretende acompañar y proyectar la asociatividad como mecanismo de inserción de los y las jóvenes organizados en las diferentes dinámicas sociales y comunitarias, a través del acceso a oportunidades que les permitan: cualificarse mediante procesos de formación, intercambiar saberes y experiencias entre los clubes juveniles, conformar redes entre colectivos, grupos y clubes de la ciudad, con sentido de corresponsabilidad, proyección y acción comunitaria, política y social en los territorios, usar de forma adecuada y productiva tiempo libre juntándose y construyendo con otros y finalmente generar reconocimiento de la ciudad, sus contextos y lecturas del entorno y sus territorios

Así mismo, con el propósito de realizar acompañamiento y promover los espacios de participación formal acorde con la Ley 1622 de 2013 y el Acuerdo 019 de 2014, en el cual se instituyen el Subsistema de Participación y Sistema Municipal de Juventud, entre los que están los Consejeros Municipales Juventud (CMJ), Plataforma de Juventud, y otros donde existen espacios en los que los jóvenes participan de manera directa y activa, tienen voz y voto en la construcción de una ciudad joven. Este es un espacio para el fortalecimiento de los procesos democráticos juveniles.

Responsable: Secretaría de Juventud

Indicadores de producto

\begin{tabular}{|l|c|}
\hline \multicolumn{1}{|c|}{ Nombre } & Unidad \\
\hline Subsistema de Participación de la Juventud operando & Porcentaje \\
\hline Grupos juveniles beneficiados & Número \\
\hline
\end{tabular}

1.2.1.8 Proyecto: Niñez y juventud construyendo ciudad

Facilitar espacios de formación para la participación de los niños y niñas entre los 8 y los 13 años, que les permita la promoción del juicio crítico, el reconocimiento de sí mismo, del otro y de lo otro y la aprehensión y defensa de los derechos, los deberes y responsabilidades; como aspectos claves para la convivencia y el ejercicio de la participación social, comunitaria, ciudadana y política, favoreciendo la multiplicidad de formas de participación ciudadana con el objetivo de lograr mejores y más potentes democracias, siendo una herramienta estratégica para lograr una ciudad que quiere ser ejemplo de participación.

Responsable: Secretaría de Participación Ciudadana 
Indicador de producto

\begin{tabular}{|l|c|}
\hline \multicolumn{1}{|c|}{ Nombre } & Unidad \\
\hline $\begin{array}{l}\text { Niños, niñas y jóvenes que permanecen a las actividades de formación para } \\
\text { la participación }\end{array}$ & Porcentaje \\
\hline
\end{tabular}

\subsubsection{PROGRAMA: PRESUPUESTO PARTICIPATIVO}

El Presupuesto Participativo es un escenario de participación para reflexionar sobre lo común, lo público y colectivo, sobre las prioridades de inversión de la ciudad y los criterios para establecerlas, la gestión del desarrollo local es su principal objetivo. El programa permite la implementación de las diferentes fases de la ruta del presupuesto participativo, entendido como instrumento de gestión público por medio del cual las comunidades planean, priorizan y gestionan parte de la inversión pública, para contribuir a superar problemáticas de sus territorios.

La Ley Estatutaria - 1757 de 2015, eleva el proceso de Presupuesto Participativo a mecanismo de participación ciudadana de asignación equitativa, racional, eficiente, eficaz y transparente de los recursos públicos que fortalece las relaciones Estado - sociedad civil.

Este programa busca establecer reglas de juego claras y coherentes con la democracia participativa y propende por el cumplimiento de las mismas por parte de todos los actores del proceso, promueve y amplía la participación de la ciudadanía y con ello estimula la activación de procesos de control social y rendición de cuentas.

Reconocemos que el presupuesto participativo requiere de una resignificación, transformaciones no solo metodológicas sino de su sentido sustancial y propósito en el campo de la participación democrática; requerimos como sociedad reflexionar sobre lo común, lo público y colectivo en el ejercicio del presupuesto participativo, sobre las prioridades de inversión de la ciudad y los criterios para establecerlas, la responsabilidad en la distribución y ejecución del recurso públicos, el debate frente a los interese y el liderazgo democrático que requiere una participación democrática para las transformaciones sociales y de futuro en la ciudad.

Las transformaciones que requieren la $\mathrm{PL}$ y $\mathrm{PP}$ serán el resultado del consenso en debates, foros y conversatorios con la ciudadanía, estos acuerdos se refrendarán jurídicamente ante las instancias pertinentes.

Reconocemos el Presupuesto Participativo como el eje principal de la democracia participativa en la ciudad y por eso lo implementaremos acompañado de estrategias de formación, movilización, gestión y control social. 
Reconocemos en este escenario la posibilidad de que las y los habitantes de comunas y corregimientos deliberen y decidan sobre asuntos y necesidades colectivas, traducidas en proyectos de inversión, articulados con los planes de desarrollo local, y también le apostamos a revisar de manera rigurosa los avances y/o aportes en los indicadores del desarrollo en los territorios. Resignificaremos el ejercicio metodológico y de interacción con los actores sociales y políticos de la ciudad de cara a los retos de la democracia, la transparencia y el aporte al desarrollo.

Cualificaremos el ejercicio de la revisión técnica y la articulación para el seguimiento al proceso de ejecución e interventoría de los proyectos de Presupuesto Participativo, mediante la activación del comité de enlace territorial (con representación de todas las dependencias). Y lideraremos la articulación y gestión interinstitucional para la cualificación de la planeación comunitaria.

Indicadores de resultado

\begin{tabular}{|c|c|c|c|c|}
\hline Nombre & Unidad & Línea de Base & Meta 2019 & Responsable \\
\hline $\begin{array}{l}\text { Jóvenes participantes en } \\
\text { Presupuesto Participativo que } \\
\text { inciden en el desarrollo de su } \\
\text { territorio }\end{array}$ & Número & 2.122 & 3000 & $\begin{array}{l}\text { Secretaria de } \\
\text { Participación } \\
\text { Ciudadana }\end{array}$ \\
\hline $\begin{array}{l}\text { Ruta metodológica y política } \\
\text { del Presupuesto Participativo } \\
\text { como estrategia pedagógica } \\
\text { para la larticipación } \\
\text { democrática implementada }\end{array}$ & Porcentaje & 0 & 100 & $\begin{array}{c}\text { Secretaria de } \\
\text { Participación } \\
\text { Ciudadana }\end{array}$ \\
\hline
\end{tabular}

\subsubsection{Proyecto: Vos sos presupuesto participativo}

Implementación y cualificación de las diferentes fases de la ruta del presupuesto participativo: desde la revisión técnica hasta la articulación para el seguimiento al proceso de ejecución e interventoría de los proyectos, entendiendo este como un instrumento de gestión pública, por medio del cual las comunidades planean, priorizan y gestionan parte de la inversión pública, para contribuir a superar problemáticas de sus territorios.

Reconocemos en este escenario la posibilidad de que las y los habitantes de comunas y corregimientos deliberen y decidan sobre asuntos y necesidades colectivas, traducidas en proyectos de inversión, articulados con los planes de desarrollo local, y también le apostamos a revisar de manera rigurosa los avances y/o aportes en los indicadores del desarrollo en los territorios. Resignificaremos el ejercicio metodológico y de interacción con los actores sociales y políticos de la ciudad de cara a los retos de la democracia, la transparencia y el aporte al desarrollo local.

Responsable: Secretaría de Participación Ciudadana 
Indicador de producto

\begin{tabular}{|l|c|}
\hline \multicolumn{1}{|c|}{ Nombre } & Unidad \\
\hline $\begin{array}{l}\text { Programa de presupuesto participativo articulado, institucional y } \\
\text { normativamente al sistema municipal de participación y al sistema municipal } \\
\text { de planeación }\end{array}$ & Porcentaje \\
\hline
\end{tabular}

\subsubsection{Proyecto: Presupuesto participativo joven cuenta con vos}

Este proyecto busca que las y los jóvenes participen y se apropien de los asuntos públicos de sus territorios. Es un ejemplo de participación con enfoque diferencial que garantiza la renovación de los liderazgos en la ciudad. Articula las acciones y estrategias de participación con la política pública de Juventud.

Responsable: Secretaría de Participación Ciudadana

Indicador de producto

\begin{tabular}{|c|c|}
\hline \multicolumn{1}{|c|}{ Nombre } & Unidad \\
\hline Jóvenes participantes en ejercicios de presupuestación participativo & Número \\
\hline
\end{tabular}

\subsubsection{PROGRAMA: FORTALECIMIENTO ESTRATÉGICO DE LA PLANEACIÓN SOCIAL Y ECONÓMICA}

El enfoque de la gobernanza es básico para entender el encuentro dentro y fuera del Estado entre los actores públicos, privados, sociales, económicos sociales y políticos, favoreciendo la interdependencia e integración para la planificación y la gestión, que redunda en buenas prácticas institucionales reflejadas en el quehacer de las secretarías misionales y en su incidencia en la planeación local y municipal. Este enfoque ha sido ya estudiado por diversos autores (Stoker, Rhodes), encontrándose que la gobernanza es un concepto descriptivo que muestra el cambio que al final del siglo $\mathrm{XX}$ experimentaron las relaciones entre el gobierno y la sociedad. Se identifica entonces el quehacer institucional como una forma de ver y entender la realidad social y las situaciones problemáticas, desde una perspectiva integradora, que favorece los procesos de corresponsabilidad para el cumplimiento y garantía de derechos y deberes, que valora la autogestión de desarrollo y que centra en el marco de su actuación a los seres humanos, ciudadanos y ciudadanas para la democracia.

El quehacer institucional se ha centrado en procesos que le permitieron posicionar su rol en el territorio y al interior de la Administración, con el desarrollo de programas y proyectos integradores, articuladores, complementarios y participativos, como el proceso de aprestamiento para la revisión y ajuste del POT, la revisión del Sistema Municipal de Planeación, la revisión y ajuste de los Planes de Desarrollo Local, la aplicación de la Metodología General Ajustada establecida por el Departamento Nacional de Planeación, definición de lineamientos para construcción de políticas públicas; el proceso de rendición publica de cuentas de niños, niñas, 
adolescentes y jóvenes en el marco del Gasto Público Social; el empoderamiento de instancias de participación[1] en la apropiación y análisis de la lectura territorial, sectorial y poblacional.

Indicador de resultado

\begin{tabular}{|c|c|c|c|c|}
\hline Nombre & Unidad & $\begin{array}{c}\text { Línea de } \\
\text { Base }\end{array}$ & Meta 2019 & Responsable \\
\hline $\begin{array}{l}\text { Estrategias para la planeación } \\
\text { social y económica que } \\
\text { impactan el desarrollo } \\
\text { municipal. Numero }\end{array}$ & N & 0 & 3 & $\begin{array}{c}\text { Departamento } \\
\text { Planistrativo de }\end{array}$ \\
\hline
\end{tabular}

1.2.3.1 Proyecto: Sistema municipal de planeación ${ }^{2}$ para el desarrollo sostenible, integral, planeado y participativo

El Sistema Municipal de Planeación articula la normatividad, la dirección de todas las dependencias Municipales, centrales y descentralizadas y las relaciones con los actores sociales, con el propósito de lograr un desarrollo autosostenible, integral, planeado y participativo en la ciudad. A su vez, incorpora las instancias y autoridades de planeación, los organismos de ejecución, administración y control y los organismos de la comunidad mediante mecanismos de información y participación y asigna competencias y responsabilidades.

Este proyecto incluye la formulación de los planes sectoriales y los planes de desarrollo administrativo como instrumentos de análisis y de gestión que faciliten tener insumos básicos para tomar decisiones y mejorar los resultados de las políticas públicas, así como favorecer el afianzamiento de los procesos de planeación.

Responsable: Departamento Administrativo de Planeación

Indicadores de producto

\begin{tabular}{|l|c|}
\hline \multicolumn{1}{|c|}{ Nombre } & Unidad \\
\hline Sistema Municipal de Planeación actualizado & Numero \\
\hline Planes de desarrollo administrativo formulados & Numero \\
\hline
\end{tabular}

\subsubsection{Proyecto: Planeación participativa del desarrollo}

Fortalecer los procesos de la planeación participativa del desarrollo, a partir de estrategias de acompañamiento a los actores comunitarios e institucionales y de la plataforma de co-creación ciudadana, MiMedellín, en donde las ideas y la inspiración de todos forman parte de la transformación de nuestra ciudad, de forma que se articulen las diferentes escalas territoriales con los instrumentos, órganos e instancias de la planeación, con el propósito de generar comprensión y acción de los alcances de cada

\footnotetext{
${ }^{2}$ El Sistema Municipal de Planeación está definido en el Acuerdo 43 de 2007 y en el nivel nacional en la Ley 152 de 1994.
} 
instrumento y proceso desde el cual se busca incidir en el desarrollo del territorio.

Responsable: Departamento Administrativo de Planeación Indicadores de producto:

\begin{tabular}{|l|c|}
\hline \multicolumn{1}{|c|}{ Nombre } & Unidad \\
\hline $\begin{array}{l}\text { Estrategias de articulación de la planeación participativa formuladas e } \\
\text { implementadas. }\end{array}$ & Numero \\
\hline $\begin{array}{l}\text { Sistema de seguimiento monitoreo y evaluación de los Planes de Desarrollo } \\
\text { Local, }\end{array}$ & Numero \\
\hline
\end{tabular}

\subsubsection{Proyecto: Políticas sociales y económicas e instrumentos de gestión para el desarrollo}

Las políticas sociales y económicas parten de considerar a la ciudadanía en un marco de derechos y promover su vinculación al ejercicio democrático y al desarrollo humano como sujetos y actores. Es así como a partir del direccionamiento de la planeación, la formulación, seguimiento y evaluación de las políticas públicas sociales y económicas para la articulación de lo poblacional y lo sectorial, y la inclusión en los instrumentos de planificación y gestión, se facilita la garantía de los derechos humanos y se responde a las demandas ciudadanas en estos ámbitos, posibilitando el mejoramiento de la calidad de vida de los habitantes de Medellín.

Además de lo anterior, y estableciendo orientaciones estratégicas para promover dicho desarrollo mediante la elaboración de planes de desarrollo sectorial en la dimensión económica, planes de acción, y ejecución de programas y proyectos sectoriales, además del diseño de sistemas y mecanismos que permitan hacer la evaluación y el seguimiento de los planes y programas, con el fin de lograr las transformaciones frente a la concentración de la riqueza y el capital, el mejoramiento del empleo y la inversión, la reducción del desempleo, la mejora del ingreso y el ahorro y calidad de vida de la población que habita la ciudad.

Responsable: Departamento Administrativo de Planeación Indicadores de producto

\begin{tabular}{|l|c|}
\hline \multicolumn{1}{|c|}{ Nombre } & Unidad \\
\hline Planes sectoriales formulados & Numero \\
\hline Políticas sociales y económicas para el desarrollo posicionadas & Numero \\
\hline
\end{tabular}




\subsection{RETO:}

\section{MEDELLÍN BIEN ADMINISTRADO}

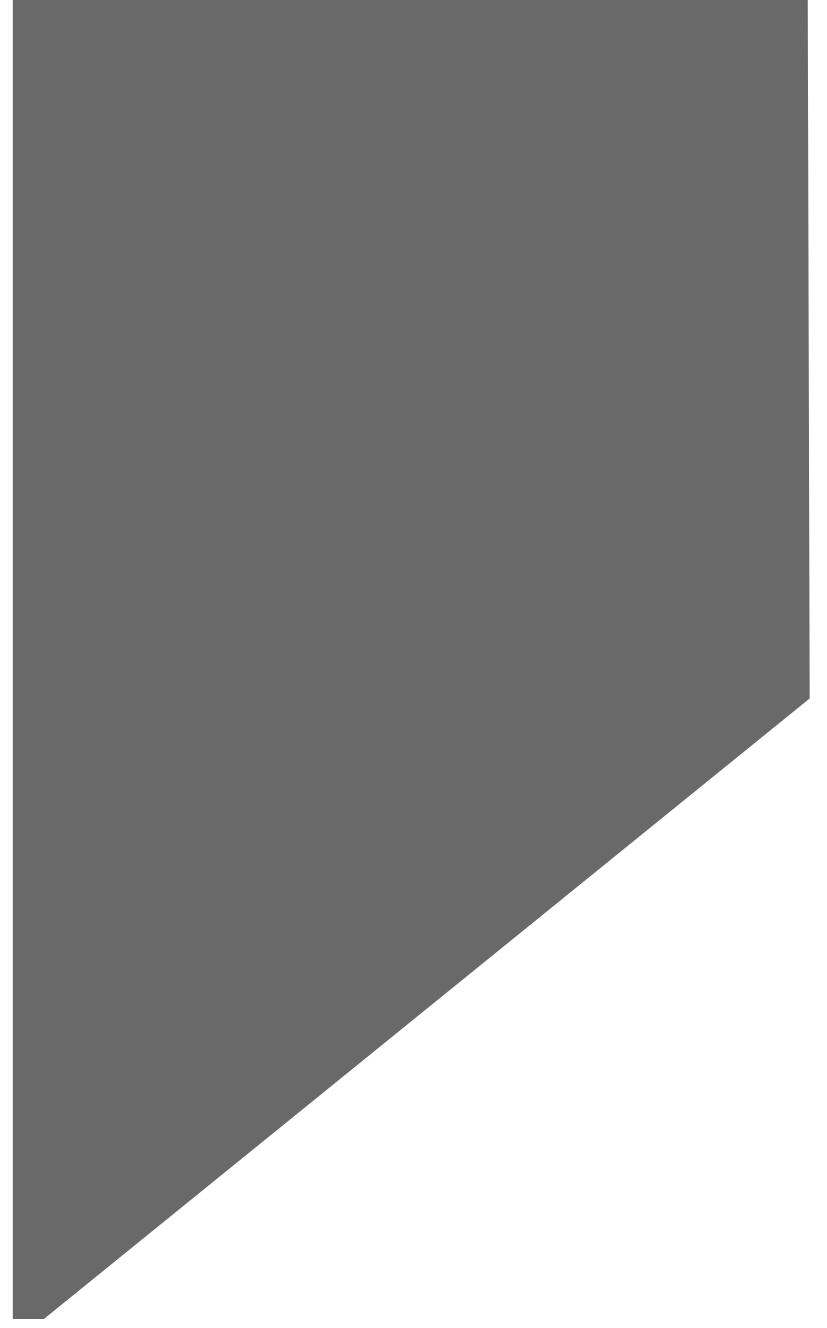

\section{OBJETIVO}

Fortalecer la institucionalidad desarrollando acciones eficaces, responsables y transparentes en todos los niveles, garantizando la prestación de los servicios a la ciudadanía.

\section{PROGRAMAS}

4 1.3.1. Gobierno visible

4 1.3.2. Transparencia como modelo de gestión

4 1.3.3. Excelente manejo de las finanzas y los recursos públicos

4 1.3.4. Gestión eficiente

$\Delta$ 1.3.5. Gestión eficaz

4 1.3.6. Innovación pública laboratorio de gobierno 


\subsection{Medellín bien administrado}

Según la ECC, el $84 \%$ de los ciudadanos de Medellín cree que más de la mitad de los funcionarios públicos son corruptos (2015). Esto sumado a los bajos índices de confianza institucional, nos muestra que Medellín enfrenta el reto de no solo ser ejemplar en el manejo de los recursos públicos, sino también ser capaz de comunicarlo de manera clara a la sociedad.

\section{Grafico 7. Ley, moral y cultura}

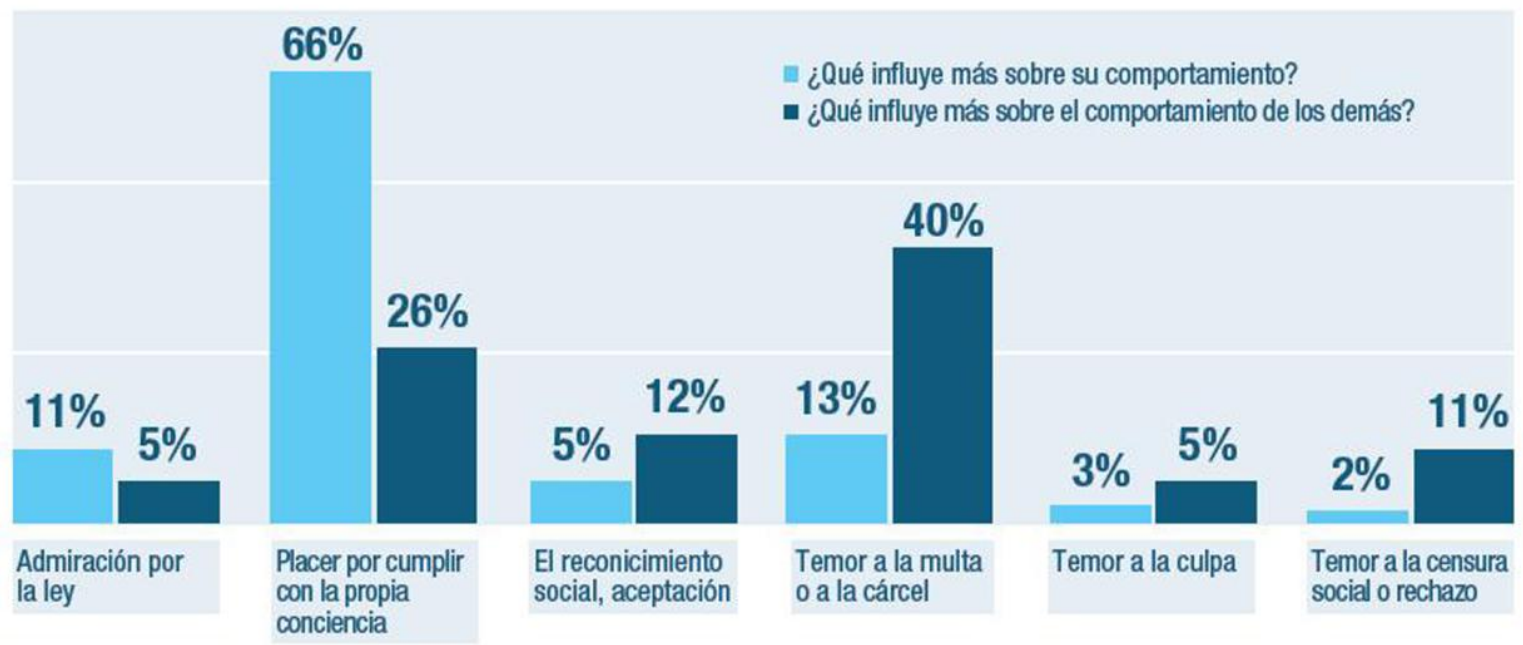

Fuente: Encuesta de calidad de vida de 2015

Por otro lado cuando relacionamos los datos anteriores con la concepción ciudadana sobre la importancia de los asuntos públicos en la vida de los ciudadanos, la ECC nos dice que solo el $19 \%$ de los medellinenses los consideran muy importantes (2015). Es decir, por un lado Medellín tienen ciudadanos que no confían en las instituciones ni en los funcionarios, y por otro lado, una parte importante de estos ciudadanos no cree que esto les afecte de manera importante.

El Plan de Desarrollo Medellín cuenta con vos debe hacer un gran esfuerzo en reconciliar los ciudadanos y las instituciones, partes imprescindibles de una sociedad, y será a través del ejemplo, como se recuperará la confianza de los ciudadanos con una administración que mejore en eficiencia y eficacia y con una gestión transparente y visible, que repercutan en la calidad de vida de los ciudadanos y en su percepción de las instituciones.

Con base a todo lo anterior, es posible pensar que el Municipio de Medellín es una ciudad que no puede volver al pasado, que avanza, mejora, y que reconoce que aún queda camino por recorrer, pero que está dispuesta y decidida a hacerlo, a recorrerlo. Una Medellín en donde 
se gobierne más para los de adentro que para los de afuera. Una ciudad en la que se priorice y se le dé importancia a lo realmente importante. Una Medellín a diciembre 31 de 2019 más segura, más legal y más equitativa; en la que los ciudadanos recuperen la esperanza y confíen en su administración y su ciudad. Una Medellín con más y mejores oportunidades, y una mejor calidad de vida para todos.

A continuación se describen los indicadores de resultado que se evaluarán en este reto:

\begin{tabular}{|l|c|c|c|c|}
\hline Nombre & Unidad & $\begin{array}{c}\text { Línea de } \\
\text { Base }\end{array}$ & Meta 2019 & Responsable \\
\hline $\begin{array}{l}\text { INDICE IGA(Índice de } \\
\text { Gobierno Abierto) }{ }^{*} \text { Y }\end{array}$ & Puntos & 85,2 & 88 & $\begin{array}{c}\text { Secretaría de } \\
\text { Evaluación y } \\
\text { Control }\end{array}$ \\
\hline $\begin{array}{l}\text { Nivel de satisfacción } \\
\text { ciudadana con la oferta } \\
\text { institucional }\end{array}$ & Porcentaje & $87,60 \%$ & $88,00 \%$ & $\begin{array}{c}\text { Secretaría de } \\
\text { Gestión Humana }\end{array}$ \\
\hline
\end{tabular}

\subsubsection{PROGRAMA: GOBIERNO VISIBLE}

El Gobierno visible es un apuesta para la legalidad y la transparencia como modelo de gestión, que le permite al Municipio de Medellín la construcción de la confianza con la ciudadanía y el fortalecimiento de la institucionalidad como garante de derecho, a través de proyectos diseñados para que el ciudadano fortalezca las relaciones con la administración municipal y pueda intervenir activamente en las decisiones públicas.

Un gobierno visible posibilita una escucha directa de las necesidades, problemáticas y requerimientos de la ciudadanía así como el ejercicio de la planificación colectiva al servicio de la búsqueda de las soluciones y mejora de la calidad de vida, un gobierno de cara a las comunidades permite un ejercicio participativo y comprometido el cual se hace transparente, público y visible acercando la administración municipal al territorio para facilitar el diálogo, la comunicación y la confianza en el gobierno en cumplimiento de sus deberes legales y constitucionales.

El programa de Gobierno visible le permite al Municipio de Medellín integrar proyectos que tienen como propósito generar en la ciudadanía un alto grado de confianza institucional, informar y rendir cuentas de la ejecución presupuestal de las finanzas, programas y proyectos así como de los avances y culminación de obras.

La información es un derecho de la ciudadanía, por lo tanto debe ser pública y publicada, socializada y explicada para que se ejerza el control social y se promueva la deliberación, el seguimiento, participación, incentivando la autorregulación. Es un deber del Municipio de Medellín entregar información veraz y real de los recursos públicos y su destinación, así como de los 
impactos y beneficios en las comunidades, grupos poblacionales, sectores sociales y económicos, entre otros. La visibilidad de la administración pública le garantiza a la ciudadanía ser parte activa en la intervención de las decisiones políticas así como de grandes transformaciones culturales.

La corrupción es una práctica inaceptable, por lo tanto debe ser erradicada con la implementación de controles administrativos basados en la ética de lo público, con la participación activa de los ciudadanía como veedores de la destinación y uso de los recursos, con pleno conocimiento de las formas legales de denuncia y de solicitud de derecho a la información y a la sustentación de la destinación y ejecución del presupuesto.

Un gobierno visible permite a la ciudadanía estar más cerca de la gobernanza, de la legitimidad y de las decisiones que hacen parte de los cambios y transformaciones de la ciudad, hace más asequible la información, el conocimiento de los procesos administrativos y las instancias de vigilancia y control social que permitan la construcción de una cultura de la legalidad, incluyente y participativa.

Indicadores de resultado

\begin{tabular}{|l|c|c|c|c|}
\hline Nombre & Unidad & $\begin{array}{c}\text { Línea de } \\
\text { Base }\end{array}$ & Meta 2019 & Responsable \\
\hline $\begin{array}{l}\text { Visibilidad de la Administración } \\
\text { Municipal en la Ciudadanía }\end{array}$ & Porcentaje & N/A & 100 & Secretaría Privada \\
\hline $\begin{array}{l}\text { Acuerdos y pactos logrados } \\
\text { del Municipio de Medellín con } \\
\text { organizaciones, entidades e } \\
\text { instituciones nacionales e } \\
\text { internacionales }\end{array}$ & Número & N/A & 16 & Secretaría Privada \\
\hline
\end{tabular}

\subsubsection{Proyecto: Realización periódica de rendiciones de cuentas públicas} integrales y específicas: seguridad e infancia

Las rendiciones públicas de cuentas se realizarán no solo en los términos de cumplimiento de ley, sino que se constituirán en un ejercicio permanente, abierto a la ciudadanía, en donde el Alcalde y su gestión sean públicos, rindiendo cuentas permanentes de los avances en el cumplimiento de sus obligaciones y de los compromisos estipulados en el Plan de Desarrollo. La interacción con la ciudadanía será una premisa.

Responsable: Departamento Administrativo de Planeación Indicador de producto

\begin{tabular}{|c|c|}
\hline \multicolumn{1}{|c|}{ Nombre } & Unidad \\
\hline Rendición de cuentas realizadas & Número \\
\hline
\end{tabular}

\subsubsection{Proyecto: Alcaldía en el territorio}

"El alcalde en el territorio" es un mecanismo de desconcentración y planeación con la ciudadanía que busca fortalecer la transparencia y eficiencia, generando confianza y visibilidad de la administración municipal. 
Esta iniciativa de gobierno en las calles, comunas y territorio hace mucho más transparente a la administración municipal permitiéndole el contacto con los ciudadanos y sus problemáticas, facilitando la interrelación y la recepción de solicitudes de interés general y particular en garantía de los derechos de la ciudadanía así como atender con oportunidad las demandas ciudadanas, aumentando la eficacia gubernamental y estrechando la relación de la administración municipal con el ciudadano al utilizar de forma estratégica las herramientas institucionales con las que cuenta para promover un gobierno eficiente, eficaz con interacción permanentemente con la población.

El alcalde al acercar la administración a la ciudadanía a través de su gabinete y colaboradores, permitirá el fortalecimiento del ejercicio del gobierno desde sus lugares de trabajo, vivienda, barrios, escenarios de esparcimiento, además de facilitar el seguimiento, medición y percepción de las intervenciones, programas, proyectos, obras y actividades de la administración municipal de cara a las mismas comunidades protagonistas de la transformación de la ciudad, haciendo visible al Alcalde como gobernante generando transparencia y eficiencia como expresión de la legalidad.

Responsable: Secretaría Privada

Indicador de producto

\begin{tabular}{|l|c|}
\hline \multicolumn{1}{|c|}{ Nombre } & Unidad \\
\hline Encuentros en el territorio del alcalde y su gabinete con la ciudadanía & Número \\
\hline
\end{tabular}

\subsubsection{Proyecto: Proyecto social lucha contra la corrupción}

Con este proyecto se busca fortalecer las políticas institucionales orientadas a disminuir la corrupción en la Administración Municipal, a través del diseño e implementación de diversas estrategias y mecanismos que promuevan la probidad y transparencia tanto en las actuaciones de los servidores públicos como en su relacionamiento con el sector privado y la comunidad en general, con el propósito de incrementar la confianza ciudadana en el manejo pulcro y eficiente de los recursos públicos.

Responsable: Secretaría de Evaluación y Control

Indicadores de producto

\begin{tabular}{|l|c|}
\hline \multicolumn{1}{|c|}{ Nombre } & Unidad \\
\hline Denuncias corrupción trasladadas órganos de control & Porcentaje \\
\hline Auditorías a la vista realizadas & Número \\
\hline
\end{tabular}

\subsubsection{Proyecto: Gobernabilidad del conglomerado público}

La comunicación pública es una de las herramientas transversales de la Administración Municipal para propiciar un diálogo directo entre los gobernantes y la ciudadanía mediante una estrategia de comunicación que 
permita divulgar la gestión de manera permanente a la ciudadanía acorde con el mandato constitucional y las normas que regulan las tareas de divulgación y comunicación pública. Además a través de este proyecto fortaleceremos la estrategia de comunicación interna como una herramienta fundamental para contribuir al fortalecimiento de la cultura organizacional, facilitando la apropiación, la participación, el sentido de pertenencia y el compromiso del personal hacia la consecución de las metas propuestas en el Plan de Desarrollo 2016-2019.

Responsable: Secretaría Privada

Indicador de producto

\begin{tabular}{|l|c|}
\hline \multicolumn{1}{|c|}{ Nombre } & Unidad \\
\hline $\begin{array}{l}\text { Eventos internacionales de Relaciones Públicas y Gobierno Corporativo } \\
\text { realizados }\end{array}$ & Número \\
\hline
\end{tabular}

1.3.1.5 Proyecto: Comunicación informativa, corporativa e institucional dirigida a la ciudadanía y en articulación con el conglomerado público La comunicación pública es una de las herramientas transversales de la Administración Municipal para propiciar un diálogo directo entre los gobernantes y la ciudadanía mediante una estrategia de comunicación que permita divulgar la gestión de manera permanente a la ciudadanía acorde con el mandato constitucional y las normas que regulan las tareas de divulgación y comunicación pública. Además a través de este proyecto fortaleceremos la estrategia de comunicación interna como una herramienta fundamental para contribuir al fortalecimiento de la cultura organizacional, facilitando la apropiación, la participación, el sentido de pertenencia y el compromiso del personal hacia la consecución de las metas propuestas en el Plan de Desarrollo 2016-2019.

Responsable: Secretaría de Comunicaciones

Indicador de producto

\begin{tabular}{|c|c|}
\hline \multicolumn{1}{|c|}{ Nombre } & Unidad \\
\hline Estrategia de comunicación para la divulgación diseñada, e implementada. & Porcentaje \\
\hline
\end{tabular}

\subsubsection{PROGRAMA: TRANSPARENCIA COMO MODELO DE GESTIÓN}

Con este programa la Alcaldía de Medellín busca fortalecer el acceso a la información relacionada con la gestión contractual, lo que garantiza la imparcialidad en la selección del contratista con unas reglas precisas, claras, completas y objetivas, permitir el debido proceso, el derecho a la contradicción, el derecho a la defensa a los proponentes y contratistas y verificación por parte de la Administración de las inhabilidades, incompatibilidades y conflicto de intereses; así mismo los impactos de las gestiones adelantadas en el territorio, conocer el presupuesto, en dónde se invierten los recursos y quiénes son los contratistas, esto permite a las 
Veedurías Ciudadanas realizar seguimiento total y le permite a la Administración estar en contacto permanente con la ciudadanía.

Igualmente a través de la implementación y el fortalecimiento de los sistemas se garantiza el derecho de acceso a la información pública, excepto la que goce de reserva legal, facilitando la participación ciudadana como un proceso de construcción, la disminución en la materialización de los riesgos de corrupción y cero tolerancia a la corrupción.

Indicadores de resultado

\begin{tabular}{|l|c|c|c|c|}
\hline Nombre & Unidad & $\begin{array}{c}\text { Línea de } \\
\text { Base }\end{array}$ & Meta 2019 & Responsable \\
\hline $\begin{array}{l}\text { Sistemas de gestión } \\
\text { mejorados }\end{array}$ & Porcentaje & $89,25 \%$ & $90 \%$ & $\begin{array}{c}\text { Secretaría de } \\
\text { Gestión Humana y } \\
\text { Servicio a la } \\
\text { Ciudadanía }\end{array}$ \\
\hline $\begin{array}{l}\text { ITM (́́ndice de Transparencia } \\
\text { Municipal de grandes } \\
\text { ciudades) }\end{array}$ & Puntos & 0 & 80 & $\begin{array}{c}\text { Secretaría de } \\
\text { Evaluación y } \\
\text { Control }\end{array}$ \\
\hline
\end{tabular}

\subsubsection{Proyecto: Ferias de la transparencia con vos}

Con este proyecto se busca aumentar la participación de los proveedores, la confianza de las partes interesadas con relación a la gestión contractual, generar las competencias en los servidores para desarrollar los procesos con eficiencia, efectividad, economía y transparencia, revisar y actualizar la política de transparencia para evaluar, continuar e implementar nuevas estrategias que permitan mejorar la operación y la toma de decisiones.

Responsable: Secretaría de Servicios y Suministros

Indicadores de producto

\begin{tabular}{|c|c|}
\hline Nombre & Unidad \\
\hline Ferias de la Transparencia realizadas en el cuatrienio & Número \\
\hline Oferentes que se presentaron en los procesos de contratación por \\
convocatoria pública. & Porcentaje \\
\hline
\end{tabular}

\subsubsection{Proyecto: Generando confianza con gobierno en línea}

Este proyecto busca la implementación de la estrategia de Gobierno en Línea en la Alcaldía de Medellín, con el fin de ofrecerles a los ciudadanos una cobertura más amplia para realizar trámites y acceder a servicios en línea, permitiendo más participación ciudadana y contribuyendo a la construcción de un estado más eficiente, transparente y participativo, mediante la optimización y el aprovechamiento de las TIC, mejorando los niveles de gestión y la relación con el ciudadano.

Con este proyecto mejoraremos la relación de la Alcaldía con los ciudadanos, apoyando la implementación de trámites y servicios, a través de canales electrónicos y la masificación del uso de herramientas tecnológicas, brindando soluciones innovadoras. Adicionalmente, mediante 
el uso de las tecnologías de la información, facilitaremos a la ciudadanía los medios para para una participación activa en la construcción de una administración transparente, participativa y colaborativa.

Responsable: Secretaría de Gestión Humana y Servicio a la ciudadanía Indicadores de producto

\begin{tabular}{|l|c|}
\hline \multicolumn{1}{|c|}{ Nombre } & Unidad \\
\hline Servicios gobierno en línea implementados & Porcentaje \\
\hline Componente de procesos con soluciones tecnológicas automatizados & Porcentaje \\
\hline
\end{tabular}

\subsubsection{Proyecto: Medellín, incluido en el índice de transparencia de grandes ciudades}

Iniciativa de la sociedad civil que busca contribuir a la prevención de hechos de corrupción en la gestión administrativa del Estado para identificar riesgos de corrupción administrativa y oportunidades de ajuste y mejoramiento en los ámbitos más claves de la gestión: contratación pública, empleo público, promoción de la participación ciudadana, rendición de cuentas y control interno, entre otras; mejorar el proceso de diseño y adopción de medidas y políticas anticorrupción e identificar falencias o debilidades en los diseños institucionales para garantizar el acceso a la información pública como derecho fundamental.

Responsable: Secretaría de Evaluación y Control

Indicador de producto

\begin{tabular}{|c|c|}
\hline \multicolumn{1}{|c|}{ Nombre } & Unidad \\
\hline Metodología para la medición Indice de transparencia de grandes ciudades & Número \\
\hline
\end{tabular}

1.3.2.3.1 Proyecto: Implementar el sistema de información territorial para la medición de impactos basados en la transversalización de las acciones

Sistema de información territorial que integre e interactúe con los más de 200 sistemas de información que existen al interior de la administración municipal, lo anterior, para facilitar la toma de decisiones y la planificación de la ciudad. Se promoverá la cultura de gobierno en línea y datos abiertos al interior de la Administración para permitir mayor acceso a la información y facilitar los procesos de investigación y medición de impactos de la inversión.

El Sistema de inteligencia para el territorio tendrá un componente asociado a la inteligencia de negocios que permitirá la integración de la información y generación de reportes requeridos por las distintas dependencias, además incluirá la georreferenciación de la información y la consulta en el sistema de información geográfica corporativa. También facilitará el seguimiento, monitoreo y control a la gestión pública. 
Responsable: Departamento Administrativo de Planeación Indicador de producto

\begin{tabular}{|c|c|}
\hline \multicolumn{1}{|c|}{ Nombre } & Unidad \\
\hline Sistema de información diseñado y desarrollado & Porcentaje \\
\hline
\end{tabular}

\subsubsection{Proyecto: Lo público cuenta con vos}

El fomento del control social a lo público como expresión de la participación ciudadana, entendido como el derecho y el deber de los ciudadanos a participar de manera individual o a través de sus organizaciones, redes sociales e instituciones, en la vigilancia de la gestión pública y sus resultados. Lo público cuenta con vos busca fortalecer en los ciudadanos la capacidad para incidir en la gestión pública, para mejorarla, disminuir los riesgos de corrupción, e intervenir en los temas que afectan el devenir de los procesos sociales, de gobernabilidad, equidad y transparencia.

El proyecto busca facilitar el ejercicio de la ciudadanía en la función de inspección y vigilancia a la gestión pública y sus políticas, mediante el desarrollo de instrumentos, estrategias y escenarios de transparencia y participación para enriquecer la democracia y la corresponsabilidad social.

Responsable: Secretaría de Participación Ciudadana

Indicadores de producto

\begin{tabular}{|c|c|}
\hline Nombre & Unidad \\
\hline Ciudadanos que participan en actividades de promoción del control social a \\
lo público & Número \\
\hline Iniciativas de control social a lo público promovidas y fortalecidas & Número \\
\hline
\end{tabular}

\subsubsection{PROGRAMA: EXCELENTE MANEJO DE LAS FINANZAS Y LOS RECURSOS PÚBLICOS}

Con el programa se busca integrar las subsecretarías de ingresos, tesorería y financiera para consolidar y optimizar las finanzas del Municipio de Medellín, a través de estrategias para la gestión adecuada de los ingresos, excedentes de liquidez y recursos públicos con la sostenibilidad adecuada de los procesos y la información para una ejecución eficiente.

El fortalecimiento de las finanzas del Municipio de Medellín se logra a través de un proceso de fiscalización, control a la evasión y elusión de la renta; es por esto que el propósito de este programa es maximizar los rendimientos financieros y afianzar las estrategias en pro de una normalización de cartera con lineamientos ajustados a la normatividad vigente, relación costo beneficio y un seguimiento periódico a los indicadores de cartera logrando un saneamiento ajustado a las posibilidades reales de recuperar los recursos. 
Así, a través de los diferentes proyectos que hacen parte de este programa se desarrollarán instrumentos actualizados y de calidad que permitan obtener una información financiera ajustada a los requerimientos de la administración pública, realizar los análisis oportunos, el monitoreo y ajustes pertinentes para un manejo eficiente de la información contable, presupuestal y fiscal del Municipio de Medellín; todo a través de herramientas tecnológicas y adición de nuevas funciones en la plataforma SAP, implementación de normas internacionales y de contabilidad para el sector público.

El proyecto conlleva a unificar lo anterior en busca de una estrategia que consolide por medio de varios canales la comunicación, atención y servicio a los ciudadanos del Municipio de Medellín, donde la relación contribuyenteAlcaldía esté basada en la satisfacción y correcta solución de sus inconvenientes, mediante una comunicación efectiva de la gestión de los recursos, transparencia, ejecución de proyectos de ciudad y un incremento en la cultura de pago.

Indicadores de resultado

\begin{tabular}{|c|c|c|c|c|}
\hline Nombre & Unidad & $\begin{array}{c}\text { Línea de } \\
\text { Base }\end{array}$ & Meta 2019 & Responsable \\
\hline $\begin{array}{c}\text { Calificación del Desempeño } \\
\text { Fiscal }\end{array}$ & $\begin{array}{c}\text { Posición } \\
\text { Ciudades } \\
\text { Capitales }\end{array}$ & $85,50 \%$ & $\begin{array}{c}\text { Entre el } \\
80 \% \text { y el } \\
100 \%\end{array}$ & $\begin{array}{c}\text { Secretaría de } \\
\text { Hacienda }\end{array}$ \\
\hline $\begin{array}{c}\text { Cumplimiento del nivel de } \\
\text { rentas y recursos proyectados } \\
\text { en el plan financiero 2016- } \\
2019\end{array}$ & Porcentaje & $100 \%$ & $100 \%$ & $\begin{array}{c}\text { Secretaría de } \\
\text { Hacienda }\end{array}$ \\
\hline
\end{tabular}

1.3.3.1 Proyecto: Generación de ingresos a través de la administración, fiscalización y regulación tributaria

Generar mecanismos que permitan una gestión eficiente de los recursos con el fin de fortalecer las finanzas del municipio a través de proceso de fiscalización, control a la evasión y la elusión de renta y la administración de excedentes de liquidez. Así, este proyecto busca contribuir a la eficiente consecución de ingresos propios generados a través de:

- La maximización de los rendimientos financieros de los excedentes de liquidez por medio de la conformación, administración y valoración de un portafolio de inversiones financieras de renta fija

- La disminución de la evasión y elusión a través de la preparación y elaboración de las actuaciones necesarias para la determinación oficial del tributo.

Indicadores de producto:

Responsable: Secretaría de Hacienda

\begin{tabular}{|l|c|}
\hline \multicolumn{1}{|c|}{ Nombre } & Unidad \\
\hline Procesos ejecutados para el control de evasión y elusión & Porcentaje \\
\hline Rendimientos financieros ejecutados por recursos propios & Porcentaje \\
\hline
\end{tabular}




\subsubsection{Proyecto: Normalización de la cartera morosa del municipio de Medellín}

Sanear la cartera morosa del Municipio de Medellín, a través de la unificación de lineamientos e instrumentos que aporta la normatividad vigente como la remisibilidad, prescripción, estabilización de la data, análisis costo beneficio y seguimiento a los indicadores de cartera con el fin de poder hacer exigibles las obligaciones que realmente están consolidadas a favor del ente territorial.

Indicadores de producto:

Responsable: Secretaría de Hacienda

\begin{tabular}{|l|c|}
\hline \multicolumn{1}{|c|}{ Nombre } & Unidad \\
\hline Cartera recuperada & $\begin{array}{c}\text { Millones de } \\
\text { pesos }\end{array}$ \\
\hline Contribuyentes con obligaciones en mora saneados & Número \\
\hline
\end{tabular}

1.3.3.3 Proyecto: Fortalecimiento de la gestión fiscal y financiera del municipio de Medellín

El proyecto busca mejorar la eficiencia y la eficacia de la gestión pública a través del desarrollo de actividades que le apunten a fortalecer la obtención de información para una mejor toma de decisiones con respecto a la gestión fiscal y financiera del Municipio de Medellín.

Así, a través del proyecto se implementarán instrumentos que permitan mejorar la calidad de la información financiera a través de: generación de estados financieros consolidados, implementación de normas internacionales de contabilidad para el sector público, desarrollo de nuevas funcionalidades en la plataforma SAP y gestión administrativa necesarias para la generación de información contable estratégica dirigida a los diferentes usuarios.

Este proyecto permite hacer seguimiento y monitorear los datos y cifras de los diferentes instrumentos financieros y efectuar los correctivos necesarios y oportunos buscando que las finanzas públicas tengan un manejo eficiente y confiable que refleje la situación contable, presupuestal y de la tesorería.

Responsable: Secretaría de Hacienda

Indicador de producto:

\begin{tabular}{|l|c|}
\hline \multicolumn{1}{|c|}{ Nombre } & Unidad \\
\hline $\begin{array}{l}\text { Datos y cifras de los diferentes instrumentos financieros, Controlados, evaluados } \\
\text { y monitoreados }\end{array}$ & Porcentaje \\
\hline
\end{tabular}

\subsubsection{Proyecto: Medellín le apuesta a las APP's}

Fortalecer la institucionalidad para la identificación, estructuración y evaluación de proyectos de Alianzas Público Privadas ya que con la correcta gestión de las APP's en el Municipio Medellín se puede generar una rápida disponibilidad de la nueva infraestructura y sus servicios; planeación óptima de recursos fiscales, garantizando esquema de pagos que se acople 
a las expectativas del marco fiscal vigente; agrupación de fortalezas del sector privado y del público; inclusión de mecanismos e incentivos que estimulen la entrega a tiempo y de acuerdo al presupuesto de los proyectos y transferencia de riesgos entre el sector público y privado.

Responsable: Agencia para la gestión del paisaje y patrimonio y APP Indicador de producto:

\begin{tabular}{|c|c|}
\hline Nombre & Unidad \\
\hline Alianzas Público Privadas Promovidas & Número \\
\hline
\end{tabular}

\subsubsection{PROGRAMA: GESTIÓN EFICIENTE}

Con este programa el Municipio de Medellín busca fortalecer la función administrativa la cual debe estar al servicio de los intereses generales, fundamentada en los principios de igualdad, moralidad, eficacia, economía, celeridad, imparcialidad, publicidad y eficiencia, con una operación centrada en los procesos y enfocada en cumplir las expectativas y necesidades de las partes interesadas, principio y fin de la gestión. Por lo tanto se deben integrar los procesos, evaluar y establecer acciones para la mejora continua; así mismo realizar procesos integrales de asesoría y evaluación institucional que permitan mejorar la gestión, garantizar la conservación de los aspectos fundamentales para la prestación de los servicios en cumplimiento de la misión y visión institucional.

Indicadores de resultado

\begin{tabular}{|c|c|c|c|c|}
\hline Nombre & Unidad & $\begin{array}{c}\text { Línea de } \\
\text { Base }\end{array}$ & Meta 2019 & Responsable \\
\hline $\begin{array}{c}\text { Nivel de Madurez } \\
\text { MECI(Modelo Estándar de } \\
\text { Control Interno) }\end{array}$ & Porcentaje & 91,5 & 95 & $\begin{array}{l}\text { Secretaría de } \\
\text { Evaluación y } \\
\text { Control }\end{array}$ \\
\hline $\begin{array}{c}\text { Desempeño de la auditoría } \\
\text { interna }\end{array}$ & Porcentaje & 76 & 85 & $\begin{array}{c}\text { Secretaría de } \\
\text { Evaluación y } \\
\text { Control } \\
\end{array}$ \\
\hline $\begin{array}{l}\text { Ahorros logrados en la } \\
\text { adquisición función } \\
\text { centralizada de las compras }\end{array}$ & Porcentaje & 0 & 1,10 & $\begin{array}{l}\text { Secretaría de } \\
\text { Suministros y } \\
\text { Servicios }\end{array}$ \\
\hline
\end{tabular}

\subsubsection{Proyecto: Realizar procesos integrales de evaluación institucional que permitan mejorar la gestión}

Busca fortalecer la práctica de la auditoría interna bajo normas internacionales, como actividad independiente y objetiva de aseguramiento y consulta que agrega valor y contribuye al mejoramiento del desempeño de la Administración Municipal en los procesos de gestión de riesgos, control y gobierno. 
Indicador de producto

\begin{tabular}{|c|c|}
\hline \multicolumn{1}{|c|}{ Nombre } & Unidad \\
\hline Plan de auditorías desarrolladas & Porcentaje \\
\hline
\end{tabular}

\subsubsection{Proyecto: Gestión eficiente para la adquisición de bienes y servicios}

Con este proyecto el Municipio de Medellín busca consolidar la centralización del proceso de manera integral, fortalecer los canales de comunicación, implementar la guía de buenas prácticas, racionalizar y automatizar la documentación, actividades y trámites para estandarizar el quehacer de los operadores del proceso, garantizar la vigilancia, seguimiento y control en la ejecución de los contratos para mejorar la gestión del proceso, realizar un programa dirigido a mejorar la planeación para disminuir la improvisación y las imprevisiones y ser más eficiente, efectivos y eficaces e identificar y establecer estrategias innovadoras de compra que permitan generar economías a escala y administrativas.

Responsable: Secretaría de Suministros y Servicios

Indicador de producto

\begin{tabular}{|c|c|}
\hline Nombre & Unidad \\
\hline Oportunidad en el proceso de selección & Días \\
\hline
\end{tabular}

\subsubsection{Proyecto: Gestión y conservación de activos}

Con este proyecto se busca que todos los equipos e instrumentos de medición sean incorporados al Programa de Aseguramiento Metrológico para garantizar la trazabilidad contra patrones nacionales e internacionales y que permanezcan en un estado ideal de conservación y funcionamiento, mantener permanentemente en condiciones óptimas de limpieza (asepsia) y preservación cada uno de los lugares de trabajo (CAM y Sedes Externas), así como garantizar la seguridad dentro y fuera de ellos, planear, programar y ejecutar el mantenimiento preventivo y correctivo de las instalaciones físicas destinadas al servicio del municipio de Medellín, impulsar y desarrollar la gestión inmobiliaria mediante una correcta articulación con APP.

Responsable: Secretaría de Suministros y Servicios

Indicadores de producto

\begin{tabular}{|l|c|}
\hline \multicolumn{1}{|c|}{ Nombre } & Unidad \\
\hline Bienes muebles gestionados & Porcentaje \\
\hline Bienes Inmuebles gestionados & Porcentaje \\
\hline
\end{tabular}




\subsubsection{PROGRAMA: GESTIÓN EFICAZ}

Medellín requiere avanzar en un modelo de gestión pública que le permita articular e identificar las ventajas competitivas y las oportunidades de la ciudad para fortalecer su modelo de desarrollo integral que garantice el mejoramiento continuo de la Administración Pública, para lo cual requiere de un talento humano altamente competente con capacidad de adaptación y flexibilidad frente a las dinámicas institucionales y del entorno, a través del desarrollo integral de los servidores públicos, la potenciación de sus capacidades y competencias, el mejoramiento de las condiciones de calidad de vida laboral en ambientes saludables, con estrategias de gestión humana centradas en la dignificación del ser.

Indicadores de resultado

\begin{tabular}{|c|c|c|c|c|}
\hline Nombre & Unidad & $\begin{array}{c}\text { Línea de } \\
\text { Base }\end{array}$ & Meta 2019 & Responsable \\
\hline $\begin{array}{c}\text { Sentencias favorables } \\
\text { ejecutoriadas / sentencias } \\
\text { totales ejecutoriadas }\end{array}$ & Porcentaje & 65 & 70 & Secretaría General \\
\hline Clima Laboral Fortalecido & Porcentaje & 71 & 75 & $\begin{array}{c}\text { Gestión Humana y } \\
\text { Servicio a la } \\
\text { Ciudadanía - }\end{array}$ \\
\hline Calidad de Vida Laboral & Índice & N/A & 80 & $\begin{array}{c}\text { Secretaría de } \\
\text { Gestión Humana y } \\
\text { Servicio a la } \\
\text { Ciudadanía - }\end{array}$ \\
\hline
\end{tabular}

1.3.5.1 Proyecto: Sistemas de gestión inteligentes para un buen gobierno El compromiso gubernamental de incorporar en la actividad cotidiana de la gestión pública los conceptos y prácticas de los sistemas de gestión, está orientado a consolidar un gobierno inteligente, que ponga en el centro del quehacer gubernamental la satisfacción de las necesidades y expectativas de la ciudadanía, mediante los más avanzados sistemas administrativos.

De esta forma, se pretende articular los diferentes sistemas de gestión del Municipio de Medellín, con el fin de lograr un ejercicio articulado y armónico para una gestión más eficaz y eficiente, optimización de los recursos, aprovechamiento de las sinergias y poder así garantizar el buen desempeño institucional, donde concurren un conjunto de condiciones favorables para la acción de gobierno.

Responsable: Secretaría de Gestión Humana y Servicio a la Ciudadanía Indicador de producto

\begin{tabular}{|c|c|}
\hline Nombre & Unidad \\
\hline Modelo Integrado de Planeación y Gestión mejorado & Porcentaje \\
\hline
\end{tabular}




\subsubsection{Proyecto: Apropiación de las TIC para una organización digital} Este proyecto busca construir una organización municipal digital, transparente, eficiente y eficaz al servicio de los servidores públicos y la ciudadanía, articulando las tecnologías de información y comunicaciones con el modelo organizacional y los lineamientos establecidos en la estrategia de gobierno en Línea.

Este proyecto tiene tres componentes principales: crecimiento y renovación, disponibilidad y transformación tecnológica de la plataforma y arquitectura tecnológica del Municipio (Hardware, software, seguridad informática y telecomunicaciones de la Alcaldía de Medellín) para la disponibilidad, crecimiento y madurez de los servicios prestados a la comunidad y al interior de la organización.

Responsable: Secretaría de Gestión Humana y Servicio a la Ciudadanía Indicadores de producto

\begin{tabular}{|l|c|}
\hline \multicolumn{1}{|c|}{ Nombre } & Unidad \\
\hline Servicios tecnológicos implementados en beneficio de la organización & Número \\
\hline Disponibilidad de la plataforma TIC lograda & Porcentaje \\
\hline Servicios de atención prestados con efectividad & Porcentaje \\
\hline Gestión documental, digital electrónica implementada & Porcentaje \\
\hline
\end{tabular}

1.3.5.3 Proyecto: Gerenciar el sistema de servicio a la ciudadanía Este proyecto permitirá fortalecer los componentes de servicio a la ciudadanía (Desarrollo de la Estrategia, Medición de la satisfacción, Gestión de PQRS, Gestión de trámites y servicios y Canales de atención); con el fin de definir los lineamientos generales que permitan uniformidad en el tratamiento y en la atención al ciudadano por los diferentes canales, con el ánimo de brindar un servicio de calidad, mejorando la percepción y satisfacción del ciudadano, fortaleciendo de esta manera la imagen institucional y la cultura de servicio. La estrategia se centrará en actividades específicas de desarrollo institucional para el mejoramiento de la gestión y en el fortalecimiento de canales de atención complementado con los avances obtenidos en otros frentes (Gobierno en Línea, Política de Racionalización de trámites, Sistemas Integrados de Gestión) además de la articulación y coordinación con el ente central, descentralizado y entidades del estado para la aplicación coordinada de instrumentos técnicos por parte de estas entidades.

Responsable: Secretaría de Gestión Humana y Servicio a la Ciudadanía Indicador de producto

\begin{tabular}{|c|c|}
\hline \multicolumn{1}{|c|}{ Nombre } & Unidad \\
\hline Trámites y servicios automatizados & Número \\
\hline
\end{tabular}




\subsubsection{Proyecto: Comprometidos con la integralidad del ser}

Promover el desarrollo integral de los servidores públicos propiciando la potenciación del talento humano de la Alcaldía de Medellín en las dimensiones de la integralidad del ser, el compromiso, el involucramiento y el empoderamiento de las competencias inherentes a su rol, permitiéndose el desarrollo de la capacidad de adaptación, la generación de ambientes sanos y el fortalecimiento de la cultura organizacional. Este proyecto comprende la promoción de buenas prácticas al interior de la organización, fortalecimiento del modelo integral de gestión humana y del sistema de formación institucional en la Alcaldía de Medellín, fortalecimiento de la cultura y clima organizacional y la construcción de redes de gestión humana con incidencia en lo local y nacional.

Responsable: Secretaría de Gestión Humana y Servicio a la Ciudadanía Indicador de producto

\begin{tabular}{|c|c|}
\hline Nombre & Unidad \\
\hline Servidores intervenidos con acciones para el desarrollo humano & Porcentaje \\
\hline
\end{tabular}

\subsubsection{Proyecto: Gerencia jurídica pública}

Se concibe como un modelo de gestión, orientación estratégica y control, al proceso de gestión jurídica del Municipio de Medellín, que incorpora las acciones y estrategias para contribuir con el logro de los objetivos propuestos en relación con la atención oportuna y efectiva de tipo preventivo en las actuaciones administrativas, acciones judiciales y extrajudiciales para la protección del patrimonio público y con aquellas tendientes a lograr la unificación del Direccionamiento Jurídico, tanto en trámites y actuaciones administrativas de todas las dependencias del nivel central como del nivel descentralizado a través de las directrices de la Secretaría General.

Responsable: Secretaría General.

Indicadores de producto

\begin{tabular}{|l|c|}
\hline \multicolumn{1}{|c|}{ Nombre } & Unidad \\
\hline Eventos realizados de transferencia del conocimiento & Número \\
\hline $\begin{array}{l}\text { Directrices de Prevención del Daño Antijurídico y de Defensa y Protección de lo } \\
\text { Público emitidas }\end{array}$ & Número \\
\hline
\end{tabular}

\subsubsection{PROGRAMA: INNOVACIÓN PÚBLICA - LABORATORIO DE GOBIERNO}

Apostaremos por generar valor público a través de una Innovación que nos permita para desarrollar iniciativas que incidan en el mejoramiento de las condiciones de los ciudadanos y hagan más eficiente la gestión del gobierno municipal, todo ello por medio de soluciones novedosas de cocreación y participación ciudadana. 
Indicador de resultado

\begin{tabular}{|c|c|}
\hline \multicolumn{1}{|c|}{ Nombre } & Unidad \\
\hline Ciudades que participan en la plataforma "mi ciudad" & Numero \\
\hline
\end{tabular}

1.3.6.1 Proyecto: Implementar la metodología de gestión por resultados Establecer acciones para propiciar y promover la planificación y presupuestación por resultados, teniendo en cuenta los impactos generados y la eficiencia en la gestión pública.

Responsable: Departamento Administrativo de Planeación Indicadores de producto

\begin{tabular}{|l|l|}
\hline \multicolumn{1}{|c|}{ Nombre } & Unidad \\
\hline Implementación de las fases de la metodología gestión por resultados & Porcentaje \\
\hline
\end{tabular}

\subsubsection{Proyecto: Estrategia de participación digital para la gestión pública}

La construcción del Plan de Desarrollo 2016-2019 contó con una estrategia de participación digital innovadora que canalizó las inquietudes e ideas de los ciudadanos. La idea es mantenerla durante el cuatrienio para que siga siendo un canal de escucha por medio del cual recibamos ideas para el desarrollo de la ciudad.

Responsable: Departamento Administrativo de Planeación

Indicador de producto

\begin{tabular}{|l|l|}
\hline \multicolumn{1}{|c|}{ Nombre } & Unidad \\
\hline Estrategia de participación digital construida & Porcentaje \\
\hline
\end{tabular}

\subsubsection{Proyecto: Continuar con el proyecto Cities for life}

Los retos de las ciudades son similares en la mayoría de los países del mundo. Muchos de los retos que tiene Medellín han sido resueltos en otros países y muchas de las soluciones que Medellín ha propuesto para sus retos, podrían ser soluciones para otras ciudades. Esta riqueza de información busca generar una mayor conexión entre ciudades a partir de sus retos. Cities For Life es una estrategia de innovación abierta global que busca conectar a las ciudades en una plataforma donde se montan los retos y las soluciones de problemáticas urbanas para que quede disponible para los demás. Así, Medellín se podría beneficiar de las soluciones de otras ciudades y vice versa. Este proyecto genera además conexiones fuertes con organizaciones multilaterales como el Banco Mundial (gran aliado) y ciudades de primer nivel (Nueva York, París, Tel-Aviv, Barcelona, entre otras). 
Responsable: Departamento Administrativo de Planeación Indicador de producto:

\begin{tabular}{|c|c|}
\hline \multicolumn{1}{|c|}{ Nombre } & Unidad \\
\hline Ciudades participando en el programa de innovación abierta & Numero \\
\hline
\end{tabular}

1.3.6.4 Proyecto: Transversalización de la innovación al interior de la administración

A través de la transversalización de Ruta $\mathrm{N}$ buscamos introducir componentes de ciencia, tecnología e innovación al interior de la administración, en pro del cumplimiento estratégico de los objetivos misionales de las entidades, promoviendo procesos de innovación pública que generen sinergias al interior de la organización y valor social a través de herramientas digitales que permitan un contacto permanente con la ciudadanía.

Responsable: Departamento Administrativo de Planeación Indicador de producto

\begin{tabular}{|l|l|}
\hline \multicolumn{1}{|c|}{ Nombre } & Unidad \\
\hline Estrategias innovadoras implementadas al interior de la administración & Número \\
\hline
\end{tabular}

\subsection{Proyecto:Red de observatorios para la trazabilidad del impacto social}

Se fortalecerá la unidad del observatorio y evaluación de políticas públicas para potencializar la capacidad de investigación de la ciudad en términos de intervenciones sociales, impacto social y eficiencia de la inversión pública, para lo anterior, se gestionarán alianzas con los distintos tanques de pensamientos, centros de estudios y centros de investigación privados y públicos de la ciudad con el objetivo de promover el intercambio de información y facilitar el análisis de las principales problemáticas de la ciudad.

Por otra parte se invertirá en las distintas herramientas para la producción de información estadística de calidad, oportuna y confiable que soporte la toma de decisiones y la realización de investigaciones que den cuenta de la situación de Medellín en las distintas dimensiones del desarrollo.

Responsable: Departamento Administrativo de Planeación Indicador de producto

\begin{tabular}{|l|l|}
\hline \multicolumn{1}{|c|}{ Nombre } & \multicolumn{1}{|c|}{ Unidad } \\
\hline Datos visibles para una ciudad competitiva y transparente & Número \\
\hline Artículos indexados sobre temáticas prioritarias & Número \\
\hline
\end{tabular}


1.3.6.6. Proyecto: Integración y gestión estratégica de la información Fábrica de pensamiento

Proyecto dedicado al aprovechamiento de la gestión de la información con metodologías de investigación cuantitativa, entrega de información necesaria para la toma informada de decisiones en temas prioritarios de ciudad.

Responsable: Departamento Administrativo de Planeación

Indicador de producto

\begin{tabular}{|l|l|}
\hline \multicolumn{1}{|c|}{ Nombre } & Unidad \\
\hline $\begin{array}{l}\text { Acuerdos interinstitucionales de intercambio de información con organismos } \\
\text { nacionales e internacionales }\end{array}$ & Número \\
\hline Diseño del modelo de la Fábrica de pensamiento & Porcentaje \\
\hline
\end{tabular}




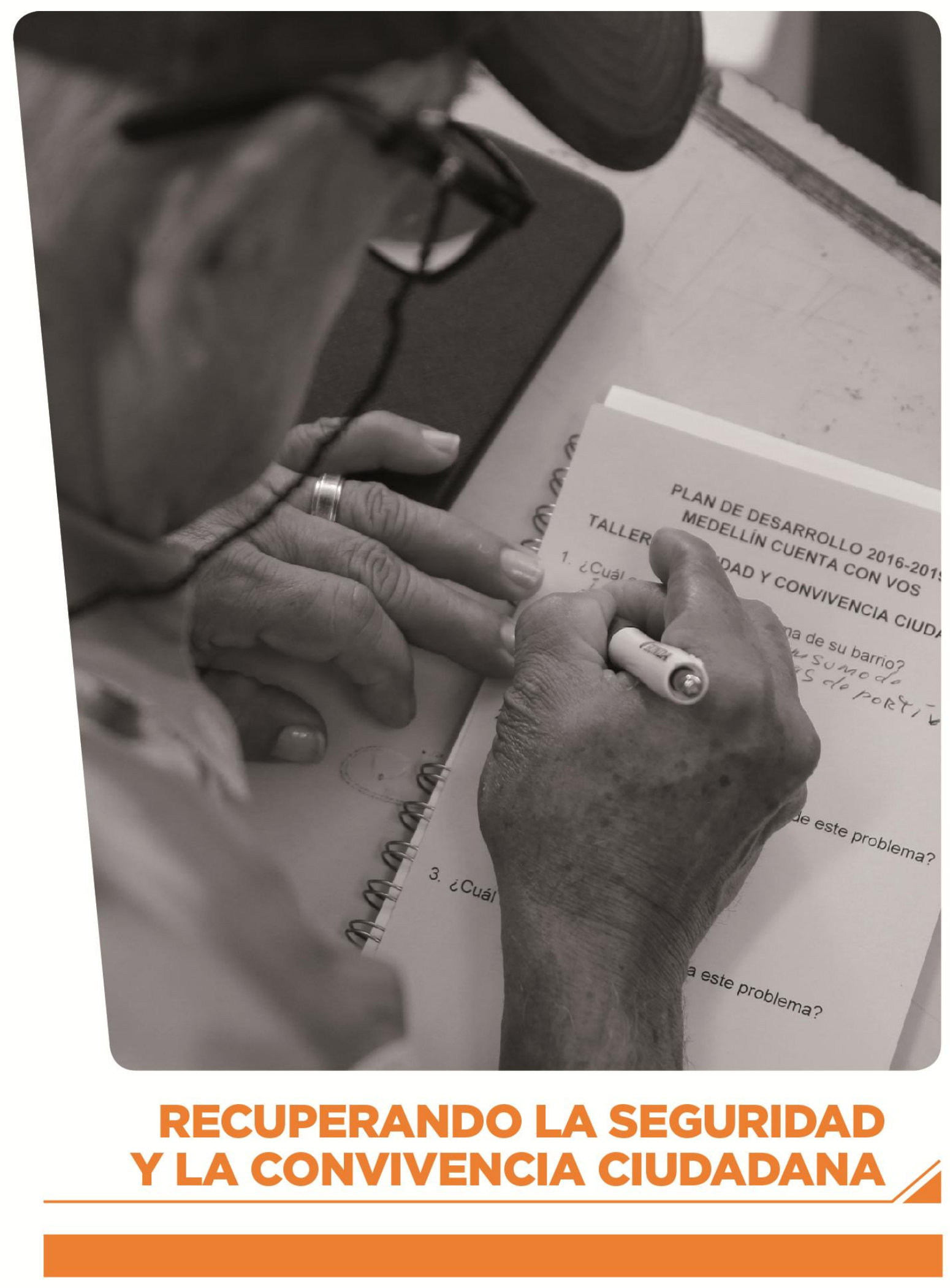




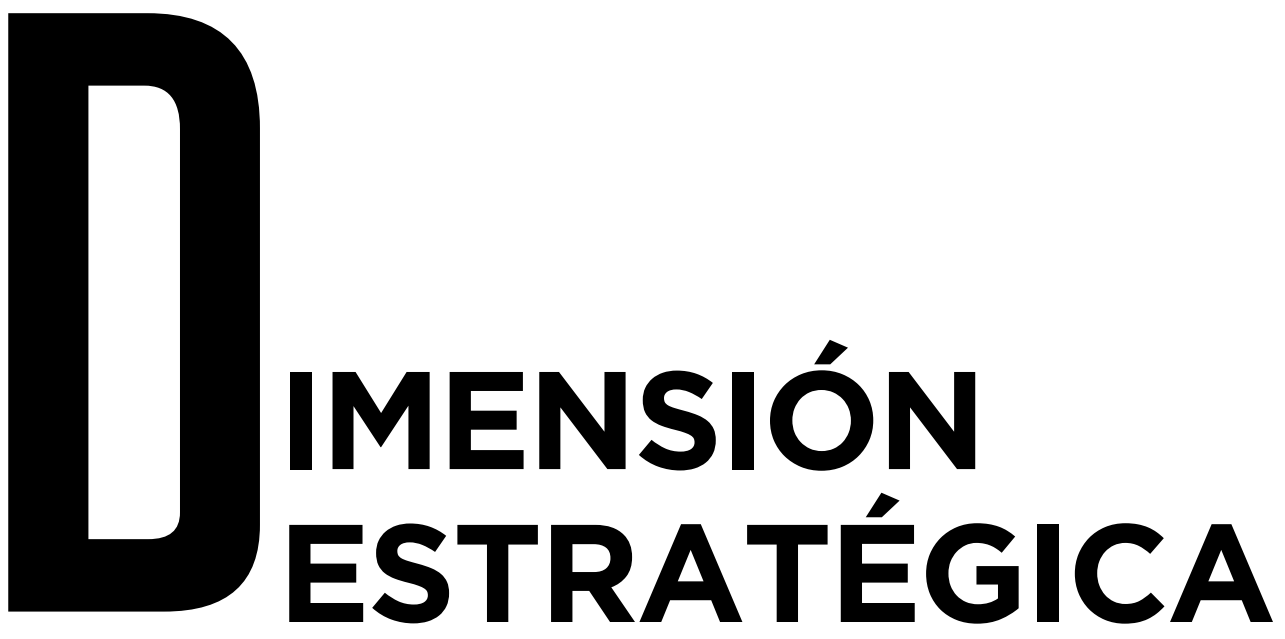

\section{Recuperando la seguridad y la convivencia ciudadana}

Restablecer progresivamente los niveles de seguridad de la ciudad, recobrando la confianza ciudadana en las instituciones y fortaleciendo a la comunidad para un escenario de construcción de paz y de respeto de los derechos. 


\section{- DIAGNÓSTICO •}

Medellín cree en una ciudad segura que trabaja conjunta y corresponsablemente para fortalecer su institucionalidad, evitar la comisión de delitos y promover la convivencia pacífica libre de violencias entre sus habitantes.

Una ciudad segura integralmente, promotora de entornos seguros, saludables y protectores, en los cuales las personas (hombres y mujeres niños, niñas, adolescentes, jóvenes, personas mayores, población víctima, y demás grupos poblacionales), gocen efectivamente del ejercicio tanto de sus derechos y del restablecimiento de los mismos cuando éstos han sido vulnerados, como de sus responsabilidades.

Una ciudad donde las relaciones sociales de convivencia obedezcan a dinámicas de respeto mutuo, estabilidad y confianza interpersonal e institucional.

Una ciudad preparada para los procesos y retos de un país que avanza hacia el post-acuerdo.

La percepción de seguridad y convivencia indica el cómo percibe la ciudadanía los acontecimientos y condiciones externas en estos temas, y cómo esta apreciación se traduce en una forma de sentir e interactuar frente a su entorno barrial, comunal/corregimental y de ciudad. Teniendo como base la Encuesta de Percepción y Victimización de Medellín- 2015, se identifica que un $26,0 \%$ de las personas encuestadas se sintieron seguras en la ciudad y un $31,0 \%$ se sintieron relativamente seguras.

Diferente a esta situación, la percepción de inseguridad alcanzó niveles altos: $35,0 \%$ de la población se sintió insegura y un $8,0 \%$ muy insegura. Esto plantea que un $43,0 \%$ de las personas habitantes de la ciudad configuraron una relación de temor y/o amenaza con la ciudad.

Se observa además que a medida que el ámbito geográfico disminuyó, la percepción de seguridad de la población aumentó (en comunas y corregimientos fue de 59,0\%, y en los barrios de la ciudad alcanzó el $69,0 \%)$.

Realizando un comparativo con tres de las principales ciudades del pais, podemos observar que para 2015 un 59,0\% de la población de Bogotá, $35,0 \%$ de Cali, y $25,0 \%$ en Barranquilla se sintió insegura en su ciudad.

A nivel de barrio un $28,0 \%$ de los bogotanos y un $17,0 \%$ de los caleños se sintieron inseguros.(Bogotá Cómo Vamos; Cali Cómo Vamos, Encuestas de Percepción Ciudadana 2015). 
Gráfico. 8. Percepción de seguridad y convivencia ciudadana, por niveles y según barrio, comuna-corregimiento y total ciudad, 2015

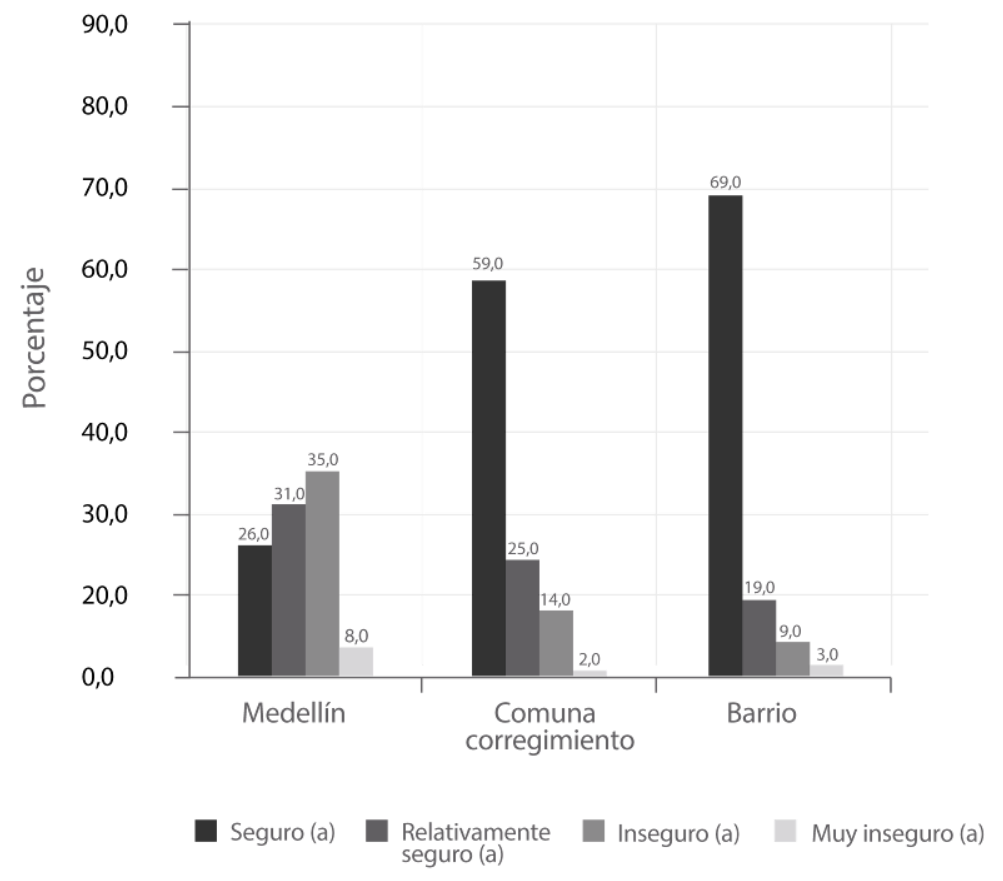

Fuente: Encuesta de Percepción y Victimización de Medellín. Alcaldía de Medellín Secretaría de Seguridad, Invamer, Universidad Eafit. 2015

La victimización de los habitantes de la ciudad, mide la incidencia y prevalencia de los delitos y en general problemas de inseguridad, convivencia y violencia, desde la experiencia y percepción de la población.

En 2015, el nivel de victimización en Medellín fue de 15,0\%, esto indica que durante este año un $15,0 \%$ de la población fue objeto de un hecho victimizante relacionado con la seguridad y la convivencia. Las comunas 11-Laureles-Estadio, 4-Aranjuez, 16-Belén y 10-La Candelaria, fueron las comunas mayores niveles de victimización en la ciudad.

Comparativamente para 2015 un 20,0\% de la población de Bogotá, un $14,0 \%$ de la de Cali y un $21,0 \%$ de la de Barranquilla fueron víctimas de algún delito.

En las tres ciudades fue el atraco, raponazo, o robo, el delito que más afectó a la ciudadanía (80,0\%, 72,0\% y 85,0\% respectivamente sobre el total de la población victima). (Bogotá Cómo Vamos; Cali Cómo Vamos, Barranquilla Cómo Vamos, Encuestas de Percepción Ciudadana 2015). 
Gráfico 9. Nivel de Victimización de la población en Medellín, 2015

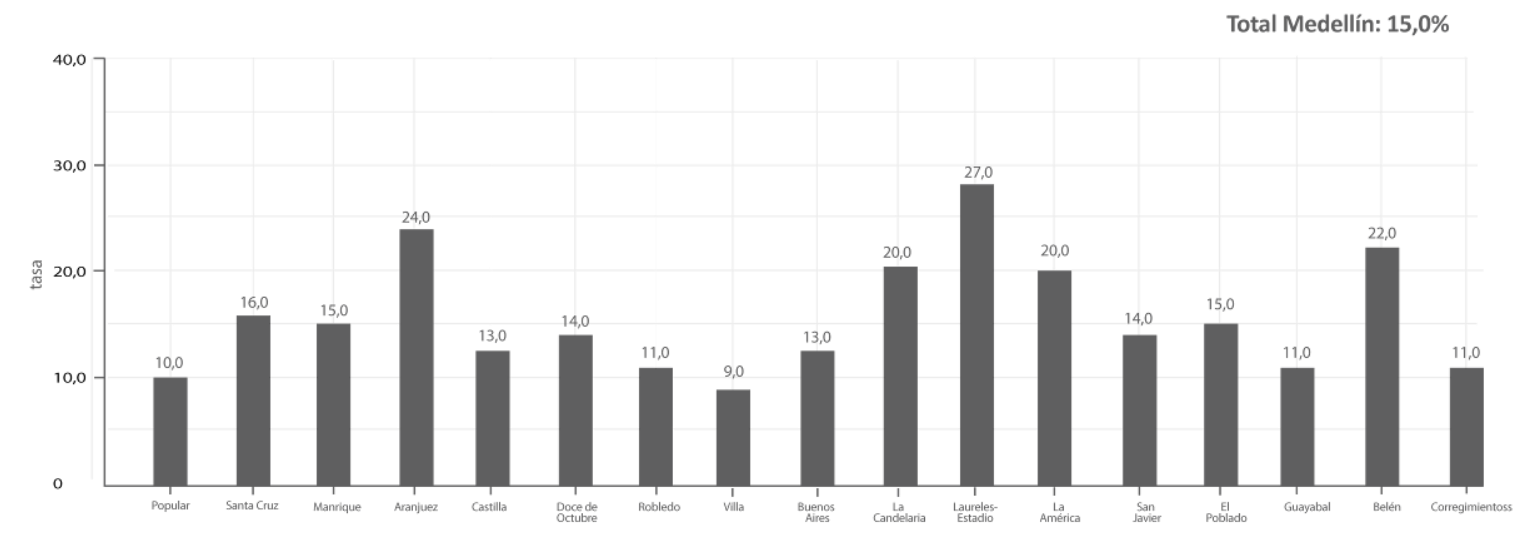

Fuente: Encuesta de Percepción y Victimización de Medellín. Alcaldía de Medellín - Secretaría de Seguridad, Invamer, Universidad Eafit. 2015

\section{- PRESENTACIÓN •}

Medellín en los últimos años ha mostrado una marcada reducción en los homicidios y otros delitos de gran impacto, pero acciones ilegales o delincuenciales, como la extorción, el control y uso indebido del espacio público y los territorios, el robo menor y situaciones asociadas a la intolerancia y a la falta de respeto por el otro, o sea las que redundan en una sana convivencia, siguen presentes y mostrando índices significativos. Estas situaciones aunadas a la percepción que se tiene de algunas instituciones encargadas de la protección y acompañamiento a la ciudadanía en el trámite de sus diferencias y situaciones críticas, generan una sensación de inseguridad que es necesario transformar.

La seguridad y la convivencia en este sentido se deben entender en el sentido más amplio del término; el resultado de la presencia del Estado en el territorio generando oportunidades económicas, sociales, culturales, políticas. Para ello es necesaria la implementación de acciones institucionales efectivas para la resolución alternativa de conflictos y con la presencia de autoridades disuasivas y de contención efectiva. El concepto de seguridad y convivencia, no sólo implica acciones militares, también implica acciones de transformación de los entornos y de las condiciones de la población y las instituciones.

Entender la seguridad y la convivencia desde un enfoque integral, implica la confluencia de otros sectores y visiones no tradicionales y que redunden en el fortalecimiento de las acciones y las percepciones que la población y la institucionalidad tienen. Es por ello que el plan integral en esta dimensión busca el fortalecimiento de la seguridad y convivencia, intervenciones de control policial del territorio, de adecuación de 
infraestructuras, de transformación de conductas y percepciones, de gestión institucional, de articulación intersectorial e interinstitucional.

A través de esta dimensión la actual administración municipal, quiere garantizar un cambio positivo y significativo en la seguridad y convivencia de todos los habitantes de Medellín, diseñando de un marco de actuación colectivo, que implicó para su construcción la participación de las comunidades de la ciudad y de los diferentes actores institucionales y que demandará para su implementación, la concurrencia articulada de las comunidades organizadas, de las autoridades competentes y de las entidades operadoras de los retos y programas, generando un marco de actuación que permita el logro de los objetivos y el cumplimiento de las metas planteados.

A continuación se describen los indicadores de impacto asociados a esta dimensión:

Indicadores de impacto

\begin{tabular}{|c|c|c|c|c|}
\hline Nombre & Unidad & Línea de Base & Meta 2019 & Responsable \\
\hline $\begin{array}{l}\text { Nivel de percepción de } \\
\text { seguridad }\end{array}$ & $\begin{array}{l}\text { Porcentaj } \\
\text { e }\end{array}$ & $26,0 \%$ & $45,0 \%$ & $\begin{array}{l}\text { Secretaría de } \\
\text { Seguridad }\end{array}$ \\
\hline Nivel de victimización & $\begin{array}{l}\text { Porcentaj } \\
\text { e }\end{array}$ & $15,0 \%$ & $12,0 \%$ & $\begin{array}{l}\text { Secretaría de } \\
\text { Seguridad }\end{array}$ \\
\hline
\end{tabular}

En este sentido proponemos para Medellín bajo esta dimensión, los siguientes retos: 


\subsection{RETO}

\section{MEDELLÍN SEGURA}

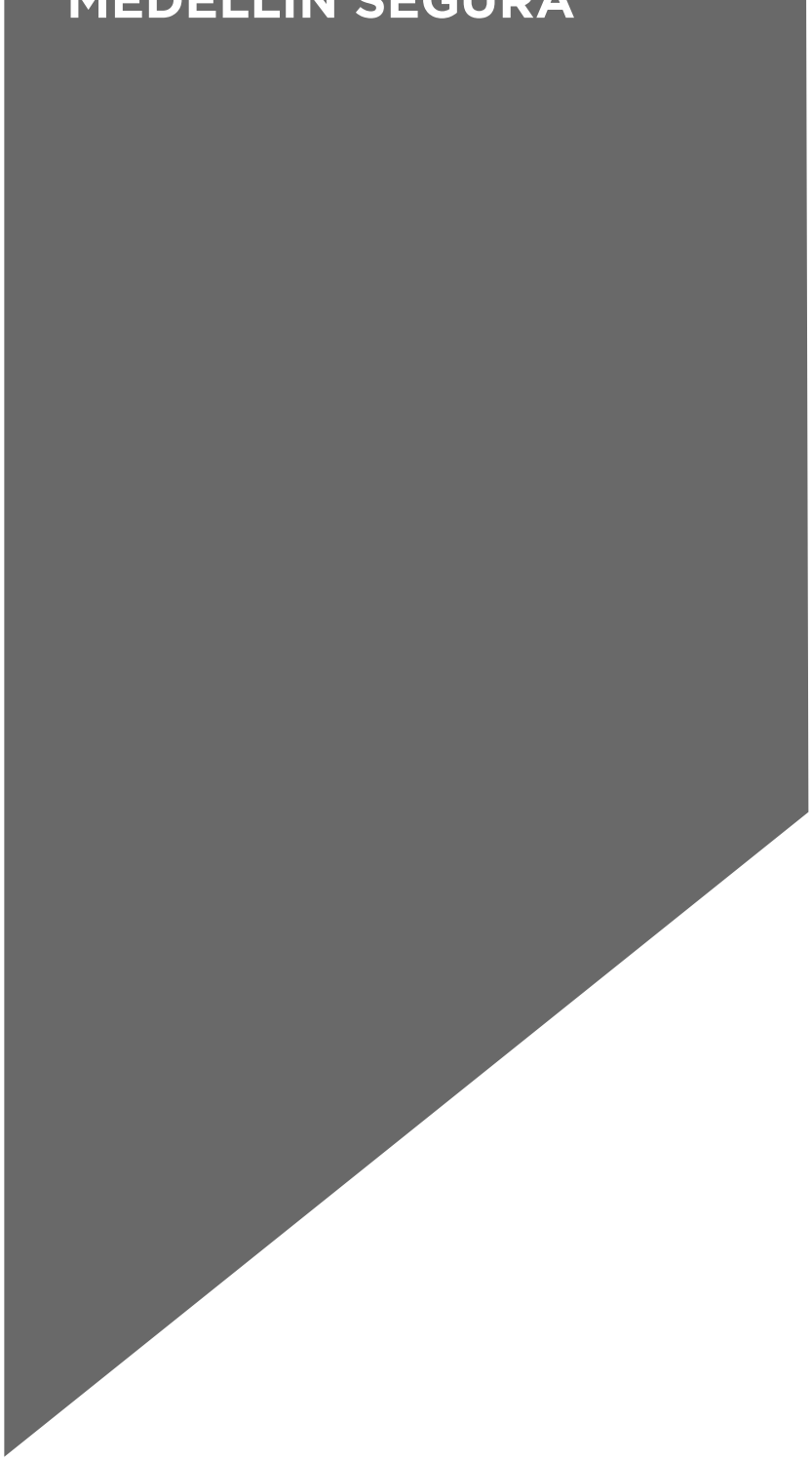

\section{OBJETIVO}

Reducir progresivamente los niveles de inseguridad con el objetivo de generar condiciones para el restablecimiento y restitución de los derechos de los ciudadanos.

\section{PROGRAMAS}

42.1.1 Planeación para la seguridad integral

4 2.1.2 Infraestructura y tecnología para la seguridad y la convivencia

$\Delta$ 2.1.3 Justicia y política criminal

4 2.1.4 Medellín segura para las mujeres y las niñas 


\subsection{Medellín Segura}

Medellín ha sido escenario de la manifestación de diversas formas de violencia como la delincuencia común, la criminalidad organizada y el trámite violento de las diferencias.

Si bien se han obtenido resultados positivos en la resolución y contención de estas problemáticas -gracias a la formulación e implementación de políticas y estrategias por parte de los autoridades competentes y corresponsables en materia de seguridad, convivencia y justicia-, no se puede obviar que aún persisten en la ciudad la ocurrencia de delitos en contra de los pobladores y su patrimonio, el irrespeto por la ley, y los problemas de coexistencia y conflictos entre ciudadanos.

En síntesis, la inseguridad y convivencia continúan siendo problemáticas estratégicas de ciudad, cuyas manifestaciones dificultan los procesos de desarrollo poblacional y territorial.

No se puede obviar que aún persisten en la ciudad la ocurrencia de delitos en contra de la ciudadanía y su patrimonio, el irrespeto por la ley, y problemas de coexistencia y conflictos entre ciudadanos. Afectaciones que además traen consigo el temor ciudadano y la pérdida de la legitimidad institucional.

Es decir, no se ha logrado para la ciudad y su población que la seguridad y la convivencia sean garantizadas como los derechos que son.

Gráfico 10. Tasa y casos de homicidio en Medellín, 1975 - 2015

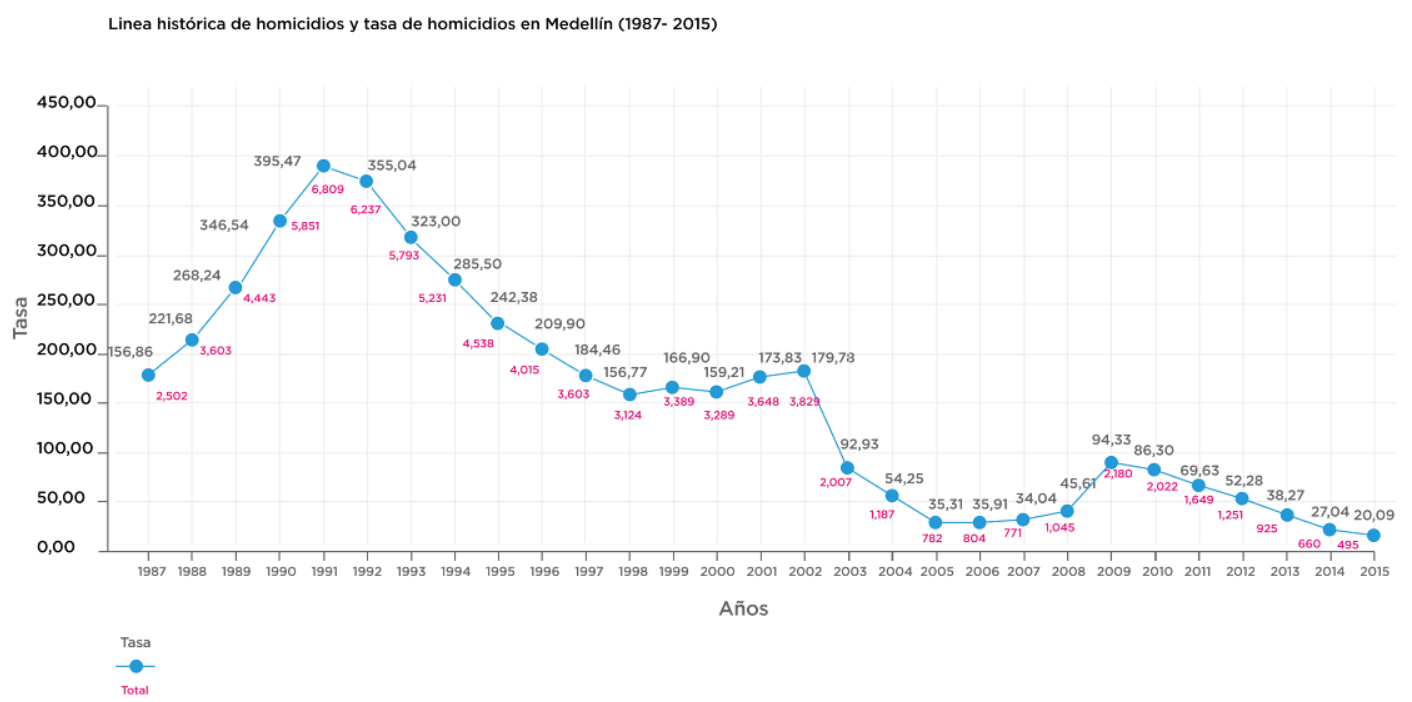

Fuente: 1987 - 2002: Estadísticas vitales DANE, SISC. 2003-2015: Series históricas con base en INML, SIJIN de la Policía, CTI de la Fiscalía.

Construcción: Secretaría de Seguridad - Sistema de Información para la Seguridad y la Convivencia -SISC-. 
La violencia homicida en Medellín ha estado relacionada de manera inequívoca a actividades propias del crimen organizado, ya que ésta ha sido instrumentalizada de forma sistemática para el ejercicio del control social y territorial que tiene como fin el acceso y control de rentas criminales como el narcotráfico, el micro tráfico, la extorsión y la trata de personas.

Si bien los homicidios se han reducido significativamente en los últimos 25 años, las cifras muestran que por cada 100.000 habitantes, ocurren 20 homicidios.

Desde un enfoque poblacional, la violencia homicida tiene como principales víctimas a la población joven de la ciudad. Entre 2003-2013, el $52,0 \%$ de las víctimas de homicidio en la ciudad se ubicaron en el rango de 14-28 años. En 2015 se presentaron 241 casos (48,7\% de los 494 registrados).

Además de víctimas los jóvenes han sido señalados como los principales victimarios de la violencia. Según el Instituto Nacional Penitenciario y Carcelario (INPEC), a 2014 la cifra de jóvenes en cárceles en Medellín fue de 3.998.

Desde un enfoque de género, durante el año 2015 se presentaron 46 casos de homicidio cuya víctima fue una mujer, de éstos 28 fueron feminicidios (es decir el 60,0\%).

Mapa 5. Tasa de homicidios por cien mil millones de habitantes por comuna y

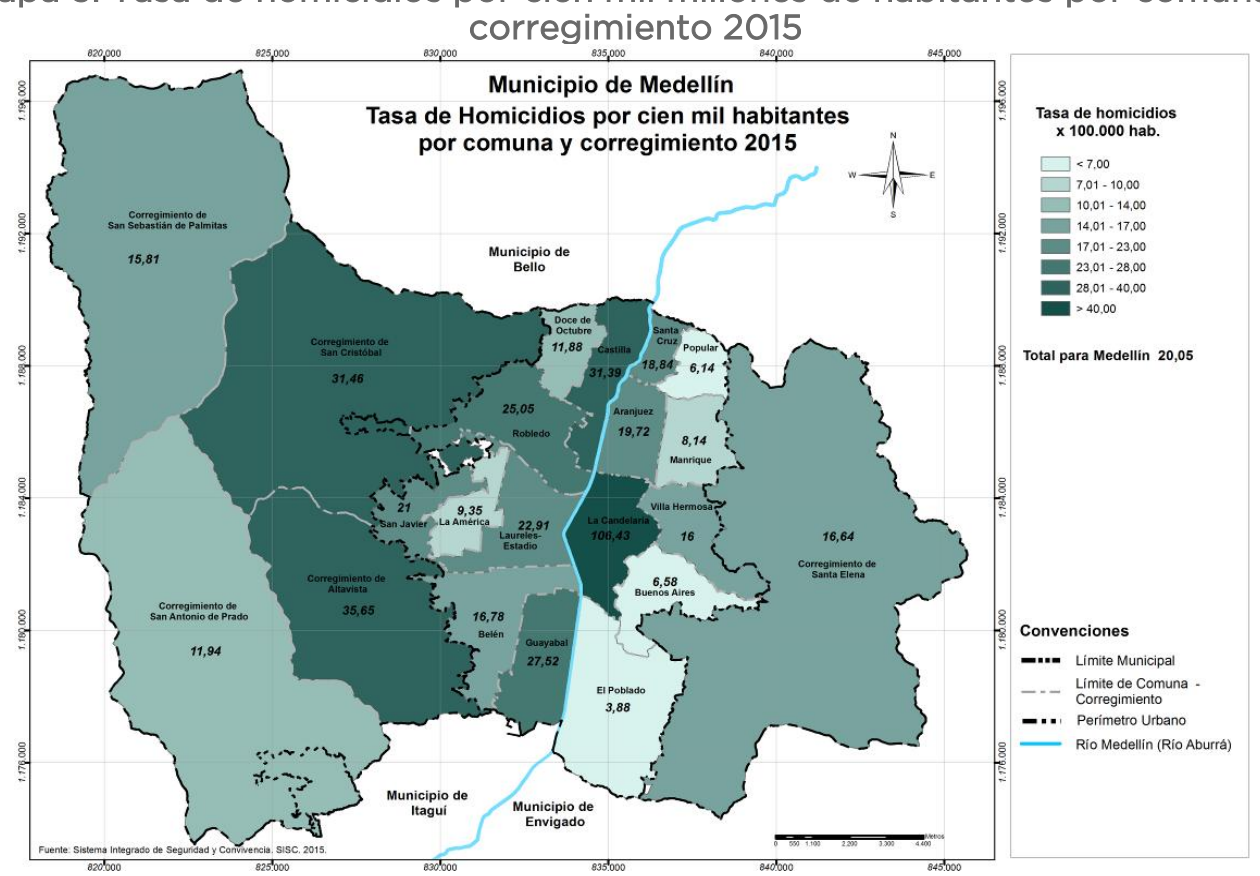

Fuente: Secretaría de Seguridad - Sistema de Información para la Seguridad y la Convivencia SISC-. 
Recuperando la seguridad y la convivencia ciudadana

Desde un enfoque territorial, las comunas 10-La Candelaria, 5-Castilla, 7-Robledo y 16-Belén registraron en 2015 la mayor proporción de casos de homicidio (43,0\% sobre un total de 214). Contrario a lo que ocurrió en los corregimientos de 50-Palmitas y 90-Santa Elena, y en las comunas 14El Poblado y 1-Popular donde se presentaron 17 casos $(3,4 \%)$ (Fuente: INML, SIJIN, CTI, SISC - Secretaría de Seguridad de Medellín como observador técnico).

Ahora bien, aunque el indicador de homicidio es estratégico al momento de evaluar la seguridad y la convivencia en un territorio, es importante hacer énfasis en otros indicadores que evidencian puntos focales de atención, los cuales no pueden ser desconocidos y que evidencian la pluralidad de la criminalidad y las problemáticas en torno a la convivencia.

Las rentas criminales (o economía criminal) por ejemplo, se configura actualmente como una problemática que no se limita a las transacciones de bienes y servicios considerados ilegales, sino que implica además el delito de la extorsión. Aunque este delito presenta un alto subregistro, los casos por extorsión o vacunas alcanzaron durante 2008-2011 las 479 denuncias y entre 2012-2015 aumentaron a 1.175.

Durante 2015 fueron denunciados 243 casos relacionados con la extorsión. Las comunas que registraron los mayores índices de denuncia fueron: 10-La Candelaria y 5-Castilla (con 39 y 30 casos respectivamente), 16-Belén, 7-Robledo y 15-Guayabal (con 26, 18 y 14 denuncias realizadas), y 12-La América y 13-San Javier (cada una con 13 casos).

En lo relacionado con el comportamiento territorial del delito del hurto durante el año 2015, se registraron en este año 7.570 bienes hurtados, cifra superior a la reportada en el 2011 (1.894 bienes), significando un aumento aproximado del 300,0\%.

Todas las comunas y corregimientos de la ciudad (con excepción de la Comuna 9-Buenos Aires), registraron incrementos en la tasa de hurtos a personas $(54,0 \%)$, hurtos a residencias $(80 \%)$ y hurtos a establecimientos comerciales $(27,0 \%)$.

Todas las modalidades de hurto a personas (atraco, factor de oportunidad, raponazo y cosquilleo), registraron incrementos en 2015. En el caso del hurto a personas el $50,0 \%$ de los casos fueron cometidos mediante la modalidad de atraco, y un $25,0 \%$ bajo la modalidad de factor de oportunidad.

El cosquilleo fue la modalidad con la variaciones porcentual más importante (registrando un incremento del 158,0\%), respectivamente. La comuna 10-La Candelaria concentró el mayor número de hurtos a 
Recuperando la seguridad y la convivencia ciudadana

personas ocurridos durante 2015 (con un 43,0\% de participación), siendo el barrio La Candelaria donde ocurrieron el 44,0\% del total de los casos.

El bien más sustraído ha sido el dinero en efectivo, seguido de los teléfonos celulares, aunque también se encuentran cifras representativas de hurto de billeteras, carteras o bolsos3.

Respecto al hurto a residencias, las comunas 7-Robledo, 10-La Candelaria, 11-Laureles Estadio, 12-La América, 14-El Poblado y 16-Belén concentraron el $53,0 \%$ del total de hurtos realizados a residencias y denunciados en 2015.

En cuanto al hurto a establecimientos comerciales, las comunas 7Robledo, 10-La Candelaria, 11-Laureles Estadio, 14-El Poblado, 15-Guayabal y 16-Belén agruparon el $74,1 \%$ del total de casos reportados en 2015 . Con respecto a las modalidades utilizadas en este tipo de hurto, predominaron en orden de participación el factor de oportunidad, mechero y atraco con 31\%, 26\% y $24 \%$ de concentración, respectivamente.

En el caso de los hurtos a vehículos y motocicletas, se reportó una disminución importante con respecto al parque automotor circulante. La tasa de hurto de vehículos para 2011 fue de 376,3 y para 2015 fue de 150,4 . En cuanto a las motocicletas, en el mismo periodo la tasa pasó de $1.014,2$ a 660,4 .

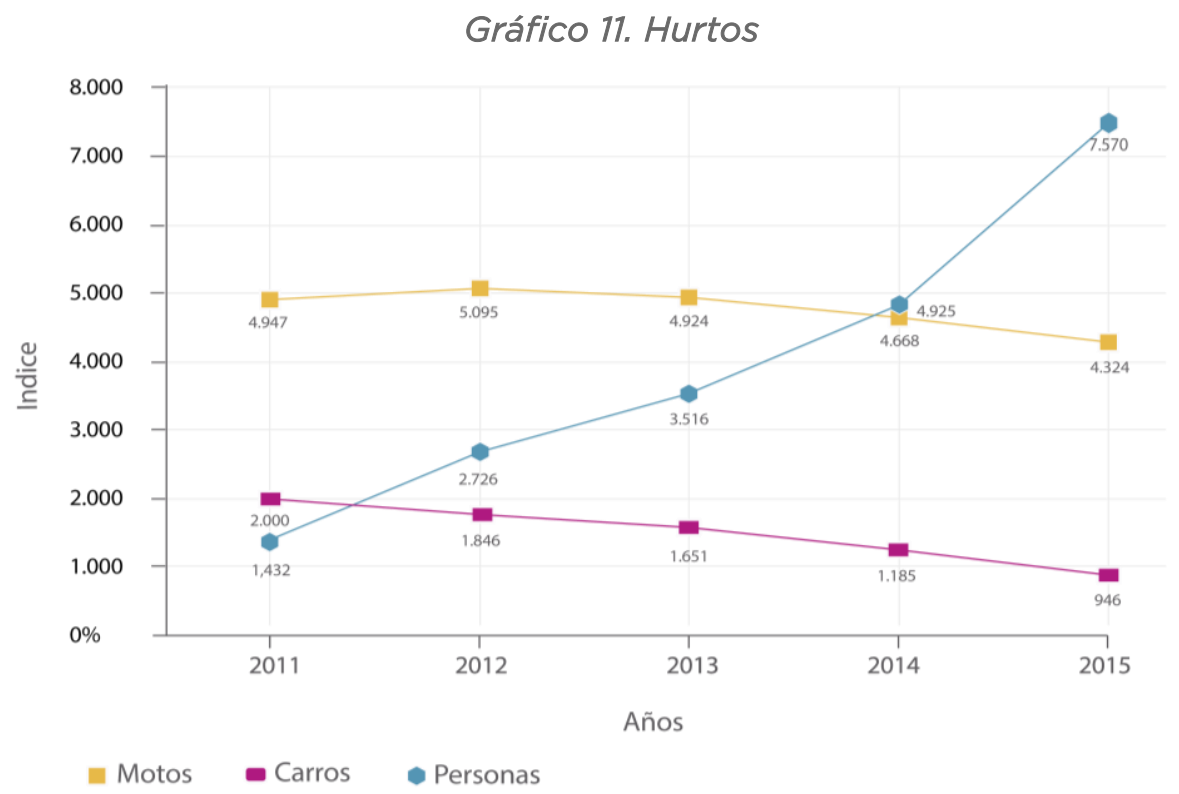

3 Desde la aplicación web Seguridad en Línea se han registrado más de 14.398 denuncias, de las cuales 5.554 pertenecen a hurto. 
A continuación se describen los indicadores de resultado que se pretenden en este reto:

\begin{tabular}{|l|c|c|c|c|}
\hline Nombre & Unidad & $\begin{array}{c}\text { Línea de } \\
\text { Base }\end{array}$ & Meta 2019 & Responsable \\
\hline Tasa de homicidios & $\begin{array}{c}\text { Tasa por cien } \\
\text { mil habitantes }\end{array}$ & 20,13 & $\begin{array}{c}\text { Secretaría de } \\
\text { Seguridad y } \\
\text { convivencia }\end{array}$ \\
\hline Tasa de hurto a personas & $\begin{array}{c}\text { Tasa por cien } \\
\text { mil habitantes }\end{array}$ & 307,2 & 277,0 & $\begin{array}{c}\text { Secretaría de } \\
\text { Seguridad y } \\
\text { convivencia }\end{array}$ \\
\hline Vehículos hurtados & Número & 946 & 823 & $\begin{array}{c}\text { Secretaría de } \\
\text { Seguridad y } \\
\text { convivencia }\end{array}$ \\
\hline Motocicletas hurtadas & Número & 4.324 & 3.892 & $\begin{array}{c}\text { Secretaría de } \\
\text { Seguridad y } \\
\text { convivencia }\end{array}$ \\
\hline Tasa de delitos sexuales & $\begin{array}{c}\text { Tasa por cien } \\
\text { mil habitantes }\end{array}$ & 54,7 & 49,0 & $\begin{array}{c}\text { Secretaría de } \\
\text { Seguridad y } \\
\text { convivencia }\end{array}$ \\
\hline Denuncias por Extorsión & Número & 243 & 225 & $\begin{array}{c}\text { Secretaría de } \\
\text { Seguridad y } \\
\text { convivencia }\end{array}$ \\
\hline Tasa de feminicidios & $\begin{array}{c}\text { Tasa por diez } \\
\text { mil mujeres }\end{array}$ & 0,2 & $\begin{array}{l}\text { Secretaría de } \\
\text { Seguridad y } \\
\text { convivencia }\end{array}$ \\
\hline
\end{tabular}

\subsubsection{PROGRAMA: PLANEACIÓN PARA LA SEGURIDAD INTEGRAL}

La historia reciente de Medellín ha generado un contexto complejo, caracterizado por la confluencia de muy diversas formas de ejercicio de la violencia, en una amalgama de prácticas ligadas al trámite violento de diferencias, dinámicas de delincuencia común, cuestionada legitimidad de las autoridades y, de manera significativa, ejercicio de poder ilegal propio de la delincuencia y criminalidad organizada. En éste contexto y teniendo como marco de actuación el Modelo Integral de Gestión Local que se propone en la Política Pública de Seguridad y Convivencia del Municipio de Medellín, es que se reconoce la necesidad de consolidar las capacidades institucionales para asumir la planeación de la seguridad y convivencia con un marcado liderazgo del Gobierno Local.

Por ello este programa busca el desarrollo de proyectos que, en un ejercicio riguroso de planeación, permitan articular y desarrollar acciones no sólo al interior de la Administración Municipal, si no en dialogo permanente con organismos de seguridad y justicia y entidades del orden departamental, metropolitano y nacional, con el propósito de garantizar condiciones para gobernar los fenómenos que afectan la seguridad y convivencia. 
Indicador de resultado

\begin{tabular}{|c|c|c|c|c|}
\hline Nombre & Unidad & $\begin{array}{c}\text { Línea de } \\
\text { Base }\end{array}$ & Meta 2019 & Responsable \\
\hline $\begin{array}{l}\text { Instrumentos de planeación } \\
\text { construidos para garantizar } \\
\text { la seguridad y promover la } \\
\text { convivencia }\end{array}$ & Número & 22 & 28 & $\begin{array}{c}\text { Secretaría de } \\
\text { Seguridad y } \\
\text { convivencia }\end{array}$ \\
\hline
\end{tabular}

2.1.1.1 Proyecto: Transversalización de la política pública de seguridad y convivencia

Aprobada por el acuerdo municipal 021 de 2015, la Política Pública de Seguridad y Convivencia entendida como un Modelo Integral de Gestión Local de la Seguridad y la Convivencia, para la toma informada de decisiones, inicia su implementación en la formulación misma del presente Plan de Desarrollo Municipal como uno de sus instrumentos de planificación fundamentales. La transversalización de la misma implica que sus lineamientos permeen y se materialicen no sólo en la dimensión actual del Plan denominada Seguridad Ciudadana y Convivencia, sino que efectivamente logre intencionar los programas y proyectos de otras dimensiones que garanticen el desarrollo de un enfoque integral de la seguridad.

Transversalizar al interior de la administración municipal, pasa por el diseño de una estrategia de comunicación interna que permita ver a cada Secretaría y ente descentralizado su rol, influencia y competencias, frente al mejoramiento de las condiciones de seguridad y convivencia entendidas como fundamento del goce efectivo de derechos y libertades por parte de la ciudadanía y además busca fortalecer la cooperación y emprenderán las acciones conducentes a garantizar la incidencia para fijar los temas en la agenda pública, de manera tal que a través de las acciones desarrolladas en el marco de la política pública, se generen sinergias entre diversos actores

Responsable: Secretaría de Seguridad y Convivencia Indicador de producto

\begin{tabular}{|c|c|}
\hline \multicolumn{1}{|c|}{ Nombre } & Unidad \\
\hline Modelo de seguimiento y evaluación de los escenarios de la política pública de & Porcentaje \\
seguridad y convivencia de Medellín diseñado e implementado
\end{tabular}

2.1.1.2 Proyecto: Formulación e implementación del plan integral de seguridad y convivencia - PISC

EI PISC es el principal instrumento de planificación a partir del cual se implementa la Política Publica de seguridad y convivencia, allí se condensan la priorización de problemáticas, estrategias, programas proyectos y acciones específicas a desarrollarse durante el cuatrienio 
para mejorar las condiciones de seguridad y convivencia a partir del trabajo articulado entre Administración Municipal, organismos de seguridad y justicia y ciudadanía en un marco de corresponsabilidad.

EI PISC se implementa a través de la Administración e inversión de los recursos propios del Fondo de Seguridad Territorial -FONSET-, en el marco de este último se da el fortalecimiento de los distintos organismos de seguridad y justicia de cara a la formulación de los programas y proyectos que ejecuten el PISC y garanticen el logro de sus metas.

Responsable: Secretaría de Seguridad y Convivencia

Indicador de producto

\begin{tabular}{|c|c|}
\hline Nombre & Unidad \\
\hline Plan integral de seguridad y convivencia (PISC) formulado e implementado & Porcentaje \\
\hline
\end{tabular}

2.1.1.3 Proyecto: Fortalecimiento y posicionamiento del Sistema de Información para la Seguridad y la Convivencia - SISC.

EI SISC deberá fortalecer sus procesos para configurarse como una herramienta para la planeación estatal en el proceso de identificación, diagnóstico y seguimiento cuantitativo, cualitativo y geográfico de las problemáticas (considerando entre otras, aquellas asociadas al crimen organizado), por medio de indicadores objetivos y subjetivos de seguridad y convivencia, mediante la articulación con Organismos de Seguridad y Justicia, otros sistemas de información de la Administración Municipal, centros de investigación y la academia.

Responsable: Secretaría de Seguridad y Convivencia

Indicadores de producto

\begin{tabular}{|l|l|}
\hline \multicolumn{1}{|c|}{ Nombre } & Unidad \\
\hline $\begin{array}{l}\text { Diseño metodológico para el seguimiento y prevención de violaciones a los } \\
\text { Derechos Humanos, asociados a la seguridad y la convivencia }\end{array}$ & Porcentaje \\
\hline $\begin{array}{l}\text { Modelo de evaluación de impacto de las intervenciones ejecutadas por la } \\
\text { Secretaría de Seguridad diseñado }\end{array}$ & Número \\
\hline $\begin{array}{l}\text { Investigaciones académicas sobre temas de seguridad, convivencia y DDHH, } \\
\text { realizadas en articulación con universidades, centros de investigación o centros } \\
\text { de consultoría }\end{array}$ & Número \\
\hline
\end{tabular}

2.1.1.4 Proyecto: Diseño e implementación de instrumentos de territorialización -Planes especiales y Plan del Centro.

Son instrumentos fundamentales que permiten la concreción del Plan de Desarrollo, el Plan Integral de Seguridad y Convivencia (PISC) y el Plan de Prevención de Violaciones a los Derechos a la Vida, Integridad y Libertad Personal, por medio de intervenciones para atender problemáticas poblacional y territorialmente focalizadas. Además, podrán ser considerados como dispositivos de intervención rápida para responder a una alteración coyuntural de las condiciones de seguridad y convivencia, donde será 
prioridad la consolidación del proceso de planeación que garantice la toma de decisiones operativas que los activa y pone en marcha, de manera ágil y efectiva.

Responsable: Secretaría de Seguridad y Convivencia

Indicador de producto:

\begin{tabular}{|c|c|}
\hline \multicolumn{1}{|c|}{ Nombre } & Unidad \\
\hline Instrumentos de territorialización diseñados e implementados & Número \\
\hline
\end{tabular}

2.1.1.5 Proyecto: Articulación y cooperación metropolitana, regional, nacional e internacional en materia de seguridad integral

Este proyecto busca garantizar que desde el escenario de la planeación se desarrollen esfuerzos e iniciativas en torno a la cooperación y el diálogo con los distintos niveles territoriales. Desde el desarrollo de Consejos de Seguridad a nivel metropolitano y regional, pasando por la concepción y ejecución conjunta de proyectos que impacten las problemáticas de seguridad que trascienden el ámbito municipal, se considera fundamental contar con un marco de actuación adecuado, basado en la fluidez y el intercambio de información entre los niveles nacional, departamental, regional o metropolitano.

Las labores de incidencia y cooperación, requieren además escalar las acciones y lograr aliados incluso en el nivel nacional, de manera que los proyectos y acciones que se desprendan de la planeación de la seguridad y la convivencia y requieran de organismos y entidades de los diferentes niveles territoriales, tengan un canal que posibilite su oportuna vinculación.

Responsable: Secretaría de Seguridad y Convivencia Indicador de producto:

\begin{tabular}{|c|c|}
\hline \multicolumn{1}{|c|}{ Nombre } & Unidad \\
\hline Consejos Metropolitanos de Seguridad realizados & Número \\
\hline
\end{tabular}

\subsubsection{PROGRAMA: INFRAESTRUCTURA PARA LA SEGURIDAD Y LA CONVIVENCIA}

Aumentar la gobernabilidad en la gestión de seguridad y convivencia implica aumentar la capacidad del Estado, y en particular de la Alcaldía, para tener incidencia sobre la infraestructura tanto física como tecnológica al servicio de la seguridad y la convivencia.

Fortalecer la presencia del Estado en cada uno de los territorios, requiere de la dotación de una infraestructura física que responda con acierto a las demandas ciudadanas en cuanto a seguridad y convivencia refiere, facilitando a todos los ciudadanos un acceso más cercano a servicios de seguridad y justicia.

La infraestructura tecnológica se constituye por su parte en la herramienta indispensable de un proceso de gestión de conocimiento que permitirá una 
toma de decisiones cada vez más informada, la implementación de soluciones tecnológicas que garanticen la confluencia de información proveniente de las diversas bases de datos, aplicativos y sistemas de información que se considere pertinentes para la gestión de las problemáticas que afectan la seguridad y la convivencia, deberá ser por tanto su horizonte.

Indicadores de resultado

\begin{tabular}{|c|c|c|c|c|}
\hline Nombre & Unidad & $\begin{array}{c}\text { Línea de } \\
\text { Base }\end{array}$ & Meta 2019 & Responsable \\
\hline $\begin{array}{l}\text { Plan destro } \\
\text { Infraestructura para la } \\
\text { seguridad y la convivencia } \\
\text { formulado e implementado }\end{array}$ & Porcentaje & 0 & $100 \%$ & $\begin{array}{c}\text { Secretaría de } \\
\text { Seguridad }\end{array}$ \\
\hline
\end{tabular}

2.1.2.1 Proyecto: Formulación e implementación de un plan maestro de infraestructura para la seguridad y la convivencia

Parte de la identificación de la situación actual de infraestructura física y tecnológica para la seguridad y la convivencia del municipio, detallando de un lado, las necesidades de mejoramiento o construcción de nuevas infraestructuras físicas, acorde a las necesidades de los territorios. Algunas zonas de la ciudad no cuentan con cobertura de infraestructura de este tipo, mientras que otras tienen una concentración mayor, lo que dificulta la labor de mantener al Estado presente en el territorio; de esta manera, se buscará que todo el territorio del municipio cuente con la adecuada cobertura de dichas instalaciones, partiendo de un análisis preciso de capacidades y necesidades.

Responsable: Secretaría de Seguridad y Convivencia.

Indicadores de producto

\begin{tabular}{|l|l|}
\hline \multicolumn{1}{|c|}{ Nombre } & \multicolumn{1}{|c|}{ Unidad } \\
\hline Nueva infraestructura para la seguridad construidas & Número \\
\hline $\begin{array}{l}\text { Plan Maestro de TIC para la seguridad y la convivencia formulado e } \\
\text { implementado }\end{array}$ & Porcentaje \\
\hline
\end{tabular}

\subsubsection{Proyecto: Gestión para el control estratégico del territorio} Las especiales condiciones geográficas del territorio de Medellín generan riesgos y oportunidades en relación con el posicionamiento estratégico de las actividades de vigilancia y control por parte de los organismos de seguridad y de justicia. La utilización de ventajas comparativas en relación con las condiciones demográficas del territorio, es una oportunidad para hacer más eficiente la prestación de los servicios de seguridad para la garantía de los derechos de la población en el territorio.

Responsable: Secretaría de Seguridad y Convivencia.

Indicador de producto

\begin{tabular}{|l|c|}
\hline \multicolumn{1}{c|}{ Nombre } & Unidad \\
\hline Gestión para el control estratégico del territorio & Número \\
\hline
\end{tabular}


2.1.2.3 Proyecto: Fortalecimiento del Sistema Integrado de Emergencias y Seguridad de Medellín - SIES-M:

Consolidar el Sistema Integrado de Emergencias y Seguridad de Medellín SIES-M, incorporando y fortaleciendo las herramientas para acercar el ciudadano y proveer de más y mejor información a los tomadores de decisiones, donde el SIES-M administra, opera y/o gestiona subsistemas y la interacción de los mismos.

Responsable: Secretaría de Seguridad y Convivencia.

Indicador de producto

\begin{tabular}{|c|c|}
\hline Nombre & Unidad \\
\hline Plan de integración y fortalecimiento del SIES-M formulado e implementado & Porcentaje \\
\hline
\end{tabular}

\subsubsection{PROGRAMA: JUSTICIA Y POLÍTICA CRIMINAL}

Aumentar la gobernabilidad en la gestión de seguridad y convivencia implica aumentar la capacidad del Estado, y en particular de la Alcaldía, para tener incidencia sobre la infraestructura tanto física como tecnológica al servicio de la seguridad y la convivencia.

Fortalecer la presencia del Estado en cada uno de los territorios, requiere de la dotación de una infraestructura física que responda con acierto a las demandas ciudadanas en cuanto a seguridad y convivencia refiere, facilitando a todos los ciudadanos un acceso más cercano a servicios de seguridad y justicia.

La infraestructura tecnológica se constituye por su parte en la herramienta indispensable de un proceso de gestión de conocimiento que permitirá una toma de decisiones cada vez más informada, la implementación de soluciones tecnológicas que garanticen la confluencia de información proveniente de las diversas bases de datos, aplicativos y sistemas de información que se considere pertinentes para la gestión de las problemáticas que afectan la seguridad y la convivencia, deberá ser por tanto su horizonte.

Indicador de resultado

\begin{tabular}{|c|c|c|c|c|}
\hline Nombre & Unidad & $\begin{array}{c}\text { Línea de } \\
\text { Base }\end{array}$ & Meta 2019 & Responsable \\
\hline $\begin{array}{l}\text { Organismos de justicia } \\
\text { articulados al Plan Integral } \\
\text { de seguridad y convivencia } \\
\text { PISC }\end{array}$ & Número & 0 & 4 & $\begin{array}{c}\text { Secretaría de } \\
\text { Seguridady } \\
\text { Convivencia }\end{array}$ \\
\hline
\end{tabular}

2.1.3.1 Proyecto: Fortalecimiento o creación de grupos especiales por delito Liderar el fortalecimiento o la creación y conformación de grupos especializados en apoyo a las estrategias de afectación y desarticulación de delincuencia y criminalidad organizada.

Responsable: Secretaría de Seguridad y Convivencia. 
Indicadores de producto

\begin{tabular}{|l|l|}
\hline \multicolumn{1}{|c|}{ Nombre } & \multicolumn{1}{|c|}{ Unidad } \\
\hline Grupos especiales de respuesta creados por delito & Número \\
\hline Grupos especiales de respuesta al delito fortalecidos & Porcentaje \\
\hline
\end{tabular}

2.1.3.2 Proyecto: Direccionamiento de la política criminal

Direccionar la política criminal local, coherente con las problemáticas y delitos priorizados en los instrumentos de planeación de la seguridad y la convivencia. Este direccionamiento deberá garantizar un mayor grado de articulación, eficacia y eficiencia en la prestación de los servicios relacionados con la administración de justicia y la labor de los organismos de seguridad, generando mejores condiciones para la operatividad en función de las estrategias de desarticulación de la delincuencia y criminalidad en la ciudad de Medellín.

Responsable: Secretaría de Seguridad y Convivencia.

Indicador de producto

\begin{tabular}{|c|c|}
\hline \multicolumn{1}{|c|}{ Nombre } & \multicolumn{1}{c|}{ Unidad } \\
\hline Jueces capacitados en el marco del direccionamiento de la política criminal & Porcentaje \\
\hline
\end{tabular}

2.1.3.3 Proyecto: Incentivos para los organismos de seguridad y justicia La prestación del servicio por parte de los organismos de seguridad de justicia en Medellín, atiene a obligaciones definidas por entidades en su mayoría del nivel nacional, en coordinación con las autoridades locales de la alcaldía de Medellín que tienen competencias en la materia. Por ello a adecuada prestación de servicio por parte de esas entidades, en cumplimiento de los instrumentos de planeación creados por la Alcaldía de Medellín en acuerdo con esas entidades, debe construirse en un escenario de reconocimiento del valor de esa actividad en favor del mejoramiento de la seguridad y la convivencia en el territorio

Responsable: Secretaría de Seguridad y Convivencia.

Indicador de producto

\begin{tabular}{|l|l|}
\hline \multicolumn{1}{|c|}{ Nombre } & \multicolumn{1}{|c|}{ Unidad } \\
\hline $\begin{array}{l}\text { Miembros de los organismos de seguridad beneficiados por el sistema de } \\
\text { estimulos }\end{array}$ & Porcentaje \\
\hline
\end{tabular}

2.1.3.4 Proyecto: Descentralización de los mecanismos de acceso a la justicia

Fortalecer el sistema de justicia de la ciudad de Medellín, pasa por

(2) hacer sus servicios más accesibles a toda la ciudadanía. Puntos móviles y descentralizados para la denuncia ciudadana y ampliación de canales deben garantizar una mayor accesibilidad y conocimiento de las comunidades de los distintos mecanismos que pueden activarse cuando han sido víctimas de algún delito, lo cual a su vez, debe redundar en mejorar la eficacia y la eficiencia del servicio 
público de la justicia de la ciudad de Medellín, tanto en lo que compete a la Fiscalía como a la Rama Judicial.

Responsable: Secretaría de Seguridad y Convivencia

Indicador de producto

\begin{tabular}{|c|c|}
\hline \multicolumn{1}{|c|}{ Nombre } & \multicolumn{1}{c|}{ Unidad } \\
\hline Nuevos puntos de acceso a la justicia creados & Número \\
\hline
\end{tabular}

\subsubsection{Proyecto: Fortalecimiento del Sistema Penal de Responsabilidad para} Adolescentes.

Fortalecer la intervención realizada con adolescentes y jóvenes en el Centro de Atención al Joven Carlos Lleras Restrepo, potenciando sus valores, habilidades y competencias, a través de programas educativos, reeducativos y de intervención psicosocial y familiar, para la construcción de su proyecto de vida en la legalidad.

Responsable: Secretaría de Seguridad y Convivencia

Indicador de producto

\begin{tabular}{|l|l|}
\hline \multicolumn{1}{|c|}{ Nombre } & \multicolumn{1}{|c|}{ Unidad } \\
\hline $\begin{array}{l}\text { Centros de atención fortalecidos para los y las adolescentes infractores en } \\
\text { conflicto }\end{array}$ & Número \\
\hline $\begin{array}{l}\text { Sedes habilitadas para la atención de mujeres infractoras y jóvenes egresados } \\
\text { del SRPA }\end{array}$ & Número \\
\hline
\end{tabular}

2.1.3.6 Proyecto: Atención integral a las problemáticas de la población carcelaria

Con este proyecto se busca adelantar el desarrollo de programas, proyectos y acciones tendientes a generar un proceso de resocialización de internos e internas en los establecimientos penitenciarios y carcelarios de la ciudad, buscando además, disminuir los índices de reincidencia de la población. Incluye acciones que van desde el acompañamiento psicosocial a los internos e internas pero también a las familias, la orientación y formación en artes y oficios, la promoción de la convivencia y el respeto por los derechos.

Responsable: Secretaría de Seguridad y Convivencia

Indicador de producto

\begin{tabular}{|l|l|}
\hline \multicolumn{1}{|c|}{ Nombre } & \multicolumn{1}{|c|}{ Unidad } \\
\hline $\begin{array}{l}\text { Personas en situación de cárcel y pos penadas atendidas por el programa de } \\
\text { intervención social en cárceles }\end{array}$ & Número \\
\hline $\begin{array}{l}\text { Familiares de personas en situación de cárcel y pos penados atendidos por el } \\
\text { programa de intervención social a cárceles }\end{array}$ & Número \\
\hline
\end{tabular}

\subsubsection{PROGRAMA MEDELLÍN SEGURA PARA LAS MUJERES Y LAS NIÑAS}

Medellín cree en un enfoque de seguridad humana, que busca una "Ciudad Segura” para el desarrollo integral de la ciudadanía, creando estrategias que 
buscan enfrentar las violencias contra las mujeres, mejorar la respuesta institucional y fortalecer la justicia de género.

La seguridad pública para las mujeres es uno de los elementos fundamentales para su desarrollo, avance y construcción de una sociedad equitativa e incluyente. La apuesta se dirige a reducir el índice de las violencias sexuales, aumentar la percepción de seguridad y movilidad en el espacio público para el uso y goce efectivo de los derechos de las mujeres y las niñas, y prevenir y atender las violencias basadas en género.

Indicador de resultado

\begin{tabular}{|l|c|c|c|c|}
\hline \multicolumn{1}{|c|}{ Nombre } & Unidad & $\begin{array}{c}\text { Línea de } \\
\text { Base }\end{array}$ & Meta 2019 & Responsable \\
\hline $\begin{array}{l}\text { Mujeres que conocen } \\
\text { mecanismos implementados } \\
\text { por la Secretaria de las } \\
\begin{array}{l}\text { Mujeres para la prevención, } \\
\text { atención, y denuncian ante la } \\
\text { entidad competente } \\
\text { violencias basadas en género }\end{array}\end{array}$ & Porcentaje & SLB & 10\% & $\begin{array}{c}\text { Secretaria de las } \\
\text { mujeres }\end{array}$ \\
\hline
\end{tabular}

\subsubsection{Proyecto: Territorios seguros para las mujeres y las niñas}

En Medellín se generan condiciones para que las mujeres disfruten de espacios seguros en la ciudad y los corregimientos, que permitan el libre ejercicio de la ciudadanía.

Un espacio público seguro e incluyente, dispuesto para las niñas y las mujeres a partir de la implementación de estrategias por el derecho de las mujeres a la ciudad, a través de la apropiación cultural de escenarios públicos, la re significación de imaginarios frente a los espacios y el uso de los mismo en horarios diurnos y nocturnos, la configuración de redes y agentes protectores para la seguridad integral de las mujeres. Este propósito además implica la generación de alianzas para un urbanismo social con perspectiva de género, que promueva la recuperación física, la iluminación, las condiciones de operación oportuna, eficiente y accesible de los sistemas de transporte público de la ciudad, que favorezca la movilidad de las mujeres para propiciar el disfrute de la ciudad en igualdad de condiciones en cada uno de sus territorios.

Responsable: Secretaría de las Mujeres

Indicador de producto

\begin{tabular}{|l|l|}
\hline \multicolumn{1}{|c|}{ Nombre } & \multicolumn{1}{c|}{ Unidad } \\
\hline $\begin{array}{l}\text { Acciones de recuperación y ap ropiación de espacios públicos para la garantía } \\
\text { de condiciones de seguridad para las mujeres }\end{array}$ & Número \\
\hline
\end{tabular}

2.1.4.2 Proyecto: Prevención y atención de las violencias basadas en género Los derechos humanos de las mujeres se garantizan desde la promoción hasta el restablecimiento, desde un enfoque de género, diferencial y de curso de vida, que habilita todas las medidas para la 
prevención y la atención de las violencias basadas en género. Las mujeres y las niñas cuentan con estrategias de prevención y promoción de la movilización social frente a las violencias sexuales, físicas y psicológicas, calidad en la atención a las víctimas, atención psicosocial, medidas de protección transitoria y representación legal.

Responsable: Secretaría de las Mujeres

Indicador de producto:

\begin{tabular}{|l|l|}
\hline \multicolumn{1}{|c|}{ Nombre } & \multicolumn{1}{c|}{ Unidad } \\
\hline $\begin{array}{l}\text { Mujeres que participan en procesos de prevención y/o atención de las } \\
\text { violencias basadas en género }\end{array}$ & Número \\
\hline
\end{tabular}

2.1.4.3 Proyecto: Comunicación pública para el empoderamiento favorable a los derechos de las mujeres

La comunicación pública está llamada a ser un activo dinámico de la gobernanza. En este sentido, y desde la perspectiva de que una sociedad se mide por la riqueza de la discusión pública y la capacidad de transformarse, su aporte consiste en favorecer los espacios de encuentro, concertación y diálogo que permitan la participación y la cohesión social. Desde este punto de vista, la comunicación pública para el empoderamiento, favorable a los derechos de las mujeres busca la transformación de las mentalidades, los imaginarios y las creencias, que subvaloran y desfavorecen a las mujeres en la sociedad. Lo que apunta al cierre de brechas de género.

La comunicación que tiene como fin último "hacerse entender", será en el tema de derechos humanos de las mujeres provocadora y generadora de reflexiones, a través de estrategias de movilización social y campañas de transformación de patrones y paradigmas culturales que contribuyan a la prevención de violencias basadas en género (VBG) y al reconocimiento y acceso a los derechos. Es una estrategia para que hombres y mujeres entiendan que las mujeres son motor de desarrollo y que es posible romper las barreras de discriminación e inequidad, para construir una ciudad más igualitaria, equitativa e incluyente

Indicador de producto

Responsable: Secretaría de las Mujeres

\begin{tabular}{|l|l|}
\hline \multicolumn{1}{|c|}{ Nombre } & \multicolumn{1}{|c|}{ Unidad } \\
\hline $\begin{array}{l}\text { Personas que participan de las diferentes estrategias de comunicación pública } \\
\text { que promueven el empoderamiento de las mujeres }\end{array}$ & Número \\
\hline
\end{tabular}




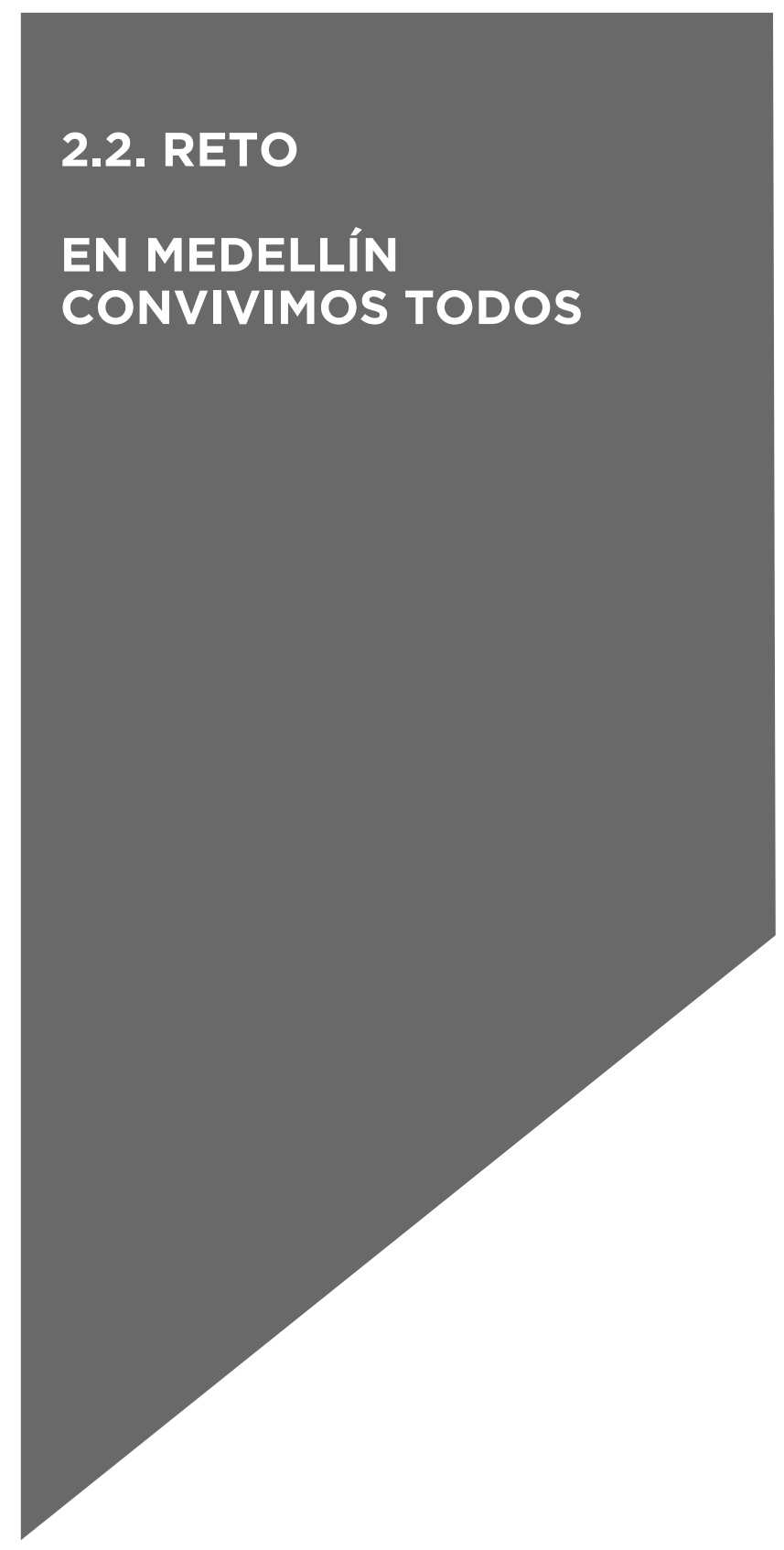

\section{PROGRAMAS}

42.2.1 Justicia cercana al ciudadano

4.2.2 Promoción de la convivencia

4 2.2.3 Todos convivimos en el espacio público

4 2.2.4 Prevención de las violencias

\section{OBJETIVO}

Generar condiciones de confianza interpersonal e institucional en la población para una convivencia pacífica. 


\subsection{En Medellín convivimos todos}

De acuerdo a la Política Pública de Seguridad y Convivencia del Municipio, la convivencia es un elemento indispensable que no debe ser desligado de la seguridad, y que se vincula con la violencia en al menos dos aspectos: la violencia ejercida por actores armados o amenaza del uso de la misma como alternativa no estatal e ilegal para tramitar conflictos de las comunidades y la violencia ejercida directamente por las partes en conflicto.

La violencia espontánea, utilizada como medio para abordar y tramitar conflictos relacionados con la convivencia ciudadana, bien sea que se trate de riñas, peleas espontáneas o de aquellos conflictos presentados al interior de los hogares, sigue manifestándose en la ciudad.

En 2015 fueron reportadas a la línea del Número Único de Seguridad y Emergencia (123), un total de 47.887 de denuncias por casos de riñas (316 menos que las 48.203 reportadas en 2014). Los barrios con mayor reporte de esta problemática fueron: La Candelaria (771), Moravia (581), Castilla (500), Kennedy (497), Pedregal (438), Loreto (435), Santo Domingo Savio (431), La Esperanza (419), Popular (412) y Las Granjas (405).

Durante 2015, se registraron 5.754 casos de violencia intrafamiliar, de los cuales 4.844 tuvieron como víctima a una mujer (84,1\%). Por otro lado el Centro de Atención a Víctimas de Abuso Sexual (CAIVAS), notificó 1.303 casos de delitos sexuales, de los cuales 1.135 (87,0\%), estuvieron dirigidos a mujeres, siendo las niñas menores de 13 años las más afectadas (47,0\%).

A continuación se describen los indicadores de resultado que se evaluarán en este reto:

\begin{tabular}{|c|c|c|c|c|}
\hline Nombre & Unidad & $\begin{array}{c}\text { Línea de } \\
\text { Base }\end{array}$ & Meta 2019 & Responsable \\
\hline $\begin{array}{l}\text { Tasa de solicitud de medidas } \\
\text { de protección por violencia } \\
\text { intrafamiliar }\end{array}$ & $\begin{array}{l}\text { Tasa por cien } \\
\text { mil habitantes }\end{array}$ & 234,6 & 211,2 & $\begin{array}{c}\text { Secretaría de } \\
\text { Gobierno }\end{array}$ \\
\hline $\begin{array}{l}\text { Tasa de contravenciones } \\
\text { realizadas por la Policía }\end{array}$ & $\begin{array}{l}\text { Tasa por cien } \\
\text { mil habitantes }\end{array}$ & 95,8 & 73,0 & $\begin{array}{c}\text { Secretaría de } \\
\text { Gobierno }\end{array}$ \\
\hline Tasa de lesiones personales & $\begin{array}{l}\text { Tasa por cien } \\
\text { mil habitantes }\end{array}$ & 127,5 & 102,0 & $\begin{array}{c}\text { Secretaría de } \\
\text { Gobierno }\end{array}$ \\
\hline
\end{tabular}

\subsubsection{PROGRAMA: JUSTICIA CERCANA AL CIUDADANO}

Se busca fortalecer las comisarías, las casas de justicia y las inspecciones, como modelo a través del cual el sistema de justicia se acerca a las comunidades más vulnerables y de esta forma suprimir el recurso a los métodos ilegales de solución de conflictos. Además se propone brindar a los ciudadanos herramientas eficaces para resolver pacíficamente los conflictos ciudadanos a través de la consolidación de mecanismos alternativos para la resolución de estos. 
Indicador de resultado

\begin{tabular}{|l|l|c|c|c|}
\hline Nombre & \multicolumn{1}{|c|}{ Unidad } & $\begin{array}{c}\text { Línea de } \\
\text { Base }\end{array}$ & Meta 2019 & Responsable \\
\hline $\begin{array}{l}\text { Cobertura de Comisarías de } \\
\text { Familia, Inspecciones, y Casas } \\
\text { le Justicia fortalecidas }\end{array}$ & Porcentaje & Por definir & Por definir & $\begin{array}{c}\text { Secretaría de } \\
\text { Gobierno }\end{array}$ \\
\hline
\end{tabular}

2.2.1.1 Proyecto: Fortalecimiento y ajustes del sistema de justicia cercana al ciudadano

Fortalecer a las autoridades pertenecientes al Sistema Municipal de Justicia Cercana al Ciudadano: comisarías de familia, inspecciones de Policía, Subsecretaría de Control Urbanístico y casas de justicia, de manera que puedan prestar una atención rápida, eficaz, eficiente, transparente y de calidad, para que sean ellas la primera autoridad a la que acuda el ciudadano.

Responsable: Secretaría de Seguridad y Convivencia

Indicador de producto

\begin{tabular}{|l|l|}
\hline \multicolumn{1}{|c|}{ Nombre } & \multicolumn{1}{|c|}{ Unidad } \\
\hline $\begin{array}{l}\text { Diseño e implementación de un plan de ajuste y mejoramiento a las Comisarías } \\
\text { de Familia, inspecciones, y casas de justicia. }\end{array}$ & Número \\
\hline
\end{tabular}

2.2.1.2 Proyecto: Implementación de mecanismos alternativos para la resolución de conflictos en el sistema de justicia cercana al ciudadano.

Promover los procesos alternativos de resolución de conflictos distintos a la vía judicial, propiciando que el ciudadano tenga la posibilidad de resolver sus conflictos de manera pacífica y pronta. Se pretende así de alguna forma evitar que otro tipo de actores asuman este rol de ayudar a los habitantes de una comuna a resolver pacíficamente sus conflictos.

Responsable: Secretaría de Seguridad y Convivencia

Indicadores de producto

\begin{tabular}{|c|c|}
\hline \multicolumn{1}{|c|}{ Nombre } & \multicolumn{1}{|c|}{ Unidad } \\
\hline Conciliadores en equidad que apoyan la resolución pacífica de conflictos & Número \\
\hline Conciliadores en derechos que apoyan la resolución pacífica de conflictos & Número \\
\hline
\end{tabular}

\subsubsection{PROGRAMA: PROMOCIÓN DE LA CONVIVENCIA}

Para promover la convivencia ciudadana es necesario aprender a vivir juntos y para ello es preciso emprender procesos pedagógicos y de fomento del deporte que fortalezcan el capital social de los ciudadanos para la convivencia, no solo entre vecinos y amigos sino también en las canchas, los parques y el estadio. 
Indicador de resultado

\begin{tabular}{|l|l|c|c|c|}
\hline \multicolumn{1}{|c|}{ Nombre } & Unidad & $\begin{array}{c}\text { Línea de } \\
\text { Base }\end{array}$ & Meta 2019 & Responsable \\
\hline $\begin{array}{l}\text { Plan de formación y ruta de } \\
\text { acción para la convivencia } \\
\begin{array}{l}\text { ciudadana formulada e } \\
\text { implementada }\end{array}\end{array}$ & Porcentaje & 0 & $100 \%$ & $\begin{array}{c}\text { Secretaría de } \\
\text { Gobierno }\end{array}$ \\
\hline
\end{tabular}

2.2.2.1 Proyecto: Promoción y formación para el fortalecimiento de las competencias ciudadanas para la convivencia

Fomentar la convivencia ciudadana a través de la difusión de los principios del manual de convivencia, en las 16 comunas y 5 corregimientos de la ciudad de Medellín. Promoviendo la autorregulación y la corresponsabilidad de los ciudadanos, a través de procesos pedagógicos que propicien la reflexión y la acción entorno a la convivencia y se busque la disminución de las indisciplinas sociales en la ciudad.

La gestión de la convivencia y la seguridad, requieren de actores corresponsables que cuenten con las competencias, y estén formados y capacitados para hacer frente a la complejidad de los problemas que de ellos se derivan. Implementar acciones para la capacitación a la ciudadanía en la atención y resolución pacífica de conflictos, brindando las competencias para la gestión, atención y trámite de diferencias y de conflictos cotidianos como riñas y altercados entre vecinos, por vías no violentas. Así mismo se promoverán acciones para trabajar las masculinidades no violentas y se favorecerá el trabajo con agresores para la prevención y atención de la violencia intrafamiliar.

Responsable: Secretaría de Seguridad y Convivencia

Indicador de producto

\begin{tabular}{|c|c|}
\hline Nombre & Unidad \\
\hline Grupos de ciudadanos formados y certificados para la convivencia ciudadana & Número \\
\hline
\end{tabular}

\subsubsection{Proyecto: Cultura del fútbol}

Realizar un apoyo técnico, estratégico y metodológico a los procesos de convivencia y cultura ciudadana para y con los jóvenes que hacen parte de las aficiones de fútbol de los equipos de la ciudad de Medellín con el propósito de prevenir los actos de violencia e inculcar la tolerancia alrededor de la pasión por sus equipos.

Responsable: Secretaría de Juventud

Indicador de producto

\begin{tabular}{|c|c|}
\hline Nombre & Unidad \\
\hline Estrategia de acompañamiento metodológico para la convivencia en el futbol. & Número \\
\hline
\end{tabular}




\subsubsection{Proyecto: Adrenalina}

Propiciar la canalización de la energía vital de niños y jóvenes, mediante oportunidades y condiciones para la práctica de actividades deportivas emergentes y extremas, como también las nuevas tendencias recreativas. Con estas acciones se propone incentivar el aprovechamiento del tiempo libre, el ocio y la sana convivencia. A través de esta iniciativa la ciudad reconoce las distintas expresiones que no atiende la práctica deportiva tradicional.

Responsable: INDER

Indicador de producto:

\begin{tabular}{|l|l|}
\hline \multicolumn{1}{|c|}{ Nombre } & \multicolumn{1}{c|}{ Unidad } \\
\hline Eventos de Adrenalina realizados & Número \\
\hline Grupos de Escuelas de Adrenalina funcionando & Número \\
\hline
\end{tabular}

2.2.2.4 Proyecto: Acompañamiento social en la conformación de propiedad horizontal

Busca la sostenibilidad de los proyectos de vivienda nueva a través de la conformación y consolidación de las copropiedades y la cualificación de los órganos de administración y dirección. Se pretende ampliar el programa hacia viviendas que han sido objeto de procesos de reconocimiento de construcciones.

Indicador de producto

Responsable: ISVIMED

\begin{tabular}{|l|l|}
\hline \multicolumn{1}{|c|}{ Nombre } & \multicolumn{1}{c|}{ Unidad } \\
\hline Conformación de copropiedades & Porcentaje \\
\hline Acompañamiento a las copropiedades conformadas & Porcentaje \\
\hline
\end{tabular}

\subsubsection{PROGRAMA: TODOS CONVIVIMOS EN EL ESPACIO PÚBLICO}

El espacio público es el elemento principal del sistema estructurante territorial, está destinado al uso común dándole prelación en su gestión y administración al bienestar general sobre el particular, es decir a la satisfacción de necesidades urbanas colectivas que transcienden los límites de los intereses individuales de los habitantes. Es por esto que este programa contiene todas las acciones para procurar la convivencia en dichos espacios.

Indicador de resultado

\begin{tabular}{|c|l|c|c|c|}
\hline Nombre & \multicolumn{1}{|c|}{ Unidad } & $\begin{array}{c}\text { Línea de } \\
\text { Base }\end{array}$ & Meta 2019 & Responsable \\
\hline $\begin{array}{l}\text { Cuadras intervenidas para la } \\
\text { recuperación de espacio } \\
\text { publico }\end{array}$ & Numero & 70 & 90 & $\begin{array}{c}\text { Secretaría de } \\
\text { Gobierno }\end{array}$ \\
\hline
\end{tabular}

\subsubsection{Proyecto: Regulación, control y recuperación del espacio público}


Es deber de administración municipal velar porque se dé un uso y aprovechamiento adecuado del espacio público, que posibilite la movilización de los ciudadanos y el encuentro e integración de la ciudadanía a través de estrategias de vigilancia, control y regulación en torno a su ocupación, así como estrategias de protección, recuperación y accesibilidad para todas las poblaciones.

Responsable: Secretaría de Seguridad y Convivencia

Indicador de producto:

\begin{tabular}{|c|c|}
\hline Nombre & Unidad \\
\hline Regulación, control y recuperación del espacio público & Número \\
\hline
\end{tabular}

\subsubsection{Proyecto: Espacio público para la ciudadanía}

Más allá de su naturaleza física y de su papel como estructurante fundamental del ordenamiento del territorio de las ciudades, el espacio público es por excelencia el escenario principal de las relaciones sociales, donde se ponen en juego los valores democráticos de una ciudad, la inclusión e integración de los ciudadanos en una cultura determinada. Entendido desde esta dimensión el espacio público, aparece como la expresión espacial de los intereses colectivos que el mismo Estado protege gracias a la democracia participativa. La Administración Municipal deberá garantizar la implementación de acciones y estrategias enfocadas a fortalecer la apropiación, disfrute y goce de los espacios públicos por parte de los ciudadanos, en un marco de solidaridad, respeto, inclusión, participación y cultura ciudadana.

Responsable: Secretaría de Seguridad y Convivencia

Indicador de producto

\begin{tabular}{|l|l|}
\hline \multicolumn{1}{|c|}{ Nombre } & Unidad \\
\hline $\begin{array}{l}\text { Comerciantes informales con acompañamiento pedagógico para la regulación del } \\
\text { espacio público }\end{array}$ & Número \\
\hline
\end{tabular}

\subsubsection{PROGRAMA: PREVENCIÓN DE LAS VIOLENCIAS}

La violencia es un mal que todos los ciudadanos de Medellín, Antioquia y Colombia han soportado por más de 60 años de guerra y por una historia de violencias que han atravesado la ciudadanía en su parte más profunda, por lo que fortalecer los entornos protectores y promover la prevención para menores mujeres y las poblaciones más vulnerables es de vitak importancia para el estado y para los ciudadanos en general.

Indicador de resultado

\begin{tabular}{|l|l|c|c|c|}
\hline \multicolumn{1}{|c|}{ Nombre } & Unidad & $\begin{array}{c}\text { Línea de } \\
\text { Base }\end{array}$ & Meta 2019 & Responsable \\
\hline $\begin{array}{l}\text { Tasa de niños, niñas y } \\
\text { adolescentes infractores }\end{array}$ & Tasa & PD & PD & $\begin{array}{c}\text { Secretaría de } \\
\text { Gobierno }\end{array}$ \\
\hline
\end{tabular}


2.2.4.1 Proyecto: Fortalecimiento de entornos protectores para niños, niñas, adolescentes y jóvenes

Consagrado desde la Constitución política de Colombia, la protección especial a algunos grupos poblacionales tales como niños, niñas, adolescentes y jóvenes, debe ser prioridad en la acción de cualquier Gobierno. Por ello, se busca a través de la acción interinstitucional, generar unos entornos protectores para ésta población.

Ello pasa por brindar y posibilitar el acceso a educación, salud, (2.2. recreación, deporte etc., sino por el diseño de estrategias que fomenten habilidades para vivir y convivir con el otro; de manera que, se generen entornos que previenen la manifestación de violencias y se tornan seguros para el desarrollo de niños, niñas, adolescentes y jóvenes.

Responsable: Secretaría de Seguridad y Convivencia

Indicador de producto:

\begin{tabular}{|c|c|}
\hline Nombre & Unidad \\
\hline Instituciones certificadas como entornos protectores & Número \\
\hline
\end{tabular}

2.2.4.2 Proyecto: Implementación y promoción de acciones institucionales para la prevención social del delito

19. Promover y fortalecer las habilidades para la vida que disminuyan I. los factores de riesgo que inciden en la vinculación de jóvenes en prácticas violentas y delictuales.

Responsable: Secretaría de Inclusión Social, Familia y Derechos Humanos. Indicador de producto

\begin{tabular}{|l|c|}
\hline \multicolumn{1}{|c|}{ Nombre } & Unidad \\
\hline Niños, niñas, adolescentes beneficiaros del programa & Número \\
\hline Gestores de Convivencia y prevención del delito certificados & Número \\
\hline
\end{tabular}

2.2.4.3. Proyecto: Prevención y atención de violencias sexuales (Explotación sexual y trata de personas)

Atenderá población exclusivamente en riesgo de prostitución y trata

$-6$ de personas, con el propósito de ofrecer información, formación y vinculación a la respuesta institucional.

Este proyecto se encargará de hacer identificación de la población en riesgo, acercamiento, procesos de sensibilización, y de formación con

82 estrategias pedagógicas sobre autocuidado, proyecto de vida, derechos sexuales (y reproductivos), además permitirá brindar información para la transformación de imaginarios y cambios de esteriotipos con relación a las violencias sexuales y la trata de personas en todas sus modalidades. 
Responsable: Secretaría de Inclusión Social, Familia y Derechos Humanos. Indicador de producto

\begin{tabular}{|l|c|}
\hline \multicolumn{1}{|c|}{ Nombre } & Unidad \\
\hline $\begin{array}{l}\text { Campañas de prevención a la trata y a la explotación sexual de niños, niña y } \\
\text { adolescentes realizadas }\end{array}$ & Número \\
\hline Personas sensibilizadas en trata de personas y ESCNNA & Número \\
\hline Victimas de trata de personas atendidas & Porcentaje \\
\hline
\end{tabular}




\subsection{RETO}

\section{MEDELLÍN CUENTA CON VOS PARA CONSTRUIR LA PAZ EN EL TERRITORIO}

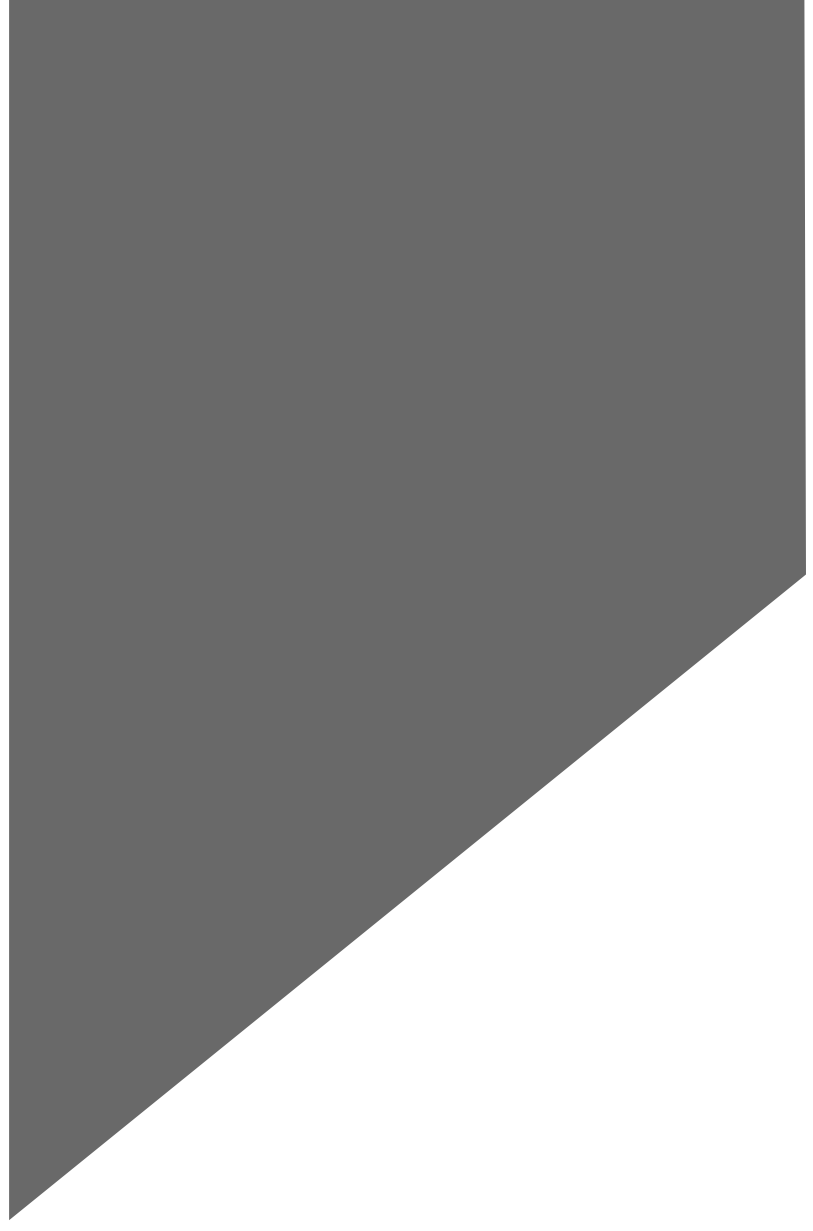

OBJETIVO

Fortalecer desarrollando acciones eficaces, responsables y transparentes en todos los niveles, garantizando la prestación de los servicios a la ciudadanía.

\section{PROGRAMAS}

4 2.3.1 Promoción de los derechos humanos

4 2.3.2 Postacuerdo y garantías de no repetición

4 2.3.3 Memoria y participación para la construcción de paz

4 2.3.4 Atención a víctimas del conflicto armado 
Recuperando la seguridad y la convivencia ciudadana

\subsection{Medellín cuenta con vos para construir la paz en el territorio}

Medellín es la segunda ciudad del país y la primera en Antioquia con el mayor número de víctimas del conflicto armado (La primera es Bogotá con 634.000 víctimas4); no obstante si la cantidad de víctimas se analiza con relación al total de habitantes que hay en la ciudad, Medellín es la primera a nivel nacional, pues el $23,0 \%$ de su población es víctima del conflicto armado, mientras que para Bogotá es el 9,0\%.

De acuerdo con el Registro Único de Víctimas (RUV), de la Unidad Nacional para la Atención y Reparación Integral a las Víctimas del Conflicto Armado (UARIV), se han registrado en la ciudad alrededor de 575.000 víctimas del conflicto armado5.

Las víctimas del conflicto armado que existen en la ciudad, gozan de algunos derechos fundamentales como son la identificación, subsistencia mínima, salud y educación. El Balance 2014 de la Política Pública Local de Atención y Reparación a Víctimas realizado por la Alcaldía de Medellín6, evidencia que en la atención de subsistencia mínima la cobertura es del $100 \%$ y en salud del $98,0 \%$, sobrepasando la media nacional. Los datos de atención en identificación y educación se toman de la medición nacional la que es homologable para Medellín, correspondientes a un 83,0\% y un 88,0\% respectivamente7.

No obstante el restablecimiento de derechos en temas como la seguridad alimentaria, la generación de ingresos y la vivienda presentan dificultades, repercutiendo en el cumplimiento de los objetivos de la política pública de garantía de derechos en las víctimas del conflicto armado. Siendo estas las dimensiones más relevantes para lograr el restablecimiento de sus derechos, y por lo tanto el cierre de proceso.

4 Ibíd.

5 Unidad Nacional para la Atención y Reparación Integral a las Víctimas del Conflicto Armado (UARIV) - Registro Único de Víctimas (RUV).

6 Unidad Municipal de Atención y Reparación a Víctimas.

7 Tercera medición para todo el país de los Indicadores GED ajustados por orden de la Corte Constitucional, que es la última medición realizada, y por lo tanto la más actualizada. Esta medición fue realizada por el Departamento Administrativo Nacional de Estadística -DANE- y la Unidad Administrativa para la Reparación Integral a las Víctimas, son promedios usados no solo para análisis a nivel país sino también para análisis a nivel territorial, se hace de esta forma pues Medellín no posee datos de medición de todos los derechos. 
Gráfico 12. Goce de derechos en las víctimas del conflicto armado en Colombia, homologable para la lectura de derechos en Medellín

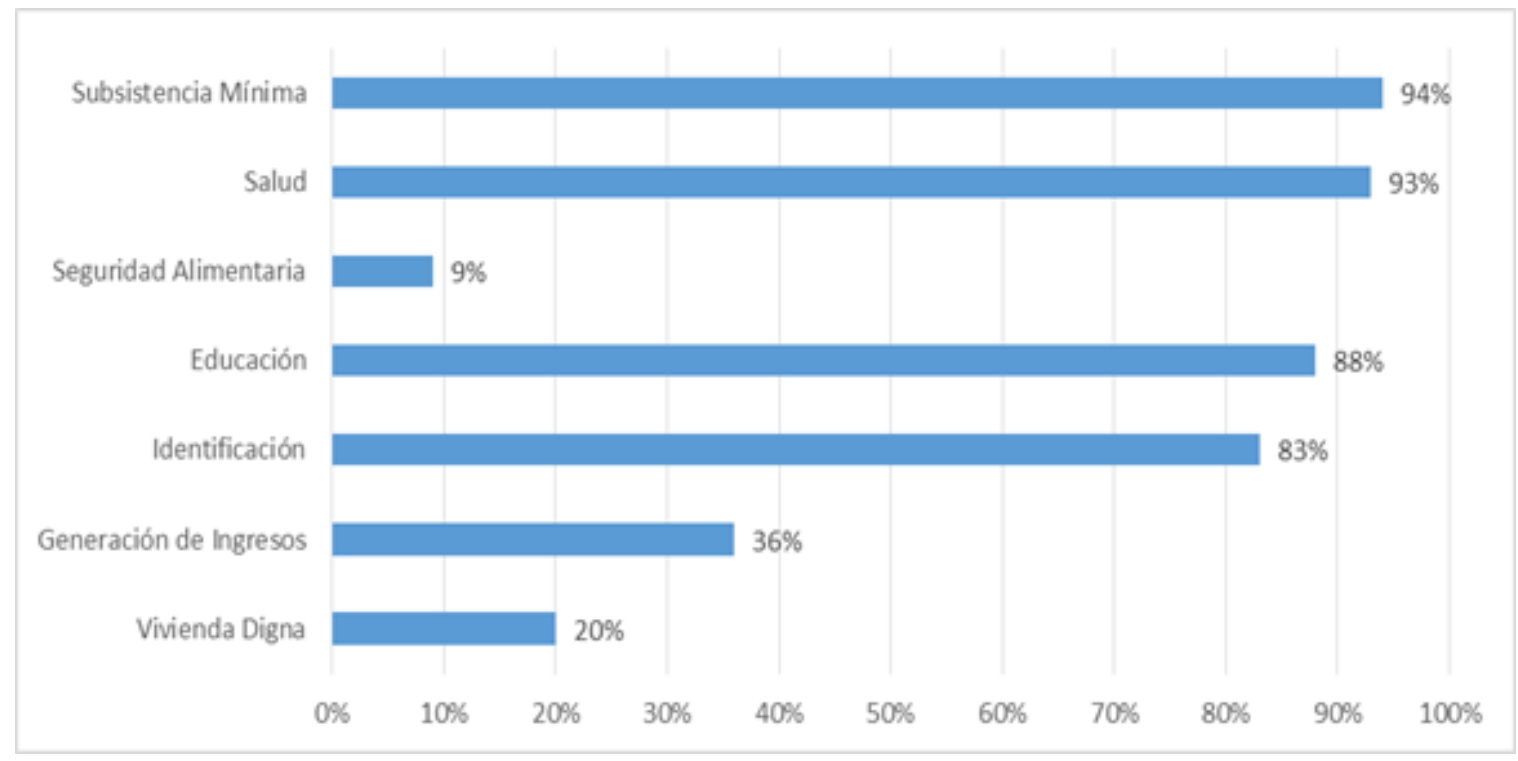

Fuente: DNP y otros. Indicadores de la Política Pública de Atención a Víctimas del Conflicto Armado. 2014.

A continuación se describe el indicador de resultado que se evaluará en este reto:

\begin{tabular}{|l|c|c|c|c|}
\hline Nombre & Unidad & $\begin{array}{c}\text { Línea de } \\
\text { Base }\end{array}$ & Meta 2019 & Responsable \\
\hline $\begin{array}{l}\text { Índice de condiciones para } \\
\text { la reconciliación nacional }\end{array}$ & Porcentaje & $56 \%$ & $60 \%$ & $\begin{array}{c}\text { Secretaría de } \\
\text { Gobierno y } \\
\text { gestión del } \\
\text { gabinete }\end{array}$ \\
\hline
\end{tabular}

\subsubsection{PROGRAMA: PROMOCIÓN DE LOS DERECHOS HUMANOS}

Vigilar y controlar que en todo su territorio, se cree una cultura ciudadana basada en el respeto por el otro que asegure una adecuada convivencia, monitoreando la armonía en sus comunas y territorios. Es por esto que el estado debe tener un sistema municipal de derechos humanos que agrupe los elementos necesarios para que la administración pública pueda cumplir con las tareas asignadas para crear esa cultura de respeto por el otro de manera integral. Y es así como con este programa se construirá Estado en el territorio para garantizarle a la ciudadanía sus derechos legales. 
Indicador de resultado

\begin{tabular}{|c|c|c|c|c|}
\hline Nombre & Unidad & $\begin{array}{c}\text { Línea de } \\
\text { Base }\end{array}$ & Meta 2019 & Responsable \\
\hline $\begin{array}{c}\text { Casos de vulneración de } \\
\text { DDHH con atención } \\
\text { institucional. }\end{array}$ & Porcentaje & Nuevo & $100 \%$ & $\begin{array}{c}\text { Secretaría de } \\
\text { Gobierno y } \\
\text { gestión del } \\
\text { gabinete }\end{array}$ \\
\hline
\end{tabular}

2.3.1.1. Proyecto: Gestión del Sistema Municipal de Derechos Humanos y Derecho Internacional Humanitario

El Sistema Municipal en Derechos Humanos y Derecho Internacional Humanitario (SMDH-DIH), a nivel territorial será la ruta pionera de articulación con la instancia nacional, que permita la protección, promoción y garantía de los Derechos Humanos y el Derecho Internacional Humanitario, promoviendo el goce efectivo de derechos y la respuesta oportuna por parte del Estado para la protección a los mismos. Teniendo como parámetros de interlocución los avances que hasta el momento ha tenido la instancia nacional en esta temática; en especial los objetivos8, los subsistemas y los avances en la creación de la política pública de Derechos Humanos y DIH, y que se enmarcan bajo los siguientes ejes: Ciudadanía, cultura y educación en DDHH y DIH, Derechos civiles y políticos, DIH y Conflicto Armado, Derechos Económicos, Sociales, Culturales y Ambientales - DESCA, Justicia, Igualdad, No Discriminación y Respeto por las Identidades, Agenda de Transición y Construcción de Paz y Gestión Pública Transparente y la Lucha contra la Corrupción.

Responsable: Secretaría de Inclusión Social, familia y derechos humanos Indicador de producto

\begin{tabular}{|c|c|}
\hline \multicolumn{1}{|c|}{ Nombre } & Unidad \\
\hline $\begin{array}{l}\text { Medidas para la promoción-prevención-protección de los DDHH que son definidas } \\
\text { por el Sistema Municipal de DDHH con oportunidad }\end{array}$ & Porcentaje \\
\hline
\end{tabular}

\subsubsection{Proyecto: Pedagogía para la cultura de los DDHH}

La construcción de una pedagogía en derechos humanos es un tema que trasciende en el orden comunitario y territorial, pero a la vez, las instituciones públicas deben propender por la obligatoriedad y la transversalización de los DDHH como un componente inherente a su labor misional. Los diálogos urbanos de paz y convivencia se destacan como una estrategia importante en este proyecto, tiene como fin la construcción de procedimientos, protocolos y rutas claras para atender a las personas que estén al margen de la ley y quieran apostarle a la paz en el territorio.

Responsable: Secretaría de Inclusión Social, familia y derechos humanos 
Indicador de producto:

\begin{tabular}{|l|c|}
\hline \multicolumn{1}{|c|}{ Nombre } & Unidad \\
\hline $\begin{array}{l}\text { Personas beneficiadas con acciones pedagógicas para la construcción de una } \\
\text { cultura de los DDHH. }\end{array}$ & Número \\
\hline
\end{tabular}

2.3.1.3. Proyecto: Prevención de violaciones a los derechos a la vida, integridad y libertad

Con este proyecto se buscar identificar y tramitar situaciones (M. 1 de riesgo de violación de derechos humanos en el marco de la violencia organizada y/o conflicto armado (desplazamiento forzado, reclutamiento y utilización de niños, niña y adolescente, desaparición forzada y despojo.

Responsable: Secretaría de Inclusión Social, familia y derechos humanos Indicador de producto

\begin{tabular}{|l|l|}
\hline \multicolumn{1}{|c|}{ Nombre } & Unidad \\
\hline $\begin{array}{l}\text { Escenarios y/o situaciones de riesgo de violación derechos humanos identificados } \\
\text { por las entidades competentes, que son atendidos con oportunidad y efectividad. }\end{array}$ & Porcentaje \\
\hline
\end{tabular}

2.3.1.4. Proyecto: Gestión territorial y fortalecimiento de los actores sociales para el ejercicio de los DDHH

La comunidad agrupada en Mesas DDHH y organizaciones de defensa de DDHH son espacios abiertos, plurales, democráticos, participativos, comunitarios e incluyentes, cuyo objetivo central es promover la sana convivencia, defender y difundir los derechos humanos fundamentales en la ciudad de Medellín.

Las mesas dignifican al ser humano sus deberes y derechos, con el objetivo de realzar los postulados éticos y humanitarios inherentes a las personas humanas. Son grupos independiente, cuyo origen se ubica en los procesos sociales y comunitarios de la ciudad de Medellín. Esta actividad social y comunitaria interactúa con organizaciones, movimientos y funcionarios de la administración municipal. Art. 38 y art 44 CP, complementado art 20 C.I.D.H, Acuerdo 028 de 2014 art. 34,55, 56. Política Pública sobre organizaciones sociales, Ley 23 de 1982 art 41.

Responsable: Secretaría de Inclusión Social, familia y Derechos Humanos Indicador de producto

\begin{tabular}{|c|c|}
\hline \multicolumn{1}{|c|}{ Nombre } & Unidad \\
\hline Mesas de DDHH y acompañados y fortalecidos para el ejercicio de los DDHH & Número \\
\hline
\end{tabular}

2.3.1.5. Proyecto: Reconocimiento y dignificación humana en el Cementerio Universal

En el cementerio se encuentran $3.000 \mathrm{NN}$ y se busca en el cuatreño hacer las exhumaciones, se tiene como meta realizar las identificaciones para dignificar las víctimas. También se busca recuperar la memoria histórica. 
Responsable: Secretaría de Inclusión Social, familia y Derechos Humanos Indicador de producto

\begin{tabular}{|c|c|}
\hline Nombre & Unidad \\
\hline Cuerpos humanos que están en el Jardín Cementerio Universal, dignificados & Número \\
\hline
\end{tabular}

2.3.1.6. Proyecto: Atención integral a víctimas y/o testigos de delitos de alto impacto social

Consiste en la atención, asesoría y representación penal a víctimas de alto impacto social de las 16 comunas y 6 corregimientos, se asiste la víctima en todas las etapas procesales y culmina con el incidente de reparación integral.

Responsable: Secretaría de Inclusión Social, familia y Derechos Humanos Indicador de producto

\begin{tabular}{|c|c|} 
Nombre & Unidad \\
\hline Víctimas y/o testigos de delitos de alto impacto social, con atención integral. & Porcentaje \\
\hline
\end{tabular}

2.3.1.7. Proyecto: Orientación y desarrollo de capacidades para personas en ejercicio y condición de riesgo de prostitución

Orientado a brindar herramientas en los ámbitos emocional, laboral y educativo que permitan identificar y potenciar las habilidades, conocimientos y destrezas que poseen las personas en ejercicio y riesgo de prostitución, buscando su inserción laboral y social.

Responsable: Secretaría de Inclusión Social, familia y Derechos Humanos Indicador de producto

\begin{tabular}{|c|c|}
\hline Nombre & Unidad \\
\hline Personas atendidas & Número \\
\hline
\end{tabular}

\subsubsection{PROGRAMA: POSTACUERDO Y GARANTÍAS DE NO REPETICIÓN}

Este programa está orientado al desarrollo y fortalecimiento de estrategias para la implementación de las garantías de no repetición tanto en su dimensión reparadora como preventiva. Esta doble perspectiva contribuye a reducir efectos negativos generados por el conflicto armado en la sociedad, así como al fomento de las condiciones necesarias para que dichas afectaciones no se vuelvan a repetir.

Indicador de resultado

\begin{tabular}{|c|c|c|c|c|}
\hline Nombre & Unidad & $\begin{array}{c}\text { Línea de } \\
\text { Base }\end{array}$ & Meta 2019 & Responsable \\
\hline $\begin{array}{c}\text { Intervenciones realizadas con } \\
\text { medidas en garantías de no } \\
\text { repetición }\end{array}$ & Porcentaje & Nuevo & $100 \%$ & $\begin{array}{c}\text { Secretaría de } \\
\text { Gobierno }\end{array}$ \\
\hline
\end{tabular}


2.3.2.1. Proyecto: Gestión de la estrategia de garantías de no repetición y cultura de paz

Las garantías de no repetición (GNR) son uno de los cuatro pilares de la justicia transicional junto con la verdad, la justicia y la reparación. El instrumento legal que ordena su aplicación en Colombia es la Ley 1448 de 2011, conocida como la Ley de Víctimas y Restitución de Tierras. Las GNR se construyen como medidas dirigidas a la sociedad enfocadas a trasformar la realidad o a trasformar las causas que en un principio posibilitaron la violación de derechos en el marco del conflicto armado y/o la violencia organizada, para prevenir que vuelvan a suceder. Además, éstas medidas buscan la reparación de los daños colectivos infligidos a una población determinada. Este proyecto busca, por un lado, fortalecer al Municipio de Medellín a través del desarrollo de capacidades institucionales en materia de GNR, y por otro, gestionar la implementación de la Estrategia de GNR que ya formulada, mediante un ejercicio de coordinación interinstitucional cuyo objetivo principal es la construcción de una cultura de paz sostenible en Medellín en el marco del proceso de paz y del posacuerdo ajustada al contexto histórico, social, político y cultural de la ciudad.

Responsable: Secretaría de Inclusión Social, familia y Derechos Humanos

Indicador de producto

\begin{tabular}{|l|c|}
\hline \multicolumn{1}{|c|}{ Nombre } & Unidad \\
\hline $\begin{array}{l}\text { Medidas que fomentan la cultura de paz, la transformación sociocultural y los } \\
\text { Derechos Humanos desde las GNR. }\end{array}$ & Porcentaje \\
\hline
\end{tabular}

2.3.2.2. Proyecto: Reintegración sostenible para un territorio en paz

La culminación responsable es el proceso por el cual una persona en Proceso de Reintegración (PPR) finaliza su ruta, con el objetivo de que ejerza su plena ciudadanía de manera responsable dentro de los límites de la legalidad, luego de haber trabajado y cumplido con unos objetivos en 8 dimensiones (personal, familiar, seguridad, salud, productividad, habitabilidad, ciudadanía y educativa). La mayor parte de nuestra población está en vía de culminar su proceso de reintegración, ya que son desmovilizados de las AUC (los ex - grupos de autodefensa); y la culminación responsable es un hecho relevante ya que refleja el compromiso de las personas con la legalidad y este redunda en una efectiva inclusión dentro de la sociedad que finalmente les permite superar sus vulnerabilidades. Esta experiencia contribuye a que se promueva el ejercicio de una ciudadanía responsable, además de continuar fortaleciéndose como un aprendizaje fundamental con miras al proceso de reintegración de los miembros de las FARC, en una eventual firma del acuerdo de Paz en la Habana. Por último, esto redunda en beneficios de seguridad para la ciudad, toda vez que esta población es proclive a repetir ciclos de violencia si no se ofrece un adecuado proceso de reintegración. 
Responsable: Secretaría de Inclusión Social, familia y Derechos Humanos Indicador de producto

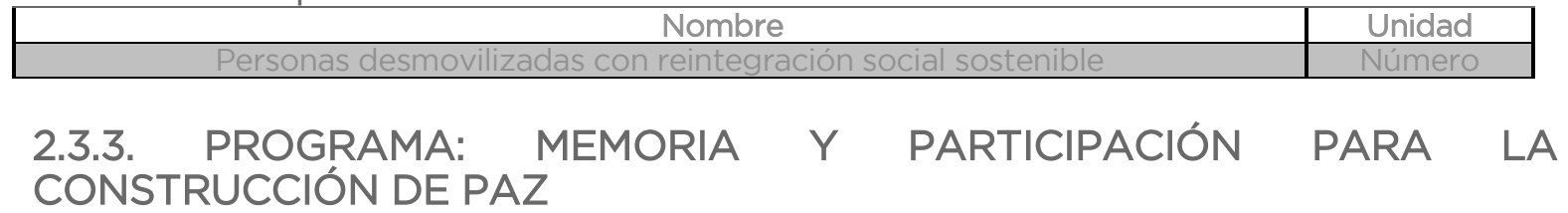

La experiencia de paz y reconciliación en los procesos de intervención social y comunitaria ha dejado aprendizajes de gran valía para la construcción de confianza, paz y reconciliación en la ciudad. Uno de los más importantes es la necesidad de llevar a cabo un eficaz análisis e interpretación del contexto, a través del cual es posible facilitar los acercamientos entre la institucionalidad y la comunidad y dar lugar a la generación de una convivencia pacífica en los territorios.

La realidad sigue mostrando que en Medellín, en cada una de sus comunas, persisten dinámicas del conflicto particulares que deben ser abordadas teniendo en cuenta las perspectivas de las comunidades que habitan dichos territorios; por lo tanto es fundamental establecer diálogos directos con ellos y con los actores que se encuentren en conflicto en los mismos, cumpliendo un rol mediador y facilitador para que se fortalezcan escenarios de paz y se avance en la verdadera reconciliación de la sociedad.

La memoria es un eje transversal de los procesos de construcción de paz, ya que esto coadyuva a minimizar la repetición de ciclos violentos que se han generado en nuestra ciudad por el olvido que se suscita en este tipo de fenómenos.

En este sentido, es relevante incluir las voces de todos los actores del conflicto, tales como las víctimas, los agentes del Estado y las personas en proceso de reintegración, quienes vivieron el conflicto desde lugares diferentes y en los que -en muchos de ellos- se confunde la condición de víctima y victimario. Por lo anterior, es importante que se tengan en cuenta estas posturas para que de manera conjunta se afronten los retos que implica reconstruir memoria.

De esta manera se aporta significativamente a las acciones de reparación simbólica. Es importante además hacer hincapié en el hecho de que las mujeres y los hombres resignifican sus experiencias de manera diferente, por esta razón, es relevante darle una mirada desde el enfoque de género que permita no solo diferenciar estas memorias sino también sus resignificaciones y que puedan aportar en la garantías de no repetición. 
Indicador de resultado

\begin{tabular}{|l|l|c|c|c|}
\hline Nombre & Unidad & $\begin{array}{c}\text { Línea de } \\
\text { Base }\end{array}$ & Meta 2019 & Responsable \\
\hline $\begin{array}{l}\text { Percepción positiva del Museo } \\
\text { Casa de la memoria como } \\
\text { facilitador de procesos de } \\
\text { construcción de paz en el } \\
\text { territorio }\end{array}$ & Porcentaje & $\begin{array}{c}\text { No } \\
\text { disponible }\end{array}$ & 70 & $\begin{array}{c}\text { Museo casa de la } \\
\text { memoria }\end{array}$ \\
\hline
\end{tabular}

2.3.3.1. Proyecto: Construcción participativa de memorias territoriales

- Un paso necesario para avanzar en el camino de la construcción de * paz es el reconocimiento de la importancia de conocer lo que pasó en nuestra historia. Por tanto, este proyecto busca la construcción de $\rightarrow$ la memoria colectiva desde los territorios, sobre las causas, actores y efectos del conflicto sobre la sociedad en general (no sólo negativos, sino también acciones y respuestas destacables frente al contexto de violencia

Indicador de producto

Responsable: Museo Casa de la Memoria

\begin{tabular}{|l|c|}
\hline \multicolumn{1}{|c|}{ Nombre } & Unidad \\
\hline Memorias participativas construidas & Número \\
\hline
\end{tabular}

2.3.3.2. Proyecto: Pedagogía de las memorias para la construcción paz

Con este proyecto se busca construir al fortalecimiento de una cultura de paz y convivencia pacífica a través de estrategias pedagógicas y de sensibilización con públicos diversos a través de transferencia de conocimiento, implementación de la cátedra de paz, diseño e implementación de herramientas pedagógicas, procesos expositivos y pedagogía sobre los acuerdos de paz, entre otros.

Indicador de producto

Responsable: Museo Casa de la Memoria

\begin{tabular}{|c|c|}
\hline Nombre & Unidad \\
\hline Personas que interactúan con los contenidos del Museo Casa de la Memoria & Número \\
\hline
\end{tabular}

2.3.3.3. Proyecto: Ciudadanía activa para el postconflicto

Este proyecto busca llevar a la ciudadanía a reflexionar sobre la responsabilidad que tenemos como sociedad y los retos para lograr

- una construcción de paz desde los territorios, para ello se pretende generar escenarios de diálogo, ejercicios de reparación simbólica para las víctimas e implementar estrategias de no repetición en articulación con diferentes instancias públicas y privadas.

Indicador de producto

Responsable: Museo Casa de la Memoria

\begin{tabular}{|c|c|}
\hline Nombre & Unidad \\
\hline Actores públicos y privados vinculados en procesos de construcción de paz & Número \\
\hline
\end{tabular}


2.3.3.4. Proyecto: Fortalecimiento institucional del Museo Casa de la Memoria

El fortalecimiento institucional del Museo Casa de la Memoria busca mejorar integralmente los recursos físicos, humanos y organizacionales de la entidad con el fin de favorecer y potenciar las condiciones para el desarrollo de los procesos internos y para la prestación del servicio, con miras a garantizar el cumplimiento de nuestros objetivos institucionales de construcción participativa de cultura de paz.

Responsable: Museo Casa de la Memoria

Indicador de producto

\begin{tabular}{|c|c|}
\hline Nombre & Unidad \\
\hline Plan de fortalecimiento formulado e implementado & Porcentaje \\
\hline
\end{tabular}

2.3.3.5. Proyecto: Mujeres constructoras de paz

En Medellín se propician espacios y escenarios para la construcción

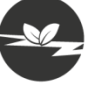
de una cultura de paz con enfoque de género, que cuenta con la incidencia de las mujeres como actoras y promotoras de estrategias para la reconciliación, la inclusión y el tejido de nuevas maneras de relacionamiento.

La voz de las mujeres enriquece y transversaliza la implementación de los procesos, programas y proyectos en el marco del posconflicto, con acciones para la formación de una pedagogía para la paz. Medellín cuenta con las mujeres como potenciadoras de una pedagogía para la paz.

Responsable: Secretaría de las Mujeres

\begin{tabular}{|c|c|}
\hline Nombre & Unidad \\
\hline Mujeres con incidencia en escenarios de participación social y política en el marco & Número \\
\hline
\end{tabular}

2.3.3.6. Proyecto: Apertura democrática para construir la paz

El proyecto busca promover en la ciudadanía la conversación, la discusión, la propuesta de agendas y la movilización social alrededor de temas referidos a la paz, como acto y condición previa para superar gradualmente la tensión y el conflicto. Honrar el valor de la palabra, practicar el ejercicio democrático de la concertación y el disenso, reconocer la memoria colectiva como una oportunidad, alimentar la cultura de la legalidad, el civismo y la convivencia, procurar la reintegración comunitaria, la construcción de confianza social e institucional, la reconstrucción del tejido social y resignificar la práctica de la democracia, se traducen en los hilos conductores del proyecto.

Responsable: Secretaria de Participación Ciudadana 
Indicador de producto:

\begin{tabular}{|c|c|}
\hline \multicolumn{1}{|c|}{ Nombre } & Unidad \\
\hline Espacios para la ampliación de la democracia y el pluralismos promovidos & Número \\
\hline
\end{tabular}

2.3.3.7. Proyecto: La educación en Medellín le apuesta a la paz y la convivencia

Potenciar las capacidades y las habilidades humanas para el - desarrollo y el progreso ciudadano, es un propósito de ciudad que requiere encaminar todos los esfuerzos hacia la calidad educativa desde la primera infancia hasta la educación para siempre. Pero las competencias cognitivas y los talentos humanos requieren de una apuesta por la calidad integral de la educación en la que no solamente se avance en estrategias para el fortalecimiento de los contenidos académicos y los resultados en pruebas estandarizadas, sino también en la generación de una cultura de paz por medio de la convivencia escolar, la inteligencia emocional, la formación para la ciudadanía y el ejercicio de los derechos humanos, sexuales y reproductivos, que en su conjunto contribuyan a la consolidación de hombres y mujeres en capacidad de aportar constructivamente a los procesos de desarrollo social, económico, político y cultural de la ciudad y el país. Este tipo de educación concibe al estudiante desde su dimensión física, psicológica y cultural y se traza entre sus objetivos fundamentales la formación de mejores seres humanos y ciudadanos para la democracia.

Responsable: Secretaría de Educación

Indicador de producto

\begin{tabular}{|c|c|}
\hline Nombre & Unidad \\
\hline Instituciones educativas acompañadas en mediación escolar & Número \\
\hline
\end{tabular}

2.3.3.8. Proyecto: Jóvenes que ayudan a reconstruir un territorio de paz se promueve el desarrollo integral y las capacidades de los jóvenes que se encuentran en riesgo de vulneración de sus derechos a nivel individual, familiar, social o en escenarios de conflicto. Esto mediante la apropiación de ciudad, el fortalecimiento de capacidades, el trabajo intersectorial y la gestión social del conocimiento, de manera que contribuya al desarrollo positivo de los jóvenes, al fortalecimiento de la confianza, la convivencia y la paz, en el marco de una realidad nacional de un futuro posconflicto.

Responsable: Secretaría de Juventud

Indicador de producto

\begin{tabular}{c|c} 
Nombre & Unidad \\
\hline & Número
\end{tabular}




\subsubsection{PROGRAMA: ATENCIÓN A VÍCTIMAS DEL CONFLICTO ARMADO}

La reparación integral a las víctimas del conflicto armado implica la acción estatal en su conjunto; es decir, implica tanto al Gobierno Nacional con sus diferentes entidades competentes y su diversa oferta, como a las alcaldías también con sus dependencias y su oferta, pues los derechos vulnerados a esta población son el conjunto de los trazados en la Constitución Política: vida, integridad, libertad, seguridad, salud, educación, identificación, vivienda, generación de ingresos, etc. La reparación a víctimas es entonces un proceso multisectorial, interinstitucional y multinivel. El programa está dirigido entonces a implementar algunas de las medidas con las que se garantizan algunos derechos, tales como la orientación jurídica, la atención humanitaria inmediata, la atención psicosocial, la protección de bienes, el fortalecimiento a la participación, las medidas de satisfacción, el retorno y la reubicación, entre otras; peor en cuanto a las demás medidas que son de competencia de otras dependencias de la Alcaldía de Medellín y que están inscritas en otras Dimensiones de este Plan de Desarrollo, el programa trae unas acciones de fortalecimiento institucional y coordinación corresponsable interinstitucional, así mismo de análisis y evaluación de política pública, con el fin de lograr coordinaciones entre las diferentes entidades competentes en función de hacer que la población goce de sus derechos.

Indicador de resultado

\begin{tabular}{|l|l|c|c|c|}
\hline \multicolumn{1}{|c|}{ Nombre } & \multicolumn{1}{|c|}{ Unidad } & $\begin{array}{c}\text { Línea de } \\
\text { Base }\end{array}$ & Meta 2019 & Responsable \\
\hline $\begin{array}{l}\text { Familias víctimas del conflicto } \\
\text { armado con derechos } \\
\text { reestablecidos }\end{array}$ & numero & 4.205 & 5.250 & $\begin{array}{c}\text { Secretaria de } \\
\text { Gobierno }\end{array}$ \\
\hline
\end{tabular}

2.3.4.1. Proyecto: Restablecimiento y reparación a víctimas del conflicto armado

El sistema de atención integral a las víctimas, es un conjunto de medidas judiciales, administrativas, sociales y económicas,

(a) individuales y colectivas, en beneficio de las víctimas de las violaciones contempladas en el artículo 3으 de la presente ley, dentro de un marco de justicia transicional, que posibiliten hacer efectivo el

- goce de sus derechos a la verdad, la justicia y la reparación con garantía de no repetición, de modo que se reconozca su condición de víctimas y se dignifique a través de la materialización de sus derechos constitucionales.

Regula lo concerniente a ayuda humanitaria, atención, asistencia y reparación de las víctimas de que trata el artículo 3ำ de la presente ley, ofreciendo herramientas para que estas reivindiquen su dignidad y asuman su plena ciudadanía. 
Responsable: Secretaría de Inclusión Social, familia y Derechos Humanos Indicadores de producto:

\begin{tabular}{|l|c|}
\hline \multicolumn{1}{|c|}{ Nombre } & Unidad \\
\hline $\begin{array}{l}\text { Familias que declararon victimización que reciben protección del derecho a la } \\
\text { subsistencia mínima. }\end{array}$ & Porcentaje \\
\hline $\begin{array}{l}\text { Familias víctimas de desplazamiento forzado beneficiados con medidas de } \\
\text { generación de ingresos }\end{array}$ & Número \\
\hline $\begin{array}{l}\text { Personas víctimas del conflicto armado beneficiadas con medidas de rehabilitación } \\
\text { y/o satisfacción. }\end{array}$ & Número \\
\hline $\begin{array}{l}\text { Familias víctimas de desplazamiento forzado cobijadas con medidas de restitución } \\
\text { para Medellín que son acompañadas institucionalmente. }\end{array}$ & Porcentaje \\
\hline
\end{tabular}

2.3.4.2. Proyecto: Acompañamiento a retornos y reubicaciones de víctimas de desplazamiento forzado - Medellín le apuesta al retorno

Con este proyecto se busca generar un proceso de retornos y
reubicaciones completamente sostenibles; es decir, una de las
condiciones sine qua non para que una familia se retorne o se
reubique es que haya seguridad y con ello no halla riesgo de
minas antipersona. Ahora la acción de desminar solo aplica en
los casos de retorno que así se requieran, no todo proceso de
retorno o reubicación implica desminado humanitario.
Responsable: Secretaría de Inclusión Social, familia y Derechos Humanos
Indicadores de producto
$\begin{aligned} & \text { Aogares víctimas de desplazamiento forzado retornados o reubicados. } \\ & \text { Alcaldías fortalecidas en materia de gestión para la Atención a las víctimas } \\ & \text { etornadas o re-ubicadas. }\end{aligned}$

2.3.4.3. Proyecto: Mejoramiento de la infraestructura para la atención humanitaria a las víctimas

Este proyecto busca mejorar la infraestructura de los Centros de Atención a Víctimas del Conflicto Armado, que son 4 para la ciudad de Medellín. Estos Centros reciben diariamente unas 1.000 personas víctimas. Estas mejoras posibilitan dar una atención digna a esta población, pues en la actualidad las condiciones de atención son revictimizantes.

El gobierno visible es un apuesta para la legalidad y la transparencia como modelo de gestión, lo cual le permite al Municipio de Medellín la construcción de la confianza con la ciudadanía y el fortalecimiento de la institucionalidad como garante de derecho, a través de proyectos diseñados para que el ciudadano fortalezca las relaciones con la administración municipal y pueda intervenir activamente en las decisiones públicas. 
Responsable: Secretaría de Inclusión Social, familia y Derechos Humanos Indicador de producto

\begin{tabular}{|c|c|}
\hline \multicolumn{1}{|c|}{ Nombre } & Unidad \\
\hline Mejoramientos en la infraestructura para la atención humanitaria a las victimas. & Porcentaje \\
\hline
\end{tabular}




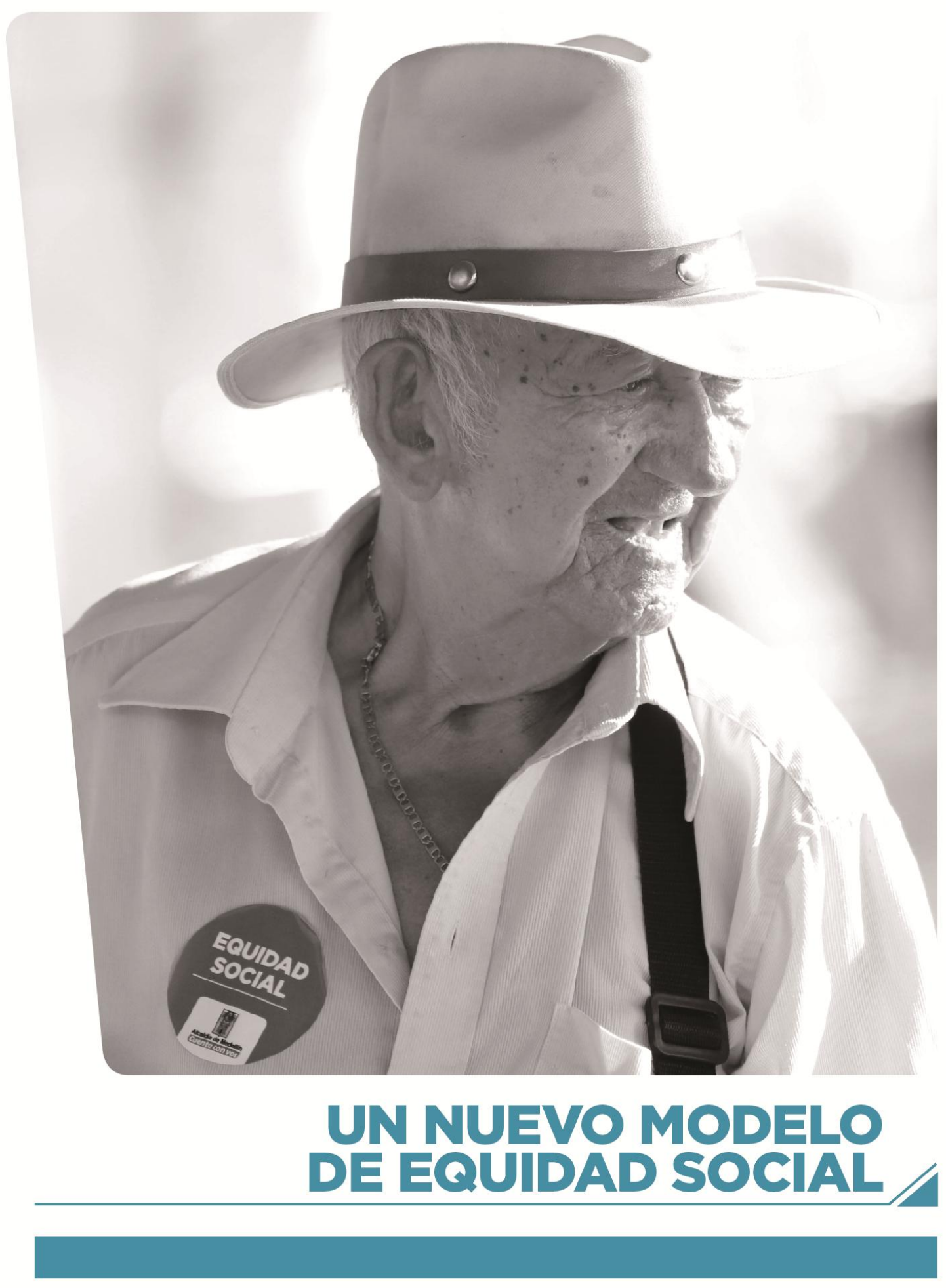




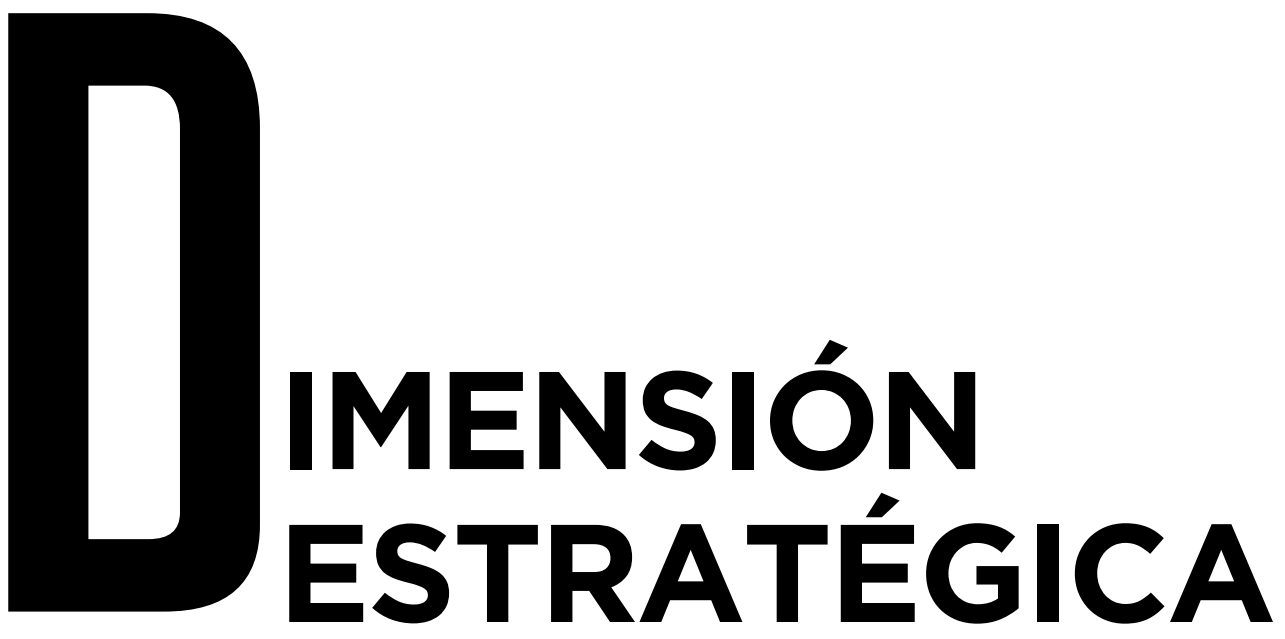

\section{Un nuevo modelo de equidad social}

Propiciar el disfrute de los ciudadanos de una vida digna y saludable, mejorando sus condiciones de vida y el respeto integral de su ser. 


\section{- DIAGNÓSTICO •}

El Plan de Desarrollo Medellín cuenta con vos 2016 -2019 incorpora la Equidad Social, entendida como elemento de cohesión que permite a los habitantes de la ciudad acceder durante el curso de vida a oportunidades que impactan a la sociedad y contribuye a disminuir las desventajas, la inequidad y la desigualdad.

Uno de los mayores retos que enfrenta la ciudad es disminuir las condiciones de desigualdad, situación que evidencia la última medición del Índice Multidimensional de Condiciones de Vida IMCV del año 2014, en la que algunas de comunas de la ciudad presentan un índice menor a 35 puntos de 100 posibles, (Popular, Santa Cruz y Palmitas) en contraste, otras comunas superan en más de 20 puntos la calificación de la ciudad $(48,1)$ entre las que se destaca El Poblado con una puntuación de 75,85 y Laureles Estadio con 70,1. Lo anterior, corrobora las brechas en el nivel de desarrollo y la calidad de vida de los habitantes de la ciudad.

Con relación a la percepción de la calidad de vida y de acuerdo con los datos reportados en la última encuesta en la ciudad para el año 2014, se encontró que el $75 \%$ de los jefes de hogar consideraron que la calidad de vida de los miembros del hogar es buena o muy buena $(62,9 \%$ y $12,1 \%$ respectivamente), el $22 \%$ consideró es aceptable y solo el $2,59 \%$ la calificaron como mala o muy mala. Esta percepción registró amplias variaciones por comuna, siendo las más bajas Popular y Santa Cruz (58\%) y las comuna de El Poblado, Laureles Estadio y la América las con mejor percepción (91,8\%, 91,3\% y 85,5\% respectivamente).

\section{- PRESENTACIÓN •}

La garantía de los derechos humanos, el respeto por la diversidad, la dignidad humana como principio y la inclusión de todos los integrantes de la sociedad en un contexto de Equidad Social, es una premisa para lograr mejores condiciones de vida para los habitantes. Por su parte el reconocimiento de la población que habita el municipio, para definir así las acciones a desarrollar y visibilizar las brechas existentes, es uno de los enfoques fundamentales: niñas, niños, adolescentes, jóvenes, mujeres, personas mayores, afrodescendientes, indígenas, rom y raizales, así como las distintas condiciones y situaciones: personas con discapacidad, personas víctimas, habitantes de calle, diversidad sexual y de género.

La Equidad Social parte también de comprender las diferencias que conforman la sociedad y las de cada ser humano que hace parte de ella. Desde esta mirada la participación en la vida social, política y comunitaria y en la conformación del territorio, como un escenario de 
construcción colectiva de comunidad y de redes requiere de derechos como la educación, trabajo decente, salud, seguridad alimentaria, vivienda digna, sano esparcimiento, seguridad, entre otros.

Es así que los diferentes enfoques con los cuales se aborda la Equidad Social son fundamentales: el enfoque de género facilita la superación de brechas al reconocer las diferencias entre los hombres y las mujeres; el enfoque del curso de vida, permite reconocer las etapas de la vida de los seres humanos y sus diferentes roles en ellas; el enfoque diferencial, reconoce y promueve la visibilización étnica, por sexo, según las etapas de la vida, para implementar los programas y proyectos que este reto establece.

La política social en Medellín, eje del desarrollo de las políticas públicas, y de la atención focalizada por parte del Estado en programas y proyectos, se espera pueda trascender a la transformación de una ciudadanía activa y participe de su desarrollo, que si bien para lograr la equidad requiere de acciones afirmativas para superar las diferencias sobrepasa las fronteras del asistencialismos cuando se vincula al ejercicio pleno de derechos y deberes y se responde en igual medida superando las condiciones de pobreza, inequidad y exclusión.

La Equidad Social propende por un desarrollo que centre a la ciudadana que participe y provoque cambios en la sociedad, en la familia y en sí mismo, para que más que un modelo, el desarrollo humano sea una esperanza para nuestra sociedad.

A continuación se describen los indicadores de impacto asociados a esta dimensión:

Indicadores de Impacto

\begin{tabular}{|l|c|c|c|c|}
\hline \multicolumn{1}{|c|}{ Nombre } & Unidad & Línea de Base & Meta 2019 & Responsable \\
\hline $\begin{array}{l}\text { Percepción de la calidad de vida } \\
\text { como buena y muy buena } \\
\text { según ECV }\end{array}$ & Porcentaje & $75 \%$ & $\begin{array}{l}\text { Mantener por } \\
\text { encima del 75\% }\end{array}$ & $\begin{array}{l}\text { Departamento } \\
\text { Administrativo } \\
\text { de Planeación }\end{array}$ \\
\hline $\begin{array}{l}\text { Comunas que mejoran el Índice } \\
\text { Multidimensional de } \\
\text { Condiciones de Vida IMCV }\end{array}$ & Porcentaje & ND & $\begin{array}{l}\text { Departamento } \\
\text { Administrativo } \\
\text { de Planeación }\end{array}$ \\
\hline $\begin{array}{l}\text { Índice de Desarrollo humano } \\
\text { IDH }\end{array}$ & Índice & 87,52 & $\begin{array}{l}\text { Mantener por } \\
\text { encima del 87 }\end{array}$ & $\begin{array}{l}\text { Departamento } \\
\text { Administrativo } \\
\text { de Planeación }\end{array}$ \\
\hline
\end{tabular}

En este sentido proponemos para Medellín bajo las condiciones generales garantía de derechos los siguientes retos: 


\subsection{RETO}

\section{MEDELLÍN PARA VIVIR} MÁS Y MEJOR

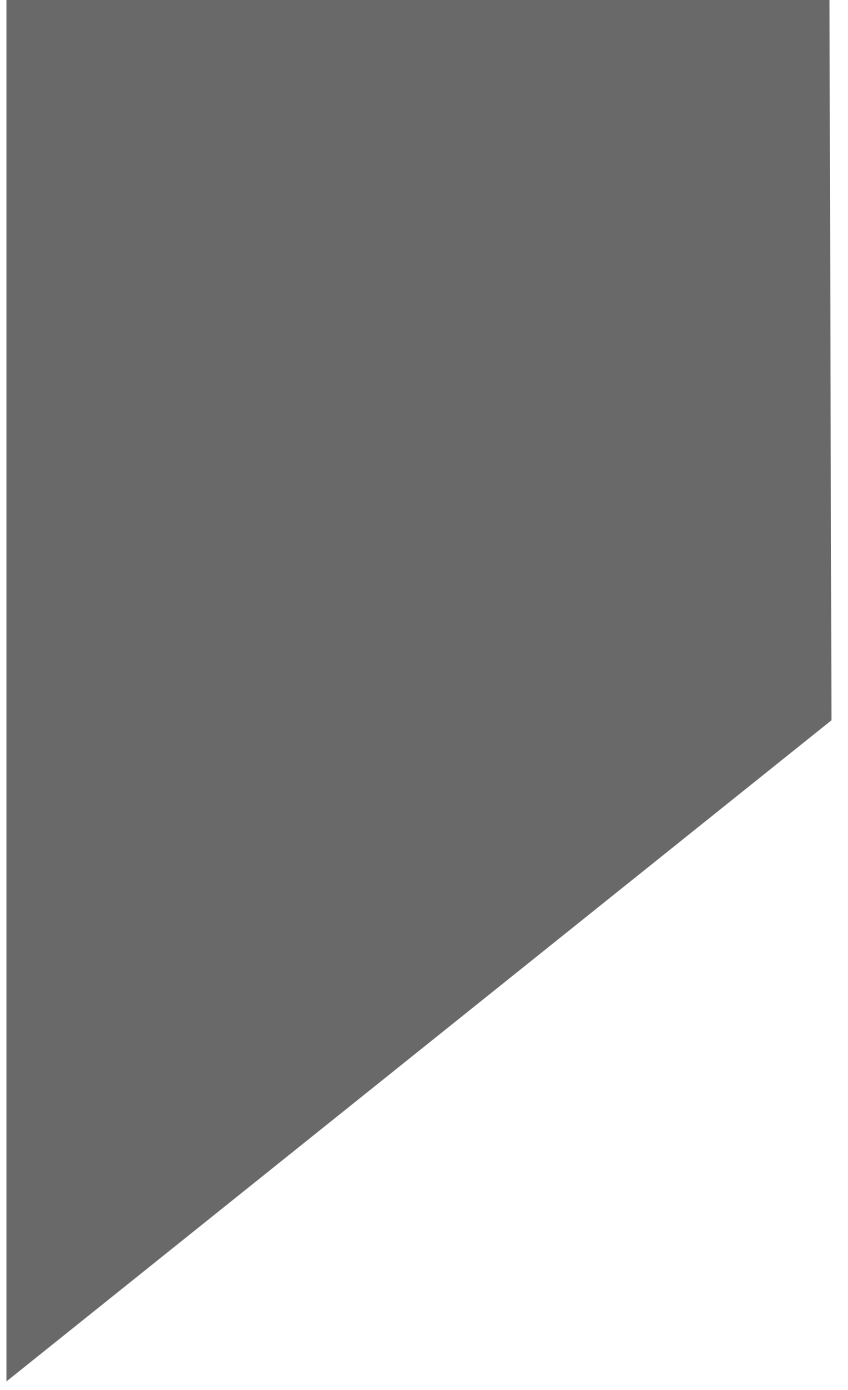

OBJETIVO

Promover el bienestar para todas las edades a través de la promoción de estilos de vidas saludables propiciando en la población el goce efectivo del derecho a la salud mediante acciones de atención integral.

\section{PROGRAMAS}

$\Delta$ 3.1.1. Fortalecimiento del acceso a los servicios de salud

$\Delta$ 3.1.2. Gestión de estrategias en salud

$\Delta$ 3.1.3. Articulación sistema de la salud

$\Delta$ 3.1.4. Vigilancia integral en salud 
Un nuevo modelo de equidad social

\subsection{Medellín garantiza la salud}

Uno de los indicadores que mejor refleja el estado de salud de una población, es la Esperanza de vida al nacer. En Medellín, este indicador ha presentado un incremento significativo, ganando casi 10 años, toda vez que paso de 68 años en 1995 a 77 en el 2015 (DANE), siendo superior la esperanza de vida en las mujeres que en los hombres (78 y 75 años respectivamente).

El incremento en la esperanza de vida está asociado al comportamiento de la carga de enfermedad, siendo los Años de Vida Potencialmente Perdidos (AVPP) indicador clave para evaluar esta condición; para el año 2014 los AVPP por enfermedades evitables fueron de 9,6 años por cada mil habitantes (23.393 años) con una tendencia estable en los últimos años, el tumor maligno de la mama de la mujer fue la causa de mortalidad que mayor peso tiene en este indicador (aproximadamente se pierden 3 años de vida por cada mil habitantes), seguido por las enfermedades crónicas de las vías respiratorias inferiores e Infecciones respiratorias agudas.

Estas cifras evidencian el cambio en el perfil de mortalidad que se ha presentado en la ciudad en los últimos años; desde el año 2003 las causas externas principalmente el homicidio dejó de ser la primera causa de muerte, dando paso a las enfermedades crónicas no transmisibles; de acuerdo al perfil de mortalidad de la ciudad para el año 2014 las primeras causas de mortalidad tanto en hombres como en mujeres están relacionadas con las enfermedades del aparato circulatorio (tasa de 142,7 por cada 100 mil habitantes) y las neoplasias (tasa de 128,4 por cada 100 mil habitantes); en mujeres el cáncer de mama y de cuello uterino representan un alto porcentaje de muertes (tasa de 17,5 y 6,7 por 100 mil) de las cuales el $52 \%$ y $45 \%$ se clasifican como muertes tempranas (antes de los 60 años); en hombres, el cáncer de próstata registro una tasa de 14,7 por cada 100 mil hombres para este mismo periodo.

Otras enfermedades crónicas con un importante peso en el perfil de mortalidad de la ciudad son las enfermedades de vías respiratorias inferiores, la diabetes mellitus y enfermedad renal crónica (tasas de 39,2, 12,3 y 18 por cada 100 mil habitantes respectivamente). En cuanto a las enfermedades transmisibles, la mortalidad por las infecciones respiratorias agudas presentó una tasa de 22,5 por cada 100 mil habitantes para el año 2014 con una tendencia al incremento en los últimos años, siendo la principal causa de muerte en este grupo de enfermedades.

Con relación a la mortalidad en menores de un año, se ha registrado una importante disminución pasando de 11.9 por mil nacidos vivos para el año 2005 a 7,8 en el año 2015; un comportamiento similar presenta la 
Un nuevo modelo de equidad social

mortalidad en menores de 5 años que pasó de 309.8 a 177,3 por cada por 100 mil niños menores de 5 en el mismo período. La mortalidad materna por su parte en 2015 fue de 23 muertes por cada cien mil nacidos vivos, cumpliendo así con los Objetivos de Desarrollo del Milenio (ODM) en estos tres indicadores.

\section{Gráfico 13. Tasa de Mortalidad en menores de cinco años}

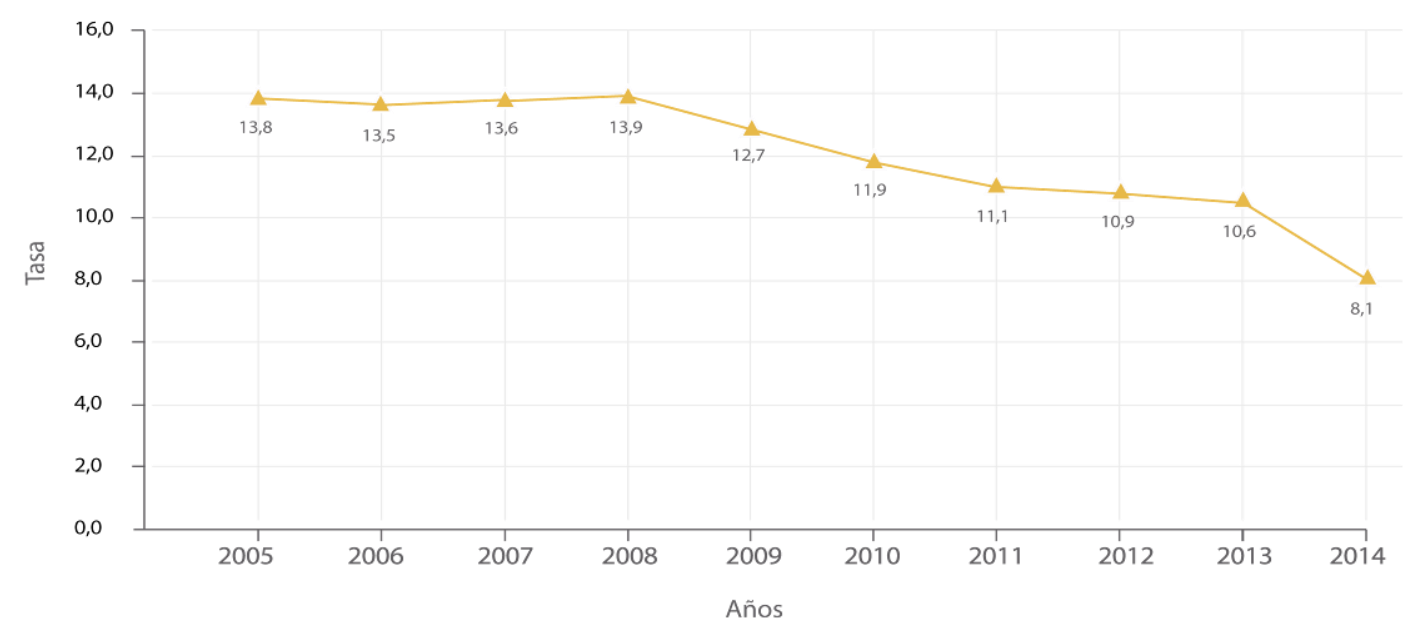

$\Delta$ Mortalidad en menores de cinco años por cada mil nacidos vivos

Fuente: Secretaría de Salud de Medellín. RUAF - DANE, Certificados de Estadísticas vitales

En cuanto a la morbilidad en Medellín durante el año 2014, la hipertensión arterial se ubicó como la primera causa de consulta externa con el 10,4\% de las consultas. En el servicio de hospitalización se observó como principales causas de egreso; la atención materna con aproximadamente $7 \%$ de los casos, seguida por el dolor abdominal y pélvico con el 5,4\%, y traumatismos de múltiples regiones del cuerpo con el 3,6\%.

Entre los factores de riesgo asociados a las principales causas de morbilidad y mortalidad, se encuentra la prevalencia de consumo de tabaco (18.22\%), el consumo excesivo de alcohol en población entre 18-65 años (prevalencia del 11.2\%), el bajo consumo de frutas o verduras al día (1\%) y el sedentarismo (51\%), entre otros.

En relación con indicadores de la salud sexual y reproductiva, se resalta el comportamiento del embarazo en adolescentes (15 a 19 años) que para el año 2014 fue de 19,9\%, con una tendencia muy estable en los últimos años. La tasa de fecundidad para las mujeres de 10 a 19 años en el año 2014, fue de 36,0 siendo mayor en el rango de las mujeres de 15 a 19 años, que se ubicó en 65,3. De acuerdo con los resultados de La Encuesta Nacional de Demografía y Salud realizada en el año 2010 a nivel nacional 


\section{Un nuevo modelo de equidad social}

señala: "Casi un 8\% de las mujeres entre 15 y 24 años de edad, abandonaron sus estudios durante los últimos años porque quedaron embarazadas" y afirma también "que el $55 \%$ de las adolescentes sin educación ya son madres o están embarazadas, este porcentaje es de 11\% de las que tienen educación superior".

Otros aspectos relevantes y relacionados íntimamente con la garantía del derecho a la salud, son el acceso, calidad y oportunidad de los servicios de salud. El acceso en la ciudad ha alcanzado la meta de cobertura superior del aseguramiento en salud durante los últimos cinco años (en 2015 la cobertura fue del 96\%), de acuerdo con las cifras reportadas en la base de datos única de afiliados - BDUA del Sistema de Seguridad Social; el $74 \%$ se encontraban afiliados el régimen contributivo, el 24\% (614.626 personas) al régimen subsidiado y 75.560 eran población pobre no asegurada. Sin embargo, según la Encuesta de Calidad de Vida ECV para el año 2014, la percepción de la población sobre la facilidad de acceso a los servicios de salud en general fue del $33,57 \%$ y de calidad de estos servicios fue de $44,74 \%$.

Respecto a la infraestructura de salud, en la última década la ciudad ha avanzado en la adecuación y modernización de su estructura física y tecnológica, hoy cuenta con una extensa red de servicios de salud con predominio de IPS privadas (91,9\%), las IPS públicas y mixtas solo alcanzan el 8,1\%. La red pública de salud de ciudad, dispone de 10 unidades hospitalarias y 42 centros de salud que conforman la Empresas Sociales del Estado Metrosalud que presta servicios de primero y segundo nivel; para la atención de alta complejidad cuenta con el Hospital General de Medellín y El Hospital Infantil Consejo de Medellín. Esta infraestructura podría dar una adecuada cobertura a la población de la ciudad de Medellín, pero resulta insuficiente observándose saturación de los servicios y demoras en la atención, al ser receptora de pacientes de diferentes zonas del país.9

A continuación se describen los indicadores de resultado que se evaluarán en este reto:

\begin{tabular}{|l|c|c|c|c|}
\hline \multicolumn{1}{|c|}{ Nombre } & Unidad & Línea de Base & Meta 2019 & Responsable \\
\hline $\begin{array}{l}\text { Años de vida potencialmente } \\
\text { perdidos por mortalidad } \\
\text { evitable }\end{array}$ & Índice & $\begin{array}{c}\text { Mantener } \\
\text { por } \\
\text { debajo de } \\
10\end{array}$ & $\begin{array}{c}\text { Secretaría de } \\
\text { Salud }\end{array}$ \\
\hline $\begin{array}{l}\text { Cobertura de afiliación al } \\
\text { Sistema General de Seguridad } \\
\text { Social en Salud SGSSS }\end{array}$ & Porcentaje & $95 \%$ & $\begin{array}{c}\text { Cobertura } \\
\text { mínima } \\
\text { del 95\% }\end{array}$ & $\begin{array}{c}\text { Secretaría de } \\
\text { Salud }\end{array}$ \\
\hline
\end{tabular}

\footnotetext{
${ }^{9}$ Diagnóstico de la demanda, oferta y déficit de servicios de salud Medellín 2011
} 


\subsubsection{PROGRAMA: FORTALECIMIENTO DEL ACCESO A LOS SERVICIOS DE SALUD}

El acceso a la atención y prestación de los servicios de salud debe ser un proceso continuo de mejoramiento, una característica importante es la adecuación del sistema de prestación de servicios de salud a las necesidades de la población, procurando la equidad en el acceso a los servicios y contribuyendo en la disminución de las barreras de acceso, además es necesario el fortalecimiento de la calidad por medio de la articulación de diferentes redes privadas, públicas y mixtas, mejorando el tiempo en la atención y buscando un fortalecimiento continuo.

Indicadores de resultado

\begin{tabular}{|l|l|c|c|l|}
\hline Nombre & Unidad & Línea de Base & Meta 2019 & Responsable \\
\hline $\begin{array}{l}\text { Instituciones que han logrado } \\
\text { nivel adecuado de la } \\
\text { implementación del PAMEC }\end{array}$ & Porcentaje & ND & $50 \%$ & $\begin{array}{l}\text { Secretaría de } \\
\text { Salud }\end{array}$ \\
$\begin{array}{l}\text { (Pautas de Auditoria para el } \\
\text { Mejoramiento a la calidad en } \\
\text { Salud) }\end{array}$ & Mortunidad en el tiempo de la \\
$\begin{array}{l}\text { Oportún dención prehospitalaria en } \\
\text { ateno de urgencias, y en } \\
\text { emergencias y desastres }\end{array}$ & Minutos & $\begin{array}{c}\text { Mantener } \\
\text { por debajo } \\
\text { de 16 }\end{array}$ & $\begin{array}{l}\text { Secretaría de } \\
\text { Salud }\end{array}$ \\
\hline
\end{tabular}

3.1.1.1 Proyecto: Fortalecimiento de la calidad de los servicios de salud Propiciar el mejoramiento de la calidad en los servicios de salud de la ciudad, con estrategias que estimulen y/o promuevan el desarrollo del modelo de calidad de la SSM, mediante la articulación con la red pública y privada, para lograr una atención segura y humanizada.

El mejoramiento de la calidad de los servicios de salud, junto con la búsqueda de equidad, eficiencia, sostenibilidad y participación social en la provisión de estos servicios, son parte inherente a la misión del sector salud.

Responsable: Secretaría de Salud

Indicador de producto

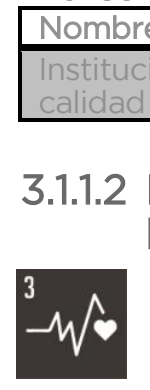

\begin{tabular}{|l|l}
\hline & Unidad \\
\hline
\end{tabular}

Proyecto: Fortalecimiento a la red pública en salud con calidad y humanización

Se busca mejorar la red pública de prestadores de servicios de salud, en especial la ESE Metrosalud como principal red de atención en el municipio, para contribuir en las condiciones de su operación de modo que sus servicios sean de alta calidad, oportunos, generen 
impacto en la comunidad y resultados en salud en su población asignada. Esto incluirá la mejora de su capacidad física y de equipamientos, considerando las necesidades y los estudios de suficiencia de la red realizados por Secretaría de Salud y Protección Social de Antioquia y de la Secretaría de Salud de Medellín.

Responsable: Secretaría de Salud

Indicador de producto

\begin{tabular}{|l|c|}
\hline Nombre & Unidad \\
\hline Cobertura de instituciones que recibieron fortalecimiento en la red & Porcentaje \\
\hline Mortalidad materna evitable & Tasa por \\
& 100,000 \\
nacidos vivos \\
\hline
\end{tabular}

\subsubsection{Proyecto: Gestión de la atención prehospitalaria, urgencias, emergencias y desastres}

La atención pre-hospitalaria es prioritaria para el fortalecimiento del sistema de salud y para el manejo de urgencias, emergencias y desastres, haciendo parte fundamental de los Sistemas de Emergencias Médicas, que permita mejorar la oportunidad, calidad e impacto de la prestación de servicios de salud.

La gestión de la atención prehospitalaria busca fortalecer a los prestadores públicos y privados para que el municipio cuente con servicios de urgencias articulados interinstitucionalmente, capacitados y desarrollados tecnológicamente, que les permita brindar una atención oportuna, eficaz e integral de las urgencias, emergencias y desastres de acuerdo a su nivel de complejidad.

Responsable: Secretaría de Salud

Indicador de producto

\begin{tabular}{|l|c|}
\hline Nombre & Unidad \\
\hline $\begin{array}{l}\text { Sistema para la atención de Urgencias, emergencias y desastres operando las 24 } \\
\text { horas de los } 365 \text { días del año }\end{array}$ & Porcentaje \\
\hline
\end{tabular}

3.1.1.4 Proyecto: Gestión del aseguramiento en salud Bajo la rectoría de la Secretaría de Salud se fortalecerá la operación del régimen subsidiado a través de Savia Salud, como principal asegurador en el municipio y se ejercerá control a la movilidad entre los regímenes subsidiado y contributivo. Igualmente, fomentará la afiliación al sistema general de seguridad social en salud no solo en lo relacionado con la atención en salud sino a pensiones y riesgos laborales para reducir la evasión a la afiliación al régimen contributivo de quienes están laboralmente activos sea de manera formal o informal. 
Indicador de producto

Nombre

Cobertura de población pobre afiliada al régimen subsidiado

Unidad

Porcentaie

3.1.1.5 Proyecto: Gestión de la prestación del servicio de salud a la población pobre no afiliada

w

En cumplimiento de las competencias municipales que otorga la ley 715 del 2001, se debe mantener disponible durante el cuatrienio una oferta de servicios de salud del primer nivel de complejidad para la atención en salud de población pobre y vulnerable no asegurada del Municipio de Medellín, la cual se atenderá a través del primer nivel de atención de la ESE pública del municipio. Por otro lado realizar el pago de facturas por las atenciones de urgencias de primer nivel de atención en salud no contratadas.

Responsable: Secretaría de Salud

Indicador de producto

Nombre

Unidad

Población pobre no asegurada con servicios de salud de primer nivel

\subsubsection{PROGRAMA: GESTIÓN DE ESTRATEGIAS EN SALUD}

Este programa incluye abordaje a los eventos priorizados en la ciudad, debido a su alta incidencia, importancia e impacto para la salud y bienestar de la población, como son las Enfermedades Crónicas no transmisibles (ECNT), la Salud Mental y Adicciones, y el Embarazo adolescente.

Indicadores de resultado

\begin{tabular}{|c|c|c|c|c|}
\hline Nombre & Unidad & Línea de Base & Meta 2019 & Responsable \\
\hline $\begin{array}{l}\text { Mortalidad infantil (menores } \\
\text { de } 1 \text { año) }\end{array}$ & Tasa & 7,8 & $\begin{array}{c}\text { Mantener } \\
\text { por debajo } \\
\text { de } 9,5\end{array}$ & $\begin{array}{l}\text { Secretaría de } \\
\text { Salud }\end{array}$ \\
\hline $\begin{array}{l}\text { Mortalidad en menores de } 5 \\
\text { años }\end{array}$ & Tasa & 177.3 & $\begin{array}{l}\text { Mantener } \\
\text { por debajo } \\
\text { de } 190\end{array}$ & $\begin{array}{l}\text { Secretaría de } \\
\quad \text { Salud }\end{array}$ \\
\hline Mortalidad por suicidio & Tasa & 4,7 & $\begin{array}{c}\text { Mantener } \\
\text { por debajo } \\
\text { de } 5 \\
\end{array}$ & $\begin{array}{l}\text { Secretaría de } \\
\text { Salud }\end{array}$ \\
\hline $\begin{array}{l}\text { Proporción de Embarazos en } \\
\text { niñas } 15-19 \text { años }\end{array}$ & Porcentaje & 19,9 & $\begin{array}{c}\text { Mantener } \\
\text { por debajo } \\
\text { de } 22 \% \\
\end{array}$ & $\begin{array}{l}\text { Secretaría de } \\
\text { Salud }\end{array}$ \\
\hline $\begin{array}{l}\text { Muertes tempranas por cáncer } \\
\text { de mama }\end{array}$ & Porcentaje & 44,7 & $\begin{array}{l}\text { No superar } \\
\text { el } 45 \% \\
\end{array}$ & $\begin{array}{l}\text { Secretaría de } \\
\text { Salud } \\
\end{array}$ \\
\hline $\begin{array}{l}\text { Muertes tempranas por } \\
\text { enfermedades hipertensivas }\end{array}$ & Porcentaje & 0,6 & $\begin{array}{l}\text { Mantener } \\
\text { por debajo } \\
\text { de } 0,6\end{array}$ & $\begin{array}{l}\text { Secretaría de } \\
\text { Salud }\end{array}$ \\
\hline $\begin{array}{l}\text { Coberturas de vacunación en } \\
\text { menores de } 1 \text { año (biológico } \\
\text { trazador SRP) }\end{array}$ & Porcentaje & $95 \%$ & $\begin{array}{c}\text { Mantener } \\
\text { por encima } \\
\text { del } 95 \% \\
\end{array}$ & $\begin{array}{l}\text { Secretaría de } \\
\quad \text { Salud }\end{array}$ \\
\hline Mortalidad por VIH & Tasa & 5.3 & $\begin{array}{l}\text { Mantener al } \\
\text { menos en } 5\end{array}$ & $\begin{array}{l}\text { Secretaría de } \\
\text { Salud }\end{array}$ \\
\hline
\end{tabular}




\section{Un nuevo modelo de equidad social}

3.1.2.1 Proyecto: Abordaje integral sociosanitario para la prevención del embarazo adolescente

Se desarrollará con la implementación de la estrategia de Servicios amigables para jóvenes y adolescentes de forma integral, tanto en la red pública como privada, llevando acciones a los diferentes entornos donde el adolescente y el joven desarrollan habilidades para a toma de decisiones acertadas en vida. Las acciones de prevención se articularán con las EAPB y sus redes de prestación.

La OPS define los servicios amigables "como servicios en los cuales los jóvenes encuentran oportunidades de salud cualquiera sea su demanda son agradables para jóvenes y sus familias por el vínculo que se establece con el proveedor de salud y por la integralidad y calidad de sus intervenciones".

Responsable: Secretaría de Salud

Indicador de producto

\begin{tabular}{|l|c|}
\hline \multicolumn{1}{|c|}{ Nombre } & Unidad \\
\hline $\begin{array}{l}\text { Plan de Abordaje Integral de Atención para la prevención del embarazo adolescente } \\
\text { implementado }\end{array}$ & Porcentaje \\
\hline
\end{tabular}

3.1.2.2 Proyecto: Implementación modelo integral de atención con enfoque de género

A través de desarrollo de este proyecto se pretende terminar la construcción y dotación del centro integral para la mujer y la familia, con el objetivo que inicie su operación para la atención de las mujeres de la ciudad.

$\boldsymbol{1}$

Así mismo, es necesario la construcción e implementación de su modelo de prestación de servicios el cual se constituye como un conjunto de principios, lineamientos y metodologías que orientan la prestación de servicios de salud para las mujeres de Medellín, en las áreas de promoción, prevención, atención y rehabilitación, desde un enfoque de derechos, de género, de curso de vida y diferencial, y con criterios de calidad en la atención, participación social, empoderamiento y acceso a la toma de decisiones.

Responsable: Secretaría de Salud

Indicador de producto

\begin{tabular}{|l|c|}
\hline \multicolumn{1}{|c|}{ Nombre } & Unidad \\
\hline $\begin{array}{l}\text { Implementación de plan de atención integral con enfoque de género para el centro } \\
\text { de atención de la mujer y la familia }\end{array}$ & Porcentaje \\
\hline
\end{tabular}


Un nuevo modelo de equidad social

3.1.2.3 Proyecto: Abordaje integral sociosanitario para poblaciones especiales

Un modelo de atención primaria sociosanitaria, la cual se entiende como el conjunto de cuidados destinados a las personas que, por causa de graves problemas de salud o limitaciones funcionales y/o de riesgo de exclusión social, necesitan una atención en salud y social simultánea, coordinada y estable, ajustada al principio de continuidad de la atención. Es decir se trata de un ámbito en el que interactúan múltiples sectores, distintos niveles asistenciales, y que necesita de una coordinación de los mismos, para construir respuestas integradas y en equidad a la población, con el propósito de mejorar sus condiciones y calidad de vida.

Indicador de producto

Responsable: Secretaría de Salud

\begin{tabular}{|l|c|}
\hline \multicolumn{1}{|c|}{ Nombre } & Unidad \\
\hline $\begin{array}{l}\text { Plan de Abordaje Integral de Atención sociosanitaria en salud mental y adicciones } \\
\text { implementado }\end{array}$ & Porcentaje \\
\hline
\end{tabular}

3.1.2.4 Proyecto: Abordaje integral de atención sociosanitaria salud mental, y adicciones

La ley 1566 de 2012 reconoce que "el consumo, abuso y adicción a sustancias psicoactivas, lícitas o ilícitas es un asunto de salud pública y bienestar de la familia, la comunidad y los individuos. Por lo tanto, el abuso y la adicción deberán ser tratados como una enfermedad que requiere atención integral por parte del Estado, conforme a la normatividad vigente y las Políticas Públicas Nacionales en Salud Mental y para la Reducción del Consumo de Sustancias Psicoactivas y su Impacto, adoptadas por el Ministerio de Salud y Protección Social." Se desarrollará bajo el modelo de atención primaria en salud y de forma articulada con los actores del sistema general de seguridad social en salud y otros sectores, enfatizando las acciones de promoción de la salud, prevención de los factores de riesgo y mitigación del daño.

Responsable: Secretaría de Salud

Indicador de producto

\begin{tabular}{|c|c|}
\hline \multicolumn{1}{|c|}{ Nombre } & Unidad \\
\hline $\begin{array}{l}\text { Plan de abordaje integral de atención sociosanitaria en salud mental y adicciones } \\
\text { implementado }\end{array}$ & Porcentaje \\
\hline
\end{tabular}

\subsubsection{Proyecto: Abordaje integral para la prevención de las enfermedades crónicas no transmisibles}

Se desarrollarán estrategias de promoción de la salud y prevención de la enfermedad, que para el caso de enfermedades crónicas no transmisibles en especial las neoplasias, las enfermedades cardiovasculares y renales se centra en los niveles de prevención primaria, secundaria y terciaria para los 
factores de riesgo modificables más importantes, a través de la articulación con los diferentes actores del Sistema General de Seguridad Social en Salud.

Responsable: Secretaría de Salud

Indicador de producto

\begin{tabular}{|l|c|}
\hline \multicolumn{1}{|c|}{ Nombre } & Unidad \\
\hline $\begin{array}{l}\text { Plan de Abordaje Integral de Atención para la prevención de las enfermedades } \\
\text { crónicas no transmisibles implementado }\end{array}$ & Porcentaje \\
\hline
\end{tabular}

\subsubsection{PROGRAMA: ARTICULACIÓN SISTEMA DE LA SALUD}

La articulación del sistema se hace con gobernanza y gobernabilidad de la Secretaría de Salud de Medellín busca la integración y articulación de las instituciones intersectoriales, sectoriales y transectoriales en un contexto sistémico y planificado, buscando la implementación de un modelo de salud para la ciudadanía soportado por el principio de la equidad, con compromisos claros para cada uno de los actores que intervienen en el fortalecimiento del sistema.

Indicador de resultado

\begin{tabular}{|l|l|l|l|l|}
\hline Nombre & Unidad & Línea de Base & Meta 2019 & Responsable \\
\hline $\begin{array}{l}\text { Instituciones que realizan } \\
\text { acciones articuladas con la } \\
\text { Secretaría de Salud }\end{array}$ & Porcentaje & ND & $50 \%$ & $\begin{array}{l}\text { Secretaría } \\
\text { Salud }\end{array}$ \\
\hline
\end{tabular}

\subsubsection{Proyecto: Gestión territorial y participación social en salud}

Conformación de equipos básicos de Salud EBAS, en articulación con la red pública y las EAPB, para acercar los servicios de salud al ciudadano, con un enfoque territorial, fortaleciendo la gestión intersectorial en el territorio para la intervención de los determinantes de la salud, y la gestión del riesgo, teniendo como enfoque central el cuidado.

Responsable: Secretaría de Salud

Indicadores de producto:

\begin{tabular}{|l|c|}
\hline \multicolumn{1}{|c|}{ Nombre } & Unidad \\
\hline Comunas con acompañamiento en gestión territorial y participación social en salud & Porcentaje \\
\hline Ciudadanos sensibilizados en educación vial para la movilidad segura & Número \\
\hline
\end{tabular}

3.1.3.2 Proyecto: Gestión de la información y el conocimiento en salud Como parte de la rectoría del sistema de salud del Municipio, es fundamental la administración, análisis y uso de la información en salud y la información proveniente de otros sectores, utilizando metodologías y herramientas avanzadas, con innovación y la tecnología.

Para ello es necesario mantener y fortalecer la operación de los sistemas de información, como herramienta fundamental para la Gestión del 


\section{Un nuevo modelo de equidad social}

conocimiento, a través del Fortalecimiento del sistema de recolección y procesamiento de datos del sector salud, mediante el apoyo técnico, tecnológico necesario para la generación de información según las políticas nacionales y municipales; el mejoramiento de la calidad de los datos reportados mediante la asistencia técnica a los proveedores de información y desarrollar los mecanismos de disposición de la información procesada a través de los diferentes medios virtuales, electrónicos y físicos a los diferentes actores internos y externos del sistema de salud. Así mismo es fundamental garantizar la seguridad de la información generada por el sistema de salud.

Indicador de producto

Responsable: Secretaría de Salud

\begin{tabular}{|c|c|}
\hline \multicolumn{1}{|c|}{ Nombre } & Unidad \\
\hline $\begin{array}{l}\text { Instituciones que reportan al sistema de información para la vigilancia en salud, } \\
\text { de acuerdo a los requerimientos del mismo }\end{array}$ & Porcentaje \\
\hline
\end{tabular}

\subsubsection{Proyecto: Conformación de redes sectoriales, intersectorialidad y transectorialidad}

Con el interés de afectar positivamente los determinantes sociales de la salud se reconoce la necesidad de fortalecer la gestión propia del sector salud, y la generación de vínculos efectivos, a manera de redes, con otros sectores públicos y privados para que se consoliden como una fuerza común y como condición para el abordaje integral y la transformación de aquellos eventos que ponen en riesgo la salud y la vida de la población en los territorios.

En este sentido se dará prioridad a la conformación de las Redes Integradas de Servicios de Salud para la Atención Materno Infantil y para la atención en Salud Mental, procurando tener un alcance regional en la operación de estas redes. Como parte de los procesos de construcción de redes y alianzas se considera el fortalecimiento de la internacionalización de la salud a través del Clúster de la Salud para la gestión del conocimiento, el turismo en salud, la participación y realización de eventos internacionales en salud.

Responsable: Secretaría de Salud

Indicador de producto

Nombre

Unidad

Planeación, desarrollo e implementación de las redes integradas de salud operando

\subsubsection{PROGRAMA: VIGILANCIA INTEGRAL EN SALUD}

Dentro de las competencias del ente territorial se encuentra la vigilancia en salud, como parte del direccionamiento del sector y de su función como autoridad sanitaria, siendo importante para el seguimiento, prevención e intervención de los eventos de interés en salud pública, a la 
carga ambiental de la enfermedad y finalmente el acceso efectivo a los servicios en salud. Si bien este programa se constituye en una pieza fundamental del plan Medellín Saludable, el proceso de vigilancia es transversal y se evidencia en cada uno de los proyectos anteriormente expuestos,

La vigilancia integral en salud estará articulada con el proyecto de gestión de la información y el conocimiento y convocará a todos los actores del sector y de otros sectores.

\section{Indicador de resultado}

\begin{tabular}{|l|c|c|c|c|}
\hline \multicolumn{1}{|c|}{ Nombre } & Unidad & Línea de Base & Meta 2019 & Responsable \\
\hline $\begin{array}{l}\text { Porcentaje de éxito terapéutico } \\
\text { de pacientes con Tuberculosis }\end{array}$ & Porcentaje & $81 \%$ & $85 \%$ & $\begin{array}{c}\text { Secretaría de } \\
\text { Salud }\end{array}$ \\
\hline Mortalidad por dengue & Porcentaje & 0,1 & $\begin{array}{c}\text { No superar } \\
\text { el 0,2 }\end{array}$ & $\begin{array}{c}\text { Secretaría de } \\
\text { Salud }\end{array}$ \\
\hline
\end{tabular}

3.1.4.1 Proyecto: Vigilancia al acceso de los servicios en salud

Fortalecer la autoridad sanitaria en materia de supervisión y vigilancia del acceso efectivo a los servicios de salud de la población del municipio de Medellín tanto a la red pública como privada, tanto desde la prestación de los servicios de salud como desde su garantía desde las EAPB, mediante la implementación del modelo de inspección y vigilancia sobre el acceso a los servicios de salud de la población del municipio de Medellín, en coordinación con la nación, el departamento y el área metropolitana.

Responsable: Secretaría de Salud

Indicador de producto

\begin{tabular}{|c|c|}
\hline Nombre & Unidad \\
\hline Formulación, implementación y evaluación de acciones en Vigilancia del Acceso & Porcentaje \\
\hline
\end{tabular}

\subsubsection{Proyecto: Vigilancia epidemiológica}

La vigilancia en salud pública y control de los riesgos y daños, es una función esencial de la salud pública que incluye el desarrollo de programas activos de vigilancia epidemiológica y de control de enfermedades, así como el fortalecimiento de la autoridad sanitaria a nivel local para generar respuestas rápidas ante eventuales problemas de salud o de riesgos específicos.

Responsable: Secretaría de Salud

Indicador de producto

\begin{tabular}{|c|c|}
\hline \multicolumn{1}{|c|}{ Nombre } & Unidad \\
\hline Cobertura de las intervenciones de vigilancia epidemiológica & Porcentaje \\
\hline
\end{tabular}

\subsubsection{Proyecto: Vigilancia en salud ambiental}

Comprende la observación, análisis de los riesgos ambientales y sus efectos en la salud, así como evaluar la carga de la enfermedad ambiental y el 


\section{Un nuevo modelo de equidad social}

fortalecimiento de la investigación relacionada con los diferentes factores de riesgo ambientales.

Responsable: Secretaría de Salud

Indicador de producto

\begin{tabular}{|c|c|}
\hline \multicolumn{1}{|c|}{ Nombre } & Unidad \\
\hline Sistema de vigilancia en salud ambiental implementado & Porcentaje \\
\hline
\end{tabular}




\subsection{RETO}

\section{MEDELLÍN DIGNA}

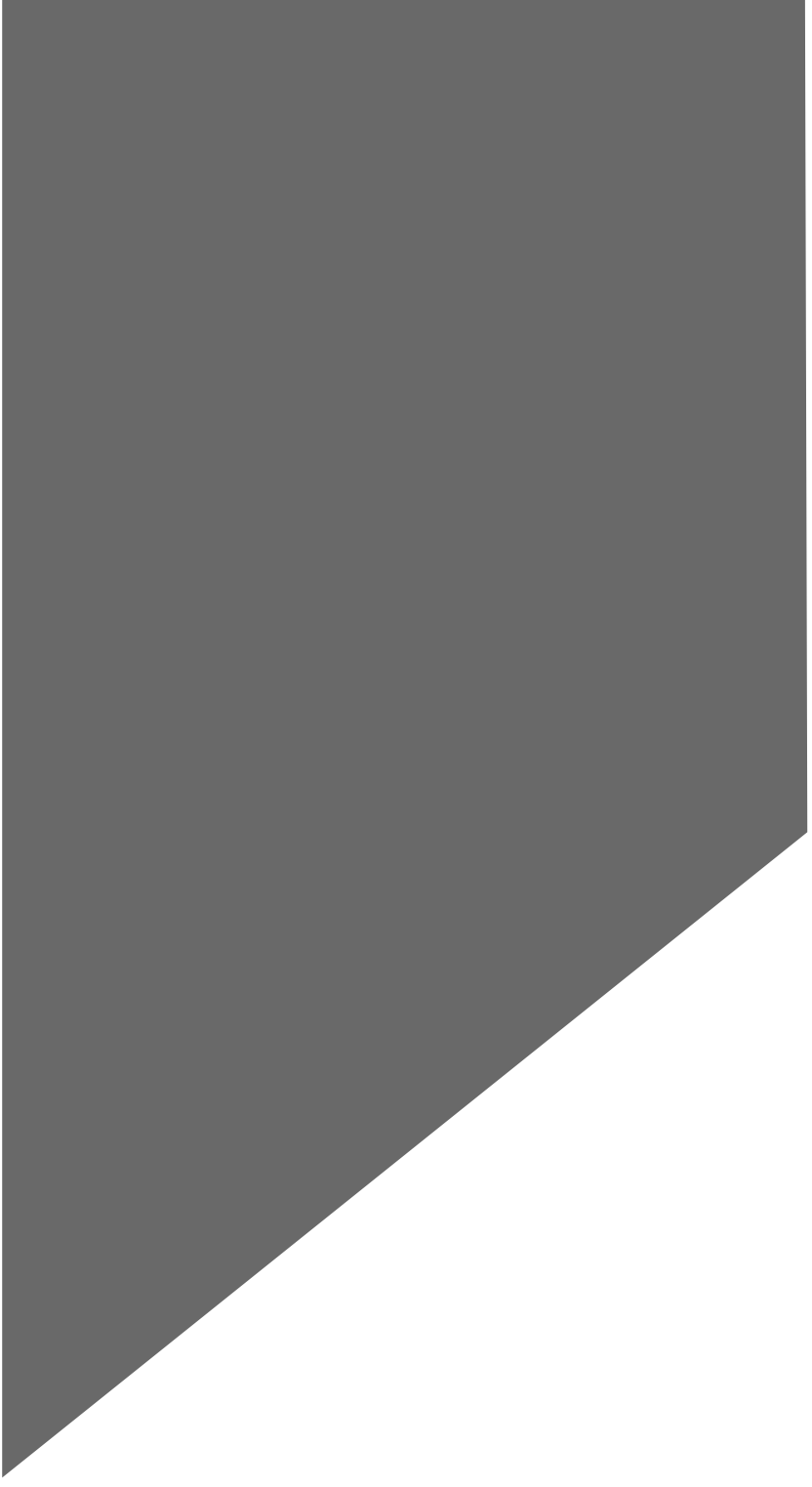

\section{OBJETIVO}

Mejorar significativamente las condiciones de vida de los ciudadanos promoviendo el reconocimiento y el respeto por el ser humano en todos los aspectos.

\section{PROGRAMAS}

4 3.2.1. Por el sueño de ciudad de la Infancia y la adolescencia

4 3.2.2. Por un envejecimiento digno

4 3.2.3. Empoderamiento y transversalización de la equidad de género

4 3.2.4. Promoción del desarrollo humano integral de la juventud

4 3.2.5. Atención e inclusión social para el habitante de calle

4 3.2.6. Seguridad alimentaria y nutricional

4 3.2.7. Ser Capaz: personas con discapacidad, familiares y cuidadores

4 3.2.8. Diversidad sexual e identidades de género

$\Delta$ 3.2.9. Diversidad étnica

3.2.10. Familia 
Un nuevo modelo de equidad social

\subsection{Medellín digna}

Entendemos la participación ciudadana como el encuentro de agencias individuales que de acuerdo a la Encuesta de Calidad de Vida del año 2014, Medellín cuenta con 796.200 hogares, de los cuales 68.054 (9\%) se encuentran en los corregimientos y los restantes 728.146 (91\%) distribuidos en las 16 comunas, siendo Belén, Robledo y San Javier las comunas con mayor concentración de población. En el 50,1\% de los hogares son las mujeres las jefes de hogar y en el $49,9 \%$ lo son los hombres.

Con relación a las condiciones socioeconómicas, se encuentra que el $79,6 \%$ de las familias de la ciudad pertenecen a los estratos socioeconómicos bajos, siendo los estratos dos y tres los que mayor proporción de familias albergan (36,91\% y 29,86\% respectivamente), estos datos son indicativos de una capacidad adquisitiva limitada en las familias de la ciudad; situación que se refleja en las condiciones de seguridad alimentaria. De acuerdo con Plan de Seguridad Alimentaria para Medellín 2016-2028, el 53,6\% de la población de la ciudad presenta algún tipo de inseguridad alimentaria y el $14,4 \%$ de los hogares se encuentran con inseguridad alimentaria severa; las comunas donde se registra mayor riesgo son Manrique, Santa Cruz, Popular y Aranjuez; esta situación afecta principalmente a la niñez, población adulta mayor y en condiciones de discapacidad.

La composición poblacional registra que para el año 2016 el municipio de Medellín cuenta con una población de 2.486 .723 habitantes $(52,9 \%$ son mujeres y $47,1 \%$ son hombres), de los cuales el 10,5\% es población adulta mayor (mayores de 65 años) y se espera que para 2019 esta población sea el $12 \%$ del total de los habitantes de la ciudad, lo que representa un incremento de dos puntos porcentuales en los próximos cuatro años. La población menor de 15 años representa el 18,12\% de los habitantes y para 2019 será del 17,8\%, lo que representa una disminución del $2 \%$ de la población infantil. El 23\% de la población del municipio son jóvenes entre los 14 a los 28 años, de los cuales el $49.4 \%$ son mujeres y el $50,6 \%$ son hombres, de estos $6.4 \%$ se reconocen como afros y el $0.2 \%$ como indígenas; el $83.3 \%$ viven en los estratos uno, dos y tres.

Dado que el $52.9 \%$ de la población de la ciudad son de mujeres, se han implementado acciones orientadas a disminución de brechas de desigualdad existentes en razón de las condiciones históricas de disparidad y el reciente reconocimiento de las mujeres como ciudadanas de primera categoría, que si bien han logrado avances significativos en cuanto a equidad, persisten situaciones que obstaculizan el pleno desarrollo y acceso a derechos por parte de las mujeres. En ese sentido se hace prioritario implementar medidas positivas que impulsen cerrar brechas de desigualdad de género, lo cual es un reto claramente considerado en el numeral 5 de los objetivos sustentables, así como lo 
Un nuevo modelo de equidad social

estipulado en el CONPES 161 y se determina en el Acuerdo 022 de 2003, política pública para mujeres urbanas y rurales.

Con relación a los grupos poblacionales minoritarios, encontramos que en Medellín habitan aproximadamente 236.222 personas afrocolombianas, entre las problemáticas encontradas está el racismo estructural; el Índice de Desarrollo Humano (IDH) en Medellín da cuenta que en cada hogar apenas el $36,8 \%$ es propietario de su vivienda y el promedio de personas por vivienda es de 4,3. Existe un alto porcentaje de dependencia de menores de 14 años (31,2\%). El 64\% de los hogares perciben ingresos inferiores a un salario mínimo. Los hogares cuya cabeza es la madre equivalen al $66 \%$. El $17 \%$ de los integrantes de las familias no tienen escolaridad formal y la tasa de afiliación al régimen subsidiado es del $63.7 \%$.

La población indígena está compuesta por aproximadamente 9.000 personas, según el Plan de Vida Cabildo indígena Chibcariwak: "Una minga para la pervivencia de los Pueblos Indígenas en la Ciudad con la voz de la Madre Tierra" 2012-2023, el 55\% ha llegado a la ciudad por desplazamiento forzado, el $30 \%$ en busca de trabajo, el $8 \%$ por estudio, el $6 \%$ para establecerse en la ciudad y el $1 \%$ por asuntos de salud. En materia de vivienda el $52 \%$ habita en vivienda arrendada, $28 \%$ tiene vivienda propia, el $11 \%$ familiar, el $7 \%$ en inquilinato (condición de mendicidad). La población indígena se encuentra ubicada principalmente en las comunas La Candelaria (29.7\%), Villa hermosa (5.3\%), Robledo (7.2\%) y Buenos Aires (4.5\%).

Con relación a la población con discapacidad ( $P C D)$, actualmente en la ciudad no hay una cifra clara sobre las personas con esta condición, aunque la Organización Mundial de la Salud OMS estima que un 15\% de la población mundial presenta algún tipo de discapacidad, sea física o cognitiva. Medellín cuenta con una caracterización de la población con discapacidad realizada por la Secretaría de Salud durante los años 20092010, la cual arrojó un total de 47.252 Pcd, el censo general del DANE 2005 dio cuenta de 117.826 y según la fuente oficial, definida a nivel Nacional, el Registro de Localización y Caracterización de las PcD (RLCPD) con corte al 20 de Enero de 2016, existen 57.796 PcD registradas en Medellín. Gran parte de ellas evidencian condiciones desfavorables de accesibilidad y oportunidad, de salud y bienestar, de seguridad económica y social y bajos niveles educativos, entre otros; situaciones que dificultan su inclusión social. Este panorama evidencia la necesidad de tener una caracterización actualizada de las PCD para planear y ejecutar acciones de impacto en esta población.

De otro lado, y de acuerdo con la última caracterización de habitantes de calle de la ciudad de Medellín 2014, se encontró a 3.250 personas en esta condición, de los cuales el $84.3 \%$ era hombres, con mayor presencia de personas entre los 33 y los 59 años (56.5\%). El 17.5\% dijo no consumir 
ningún tipo de sustancia psicoactiva y reportaron que antes de habitar la calle la mayoría de la población vivía con la familia, 2.514 (84.9\%), así mismo refirieron que los Centros Día son el tipo de institución de apoyo que más frecuentan (44.5\%).

Si bien la ciudad no cuenta con un censo de población LGBTI, de acuerdo con la última caracterización realizada en el Municipio de Medellín para el año 2015 en el que participaron 1478 personas, el 40.3\% de los encuestados se auto/reconoce como hombre gay, el 39.2\% como mujer lesbiana, el 13, 3\% como bisexual, el 0.5\% como intersexual, y el $6.7 \%$ como transgénero.

Dada la diversidad de grupos poblacionales que habitan la ciudad, desde la administración municipal se cuenta con políticas públicas que buscan garantizar y potencializar las condiciones de vida de cada grupo poblacional; en el marco de estas iniciativas se han implementado estrategias como los centros de Protección al Adulto Mayor que brinda atención integral a 1.285 personas mayores de 1.467 focalizadas. Así mismo, la ciudad cuenta con un Cabildo Mayor como instancia de participación democrática que permite a las personas mayores de 50 años elegir y ser elegidas para ser incluidas en los procesos de planificación del desarrollo municipal, todo ello fundamentado en un enfoque de derechos y deberes. En el Municipio de Medellín 45.266 personas mayores de 50 años participan en clubes de vida y 43.590 personas mayores en extrema pobreza reciben subsidio económico directo de 73.237 que se tienen focalizadas.

Así mismo, se han abordado acciones orientadas a fortalecer la política de equidad de género, elemento integral e integrador de las políticas de equidad social, evitando su asociación netamente con programas asistenciales de corto plazo y garantizando que el enfoque de equidad de género sea comprendido e incorporado en los diversos niveles de planeación e implementación de programas y proyectos tanto en el sector público y privado.

A continuación se describen los indicadores de resultado asociados a este reto:

\begin{tabular}{|l|c|c|c|c|}
\hline Nombre & Unidad & Línea de Base & Meta 2019 & Responsable \\
\hline $\begin{array}{l}\text { Hogares que superan su } \\
\text { condición de pobreza extrema } \\
\text { por medio del proceso de } \\
\text { acompañamiento de la } \\
\text { estrategia Familia Medellin }\end{array}$ & Numero & 5000 & 12000 & $\begin{array}{c}\text { Secretaría de } \\
\text { Inclusión, Familia } \\
\text { y D.D.H.H }\end{array}$ \\
\hline $\begin{array}{l}\text { Componente de vulnerabilidad } \\
\text { del IMCV mejorado }\end{array}$ & Índice & 12.09 & 14 & $\begin{array}{l}\text { Departamento } \\
\text { Administrativo } \\
\text { de Planeación }\end{array}$ \\
\hline Índice de Desarrollo Juvenil & Porcentaje & 72,6 & 74 & $\begin{array}{c}\text { Secretaria de } \\
\text { Juventud }\end{array}$ \\
\hline
\end{tabular}




\section{Un nuevo modelo de equidad social}

\subsubsection{PROGRAMA: POR EL SUEÑO DE CIUDAD DE LA INFANCIA Y ADOLESCENCIA}

Promover la dignidad y los derechos de niños, niñas y adolescentes del Municipio de Medellín, prevenir su inobservancia y protegerlos en caso de vulneración, es una labor que solo es posible desde la acción articulada, coordinada, comprometida y efectiva de las instancias estatales de orden local, departamental y nacional, en corresponsabilidad con otros entes territoriales como las familias, las instituciones de la sociedad civil y la ciudadanía en general.

El conjunto de acciones articuladas y planteadas en el Plan de Desarrollo, han sido diseñadas en el marco de la legislación nacional y municipal correspondiente a temas de primera infancia, infancia y adolescencia, como la Ley 1098, que desde sus reglamentaciones constituyen una Política Pública de Protección y Atención integral a niños, niñas y adolescentes del Municipio de Medellín, implementadas desde estrategias de promoción, prevención, incidencia y articulación y direccionadas estratégicamente desde la gestión del conocimiento, la información y la administración, aportando a la construcción de una ciudad rural y urbana con ambientes protectores.

Indicadores de resultado

\begin{tabular}{|l|l|l|c|l|}
\hline Nombre & Unidad & Línea de Base & Meta 2019 & Responsable \\
\hline $\begin{array}{l}\text { Niños, Niñas y Adolescentes } \\
\text { que reducen sus condiciones de } \\
\text { vulnerabilidad. }\end{array}$ & Porcentaje & SLB & $\begin{array}{l}\text { Secretaría } \\
\text { Inclusión, Familia } \\
\text { D.D.H.H }\end{array}$ \\
\hline $\begin{array}{l}\text { Plan docenal Medellín ciudad y } \\
\text { ruralidad de niños, niñas y } \\
\text { adolescentes Implementado }\end{array}$ & Porcentaje & SLB & $\begin{array}{l}\text { Mantener } \\
\text { por debajo } \\
\text { de 16 }\end{array}$ & $\begin{array}{l}\text { Secretaría } \\
\text { Inclusión, Familia } \\
\text { y D.D.H.H }\end{array}$ \\
\hline $\begin{array}{l}\text { Mortalidad por desnutrición en } \\
\text { menores de 5 años }\end{array}$ & $\begin{array}{l}\text { Tasa por } \\
100,000 \text { mantener } \\
\text { menores de 5 } \\
\text { años }\end{array}$ & O Secretaría Salud \\
\hline
\end{tabular}

3.2.1.1 Proyecto: Dignidad y protección integral de la infancia y la adolescencia

Coordinación de acciones conducentes al restablecimiento de los derechos de los niños, niñas y adolescentes que se encuentren en riesgo, situación o condición de inobservancia, amenaza y/o vulneración en el municipio de Medellín a través de programas de atención especializada, en articulación con autoridades de orden municipal, departamental y nacional.

Responsable: Secretaría de Inclusión Social, Familia y Derechos Humanos 
Indicador de producto

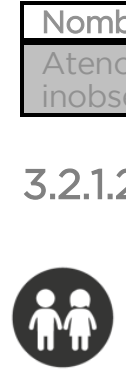

$$
\text { bre }
$$

ención y acompana

servados, vulnerados $\mathrm{y} / \mathrm{O}$ amenazados

sy adolescentes con derechos
s.

Proyecto: Incentivar la niñez talentosa (arte, cultura, expresión)

Este proyecto busca estimular, reconocer y visibilizar los niños, niñas y adolescentes talentosos de Medellín como referentes ciudadanos y promover otros imaginarios en esta población, para que a través del arte y la cultura, asimilen prácticas que generan y fortalecen experiencias de acceso, goce, participación, convivencia y aprendizaje a través de actividades artísticas y culturales, movilizando esta población hacia otras formas de comprensión de la ciudadanía cultural.

Responsable: Secretaría de Cultura Ciudadana

Indicadores de producto:

\begin{tabular}{|l|c|}
\hline Nombre & Unidad \\
\hline Eventos realizados para la niñez talentosa & Número \\
\hline Estímulos otorgados a niños talentosos & Número \\
\hline
\end{tabular}

\subsubsection{Proyecto: Recreando nuestros barrios y corregimientos}

Desde el año 1983 los voluntarios recreativos son pilar fundamental en la ciudad para el desarrollo social de los territorios. Desde allí, nace el proyecto enfocado en el fortalecimiento y consolidación de la cultura existente y la generación de nuevas dinámicas barriales y veredales a partir de la recreación.

1.1.

El proyecto es desarrollado por líderes recreativos como agentes de transformación social de los diferentes sectores de Medellín. Se fundamenta en la recreación para el aprendizaje de habilidades sociales, la adecuada ocupación del tiempo libre y la apropiación de los espacios públicos, procurando el encuentro entre vecinos, familiares y amigos. Otras de las actividades que comprende este proyecto son las vacaciones al parque proyectadas durante los tres periodos vacacionales del calendario académico.

Responsable: INDER

Indicador de producto

\begin{tabular}{|l|c|}
\hline Nombre & Unidad \\
\hline $\begin{array}{l}\text { Niños, niñas y adolescentes menores de } 18 \text { años que ocupan su tiempo libre en } \\
\text { actividades recreativas }\end{array}$ & Porcentaje \\
\hline
\end{tabular}

3.2.1.4 Proyecto: Implementación y seguimiento de la Política Pública de Infancia y Adolescencia

M. Promueve, concreta y fortalece la acción articulada y concertada de los distintos actores con responsabilidades en la implementación de 
la política de infancia y adolescencia del municipio de Medellín desde distintas perspectivas: la participación ciudadana y la movilización social, promoviendo particularmente la de los niños, niñas y adolescentes; la coordinación intersectorial e intra-administrativa; la articulación con otras políticas públicas poblacionales y sectoriales del Municipio; y la promoción de la articulación e incidencia de las organizaciones de la sociedad civil, la academia, el sector productivo y la Cooperación Internacional

Responsable: Secretaría de Inclusión Social, Familia y Derechos Humanos

Indicador de producto

Nombre

Unidad

Escenarios de incidencia y seguimiento a la política pública

3.2.1.5 Proyecto: Centros lúdicos formativos para la población

Teniendo en cuenta la importancia del inicio del ciclo de la vida, desde la gestación hasta la etapa de adultos, las ludotecas y los núcleos recreativos ofrecen alternativas de formación a través del juego. En el año 2000 se crea las ludotecas como espacios dinámicos y alternativos frente al uso del tiempo libre, el ocio, la adquisición de hábitos saludables, la interacción social, el sano esparcimiento. Hoy como estrategia para la construcción de convivencia y el fortalecimiento del tejido social, ofrece por medio de acciones como futvalores, la feria del juego y el juguete, salidas ecológicas, campamentos juveniles, el festival literario, los juegos múltiples, entre otras, diferentes opciones jugadas que convocan a niños, padres y comunidad en general para dinamizar el encuentro ciudadano.

Responsable: INDER

Indicador de producto

\begin{tabular}{|l|l|}
\hline $\begin{array}{l}\text { Nombre } \\
\text { Madres gestantes, niños y niñas menores de } 12 \text { años participantes de actividades } \\
\text { recreativas }\end{array}$ & Unidad \\
\hline
\end{tabular}

3.2.1.6 Proyecto: Sin violencia y sin drogas, la vida es una nota

Desarrolla y coordina acciones de promoción de los derechos de los

(1) niños, niñas y adolescentes y estrategias de prevención de su amenaza o vulneración, a través de alternativas comunicativas, artísticas, deportivas y educativas que fomentan capacidades y potencialidades para su desarrollo integral y la construcción de

7 ambientes protectores desde el fortalecimiento de las capacidades de familias, instituciones y comunidades corresponsables en la garantía de los derechos de los niños, niñas y adolescentes.

Responsable: Secretaría de Inclusión Social, Familia y Derechos Humanos 
Indicador de producto

\begin{tabular}{|l|c|}
\hline Nombre & Unidad \\
\hline $\begin{array}{l}\text { Niños, niñas y adolescentes atendidos en procesos de prevención de la } \\
\text { drogadicción, reclutamiento forzosos y delincuencia }\end{array}$ & Número \\
\hline
\end{tabular}

\subsubsection{PROGRAMA: POR UN ENVEJECIMIENTO DIGNO}

El programa de Envejecimiento y vejez digna tiene el propósito, a través de la implementación de la política pública, de direccionar, formular, coordinar y gestionar las políticas, planes, programas y proyectos estratégicos de prevención, promoción, intervención y asistencia de las personas mayores, contribuyendo al mejoramiento de las condiciones de vida de esta población.

El programa busca también incentivar la cultura del envejecimiento, donde los habitantes de Medellín sean corresponsables con el cuidado, promoción y protección de las condiciones que conlleven a vivir más y mejor: las relaciones afectuosas con las familias, las relaciones solidarias intergeneracionales y cambios de estilos de vida, con el propósito de llegar a una vejez digna.

Indicadores de resultado

\begin{tabular}{|l|l|c|c|c|}
\hline Nombre & Unidad & Línea de Base & $\begin{array}{c}\text { Meta } \\
2019\end{array}$ & Responsable \\
\hline $\begin{array}{l}\text { Personas con restitución de } \\
\text { derechos a través de la } \\
\text { atención y el acompañamiento } \\
\text { en redes de apoyo social. }\end{array}$ & Número & 1792 & 2152 & $\begin{array}{l}\text { Secretaría } \\
\text { Inclusión, Familia } \\
\text { y.D.H.H }\end{array}$ \\
\hline $\begin{array}{l}\text { Personas Mayores que } \\
\text { favorecen su autonomía e } \\
\text { independencia través de la } \\
\text { participación en las estrategias } \\
\text { que promueven la integración } \\
\text { social y familiar y el ejercicio de } \\
\text { la ciudadanía. }\end{array}$ & Número & 47471 & 58911 & $\begin{array}{l}\text { Secretaría } \\
\text { Inclusión, Familia } \\
\text { y.D.H.H }\end{array}$ \\
\hline
\end{tabular}

\subsubsection{Proyecto: Implementación y seguimiento a la política pública de envejecimiento y vejez}

Con este proyecto se busca consolidar la cultura del envejecimiento en la ciudad de Medellín en los diferentes sectores poblacionales, en procura de lograr el reconocimiento de la situación de vejez como el resultado del proceso vital de los seres humanos, dando relevancia a las condiciones de ser viejo respecto a las necesidades que en esta etapa de la vida se presentan, inherente a la condición humana misma y su curso de vida.

Responsable: Secretaría de Inclusión Social, Familia y Derechos Indicador de producto

Humanos

\begin{tabular}{l} 
Nombre \\
\hline $\begin{array}{l}\text { Comités técnicos realizados para el seguimiento de la política pública de } \\
\text { enveiecimiento v veiez. }\end{array}$
\end{tabular}




\section{Un nuevo modelo de equidad social}

\subsubsection{Proyecto: Envejecimiento digno y acompañado}

Se busca fomentar en la ciudad de Medellín la permanencia e integración de las personas mayores en el núcleo de sus familias y/o en el entorno social habitual, mediante la integración multigeneracional para la productividad social y económica. Proyecto que abarca todas las acciones orientadas a favorecer un envejecimiento "sano" y una condición de vejez digna. e identifica los siguientes componentes: Día de sol para personas mayores, Centro de Servicios Sociales Amautta, apoyo económico, promoción del envejecimiento activo, servicios sociales complementarios a personas mayores, implementar la estrategia de cuidadores y voluntarios.

\section{Responsable: Secretaría de Inclusión Social, Familia y Derechos} Humanos

Indicador de producto

\begin{tabular}{|l|c|}
\hline Nombre & Unidad \\
\hline $\begin{array}{l}\text { Personas Mayores que participan en las actividades que promueven el } \\
\text { envejecimiento digno fortaleciendo habilidades y competencias }\end{array}$ & Número \\
\hline
\end{tabular}

\subsubsection{Proyecto: Atención y acompañamiento integral para personas mayores}

Se busca ofrecer los servicios de la seguridad social integral a las personas mayores de 60 años en extrema vulnerabilidad, sin seguridad social, sin redes de apoyo familiar $\mathrm{y} / \mathrm{o}$ social, en abandono, por emergencia biopsicosocial, y que no se valgan por sí mismos. Brinda atención integral a través de modelos semi-institucionalizados y de larga estancia.

Responsable: Secretaría de Inclusión Social, Familia y Derechos Humanos

Indicador de producto

\begin{tabular}{|l|c|}
\hline Nombre & Unidad \\
\hline $\begin{array}{l}\text { Cupos atendidos en modelos de atención integral institucionalizadas a personas } \\
\text { mayores con alto grados de vulnerabilidad social }\end{array}$ & Número \\
\hline
\end{tabular}

\subsubsection{PROGRAMA: EMPODERAMIENTO Y TRANSVERSALIZACIÓN DE LA EQUIDAD DE GÉNERO}

La implementación de acciones que promuevan el empoderamiento de las mujeres, buscando el reconocimiento y acceso oportuno a derechos, el aumento y cualificación de su participación en los escenarios donde se concertan las decisiones, la toma de conciencia del poder individual y colectivo, y desde allí la construcción de proyectos de vida enmarcados en nuevas oportunidades, será nuestro objetivo.

Frente a ello tenemos clara la responsabilidad de transformar obstáculos institucionales y estructurales para el acceso pleno a los derechos desde un enfoque de equidad de género, por ello continuaremos avanzando en la transversalización del enfoque en los diversos estamentos públicos y 


\section{Un nuevo modelo de equidad social}

privados, para la transformación de imaginarios, y el mejoramiento de la condición y posición de las mujeres urbanas, rurales y campesinas.

Indicador de resultado

\begin{tabular}{|l|c|c|c|c|}
\hline \multicolumn{1}{|c|}{ Nombre } & Unidad & Línea de Base & Meta 2019 & Responsable \\
\hline $\begin{array}{l}\text { Mujeres empoderadas y que } \\
\text { acceden a derechos por el } \\
\text { acompañamiento brindado por } \\
\text { la Secretaría de las Mujeres }\end{array}$ & Porcentaje & SLB & $30 \%$ & $\begin{array}{c}\text { Secretaría de las } \\
\text { Mujeres }\end{array}$ \\
\hline
\end{tabular}

3.2.3.1 Proyecto: Promoción de los derechos de las mujeres, las jóvenes y las niñas

Las niñas, jóvenes y adultas de Medellín participan de estrategias formativas para la reflexión sobre sus proyectos de vida, el desarrollo de sus potencialidades en los ámbitos individual, familiar y local, para la toma de decisiones, la gestión, incidencia y el acceso a derechos en condiciones de equidad.

Las organizaciones sociales de mujeres se fortalecen como potenciadoras del desarrollo individual y social, a través de acciones de acompañamiento y asesoría y la ciudadanía potencia sus capacidades para la gestión de estrategias para el empoderamiento de las mujeres y la promoción de la equidad de género. Adicionalmente, se mejora la atención liderada por las madres comunitarias, a través de acciones de formación y acompañamiento pedagógico para la cualificación de su labor.

Responsable: Secretaría de las Mujeres

Indicador de producto

\begin{tabular}{|l|c|}
\hline Nombre & Unidad \\
\hline $\begin{array}{l}\text { Personas que participan en las acciones que promueven el acceso de las mujeres a } \\
\text { sus derechos y el empoderamiento }\end{array}$ & Número \\
\hline $\begin{array}{l}\text { Organizaciones de mujeres rurales y urbanas con acompañamiento y asesoría para } \\
\text { su fortalecimiento }\end{array}$ & Porcentaje \\
\hline
\end{tabular}

3.2.3.2 Proyecto: Fortalecimiento y creación de centros de equidad de género

Los Centros de Equidad de Género -CEG- son potenciados como instancias para la articulación de servicios dirigidos a las mujeres y contribuyen a la satisfacción de sus necesidades e intereses, especialmente en las áreas de: salud sexual y reproductiva, violencia basada en el género, autonomía económica, educación y participación social.

Se desarrollan procesos de gestión interinstitucional e intersectorial para la remisión a servicios, seguimiento y disposición de la 


\section{Un nuevo modelo de equidad social}

plataforma institucional para la atención de mujeres por parte de otros actores.

Responsable: Secretaría de las Mujeres

Indicador de producto

\begin{tabular}{|l|c|}
\hline Nombre & Unidad \\
\hline Centros de Equidad de Género creados y fortalecidos en la ciudad de Medellín & Número \\
\hline
\end{tabular}

\subsubsection{Proyecto: Transversalización del enfoque de género}

Medellín avanza en la transversalización de la equidad de género en instancias gubernamentales y gremiales, para la sensibilización sobre las desigualdades de género que afectan a las mujeres, jóvenes y niñas, a partir de un trabajo de coordinación e incidencia en acciones en beneficio de la igualdad de género.

Se actualiza la política pública para las mujeres del municipio de Medellín y se implementan medidas de cualificación técnica y $\oplus^{\pi}$ administrativa para el fortalecimiento de la Secretaría de las Mujeres.

Los planes, programas y proyectos municipales cuentan con asesoría técnica para la incorporación del enfoque de género, se fortalece el sistema de información -SICGEM - y se promueve la gestión y producción del conocimiento a través de la elaboración de informes sobre condición y posición de las mujeres.

Responsable: Secretaría de las Mujeres

\begin{tabular}{|l|c|}
\hline Nombre & Unidad \\
\hline $\begin{array}{l}\text { Actualización y formulación de la Política pública para las mujeres del municipio de } \\
\text { Medellín }\end{array}$ & Número \\
\hline $\begin{array}{l}\text { Dependencias de la administración municipal sensibilizadas, capacitadas y/o } \\
\text { fortalecidas para la incorporación del enfoque de genero }\end{array}$ & Número \\
\hline
\end{tabular}

3.2.3.4. Proyecto: Acciones afirmativas en el sistema educativo para las mujeres y las niñas

En Medellín se implementan acciones afirmativas para el acceso y permanencia de las niñas y las mujeres en el sistema educativo, para el disfrute pleno del derecho a la educación.

Se adelantan prácticas pedagógicas para la inclusión del enfoque de

i género en los procesos educativos, en articulación con las diferentes instituciones de educación formal y no formal.

Responsable: Secretaría de las Mujeres 


\section{Un nuevo modelo de equidad social}

Indicador de producto

\begin{tabular}{|l|c|}
\hline Nombre & Unidad \\
\hline $\begin{array}{l}\text { Mujeres que participan en estrategias para la permanencia en el sistema educativo y } \\
\text { para la incorporación del enfoque de género. }\end{array}$ & Número \\
\hline $\begin{array}{l}\text { Personas que participan en estrategias para la transformación de estereotipos que } \\
\text { promueven las relaciones no sexistas en el ámbito educativo y otros. }\end{array}$ & Número \\
\hline
\end{tabular}

\subsubsection{PROGRAMA: PROMOCIÓN DEL DESARROLLO HUMANO INTEGRAL DE LA JUVENTUD}

La población juvenil es parte estructurante del ciclo vital, de la dinámica presente y futura de la ciudad, es por esto que la Secretaría de la Juventud tiene un enfoque transversal dentro de las acciones del gobierno municipal, ya que es necesario integrar desde la institucionalidad las diferentes oportunidades que podemos ofrecer. La juventud es una construcción cultural, que con el transcurrir de los años ha evolucionado acorde a los diferentes momentos históricos de país, hasta llegar al momento en que la juventud trasciende la mirada peligrosista y se constituye en una sujeto social objeto de derechos y deberes, en el que la institucionalidad debe aunar esfuerzos para proveer las diferente oportunidades, que conduzcan a su desarrollo integral, desde un abordaje que le da prioridad a la diversidad y equidad de género, al goce efectivo de los derechos humanos, el fortalecimiento de las habilidades y potencialidades para la vida de los jóvenes.

Partiendo de las necesidades, demandas y dificultades particulares a su edad y que deben ser atendidas de manera específica con el fin de generar promoción e impacto en su desarrollo humano integral, entendiendo éste como la realización de los jóvenes en todas sus dimensiones y una sana experiencia en el transcurrir de esta época de la vida, y para el desarrollo de una sociedad, en tanto, la participación del joven como sujeto social es clave en la construcción de ciudad. Es por esto que desde la Secretaría de Juventud se considera acompañamiento e intervenciones que promocionen y faciliten el acceso a los jóvenes a oportunidades y a la vivencia de su territorio.

Indicador de resultado

\begin{tabular}{|c|c|c|c|c|}
\hline Nombre & Unidad & Línea de Base & Meta 2019 & Responsable \\
\hline $\begin{array}{l}\text { Jóvenes que acceden a } \\
\text { oportunidades }\end{array}$ & Número & 12.017 & 15.000 & $\begin{array}{c}\text { Secretaría de la } \\
\text { Juventud }\end{array}$ \\
\hline
\end{tabular}

\subsubsection{Proyecto: Planeación del territorio joven}

Se fortalecerá el sistema de gestión de información y conocimiento de la Secretaría de la Juventud con el fin de realizar una transversalización efectiva en el marco de las 8 líneas que establece el Plan Estratégico de Juventud 2015-2027, dispone de una estrategia de articulación interinstitucional que permite gestionar y hacer efectivo la implementación de las diferentes líneas, componentes y 


\section{Un nuevo modelo de equidad social}

proyectos determinadas en Plan Estratégico, desde un acompañamiento técnico con calidad en los procesos e información, que son proyectados desde la implementación procesos de comunicación interna y externa para la promoción de las acciones en favor de los jóvenes.

Indicador de producto

Responsable: Secretaría de Juventud

\begin{tabular}{|l|c|}
\hline \multicolumn{1}{|c|}{ Nombre } & Unidad \\
\hline $\begin{array}{l}\text { Acciones de transversalización y articulación realizadas para la población joven } \\
\text { (sello joven) }\end{array}$ & Número \\
\hline Aliados internos y externos para tranversalizar enfoque juventud & Número \\
\hline
\end{tabular}

\subsubsection{Proyecto: Juventud con oportunidades}

Acercar y ofrecer oportunidades a las juventudes del municipio, mediante la lectura continua de contextos territoriales, la difusión de las oportunidades de ciudad de manera presencial y virtual, la generación de alianzas y sinergias con entidades y grupos que hacen ya presencia en los territorios y la sistematización de rutas de atención efectivas. Bajo la premisa de callejear educa permite expandir los territorios de la ciudad para jóvenes y adultos en busca de generar soluciones locales, que propicie el trabajo colaborativo y fomente la apropiación de territorios para que amplíen sus horizontes, conozcan las oportunidades, ofertas y realidades de Medellín, con base en ellas tomen decisiones informadas, que les permitan tener mayores herramientas para transformar su realidad y la de su entorno con capacidad instalada y desde la afirmación de lazos intergeneracionales.

A la vez para facilitar el acceso de los jóvenes a las oportunidades se fortalecerá el servicio de información y orientación para el acceso a oportunidades y servicios gratuitos para los jóvenes que viven en Medellín; se realiza de manera presencial y digital para acercar ofertas, programas, proyectos, convocatorias, actividades y servicios gratuitos que entidades públicas, privadas, mixtas y comunitarias tienen disponibles para los jóvenes de Medellín.

Responsable: Secretaría de Juventud

Indicador de producto

\begin{tabular}{|l|c|}
\hline Nombre & Unidad \\
\hline Orientaciones efectivas para acceso oferta y oportunidades para jóvenes & Número \\
\hline Jóvenes y multiplicadores que acceden rutas para apropiación de ciudad & Número \\
\hline
\end{tabular}


Un nuevo modelo de equidad social

\subsubsection{PROGRAMA: ATENCIÓN E INCLUSIÓN SOCIAL PARA EL HABITANTE DE CALLE}

Según el último censo de habitantes en situación de calle realizado en el año 2009 por la Secretaría de Bienestar Social y la Universidad de Antioquia, a través del Centro de estudios de Opinión (CEO), se identifica en Medellín, un total de 24.352 personas en esta condición, de los cuales $3.381(13.89 \%)$ son habitantes en la calle, entendiendo este término como "persona cuya vida se desenvuelve fundamentalmente en la calle, como espacio físico- social, donde resuelve necesidades vitales, construye relaciones afectivas y mediaciones socio - culturales estructurando un estilo de vida". De acuerdo a este mismo censo, el $87.2 \%$ de los habitantes de la calle tienen entre 18 y 59 años de edad, esto es, 2970 personas. Así mismo, en el mes de febrero 2014 se realizó una caracterización de habitantes de calle de la ciudad de Medellín; con la misma entidad donde se logra identificar un total de 3.250 personas en esta condición, con lo cual se evidencia un notable incremento en la población.

Muchos de los habitantes de calle, padecen discapacidad física y/o mental, careciendo así de las habilidades necesarias para ocuparse de sí mismos, lo cual los pone en condición de extrema vulnerabilidad, aumentando su cronicidad por su hábitat, el rechazo familiar y social y las condiciones propias de una enfermedad no tratada o manejada en inadecuadas condiciones. La carencia de autonomía, la incapacidad de vivir en comunidad y el rechazo familiar y social, hace que la población en calle con trastorno mental y/o físico pierda un lugar en la sociedad, sufriendo en muchos casos las consecuencias de los procesos de pauperización, exclusión y expulsión de otros sistemas de protección social (sanitario, vivienda, empleo) e incluso de la propia red de relaciones sociales.

Este programa se convierte en una oferta institucional única, para este grupo poblacional específicamente dirigida a las personas de ambos sexos, entre los 18 y 59 años de edad; sin hogar, personas que tienen como característica básica el desarraigo y en la mayoría de los casos sufre una situación de extrema pobreza y de exclusión social; carecen de un espacio de referencia estable de convivencia socio-familiar y en algunas ocasiones, mantienen un comportamiento trashumante debido al deseo de anonimato o de huida, o la búsqueda de oportunidades para promoción personal, social y económica. Generalmente son, desvinculadas de su hogar, en situación de Calle y con patologías conexas, sin ubicación laboral definida, quienes perciben sus ingresos de actividades marginales, como ventas ambulantes, reciclaje, lustrador de botas, mendicidad, prostitución, lavada, vigilancia de carros y personas de cualquier edad quienes se encuentren en la ciudad temporalmente desamparada e imposibilitada para regresar a su ciudad de origen. 


\section{Un nuevo modelo de equidad social}

Este programa brinda una oportunidad para aplicar procesos de disminución del daño, resocialización social y familiar, manejo de trastornos dual y atención integral a fin que esta población mejoren su calidad de vida y reduzcan el impacto social de la problemática.

Indicador de resultado

\begin{tabular}{|c|c|c|c|c|}
\hline Nombre & Unidad & Línea de Base & Meta 2019 & \multicolumn{1}{|c|}{ Responsable } \\
\hline $\begin{array}{l}\text { Personas que superan su } \\
\text { situación de calle en la } \\
\text { ciudad de Medellín }\end{array}$ & Numero & 324 & 600 & $\begin{array}{l}\text { Secretaría } \\
\text { Inclusión, Familia y } \\
\text { D.D.H.H.H }\end{array}$ \\
\hline
\end{tabular}

\subsubsection{Proyecto: Política pública social para los habitantes de calle}

Este proyecto tiene por objeto asegurar la construcción, implementación, transversalización y seguimiento de la política pública social para los habitantes de calle del municipio de Medellín, teniendo en cuenta el enfoque de curso de vida en cada uno de los momentos de la construcción de este instrumento de gestión. Para ello se contaría como herramienta principal el censo y diagnóstico de la población.

Responsable: Secretaría de Inclusión Social, Familia y Derechos Humanos

Indicador de producto

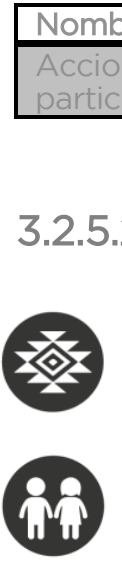

3.2.5.2 Proyecto: Fortalecimiento del sistema de atención para la población de calle

Este proyecto busca atender de manera integral durante 24 horas y 7 días a la población crónica en calle con discapacidad física y enfermedad mental, atender de manera integral a los jóvenes entre 18 y 32 años de edad que están en situación de y en calle a través de procesos que permitan la recuperación revinculación familiar y social del joven, garantizar la atención de los habitantes de calle con trastorno dual, facilitando así el manejo de su patología, promoviendo la revinculación social y familiar y brindar atención básica (aseo, alimentación, hospedaje ) a todos los habitantes de calle adulto, así mismo propiciar la gestión y el efectivo acceso a la oferta institucional incluida la salud; también busca propiciar procesos de resocialización y revinculación social y familiar. Implementar un programa para la atención y reinserción social de la población indígena en situación de mendicidad.

Responsable: Secretaría de Inclusión Social, Familia y Derechos Humanos 
Indicador de producto

\begin{tabular}{|l|l|}
\hline Nombre & Unidad \\
\hline Habitantes de y en calle con atención básica epidemiológica & Número \\
\hline Habitantes de calle con trastorno mental atendidos integralmente & Número \\
\hline
\end{tabular}

\subsubsection{Proyecto: Intervención deportiva, recreativa y de actividad física para la población en riesgo social}

Desde el 2004, se implementa el proyecto para la restitución del derecho al deporte, la recreación, la actividad física y el aprovechamiento del tiempo libre de la población en riesgo social. La oferta aporta al desarrollo humano integral y contribuye a mitigar el impacto negativo por medio del juego, como acción innata, promovida especialmente en los tiempos libres o espacios acondicionados para el descanso.

Responsable: INDER

Indicador de producto

\begin{tabular}{|l|l|}
\hline Nombre & Unidad \\
\hline
\end{tabular}

\begin{tabular}{|l|l|l}
\hline Puntos funcionando con actividades recreativas para la población en riesgo social & Número \\
\hline
\end{tabular}

\subsubsection{Proyecto: Granjas agrícolas y terapeúticas para habitantes de} calle: la vida desde otro lugar

Brindarán servicios orientados al fortalecimiento de las capacidades y el desarrollo de habilidades para el desempeño socio-laboral de hombres y mujeres habitantes de y en calle, que avanzan en su proceso de resocialización e inclusión social y familiar en el marco de ecología humana.

Responsable: Secretaría de Inclusión Social, Familia y Derechos Humanos

Indicador de producto

\begin{tabular}{|l|c|}
\hline Nombre & Unidad \\
\hline Granjas comunitarias implementadas y funcionando & Número \\
\hline
\end{tabular}

\subsubsection{PROGRAMA: SEGURIDAD ALIMENTARIA Y NUTRICIONAL}

Desarrollar proyectos que contribuyan al cumplimiento del derecho a la alimentación y nutrición de la población en situación de vulnerabilidad alimentaria y social del Municipio de Medellín, con el suministro de complemento alimentario con un aporte nutricional, formativo y social, mediante alianzas estratégicas con entidades públicas, privadas y comunitarias.

Hace referencia a la disponibilidad de alimentos, el acceso de las personas a ellos y el aprovechamiento biológico de los mismos. Se considera que un hogar está en una situación de seguridad alimentaria cuando sus miembros disponen de manera sostenida a alimentos suficientes en cantidad y calidad según las necesidades biológicas. 


\section{Un nuevo modelo de equidad social}

Indicadores de resultado

\begin{tabular}{|c|c|c|c|c|}
\hline Nombre & Unidad & Línea de Base & Meta 2019 & Responsable \\
\hline $\begin{array}{l}\text { Hogares con inseguridad } \\
\text { alimentaria moderada y } \\
\text { severa }\end{array}$ & Porcentaje & $31.1 \%$ & $25 \%$ & $\begin{array}{l}\text { Secretaría } \\
\text { Inclusión, Familia y } \\
\text { D.D.H.H } \\
\end{array}$ \\
\hline $\begin{array}{l}\text { Desnutrición aguda en } \\
\text { menores de } 5 \text { años }\end{array}$ & Porcentaje & $1.7 \%$ & $1,2 \%$ & $\begin{array}{l}\text { Secretaría } \\
\text { Inclusión, Familia y } \\
\text { D.D.H.H }\end{array}$ \\
\hline
\end{tabular}

\subsubsection{Proyecto: Huertas para el abastecimiento de alimentos}

El mejoramiento de capacidades institucionales para el abastecimiento de alimentos con enfoque de ciudad región desarrollando un sistema para el abastecimiento de alimentos con énfasis en poblaciones vulnerables; Huertas para autoconsumo y fortalecimiento a Bancos de Alimentos (Fundación Banco Arquidiocesano de Alimentos y Fundación Saciar).

Responsable: Secretaría de Desarrollo Económico

Indicador de producto

\begin{tabular}{|l|c|}
\hline Nombre & Unidad \\
\hline Huertas para el autoconsumo y/o comercialización establecidas & Número \\
\hline
\end{tabular}

\subsubsection{Proyecto: Acceso a los alimentos y complementación alimentaria}

Garantizar el acceso físico y económico de los alimentos es vital para que exista seguridad alimentaria y nutricional. La autonomía económica de los hogares, materializada a través de los ingresos, es uno de los determinantes más fuertes del acceso y por tanto del consumo de los alimentos; cuando las personas cuentan con los recursos suficientes para satisfacer sus necesidades básicas, pueden tomar mejores decisiones frente a su alimentación, dado que, las personas y hogares con más bajos ingresos, tienden a convertir la alimentación en uno de los asuntos, que siendo un derecho fundamental y un acto indispensable para la supervivencia, es el que más se sacrifica desde el punto de vista de la cantidad, la calidad y la variedad.

Responsable: Secretaría de Inclusión Social, Familia y Derechos Humanos

Indicador de producto

\begin{tabular}{|l|c|}
\hline Nombre & Unidad \\
\hline $\begin{array}{l}\text { Personas participantes en programas o proyectos de complementación o } \\
\text { asistencia alimentaria }\end{array}$ & Número \\
\hline
\end{tabular}

\subsubsection{Proyecto: Nutrición para la salud}

Comprende acciones relacionadas con la promoción de la salud, la prevención de la enfermedad, la atención y la recuperación o rehabilitación, para el mantenimiento de las condiciones de salud, ligadas al estado nutricional de la población que habita en el 


\section{Un nuevo modelo de equidad social}

municipio de Medellín, este programa requiere una articulación estrecha con la Secretaría de Salud. Las principales acciones son: Evaluación alimentaria y nutricional, Educación alimentaria y nutricional indispensable para la supervivencia, es el que más se sacrifica desde el punto de vista de la cantidad, la calidad y la variedad.

Responsable: Secretaría de Inclusión Social, Familia y Derechos Humanos

Indicador de producto

\begin{tabular}{|l|c|}
\hline Nombre & Unidad \\
\hline $\begin{array}{l}\text { Personas participantes de acciones de información, educación y comunicación en } \\
\text { temas de alimentación y nutrición }\end{array}$ & Número \\
\hline
\end{tabular}

3.2.6.4 Proyecto: Política Pública de Seguridad Alimentaria y Nutricional El seguimiento a la implementación de la política pública, permitirá la toma de decisiones estratégicas y operativas y la optimización de los recursos disponibles. La operacionalización de esta estrategia debe estar orientada por los principios de oportunidad, confiabilidad y pertinencia de la información como insumos indispensables para la eficiencia, eficacia y transparencia de la gestión pública. Los principales subproyectos son: Diseño e implementación del Observatorio Local en SAN, Diseño y puesta en marcha de un sistema de monitoreo y evaluación, Desarrollo de investigación y de innovación, Participación y Movilización Social.

Responsable: Secretaría de Inclusión Social, Familia y Derechos Humanos

Indicador de producto

\begin{tabular}{|l|c|}
\hline Nombre & Unidad \\
\hline Comités de seguridad alimentaria establecidos & Número \\
\hline
\end{tabular}

\subsubsection{PROGRAMA: SER CAPAZ: PERSONAS CON DISCAPACIDAD, FAMILIARES Y CUIDADORES}

El Programa Ser Capaz coordina la implementación de la Política Pública de Discapacidad, orienta y asesora a la población en la oferta de servicios de la ciudad, promueve servicios de habilitación, rehabilitación, procesos de participación ciudadana y promociona los derechos de las personas con discapacidad de la ciudad de Medellín.

Indicadores de resultado

\begin{tabular}{|l|l|l|l|l|}
\hline Nombre & Unidad & Línea de Base & Meta 2019 & Responsable \\
\hline $\begin{array}{l}\text { Personas con discapacidad } \\
\text { que mejoran sus } \\
\text { competencias, a través de } \\
\text { procesos de habilitación y } \\
\text { rehabilitación }\end{array}$ & Número & ND & 1000 & $\begin{array}{l}\text { Secretaría Inclusión, Familia y } \\
\text { D.D.H.H }\end{array}$ \\
\hline
\end{tabular}


Un nuevo modelo de equidad social

3.2.7.1 Proyecto: Inclusión social de las personas con discapacidad y fortalecimiento a cuidadores

Se busca la inclusión de las personas con discapacidad y cuidadores con el fin de lograr la equiparación de oportunidades, autonomía e independencia por medio del desarrollo de componentes como: Ser capaz en casa, Inclusión e intermediación socio-laboral, rehabilitación funcional, equinoterapia a personas con discapacidad, habilitaciónrehabilitación a niños niñas y adolescentes con discapacidad intelectual, emprendimiento a cuidadores de personas con discapacidad, apoyo económico para personas con discapacidad.

Responsable: Secretaría de Inclusión Social, Familia y Derechos Humanos

Indicador de producto

\begin{tabular}{|l|c|}
\hline \multicolumn{1}{|c|}{ Nombre } & Unidad \\
\hline $\begin{array}{l}\text { Personas con discapacidad y cuidadores atendidos en procesos de habilitación, } \\
\text { rehabilitación y equiparación de oportunidades. }\end{array}$ & Número \\
\hline
\end{tabular}

\subsubsection{Proyecto: Plan municipal de discapacidad - ejercicio de derechos de las personas con discapacidad}

A través del proyecto se busca contribuir a la garantía de los derechos de las personas con discapacidad, familiares y cuidadores, mediante la atención psicosocial y la adopción de acciones afirmativas que permitan su autonomía e independencia, por medio de procesos participativos, intersectoriales e interinstitucionales. Incluye fortalecimiento del sistema de seguimiento y evaluación a la Política Pública de Discapacidad, Plan Municipal de Discapacidad, consolidación de espacios de participación, deliberación y gestión en torno a la discapacidad, formación en discapacidad, sensibilización en diseño universal, orientación y seguimiento a las personas con discapacidad, familiares y cuidadores y fortalecimiento institucional para la garantía de derechos.

Responsable: Secretaría de Inclusión Social, Familia y Derechos Humanos

Indicador de producto

\begin{tabular}{|l|c|}
\hline \multicolumn{1}{|c|}{ Nombre } & Unidad \\
\hline $\begin{array}{l}\text { Actores que participan en espacios de deliberación, sensibilización y orientación } \\
\text { que contribuyen a la garantía de derechos de las personas con discapacidad, } \\
\text { familiares y cuidadores. }\end{array}$ & Número \\
\hline
\end{tabular}

\subsubsection{Proyecto: Deporte sin límites}

Desde el año 2004 la práctica de actividad física, el deporte y la recreación, descubre, potencia e impulsa a la persona con discapacidad al ejercicio de sus derechos. El proyecto contribuye a disminuir el sedentarismo, favorece la adopción de estilos de vida saludables para que las personas sean más funcionales e independientes y se restablezca la inclusión a la vida social. 


\section{Un nuevo modelo de equidad social}

Comprende una oferta de actividad física permanente, los Juegos Deportivos y Recreativos, un componente pedagógico y otras actividades complementarias como los ciclopaseos, los campamentos y las jornadas pedagógicas.

Responsable: INDER

Indicador de producto

\begin{tabular}{|l|c|}
\hline \multicolumn{1}{|c|}{ Nombre } & Unidad \\
\hline Personas usuarias del proyecto que participan en actividades deportivas & Número \\
\hline Juegos deportivos y recreativos para personas con discapacidad realizados & Número \\
\hline
\end{tabular}

\subsubsection{PROGRAMA: DIVERSIDAD SEXUAL E IDENTIDADES DE GÉNERO}

En aras de que la población diversa sexualmente goce de manera efectiva sus derechos, se busca la transformación de imaginarios, comportamientos y actitudes a contrarresten situaciones de discriminación y de exclusión en la ciudad de Medellín, partiendo de la articulación institucional y la transversalización de enfoques de derechos, de género y de curso de vida, buscando a través de acciones afirmativas la reducción de cualquier forma de estigmatización o estereotipo que sea una barrera para la inclusión social de la población LGBTI.

Indicador de resultado

\begin{tabular}{|c|c|c|c|c|}
\hline Nombre & Unidad & Línea de Base & Meta 2019 & Responsable \\
\hline $\begin{array}{l}\text { Personas que transforman } \\
\text { su imaginarios y cambian } \\
\text { sus estereotipos en pro de la }\end{array}$ & Número & NA & 10.800 & $\begin{array}{c}\text { Secretaría de } \\
\text { Inclusión, Familia y } \\
\text { Inclusión de la Población } \\
\text { Diversa Sexualmente }\end{array}$ \\
\hline
\end{tabular}

\subsubsection{Proyecto: Reconocimiento de la diversidad sexual e identidades de} género desde una pedagogía de la inclusión

Este proyecto busca reconocer y empoderar la diversidad sexual e identidades de género a través del fortalecimiento cultural, social y comunicacional, con el fin de brindar una vida digna, gratificante y sin prejuicios basados en la orientación sexual o identidad de género, visualizando así a las personas Lesbianas, Gay, Bisexuales, Transgenerista e Intersexuales (LGBTI) habitantes de Medellín como seres humanos que viven abiertamente y con dignidad, garantizando la protección, restablecimiento, atención y garantía de derechos para la aceptación e igualdad.

Responsable: Secretaría de Inclusión Social, Familia y Derechos Humanos

Indicador de producto

\begin{tabular}{|l|c|}
\hline Nombre & Unidad \\
\hline Personas LGBTI que reciben orientación en inclusión laboral & Número \\
\hline Personas sensibilizadas en Diversidad sexual e identidades de género & Número \\
\hline
\end{tabular}


3.2.8.2 Proyecto: Implementación y seguimiento de la política pública para el reconocimiento de la diversidad sexual e identidades de género

Este proyecto busca asegurar la creación, implementación transversalización y seguimiento del plan de acción y cumplimiento de la política pública de la diversidad sexual e identidad de género para la protección, restablecimiento, atención, y la garantía de derechos de la personas lesbianas, gays, bisexuales, transgenersitas e intersexuales (LGBTI) habitantes de Medellín.

Responsable: Secretaría de Inclusión Social, Familia y Derechos

Humanos

Indicador de producto

\begin{tabular}{|l|c|}
\hline \multicolumn{1}{|c|}{ Nombre } & Unidad \\
\hline Grupos y colectivos LGBTI fortalecidos para ejercicio de sus derechos & Número \\
\hline $\begin{array}{l}\text { Instituciones educativas sensibilizadas en el reconocimiento de la diversidad } \\
\text { sexual e identidades de género }\end{array}$ & Número \\
\hline
\end{tabular}

\subsubsection{PROGRAMA: DIVERSIDAD ÉTNICA}

Su propósito es promover la inclusión social de los grupos étnicos de la ciudad con equidad, bajo principios y valores de identidad cultural y corresponsabilidad, con un enfoque poblacional de acciones afirmativas y atención diferencial étnica, mediante el desarrollo de estrategias, políticas, planes, programas y proyectos de inclusión social y restablecimiento de derechos.

Fomenta la transversalización del enfoque étnico en la gestión pública local, propiciando que sea parte de la agenda pública del Municipio de Medellín a la hora de comprender la realidad y dinámica de las poblaciones étnicas, principalmente afrodescendientes e indígenas, así como en la construcción de propuestas adecuadas y pertinentes a su contexto étnico y cultural.

Indicador de resultado

\begin{tabular}{|l|c|c|c|c|}
\hline Nombre & Unidad & Línea de Base & Meta 2019 & Responsable \\
\hline $\begin{array}{l}\text { Transversalización de la } \\
\text { implementación de la } \\
\text { variable y el enfoque étnico } \\
\text { en la administración } \\
\text { Municipal. Porcentaje }\end{array}$ & 0 & $80 \%$ & $\begin{array}{c}\text { Secretaría de } \\
\text { Inclusión, Familia y } \\
\text { D.D.H.H }\end{array}$ \\
\hline
\end{tabular}

\subsubsection{Proyecto: Transversalización y educación en asuntos étnicos}

Este proyecto comprende acciones como: Transversalización del enfoque y la variable étnica en cada una de las dependencias y entes descentralizados del municipio de Medellín, estructuración de la variable étnica en los sistemas de información de la Alcaldía. Fortalecimiento administrativo en términos de recursos humanos, 


\section{Un nuevo modelo de equidad social}

técnicos, logísticos, para la gestión eficiente de los asuntos étnicos, fortalecimiento y adecuación del Centro de Integración Afrodescendiente, culminación locativa, dotación, dinamización, administración del centro y suministro de genéricos. Plan de medios y comunicaciones con enfoque étnico, gestión de información, gestión de cooperación internacional. Gestión acciones afirmativas en el tema educativo, celebración de convenios y alianzas para el beneficio de la población étnica, estímulo y articulación de procesos de investigación y sistematización que permitan el análisis de los programas de impacto orientados a la calidad de vida de la población étnica.

Responsable: Secretaría de Inclusión Social, Familia y Derechos Humanos

Indicador de producto

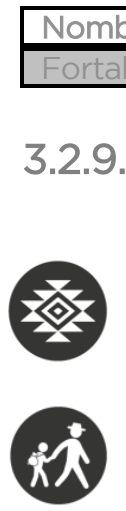

En corresponsabilidad con la Unidad de víctimas se diseñará un programa de reparación colectiva con enfoque diferencial, se desarrollarán acciones deportivas, lúdicas y de sano esparcimiento, salud, educación (básica primaria, secundaria, superior y complementaria), empleabilidad, habitante de calle, seguridad alimentaria, dignificación del empleo en construcción y servicio doméstico, servicios públicos, salud mental, discapacidad, género y mujer, adulto mayor, niñez, acompañamiento psicosocial a familias en territorio y fortalecimiento a organizaciones afrodescendientes de la ciudad de Medellín.

Responsable: Secretaría de Inclusión Social, Familia y Derechos Humanos

Indicador de producto

\begin{tabular}{|l|c|}
\hline Nombre & Unidad \\
\hline $\begin{array}{l}\text { Implementación de la política pública Afrodescendiente y el plan de } \\
\text { Etnodesarollo }\end{array}$ & Porcentaje \\
\hline
\end{tabular}




\section{Un nuevo modelo de equidad social}

\subsubsection{Proyecto: Reconocimiento y garantía de derechos de los pueblos indígenas en Medellín}

Se hace necesario formular y reglamentar la política pública indígena. En corresponsabilidad con la Unidad de Victimas diseñar un programa de reparación colectiva con enfoque diferencial, en concordancia con el Isvimed adelantar soluciones de vivienda, en armonía con el Inder desarrollar acciones deportivas, lúdicas y de sano esparcimiento, salud, educación (básica primaria, secundaria, superior y complementaria), empleabilidad, habitante de calle, seguridad alimentaria, dignificación del empleo en construcción y servicio doméstico, servicios públicos, salud mental, discapacidad, género y mujer, adulto mayor, niñez, acompañamiento psicosocial a familias en territorio y fortalecimiento a organizaciones indígenas de la ciudad de Medellín.

En coordinación con las dependencias necesarias, diseñar la ruta para la restitución de derechos de niños, niñas y adolescentes indígenas en situación de explotación. Realización de acciones afirmativas en el marco de conmemoraciones.

Responsable: Secretaría de Inclusión Social, Familia y Derechos Humanos

Indicador de producto

\begin{tabular}{|l|c|}
\hline Nombre & Unidad \\
\hline Formulación e implementación de política pública para población indígena & Porcentaje \\
\hline
\end{tabular}

\subsubsection{PROGRAMA: FAMILIA}

Familia es un programa que tiene como marco la Política Pública para la Familia y pretende desplegar estrategias, acciones, colocando a la familia en el centro de atención de los procesos buscando reconocer y potencializar en ella su capacidad de agencia alrededor de temas como vida digna, formación de seres y vínculos y participación democrática. En éste, se tienen presente a todos los grupos poblacionales, en el curso de vida, independiente de su condición, bajo un trabajo de corresponsabilidad y oportunidades.

Indicadores de resultado

\begin{tabular}{|l|l|c|c|c|}
\hline \multicolumn{1}{|c|}{ Nombre } & Unidad & Línea de Base & Meta 2019 & Responsable \\
\hline $\begin{array}{l}\text { Personas que mejoran sus } \\
\text { relaciones familiares y/o } \\
\text { sociales por medio del } \\
\text { acompañamiento de la } \\
\text { estrategia Familia Medellín. }\end{array}$ & Número & 5000 & 6000 & $\begin{array}{l}\text { Secretaría Inclusión, Familia y } \\
\text { D.D.H.H }\end{array}$ \\
\hline $\begin{array}{l}\text { Personas acompañadas que } \\
\text { se reintegran a sus núcleos } \\
\text { familiar }\end{array}$ & Número & NA & 1000 & $\begin{array}{l}\text { Secretaría Inclusión, Familia y } \\
\text { D.D.H.H }\end{array}$ \\
\hline
\end{tabular}




\section{Un nuevo modelo de equidad social}

\subsubsection{Proyecto: Familias Medellín - Medellín solidaria}

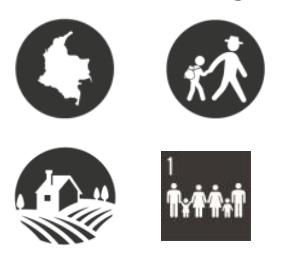

A través del proyecto se busca atender a la población en pobreza extrema, por medio del acompañamiento familiar, acercamiento de oportunidades, acciones de innovación ciudadana para la familia, acompañamiento comunitario considerando los grupos diferentes grupos poblacionales; así mismo por medio del proyecto se realiza la operación de programas con Prosperidad Social como una estrategia del nivel nacional para la superación de la pobreza extrema.

Responsable: Secretaría de Inclusión Social, Familia y Derechos Humanos

Indicador de producto

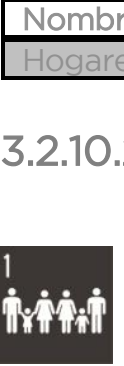

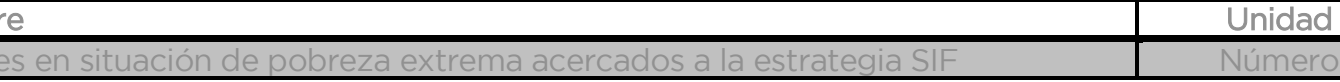

A través del proyecto se busca atender a las familias de Medellín, considerando los grupos diferentes grupos en el marco del curso de vida (niñez y adolescencia, juventud, adultos y adultos mayores; igualmente población en condición de discapacidad, étnica, LGTBI, desplazamiento, entre otros) por medio del acompañamiento familiar, acercamiento de oportunidades, acciones de innovación ciudadana para la familia, acompañamiento comunitario, redes de apoyo social, pedagogía hacia la cultura ciudadana y la dinamización de acciones en alrededor de la estrategia de cuidadoras y cuidadores en enlace con las Unidades de Adulto Mayor y Discapacidad.

Igualmente, por medio del proyecto se pretenden realizar acciones de acompañamiento individual, familiar, grupal, y acciones de promoción y prevención de problemáticas psicosociales que se presentan en Medellín como: violencia social, violencia intrafamiliar, violencias sexuales, consumo problemático de sustancias psicoactivas, embarazo en niñas y adolescentes, entre otros.

Responsable: Secretaría de Inclusión Social, Familia y Derechos Humanos

Indicadores de producto:

\begin{tabular}{|l|c|}
\hline Nombre & Unidad \\
\hline Hogares en acompañamiento familiar para la superación de la pobreza extrema & Número \\
\hline $\begin{array}{l}\text { Centros integrales para la familia funcionando en cada una de las comunas y } \\
\text { corregimientos }\end{array}$ & Número \\
\hline Familias que mejoran su calidad de vida a través de procesos de inclusión social. & Número \\
\hline
\end{tabular}




\section{Un nuevo modelo de equidad social}

\subsubsection{Proyecto: Volver a casa}

A través del proyecto, se potenciará el retorno o regreso de los seres humanos en diversas situaciones de vulnerabilidad social a sus familias, en enlace especialmente las unidades de la Secretaría de Inclusión Social y Familia y las demás secretarías de la Alcaldía de Medellín.

Responsable: Secretaría de Inclusión Social, Familia y Derechos Humanos

Indicador de producto

\begin{tabular}{|l|c|}
\hline Nombre & Unidad \\
\hline Personas acompañadas para su reintegración familiar & Número \\
\hline Seguimiento a personas reintegradas familiarmente & Número \\
\hline
\end{tabular}




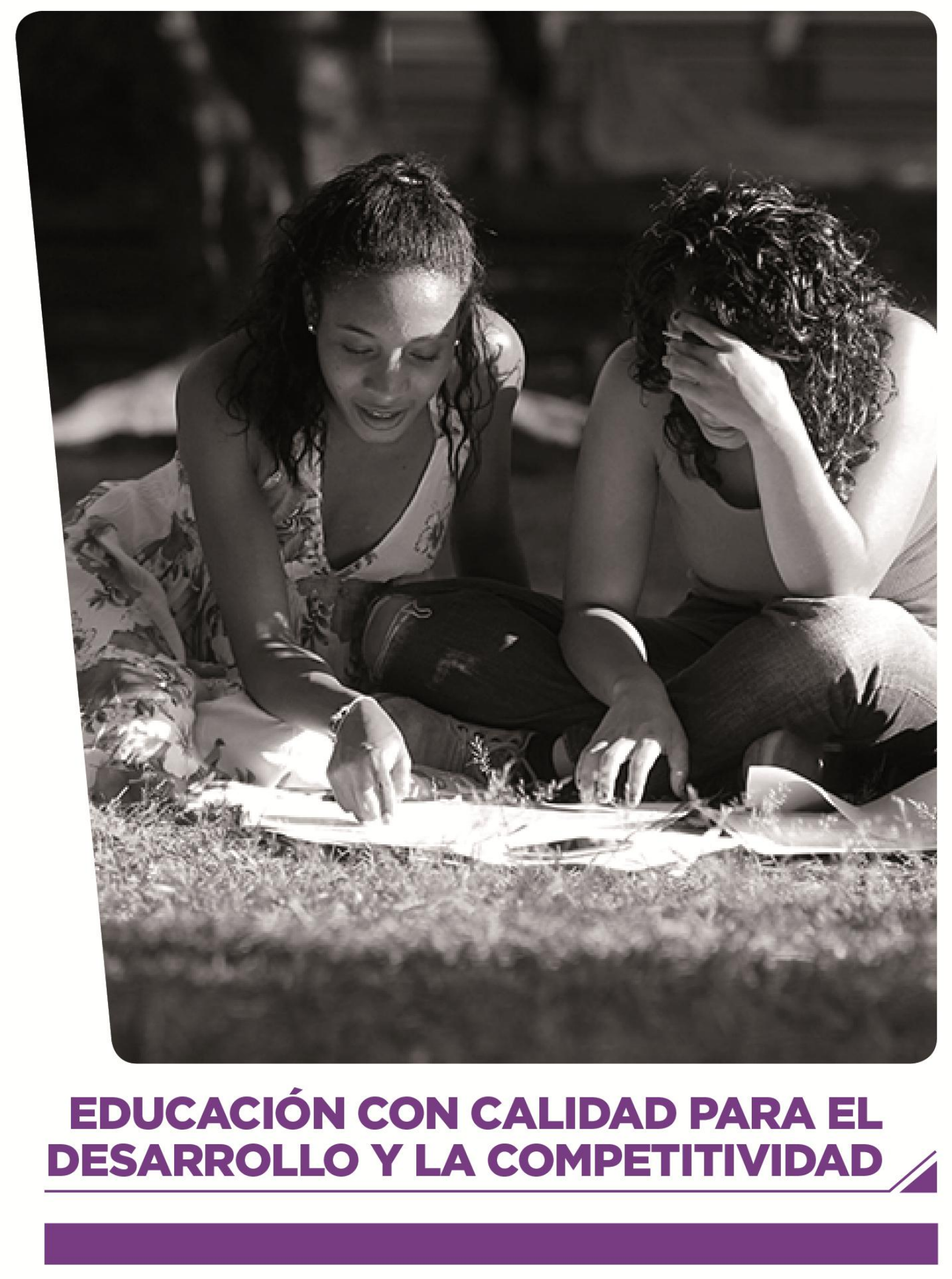




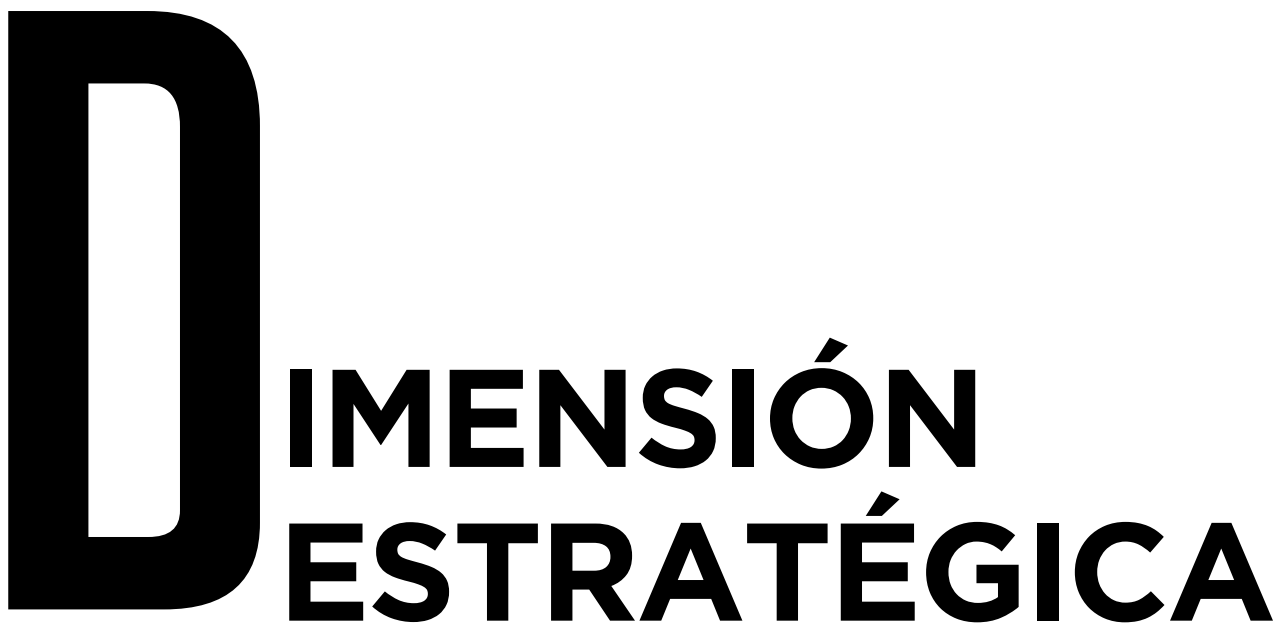

\section{Educación con calidad para el desarrollo y la competitividad}

Promover una educación pertinente e integral para los ciudadanos, que contribuya de manera estratégica al desarrollo y la competitividad de la ciudad y promueva procesos innovadores y de investigación. 


\section{- DIAGNÓSTICO •}

Una de las premisas del Plan de Desarrollo Medellín Cuenta con Vos 20162019, hace referencia a la importancia de ofrecer a la población acceso a educación de calidad, pertinente, y que responda al fortalecimiento de las capacidades de cada ciudadano y el uso de estas en la sociedad, lográndose de este modo un desarrollo integral.

El desarrollo de Medellín tiene una clara orientación hacia el ser humano, resaltando sus capacidades productivas enmarcadas dentro de su entorno cultural; es por ello que no solo se habla de crecimiento, de máquinas o de más estudios, sino que se trascienda a la generación de conocimientos que dinamicen el entorno, bajo el fundamento de una destrucción creativa (Acemoglu \& Robinson, 2014) que mejore las condiciones de vida en el territorio. Para que se alcancen este objetivo, la corresponsabilidad entre gobierno nacional, local, empresas y familias es fundamental para estimular proyectos productivos y sociales que permitan la generación de incentivos a la innovación, el ahorro y la inversión, generando de este modo el fortalecimiento institucional requerido.

El fundamento de dicho desarrollo se encuentra en la educación, la cultura, el emprendimiento, la innovación, la tecnología y la articulación institucional con el resto del mundo. Estos componentes deben permitir la incorporación de saberes que potencialicen el desarrollo de los ciudadanos en todos los ámbitos del desarrollo humano; teniendo claro que en todas las sociedades se deben de proveer los mecanismos suficientes para poder acceder al conocimiento y a la cultura artística y científica, que constituyen los objetivos mismos de la civilización (Piketty, 2013). La educación como herramienta de desarrollo permite seguir ampliando, entre otros componentes, las oportunidades de los ciudadanos a una oferta laboral más diversa e incluyente, acercando ésta, generada por mano de obra calificada, a la demanda laboral requerida por los entes económicos asentados en la ciudad, quienes tienen requerimientos de conocimientos específicos en el desarrollo de su actividad productiva.

Tal como se ha expuesto, es fundamental el enfoque de la educación para el desarrollo, este puede ser uno de los instrumentos más importantes para atacar uno de los factores que limitan el bienestar, como es la desigualdad económica, la desigualdad en los ingresos, medida por el Coeficiente de Gini que en Medellín y su Área Metropolitana para el año 2014 se ubica 0.526.

El alcance de la pertinencia educativa, en aras de contribuir al mejoramiento de la calidad de vida de los habitantes de la ciudad de Medellín, debe abarcar, no sólo el ámbito del desarrollo económico, sino 
también el de la formación de ciudadanos como una fórmula de gran valía para el fortalecimiento de las bases de una sociedad, tanto próspera, como democrática. En este sentido Medellín presenta las siguientes condiciones generales en educación, cultura y desempeño económico.

\section{- PRESENTACIÓN •}

Las diferentes políticas públicas aprobadas para el municipio de Medellín sirven de guía para que el eje articulador de la dimensión sea la calidad de la educación. Así por ejemplo, politicas públicas educativas10 llevan a asumir el Reto de Medellín camino a la excelencia y la calidad, de ahí que, los diferentes retos de la dimensión buscan la generación de capacidades humanas para el desarrollo económico y social

Se parte de que Medellin se construye desde la cultura y por lo tanto ella es transversal a todas las dimensiones del plan de Desarrollo, y en concordancia con el Plan de cultura al 2020, se asume la cultura11 como un factor de competitividad, articulado con la búsqueda de generación de cultura innovadora del ciudadano de Medellín.

El compromiso adquirido de avanzar a un sistema de jornada única escolar permitirá responder a la necesidades surgidas de los encuentros comunitarios de formulacion del plan de desarrollo, de ampliar la formación en las áreas del arte y la cultura.

Para el desarrollo económico se afronta el compromiso de una Medellín con acceso al empleo de calidad $^{12}$ es así como el reto cuenta con el programa de educación pertinente a la dinámica laboral y de acercamiento de la oferta y demanda laboral en la ciudad.

Se busca una formación bilingüe ${ }^{13}$ que potencie, entre otras, la vocación turística urbana y rural de la ciudad ${ }^{14}$ al igual forma la generación de oportunidades de desarrollo social, cultural y de crecimiento económico incentivando el turismo deportivo y la masificación del deporte con la realización de eventos de gran formato.a mejorar la compertividad de nuestra ciudad.

\footnotetext{
10 Acuerdo 19 de 2015: "Política pública de formación de Maestros y Maestras en el municipo de Medellin".

${ }^{11}$ Acuerdo 22 de 2015: "Política pública para el fortalecimiento del sector cinematográfico de Medellín”.

${ }_{12}^{12}$ Acuerdo 64 de 2013: "Política pública de trabajo decente".

13 Acuerdo 089 de 2013: "Política de idiomas para Medellín"

14 Acuerdo 020 de 2015: "Política Pública de turismo" y Acuerdo 078 de 2013: "Política de Turismo Corporativo, grandes eventos y eventos del conocimiento".
} 
Para mejorar la compertividad se contemplan programas para fortalecer la educación técnica y superior pertinentes y de calidad, ligadas a la estrategia de los cluster.

Se asume el reto de Medellín innovadora15 de alto impacto apoyada en procesos de formación virtual y presencial que fortalezcan las capacidades de innovación, mediante la apropiación social de la investigación científica, apoyo a semilleros y grupos de investigación, formación de científicos en nivel de posgrado y apoyo financiero para la investigación científica del sistema de educación superior.

El alcanzar los objetivos de la dimension han de llevar a Medellin a liderar un modelo educativo integral que ha de extenderse al Area Metropolitana y Valle de aburrá con vision regional y proyección Internacional del sistema de educación superior.

A continuación se presentan los indicadores de impacto de la dimensión:

Indicadores de impacto

\begin{tabular}{|c|c|c|c|c|}
\hline Nombre & Unidad & Linea de Base & Meta 2019 & Responsable \\
\hline Índice de Desarrollo Humano & Número & 87.52 & $>=87.52$ & $\begin{array}{l}\text { Departamento } \\
\text { Administrativo de } \\
\text { Planeación }\end{array}$ \\
\hline Tasa de desempleo & Porcentaje & 10.6 & $<=10.6$ & $\begin{array}{l}\text { Secretaría } \\
\text { Desarrollo } \\
\text { Económico }\end{array}$ \\
\hline $\begin{array}{l}\text { Cobertura del Sistema de } \\
\text { Seguridad Social Integral } \\
\text { (Régimen Contributivo) }\end{array}$ & Porcentaje & 4.7 & $>=45$ & $\begin{array}{l}\text { Secretaría } \\
\text { Desarrollo } \\
\text { Económico }\end{array}$ \\
\hline Erradicación del trabajo infantil & Porcentaje & 9.2 & $<=9$ & $\begin{array}{l}\text { Secretaría } \\
\text { Desarrollo } \\
\text { Económico }\end{array}$ \\
\hline $\begin{array}{l}\text { Índice de competitividad urbana } \\
\text { (ICUR) }\end{array}$ & Número & 15 & $<=15$ & $\begin{array}{l}\text { Secretaría } \\
\text { Desarrollo } \\
\text { Económico }\end{array}$ \\
\hline Producto Interno Bruto & $\begin{array}{l}\text { Millones de } \\
\text { pesos }\end{array}$ & 36188511 & $>=36188511$ & $\begin{array}{l}\text { Departamento } \\
\text { Administrativo } \\
\text { Planeación }\end{array}$ \\
\hline $\begin{array}{l}\text { Años promedio de estudio de la } \\
\text { población de } 15 \text { a } 24 \text { años }\end{array}$ & Número & 10.57 & 10.8 & $\begin{array}{l}\text { Secretaría } \\
\text { Educación }\end{array}$ \\
\hline
\end{tabular}

En este sentido proponemos para Medellín bajo las condiciones generales en educación, cultura y desempeño económico los siguientes retos:

15 Acuerdo 35 de 2014: "Política Pública de innovación y emprendimiento social para Medellín". 
4.1. RETO

MEDELLÍN, CAMINO A LA EXCELENCIA Y LA CALIDAD

\section{PROGRAMAS}

4 4.1.1 Maestros y maestras sujetos de saber

$\Delta$ 4.1.2. Infraestructura para la calidad de la educación

$\Delta$ 4.1.3. Medellín multilingüe

4 4.1.4 Promoción de las capacidades y talentos de los ciudadanos

4 4.1.5. Comunidad educativa como escenario de desarrollo
OBJETIVO

Garantizar una educación inclusiva y pertinente, promoviendo oportunidades educativas de calidad desde la primera infancia hasta el final de proceso educativo de las personas, generando oportunidades y creando ciudadanos más críticos que 


\subsection{Medellín, camino a la excelencia y la calidad}

El acceso a una educación con calidad es uno de los motores principales del desarrollo social y económico de una ciudad. Medellín ha considerado de vital importancia y como base de la calidad educativa el incidir positivamente en la formación de los maestros, de ello da cuenta que al 2014 el 51,5\% de los maestros vinculados a la Secretaría de Educación han alcanzado estudios de posgrado; lo cual también genera el imperativo de seguir avanzando en la materia, haciéndose fundamental concentrar esfuerzos en el $48,5 \%$.

En relación con la calidad, se ha evidenciado a través de las pruebas Saber de $3^{\circ}, 5^{\circ}, 9^{\circ}$ y $11^{\circ}$ que el área de matemáticas presenta los resultados más bajos en cada grado comparado con lenguaje y ciencias naturales. Esta situación se ve reflejada por igual tanto en el sector oficial como en el no oficial, aunque las brechas existentes entre ambos sectores continúan siendo amplias. Al analizar los resultados con el agregado nacional, Medellín cuenta con mayores porcentajes de estudiantes en niveles satisfactorios y avanzado en la mayoría de las áreas y grados, exceptuando matemáticas de $5^{\circ}$, sin embargo, la ciudad presenta menores niveles de desempeño Bogotá, Bucaramanga y Manizales. Lo anterior se refleja de manera similar en las pruebas internacionales PISA, donde en 2012 cerca de $67 \%$ de los estudiantes están por debajo del nivel 2 (insuficiente) en matemáticas y $46 \%$ en lenguaje. Específicamente, en materia de resultados en inglés en la prueba Saber 11, aún se presentan bajos niveles de comprensión y comunicación. Así, para 2014 el 49\% de los evaluados se ubicaron en nivel A- lo que implica que no se alcanzan los niveles mínimos de comprensión de la segunda lengua y tan solo un 9\% alcanza los niveles avanzados B1 y B+. Por otro lado, según la Encuesta de Calidad de Vida (ECV) del año 2014, el porcentaje de mujeres mayores de 15 años que manifiestan no saber escribir y leer más de un párrafo es de $2.8 \%$, frente a los hombres que es de $2.7 \%$, por lo que los esfuerzos en la realización de programas de validación para la educación básica y media la deben continuar.

A su vez, la plataforma de infraestructura con la que cuenta Medellín, garantiza el acceso de toda la población, con Instituciones Educativas (IE) de alta calidad como los colegios maestros. De acuerdo al directorio de establecimientos educativos con corte a diciembre de 2015, está representada por 812 plantas físicas educativas; de las cuales 408 son oficiales, 4 de régimen especial (plantas que no reciben recursos del ente central), 11 en comodato, 61 de cobertura contratada y 328 privadas. El total de estas instituciones educativas (IE), prestan sus servicios a 435.909 en diferentes niveles del proceso educativo estudiantes, de los cuales un $88 \%$ están en edad escolar, $75 \%$ están matriculados en IE públicas, $9 \%$ por cobertura contratada y $16 \%$ en privadas. 
Otro aspecto importante en términos de la calidad es la aplicación de la encuesta de ambiente escolar, la cual mide la percepción de las expectativas académicas, la comunicación, participación, seguridad y respeto de la IE y su comunidad educativa, aportando información relevante sobre diferentes aspectos de la calidad. En el 2014, la percepción promedio total en el sector oficial fue de 6,7 puntos sobre 10 y aunque se han presentado mejoras en la dimensión de seguridad y respeto alcanzando los 7,1 , las dimensiones de participación y comunicación aún mantienen valoraciones por debajo del promedio del sector oficial (6,3 y 6,7 respectivamente). Esta encuesta, a su vez, permite calcular instrumentos complementarios como el índice multidimensional de calidad educativa, que se compone de tres dimensiones: rendimiento académico (resultado en las pruebas Saber $5^{\circ}, 9^{\circ}$ y $11^{\circ}$, tasas de extraedad y tasas de aprobación), progreso (mejoramiento de la IE en términos de lograr mejores puntajes en Saber $5^{\circ}, 9^{\circ}$ y $11^{\circ}$ ) y el ambiente escolar, aportando información relevante sobre diferentes aspectos de la calidad. El índice ha tenido un comportamiento estable, permaneciendo alrededor de 50 puntos de 100 posibles desde el 2011 al 2014.

A continuación se describen los indicadores de resultado que evaluarán este reto:

\begin{tabular}{|l|c|c|c|c|}
\hline Nombre & Unidad & Línea de Base & Meta 2019 & Responsable \\
\hline $\begin{array}{l}\text { Índice Multidimensional de } \\
\text { Calidad Educativa de IE } \\
\text { oficiales }\end{array}$ & Número & 47.29 & 49 & $\begin{array}{l}\text { Secretaría de } \\
\text { Educación }\end{array}$ \\
\hline $\begin{array}{l}\text { Estudiantes K11 (ciclo regular } \\
\text { educativo) inscritos a carreras } \\
\text { STEM (Ciencia, tecnología, } \\
\text { ingeniería y matemáticas) }\end{array}$ & Número & 85104 & 90000 & Ruta N \\
\hline
\end{tabular}

\subsubsection{PROGRAMA: MAESTROS Y MAESTRAS SUJETOS DE SABER}

La calidad de la educación se ha asumido como un eje fundamental en la ciudad de Medellín. El aumento de los niveles de la calidad en todo el proceso educativo está ligado a la preparación y capacitación de los maestros. Sin embargo, para que los maestros de calidad generen entornos de protección a los niños y jóvenes y conocimiento para el desarrollo de capacidades humanas necesitan ser dignificados, ser sujetos de admiración y respeto, un modelo a seguir para los niños y jóvenes de la ciudad.

De tal forma, pensar en la calidad educativa, implica abordar la calidad de los estudiantes por un lado, y, por otro, la calidad de los maestros. La CEPAL y la Organización de Estados Americanos, en el libro "2021, metas educativas", consideran que el fortalecimiento de los maestros debe ser la prioridad en América Latina para lograr el fortalecimiento educativo 
(CEPAL \& OEI, 2010, p. 74). Señalan además que "un profesor que cuente con una formación inicial de calidad y con las oportunidades de acceder a

programas de capacitación continua, puede contribuir al mejoramiento de los resultados de los niños en su rendimiento. Sin embargo, en la mayor parte de los países de la región, las inmensas demandas de transformación pedagógica que se les ha exigido a los docentes en las últimas décadas no han sido acompañadas de los debidos procesos de cambio de las instituciones que los forman, ni de las condiciones de trabajo y de desarrollo profesional necesarias" (pp. 74-75).

Para que los Maestros de la ciudad sean los líderes de la calidad, deben abordarse asuntos de forma integral, como: brindar acceso a la profesionalización y posgrados, generar espacios de capacitación y actualización, mejorar sus condiciones laborales, dar un trato digno al maestro, recuperar su imagen en la sociedad, recuperar su autoridad en las aulas y satisfacer sus necesidades como sujeto transformados de la sociedad (Guadamuz, 2006, citado en Chavarría, Fernández, Gaete, \& Masis, 2013, pp. 7-8).

No obstante, que los Maestros sean Líderes de la Calidad, no se limita sólo a una mención de categorías específicas que deban ser abordadas desde la institucionalidad. No. Se trata de un proceso de participación ciudadana en el cual se construya la dignificación del maestro teniendo en cuenta que es una persona que cumple un rol fundamental y transformador de toda sociedad. Bajo esta perspectiva, se debe aprender de modelos internacionales que han tenido éxito en el mundo. Cabe resaltar, que se trata de acciones a largo plazo y que en su transcurrir deben estar acompañadas de variaciones sociales profundas.

En Finlandia, por ejemplo, la educación de los niños está a cargo de los maestros mejor capacitados. Los requerimientos básicos son que los maestros tengan maestrías, buenos salarios y condiciones laborales. De ahí que ser maestro en Finlandia sea una profesión cada vez más popular y un sinónimo de prestigio, pues los maestros tienen un estatus social muy elevado (Oppenheimer, 2010, p. 70). La clave de los altos estándares educativos de Finlandia se basa en tres secretos "los maestros, los maestros y los maestros" (Oppenheimer, 2010, p. 321). Este debe ser un modelo inspirador para el programa Maestros Líderes de la Calidad.

\section{Indicadores de resultado}

\begin{tabular}{|l|c|c|c|c|}
\hline \multicolumn{1}{|c|}{ Nombre } & Unidad & Línea de Base & Meta 2019 & Responsable \\
\hline $\begin{array}{l}\text { Investigaciones realizadas por } \\
\text { maestros }\end{array}$ & Número & 43 & 100 & $\begin{array}{c}\text { Secretaría de } \\
\text { Educación }\end{array}$ \\
\hline $\begin{array}{l}\text { Estrategias Educativas } \\
\text { diseñadas por maestros para } \\
\text { implementar en el aula }\end{array}$ & Número & ND & 2,000 & $\begin{array}{c}\text { Secretaría de } \\
\text { Educación }\end{array}$ \\
\hline
\end{tabular}




\subsubsection{Proyecto: Sistema de formación de maestros}

Este será el horizonte que articule en sus procesos a los maestros y maestras, a los directivos docentes y agentes educativos como

sujetos de saber pedagógico, a la escuela como organización educativa y a la ciudad como territorio educador. A través de las líneas de formación que lidera el Centro de Innovación del Maestro MOVA: desarrollo humano, reflexión metodológica, formación situada e Investigación educativa, se diseñará e implementará la política de formación para maestros y maestras, identificando y profundizando en los saberes escolares y las áreas de trabajo de los maestros; y fortaleciendo la estrategia de acompañamiento permanente a la directiva docente de las instituciones educativas de la ciudad.

Responsable: Secretaría de Educación

Indicador de producto

\begin{tabular}{|l|c|}
\hline \multicolumn{1}{|c|}{ Nombre } & Unidad \\
\hline $\begin{array}{l}\text { Instituciones a las cuales se les realiza asistencia técnica en salud en procesos } \\
\text { de calidad }\end{array}$ & Número \\
\hline
\end{tabular}

4.1.1.2 Proyecto: Medellín, destino del conocimiento

Convertir a Medellín en ciudad y destino de los mejores docentes del país implica fortalecer el sistema de intercambios educativos y formativos con ciudades que tengan sistemas educativos y prácticas pedagógicas que puedan ser implementadas y profundizadas en la ciudad, y que, como consecuencia, se establezca un canal para la asesoría, el intercambio de saberes y la producción académica alrededor de la formación de los maestros y maestras.

Responsable: Secretaría de Educación

Indicador de producto:

\begin{tabular}{|l|c|}
\hline \multicolumn{1}{|c|}{ Nombre } & Unidad \\
\hline Docentes con intercambios académicos y educativos & Número \\
\hline $\begin{array}{l}\text { Maestros nacionales o extranjeros que hacen pasantía pedagógica en la } \\
\text { ciudad }\end{array}$ & Número \\
\hline
\end{tabular}

\subsubsection{Proyecto: Alianzas estratégicas para el mejoramiento de la calidad} Estas alianzas estratégicas pretenden afianzar la corresponsabilidad educativa entre los establecimientos educativos oficiales, que tienen como objeto el fortalecimiento $\mathrm{y} / \mathrm{o}$ sostenibilidad a nivel de calidad y el sector privado con miras al cumplimiento de dicho fin. En el desarrollo de estas alianzas se debe observar el principio de la corresponsabilidad, como parámetro para aprender en forma conjunta sobre las prácticas administrativas, directivas, pedagógicas, académicas-formativas y de proyección comunitaria, que se llevan a cabo de manera sistémica en las diversas dinámicas de la gestión escolar. 
Responsable: Secretaría de Educación

Indicador de producto:

\begin{tabular}{|c|c|}
\hline Nombre & Unidad \\
\hline Instituciones educativas apadrinadas para el mejoramiento de la calidad & Número \\
\hline
\end{tabular}

4.1.1.4 Proyecto: Incentivos para la calidad

El gran propósito de la calidad educativa, requiere no solamente el planteamiento de políticas y estrategias que conduzcan a este fin, sino también la generación de incentivos y reconocimientos a las instituciones educativas que las favorezcan y que lideren procesos transformadores que impacten positivamente en el desarrollo y la calidad de vida de los actores de la comunidad educativa y de la sociedad en general. Incentivar a directivos, docentes y estudiantes de los establecimientos educativos públicos, de cobertura y privados de la ciudad, es enaltecer su labor y significar la gran importancia que tiene el trabajo conjunto en pro de la calidad de la educación desde su visión integral, en la que se requieren compromisos en lo académico e intelectual, pero también en los procesos pedagógicos que se traduzcan en experiencias que promuevan la participación, el liderazgo y la paz en las escuelas como escenarios de desarrollo social y progreso humano.

Premio Ciudad de Medellín a la Calidad de la Educación, busca hacer de la calidad un propósito colectivo que parte del reconocimiento de las potencialidades de cada institución y la capacidad de trabajo colaborativo institucional para posicionar a la Ciudad de Medellín con mejores indicadores educativos.

Responsable: Secretaría de Educación

Indicador de producto:

\begin{tabular}{|c|c|}
\hline Nombre & Unidad \\
\hline IE que reciben incentivos para el mejoramiento de la calidad & Número \\
\hline
\end{tabular}

\subsubsection{PROGRAMA: INFRAESTRUCTURA PARA LA CALIDAD DE LA EDUCACIÓN}

La calidad de la educación se relaciona, además, con ambientes adecuados para el aprendizaje y la dignificación del proceso formativo. En este componente se asocian aspectos como la dotación y la infraestructura educativa. Es decir, la calidad educativa está ligada a la calidad del equipamiento educativo y, en sentido más amplio, del equipamiento de ciudad en el que se apoya el proceso educativo en general. La investigación demuestra que la infraestructura educativa está atravesado por cantidad de variables que inciden directamente en: la convivencia cotidiana de sus ocupantes, la disposición anímica y física de la persona, el desempeño académico de estudiantes y/o académico 
laboral de docentes y directivas, el sentido de pertenencia y en la participación en general de la comunidad educativa. Dichas variables deben ser identificadas y analizadas de forma crítica y, sus derivaciones, articuladas creativamente para proyectar, no simplemente una edificación, sino la vida y, en particular, el proyecto educativo.

Las condiciones mínimas con que deben contar las áreas físicas y las dotaciones escolares se Instauran en criterios como:

- Accesibilidad (inclusión asociada a las particularidades de las limitaciones y la diversidad)

- Comodidad (espacio por alumnos, circulación, estancia-estadía, entre otros)

- Seguridad (sismo resistentes, confiables, protegido, estable, eficaz, seguro, entre otros)

- Sostenibilidad ambiental (mantenimiento, ventilados, iluminados, acústicos, fluidos, manutenibles (mantenimiento), con buenas condiciones térmicas, de escorrentía y filtración, consideración de manejo de residuos sólidos, con eficiencias energética, energías alternativas)

- Economía (bajos costos de funcionamiento, mantenimiento y reparación)

- Confort (niveles de bienestar directivo, laboral y estudiantil)

- Monumentalidad (embellecimiento, acondicionamiento estéticocultural que genera cambio de actitud y sentido de pertenencia en los habitantes de la infraestructura)

- Pertinencia (Aumenta la utilidad-aplicabilidad en el orden pedagógico, lúdico, recreativo y/o deportivo)

Indicador de resultado

\begin{tabular}{|l|l|l|l|l|}
\hline Nombre & Unidad & Línea de Base & $\begin{array}{l}\text { Meta } \\
2019\end{array}$ & Responsable \\
\hline $\begin{array}{l}\text { Construcción y reposición } \\
\text { de plantas físicas educativas }\end{array}$ & Número & 7 & 16 & $\begin{array}{l}\text { Secretaría de } \\
\text { Educación }\end{array}$ \\
\hline
\end{tabular}

4.1.2.1 Proyecto: Ambientes de aprendizajes dignos y adecuados para la calidad

Garantizar la prestación del servicio educativo, especialmente en las comunas y corregimientos donde existe elevada demanda, mediante la construcción, ampliación y/o reposición de la infraestructura educativa, propiciando ambientes de aprendizaje eficientes y funcionales acordes con las necesidades físicas y tecnológicas de cada contexto escolar, que fortalezcan procesos formativos de calidad y que estimulen el desarrollo de las competencias del estudiante, transformando las relaciones pedagógicas y promoviendo el trabajo colaborativo y la búsqueda del conocimiento. Del mismo modo, en pro del adecuado desarrollo de la Jornada única, se 
adecuará la infraestructura física de los restaurantes escolares de los establecimientos educativos con el fin de garantizar la prestación continua del servicio del Programa de Alimentación Escolar y la normativa sanitaria vigente.

Responsable: Secretaría de Educación

Indicador de producto

\begin{tabular}{|l|c|}
\hline \multicolumn{1}{|c|}{ Nombre } & Unidad \\
\hline Ampliaciones de plantas físicas educativas & Número \\
\hline Construcción de nuevos jardines y centros infantiles & Número \\
\hline $\begin{array}{l}\text { Obras de mantenimiento mayores y menores de plantas físicas, centros y jardines } \\
\text { infantiles }\end{array}$ & Número \\
\hline
\end{tabular}

4.1.2.2 Proyecto: Infraestructura y equipos para investigación científica y desarrollo tecnológico en la educación superior Apoyar la construcción y el mejoramiento la de infraestructura de laboratorios y su dotación con equipos para la investigación científica y el desarrollo tecnológico en el sistema de educación superior.

Indicador de producto:

\begin{tabular}{|c|c|}
\hline Nombre & Unidad \\
\hline Dotación de equipos de laboratorio para la investigación y el desarrollo & Porcentaje \\
\hline
\end{tabular}

4.1.2.3. Proyecto: Ciudadelas Universitarias Sostenibles

4 Desde SAPIENCIA se liderará el modelo de sostenibilidad para las Uil Ciudadelas Universitarias de conformidad con las disposiciones de pertinencia y calidad de la educación superior en la ciudad de Medellín.

Responsable: Sapiencia

Indicador de producto

\begin{tabular}{|l|c|}
\hline \multicolumn{1}{|c|}{ Nombre } & Unidad \\
\hline Plan de sostenibilidad elaborado e implementado & Porcentaje \\
\hline Proyectos hitos implementados & Número \\
\hline
\end{tabular}

\subsubsection{PROGRAMA: MEDELLÍN BILINGÜE}

La calidad educativa se refleja, igualmente, en las capacidades y/o competencias que alcanza la la población para su perfeccionamiento, adaptabilidad y, especialmente, para la contingencia, para lo dinámico, lo cambiante, lo informe, lo múltiple. Dichos niveles están asociados a la preparación de docentes y estudiantes, de la comunidad en general, en el dominio de una o varias lenguas extranjeras, es decir, en la ampliación de 
la capacidad de comunicación con el mundo y de respuesta ante retos, actuales, de información científica, tecnológica y de relacionamiento en escala tanto local como global. Tanto la perspectiva laboral como la actividad estudiantil, investigativa, de gestión, entre otras, lo requieren.

Además, la segunda lengua se ha tornado, en la ciudad de Medellín, en una necesidad sentida en general puesto que:

- Mejora la calidad de vida de las personas al fortalecer su perfil laboral con del dominio de una segunda lengua.

- Fortalece las condiciones de empleabilidad de la población a nivel general y, especialmente, en la oferta laboral de la ciudad.

- Fomenta la educación superior y permanencia beneficiando a estudiantes a través de condiciones que faciliten el acceso y la sostenibilidad.

- Mejora la interacción con el visitante extranjero (turista) a través del dominio de una lengua extranjera y de gestión en las distintas escalas.

- Fortalece la calidad como destino turístico, de gran importancia a nivel de ciudad y en su fortalecimiento económico.

- Finalmente, a través de la formación en lengua extranjera se garantiza, a su vez, el derecho a la educación.

Indicador de resultado

\begin{tabular}{|c|c|c|c|c|}
\hline Nombre & Unidad & Línea de Base & Meta 2019 & Responsable \\
\hline $\begin{array}{l}\text { Estudiantes de Medellín en } \\
\text { niveles de competencia B1 y } \\
\text { Bt en Saber } 11^{\circ}\end{array}$ & Porcentaje & 8.63 & 10.00 & $\begin{array}{c}\text { Secretaría de } \\
\text { Educación }\end{array}$ \\
\hline
\end{tabular}

4.1.3.1 Proyecto: Ambientes de profundización y formación de docentes y estudiantes en una lengua extranjera

- Fortalecer el aprendizaje de una lengua extranjera en la educación básica y media, así como facilitar espacios de familiarización e inmersión en lenguas extranjeras que participan en el aspecto globalizante de la cultura, tanto en la educación superior como en los Rerfiles laborales. Entendiendo que en la sociedad de la información y el conocimiento el dominio de, por lo menos, una lengua extranjera es determinante en la adaptación del ciudadano local.

Se apostará por el fortalecimiento de convenios que de manera efectiva conlleven a la expansión de nuevas competencias comunicativas, por medio de intercambios en territorio, pasantías, estrategias de participación comunitarias, alianzas y convenios internacionales y apoyos de colectivos en los territorios.

Responsable: Secretaría de Educación 
Indicador de producto

\begin{tabular}{|c|c|}
\hline Nombre & Unidad \\
\hline Docentes formados en segunda lengua & Porcentaje \\
\hline
\end{tabular}

4.1.3.2 Proyecto: Diseñar modelo y realizar prueba piloto de bachillerato internacional

Certificación internacional de la educación secundaria ofrece a los

jóvenes la posibilidad de habilitarse para realizar estudios en cualquier universidad del mundo, con un diploma avalado por la Organización Bachillerato Internacional (BI). Se implementará en instituciones educativas con altos resultados en gestión educativa y se promoverán, en las demás, acciones de mejoramiento para cumplir con las condiciones de la Organización Bl. También, se implementará un plan padrino de colegios privados locales y nacionales, que cuenten con esta certificación, como orientadores del proceso en la modalidad de trabajo colaborativo. El proyecto preparará a los jóvenes para vivir en un mundo globalizado, desarrollando habilidades y destrezas encaminadas a ser más competitivos y abordando la dimensión humana en una educación integral.

Responsable: Secretaría de Educación

Indicador de producto

\begin{tabular}{|l|c|}
\hline \multicolumn{1}{|c|}{ Nombre } & Unidad \\
\hline Docentes capacitados para la implementación del bachillerato internacional & Número \\
\hline Instituciones oficiales en proceso de implementación del bachillerato internacional & Número \\
\hline
\end{tabular}

\subsubsection{PROGRAMA: PROMOCIÓN DE LAS CAPACIDADES Y TALENTOS DE LOS CIUDADANOS}

El fortalecimiento de competencias cognitivas y meta cognitivas mejora la calidad educativa, les da a los estudiantes confianza, fuerza y conocimiento, apropiación de los espacios y las herramientas para lograr los objetivos de mejorar los índices propios. Estimula la continuidad de la vida académica, se pretende con esto incidir en el ofrecimiento de una formación de calidad y en el desarrollo integral de los jóvenes que accedan a la educación superior a través de estímulos (becas, examen de ingreso, etc), lleva consigo un componente en proyecto de vida donde ayuda a orientar vocacionalmente la decisión de formación académica en el nivel superior.

Mediante el desempeño de competencias en matemáticas, lenguaje, ciencias sociales, ciencias naturales y competencia ciudadana a estudiantes de 3, 5, 9 y 11. Ajustado a las pruebas estandarizadas SABER PRO se darán la herramientas necesarias para que los estudiantes de las IEO puedan obtener buenos resultados y mejorar su desempeño y el de sus instituciones para ubicar a la ciudad de Medellín como un referente en educación, sitio en el que debe estar hace muchos años. No se trata de estimular una destreza mecanicista que les permita responder a las peculiaridades de las distintas 
evaluaciones, sino que incorporen las habilidades y las competencias a su desarrollo cognitivo, de tal manera que puedan responder a todas las exigencias de su vida académica y personal que además va en busca de nuevos retos, en la generación de espacios de reflexión que le ayuden a repensarse como persona en función de una sociedad competitiva y llena

de carencias investigativas, críticas y restauradoras, que sólo pueden provenir de individuos gestores de su propio desarrollo.

Las Olimpiadas del conocimiento promueven la sana competencia, el desarrollo de habilidades, mejorar y seguir adelante en todo el proceso de formación, incentiva a los estudiantes a asumir retos y aleja temores, estimula el deseo de aprender y de usar herramientas tecnológicas, induce a la investigación y lleva a los estudiantes a ser autodidactas a seguir en el camino de la educación superior y a ser unos promotores de la educación en toda la ciudad.

Indicador de resultado

\begin{tabular}{|l|c|c|c|c|}
\hline Nombre & Unidad & Línea de Base & Meta 2019 & Responsable \\
\hline $\begin{array}{l}\text { Porcentaje de } \\
\text { establecimientos oficiales en } \\
\text { categoría A+y A en pruebas } \\
\text { saber } 11\end{array}$ & Porcentaje & 9.20 & 15.00 & $\begin{array}{c}\text { Secretaría de } \\
\text { Educación }\end{array}$ \\
\hline $\begin{array}{l}\text { Porcentaje de estudiantes en } \\
\text { los primeros 400 puestos en } \\
\text { pruebas Saber } 11 \text { Medellín }\end{array}$ & Porcentaje & 53.20 & 60.00 & $\begin{array}{c}\text { Secretaría de } \\
\text { Educación }\end{array}$ \\
\hline
\end{tabular}

\subsubsection{Proyecto: Estrategias para el seguimiento y el fortalecimiento de} competencias cognitivas y metacognitivas

(1) La formación basada en competencias exige el despliegue de distintas estrategias de fortalecimiento tanto de competencias cognitivas como metacognitivas, a través de estas, se mejora la calidad educativa, se da mayor confianza y afianzamiento de conocimientos a los estudiantes, mejor nivel de apropiación de espacios y herramientas para mejorar los indicadores de logro

(1) propios y, además, estimula la continuidad de la vida académica.

Las distintas estrategias buscan, a su vez, incidir en la calidad educativa y en el desarrollo integral de los jóvenes mejorando su potencial para acceder y continuar la educación ba y su oportunidad laboral. El proyecto comprende una serie de pruebas, tipo saber, de diagnóstico o entrada a las olimpiadas.

Responsable: Secretaría de Educación 
Indicador de producto

\begin{tabular}{|c|c|}
\hline \multicolumn{1}{|c|}{ Nombre } & Unidad \\
\hline Estudiantes que reciben formación por competencias & Número \\
\hline
\end{tabular}

4.1.4.2 Proyecto: Educación complementaria para el fortalecimiento de las capacidades humanas

La educación complementaria a partir del concepto de ciudad escuela o ciudad educadora, promueve la participación de las y los estudiantes en programas y escenarios de ciudad que, en esa gran aula y articulados a las instituciones educativas, fortalecen su desarrollo integral como ser único, histórico, político, trascendente, social y apropiado de su territorio, permitiendo el reconocimiento de talentos y la valoración de estos en el mismo territorio, así como el estímulo hacia la continuidad de la educación, en los programas de jornada complementaria. Es una estrategia que tiene oferta propia a nivel de Secretaría de Educación Medellín y articula la oferta institucional de las distintas dependencias de la Alcaldía Municipal e, incluso, de organizaciones privadas con los procesos de formación lúdicos y académicos de los estudiantes.

La jornada complementaria además debe estar acompañada por todos los que intervienen en la formación educativa de la persona, por lo tanto la intervención e implementación de estos espacios no solo le corresponde al instituto educativo sino también y aún más a la familia, pues del compromiso que ella tenga depende que este tipo de iniciativas pueden llegar a buen puerto.

Responsable: Secretaría de Educación

Indicador de producto:

\begin{tabular}{|l|c|}
\hline \multicolumn{1}{|c|}{ Nombre } & Unidad \\
\hline Programas STEM (Ciencia, tecnología, ingeniería y matemáticas) realizados & Número \\
\hline Estudiantes K11 (ciclo regular educativo) beneficiados en el programa & Número \\
\hline Estudiantes de IE oficiales atendidos en programas de jornada complementaria & Porcentaje \\
\hline
\end{tabular}

\subsubsection{Proyecto: Encuentro de saberes}

El encuentro de saberes, es un encuentro por el cual se ponen en contexto las experiencias pedagógicas, lo cual fortalece la comprensión, integración y aplicación de los conocimientos. Es un encuentro donde convergen los saberes sociales, culturales, ambientales, políticos, entre otros. La finalidad de este tipo de encuentros es propiciar un lugar adecuado para que se implante el diálogo de saberes, debido a que, no hay mejor forma de construir sociedad que de la poder compartir por medio del debate los conocimientos adquiridos por la experiencia investigativa, incrementando de esta manera el conocer comunitario y retroalimentando el estado del arte de las ciencias. Permitir que los niños y jóvenes puedan compartir sus conocimientos en un entorno protector es la mejor manera de incentivar el espíritu investigativo, 
creativo e innovador. De esta manera tendremos estudiantes preocupados por su entorno, por su sociedad y por las dinámicas en las cuales él se desenvuelve.

Responsable: Secretaría de Educación

Indicador de producto:

Nombre

Unidad

\subsubsection{PROGRAMA: COMUNIDAD EDUCATIVA COMO ESCENARIO DE DESARROLLO}

El programa permite abrir la escuela al intercambio de saberes acumulados en el territorio para direccionar las potencialidades de sus actores.Parte esencial del funcionamiento de la escuela está en empoderar a la comunidad (entorno) en acciones que permitan nutrir la concepción del ciudadano, para ello se debe acoger las reflexiones sobre el papel de la apropiación de las TIC en la configuración de ciudadanía, del ciudadano y de ciudad; el modelamiento de prácticas culturales de acompañamiento y cuidado del desempeño escolar como opción clara de vida, el territorio como un entorno protector, como inteligencia colectiva, como comunidad de acogida; finalmente, este programa se concibe como encuentro de saberes sobre lo comunitario y la participación ciudadana. Visto así, la comunidad Educativa se torna un escenario de desarrollo, la escuela encuentra la posibilidad de articular su PEI a las potencias del territorio y el territorio encuentra en la escuela un aliado más de cara a la construcción de la realidad.

Indicador de resultado

\begin{tabular}{|c|c|c|c|c|}
\hline Nombre & Unidad & Línea de Base & $\begin{array}{c}\text { Meta } \\
2019\end{array}$ & Responsable \\
\hline $\begin{array}{l}\text { Instituciones que mejoran } \\
\text { sus resultados en la } \\
\text { autoevaluación institucional }\end{array}$ & Porcentaje & 84 & 100 & $\begin{array}{c}\text { Secretaría de } \\
\text { Educación }\end{array}$ \\
\hline
\end{tabular}

\subsubsection{Proyecto: Escuela abierta}

Contribuye a garantizar el derecho a la educación y al empoderamiento a través de ella. Escuela Abierta, contribuye a la

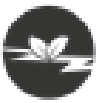
consolidación de una ciudadanía digital, a la democratización, apropiación y uso de las TIC en estudiantes, padres de familia y ciudadanía. Escuela Abierta propende entonces por la formación y certificación de competencias digitales y ciudadanas a través del ciberaprendizaje cooperativo. Incluye también la formación de semilleros de investigación en Ciencias y Tecnología y Clubes de informática para el fomento de la creatividad y la innovación. Igualmente, se gestionan alianzas que permitan un mejor presente y 
futuro digital en la ciudad, promoviendo la investigación y la innovación de prácticas educativas que generen oportunidades profesionales y laborales.

Responsable: Secretaría de Educación

Indicador de producto:

\begin{tabular}{|l|l|}
\hline \multicolumn{1}{|c|}{ Nombre } & Unidad \\
\hline $\begin{array}{l}\text { Instituciones educativas acompañadas en la incorporación de las TIC al curriculo } \\
\text { escolar }\end{array}$ & Número \\
\hline
\end{tabular}

\subsubsection{Proyecto: Transformación de la gestión escolar desde el PEI} La estrategia de asesoría y asistencia técnica a los PEl enfatizará en la formulación, actualización y gestión a través de una co-construcción con las comunidades educativas de los establecimientos educativos. Fortaleciendo, de esta manera, el modelo de gestión pedagógica, la evaluación y el seguimiento, las herramientas de autoevaluación, los planes de mejoramiento y los planes de acción asociados al PEI.

Responsable: Secretaría de Educación

Indicador de producto:

\begin{tabular}{|l|c|}
\hline \multicolumn{1}{|c|}{ Nombre } & Unidad \\
\hline $\begin{array}{l}\text { Proyectos Educativos Institucionales actualizados para el fortalecimiento del modelo } \\
\text { de gestión pedagógica }\end{array}$ & Número \\
\hline
\end{tabular}




\subsection{RETO}

\section{MEDELLÍN GESTIONA SU OFERTA EDUCATIVA}

\section{PROGRAMAS}

4 4.2.1. Educación inicial, preescolar, básica y media

4 4.2.2. Fortalecer el sistema de educación técnica y superior

\section{OBJETIVO}

Mejorar sustancialmente el contenido de los cursos ofrecidos en las diferentes instituciones educativas para satisfacer la demanda en los diferentes niveles del proceso educativo. 


\subsection{Medellín gestiona su oferta educativa}

La oferta Educativa en Medellín se estructura desde los siguientes niveles: educación inicial, preescolar, secundaria, media y la educación terciaria compuesta por la educación técnica, educación para el trabajo y desarrollo humano (ETDH) y educación superior. Si bien hoy la ciudad cuenta con tasas de cobertura superior a la media nacional, identificamos oportunidades en secundaria y terciaria, donde dirigiremos parte de nuestros esfuerzos. Hoy creemos en la importancia de tener jóvenes que continúen su ciclo escolar.

Medellín ha logrado aumentar su tasa de cobertura mejorado los índices desde educación inicial hasta secundaria. Con respecto a las tasas de cobertura bruta de prescolar hasta media presentan cifras superiores al $100 \%$ desde el año 2005, sin embargo en la educación media estos avances aún no son suficientes; en este nivel la tasa de cobertura bruta para 2014 es 77,5\%. Ahora bien, las coberturas netas de prescolar hasta media aún se encuentran en niveles del 90\% (de cada diez niños y jóvenes en edad escolar nueve están matriculados en el nivel correspondiente a su edad), destacando una cobertura neta superior al $100 \%$ en básica primaria y en contraste una tasa baja en media del 57,4\%. Es necesario precisar que mejores resultados en las coberturas brutas y netas en el nivel de media dependen especialmente del resultado de la situación actual del nivel de secundaria en materia de deserción y extraedad.

Gráfico 14. Tasa neta de cobertura por niveles educativos, 2004-2014

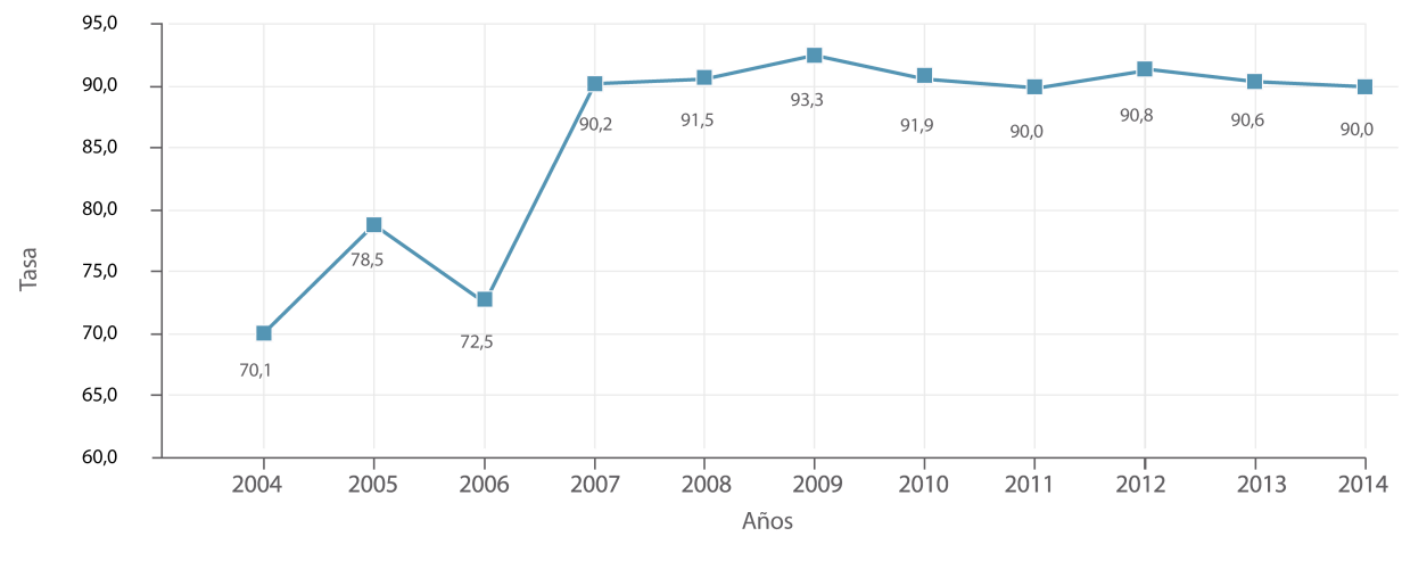

- Cobertura Educativa neta total

Fuente: Secretaría de Educación - Sistema de matrícula en línea SIMAT 
En primera infancia la ciudad ha consolidado el programa Buen Comienzo como la principal estrategia de atención integral a esta población. En el

año 2015, la tasa de cobertura de atención acumulada del programa se mantuvo en $72,5 \%$ (75.858 niños entre los $O$ y los 5 años y 11.954 madres gestantes y lactantes) de la población SISBEN. No obstante, se han presentado algunas reducciones especialmente por la disminución de cifras poblaciones como el número de embarazos y nacimientos y el comportamiento de la población SISBEN en este rango, que presentó decrecimiento de un 14,9\% (18.281 niños y niñas) entre 2009 y $2015 .$.

Desde el punto de vista de la eficiencia, en Medellín se ha disminuido la tasa de deserción intra-anual cerca de un 3,11\% en 2013 (cerca de 10.070 desertores). Sin embargo, en el nivel de secundaria se presentan los indicadores con mayor deterioro (4,36\% tasa de deserción en 2013 y 10\% en la tasa de extraedad en 2014), aspecto que dificulta el flujo adecuado de los estudiantes hacia la educación media. La deserción escolar se constituye en una alerta general para la ciudad, si bien las cifras de la Secretaría de Educación reporta que el año 2013 ha sido el periodo con los índices más bajos, es necesario fortalecer los programas y proyectos dirigidos a la permanencia escolar.

La educación superior ocupa uno de los principales puntos de la agenda de desarrollo de la ciudad de Medellín, considerándola como una herramienta de gran valor estratégico para superar problemas públicos complejos como la desigualdad, la pobreza y la exclusión social, razón por la cual se ha hecho una apuesta significativa por robustecer, a partir del trabajo interinstitucional, un sistema de educación superior a partir de los criterios de cobertura, calidad y pertinencia.

En lo que respecta a los grupos de investigación del municipio de Medellín se destaca que, con base en datos aportados por Colciencias para el año 2014, en la ciudad se registraron 493 grupos de esta naturaleza, de los cuales 85 se encontraban ubicados en la categoría A (17,2\%), 97 en la categoría A1 (19,6\%), 116 en la categoría B (23,5\%), 135 en la categoría C (27,3\%) y, finalmente, 60 grupos en la categoría D (12,1\%). Lo anterior, si se contrasta con cifras arrojadas por Colciencias a nivel nacional indica un porcentaje de grupos de investigación en las categorías A, A1 y B superior al de la media nacional, así como un menor porcentaje en las categorías C, D y otras.

El fortalecimiento del sistema de educación superior continúa siendo un reto, donde se debe seguir trabajando por un modelo de educación superior cimentado en un criterio de pertinencia, por la promoción de semilleros y grupos de investigación del sistema de educación superior y por la consolidación de la infraestructura especializada para la investigación científica y el desarrollo tecnológico. 
A continuación se describen los indicadores de resultado que evaluaran en este reto:

\begin{tabular}{|l|c|c|c|c|}
\hline Nombre & Unidad & Línea de Base & $\begin{array}{c}\text { Meta } \\
2019\end{array}$ & Responsable \\
\hline $\begin{array}{l}\text { Años promedio de estudio } \\
\text { de la población de 15 a 24 } \\
\text { años }\end{array}$ & Numero & 10.57 & 10.80 & $\begin{array}{c}\text { Secretaría de } \\
\text { Educación }\end{array}$ \\
\hline $\begin{array}{l}\text { Tasa de deserción total en } \\
\text { edad escolar }\end{array}$ & Porcentaje & 3.11 & 2.8 & $\begin{array}{c}\text { Secretaría de } \\
\text { Educación }\end{array}$ \\
\hline
\end{tabular}

\subsubsection{PROGRAMA: EDUCACIÓN INICIAL, PREESCOLAR, BÁSICA Y MEDIA}

El derecho fundamental a la educación se garantiza hoy dentro de una perpectiva incluyente y flexible que propicie el acceso y la permanencia a la población en edad escolar, desde la educación inicial hasta la educación media y procurando eliminar barreras sociales, económicas y culturales que impiden la garantía y ejercicio de este derecho. Esto toca con las oportunidades educativas para desertores tempranos, población en extraedad y analfabetas o iletrados, adolescentes, jóvenes y adultos.

En el marco de una educación inclusiva y flexible, el programa Educación inicial, preescolar, básica y media se desarrollará a través de:

- La garantía del acceso a la población en edad escolar y a la población en extraedad a la educación pública, mediante la oferta de cupos en las instituciones educativas oficiales $y$, a través de contratación de cupos en cobertura educativa, de manera subsidiaria, con soporte en estudios de insuficiencia educativa.

- El desarrollo de estrategias para la erradicación gradual del analfabetismo en población menor de 18 años con metodologías flexibles, que les permita insertarse en la educación regular, y para la población adulta, programas que comiencen por la alfabetización y les abra una segunda oportunidad a la educación.

- El acceso y permanencia a la escuela para grupos poblacionales en situación de vulnerabilidad menores en riesgo social, niñez trabajadora, niños y niñas en protección y en riesgo de vulneración de sus derechos; población en discapacidad, población afectada por la violencia, población afro-descendiente e indígena con estrategias inclusivas, metodologías flexibles, maestros formados para la atención en la diversidad y profesionales de apoyo idóneos.

- Brindar beneficios educativos para el acceso y la permanencia, mediante estrategias interinstitucionales de la Alcaldía tales como: 
complemento nutricional, transporte escolar y tiquete estudiantil, kits escolares, seguro de protección escolar, atención a factores de riesgo psicosocial y hábitos de vida saludable.

\section{Indicadores de resultado}

\begin{tabular}{|l|c|c|c|c|}
\hline \multicolumn{1}{|c|}{ Nombre } & Unidad & Línea de Base & $\begin{array}{c}\text { Meta } \\
2019\end{array}$ & Responsable \\
\hline $\begin{array}{l}\text { Tasa de cobertura del } \\
\text { Programa Buen Comienzo }\end{array}$ & Porcentaje & 72.47 & 75.00 & $\begin{array}{c}\text { Secretaría de } \\
\text { Educación }\end{array}$ \\
\hline $\begin{array}{l}\text { Tasa neta de cobertura en } \\
\text { educación media }\end{array}$ & Porcentaje & 57.38 & 60.20 & $\begin{array}{c}\text { Secretaría de } \\
\text { Educación }\end{array}$ \\
\hline $\begin{array}{l}\text { Tasa de extraedad en } \\
\text { secundaria }\end{array}$ & Porcentaje & 10.09 & 9.00 & $\begin{array}{c}\text { Secretaría de } \\
\text { Educación }\end{array}$ \\
\hline $\begin{array}{l}\text { Tasa de deserción total en } \\
\text { edad escolar }\end{array}$ & Porcentaje & 3.11 & 2.80 & $\begin{array}{c}\text { Secretaría de } \\
\text { Educación }\end{array}$ \\
\hline
\end{tabular}

\subsubsection{Proyecto: Fortalecer la educación inicial Buen Comienzo}

La educación Inicial se fortalece como garantía de derecho de la primera infancia, promueve el desarrollo de habilidades comunicativas, cognitivas, físicas, sociales y emocionales, de gran importancia en el proceso de desarrollo de la persona. Se profundizará en las habilidades comunicativas relacionadas con el desarrollo del pensamiento verbal, no verbal, la conciencia fonológica, la expresión gestual, corporal y gráfica, que son lenguajes naturales de los niños y las niñas, y se potencia en la interacción con experiencias significativas que proponen los agentes educativos en ambientes, cálidos, estéticos, seguros y afectuosos para el desarrollo integral.

Los procesos de educación para la primera infancia, comprenden desde la gestación hasta los 6 años, ciclo de la vida de mayor trascendencia en el desarrollo de las personas y de la sociedad en su conjunto, dado que en ella se estructuran y potencializan las capacidades psíquicas, físicas, afectivas y sociales de todo ser humano, siendo determinantes la comunicación, el afecto, la nutrición, la atención en salud, ambientes adecuados e interacciones permanentes y de calidad del niño y la niña consigo mismo, con los otros y con el entorno.

Responsable: Secretaría de Educación

Indicadores de producto:

\begin{tabular}{|l|c|}
\hline \multicolumn{1}{|c|}{ Nombre } & Unidad \\
\hline Madres gestantes y lactantes atendidas por el programa Buen Comienzo & Número \\
\hline Niños y niñas atendidos entre O y 5 años por el programa Buen Comienzo & Número \\
\hline
\end{tabular}


4.2.1.2 Proyecto: Avanzar en la implementación de la Jornada Única

La baja calidad educativa de los colegios oficiales, los bajos resultados del país en la prueba internacional Pisa, la brecha entre los colegios públicos y los privados, y la preocupación en la utilización del tiempo libre por parte de los estudiantes, ha llevado al Gobierno Nacional a desarrollar la estrategia de Jornada Única para aumentar la calidad educativa.

Esta apuesta liderada por el Ministerio de Educación NAional está basada en el aumento de horas en las aulas, ya que mientras los privados estudian 8 horas al día, los públicos lo hacen 5,5 horas, por ello la jornada única es de 7 horas para preescolar, 8 horas para primaria y 9 horas para secundaria y media, tiempo durante el cual se fortalecen las áreas de matemáticas, ciencias naturales, lenguaje e inglés.

Dentro de las dificultades que supone la implementación de esta directriz nacional están los altos costos en materia de contratación, infraestructura y alimentación, pero esto no solo requiere un esfuerzo presupuestal, sino que supone un reto para la Secretaría de Educación de Medellín, implementar estrategias creativas e innovadoras para darle a los estudiantes herramientas pedagógicas que les permitan desarrollar nuevas habilidades.

Responsable: Secretaría de Educación

Indicador de producto:

\begin{tabular}{|c|c|}
\hline Nombre & Unidad \\
\hline Estudiantes matriculados en jornada única & Número \\
\hline
\end{tabular}

4.2.1.3 Proyecto: Potenciar habilidades y capacidades en los niños y niñas desde la gestación hasta la educación media

Potencializar las capacidades psíquicas, físicas, afectivas y sociales de

(17) los niños y niñas de Medellín ofrece la oportunidad de construir valores de cultura ciudadana para transformar comportamientos como ciudadanos del cambio; porque desde su autorrealización se pueden potenciar en ellos habilidades para el desarrollo del ser, el hacer, y el estar en la interacción con otros en su entorno natural y social.

Por ello se hace necesario atender determinantes como la comunicación, el afecto, la atención en salud y la inclusión social con programas que garanticen y materialice el derecho a una adecuada atención educativa Inicial de calidad corrigiendo desde los inicios desigualdades sociales contando con la herramienta de la educación disruptiva, generando espacios de encuentro para que los niños y niñas, donde observen su entorno, reflexionen, desarrollen percepciones sobre la sociedad, construyan valores de manera 
colaborativa y se aproximen a los compromisos individuales y colectivos en la construcción de valores de cultura ciudadana.

Responsable: Secretaría de Educación

Indicador de producto

\begin{tabular}{|l|l|}
\hline e cobertura contratada en media & Unidad \\
\hline
\end{tabular}

\section{Estecto: Permanencia en el sistema escolar}

Este proyecto pretende diseñar y ejecutar el programa de excelencia educativa, además de implementar las estrategias pertinentes para promover la lucha contra la deserción escolar en todos los niveles del sistema educativo, garantizando de este modo alcanzar los máximos niveles de escolaridad

Responsable: Secretaría de Educación

Indicador de producto

\begin{tabular}{|l|c|}
\hline \multicolumn{1}{|c|}{ Nombre } & Unidad \\
\hline $\begin{array}{l}\text { Estudiantes con talentos excepcionales que reciben atención especializada en el } \\
\text { sector oficial }\end{array}$ & Número \\
\hline $\begin{array}{l}\text { Estudiantes atendidos con modelos flexibles que se encuentran en condición de de } \\
\text { enfermedad, privados de la libertad o en extraedad en secundaria }\end{array}$ & Número \\
\hline
\end{tabular}

\subsubsection{Proyecto: Inclusión en el sistema escolar}

A partir de la identificación y clasificación de la población escolar con

( necesidades educativas especiales, se debe diseñar e implementar modelos flexibles pertinentes y estrategias inclusivas en la educación regular, que permitan atender las necesidades de los estudiantes de la

1.7 ciudad, en aras de garantizar la permanencia en el sistema educativo, deserción, como niños, niñas y adolescentes en situación de protección, en condición de discapacidad física y cognitiva, víctimas del conflicto armado o extraedad; fortaleciendo además el desarrollo de competencias y su proyecto de vida. Y para la población con capacidades o talentos excepcionales, se buscarán estrategias educativas para lograr el desarrollo de sus potencialidades, todo ello desde el enfoque de educación inclusiva, promoviendo igualdad de oportunidades para el acceso, la permanencia y la promoción en el sistema educativo oficial de todos estos niños, niñas, jóvenes y adultos.

Indicador de producto

Responsable: Secretaría de Educación

\begin{tabular}{|l|l|}
\hline \multicolumn{1}{|c|}{ Nombre } & \multicolumn{1}{c|}{ Unidad } \\
\hline $\begin{array}{l}\text { Estudiantes con talentos excepcionales que reciben atención especializada en el } \\
\text { sector oficial }\end{array}$ & Número \\
\hline
\end{tabular}




\subsubsection{PROGRAMA: FORTALECER EL SISTEMA DE EDUCACIÓN TÉCNICA Y SUPERIOR}

Para garantizar el fortalecimiento de la educación postsecundaria se hace necesario cimentarla bajo los criterios de pertinencia y calidad que permita garantizar el desarrollo económico, social y cultural de nuestra ciudad, para lo cual se desarrollarán proyectos orientados a: propiciar los procesos innovadores y creativos desde la educación inicial Buen Comienzo, avanzar en la implementación de la jornada única como espacio para el fortalecimiento de habilidades desde la investigación, lógica, matemática y comprensión lectora, las cuales son necesarias para desarrollar competencias básicas en nuestros estudiantes en todo nivel, permitiéndonos mejorar el posicionamiento de la educación en la ciudad; pero de igual forma el buen tránsito a la educación superior garantizará una orientación vocacional para que los estudiantes escojan programas orientados a su proyecto de vida y a la vocación de la ciudad, teniendo así estudiantes formados para la competitividad de la ciudad y llevando la educación postsecundaria a un nuevo nivel.

La articulación con el sector productivo de la ciudad es fundamental para orientar los esfuerzos y el fortalecimiento institucional para trabajar conjuntamente proyectos que apunten la competitividad de la ciudad, desde el trabajo conjunto entre el Estado, la Universidad y la Empresa; bajo los principios de calidad y competitividad a nivel local, regional, nacional e internacional.

Indicador de resultado

\begin{tabular}{|c|c|c|c|c|}
\hline Nombre & Unidad & Línea de Base & $\begin{array}{c}\text { Meta } \\
2019\end{array}$ & Responsable \\
\hline $\begin{array}{l}\text { Nivel de continuidad de los } \\
\text { estudiantes a educación } \\
\text { superior Número }\end{array}$ & 5000 & 6500 & Sapiencia \\
\hline
\end{tabular}

\subsubsection{Proyecto: Apoyo para el accesoa la educación superior}

Otorgar tantas becas de educación superior como sean posibles a los mejores estudiantes según pruebas saber, además de aquellos estudiantes con buen desempeño deportivo, cultural, artístico y a estudiantes que se destacan por su calidad humana e integral como miembros de su entorno social y de ciudad. Además se garantizará la continuidad de algunos fondos de becas para eduación superior con el objeto de permitir a los jóvenes de nuestra ciudad el acceso a educación superior pertinente y de calidad mediante la modalidad de créditos condonables.

Responsable: Sapiencia 


\section{Educación de calidad para el desarrollo y la competitividad}

Indicadores de producto

\begin{tabular}{|l|c|}
\hline \multicolumn{1}{|c|}{ Nombre } & Unidad \\
\hline Becas otorgadas para educación superior & Número \\
\hline
\end{tabular}

4.2.2.2 Proyecto: Apoyar los planes de acreditación y re acreditación de las Instituciones públicas de educación superior del Municipio

Desde Sapiencia acompañar el proceso de acreditación y re acreditación de las instituciones de educación superior del municipio de Medellín con el objeto de consolidad el modelo de calidad y pertinencia educativa, siguiendo los lineamientos de este plan de desarrollo.

Responsable: Sapiencia

Indicador de producto

\begin{tabular}{|l|c|}
\hline \multicolumn{1}{|c|}{ Nombre } & Unidad \\
\hline Instituciones acreditadas y reacreditadas & Número \\
\hline
\end{tabular}

4.2.2.3 Proyecto: Fortalecimiento de ciudadela universitaria digital @Medellín Consolidarla como la plataforma educativa con base en las tecnologías de la información para apoyar el mejoramiento de la calidad de la educación regular y la formación de los ciudadanos en diferentes campos, convirtiéndose en una plataforma educativa en la que se puede concentrar la oferta educativa en todos los niveles a través de la interacción digital o que tengan un componente de e-learning.

Responsable: Sapiencia

Indicador de producto

\begin{tabular}{|c|c|}
\hline Nombre & Unidad \\
\hline Modelo académico y de sostenibilidad & Porcentaje \\
\hline
\end{tabular}




\subsection{RETO MEDELLIIN SE CONSTRUYE DESDE LA CULTURA}

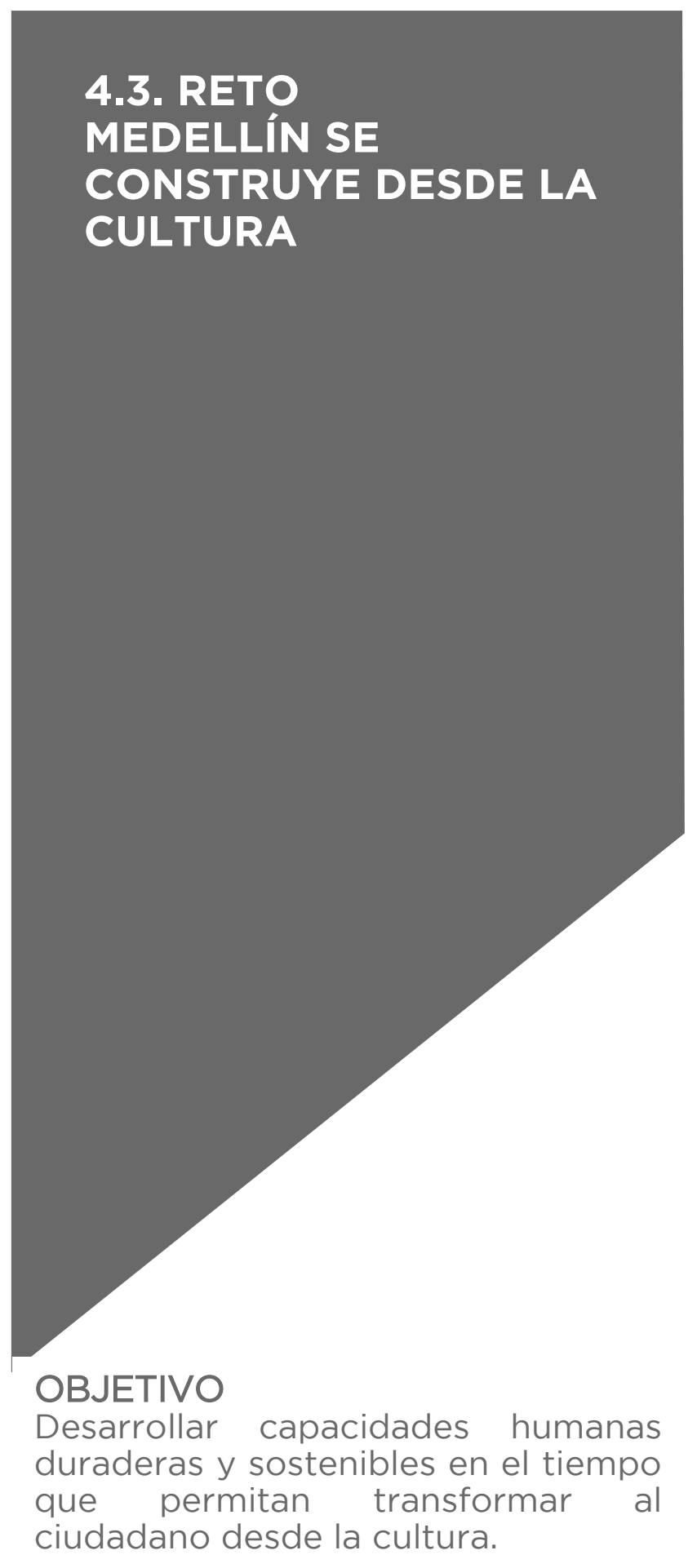

\section{PROGRAMAS}

4 4.3.1. Bibliotecas para una sociedad del conocimiento

4 4.3.2. Movilización por la cultura

$\Delta$ 4.3.4. Creación, formación, fomento y circulación 


\subsection{Medellín se construye desde la cultura}

Medellín cuenta con un proyecto cultural, fruto de una institucionalidad fortalecida y un sector cultural participante en la construcción de los procesos político-culturales, y que apuntan a transformar la cultura ciudadana y ampliar el horizonte de las políticas culturales de la ciudad a partir de la concepción y práctica de los derechos culturales en los que, categorías como inclusión, territorio, economía, educación, participación ciudadana y ejercicio de la democracia han moldeado el proyecto cultural de la ciudad y su transformación política, urbana, social y ambiental, haciendo de la cultura, fuente vital de educación ciudadana.

En el Plan de Desarrollo Cultural de Medellín 2011-2020 se asume la cultura como factor de competitividad sin abandonar la equidad y la atención a poblaciones vulnerables para el logro de la justicia social en un escenario de garantía de derechos, valoración de la diversidad, el territorio, las estéticas y comprensión de las creaciones, memorias y el patrimonio como fundamento de significados compartidos. Para lo que es fundamental continuar con procesos de los que han hecho parte creadores, gestores, empresarios, organizaciones, entidades educativas, comunidades y actores sociales que apuestan por la cultura como eje de las políticas económicas, sociales y territoriales, con capacidad de construir acuerdos participativos fortalecidos desde la institucionalidad, el incremento continuo de la inversión social e intervenciones urbanas que procuran la igualdad de los ciudadanos, el uso del espacio público para el encuentro ciudadano, la participación comunitaria y el acceso a la cultura a través de una amplia oferta de programas y proyectos en los ámbitos de la ciudadanía cultural, las bibliotecas, los centros de documentación, el archivo histórico, el patrimonio y las memorias, las lecturas y las escrituras, y las manifestaciones artísticas y culturales en general (Alcaldía de Medellín, 2011).

En lo últimos años, esta estrategia cultural se ha venido materializando de forma notoria a partir de la participación de los hogares en los diferentes encuentros de ciudad, realizados a través de eventos culturales. Para el año 2009 se registró un porcentaje de participación de hogares del 5,8\%, frente a un $21 \%$ para el 2014, lo que equivale a 167.239 hogares participantes. No obstante, la inasistencia sigue siendo alta en relación con los resultados publicados en Medellín Cómo Vamos 2014, donde relacionan que Medellín se ubicó por debajo del promedio de la Red de Ciudades Cómo Vamos (60\% versus 70\%).

Por lo tanto, se deben acometer diferentes retos, tales como gestionar estímulos a la creación y la producción cultural, participación y disfrute de la oferta cultural, circulación, visibilización de manifestaciones culturales emergentes 0 no reconocidas; reconocer socialmente el patrimonio y las memorias; fomentar y fortalecer la formación y de la educación artística y cultural; gestionar el conocimiento; acceso a la 
información y a las tecnologías en diálogo con la cultura: investigación e innovación; ciencia y TIC; lectura y escritura, consolidación del Sistema de Bibliotecas Públicas; promover la profesionalización y especialización del sector cultural para potenciar su competitividad y el desarrollo local, articulando emprendimientos culturales y vocación productiva de la ciudad; fortalecer la interacción de Medellín con la región metropolitana, el departamento, el país y el mundo.

A continuación se describe el indicador de resultado que se pretende con este reto:

\begin{tabular}{|c|c|c|c|c|}
\hline Nombre & Unidad & Línea de Base & $\begin{array}{c}\text { Meta } \\
2019\end{array}$ & Responsable \\
\hline $\begin{array}{l}\text { Participación de los hogares } \\
\text { en actividades en eventos de } \\
\text { música, danza, teatro, cultura } \\
\text { y otros }\end{array}$ & Porcentaje & PD & PD & $\begin{array}{c}\text { Departamento } \\
\text { Adminitrativo de } \\
\text { Planeación }\end{array}$ \\
\hline
\end{tabular}

\subsubsection{PROGRAMA: BIBLIOTECAS PARA UNA SOCIEDAD DEL CONOCIMIENTO}

Los lineamientos internacionales, nacionales y municipales dados en favor de la biblioteca pública, se constituyen como esenciales para respaldar la intención de seguir planificando y gestionando de manera compartida entre el estado y las instituciones privadas y comunitarias con bibliotecas y unidades de información, un proyecto cultural públicoprivado de un sistema bibliotecario en Medellín, pues dichas recomendaciones reconocen que el desarrollo de la sociedad y de las personas son derechos fundamentales que sólo podrán alcanzarse si hay ciudadanos bien informados, con acceso gratuito a la cultura y el conocimiento sin ninguna restricción y con posibilidades de encuentro para ejercer sus derechos democráticos y desempeñar un papel activo dentro de las comunidades y la sociedad en general.

En este marco, es preponderante el papel de los gobiernos, pero también de las organizaciones privadas y comunitarias, en el desarrollo del sector de las bibliotecas públicas y como lo recomienda la UNESCO en el Manifiesto de las bibliotecas: la necesidad de definir políticas que garanticen la adecuada organización de los sistemas y redes bibliotecarias, su gestión, financiamiento, la articulación entre los diversos tipos de unidades de información y bibliotecas públicas, escolares, universitarias, especializadas y de investigación, entre otras. De igual manera, es importante retomar su recomendación de articulación de las políticas de bibliotecas con las políticas no solo culturales, sino también educativas, de información y comunicación.

El contexto político, cultural y social en Medellín es propicio para avanzar en el programa de bibliotecas para una sociedad del conocimiento, que comprende el fortalecimiento de un sistema bibliotecario que conecta 
territorios y desde donde es posible una gestión sistemática de servicios con sentido público, pues se hace evidente la voluntad en los planteamientos y programas de los planes de desarrollo municipal entre el 2004 y el 2015, en el plan de desarrollo cultural a 2020, en el plan maestro de bibliotecas del 2004, en el plan estratégico del sistema de bibliotecas públicas a 2018, y en los diferentes decretos y acuerdos que existen referentes a estos asuntos en Medellín. Todo esto, denota la vitalidad de los procesos que desde la cultura, la lectura y las bibliotecas se han venido construyendo y consolidando en Medellín, y su aporte valioso a la transformación de la Ciudad en los últimos años, centrados en la construcción de ciudadanía cultural, garantía de derechos y consolidación del tejido cultural y social, mediante una decidida alianza entre Estado y Sociedad desde el sector cultural y bibliotecario.

En el marco de este programa se pretende entonces seguir trabajando por consolidar la comprensión y el trabajo que se viene haciendo en Medellín desde la función pública de la biblioteca, como aquella institución social desde donde se facilita el acceso libre, sin ninguna distinción, a la cultura, el conocimiento y la información para el bienestar y desarrollo de todos los que se encuentran en el territorio, es decir en el barrio y la comuna, tan diversos que requieren intervenciones de todos los actores posibles que los habitan: instituciones, programas, proyectos y ciudadanos para que su impacto sea oportuno y colectivo.

Indicador de resultado

\begin{tabular}{|c|c|c|c|c|}
\hline Nombre & Unidad & Línea de Base & $\begin{array}{c}\text { Meta } \\
2019\end{array}$ & Responsable \\
\hline $\begin{array}{l}\text { Beneficiarios de servicios y } \\
\text { programas de las bibliotecas } \\
\text { públicas }\end{array}$ & Número & 3418305 & 3420000 & $\begin{array}{c}\text { Secretaría de } \\
\text { Cultura } \\
\text { Ciudadana }\end{array}$ \\
\hline
\end{tabular}

\subsubsection{Proyecto: Bibliotecas conectando territorios}

Lo que se busca desde las bibliotecas de la ciudad está determinado en cinco ámbitos de impacto que garanticen: el acceso de los ciudadanos a la información pertinente a cada territorio, el acceso de los ciudadanos a la formación para su desarrollo humano, el fomento de la innovación colaborativa, espacios de encuentro acogedores y plurales con entornos virtuales de interacción y dispuestos en toda la ciudad, intercambio e incidencia en el conocimiento.

El fortalecimiento y visibilización de la Biblioteca Escolar dentro de la apuesta educativa de la ciudad de Medellín, tiene la intención de volcar la mirada sobre las prácticas de lectura, escritura y oralidad enfocadas en el desarrollo de competencias en todas las áreas del currículo, desde el diseño, implementación y evaluación de Planes Institucionales de lectura, escritura y oralidad. La biblioteca escolar en tanto componente de apoyo a los procesos de formación en el interior de las instituciones educativas, es el eje de dicha formulación 
que, en diálogo con el Plan Nacional de Lectura y Escritura: Leer es mi cuento del Ministerio de Educación Nacional, se enmarca en el Proyecto Educativo Institucional, los planes de área, los programas y proyectos de cada una de las instituciones educativas.

Responsable: Secretaría de Cultura Ciudadana

Indicadores de producto:

\begin{tabular}{|l|c|}
\hline \multicolumn{1}{|c|}{ Nombre } & Unidad \\
\hline Visitas a las bibliotecas públicas & Número \\
\hline $\begin{array}{l}\text { Proyectos bibliotecarios, de cultura digital, de memoria y de fomento de } \\
\text { lectura y escritura en los territorios }\end{array}$ & Porcentaje \\
\hline
\end{tabular}

\subsubsection{Proyecto: Archivo Histórico de Medellín y Patrimonio Documental}

Fortalecer el archivo histórico como la fuente primaria de la historia de la ciudad, para la recuperación del patrimonio documental, su conservación y restauración, y promover políticas públicas y lineamientos en el campo del patrimonio documental de la ciudad y el país.

Responsable: Secretaría de Cultura Ciudadana

Indicadores de producto:

\begin{tabular}{|l|c|}
\hline \multicolumn{1}{|c|}{ Nombre } & Unidad \\
\hline $\begin{array}{l}\text { Acciones realizadas para la preservación de los archivos documentales del } \\
\text { Municipio de Medellín }\end{array}$ & Número \\
\hline Investigaciones culturales realizadas & Número \\
\hline
\end{tabular}

\subsubsection{PROGRAMA: MOVILIZACIÓN POR LA CULTURA}

La Ciudad hoy tiene el reto de seguir implementando su plan de desarrollo cultural a 2020, que comprende los sentidos de la cultura como motor de desarrollo y que se materializa en desafíos, objetivos y enfoques, así como en unos lineamientos político-culturales que interpretan un acuerdo con amplia participación de la base social de la ciudad, donde se tiene ruta estratégica en la que sectores privados, académicos, civiles y gubernamentales trabajan por propósitos y acciones unificadas dentro del sector cultural y artístico.

En Medellín el Estado dispone de los escenarios para que ello suceda, escuelas de música, teatros, uvas, archivo histórico, bibliotecas, centros de documentación, entre otros equipamientos culturales que como las casas de la cultura buscan ser los espacios en la Ciudad para la creación, preservación, transmisión, circulación y fomento de la cultura y las manifestaciones artísticas propias de las comunidades. Así mismo, espacios para la formación de públicos y la generación de procesos de desarrollo cultural concertados entre la ciudadanía y el Estado. 
De la misma manera promueve procesos de apropiación social del patrimonio que favorecen el ejercicio de una ciudadanía cultural que evita olvidar, recrea sus memorias, fortalece sus identidades desde una perspectiva democrática, incluyente e innovadora.En este sentido, este programa busca que cada vez más en Medellín se cumpla con la garantía de los derechos culturales con una perspectiva de enfoques territorial, poblacional y de gobernanza que contribuya en últimas al desarrollo de la ciudadanía y de la ciudad.

Indicador de resultado:

\begin{tabular}{|l|c|c|c|c|}
\hline \multicolumn{1}{|c|}{ Nombre } & Unidad & Línea de Base & $\begin{array}{c}\text { Meta } \\
2019\end{array}$ & Responsable \\
\hline $\begin{array}{l}\text { Beneficiarios de servicios y } \\
\text { programas de la Red de } \\
\begin{array}{l}\text { Casas de la Cultura y otros } \\
\text { equipamientos culturales } \\
\text { públicos }\end{array}\end{array}$ & Número & 543509 & 625035 & $\begin{array}{c}\text { Secretaría de } \\
\text { Cultura } \\
\text { Ciudadana }\end{array}$ \\
\hline
\end{tabular}

\subsubsection{Proyecto: Fortalecimiento de la red Casas de la Cultura}

Fortalecer los equipamientos culturales que están dispuestos para la creación, preservación, transmisión, circulación y fomento de la cultura y las manifestaciones artísticas propias de las comunidades. Así mismo, como espacios para la formación de públicos y la generación de procesos de desarrollo cultural concertados entre la ciudadanía y el Estado.

Responsable: Secretaria de Cultura Ciudadana

Indicadores de producto:

\begin{tabular}{|l|l|}
\hline \multicolumn{1}{|c|}{ Nombre } & Unidad \\
\hline Procesos comunitarios apoyados & Número \\
\hline Beneficiarios de procesos formativos & Número \\
\hline
\end{tabular}

\subsubsection{Proyecto: Fortalecimiento del Museo de Antioquia}

Atender obligación contraída con Empresas Públicas de Medellín, por la adquisición de los inmuebles denominados: Antiguo Palacio Municipal y Parqueadero Calibío, destinados a la construcción del Museo de Antioquia y Parque de las Esculturas. Proyecto con vigencia futura hasta el 2020. Normativa: Acuerdo Municipal No. 20 de 2000.

Responsable: Secretaria de Hacienda Indicador de producto

\begin{tabular}{|l|c|}
\hline \multicolumn{1}{|c|}{ Nombre } & Unidad \\
\hline $\begin{array}{l}\text { Porcentaje de cumplimiento de amortización de recursos destinados a } \\
\text { Equipamientos culturales construidos }\end{array}$ & Porcentaje \\
\hline
\end{tabular}




\subsubsection{Proyecto: Creación y circulación}

Se hace vital rescatar la memoria escritra, potencial los talentos, estimular la creación literaria, la producción editorial y mejorar los canales de dicvulgación y distribución del libro a través del fondo editorial y disponer de diversos escnarios para que la ciudadanía pueda acercarse al univeso del libro en todos sus formatos y a la literatura a través de los eventose del libro y la circulación de los autores en el ámbito local, departametal, nacional e internacional.

Responsable: Secretaria de Cultura y Convivencia Ciudadana

\subsubsection{PROGRAMA: CREACIÓN, FORMACIÓN, FOMENTO Y CIRCULACIÓN}

En este programa se encuentran distintos proyectos que propenden por el acceso a la cultura como derecho y que fortalecerán el proyecto cultural de Medellín como motor de transformación y desarrollo, así como seguirán consolidando a la ciudad como un referente iberoamericano.

Por una parte las convocatorias Públicas de Arte y Cultura como mecanismo de participación y acceso equitativo a los recursos del Estado para los procesos de creación, fomento, formación, producción, circulación y proyección. Así como una apuesta por la cualificación de los sectores artísticos y culturales a través del ejercicio de planificación y presentación de proyectos; por la puesta en circulación de unos estímulos que propenden por la reflexión del quehacer y la prospectiva del mismo; por incentivar nuevas propuestas; por fortalecer iniciativas, programas, proyectos e instituciones; y fomentar la innovación y sostenibilidad del sector artístico y cultural.

Por otra parte las redes de formación artística y cultural, como un proyecto de larga tradición en la Ciudad pero en constante renovación que busca movilizar a los niños y jóvenes hacia el desarrollo de capacidades que favorecen finalmente su desarrollo humano; que tienen como propósito incidir en la construcción de sus identidades, sus formas de concebir el mundo, su país, su ciudad, y relacionarse en él. Así mismo, estas redes se constituyen como el espacio de los barrios y las comunas donde se garantiza el acceso y disfrute de diferentes manifestaciones artísticas, tanto para los que hacen parte de los procesos de formación como para su entorno familiar y social, lo que las ha convertido en espacios para el ejercicio de la ciudadanía democrática, la convivencia y la cultura ciudadana.

En lo que se refiere a la formación de públicos hoy Medellín tiene grandes retos, pues este proyecto debe lograr que en la Ciudad se pase del acceso al consumo cultural, se debe trabajar de manera más articulada con las distintas instituciones de la Ciudad para que no sólo se garantice la visita y circulación 
por los distintos escenarios de la ciudad, si no también para que se promueva el disfrute y finalmente el hábito en los ciudadanos de Medellín por un consumo más que cuantificado, cualificado. Es decir, a través de la formación de públicos se debe lograr que en Medellín no sólo se tenga una agenda u oferta cultural de calidad, si no unos públicos con alta valoración de la misma.

Respecto a los intercambios culturales con el mundo, es sin lugar a dudas un camino que ya ha tenido recorridos, pes la ciudad ha sido anfitriona de importantes certámenes y hechos culturales para el mundo, pero también ha desarrollado y realizado importantes hermanamientos y transferencias con otras ciudades del país y del mundo, por tanto lo que se buscará será seguir consolidando este espacio para la transferencia de buenas prácticas, para el desarrollo conjunto de iniciativas y proyectos que fortalecen el proyecto

cultural y que finalmente colocan a Medellín como una ciudad que se referencia desde la cultura en Iberoamérica.

Finalmente fortalecer el proyecto de casas de música y crear la cinemateca municipal son apuestas necesarias para fortalecer las vocaciones de la ciudad en innovación social y sostenibilidad económica, pues estos dos proyectos serán generadores de la consolidación de memorias e identidades por una parte, y emprendimientos culturales por otra, que contribuirán al desarrollo humano y económico de los ciudadanos, así como también seguirán colocando a la Ciudad en importantes escenarios internacionales.

Indicador de resultado

\begin{tabular}{|l|l|c|c|l|}
\hline \multicolumn{1}{|c|}{ Nombre } & Unidad & Línea de Base & $\begin{array}{c}\text { Meta } \\
2019\end{array}$ & \multicolumn{1}{c|}{ Responsable } \\
\hline $\begin{array}{l}\text { Hogares que participan al } \\
\text { menos en una actividad } \\
\text { cultural al año }\end{array}$ & Número & 174,000 & 174,000 & $\begin{array}{l}\text { Secretaría de } \\
\text { Cultura Ciudadana }\end{array}$ \\
\hline
\end{tabular}

\subsubsection{Proyecto: Fortalecimiento Convocatorias Públicas de Arte y Cultura} Fortalecer las convocatorias públicas para garantizar la innovación, creación, equidad, transparencia y sostenibilidad, a través de la asignación de recursos destinados a estimular y fomentar al sector cultural y artístico de la ciudad, para la consolidación de las iniciativas, programas y proyectos del sector, desde los procesos de formación, pasando por la producción y su posterior circulación.

Responsable: Secretaria de Cultura Ciudadana

Indicadores de producto:

\begin{tabular}{|l|l|}
\hline Nombre & Unidad \\
\hline Beneficiarios que se presentan a convocatorias de estímulos culturales & Número \\
\hline Beneficiarios que se ganan convocatorias & Número \\
\hline
\end{tabular}




\subsubsection{Proyecto: Redes de formación artística y cultural}

Consolidar el proyecto de formación que ofrece espacios y prácticas que generan y fortalecen experiencias de convivencia, goce y aprendizaje a través de la formación artística y cultural que se materializa en actividades creativas mediante la música, las artes visuales, la danza y las artes escénicas.

Responsable: Secretaria de Cultura Ciudadana

Indicadores de producto:

Nombre

Beneficiarios de las redes de formación artística y cultural

Unidad

Número

\subsubsection{Proyecto: Formación de públicos - Tarjeta única ciudadana} Redireccionar la apuesta pública más allá del acceso a que se promueva conjuntamente con las distintas entidades, agentes y programas de la ciudad unos programas de formación de públicos que cualifiquen e incrementen la participación de los ciudadanos en la agenda cultural de la ciudad.

Responsable: Secretaria de Cultura Ciudadana

Indicadores de producto:

\begin{tabular}{|l|c|}
\hline \multicolumn{1}{|c|}{ Nombre } & Unidad \\
\hline Asistentes a eventos culturales de ciudad y en equipamientos públicos & Número \\
\hline $\begin{array}{l}\text { Ciudadanos con ingreso gratuito a museos, teatros, parques y eventos culturales } \\
\text { especiales }\end{array}$ & Número \\
\hline
\end{tabular}

\subsubsection{Proyecto: Intercambios culturales con el mundo (Ciudades} Hermanas y aliados de Medellín)

Promover intercambios que sigan enriqueciendo el proyecto cultural de la ciudad y que garanticen un flujo de circulación de proyectos conjuntos con otras ciudades y países, que fortalezcan con buenas prácticas la inversión que hace el estado, y que de igual manera sigan posicionando a Medellín como una ciudad que se referencia desde la cultura en Iberoamérica.

Fortalecer la agenda cultural de Medellín y estrechar los lazos con sus aliados internacionales a través de la promoción de la cultura de otras ciudad en Medellín y la promoción de la cultura nuestra en otras ciudades.

Responsable: Secretaria de Cultura Ciudadana Indicador de producto

\begin{tabular}{|l|c|}
\hline \multicolumn{1}{|c|}{ Nombre } & Unidad \\
\hline Número de intercambios culturales de Medellín con otras ciudades del mundo & Número \\
\hline
\end{tabular}




\subsubsection{Proyecto: Fortalecer casas de música}

Establecer un modelo de gestión del sector de la música que articule de manera transversal las iniciativas, programas, proyectos y acciones que realiza la Secretaría de Cultura Ciudadana y que se direccionarán y acogerán desde las distintas casas de música, movilizando estrategias de cooperación local, nacional e internacionalmente.

Responsable: Secretaria de Cultura Ciudadana Indicadores de producto:

\begin{tabular}{|l|c|}
\hline \multicolumn{1}{|c|}{ Nombre } & Unidad \\
\hline Fortalecimiento de Medellín en la Red de Ciudades Creativas de la Música Unesco & Número \\
\hline Eventos realizados para la circulación y proyección para el sector musical & Número \\
\hline Procesos de emprendimientos musicales & Número \\
\hline
\end{tabular}

\subsubsection{Proyecto: Apoyar la industria audiovisual de la ciudad y} Cinemateca

Generar alianzas para que la ciudad se convierta en un excelente espacio para los diferentes procesos audiovisuales, preproducción, producción y postproducción, al mismo tiempo lograr un intercambio de conocimientos entre los profesionales de la industria que visitan la ciudad y los ciudadanos interesados en aprender sobre los procesos audiovisuales y cinematográficos. También promover alianzas con los canales de la ciudad para que incluyan en sus parrillas producciones locales de cineastas y realizadores audiovisuales.

Fortalecer la cinemateca municipal de la Ciudad, desde donde se fortalecerá los procesos de creación, memoria y circulación.

Indicadores de producto:

Responsable: Secretaria Desarrollo Económico

\begin{tabular}{|l|l|}
\hline Nombre & Unidad \\
\hline Proyectos audiovisuales apoyados & Número \\
\hline Cinemateca municipal creada y en funcionamiento & Porcentaje \\
\hline
\end{tabular}




\subsection{RETO \\ MEDELLÍN CON ACCESO \\ AL EMPLEO}

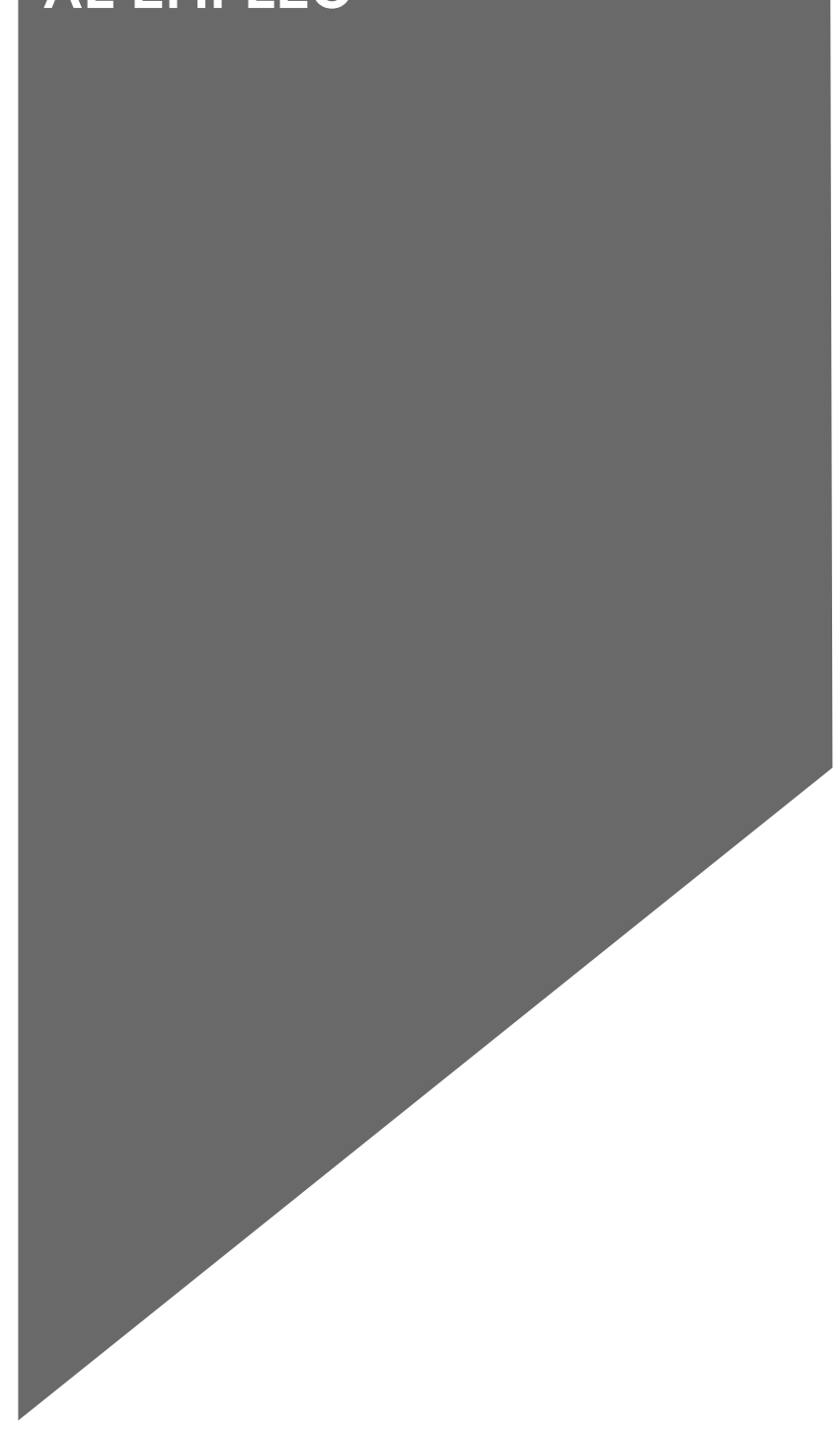

\section{OBJETIVO}

Generar oportunidades de acceso a empleo digno basado en la oferta y la demanda del mercado y alineando los conocimientos y capacidades de las personas a los requerimientos del sector empresarial.

\section{PROGRAMAS}

4 4.4.1. Desarrollo empresarial

$\Delta$ 4.4.2. Educación pertinente a la dinámica laboral

44.4.3. Generación de empleo

4.4.4. Medellín Emprendedora

4 4.4.5. Desarrollo empresarial rural

4 4.4.6. En búsqueda de la competitividad 


\subsection{Medellín con acceso al empleo}

Un componente fundamental para la economía de una ciudad es propender la atracción de inversiones tanto nacionales como extranjeras para lograr un más alto crecimiento económico, generar más puestos de trabajo y, por consecuencia, un mayor nivel de bienestar de sus ciudadanos. Medellín, durante largo tiempo ha procurado por mejorar su competitividad a partir de la construcción de infraestructuras de salud, educación, recreación y vías, a su vez ha buscado la apertura de diferentes oportunidades educativas para la población, fomentando el aumento del desarrollo.

Una forma de poder evaluar estos avances es a partir del Ranking de la mejores Ciudades para Hacer Negocios en Latino América. Este es una publicación de la Revista América Economía que rankea a 52 ciudades de Latino América, donde para su cálculo es construido una medida denominada Índice de Competitividad Urbana (ICUR) que se compone de ocho dimensiones, a saber: marco social y político; marco y dinamismo económico; servicios a las empresas; servicios a ejecutivos; infraestructura y conectividad física; capital humano; sostenibilidad medioambiental; poder de marca.

Como se visualiza en el Gráfico 2, se encuentra que las tres principales ciudades de Colombia como son Cali, Bogotá y Medellín vienen en una tendencia decreciente (aumento de la competitividad) desde 2001, ocupando la segunda posición Medellín. De acuerdo al informe que publica la revista, dice que Medellín ha mejorado su posicionamiento gracias al mejoramiento en el tema de sustentabilidad ambiental a partir del cada vez más desarrollado e integrado sistema masivo de transporte, reducción de $\mathrm{CO} 2$ y aumento del dinamismo económico.

Gráfico 15. Evolución de Medellín, Bogotá y Cali en el ranking de las mejores ciudades para hacer negocios en América Latina 2001-2015

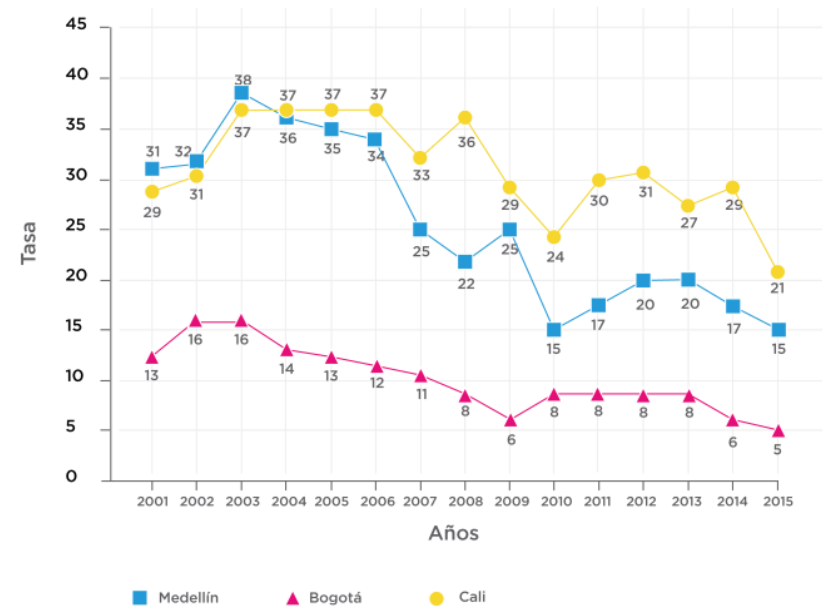

Fuente: Revista Económia 
En el Gráfico 3 se muestra como se encuentra la ciudad de Medellín en las diferentes dimensiones contenidas en el índice. En este caso, se alcanza a visualizar que de estas los mayores valores se tienen (siendo el 100 el valor máximo) en Sustentabilidad ambiental $(82,14)$, Marco social y político $(74,81)$ y Poder de marca $(74,35)$, en contraste, la dimensión con peores condiciones es Infraestructura y conectividad $(35,01)$.

Gráfico 16. Estado de los diferentes indicadores del ranking de la mejores ciudades para hacer negocios para la ciudad de Medellín, 2015

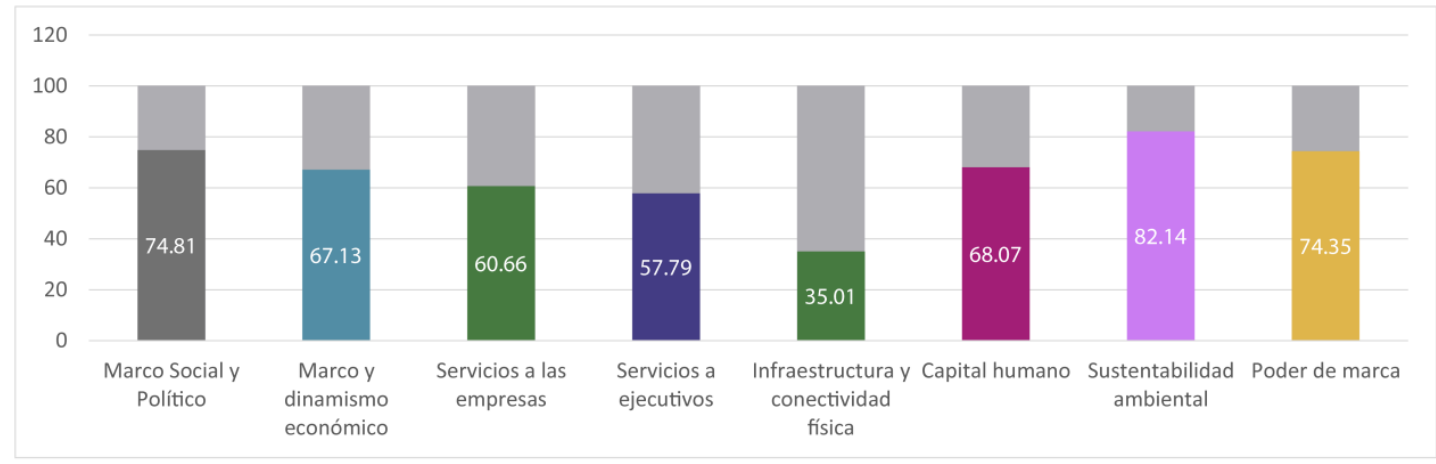

Fuente: Revista América Economía.

La evolución de la economía de Medellín en cuanto a el Producto Interno Bruto (PIB) durante el periodo 2005-2013preliminar ( $p$ ) presentó un crecimiento promedio anual de 5,9\% para la ciudad de Medellín, siendo hasta el año 2012 el mayor crecimiento en relación al Departamento de Antioquia y a nivel Nacional, para el año 2013 se sigue una tendencia positiva del crecimiento económico de la ciudad (3,7\%), sin embargo, esta se encuentra por debajo del Departamento de Antioquia y el Nacional.

Gráfico 17. Evolución del PIB de Medellín a precios constantes de 2005 (2006-2013p) y comparativo del crecimiento de Medellín, Antioquia y Nacional

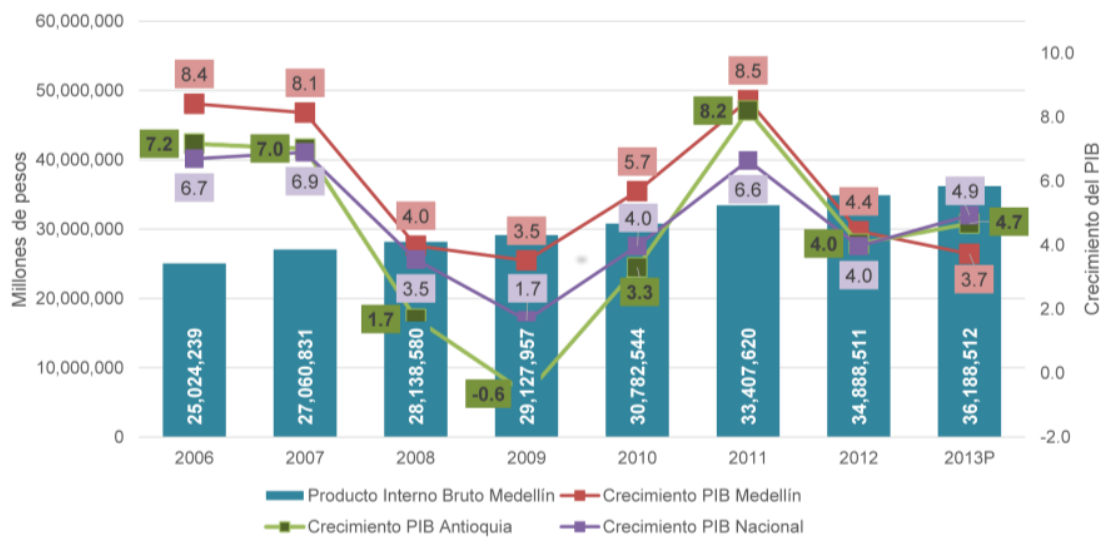

Fuente: Contrato de Consultoría Departamento Administrativo de Planeación de Medellín-Unión Temporal Centanaro-Mahecha. P Cifras preliminares. 
De las ramas de actividad económica que más aportan en el PIB para el año 2013 se encuentra la Industria Manufacturera (16,9\%), Actividades de servicios a las empresas $(12,8 \%)$ y Comercio y servicios de reparación $(12,4 \%)$ (véase Gráfico 5). Una rama de menor aporte es la Agricultura, ganadería, silvicultura y pesca $(0,6 \%)$, la cual se desarrolla principalmente en los corregimientos de la ciudad, haciendo necesario emprender acciones hacia una ruralidad sostenible, reconociendo su importancia como proveedora de servicios ecosistémicos, soporte para un futuro ambientalmente sano, y la productividad agraria como parte de la seguridad alimentaria (Alcaldía de Medellín, 2014).

Gráfico 18. Participación del PIB por ramas de actividad económica, 2013

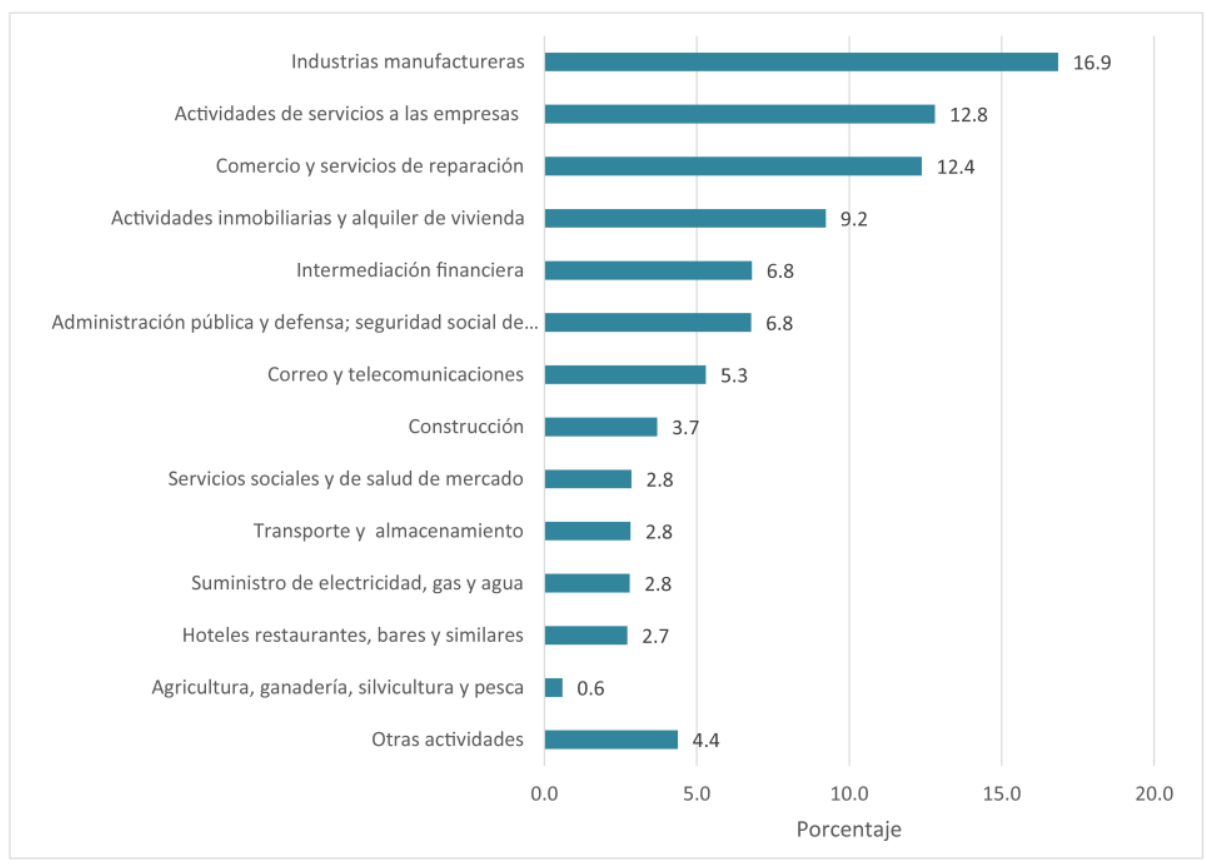

Fuente: Revista América Economía

En cuanto a las empresas, para el periodo 2011-2014 se presentó un crecimiento promedio del 7,2\%, ubicándose para 2014 en 75.916 establecimientos registrados en la Cámara de Comercio de Medellín, de las cuales la mayoría son microempresas (86\%) y pequeñas empresas (10\%), donde un $50 \%$ del total pertenecen a uno de los clúster.

Esta configuración y la gestión pública en la materia ha propiciado el emprendimiento en todas sus manifestaciones, haciendo énfasis en el denominado emprendimiento social de impacto basado en la generación de innovaciones y en formalización empresarial, arrojando una inversión de capital privado en nuevas empresas que asciende a 9.879 millones de pesos. Ligado a lo anterior, Medellín viene identificando y promoviendo 
diversas estrategias enfocadas en aumentar la productividad de su tejido empresarial, basado en su legado industrial.

La dinámica empresarial se ve reflejada en el mercado laboral con: una reducción de 3,4 puntos porcentuales (pp) de la tasa de desempleo, pasando del 12,2\% en 2011 al 8,8\% en 2014, congruente con otras áreas metropolitanas; siendo las ramas de actividad económica que mayor cantidad de empleo generaron fueron: Comercio al por mayor y al por menor (22,6\%), Industria manufacturera (19,0\%) y Actividades inmobiliarias, empresariales y de alquiler (12,3\%); esta información, resulta de gran interés, de cara a conocer cuáles son los sectores en que deberá enfocarse el apoyo de la Administración Municipal en sus diferentes programas de creación, fortalecimiento empresarial y formación para el empleo. Propendiendo por un incremento de la productividad que se puede ver reflejado en la reducción de la tasa de informalidad, que en 2014 se ubicó en 44,93\%.

De los resultados de la economía de Medellín en relación a otras ciudades, se presentan un conjunto de retos para el periodo 2016-2019, entre los que se encuentra: potencializar el emprendimiento, innovación y consolidación de sectores que se vuelven claves para el desarrollo económico y social de la ciudad, estos son los casos del sector tecnológico, turístico, agrícola y educativo, lo que puede propender por una ciudad que crezca y se desarrolle bajo condiciones sostenibles; asociado al punto anterior, es necesario seguir apostándole a crecimiento del empleo bajo condiciones de formalidad, lo que se traduce en una mayor productividad de los factores.

\subsubsection{PROGRAMA: DESARROLLO EMPRESARIAL}

Impulsar el desarrollo empresarial de Medellín, con la participación de los diversos agentes productivos público privados de la Ciudad, generando acciones orientadas a fortalecer, fomentar, promover, difundir e implementar la inversión y la reinversión empresarial, contribuyendo al fortalecimiento del tejido empresarial existente y al asentamiento de nuevas inversiones productivas en el territorio de Medellín.

\section{Indicadores de resultado}

\begin{tabular}{|l|c|c|c|c|}
\hline \multicolumn{1}{|c|}{ Nombre } & Unidad & Línea de Base & $\begin{array}{c}\text { Meta } \\
2019\end{array}$ & Responsable \\
\hline $\begin{array}{l}\text { Empresas que mejoran } \\
\text { integralmente sus } \\
\text { capacidades competitivas } \\
\begin{array}{l}\text { con instrumentos de } \\
\text { fortalecimiento empresarial }\end{array}\end{array}$ & Número & 800 & 800 & $\begin{array}{c}\text { Secretaría de } \\
\text { Desarrollo } \\
\text { Económico }\end{array}$ \\
\hline $\begin{array}{l}\text { Empresas pertenecientes a } \\
\text { Cluster estratégicos }\end{array}$ & Número & 33097 & $>=33097$ & $\begin{array}{c}\text { Secretaría de } \\
\text { Desarrollo } \\
\text { Económico }\end{array}$ \\
\hline $\begin{array}{l}\text { Compañías asentadas en el } \\
\text { Distrito de Innovación }\end{array}$ & Número & 71 & 200 & Ruta N \\
\hline
\end{tabular}




\subsubsection{Proyecto: Medellín, Ciudad Cluster y de Servicios}

Fortalecer el desarrollo y la competitividad empresarial en las líneas ofrecidas en cada uno de los Clústeres estratégicos que tiene la ciudad, como parte del proceso de desarrollo económico de la ciudad, y de acuerdo a las necesidades económicas y sociales de las comunidades beneficiadas. Fortalecer los 6 clústeres estratégicos asegurando que la mano de obra adquiera las competencias necesarias alrededor de estos. Continuar con alianzas estratégicas nacionales e internacionales alrededor del fortalecimiento de los clústeres de ciudad.

Responsable: Secretaría de Desarrollo Económico

Indicadores de producto:

\begin{tabular}{|l|l|}
\hline \multicolumn{1}{|c|}{ Nombre } & \multicolumn{1}{|c|}{ Unidad } \\
\hline Empresas Medellinenses, fortalecidas dentro de la estrategia cluster & Número \\
\hline Empresas con procesos de aceleración empresarial implementadas & Número \\
\hline Empresas intervenidas con procesos de sustitución de importaciones & Número \\
\hline Empresas acompañadas con presencia en colombiamoda & Número \\
\hline
\end{tabular}

\subsubsection{Proyecto: Atracción de Inversión Nacional y Extranjera Directa} Fortalecer la dinámica económica local a partir de la promoción y gestión de llegada de empresas que se instalen en Medellín y generen empleo de calidad para los habitantes de la ciudad.

Responsable: Desarrollo Ecnonómico

Indicador de producto

Inversiones y reinversiones en el Municipio de Medellín

Núnero

\subsubsection{Proyecto: Fortalecer el Pacto por la Innovación}

La inversión en $\mathrm{CT}+\mathrm{i}$ es uno de los pilares fundamentales para dinamizar el ecosistema de innovación. Se ha demostrado que los países que han enfocado sus esfuerzos en innovación a partir de las inversiones, han logrado incrementos extraordinarios en su PIB, empleo y desarrollo en general.

Los esfuerzos de inversión en países emergentes los hace principalmente el sector público, hace falta un gran esfuerzo para que el sector privado invierta. La balanza ideal es llegar a que el sector público invierta el 30\%, y el sector privado el $70 \%$.

Responsable: Desarrollo Ecnonómico

Indicador de producto

\begin{tabular}{|l|c|}
\hline \multicolumn{1}{|c|}{ Nombre } & Unidad \\
\hline $\begin{array}{l}\text { Acciones realizadas para la preservación de los archivos documentales del Municipio } \\
\text { de Medellín }\end{array}$ & Número \\
\hline Investigaciones culturales realizadas & Número \\
\hline
\end{tabular}




\subsubsection{Proyecto: Impulsar el desarrollo sectorial para el fomento del comercio organizado}

Desarrollo de proyectos tendientes a mejorar la competitividad del sector comercio de Medellín, a través de una mayor integración de este sector, con la economía de la Ciudad.

Responsable: Secretaría de Desarrollo Económico

Indicador de producto

\begin{tabular}{|c|c|}
\hline \multicolumn{1}{|c|}{ Nombre } & Unidad \\
\hline Empresas intervenidas en buenas prácticas comerciales & Número \\
\hline
\end{tabular}

\subsubsection{PROGRAMA: EDUCACIÓN PERTINENTE A LA DINÁMICA LABORAL}

Lograr una mayor productividad y competitividad de la economía de la ciudad, implica mejorar las condiciones tanto de los trabajadores actuales, como de los potenciales, a través de la mejora de sus perfiles ocupacionales. Por lo anterior, el sector educativo es responsable directo de incidir en variables asociadas a la generación del capital humano necesario para el adecuado nivel de desarrollo económico de la ciudad, tales como: la calidad de la educación, el promedio de años de escolaridad, y los indicadores de matrícula, que han sido resaltadas por el Foro Económico Mundial como determinantes de la competitividad de los territorios.

A través de la educación, la Ciudad busca lograr una mayor adaptación y mayor velocidad de respuesta a las necesidades de un entorno económico cambiante, además de incrementar la calidad y pertinencia de los programas educativos y sobre todo, en mejorar la vinculación de la capacitación con las transformaciones de la estructura productiva deseada.

Indicador de resultado

\begin{tabular}{|c|c|c|c|c|}
\hline Nombre & Unidad & Línea de Base & $\begin{array}{c}\text { Meta } \\
2019\end{array}$ & Responsable \\
\hline $\begin{array}{l}\text { Inserción laboral de jóvenes } \\
\text { y adultos }\end{array}$ & Número & 500 & 1200 & Sapiencia \\
\hline
\end{tabular}

4.4.2.1 Proyecto: Fomentar la inserción formal laboral

Promover el acceso de los ciudadanos, a un trabajo formal digno y productivo, a través del acompañamiento e intermediación en el proceso de inserción laboral.

Responsable: Secretaria de Desarrollo Económico 
Indicador de producto

\begin{tabular}{|c|c|}
\hline Nombre & Unidad \\
\hline Estudiantes vinculados a programas de exploración y orientación vocacional & Número \\
\hline
\end{tabular}

\subsubsection{Proyecto: Talento joven, Medellín le apuesta al primer empleo} Es un proyecto liderado por la Secretaría de la Juventud de Medellín, que busca ofrecer una respuesta en materia de formación para el empleo y emprendimiento a jóvenes urbanos y rurales que no estudian o no trabajan, en busca de mejorar su vocación y condición laboral o que desean asociarse con otros jóvenes en torno a ideas productivas. El proyecto tiene como estrategias principales el fortalecimiento de la formación vocacional y preparación para el empleo en habilidades prosociales de los jóvenes estudiantes o de quienes se preparan para ingresar al mercado laboral; eliminar las barreras e imaginarios que existen entre el sector empresarial y el mundo juvenil, crear una plataforma virtual y una estrategia de mercadeo

para que los jóvenes intercambien y oferten sus productos y talentos, y promover una serie de estímulos económicos, especialmente en el campo de las empresas culturales y creativas.

Responsable: Secretaría de Juventud

Indicador de producto

\begin{tabular}{|c|c|}
\hline Nombre & Unidad \\
\hline $\begin{array}{c}\text { Procesos de articulación y formación para el empleo, orientación vocacional } \\
\text { para visibilizar los saberes juveniles }\end{array}$ & Número \\
\hline
\end{tabular}

\subsubsection{Proyecto: Formar y educar en competencias de acuerdo a la demanda y necesidades del mercado laboral}

Propiciar la formación en competencias laborales que respondan realmente a las necesidades del mercado laboral actual; puesto que cada vez es más reconocida la necesidad de una formación laboral, que sea pertinente para la sociedad. Por lo anterior, la formulación de competencias genéricas, que derivan en otras más especializadas, constituye el horizonte de acciones de formación deseables en todos los ámbitos de la educación y son a la vez, un referente de gran importancia para poder hacer un seguimiento adecuado a

la calidad de la formación, principalmente en los sectores más generadores de empleo en la Ciudad. No obstante lo anterior, es claro que las competencias genéricas no pueden suplantar las competencias específicas que se forman en los distintos centros de formación, pues su desarrollo, con respecto a estas últimas, tiene un carácter a la vez complementario e integrador. 
Indicador de producto

\begin{tabular}{|c|c|}
\hline Nombre & Unidad \\
\hline Jóvenes y adultos formados en competencias laborales para el trabajo. & Número \\
\hline
\end{tabular}

\subsubsection{Proyecto: Alianzas estratégicas entre el sector productivo y la educación superior}

Generar una mayor interacción entre las empresas y los centros de educación superior, para que de manera articulada se realicen proyectos conjuntos con el fin de promover diferentes tipos de innovación y de gestión tecnológica al interior de los sectores económicos más importantes para la Ciudad. Lo anterior redundará en el aprovechamiento de sinergias y de aplicación de experiencias exitosas de estas dinámicas que son evidentes en economías más desarrolladas. Se tiene el reto de consolidar, cada vez más, estas alianzas estratégicas en la Ciudad con el apoyo de la presente administración en donde se dé una mayor apertura del sector empresarial hacia la educación superior y el compromiso social de las universidades para apoyar proyectos de investigación articulada.

Responsable: Sapiencia

Indicador de producto

\begin{tabular}{|c|c|}
\hline Nombre & Unidad \\
\hline Alianzas realizadas para la inserción laboral & Número \\
\hline Alianzas realizadas para el apoyo a proyectos de investigación & Número \\
\hline
\end{tabular}

\subsubsection{Proyecto: Consolidación del sistema de educación terciaria} (ETDH, técnica, tecnológica, y universitaria)

Estructurar un proceso de fortalecimiento de las alianzas que se generan entre la media y la técnica, a partir de programas ajustados al futuro sistema terciario de la ciudad; y en desarrollo de una política pública que permita el fortalecimiento de la calidad de los programas de educación para el trabajo y el desarrollo humano, de formación técnica laboral, técnica profesional, tecnológica y profesional universitaria para la creación de una ruta de formación y progresión laboral en Medellín, ajustada a la vocación productiva de la ciudad y en el marco de lo que se puede denominar la “Triple E”, Educación, Empresa, Estado. Esto debe promover, a su vez, una propuesta de educación inclusiva, dirigida a la población en condición de discapacidad.

Se le dará la relevancia y el status que requiere a la Educación para el Trabajo y el Desarrollo Humano, llamada en todo el mundo formación profesional integral. Se revisará la regulación en la apertura de instituciones y programas de este tipo para garantizar la calidad del sistema y que se convierta en una herramienta social que permita dar respuesta rápida al sector productivo y al desarrollo de una ciudad como Medellín. Además de 
fortalecer y acompañar a las Instituciones que a la fecha cuentan con certificación de Calidad.

Responsable: Sapiencia

Indicador de producto

\begin{tabular}{|c|c|}
\hline \multicolumn{1}{|c|}{ Nombre } & \multicolumn{1}{|c|}{ Unidad } \\
\hline Prueba piloto implementada sobre educación terciaria & Número \\
\hline
\end{tabular}

\subsubsection{PROGRAMA: GENERACIÓN DE EMPLEO}

A través del diseño y la puesta en marcha, de una estrategia de desarrollo económico fundamentada en la participación de los sectores público y privado de la ciudad, se busca aprovechar la utilización eficiente de los recursos y las ventajas competitivas de Medellín con el fin de estimular tanto la creación de empleo decente como la actividad económica en general, para que a través de un proceso de crecimiento económico y un cambio hacia una estructura productiva moderna, nos conduzca hacia una mejora en el nivel de vida de toda la población.

\section{Indicador de resultado}

\begin{tabular}{|l|c|c|c|c|}
\hline \multicolumn{1}{|c|}{ Nombre } & Unidad & Línea de Base & $\begin{array}{c}\text { Meta } \\
2019\end{array}$ & Responsable \\
\hline $\begin{array}{l}\text { Personas vinculadas al } \\
\text { mercado laboral a través del } \\
\text { PIL (punto de intermediación } \\
\text { laboral) }\end{array}$ & Número & 1672 & 3200 & $\begin{array}{c}\text { Secretaría de } \\
\text { Desarrollo } \\
\text { Económico }\end{array}$ \\
\hline $\begin{array}{l}\text { Empleos generados por la } \\
\text { inversión nacional y extranjera }\end{array}$ & Número & 0 & 500 & $\begin{array}{c}\text { Secretaría de } \\
\text { Desarrollo } \\
\text { Económico }\end{array}$ \\
\hline
\end{tabular}

\subsubsection{Proyecto: Estrategias para el trabajo decente}

Tomando como punto de partida que los ingresos derivados del empleo son, por mucho, la principal fuente de financiamiento de las necesidades básicas para la gran mayoría de las familias, se hace evidente que el aumento del desempleo y la informalidad así como los bajos ingresos derivados de estos dos fenómenos hayan agravado los problemas de equidad y pobreza en los países, hace necesario implementar estrategias para la generación de trabajo decente en Medellín, con el fin de atacar la exclusión social y propender por mejorar la calidad de vida de toda la población.

Responsable: Secretaria de Desarrollo Económico Indicador de producto 
4.4.3.2 Proyecto: Promoción de la autonomía económica para las mujeres

Se desarrollan estrategias para el empoderamiento y el fortalecimiento de la autonomía económica de las mujeres urbanas y rurales de Medellín, articulando la oferta pública y privada, con el fin de potenciar condiciones de acceso y manejo de los ingresos a través del trabajo remunerado, el empleo decente y los recursos productivos.

Las mujeres acceden a medidas afirmativas que promueven la autonomía económica, desde la habilitación de mecanismos para la formación técnica, la gestión para vinculación laboral, el seguimiento a decretos especiales para vinculación laboral, entre otras.

Responsable: Secretaria de las mujeres

Indicador de producto

\begin{tabular}{|c|c|}
\hline Nombre & Unidad \\
\hline $\begin{array}{c}\text { Mujeres intervenidas con medidas que fortalecen la autonomía económica } \\
\text { parte rural y urbana }\end{array}$ & hero \\
\hline
\end{tabular}

\subsubsection{Proyecto: Crear una gran base empresarial de oferta y demanda de empleo}

Propiciar un lugar de encuentro entre las empresas de la ciudad que buscan trabajadores y los ciudadanos que buscan trabajo para ofrecerles un servicio de intermediación laboral que adecue los perfiles de las ofertas presentadas por las empresas, con los distintos perfiles de los usuarios inscritos en la base de datos, facilitando así la inserción laboral de nuestros ciudadanos y las tareas de reclutamiento de personal de nuestras empresas.

Responsable: Secretaria de Desarrollo Económico

Indicador de producto

\begin{tabular}{|c|c|}
\hline Nombre & Unidad \\
\hline $\begin{array}{c}\text { Empresas nuevas registradas en el sistema de información del PIL (punto de } \\
\text { intermediación laboral) }\end{array}$ & Número \\
\hline
\end{tabular}

\subsubsection{PROGRAMA: MEDELLÍN EMPRENDEDORA}

Las ciudades modernas, están obligadas hoy, a afrontar el problema de su economía local con una especial atención puesta en las condiciones, favorables y desfavorables, con que cuenten para diferentes estudios, han mostrado que la contribución de las nuevas empresas a la generación de empleos de calidad, a la innovación y al crecimiento económico, depende 
primordialmente de la cantidad de nuevas empresas que logren sobrevivir sus primeros años y, en especial, crecer de manera significativa.

En este sentido, Medellín debe consolidar su estrategia de conformación de entornos innovadores que faciliten a los nuevos emprendimientos, el acceso a diferentes servicios de apoyo a la producción, y a líneas de financiación apropiadas para este tipo de empresas.

Indicador de resultado:

\begin{tabular}{|c|c|c|c|c|}
\hline Nombre & Unidad & Línea de Base & $\begin{array}{l}\text { Meta } \\
2019\end{array}$ & Responsable \\
\hline $\begin{array}{l}\text { Medellín reconocido como HUB } \\
\text { de Capital Emprendedor }\end{array}$ & Número & 0 & 1 & $\begin{array}{c}\text { Secretaría de } \\
\text { Desarrollo } \\
\text { Económico y Ruta } \\
N\end{array}$ \\
\hline $\begin{array}{c}\text { Empresas constituidas en } \\
\text { Medellín }\end{array}$ & Número & 75916 & & $\begin{array}{l}\text { Secretaría de } \\
\text { Desarrollo } \\
\text { Económico }\end{array}$ \\
\hline
\end{tabular}

\subsubsection{Proyecto: Fortalecer el Ecosistema de Emprendimiento}

Consolidar de forma intuitiva, centrada en el emprendedor y en función de las necesidades de cada negocio, el ecosistema de emprendimiento e innovación de la ciudad y sus conexiones con otros ecosistemas clave.

Responsable: Secretaria de Desarrollo Económico

Indicador de producto

\begin{tabular}{|l|l|}
\hline Nombre & Unidad \\
\hline Talleres realizados para fomentar el emprendimiento & Número \\
\hline
\end{tabular}

\subsubsection{Proyecto: Fortalecimiento del banco de las oportunidades y acceso a recursos}

Fortalecimiento de las actividades productivas de las personas pertenecientes a los estratos uno, dos y tres, a través de alternativas de financiación mediante créditos pequeños que pueden pagarse en cuotas y tiempos flexibles, facilitando así la generación de ingresos y el mejoramiento de la calidad de vida de las personas con alta vulnerabilidad de ingresos, asentadas en el municipio de Medellín.

Responsable: Secretaria de Desarrollo Económico

Indicador de producto

Nombre 1 Unidad

Créditos otorgados a Mipymes de la ciudad de Medellín

Número 
4.4.4.3 Proyecto: Apoyar emprendimiento social, educativo, cultural, deportivo y artesanal.

Redireccionar la apuesta pública más allá del acceso a que se promueva conjuntamente con las distintas entidades, agentes y programas de la ciudad unos programas de formación de públicos que cualifiquen e incrementen la participación de los ciudadanos en la agenda cultural de la ciudad.

Responsable: Secretaria de Desarrollo Económico Indicador de producto

\begin{tabular}{|l|c|}
\hline \multicolumn{1}{|c|}{ Nombre } & Unidad \\
\hline $\begin{array}{l}\text { Emprendimientos sociales, culturales, deportivos y } \\
\text { artesanales apoyados }\end{array}$ & Número \\
\hline
\end{tabular}

\subsubsection{Proyecto: Distrito de Innovación y Emprendimiento}

La ciudad de Medellín ha venido redefiniendo su vocación económica, pasando de una economía industrial a una economía del conocimiento. En este sentido, el Distrito de la Innovación, es la apuesta de ciudad, para ordenar el desarrollo de estas actividades del conocimiento en el territorio potenciando su impacto e incrementando la competitividad de la ciudad, logrando con esto consolidarse como el "Hub" de innovación líder en Latinoamérica.

El Acuerdo 048 de 2014, por medio del cual se adopta la revisión y ajuste del Plan de Ordenamiento Territorial de Medellín, incluye en el Artículo 62 al Distrito de la Innovación. Posteriormente esta iniciativa de consolidar el Distrito de la Innovación para Medellín, se formaliza y soporta normativamente en el Decreto municipal No. 2053 de 2015 "Por medio del cual se adopta el Macroproyecto para el Área de Intervención Estratégica MEDRio, Zona RioCentro y se dictan otras disposiciones."

La innovación y el emprendimiento han posicionado en el mapa mundial de los negocios a Medellín, ciudad que ha venido cambiando su esquema industrial por un modelo basado en el conocimiento; todo lo anterior, basado en un ecosistema a la vanguardia en emprendimiento, tecnología y negocios

innovadores.

Responsable: Secretaría de Desarrollo Económico

Indicador de producto

\begin{tabular}{|l|c|}
\hline \multicolumn{1}{|c|}{ Nombre } & Unidad \\
\hline Metros cuadrados construidos & $\begin{array}{c}\text { Metros } \\
\text { cuadrados }\end{array}$ \\
\hline
\end{tabular}


4.4.4.5 Proyecto: Fortalecer CEDEZOS para impulsar la economía social y solidaria:

CEDEZOS (Centros de Desarrollo Empresarial Zonal) brindar un mayor impulso a las iniciativas orientadas desde los barrios, a apoyar el emprendimiento, la generación de ingresos, el desarrollo y consolidación de fami y microempresas; contribuyendo al desarrollo económico del territorio en la zona de intervención, en función de los sectores productivos más estratégicos para la Ciudad.

Responsable: Secretaría de Desarrollo Económico

Indicador de producto

\begin{tabular}{|l|c|}
\hline \multicolumn{1}{|c|}{ Nombre } & Unidad \\
\hline CEDEZOS fortalecidos con inversión financiera & $\begin{array}{c}\text { Millones de } \\
\text { pesos }\end{array}$ \\
\hline
\end{tabular}

\subsubsection{PROGRAMA: DESARROLLO EMPRESARIAL RURAL}

Cada día hay un mayor consenso en reconocer que las empresas rurales y la diversificación hacia actividades orientadas al mercado y que generen ingresos, constituyen un instrumento que permite mejorar los medios de vida en el campo y la seguridad alimentaria.

La participación en la economía de mercado, desde los territorios rurales de nuestros corregimientos deberá hacerse de modo que se produzca un incremento en los ingresos, equitativo y sostenible, además que deberá darse en condiciones laborales justas.

La ciudad deberá promover diferentes formas asociativas, orientadas hacia el desarrollo empresarial rural para volverlo una alternativa atractiva para todos los implicados en el desarrollo rural; sobre todo en la medida en que contribuya a la equidad gracias al crecimiento económico generado en los corregimientos en particular, y de la ciudad en general.

\section{Indicador de resultado}

\begin{tabular}{|c|c|c|c|c|}
\hline Nombre & Unidad & Línea de Base & $\begin{array}{c}\text { Meta } \\
2019\end{array}$ & Responsable \\
\hline $\begin{array}{c}\text { Agroempresas creadas en los } \\
\text { corregimientos de Medellín }\end{array}$ & Número & 0 & 20 & $\begin{array}{c}\text { Secretaría de } \\
\text { Desarrollo } \\
\text { Económico }\end{array}$ \\
\hline
\end{tabular}

\subsubsection{Proyecto: Implementar la política pública rural y fortalecer el Consejo Municipal de Desarrollo Rural}




\section{Educación de calidad para el desarrollo y la competitividad}

corregimientos

de

Medellín.

Responsable: Secretaria Desarrollo Económico

Indicador de producto

\begin{tabular}{|l|c|}
\hline \multicolumn{1}{|c|}{ Nombre } & Unidad \\
\hline Distrito rural campesino implementado & Porcentaje \\
\hline
\end{tabular}

\subsubsection{Proyecto: Fortalecer y realizar los mercados campesinos}

Siguiendo la misma línea de potencializar el sector agropecuario de

1. Medellín se hace necesario desarrollar más mercados campesinos y

N. mejorar los actuales, como estrategia de venta de los productos agrícolas y transformados producidos en la ciudad.

Responsable: Secretaria Desarrollo Económico

Indicador de producto

\begin{tabular}{|l|c|}
\hline \multicolumn{1}{|c|}{ Nombre } & Unidad \\
\hline Participantes de los mercados campesinos & Número \\
\hline
\end{tabular}

\subsubsection{Plan Municipal rural}

\subsubsection{PROGRAMA: EN BUSQUEDA DE LA COMPETITIVIDAD}

La gestión de las ciudades del siglo XXI es una tarea inmensamente compleja. Medellín busca adecuarse a los nuevos enfoques de gestión orientados a transformarse en una ciudad cada vez más competitiva, para alcanzar su real potencial económico y ofrecerles una buena calidad de vida a sus ciudadanos.

Ciudades como Medellín, han venido desarrollado en la última década formas innovadoras de trabajar en estrecha colaboración con las empresas privadas y la institucionalidad locales, y así comprender las limitaciones con las que se enfrentan sus empresas cuando intentan crecer a nivel local, para poder superarlas a través de la creación de oportunidades para la acción conjunta, en áreas donde la ciudad pretende obtener ventajas comparativas frente a sus competidoras.

Indicador de resultado

\begin{tabular}{|c|c|c|c|c|}
\hline Nombre & Unidad & Línea de Base & $\begin{array}{c}\text { Meta } \\
2019\end{array}$ & Responsable \\
\hline $\begin{array}{l}\text { Nivel de penetración de } \\
\text { intenet fijo dedicado }\end{array}$ & Porcentaje & 20.3 & 25 & $\begin{array}{c}\text { Ruta N } \\
\text { Secretaria } \\
\text { Desarrollo } \\
\text { Económico }\end{array}$ \\
\hline $\begin{array}{l}\text { Empresas intervenidas que } \\
\text { mejoran su posición } \\
\text { competitiva en el mercado }\end{array}$ & Número & 0 & 40 & $\begin{array}{c}\text { Secretaría de } \\
\text { Desarrollo } \\
\text { Económico }\end{array}$ \\
\hline
\end{tabular}


4.4.6.1 Proyecto: Medellín Ciudad Inteligente y gerencia de TIC

La infraestructura física es necesaria, pero sin una infraestructura TIC muy avanzada; la competitividad de la ciudad nacional e internacionalmente está gravemente amenazada. Es bien conocido cuanto se puede lograr en crecimiento económico, por cada incremento porcentual en el aumento de capacidad de ingreso a Internet de toda la población (más ancho de banda a igual o menor precio).

De la misma forma está probado que uno de los pilares de innovación es la capacidad de conectarse con otros para compartir y discutir ideas, acceder a nuevo conocimiento este donde este, así como realizar proyectos en conjunto. Se ha medido también cada incremento porcentual de infraestructura TIC apropiada hace subir una ciudad en sus índices globales de Innovación.

Hoy se reconoce que el nivel de innovación de una sociedad es indicativo de sus capacidades para generar mejores condiciones de vida (actual y

futura). Bajo esas premisas es imperativo que la ciudades tenga metas en infraestructura TIC a mediano y largo plazo que vayan más allá de sus inversiones en empresas del sector y cree proyectos ambiciosos con integración del gobierno nacional y organismos multilaterales.

Responsable: Desarrollo Económico

Indicador de producto

\begin{tabular}{|l|c|}
\hline \multicolumn{1}{|c|}{ Nombre } & Unidad \\
\hline Diagnóstico y plan de acción para la digitalización de Medellín implementados & Porcentaje \\
\hline Espacios con acceso gratuito a internet & Número \\
\hline
\end{tabular}

\subsubsection{Proyecto: Open Data Medellín}

Es conocido el efecto de la aplicación correcta de las TIC para la generación de mejores condiciones de vida para la población, de la misma forma la Innovación permite también aumento en la calidad de vida de las personas, mientras es a la vez la mejor herramienta para buscar solucionar los problemas sociales más apremiantes de la sociedad. Es la innovación entonces un enorme generador de nuevo valor tanto en las entidades públicas como en las privadas.

Cada vez es mayor la digitalización de todos los negocios y la gran mayoría de ellos están centrándose en el poder de los datos como generador de nuevas innovaciones. Los datos son el activo principal de las organizaciones en la sociedad del conocimiento, sin embargo 
ese activo solo puede generar valor si se extrae información y conocimiento desde ellos (analítica).

Los datos producidos por las corporaciones públicas, son por definición de todas las personas y dar correcto acceso a ellos, permite a cualquier integrante de la sociedad hacer análisis y proponer alternativas de mejora y solución a problemas latentes de la sociedad.

Indicador de producto:

Responsable: Desarrollo Económico

\begin{tabular}{|l|c|}
\hline \multicolumn{1}{|c|}{ Nombre } & Unidad \\
\hline Datos abiertos disponibles & Número \\
\hline
\end{tabular}




\subsection{RETO MEDELLÍN INNOVADORA}

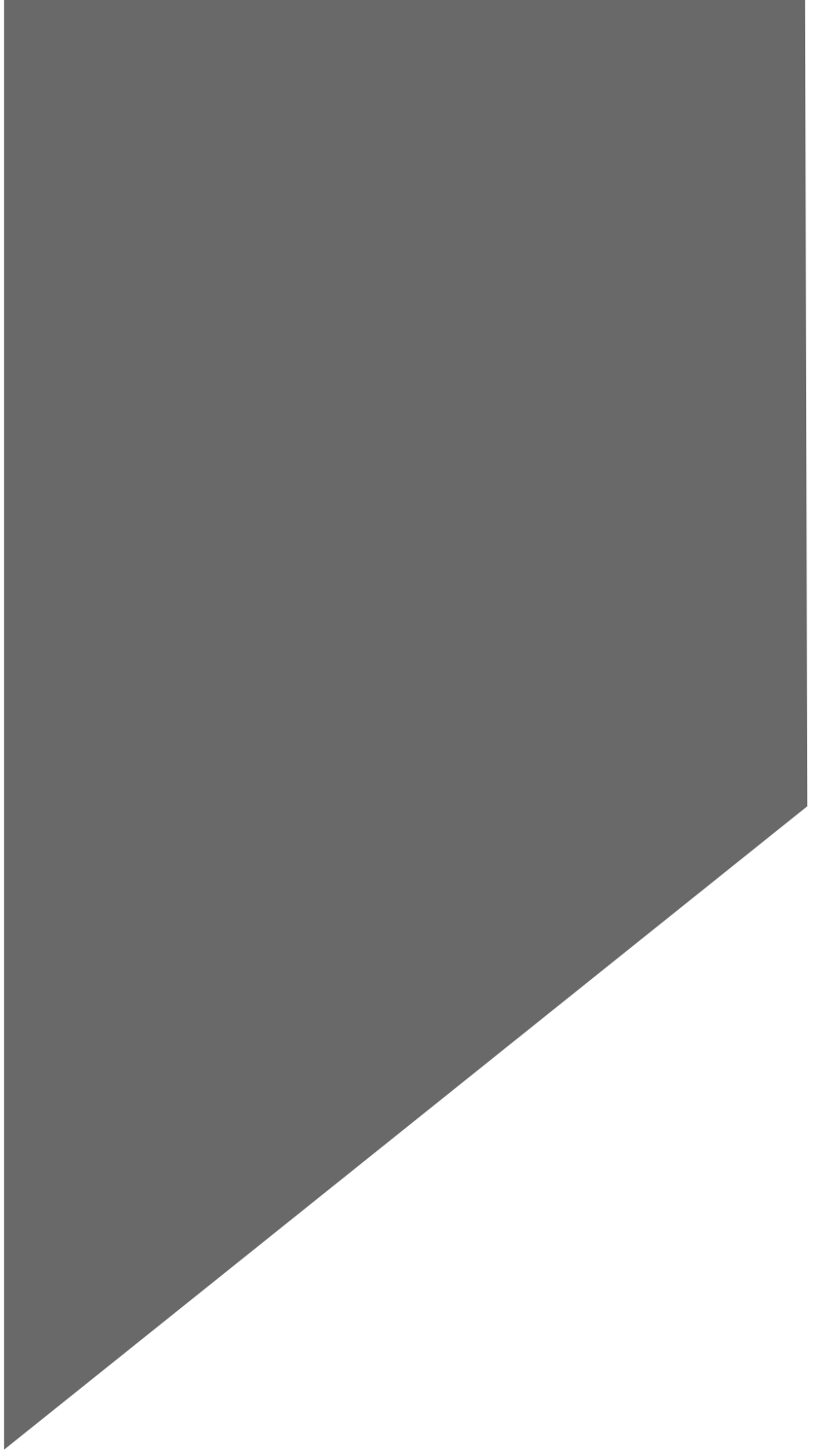

\section{OBJETIVO}

Aumentar los procesos investigativos y tecnológicos en todos los sectores de la industria de manera articulada a través de prácticas que fomenten la innovación.

\section{PROGRAMAS}

4 4.5.1. Ciencia, innovación y tecnología para la sociedad

4 4.5.2. Turismo

4 4.5.3. Internacionalización

4 4.5.4. Investigación científica y desarrollo tecnológico 


\subsection{Medellín Innovadora}

En materia de innovación, las inversiones en $\mathrm{CT}+\mathrm{i}$, logran que las regiones, sociedades y países, obtengan mejores condiciones objetivas en su calidad de vida. En este sentido, la ciudad ha logrado avanzar en relación con su PIB per cápita en innovación lo que evidencia que está en el camino de ciudades que han invertido estratégicamente en $\mathrm{CT}+\mathrm{i}$ y que son reconocidas en el mundo por brindar mejores condiciones de vida a sus habitantes.

Un indicador estandarizado internacionalmente para conocer la evolución de esta situación es denominado: nivel de inversión respecto al tamaño de la economía de la Región (PIB) en Actividades de Ciencia Tecnología e Innovación: ACTI /PIB. Uno de los principales elementos para lograr metas de ciudad, consiste en lograr que los valores de inversión mínimos necesarios estén en concordancia con la experiencia de los países que hoy lideran esas inversiones en el mundo. La estrategia para alcanzar ese objetivo es el Pacto por la Innovación, iniciativa que ha convocado a más de 2000 organizaciones.

De igual manera, Medellín, de acuerdo con mediciones sobre el crecimiento de la economía y generación de empleo realizadas por el instituto Brookings de EUA en 2015, ocupó el primer lugar en Latinoamérica y puesto 46 en el mundo, lo cual demuestra que la innovación ha logrado cambiar las condiciones de vida de la ciudad.

De otro lado, la ciudad se ha promocionado como un destino turístico que ha experimentado en lo últimos 20 años un proceso de transformación, lo cual ha permitido su reconocimiento nacional e internacional como un lugar vacacional y apto para la realización de eventos de como ferias y convenciones.

Así mismo, el turismo de reuniones ha alcanzado un importante nivel de posicionamiento a nivel nacional e internacional lo que se refleja en el ranking de la International Congress and Convention Association (ICCA) que mide la cantidad de eventos que se realizan cada año, y en el cual Medellín pasó de ocupar la posición número 265 a nivel mundial en 2008, con la realización de cinco eventos, a estar en la posición 72 con 33 eventos en 2014, lo cual significa escalar 193 posiciones, por lo que el Plan de Desarrollo Medellín Cuenta con vos seguirá impulsando y posicionando la ciudad en este tipo de espacios.

Finalmente, como destino de turismo de cultura y naturaleza, Medellín ha enfocado su promoción a unos productos priorizados, con lo cual se han fortalecido los incentivos y beneficios que promueven nuevas rutas aéreas internacionales. El total de pasajeros movilizados en el Aeropuerto José María Córdova en el año 2014 fue 6.465 .351 y en el año 2015, ascendió a 6.809.036 representando crecimiento del 5,18\%. 
Abordando lo concerniente a la inversión extranjera directa (IED) y a la cooperación internacional, la ciudad ha sido protagonista de un cambio ya mencionado, que la ha puesto en la vitrina global, por ser un nuevo laboratorio de buenas prácticas y ser reconocida por la implementación de programas innovadores para el bienestar de sus ciudadanos. La IED captada por la ciudad ha venido disminuyendo desde el año 2011, reflejando un comportamiento consistente con la IED nacional. Los principales países inversionistas en Medellín han sido Estados Unidos, Chile, México y Francia, representando el $63 \%$ de las inversiones en los últimos 8 años.

Es importante tener en cuenta que para establecer hoy una relación de cooperación con grandes recursos, la ciudad debe tener presente que el presupuesto o la apuesta local, debe ser igual o mayor a la que aporte el cooperante, debido a que es un actor inmerso en un país de renta media y por este motivo, los cooperantes establecen políticas de actuación más limitadas que con otros países.

A continuación se describen los indicadores de resultado que se pretenden con este reto:

\begin{tabular}{|c|c|c|c|c|}
\hline Nombre & Unidad & Línea de Base & $\begin{array}{l}\text { Meta } \\
2019\end{array}$ & Responsable \\
\hline Capital de riesgo disponible & Millones & 385,000 & 800,000 & Ruta N \\
\hline Ocupación Hotelera & Porcentaje & 63.7 & 65 & $\begin{array}{c}\text { Secretaría de } \\
\text { Desarrollo } \\
\text { Económico } \\
\end{array}$ \\
\hline $\begin{array}{l}\text { Reconocimiento del destino a } \\
\text { nivel nacional e internacional } \\
\text { a nivel Mundial }\end{array}$ & Índice & 72 & 72 & Bureau \\
\hline 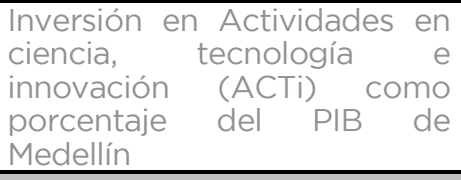 & Porcentaje & 1.33 & 2.2 & Ruta N \\
\hline $\begin{array}{l}\text { Inversión en I+D como } \\
\text { porcentaje del PIB }\end{array}$ & Porcentaje & 0.56 & 1 & Ruta N \\
\hline $\begin{array}{l}\text { Alianzas de cooperación } \\
\text { nacional e internacional, } \\
\text { gestionadas para el Municipio } \\
\text { de Medellín y las prioridades } \\
\text { del Plan de Desarrollo } \\
\begin{array}{l}\text { Municipal, } \\
\text { cuatrienio }\end{array} \\
\end{array}$ & Número & 35 & 27 & $\mathrm{ACl}$ \\
\hline $\begin{array}{l}\text { Innovaciones generadas } \\
\text { según el modelo de la OCDE }\end{array}$ & Número & 800 & 8400 & Ruta N \\
\hline $\begin{array}{l}\text { Compañías innovadoras } \\
\text { desarrolladas por cada } 1000 \\
\text { habitantes }\end{array}$ & Número & 33 & 50 & Ruta N \\
\hline $\begin{array}{l}\text { Porcentaje de empresas } \\
\text { innovando }\end{array}$ & Porcentaje & 6 & 15 & Ruta N \\
\hline
\end{tabular}




\begin{tabular}{|c|c|c|c|c|}
\hline Nombre & Unidad & Línea de Base & $\begin{array}{c}\text { Meta } \\
2019\end{array}$ & Responsable \\
\hline $\begin{array}{l}\text { Densidad de técnicos e } \\
\text { investigadores trabajando en } \\
\text { I+D por cada 10.000 } \\
\text { habitantes }\end{array}$ & Porcentaje & 5.3 & 40 & Ruta N \\
\hline
\end{tabular}

\subsubsection{PROGRAMA: CIENCIA, INNOVACIÓN Y TECNOLOGÍA PARA LA SOCIEDAD}

Hoy es claro en el mundo que no hay mayor generador de bienestar para los sociedades, que aquel que se produce dese el desarrollo generado desde la Ciencia, la Tecnologia y en especial desde la innovación.

El principal foco de atención sobre el que se debe fundamentar esa estrategia de desarrollo económico de la ciudad sustentada en la innovación, debe ser el de propiciar una evolución más inclusiva de la economía de Medellín, asegurando que los mayores ingresos fruto del crecimiento económico se irriguen hacia el grueso de la población y no únicamente a los quintiles más altos del ingreso.

De la misma forma la principal prioridad debe ser desde la innovación solucionar primero los mayores problemas sociales que afectan a nuestra sociedad.

Indicador de resultado

\begin{tabular}{|l|l|l|l|l|}
\hline Nombre & Unidad & Línea de Base & $\begin{array}{c}\text { Meta } \\
2019\end{array}$ & Responsable \\
\hline $\begin{array}{l}\text { Productos y mejoras a procesos } \\
\text { generados en actividades } \\
\text { productivas a partir de los } \\
\text { laboratorios de creación }\end{array}$ & Número & 0 & 1500 & Ruta N \\
\hline
\end{tabular}

\subsubsection{Proyecto: Plan CT + I Medellín}

En 2012, el Concejo de la ciudad aprueba convertir el plan de la política pública de la ciudad en CT+i mediante el acuerdo 024. Le asigna también a Ruta n el papel de liderar su ejecución y ordena destinar año a año hasta el 2021.

Indicador de producto

Responsable: Desarrollo Económico

$$
\begin{aligned}
& \text { Nombre } \\
& \text { de I+ D cofinanciados }
\end{aligned}
$$

4.5.1.2 Proyecto: Implementar el sistema de movilidad inteligente

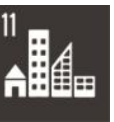

Crear un sistema inteligente que permita saber el estado de las vías, donde se pueda poner en conocimiento de las autoridades hechos que ameritan una solución y donde se pueda conocer en su totalidad el sistema de transporte público: rutas, horarios, etc.

Responsable: Secretaría de Movilidad 
Indicador de producto Dispositivos para el Sistema de Movilidad de Medellín (SMM) instalados Número

4.5.1.3 Proyecto: Construcción de vivienda ambientalmente sostenible

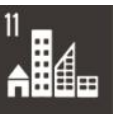
Diseñar y construir viviendas que garantice el uso eficiente de los recursos disponibles y que permita el uso en el tiempo con altos estándares de calidad habitacional, bajo estrictos parámetros ambientales y técnicos para la generación de bienestar.

Responsable: ISVIMED

Indicador de producto Viviendas construidas ambientalmente sostenibles Unidad Número

4.5.1.4 Proyecto: Implementar la tecnología en la salud

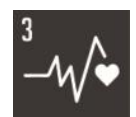
Implementar plataformas de salud con base en nuevas tecnologías para apoyar el mejoramiento de la calidad del servicio, la prevención y el bienestar de la ciudadanía.

Indicador de producto

Responsable: Secretaría de Salud Tecnología en salud implementada Porcentaie

4.5.1.5 Proyecto: Adelantar la innovación para la eficiencia energética y energías renovables

Desarrollar instrumentos para el diseño y construcción de viviendas y edificaciones ambientalmente sostenibles; incluyendo la creación de una norma técnica de construcción sostenible para acceder al sello ambiental municipal en el que se promueve la eficiencia energética y las energías renovables además de incorporar el reciclaje en los procesos deconstrucción.

Responsable: EPM

Indicador de producto

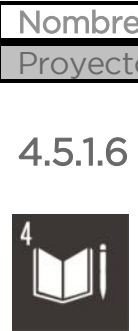

Nombre

Unidad

Número

4.5.1.6 Proyecto: Laboratorios de creación

Los Laboratorios de Creación son espacios donde se incuban, nacen y se echan a andar ideas. Son fábricas para enfocar talento y enriquecer conocimiento a través de la práctica creativa, del uso de herramientas de alta tecnología y del asesoramiento experto de un grupo de profesionales. Allí, con acceso gratuito al uso de infraestructura tecnológica avanzada, se producirán respuestas 
ingeniosas a problemas cotidianos; dándole cuerpo y uso a las ideas que están en la mente de los ciudadanos.

Laboratorios de Creación surgen en el importante contexto cultural en el que Medellín se transforma empleando las mentes de sus propios habitantes y su capacidad ancestral de emprender nuevos caminos. En este contexto histórico, la innovación y la tecnología no son algo exclusivo de la academia, las empresas o el Estado, sino que, principalmente, es la ciudadanía la llamada a tomar las riendas de su destino y a ser partícipe de dicha transformación. En una época en la que la ciudad de Medellín se propone ser la más innovadora del país, una verdadera cultura de la innovación es el camino escogido por sus habitantes para alcanzar este objetivo histórico, en los Laboratorios de Creación se incuban las ideas que transformarán el mañana.

Responsable: Desarrollo Económico Indicadores de producto Indicador de Prodcuto

\begin{tabular}{|l|c|}
\hline \multicolumn{1}{|c|}{ Nombre } & Unidad \\
\hline Laboratorios de creación desarrollados & Número \\
\hline Personas beneficiadas por laboratorios de creación & Número \\
\hline
\end{tabular}

\subsubsection{PROGRAMA: TURISMO}

El sector turístico se ha venido convirtiendo en los últimos años, en uno de los pilares fundamentales para el desarrollo económico de nuestras ciudades; lo que se refleja en los datos del número de empleos que genera y la inyección económica de ingresos que cada año se genera debido a la creciente actividad empresarial de este importante sector de nuestra economía.

Dado que el turista actual que llega a ciudades como Medellín, es cada vez más exigente, se hace necesario brindar unos servicios de mayor nivel de sofisticación, donde el sector público, en unión con la contribución de los privados, vienen trabajando para hacer de Medellín un cada vez más interesante y concurrido destino turístico en los ámbitos nacional e internacional.

\section{Indicador de resultado}

\begin{tabular}{|c|c|c|c|c|c|}
\hline Nombre & $\begin{array}{c}\text { Descripción } \\
\text { variables }\end{array}$ & Unidad & $\begin{array}{c}\text { Línea de } \\
\text { Base }\end{array}$ & Meta 2019 & Responsable \\
\hline $\begin{array}{c}\text { Viajeros } \\
\text { nacionales e } \\
\text { internacionales } \\
\text { ingresando a la } \\
\text { ciudad }\end{array}$ & $\begin{array}{c}\text { Viajeros nacionales } \\
\text { internacionales } \\
\text { ingresando a la } \\
\text { ciudad }\end{array}$ & Personas & $1,943,702$ & $2,100,000$ & $\begin{array}{c}\text { Secretaría de } \\
\text { Desarrollo } \\
\text { Económico }\end{array}$ \\
\hline
\end{tabular}


4.5.2.1 Proyecto: Propender por la creación y el fortalecimiento de proyectos turísticos de ciudad El arte, la gastronomía y la cultura también cumplen el papel de ser foco de atracción para visitantes nacionales e internacionales por esto es importante desarrollar productos turísticos experienciales que potencialicen este tipo de turismo en Medellín.

Responsable: Secretaria de Desarrollo Económico

Indicador de producto

\begin{tabular}{|l|c|}
\hline Nombre & Unidad \\
\hline Proyectos creados y fortalecidos & Número \\
\hline
\end{tabular}

\subsubsection{Proyecto: Constituir cerro Nutibara parque turístico}

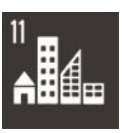
Se llevará a cabo una intervención integral con el objetivo de rescatar el valor de nuestros cerros tutelares. Se hará una intervención con un sello urbano pero también con miras a un posible desarrollo comercial en ellos.

Responsable: Secretaría de Desarrollo Económico

Indicador de producto

\begin{tabular}{|l|c|}
\hline Nombre & Unidad \\
\hline Parque natural Cerro Nutibara construido & Número \\
\hline
\end{tabular}

4.5.2.3 Proyecto: Constituir cerro el volador parque turístico

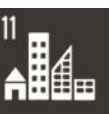

Se llevará a cabo una intervención integral con el objetivo de rescatar el valor de nuestros cerros tutelares. Se hará una intervención con un sello urbano pero también con miras a un posible desarrollo comercial en ellos

Responsable: Secretaría de Infraestructura

Indicador de producto

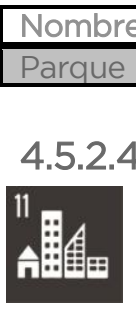

Parque natural Cerro el Volador construido

Unidad

Número

4.5.2.4Proyecto: Fortalecimiento del sistema turístico local sostenible Posicionamiento en los ámbitos nacional e internacional, de los principales productos turísticos que ofrece la Ciudad a sus visitantes.

Responsable: Secretaria de Desarrollo Económico

Indicador de producto

\begin{tabular}{|l|c|}
\hline Nombre & Unidad \\
\hline Sistema turístico fortalecido & Número \\
\hline
\end{tabular}




\subsubsection{PROGRAMA: INTERNACIONALIZACIÓN}

Medellín, una ciudad que hoy es reconocida en el mundo por su transformación y sus capacidades de establecer soluciones innovadores a los problemas locales, ha logrado insertarse en el escenario global gracias a que cuenta con una apuesta clara por la internacionalización. La ciudad ha comprendido que la internacionalización es un verdadero mecanismo para la generación de desarrollo local y, lo ha logrado a través de varios enfoques como la atracción de inversión extranjera directa, la generación de alianzas claves de cooperación internacional y de intercambio de conocimiento, el posicionamiento de Medellín como un destino turístico y como sede de grandes eventos. Todo este trabajo es entendido como una apuesta clave para que los habitantes de la ciudad cuenten con mayor calidad de vida y mayores oportunidades y por esto debemos promover que la internacionalización le siga sumando a Medellín.

Hoy es una ciudad diferente, pero todavía tenemos muchos retos, por esto se debe continuar con una estrategia de internacionalización que le permita continuar el fortalecimiento local a partir de estas conexiones globales. Todo este propósito se encuentra en coherencia, con el nuevo rol de las ciudades en el ámbito global, en el cual cada vez más los gobiernos locales, son los llamados a brindar soluciones que incidan en la toma de decisiones para el desarrollo de los territorios y cada vez más somos llamados a trabajar en red para aprender y enseñar, para fortalecernos de la voluntad del trabajo entre gobiernos y organizaciones tanto públicas como privadas, de las visitas de turistas internacionales y de los flujos de capital internacional.

Nuestro propósito es seguir impulsando la internacionalización de Medellín, para habilitar a la ciudad para que continúe fuerte en sus prioridades y retos. Para que podamos asumir un rol protagónico en el contexto global y podamos llevar a Medellín de una manera más acertada hacia una economía de conocimiento y de innovación. Esta apuesta, no es más que una herramienta sintonizada con la visión de Medellín y permite sumar hacia mejores condiciones para todos los ciudadanos de la ciudad.

Indicadores de resultado

\begin{tabular}{|c|c|c|c|c|c|}
\hline Nombre & Descripción variables & Unidad & $\begin{array}{c}\text { Línea de } \\
\text { Base }\end{array}$ & $\begin{array}{c}\text { Meta } \\
2019\end{array}$ & Responsable \\
\hline $\begin{array}{c}\text { Eventos captados } \\
\text { para la ciudad }\end{array}$ & $\begin{array}{c}\text { Número de eventos } \\
\text { captados nacionales } \\
\text { e internacionales }\end{array}$ & Número & 280 & 452 & Bureau \\
\hline $\begin{array}{c}\text { Alianzas de } \\
\text { cooperación sur } \\
\text { sur (Oferta de } \\
\text { cooperación) en } \\
\text { las cuales Medellín } \\
\text { comparta sus } \\
\text { buenas prácticas }\end{array}$ & $\begin{array}{c}\text { Número de alianzas } \\
\text { en las cuales Medellín } \\
\text { actúe como oferente } \\
\text { de sus buenas } \\
\text { prácticas }\end{array}$ & Número & 7 & 12 & $\mathrm{ACl}$ \\
\hline
\end{tabular}




\begin{tabular}{|c|c|c|c|c|c|}
\hline $\begin{array}{c}\text { Eventos que } \\
\text { adquieren la huella } \\
\text { de carbono, como } \\
\text { una forma de } \\
\text { devolver el costo } \\
\text { ambiental de su } \\
\text { realización. } \\
\end{array}$ & Número de eventos & Número & $\mathrm{O}$ & 28 & Bureau \\
\hline $\begin{array}{c}\text { Valoración } \\
\text { económica de las } \\
\text { publicaciones } \\
\text { generadas } \\
\text { mediante la } \\
\text { estrategia de } \\
\text { freepress de } \\
\text { Ciudad } \\
\end{array}$ & Freepress valorado & Millones & 163,184 & 180,000 & Bureau \\
\hline $\begin{array}{c}\text { Derrama } \\
\text { económica en } \\
\text { realización de } \\
\text { eventos captados } \\
\text { con el apoyo de El } \\
\text { Bureau. }\end{array}$ & Derrama económica & $\begin{array}{c}\text { Millones de } \\
\text { pesos }\end{array}$ & 35416 & 38957 & Bureau \\
\hline
\end{tabular}

\subsubsection{Proyecto: Regionalización e internacionalización del deporte} Se diseñará e implementará la estrategia de articulación y cooperación con instituciones y organizaciones del orden nacional e internacional, para el posicionamiento estratégico de la ciudad a través del deporte, la recreación y la actividad física saludable. Esta estrategia de diplomacia deportiva, busca articular esfuerzos con otras entidades de la ciudad para generar oportunidades de desarrollo social, cultura ciudadana, crecimiento económico e incentivar el turismo deportivo y la masificación del deporte a través de la realización de eventos deportivos de gran formato.

Responsable: INDER

Indicadores de producto

\begin{tabular}{|c|c|}
\hline Nombre & Unidad \\
\hline Eventos nacionales e internacionales apoyados & Número \\
\hline Personas participando de manera directa en eventos nacionales e internacionales & Número \\
\hline
\end{tabular}

\subsubsection{Proyecto: Impulsar la promoción y mercadeo de la ciudad como destino turístico}

Continuar con la promoción de Medellín como destino turístico innovador, sostenible, responsable y competitivo tanto para turismo vacacional como de negocios a nivel nacional e internacional.

Indicador de producto

Responsable: Desarrollo Económico

\begin{tabular}{|c|c|}
\hline Nombre & Unidad \\
\hline Participación en ferias y eventos de carácter internacional, que generen visibilidad & Número \\
para el destino.
\end{tabular}

4.5.3.3 Proyecto: Medellín ciudad de grandes eventos, convenciones y ferias Es necesario continuar estructurando la idea de un centro para grandes eventos deportivos, culturales y académicos a nivel 
metropolitano, para que Medellín sea eje de atracción de grandes iniciativas, y la ciudad continúe posicionándose como un referente de transformación social y económico. Incluir a los corregimientos de Medellín como fuentes de información y actividades patrimoniales y culturales, así como realizar actividades de los grandes eventos en los territorios rurales, tales como Feria de las Flores, Festival Buen Comienzo, Festival de Tango, Fiesta del Libro y la Cultura y, Altavoz.

Mantener el respaldo del Municipio a las iniciativas del empresariado local que promueven la exposición internacional de los atributos y fortalezas de la ciudad, y que repercuten en el dinamismo y la sostenibilidad económica de los clúster -consolidados y emergentesque son prioritarios para la ciudad.

Responsable: Secretaria de Desarrollo Económico

Indicador de producto

\begin{tabular}{|l|c|}
\hline \multicolumn{1}{|c|}{ Nombre } & Unidad \\
\hline $\begin{array}{l}\text { Capacitaciones encaminadas al mejoramiento, dictadas a los diferentes actores del } \\
\text { sector turístico de la ciudad. }\end{array}$ & Número \\
\hline
\end{tabular}

\subsubsection{Proyecto: Medellín, laboratorio de prácticas vivas}

Posicionar a Medellín como una ciudad de intercambio de conocimiento que le permite ser un actor clave en la transición del país como oferente de cooperación.

Responsable: Desarrollo Económico Educación de calidad para el desarrollo y la competitividad

Indicador de producto

\begin{tabular}{|c|c|}
\hline \multicolumn{1}{|c|}{ Nombre } & Unidad \\
\hline Buenas prácticas implementadas para los programas del Plan de Desarrollo & Millones \\
\hline
\end{tabular}

\subsubsection{Proyecto: Promoción de la ciudad como destino de inversión}

Lograr que empresas nacionales y extranjeras se interesen en Medellín como destino ideal para expandir su operación o establecer nuevos negocios que generen empleo de calidad para los ciudadanos.

Indicador de producto

Responsable: Desarrollo Económico 
inversión nacional y extranjera

Educación de calidad para el desarrollo y la competitividad

4.5.3.6Proyecto: Fortalecimiento de la Red de Antioqueños en el exterior (SosPaisa)

La Red de Antioqueños y Antioqueñas en el exterior cuenta con más de 10.000 paisas que han querido mantener su vinculación con la ciudad a pesar de vivir en el exterior. Es un escenario de divulgación de la transformación de Medellín y una red para la búsqueda de ciudadanos aliados, que quieren contribuir desde su alcance a los temas de ciudad. Se propone continuar fortaleciendo esta red, para que cada una de las acciones que estos paisas realice en coordinación con la $\mathrm{ACl}$ Medellín, pueda sumar para el desarrollo local.

Responsable: Desarrollo Económico

Indicadores de producto:

\begin{tabular}{|l|c|}
\hline \multicolumn{1}{|c|}{ Nombre } & Unidad \\
\hline $\begin{array}{l}\text { Aportes de paisas residentes en el exterior, que contribuyan al fortalecimiento de } \\
\text { las apuestas de desarrollo local }\end{array}$ & Número \\
\hline $\begin{array}{l}\text { Activaciones realizadas para fortalecer la Red de Antioqueñas y Antioqueños en } \\
\text { el exterior (SosPaisa) }\end{array}$ & Número \\
\hline
\end{tabular}

\subsubsection{Proyecto: Alianzas de cooperación internacional}

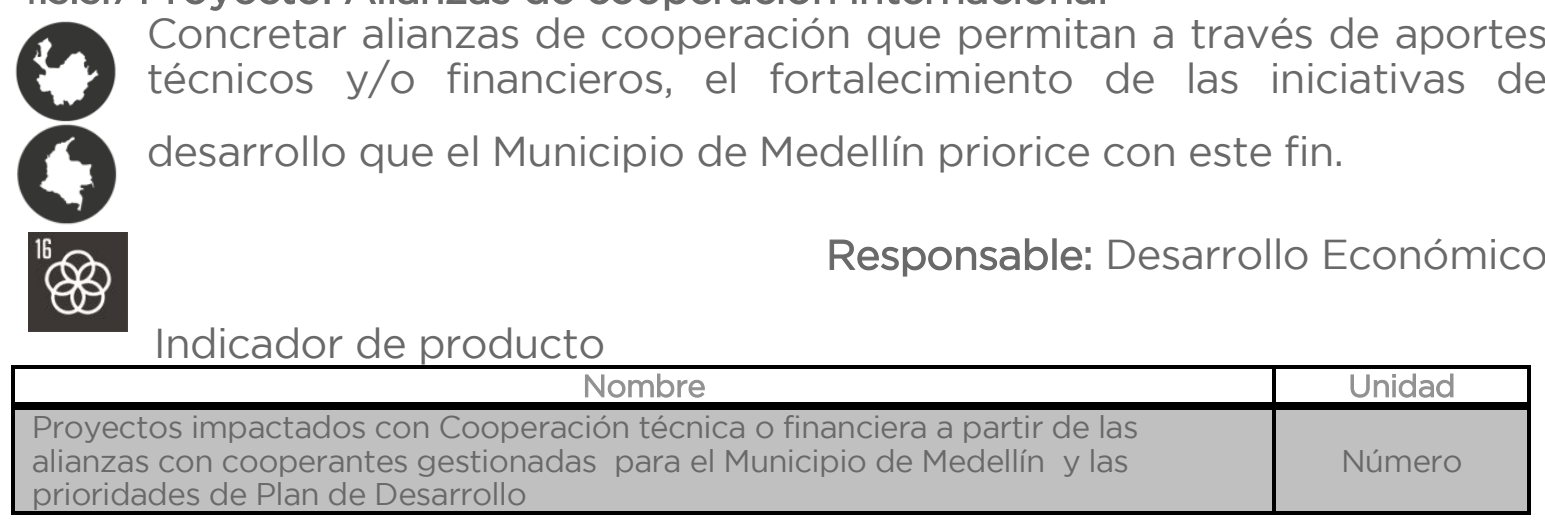

\subsubsection{PROGRAMA: INVESTIGACIÓN CIENTÍFICA Y DESARROLLO TECNOLÓGICO}

El programa de investigación científica y desarrollo tecnológico busca el aprovechamiento del talento y el potencial investigativo de nuestros habitantes con el ánimo de contribuir al desarrollo de conocimientos que impacten en la calidad de vida de las personas. Con este propósito desde nuestra administración buscamos propiciar un ecosistema que favorezca la investigación científica y el desarrollo tecnológico en la ciudad a partir del fortalecimiento del capital humano y la oferta de espacios físicos de calidad. 
El plan de desarrollo Medellín Cuenta con Vos busca implementar un modelo de competitividad apostandole al fortalecimiento de los semilleros y grupos de investigación desde las universidades y la profesionalización de investigadores; generando así capacidades para la ciudad y la internacionalización del sistema de educación superior y los procesos de investigación generados desde la ciudad.

Indicador de resultado

\begin{tabular}{|l|c|c|c|c|}
\hline Nombre & Unidad & Línea de Base & Meta 2019 & Responsable \\
\hline $\begin{array}{l}\text { Productos y mejoras a procesos } \\
\text { generados en actividades } \\
\text { productivas a partir de los } \\
\text { laboratorios de creación }\end{array}$ & Número & 0 & & \\
\hline
\end{tabular}

\subsubsection{Proyecto: Apoyo a semilleros y grupos de investigación}
9 Apoyo a los semilleros del sistema de educación superior con el objeto de fortalecer la investigación desde el primer eslabón de formación de científicos.

Responsable: Sapiencia

Indicador de producto

\begin{tabular}{|l|c|}
\hline \multicolumn{1}{|c|}{ Nombre } & Unidad \\
\hline Semilleros y grupos de investigación apoyados & Número \\
\hline
\end{tabular}

4.5.4.2 Proyecto: Internacionalización del sistema de educación superior. Hacer atractiva a Medellín como destino de investigación para científicos, investigadores y académicos nacionales y extranjeros con el fin de generar intercambio de saberes y la cooperación en la construcción de redes de conocimiento.

Indicador de producto

Responsable: Sapiencia

\begin{tabular}{|c|c|}
\hline Nombre & Unidad \\
\hline Alianzas, eventos, intercambios internacionales realizados & Número \\
\hline
\end{tabular}

4.5.4.3 Proyecto: Fondo local para la investigación científica del sistema de educación superior

Crear y gestionar recursos públicos, privados y del sistema de educación superior para la financiación de proyectos de investigación y acceso a bases de datos científicas internacionales de alta

calidad.

Responsable: Sapiencia 


\section{Educación de calidad para el desarrollo y la competitividad}

Indicador de producto

Nombre

Proyectos de investigación científica apoyados

Unidad

Número 


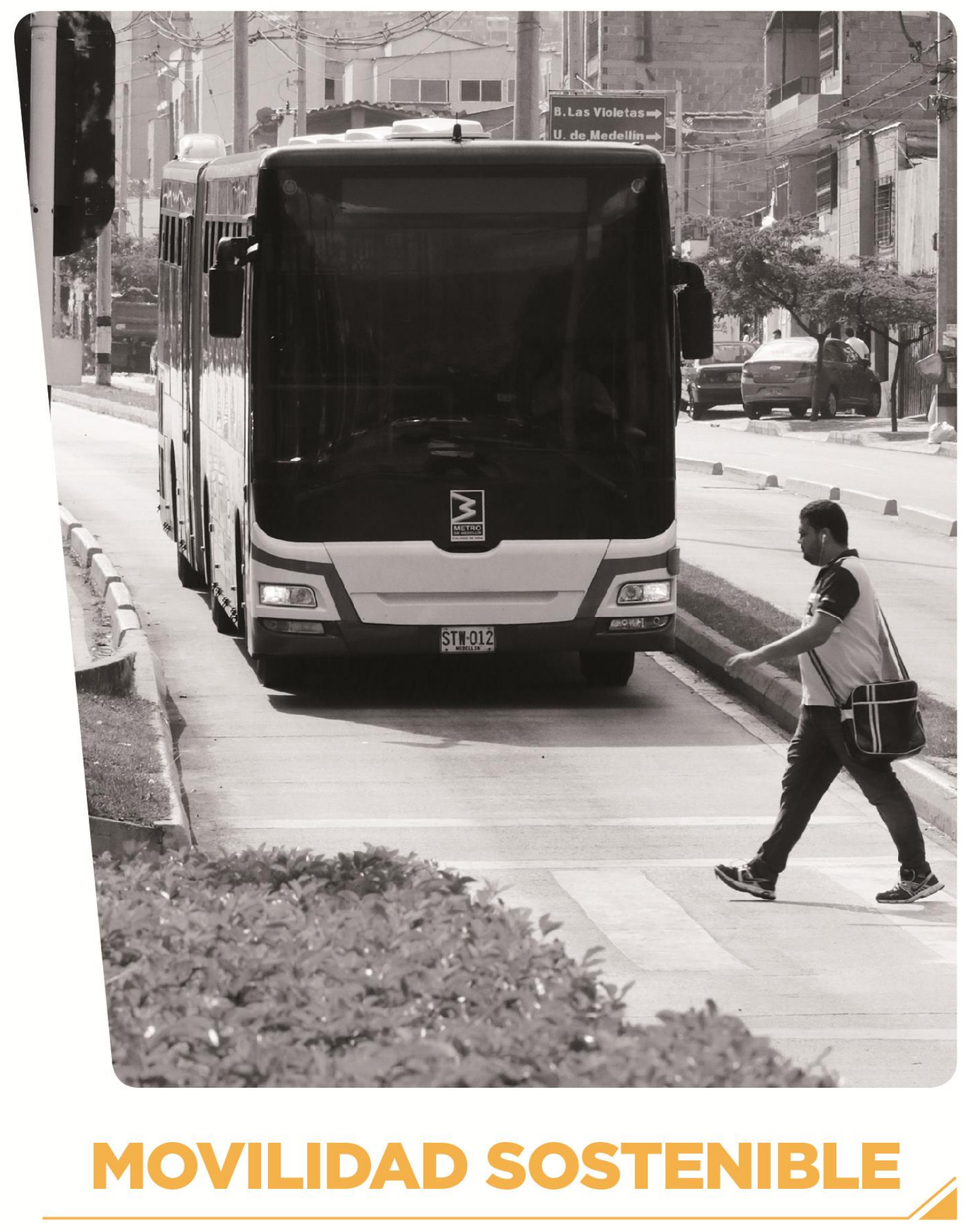




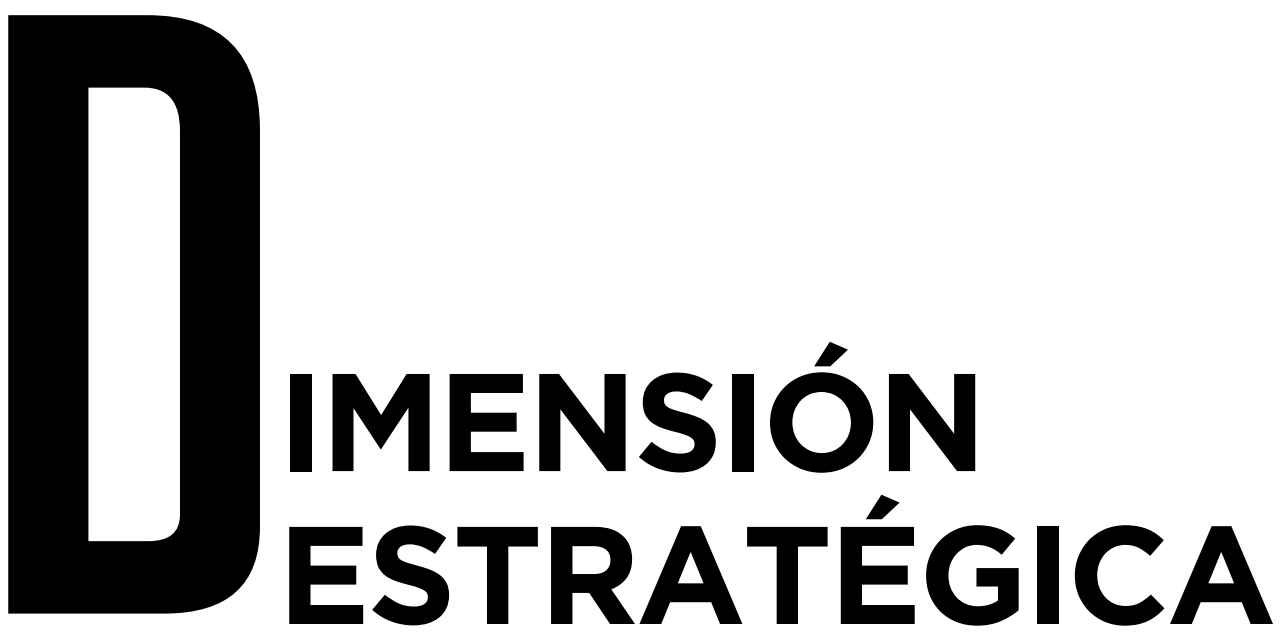

\section{Movilidad sostenible}

Integrar los sistemas y medios de transporte de Medellín con la infraestructura existente, proporcionando a los ciudadanos un transporte accesible, fluido, seguro y de calidad, que aporte a su calidad de vida y a la sostenibilidad de la ciudad. 


\section{- DIAGNÓSTICO •}

Al hablar de movilidad sostenible, es necesario entender por esta una diversidad amplia de posibilidades para que toda persona tenga acceso de manera libre, ágil, segura y eficiente a cualquier lugar de la ciudad. La conectividad y el acceso son elementos determinantes de la movilidad, pues la posibilidad de que la ciudad esté conectada y al alcance de quienes la habitan, es fundamental en la construcción de equidad e igualdad social en el territorio.

Una definición de movilidad, debe ir sin embargo más allá de esa posibilidad, pues no se limita al derecho de circulación sino que representa al mismo tiempo diferentes potenciales, tanto económicos, productivos, competitivo y ambientales que son determinantes en la construcción del perfil de una ciudad.

En materia de movilidad, si bien Medellín evidencia avances en ciertos frentes y cuenta con unos de los sistemas multimodales pioneros del país, al mismo tiempo presenta muchas situaciones que resultan alarmantes de cara al futuro cercano y a la planeación de una ciudad sostenible en el largo plazo, entendiendo por sostenible aquello que es económicamente razonable, ambientalmente responsable y socialmente dignificante. Es ahí entonces donde se encuentran los principales retos.

La ciudad necesita entonces de acciones contundentes en materia de movilidad sostenible, que amplíen las posibilidades de movilizarse de sus ciudadanos de manera confiable, segura y responsable ambientalmente, estimulando su conciencia y compromiso; y que también potencien la competitividad de la ciudad en la región y en el país.

\section{- PRESENTACIÓN •}

El sistema de movilidad de una ciudad puede entenderse como aquel que integra de manera jerarquizada e interdependiente los modos de transporte de personas y de carga con los diferentes tipos de vías y espacios públicos, permitiendo a los ciudadanos, comunidad y empresas acceder a la multiplicidad de servicios, equipamientos y oportunidades que ofrece el territorio y buscando una estrategia de ordenamiento que permita la consolidación urbano-regional y en general el aumento de la competitividad de una ciudad.

El concepto de movilidad permite abordar, de manera integral y detallada, la tradicional visión sectorial del transporte, permitiendo afrontar con exactitud problemas de accesibilidad y movilidad urbana y rural de manera conjunta, de los individuos y su entorno, teniendo en cuenta; además, 
aspectos ambientales, que conlleven a la mitigación de externalidades negativas, la optimización y aprovechamiento eficiente de los recursos.

Para llegar a una movilidad eficaz, efectiva y segura, se propone una circulación racionalizada, segura y ambientalmente sostenible y el desarrollo y culminación de un sistema vial jerarquizado que sea integrador y que tenga en cuenta los sistemas de transporte público, la estructura vial y sus diferentes modos, la circulación peatonal y otros modos alternativos de transporte. Todo esto basado en una gestión eficiente y participativa y en un entorno de educación y cultura ciudadana con reglas claras para el manejo de la movilidad.

Esta movilidad no solo tiene que ver con la afectación primaria sobre los ciudadanos, es decir, con la facilidad con la que una persona se desplaza de un lugar a otro dentro del territorio, sino también con el abastecimiento de bienes y mercancías, así como la disposición de residuos; factores que son fundamentales para el bienestar de los habitantes de la ciudad.

Por lo tanto la administración municipal gestionará la movilidad sostenible como un componente estructurante para la planificación y desarrollo del territorio y para mejorar la calidad de vida de la población garantizando estándares de ciudad adecuados a la realidad, bajo mecanismos necesarios de planificación, que impacten el territorio de una manera adecuada e integral, articulado con los componentes social, económico, ambiental y cultural; buscando un resultado óptimo que permita la transformación para el desarrollo integral, tanto de la ciudad como de la región.

Indicadores de Impacto

\begin{tabular}{|c|c|c|c|c|}
\hline Nombre & Unidad & Línea de Base & Meta 2019 & Responsable \\
\hline $\begin{array}{l}\text { Emisiones contaminantes de } \\
\mathrm{CO} 2 \text { medido en toneladas de } \\
\mathrm{CO} 2 \text { dejadas de emitir al } \\
\text { ambiente }\end{array}$ & $\begin{array}{l}\text { Toneladas } \\
\text { de } \mathrm{CO} 2\end{array}$ & 199.416 & 199.416 & Metro \\
\hline $\begin{array}{l}\text { Tiempo Promedio de } \\
\text { Desplazamiento por modo }\end{array}$ & Minutos & $\begin{array}{l}\text { Caminata: } 18 \\
\text { Bicicleta: } 33 \\
\text { Moto: } 31 \\
\text { Auto: } 32 \\
\text { Bus - Buseta: } 43 \\
\text { Microbús: } 40 \\
\text { Metroplús: } 39 \\
\text { Metro: } 55 \\
\text { Taxi: } 28 \\
\end{array}$ & $\begin{array}{l}\text { Caminata: } 18 \\
\text { Bicicleta: } 33 \\
\text { Moto: } 31 \\
\text { Auto: } 32 \\
\text { Bus - Buseta: } 43 \\
\text { Microbús: } 40 \\
\text { Metroplús: } 39 \\
\text { Metro: } 55 \\
\text { Taxi: } 28 \\
\end{array}$ & $\begin{array}{l}\text { Secretaría de } \\
\text { Movilidad }\end{array}$ \\
\hline Distribución modal & Porcentaje & $\begin{array}{l}\text { Caminata: } 26,1 \% \\
\text { Bicicleta: } 0,5 \% \\
\text { Moto: } 10,9 \% \\
\text { Auto: } 14,7 \% \\
\text { Bus - Buseta: } \\
26,6 \% \\
\text { Microbús: } 2,2 \% \\
\text { Metroplús: 0,6\% } \\
\text { Metro: 8,2\% } \\
\text { Taxi: } 7,4 \%\end{array}$ & $\begin{array}{l}\text { Caminata: } 26,1 \% \\
\text { Bicicleta: } 0,5 \% \\
\text { Moto: } 10,9 \% \\
\text { Auto: } 14,7 \% \\
\text { Bus - Buseta: } \\
26,6 \% \\
\text { Microbús: } 2,2 \% \\
\text { Metroplús: 0,6\% } \\
\text { Metro: 8,2\% } \\
\text { Taxi: } 7,4 \%\end{array}$ & $\begin{array}{l}\text { Secretaría de } \\
\text { Movilidad }\end{array}$ \\
\hline
\end{tabular}


En este sentido proponemos para Medellín bajo las condiciones generales de articulación e integración de la infraestructura con la región, la nación y los sistemas de transporte locales para ofrecerle a la ciudad una movilidad accesible, sostenible y segura. 


\subsection{RETO}

MEDELLINN SE INTEGRA CON LA REGIÓN, EL ÁREA METROPOLITANA Y LA NACIÓN
PROGRAMA

4 5.1.1. Gestión de planes regionales y metropolitanos

\section{OBJETIVO}

Promover y apoyar el desarrollo de infraestructura requerida por la región para facilitar el desarrollo eronómirn v el hienectar hımann 


\subsection{Medellín se integra con la región, el Área Metropolitana y la Nación}

Los artículos 10 y 175 del Plan de Ordenamiento Territorial, hacen énfasis en las estrategias territoriales de conectividad de Medellín con la región y el país, y puntualmente en las acciones territoriales a desarrollar en la ejecución de los proyectos estratégicos metropolitanos de liderazgo supramunicipal tales como las Autopistas por la Prosperidad o el Túnel el Toyo.

En un panorama de Autopistas por la Prosperidad, cuyo propósito último es conectar a Medellín con el resto de la Nación, según se señala en el documento III de evaluación al POT (2014), los centros urbanos distantes a 1 hora tales como San Pedro, Don Matías, Guarne, el Retiro, Amagá, San Jerónimo y Santa Fe de Antioquia, estarían funcionalmente atrapados en la órbita urbana de Medellín (Documento de evaluación al POT, 2014)

Según esa misma evaluación, las Autopistas para la Prosperidad, supondrían un incremento en el volumen tanto de carga como de pasajeros, toda vez que el tiempo de marcha se reduciría enormemente, por ejemplo en el caso Medellín-Turbo hasta en un 60\% al pasar de 10 a 4 horas, lo que posiblemente implicaría una saturación de vehículos entre Santa Fe de Antioquia y Medellín.

En relación al Túnel del Toyo, Medellín aportará 186.000 millones de pesos, del total de 1.83 billones del presupuesto que se requiere para la construcción del túnel.

Respecto al transporte de carga, la ciudad y la región actualmente no cuentan con una infraestructura adecuada, así como tampoco con una regulación eficaz para las actividades de cargue y descargue, lo que contribuye a algunos problemas de movilidad que hoy enfrenta la ciudad. Por ello se hace necesario aunar esfuerzos con el Área Metropolitana con el fin de gestionar con el gremio la construcción de centros logísticos, con un estudio previo que permita caracterizar el transporte de carga, sus impactos en la movilidad y las posibles alternativas de solución.

A continuación se describe el indicador de resultado con el cual se evaluará este reto

\begin{tabular}{|l|c|c|c|c|}
\hline Nombre & Unidad & Línea de Base & Meta 2019 & Responsable \\
\hline $\begin{array}{l}\text { Participación municipal en } \\
\text { proyectos regionales }\end{array}$ & Porcentaje & $0 \%$ & $50 \%$ & $\begin{array}{c}\text { Secretaría de } \\
\text { Infraestructura } \\
\text { Física }\end{array}$ \\
\hline
\end{tabular}




\subsubsection{PROGRAMA: GESTIÓN DE PLANES REGIONALES $Y$ METROPOLITANOS}

Medellín ha venido avanzando a ritmos agigantados en el mejoramiento de sus vías de acceso por los cuatro puntos cardinales, con salidas/entradas en doble calzada que brindan recorridos más cómodos, seguros y eficientes. Sin embargo, es importante continuar con la planeación y ejecución de planes de movilidad y grandes obras de infraestructura, que permitan encauzar y coordinar los esfuerzos hacia una misma dirección, propendiendo hacia una región más articulada, con mejor accesibilidad y movilidad.

\section{Indicadores de resultado}

\begin{tabular}{|c|c|c|c|c|}
\hline Nombre & Unidad & Línea de Base & Meta 2019 & Responsable \\
\hline $\begin{array}{l}\text { Proyectos regionales y } \\
\text { metropolitanos gestionados }\end{array}$ & Número & 0 & 10 & $\begin{array}{l}\text { Secretaría de } \\
\text { Infraestructura } \\
\text { Física }\end{array}$ \\
\hline
\end{tabular}

5.1.1.1. Proyecto: Estructurar Sistema Férreo Multipropósito (tren de cercanías para pasajeros y tren de carga o residuos sólidos a la Pradera)

Avanzar en los estudios sobre la viabilidad técnica, legal y financiera del sistema férreo multipropósito como obra metropolitana y de región, que incluye tren de cercanías para pasajeros y tren de carga o residuos sólidos (La Pradera) con estaciones multimodales de transbordo de pasajeros y de transferencias de residuos o carga.

Responsable: Metro de Medellín

Indicador de producto

\begin{tabular}{|l|l|}
\hline Nombre Unidad & Un \\
\hline $\begin{array}{l}\text { Estudios realizados de prefactibilidad y/o factibilidad del Sistema Férreo } \\
\text { Multipropósito }\end{array}$ & Porcentaje \\
\hline
\end{tabular}

5.1.1.2. Proyecto: Cofinanciar Autopistas para la prosperidad Apoyar financieramente el proyecto nacional y departamental de las Autopistas para la prosperidad como el Túnel del Toyo como estrategia de conectividad con la región y promoción del desarrollo económico del departamento y la ciudad.

El Túnel del Toyo y sus conexiones viales permiten la conexión entre la capital del departamento y el Urabá antioqueño, lo cual jalonará el desarrollo de Medellín, teniendo en cuenta la posición estratégica que tiene la región urabaense respecto a los sistemas portuarios de Colombia, América Latina y la Cuenca del Caribe, su cercanía al canal de Panamá y la Zona Libre de Colón, y las grandes posibilidades que tiene de desarrollar la industria marítima y portuaria. 
Movilidad sostenible

Responsable: Secretaría de Infraestructura Física

Indicador de producto

Nombre

Recursos desembolsados para la ejecución de Autopistas de la Prosperidad Unidad

5.1.1.3. Proyecto: Gestionar la estructuración del sistema de transporte logístico de carga

Realizar una caracterización del transporte de carga en la ciudad de Medellín y su región desde el punto de vista de la infraestructura vial, modos de transporte de carga, tipo de carga, horarios de cargue y descargue, entre otros, además de evaluar su impacto en la movilidad relacionada con actividad de cargue y descargue y la circulación de los vehículos de carga sobre la malla vial existente, con el fin de establecer soluciones enfocadas a una adecuada movilidad.

Responsable: Área Metropolitana del Valle de Aburrá

Indicador de producto

\begin{tabular}{|l|c|}
\hline Nombre & Unidad \\
\hline Estudio realizado para estructurar el Sistema logístico de Carga & Porcentaje \\
\hline
\end{tabular}

\subsubsection{Proyecto: Estructurar la centralidad sur}

Teniendo en cuenta que Medellín hace parte del Área Metropolitana y el desarrollo de los municipios adyacentes a Medellín, la ciudad apoyará la reorganización en tema de transporte de pasajeros, carga y logística en la centralidad sur de la región.

Responsable: Área Metropolitana del Valle de Aburrá

Indicador de producto

\begin{tabular}{|l|c|}
\hline Nombre & Unidad \\
\hline $\begin{array}{l}\text { Estudios de prefactibilidad realizados para el traslado de la Terminal Sur en la } \\
\text { Centralidad Sur }\end{array}$ & Porcentaje \\
\hline
\end{tabular}

5.1.1.5. Proyecto: Túnel de Occidente

$\boldsymbol{0}$

Cofinanciación convenio interadministrativo No. 0583 de 1996, para el proyecto de comunicación vial entre los Valles de Aburrá y el río Cauca, además de todas las actividades, obras y proyectos que se requieran para evitar, mitigar o compensar los impactos social y ambiental que se causen por efecto de la construcción de los accesos viales y del túnel mismo. Proyecto con vigencia futura hasta el 2020. Normativa: Acuerdo Municipal No. 17 de 1998.

Responsable: Secretaría de Hacienda 
Indicador de producto

\begin{tabular}{|l|c|}
\hline Nombre & Unidad \\
\hline Porcentaje cumplido en los recursos de cofinanciación & Porcentaje \\
\hline
\end{tabular}

5.1.1.6. Proyecto: Estructurar la conexión de Medellín con el Valle de San Nicolás a través del Túnel de Oriente

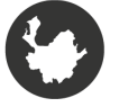
Estudio de selección tecnológica y de prefactibilidad de la conexión en transporte público masivo, entre el Valle de Aburrá y el Valle de San Nicolás a través del Túnel de Oriente (Conexión al aeropuerto José María Córdova).

Responsable: Metro de Medellín

Indicador de producto

\begin{tabular}{|l|c|}
\hline Nombre & Unidad \\
\hline Estudios realizados para la prefactibilidad y/o factibilidad para obras de movilidad & Porcentaje \\
\hline
\end{tabular}

5.1.1.7. Proyecto: Conexión Metropolitana con la centralidad sur del Valle de Aburrá

La accesibilidad al corregimiento San Antonio de Prado y su conectividad con los municipios del sur y el resto del Área Metropolitana, está supeditada a la conexión vial que se realiza desde el Municipio de Itagüí. Las competencias jurisdiccionales han dificultado adelantar proyectos de manera oportuna para la atención de la significativa cantidad de viajes que tienen como origen o destino el corregimiento 0 algunos municipios del occidente del departamento.

Se requiere que el municipio de Medellín tome la iniciativa del desarrollo de nuevas infraestructuras que mejoren la interconectividad física entre los municipios del sur del Valle de Aburrá, procurando superar las dificultades que tienen la gestión concertada entre varias administraciones municipales.

El corregimiento de San Antonio de Prado requiere integrarse de una manera más efectiva con la zona que integra el sur del Valle de Aburrá, especialmente con la centralidad metropolitana propuesta entre los municipios de Itagüí y Sabaneta, en las aproximaciones de la estación del Metro. La recualificación del sistema de movilidad en el sur del Área Metropolitana, que incluye además la doble calzada de las futuras circunvalares de Medellín por medio de la calle 77 Sur y un intercambio vial sobre el río con esta vía, y el fortalecimiento del sistema de integrado de transporte con el Metroplús, abrirá nuevas oportunidades al territorio corregimental, entre estas la relocalización industrial en parte de su jurisdicción, gracias al incremento de la accesibilidad urbana.

Responsable: Secretaría de Infraestructura Física 
Movilidad sostenible

Indicador de producto

\begin{tabular}{|l|c|}
\hline Nombre & Unidad \\
\hline Estudios realizados para el prefactibilidad y/o factibilidad para obras de movilidad & Fases \\
\hline
\end{tabular} 


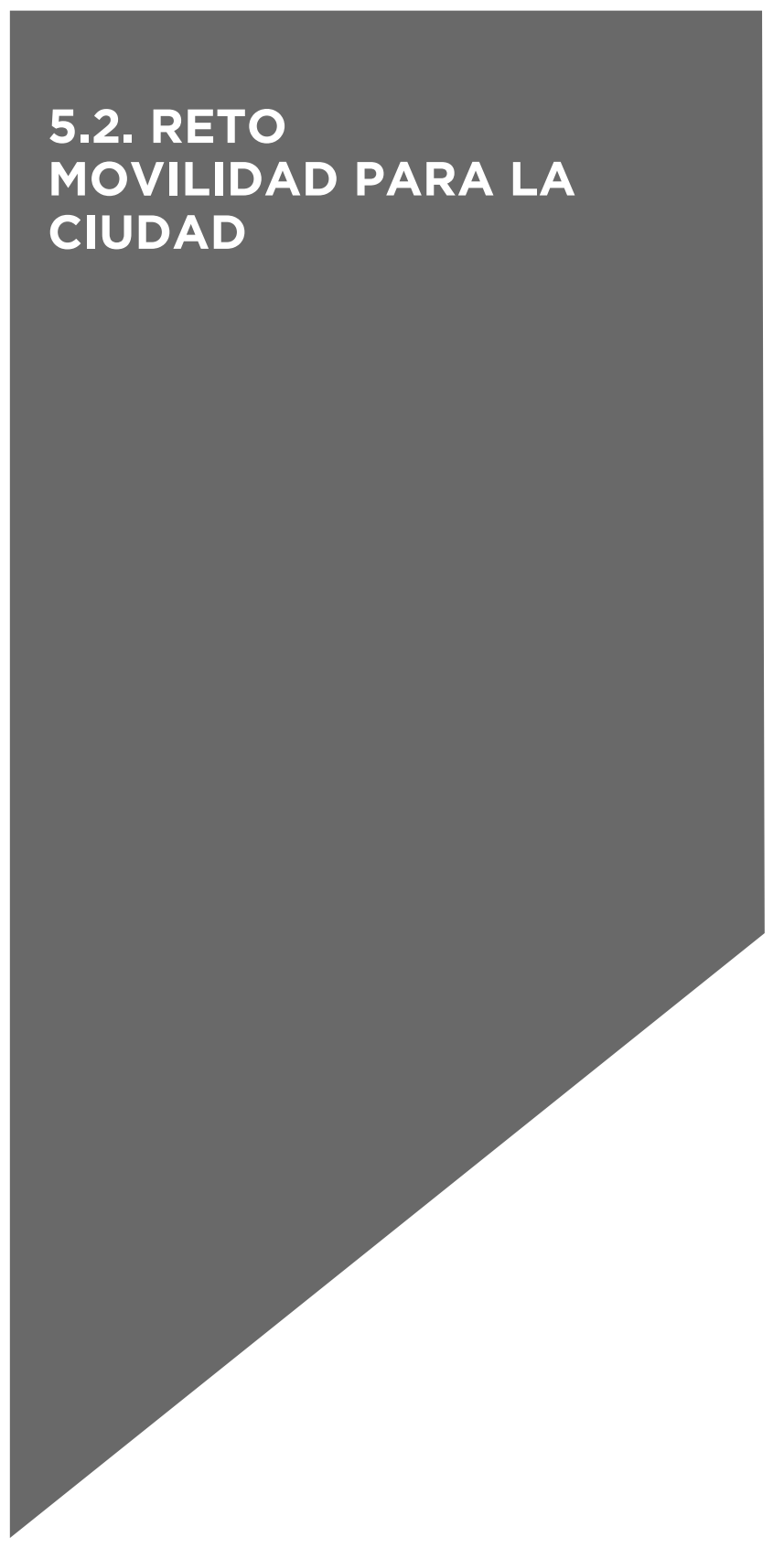

\section{PROGRAMA}

4.2.1. Planificación del Sistema de movilidad de la ciudad

4 5.2.2. Proyectos de infraestructura para la movilidad de la ciudad

\section{OBJETIVO}

Desarrollar e Integrar la infraestructura existente, con los diferentes sistemas y medios de transporte de la ciudad de manera que su funcionamiento sea sostenible, incluyente, fluido, cómodo y seguro para todos los ciudadanos. 


\subsection{Movilidad para la ciudad}

La implementación de un Centro de Control que integra componentes técnicos y tecnológicos para la gestión del tránsito y el transporte, ha sido otro elemento constitutivo de la movilidad para el mejoramiento de la Ciudad. En este momento, el Centro de Control cuenta con 22 paneles de mensajes variables en las vías, 40 cámaras de fotodetección, 48 cámaras de circuito cerrado de televisión, 40 cámaras evaluadoras de tránsito y optimización de la red de semáforos y una web 2.0 que envía información en tiempo real a través de Twitter. Los dispositivos se encuentran instalados en los sitios donde se registra mayor índice de infracciones y accidentalidad, lo que ha permitido, en el corto tiempo de su funcionamiento, que en estos sitios se registre una disminución de la tasa de accidentes y se genere una nueva cultura en el comportamiento de los conductores y diferentes actores de la movilidad, además de una disminución de los tiempos de atención a los eventos de tránsito, pasando de 40 minutos a 17 en promedio.

En materia de infraestructura para la movilidad, las cifras dejan ver que la densidad vial (suelo ocupado por vías), presenta un incremento mínimo pero constante entre los años 2008 y 2012, pasando de 3,22 mt2 a 3,58 $\mathrm{mt} 2$ respectivamente. Esta cifra es necesario compararla con los datos relacionados al crecimiento del parque automotor el cual durante los últimos 7 años ha tenido un incremento del 61\%, según los vehículos matriculados en las diferentes secretarías de tránsito del Área Metropolitana, dejando en evidencia una relación desigual entre el ritmo de crecimiento de la densidad vial y el parque automotor, el cual pasó de 767.548 vehículos en 2008 a 1.234.946 en 2014.

Con respecto a la malla vial, para el año 2015 se contabilizan 2.053 kilómetros de vías vehiculares, de los cuales 1.810 kilómetros son en pavimento flexible en el perímetro urbano, de estos, casi la mitad (49.01\%) son vías de servicio que se emplean como conexión con vías colectoras y arterias del sistema vial, seguidas por el $21 \%$ que representan las vías colectoras, encargadas de llevar los flujos vehiculares de las vías de servicio a las arterias menores, arterias principales o a las autopistas. Estas últimas suman casi un $20 \%$ del total de longitud de la malla vial y su principal función es permitir la movilidad entre los diferentes puntos cardinales de la ciudad. Para dar continuidad a las vías sobre quebradas y otros puntos de difícil acceso, se cuenta con cerca de 3.000 puentes entre peatonales y vehiculares, de los cuales, los principales ya llegan a los 20 años de vida útil o más.

En los organismos de tránsito del Valle de Aburra actualmente se cuenta con un registro de 1.347.067 vehículos en sus diferentes composiciones (autos, micros y buses, camiones, motos, etc), haciendo diferentes recorridos por la malla vial de la ciudad. Según las tendencias y líneas de viaje de los habitantes y transeúntes, queda en evidencia en algunas 
horas del día, la insuficiente capacidad de este tejido vial, que debe soportar la mayoría de los 5.6 millones de viajes al día que se generan en el Área Metropolitana del Valle de Aburrá.

Por otra parte, es importante mencionar que según la Encuesta Origen y Destino el tiempo promedio de desplazamiento de la ciudad en 2012 se calculó en 34 minutos. Esto habla de un incremento de 9 minutos en menos de cinco años, si se tiene en cuenta que según la misma encuesta para el 2005 el desplazamiento se calculó en 25 minutos. Si bien esto está relacionado con diferentes variables, vale la pena mencionar el último estudio realizado por el AMVA en el que se calculó que al año en el Área se pierden 76 millones de horas/pasajero, cifras que derivan en costos anuales que oscilan entre los 82 y los 287 millones de dólares y en la pérdida de competitividad derivada de este gasto.

Según se señala en ese mismo estudio, el vehículo que más influye en la congestión es el automóvil y luego la motocicleta, pues estos son sistemas menos eficientes y tienen un bajo nivel de ocupación en comparación con el transporte público.

A continuación se describen el indicador de resultado con el que se evaluará este reto:

\begin{tabular}{|l|c|c|c|c|}
\hline Nombre & Unidad & Línea de Base & Meta 2019 & Responsable \\
\hline $\begin{array}{l}\text { Medida implementadas para } \\
\text { el mejoramiento de la } \\
\text { movilidad }\end{array}$ & Número & 0 & 5 & $\begin{array}{l}\text { Secretaría de } \\
\text { Movilidad }\end{array}$ \\
\hline
\end{tabular}

\subsubsection{PROGRAMA: PLANIFICACIÓN DEL SISTEMA DE MOVILIDAD} DE LA CIUDAD

La ciudad debe seguir avanzando en la estructuración, ejecución y priorización de proyectos asociados a la movilidad, para lo cual es fundamental contar con soportes técnicos que permitan la correcta toma de decisiones que optimicen la inversión de recursos y gestión de la infraestructura para la movilidad.

\section{Indicador de resultado}

\begin{tabular}{|l|c|c|c|c|}
\hline \multicolumn{1}{|c|}{ Nombre } & Unidad & Línea de Base & Meta 2019 & Responsable \\
\hline $\begin{array}{l}\text { Estudios para la Movilidad } \\
\text { Sostenible realizados }\end{array}$ & Porcentaje & $0 \%$ & $100 \%$ & $\begin{array}{l}\text { Departamento } \\
\text { Administrativo } \\
\text { de Planeación }\end{array}$ \\
\hline
\end{tabular}

\subsubsection{Proyecto: Formulación del Plan Integral de Movilidad Sostenible}

Formular y realizar estudio de pre inversión del Plan Maestro Integral de Movilidad para el municipio de Medellín, con miras a ejecutar las propuestas planteadas en el componente de movilidad del Acuerdo 048 de 2014 del Plan de Ordenamiento Territorial, teniendo presente los nuevos usos y densidades planteadas y bajo los lineamientos de la Ley 1083 del 31 de julio de 2006 y el Decreto Nacional 736 de 2014 
sobre intermultimodalidad en los sistemas de transporte público. Son componentes de análisis de estos estudios los corredores exclusivos para motos, peatonales y bicicletas.

Responsable: Departamento Administrativo de Planeación

Indicador de producto

\begin{tabular}{|l|c|}
\hline Nombre & Unidad \\
\hline Plan Integral de Movilidad Sostenible formulado & Número \\
\hline
\end{tabular}

5.2.1.2. Proyecto: Formulación de un plan integral de intervenciones sobre los corredores de transporte y su área de influencia de los existentes y futuros

Este proyecto tiene como objetivo formulación y estudio del desarrollo de los corredores articulados al Plan rector de movilidad de transporte público Masivo en Medellín y sus corregimientos, con miras a lograr la financiación de los mismos y el desarrollo integral de la ciudad.

Responsable: Metro de Medellín

Indicador de producto

\begin{tabular}{|l|c|}
\hline Nombre & Unidad \\
\hline $\begin{array}{l}\text { Plan integral de intervenciones sobre los corredores de transporte y su área de } \\
\text { influencia de los existentes y futuros formulado }\end{array}$ & Porcentaje \\
\hline
\end{tabular}

5.2.1.3. Proyecto: Estructuración del corredor de la avenida 34 para transporte masivo

Se trata de la estructuración del corredor de $10.5 \mathrm{~km}$ ubicado entre la estación Aguacatala y Palos Verdes de la L1 de buses, el cual mejorará la movilidad.

Responsable: Metro de Medellín

Indicador de producto

\begin{tabular}{|l|c|}
\hline Nombre & Unidad \\
\hline Proyectos de transporte masivo estructurados & Número \\
\hline
\end{tabular}

\subsubsection{Proyecto: Estructurar Estación Entre Orillas}

Estructurar la estación Entre Orillas que estaría ubicada entre las estaciones de Industriales y Poblado de la Línea A, contribuyendo al desarrollo del sector sur del río y generando alternativa de transporte masivo para la población del sector. Incluye los diseños definitivos de la Estación y las pasarelas Oriente- Occidente.

Responsable: Metro de Medellín

Indicador de producto

\begin{tabular}{|l|c|}
\hline Nombre & Unidad \\
\hline Proyectos de transporte masivo estructurados & Número \\
\hline
\end{tabular}


5.2.1.5. Proyecto: Estructurar Corredores de transporte transversales a la Avenida El Poblado

Estructurar una solución de transporte de mediana capacidad para la comuna $14 \mathrm{El}$ Poblado que comunique transversalmente (Oriente Occidente y viceversa) las zonas altas de El Poblado con el corredor multimodal del río.

Responsable: Metro de Medellín

Indicador de producto

\begin{tabular}{|l|c|}
\hline Nombre & Unidad \\
\hline Proyectos de transporte masivo estructurados & Número \\
\hline
\end{tabular}

5.2.1.6. Prueba piloto de carriles especiales para motos Elaborar los estudios previos de su viabilidad, pruebas pilotos y campañas pedagógicas para su posterior implementación total, con lo que se pretende disminuir la problemática de la accidentalidad de los motociclistas.

Responsable: Secretaría de Movilidad

Indicador de producto

\begin{tabular}{|l|c|}
\hline Nombre & Unidad \\
\hline Implementación de prueba piloto para de carriles solo motos & Fases \\
\hline
\end{tabular}

5.2.1.7. Proyecto: Vigilancia y control de la movilidad segura Fortalecer la capacidad operativa y tecnológica para un eficiente control en las vías que mitigue los factores de riesgo sobre la movilidad. Forma parte de este proyecto la dotación e incremento de recursos tecnológicos y logísticos, el fortalecimiento al control de la embriaguez y la gestión de zonas de estacionamiento regulado.

Responsable: Secretaría de Movilidad

Indicador de producto

\begin{tabular}{|l|c|}
\hline Nombre & Unidad \\
\hline Operativos de control & Número \\
\hline
\end{tabular}

5.2.1.8. Proyecto: Señalización para la seguridad vial de los ciudadanos Mantener y ampliar la infraestructura de semaforización y señalización vial necesaria para brindar a los usuarios de las vías condiciones de seguridad adecuadas, de tal forma que se propicie una cultura de respeto y compartimiento de los espacios donde se generan conflictos debido al incremento de los volúmenes vehículares.

Responsable: Secretaría de Movilidad 
Indicador de producto

\begin{tabular}{|l|c|}
\hline Nombre & Unidad \\
\hline Señalización vial mantenida en buen estado & Km \\
\hline Red semafórica de la ciudad mantenida en buen estado & Número \\
\hline
\end{tabular}

\subsubsection{PROGRAMA: PROYECTOS DE INFRAESTRUCTURA PARA LA MOVILIDAD DE LA CIUDAD}

El rápido crecimiento del parque automotor ha disminuido la eficiencia en la movilidad a lo largo y ancho de la ciudad. En la búsqueda de mejorar dicha eficiencia, se proponen acciones puntuales en cada una de las zonas, como pequeños broches, puentes, deprimidos, segundas calzadas y el mejoramiento integral de las vías existentes, entre otros, con el fin de optimizar la red vehicular y alcanzar mejores tiempos de recorrido que mejoren la calidad de vida de los medellinenses.

\section{Indicador de resultado}

\begin{tabular}{|l|c|c|c|c|}
\hline \multicolumn{1}{|c|}{ Nombre } & Unidad & Línea de Base & Meta 2019 & Responsable \\
\hline $\begin{array}{l}\text { Proyectos de infraestructura } \\
\text { realizados }\end{array}$ & Porcentaje & $0 \%$ & $100 \%$ & $\begin{array}{l}\text { Secretaría de } \\
\text { Infraestructura }\end{array}$ \\
\hline $\begin{array}{l}\text { Percepción del estado de } \\
\text { andenes, separadores y calles }\end{array}$ & Porcentaje & $72 \%$ & $72 \%$ & $\begin{array}{l}\text { Secretaría de } \\
\text { Infraestructura }\end{array}$ \\
\hline $\begin{array}{l}\text { Percepción del cumplimiento de } \\
\text { las normas de tránsito }\end{array}$ & Porcentaje & $91 \%$ & $91 \%$ & $\begin{array}{l}\text { Secretaría de } \\
\text { Movilidad }\end{array}$ \\
\hline
\end{tabular}

\subsubsection{Proyecto: Mantenimiento de la infraestructura para el mejoramiento de la movilidad}

Este proyecto incluye el mantenimiento de la malla vial de Municipio de Medellín, priorizando por Corredores Viales Estratégicos y de acuerdo a la jerarquía vial del Plan de Ordenamiento Territorial, mejorando el estado existente de la red vial por tipo de intervención y de su infraestructura asociada como andenes, cordones, defensas viales, obras de estabilización, contención, protección, mitigación y drenaje, para garantizar así una movilidad segura tanto para los vehículos como para los peatones.

Además mejorar la conectividad vial en la escala veredal, que permita mayor movilidad ciudadana y de productos agroindustriales, mediante la construcción, adecuación y el mantenimiento de vías veredales en los cinco corregimientos de Medellín.

Responsable: Secretaría de Infraestructura

Indicador de producto

\begin{tabular}{|l|c|}
\hline Nombre & Unidad \\
\hline Infraestructura peatonal con mantenimiento & Porcentaje \\
\hline Infraestructura vial con mantenimiento de la ciudad (Ciclorrutas y vías) & Porcentaje \\
\hline
\end{tabular}


5.2.2.2. Proyecto: Intervenciones de infraestructura para el mejoramiento de la red de movilidad

Este proyecto contiene la realización de los estudios y diseños para nuevos proyectos viales, y la construcción de pequeñas obras de gran impacto (retornos en u, carriles de mezclamiento, en tramos de red caminera, en tramos de ciclo ruta, entre otros), que conlleven una movilidad eficiente, confortable y ágil que garanticen mejor calidad de vida con un ambiente sano para todos los ciudadanos de Medellín.

Además incluye el análisis de soluciones de mezclamiento entre las diferentes vías que componen el sistema vial del río, estudiando las soluciones que este necesita con respecto al entremezclamiento y las incorporaciones que se producen en las calzadas existentes (Vía Travesía, Vía Arteria y Vía de Servicio), mediante carriles de incorporación y salida, teniendo en cuenta las longitudes de desarrollo que necesitan cada tipo de vía según la velocidad de diseño y su tipología (Vía Regional y Urbana).

Responsable: Secretaría de Infraestructura

Indicador de producto

\begin{tabular}{|l|c|}
\hline Nombre & Unidad \\
\hline Sitios neurálgicos intervenidos para el mejoramiento de la red de movilidad & Porcentaje \\
\hline
\end{tabular}

\subsubsection{Proyecto: Construir y mantener los puentes vehiculares y peatonales de la ciudad}

Realizar la construcción y el sostenimiento de puentes levantados para mantener en estado óptimo la red vial, con el fin de ofrecer una conectividad cómoda y segura para el desplazamiento vehicular y peatonal, en especial para las personas con movilidad reducida, acorde con los objetivos del Plan de Desarrollo de mejorar la movilidad y reducir la tasa de accidentalidad por el estado de los mismos.

Indicador de producto

Responsable: Secretaría de Infraestructura

\begin{tabular}{|l|c|}
\hline Nombre & Unidad \\
\hline Puentes intervenidos en la ciudad de Medellín & Número \\
\hline
\end{tabular}

\subsubsection{Proyecto: Diseñar y construir Autopista Regional Norte Oriental} (Doble calzada a nivel)

Terminar la autopista Regional hacia el norte del Valle de Aburrá, desde Moravia hasta Zamora, conectando con la autopista MedellínBogotá.

Responsable: Secretaría de Infraestructura

Indicador de producto

\begin{tabular}{|l|c|}
\hline Nombre & Unidad \\
\hline Autopista Regional Norte Margen Oriental construida & Fases \\
\hline
\end{tabular}


5.2.2.5. Proyecto: Terminar la construcción del Puente de la Madre Laura y obras complementarias

Continuar con la construcción del puente de la Madre Laura y sus obras complementarias como el Puente Moravia.

Responsable: Secretaría de Infraestructura

Indicador de producto

\begin{tabular}{|l|c|}
\hline Nombre & Unidad \\
\hline Puente de la Madre Laura y sus obras complementarias construidas & Fases \\
\hline
\end{tabular}

5.2.2.6. Diseñar soluciones viales del corredor de La Iguaná, entre la Av. 80 y el Sistema Vial del Río y construir una primera fase

Este proyecto debe permitir la conectividad con occidente, solucionando los problemas de movilidad de las vías adyacentes de la quebrada de La Iguaná desde el Sistema Vial del Río conectando con la doble calzada hacia el Túnel de Occidente, ya que actualmente se presentan demoras por las intersecciones semaforizadas con el Sistema Vial del Río, la carrera 65, la carrera 70 y la carrera 74.

Responsable: Secretaría de Infraestructura

Indicador de producto

\begin{tabular}{|l|c|}
\hline Nombre & Unidad \\
\hline Intersecciones intervenidas en el corredor de la Q. La Iguaná & Porcentaje \\
\hline
\end{tabular}

5.2.2.7. Proyecto: Diseñar y construir intercambios en la Av. 80 necesarios para la implementación del corredor de transporte masivo y mejoramiento del corredor vial de la 80 entre Pichincha y la calle 65

De acuerdo al sistema de transporte masivo que se implemente en el corredor de la Av. 80, se necesitará diseñar y construir intercambios en las actuales intersecciones semaforizadas de la calle 65, Colombia, San Juan, calle 35, calle 33, calle 30, carrera 76 y carrera 70 para permitir el flujo continuo del sistema.

Indicador de producto

Responsable: Secretaría de Infraestructura

\begin{tabular}{|l|c|}
\hline Nombre & Unidad \\
\hline $\begin{array}{l}\text { Intercambios ejecutados en la Av. } 80 \text { necesarios para la implementación del } \\
\text { corredor de transporte masivo }\end{array}$ & Número \\
\hline
\end{tabular}

5.2.2.8. Proyecto: Construir intercambio de la avenida El Poblado con la calle 4 Sur

Agilizar la movilidad vial y peatonal de la calle 4 Sur entre las carreras 43 y 43C, y permitir el flujo vehicular continuo en la Av. el Poblado, para la cual es necesario mejorar 300 metros de vía, construir un paso a desnivel y construir espacio público para facilitar el traslado de los peatones incluyendo la comunidad con discapacidad, adicionalmente reducir la tasa de accidentalidad y el impacto de la contaminación. 
Responsable: Secretaría de Infraestructura

Indicador de producto

\begin{tabular}{|l|c|}
\hline Nombre & Unidad \\
\hline Intercambio ejecutado de la Avenida El Poblado con la Calle 4 Sur & Número \\
\hline
\end{tabular}

5.2.2.9. Proyecto: Construir las obras de valorización de la comuna 14 Construir las obras pendientes en el proceso de valorización de El Poblado entendiendo las quejas y el malestar de la ciudadanía por los retrasos presentados y buscando las soluciones pertinentes para la finalización del proyecto.

Indicador de producto

Responsable: Fondo de Valorización de Medellín

\begin{tabular}{|l|c|}
\hline Nombre & Unidad \\
\hline Obras de Valorización del Poblado ejecutadas & Porcentaje \\
\hline
\end{tabular}

5.2.2.10. Proyecto: Construcción y mejoramiento de la vía Altos del Rodeo (Calle 6 sur entre carreras 53 y 89)

Construcción y mejoramiento de esta vía para garantizar el acceso adecuado al sector de Altos del Rodeo.

Indicador de producto

Responsable: Secretaría de Infraestructura

\begin{tabular}{|l|c|}
\hline Nombre & Unidad \\
\hline Vía Altos del Rodeo ampliada & Porcentaje \\
\hline
\end{tabular}

5.2.2.11. Proyectos de infraestructura para la movilidad de los Corregimientos

De otro lado, los 5 corregimientos del Municipio de Medellín han venido desarrollándose exigiendo mejor infraestructura para suplir las necesidades de las comunidades que allí habitan. Por lo tanto se ha planteado una serie de proyectos encaminados a suplir dichas deficiencias y poder mejorar la conectividad de los corregimientos a nivel regional y nacional, que brinden mayor competitividad y desarrollo de dichos territorios.

Indicador de producto

Responsable: Secretaría de Infraestructura

\begin{tabular}{|l|c|}
\hline Nombre & Unidad \\
\hline $\begin{array}{l}\text { Intervenciones realizadas para mejorar la infraestructura en movilidad en los } \\
\text { corregimientos }\end{array}$ & Porcentaje \\
\hline
\end{tabular}




\subsection{RETO GESTIÓN DE LA MOVILIDAD ACCESIBLE, SOSTENIBLE Y SEGURA}

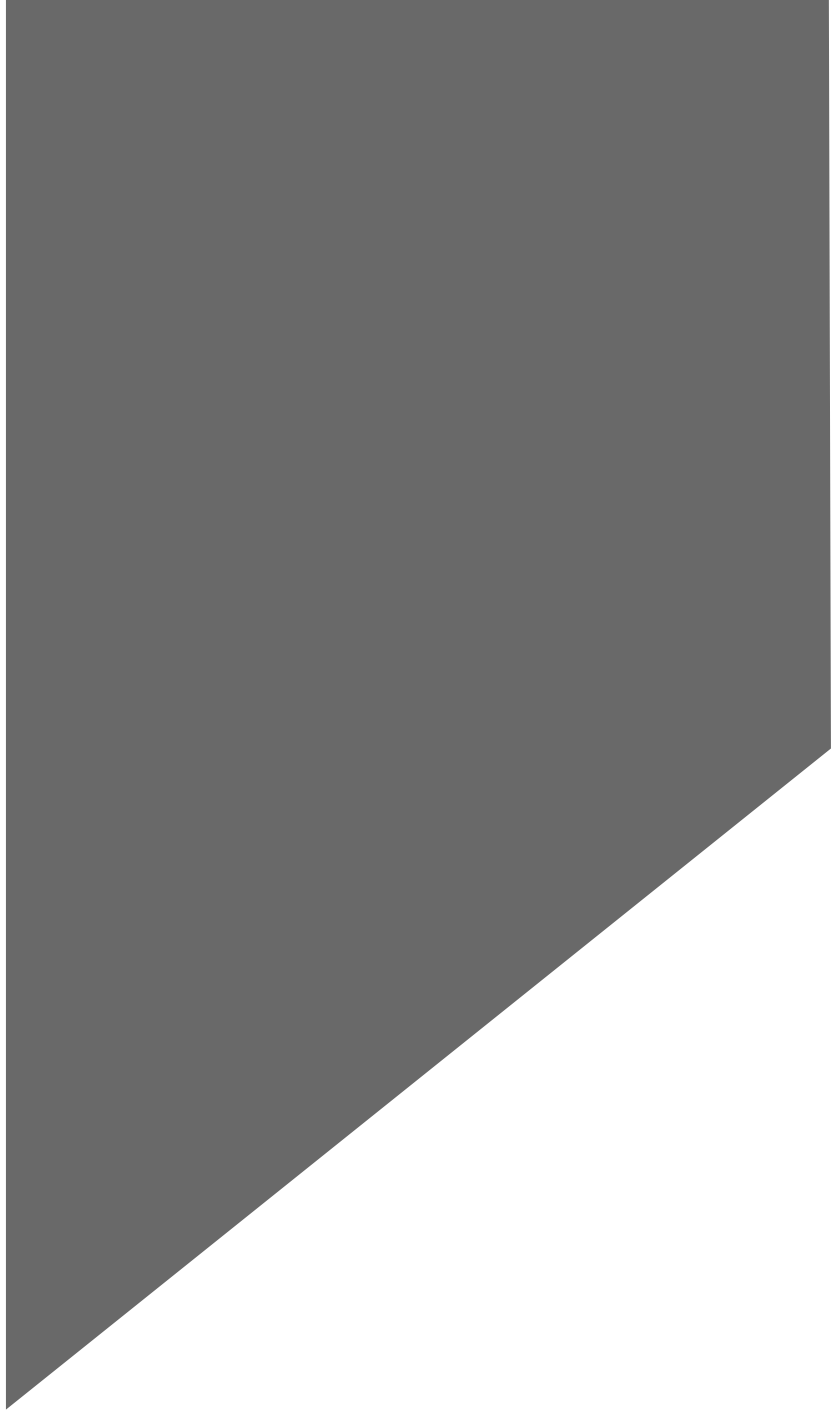

\section{OBJETIVO}

Proporcionar acceso a sistemas de transporte accesibles, seguros, de calidad y sostenibles a la población de Medellín.

\section{PROGRAMA}

$\Delta$ 5.3.1. Fortalecimiento a la integración multimodal del transporte público

4 5.3.2. Intervenciones movilidad para transporte público multimodal

4 5.2.3. Gestión intengral para la movilidad no motorizada 


\subsection{Gestión de la movilidad accesible, sostenible y segura}

El fortalecimiento del sistema de movilidad es importante para el mejoramiento de las condiciones de accesibilidad de la población mediante el ordenamiento del tránsito de las personas, animales y vehículos por las vías públicas y privadas abiertas al público, empleando diferentes mecanismos para prevenir, reglamentar e informar a los usuarios sobre las vías, que asegure a todos los usuarios un desplazamiento seguro y confiable por lo tanto se hace necesario año tras año realizar el mantenimiento de la señalización vial y ampliar su cobertura.

En cuanto a la infraestructura para movilidad no motorizada, se cuenta con 49 kilómetros de ciclorutas y un total de 4.100 kilómetros de andenes, como franja de circulación peatonal. Datos que son realmente insuficientes para el cumplimiento del modelo de ciudad que se ha establecido en el actual Plan de Ordenamiento Territorial, el cual pretende tener en la ciudad una infraestructura física apropiada para los medios no motorizados, teniendo como principal protagonista al peatón, generando las dinámicas adecuadas para contar con una ciudad accesible y con una movilidad sostenible.

En los últimos siete años, los índices de metros cuadrados de vía peatonal por habitante se han mantenido estables sin evidenciar un incremento representativo, para el 2014 la cantidad de cobertura peatonal fue igual a la de 2007, con un total de $1,74 \mathrm{~m} 2$ por habitante. Si este dato se compara con el incremento constante de la densidad vial durante ese mismo período de tiempo, el resultado es negativo para la ciudad en materia no solo de movilidad sino también ambiental, pues estas cifras no coinciden con el interés y la urgencia que existe porque las personas se desplacen en modos alternativos de transporte.

Este dato es importante contrastarlo también con las cifras que existen entre los años 2007 y 2014 en relación al espacio público efectivo por habitante (parques, plazas, plazoletas y zonas verdes disponibles por habitante), y las cuales permiten ver que, contrario a haber un aumento, los años 2013 (3.50mt2/hab) y 2014 (3.57 mt2/hab) han dejado las cifras más bajas en este tema en comparación con las registradas por ejemplo en 2007 (3.82 $\mathrm{mt} 2 / \mathrm{hab})$. Importante mencionar que la media mundial es de $7 \mathrm{mt} 2 /$ hab, cifra muy superior a la registrada por Medellín.

Vale la pena señalar que la ciudad ha impulsado el mejoramiento de su espacio público para favorecer la movilidad peatonal teniendo en cuenta que cerca del $30 \%$ de los viajes, en un día típico laboral, está representado por la caminata, a fin de garantizar accesibilidad a toda la población, especialmente a personas con movilidad reducida. 
En la actualidad, la ciudad cuenta con 627 cruces semaforizados, recientemente modernizados en sus componentes de software y hardware, con tecnología abierta única en el país que permite la integración con otros sistemas como es el caso de la red semafórica del tranvía de Ayacucho, así como la implementación de sistemas por prioridad para el transporte público, en este caso Metroplús. Se requiere seguir avanzando en la aplicación de software que permitan una planificación de la red semafórica acorde con la dinámica del tráfico de la ciudad y la articulación con los demás municipios del Valle de Aburrá.

Adicionalmente, la ciudad también cuenta con un sistema estructurado de transporte con enfoque multimodal pionero en todo el país, es decir, diferentes medios y modos de transporte como Metro, cables, buses, bicicletas y tranvía. Gracias a esto el número de pasajeros ha incrementado en los últimos años, especialmente en el Sistema Integrado de Transporte del Valle de Aburrá - SITVA (Metro, Cables, BRT, servicios alimentadores) lo cual se ha traducido en grandes beneficios e impacto social a través del ahorro en los tiempos de viaje y dinero, favoreciendo a usuarios que se movilizan por una sola tarifa de manera rápida, segura y económica, así como a estudiantes, personas en situación de discapacidad y adultos mayores mediante tarifas diferenciales, y el transporte de niños menores de un metro de estatura que ingresan al sistema gratuitamente.

En materia de servicios públicos de transporte, la Encuesta de Calidad de vida de 2014, arrojó que en general la cobertura del transporte en la ciudad es positiva en términos generales, las personas consideran la calidad como "buena". Vale la pena destacar que la percepción negativa frente a este tema se evidencia principalmente en los corregimientos y en los barrios de borde urbano del norte de la ciudad.

Frente al tema de percepción de cobertura del transporte público, en general en la ciudad hay percepciones positivas frente al servicio, siendo de nuevo importante destacar que allí donde se evidencia una percepción negativa frente al tema es en corregimiento y sectores de borde urbano. Por último, vale la pena mencionar que un importante número de viajes (aproximadamente 1'100.000) son atendidos por el transporte público colectivo urbano de Medellín y 386.000 por el transporte Metropolitano que ingresa a la ciudad.

A continuación se describen los indicadores de resultado que se evaluarán en este reto: 


\section{Movilidad sostenible}

\begin{tabular}{|l|c|c|c|c|}
\hline \multicolumn{1}{|c|}{ Nombre } & Unidad & Línea de Base & Meta 2019 & Responsable \\
\hline $\begin{array}{l}\text { Vehículos de transporte público } \\
\text { accesibles Tr }\end{array}$ & Número & 338 & 405 & $\begin{array}{c}\text { Secretaría de } \\
\text { Movilidad }\end{array}$ \\
\hline $\begin{array}{l}\text { Reducción de la tasa de } \\
\text { mortalidad por cada 10.000 } \\
\text { vehículos registrados }\end{array}$ & $\begin{array}{c}\text { Tasa de } \\
\text { muertos por } \\
\text { cada 10.000 } \\
\text { vehículos } \\
\text { registrados }\end{array}$ & 2,01 & 1,77 & $\begin{array}{c}\text { Secretaría de } \\
\text { Movilidad }\end{array}$ \\
\hline
\end{tabular}




\subsubsection{PROGRAMA: FORTALECIMIENTO A LA INTEGRACIÓN MULTIMODAL DEL TRANSPORTE PÚBLICO}

La movilidad de la ciudad se articula en torno a un sistema vial jerarquizado, dos terminales aéreas, dos terminales terrestres y un sistema de transporte público conformado por un Metro como eje estructurante complementado con cables, troncal y pretroncal para buses de tránsito rápido, un sistema de transporte público colectivo, un transporte público individual, un sistema de escaleras eléctricas, un sistema de bicicletas públicas y próximamente con un tranvía.

De cara al usuario se requiere una intermodalidad del servicio de transporte que integre física y tarifariamente para que el usuario se vea beneficiado con una mayor cobertura y un menor costo en sus desplazamientos bajo condiciones de eficiencia, calidad y seguridad.

Indicador de resultado

\begin{tabular}{|c|c|c|c|c|}
\hline Nombre & Unidad & Línea de Base & Meta 2019 & Responsable \\
\hline $\begin{array}{l}\text { Usuarios nuevos del transporte } \\
\text { público }\end{array}$ & Número & 1.980 & 2.138 & $\begin{array}{l}\text { Secretaría de } \\
\text { Movilidad }\end{array}$ \\
\hline
\end{tabular}

5.3.1.1. Proyecto: Mejorar el Sistema de Transporte Masivo de la Metrópoli (Apoyo Plan Maestro SITVA)

Son todas las acciones para brindarles a nuestros usuarios un mejor servicio. Son componentes de este proyecto: la ampliación de la Estación Poblado, el Mejoramiento de la accesibilidad, la compra de 20 trenes, la modernización del PCC, la ampliación de los talleres en Bello y la nueva sede administrativa del Metro, la ampliación de talleres en Bello y la nueva sede administrativa del Metro, vías de estacionamiento para ampliación de talleres.

Responsable: Metro de Medellín

Indicador de producto

\begin{tabular}{|l|l|l|}
\hline Nombre Unidad & Un \\
\hline $\begin{array}{l}\text { Acciones implementadas para mejoramiento de la prestación del servicio de } \\
\text { transporte público másivo }\end{array}$ & Porcentaje \\
\hline
\end{tabular}

5.3.1.2. Proyecto: Fortalecer la operación de Metroplús en las cuencas 3 y 6 Aportar los recursos al fondo de estabilidad que permitan cubrir la diferencia entre la tarifa del usuario y la tarifa técnica, que garantice la estabilidad financiera de la operación de Metroplús cuencas 3 y 6.

Responsable: Secretaría de Movilidad

Indicador de producto

\begin{tabular}{|l|c|}
\hline Nombre & Unidad \\
\hline $\begin{array}{l}\text { Recursos desembolsados para la estabilidad financiera de la operación de Metroplús } \\
\text { (cuencas } 3 \text { y6) durante el cuatrienio }\end{array}$ & Número \\
\hline
\end{tabular}


5.3.1.3. Proyecto: Gestionar y fortalecer la operación del transporte público colectivo e individual de Medellín y sus corregimientos

Impulsar la implementación de la transformación de la operación del transporte público colectivo integrado al sistema masivo, bajo principios de eficiencia, calidad, económica y sostenibilidad. Incluye componentes de mejoramiento de la infraestructura vial mediante la construcción carriles segregados o preferenciales, construcción de estaciones de transferencia, señalización vial, paraderos, gestión para la implementación de centros logísticos, incorporación de medios tecnológicos para la gestión y control de flota, sistema de recaudo electrónico, plataformas informativas, interactivas e incluyentes que generan procesos de información y comunicación en tiempo real entre los usuarios y el servicios de transporte, vehículos accesibles con tecnología de combustibles limpios y transformación empresarial.

Responsable: Secretaría de Movilidad

Indicador de producto

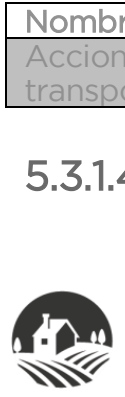

5.3.1.4. Proyecto: Fortalecer el programa de racionalización del transporte público asociados a corredores de transporte

Apropiar los recursos para la compra de los vehículos de trasporte público colectivo que deban ser racionalizados, con ocasión de la implementación de otros sistemas de transporte que eviten la superposición, duplicidad y competencia entre los servicios de transporte.

Indicador de producto

Responsable: Secretaría de Movilidad

\begin{tabular}{|l|c|}
\hline Nombre & Unidad \\
\hline $\begin{array}{l}\text { Racionalización de vehículos a razón de la implementación de otros sistemas de } \\
\text { transporte. }\end{array}$ & Número \\
\hline
\end{tabular}

5.3.1.5. Proyecto: Gestionar y estructurar equipamientos para el parqueo adyacente a los sistemas de transporte público

Adelantar las acciones necesarias para la consecución de lotes, adecuación, administración y funcionamiento como zonas de estacionamiento directo o través de terceros, que motive a los usuarios a hacer un uso racional de su vehículo particular integrándose al sistema de transporte público. Articulación del sistema público de movilidad directo al parque automotor particular.

Indicador de producto

Responsable: Metro de Medellín

\begin{tabular}{|l|c|}
\hline Nombre & Unidad \\
\hline $\begin{array}{l}\text { Equipamentos gestionados para el parqueo adyacente a los sistemas de transporte } \\
\text { público }\end{array}$ & Porcentaje \\
\hline
\end{tabular}




\subsubsection{Proyecto: Potencializar el sistema de recaudo electrónico para el transporte público}

Impulsar la implementación de un sistema de recaudo electrónico, a través de la tarjeta única de ciudad (Cívica) para todos los modos de transporte (Transporte Público Colectivo, Transporte Público Masivo, Transporte Público Individual) que permita la integración tarifaria (actualmente existe un Convenio Interadministrativo -CN2015-0426-, suscrito entre el municipio de Medellín y la Empresa de Transporte Masivo del Valle de Aburrá Limitada, con el propósito de implementar el sistema de recaudo electrónico con tarjeta cívica en el transporte público).

Responsable: Secretaría de Movilidad

Indicador de Producto

\begin{tabular}{|l|c|}
\hline Nombre & Unidad \\
\hline Sistema de recaudo electronico implementado en el transporte público colectivo & Porcentaje \\
\hline
\end{tabular}

\subsubsection{PROGRAMA: INTERVENCIONES MOVILIDAD PARA TRANSPORTE PÚBLICO MULTIMODAL}

Son todas las soluciones de movilidad y corredores de transporte con sus obras complementarias para la operación de los diferentes modos de transporte.

Indicador de Resultado

\begin{tabular}{|c|c|c|c|l|}
\hline Nombre & Unidad & Línea de Base & Meta 2019 & Responsable \\
\hline $\begin{array}{l}\text { Intervenciones movilidad para el } \\
\text { transporte público multimodal } \\
\text { ejecutadas }\end{array}$ & Número & 0 & 10 & $\begin{array}{l}\text { Metro } \\
\text { Medellín }\end{array}$ \\
\hline
\end{tabular}

5.3.2.1. Proyecto: Revisar y ajustar los diseños y el desarrollo de la primera fase corredor de transporte de la 80

Empezar la ejecución del corredor de la 80, diseñando a punto, revisando los diseños frente al POT y evaluando con rigor todos los componentes del mismo e iniciar construcción de una primera fase en el norte de la ciudad donde permite integrar gran parte de la oferta de educación superior de la ciudad al sistema integrado de transporte público. En resumen es el desarrollo, construcción de la infraestructura y equipos técnicos y rodantes del sistema de transporte entre la estación Floresta y la Estación Caribe.

Indicador de producto

Responsable: Metro de Medellín

\begin{tabular}{|l|c|}
\hline Nombre & Unidad \\
\hline Primera fase del corredor de transporte de la 80 construido & Número \\
\hline
\end{tabular}


Movilidad sostenible

5.3.2.2. Proyecto: Plan integral Tranvía de Ayacucho Continuar con el proceso de ejecución en cuanto a la construcción del tranvía de Ayacucho y los dos metrocables. (Incluye intervención par vial Bombona, el Plan integral de Ayacucho -PIA- y la operación urbana en San Luis).

Indicador de producto

Responsable: Metro de Medellín

\begin{tabular}{|l|c|}
\hline Nombre & Unidad \\
\hline Tranvía Ayacucho y los dos metrocables construidos & Porcentaje \\
\hline
\end{tabular}

5.3.2.3. Proyecto: Terminar y construir los patios U. de M. y alterno de Metroplús (para las líneas L1 y L2 de buses)

Terminar la construcción del patio de U. de M. y construcción del patio Alterno para el adecuado funcionamiento de la L1 y L2 de buses, por la empresa Metroplús a la empresa Metro de Medellín.

Responsable: Metroplús

Indicador de producto

\begin{tabular}{|l|c|}
\hline Nombre & Unidad \\
\hline Centros Logisticos de Transporte para la operación de Metroplús construidos & Porcentaje \\
\hline
\end{tabular}

5.3.2.4. Proyecto: Terminar los diseños y construir el corredor Troncal Metroplús por la Av. Oriental

Gestionar y ejecutar los recursos para la implementación del Sistema Metroplús por la Avenida Oriental como troncal, que permita la migración de la actual operación pretroncal a una operación más eficiente por carril exclusivo y estaciones centrales de conformidad con los diseños adelantados.

Responsable: Metroplús

Indicador de producto

\begin{tabular}{|l|c|}
\hline Nombre & Unidad \\
\hline Corredor Troncal Metroplús Av. Oriental construida & Número \\
\hline
\end{tabular}

5.3.2.5. Proyecto: Construir el Cable Picacho y su complementario al cerro el Picacho

Construcción de la línea de cable del sector Noroccidental de la ciudad de Medellín, con las 4 estaciones articuladas al corredor vial Norte del Departamento de Antioquia.

Responsable: Metro de Medellín

Indicador de producto

\begin{tabular}{|l|c|}
\hline Nombre & Unidad \\
\hline Cable Picacho y su complementario al cerro el Picacho construidos & Porcentaje \\
\hline
\end{tabular}

5.3.2.6. Proyecto: Construir la troncal sur de Metroplús en jurisdicción de Medellín 
Construcción del tramo del Sistema Metroplús de la Pretroncal del Sur en la calle 12 Sur entre las avenidas Guayabal y Poblado, y gestionar los recursos para la troncalización de los tramos de la Avenida Guayabal entre calle 12 Sur y calle 15C Sur (en límites con el municipio de Itagüí), y la avenida El Poblado entre la calle 12 Sur y calle 21 Sur (en límites con el municipio de Envigado), como corredor del SITVA contemplado en el documento Conpes 3573 de 2009 y en Convenio de Cofinanciación suscrito entre la Nación y los Municipios de Medellín, Envigado e Itagüí.

Responsable: Metroplús

Indicador de producto

\begin{tabular}{|l|l|}
\hline Nombre & Unidad \\
\hline Corredor Troncal Sur Medellín construido & Porcentaje \\
\hline
\end{tabular}

5.3.2.7. Proyecto: Estructurar y desarrollar la primera fase del corredor de transporte de la Av. Guayabal y sus obras complementarias

Gestionar y ejecutar los recursos para la implementación del corredor del Sistema Metroplús por la avenida Guayabal entre la calle 12 Sur y la calle 30, como corredor potencializador de la pretroncal del Sur y complementario al Metro y como expansión del SITVA. Si bien este proyecto no ha empezado su construcción, viene siendo gestionado desde la administración anterior dada su relevancia para el óptimo funcionamiento de la pretroncal del Sur.

Responsable: Secretaria de Infraestructura Fisica

Indicador de producto

\begin{tabular}{|l|c|}
\hline Nombre & Unidad \\
\hline Corredor Pretroncal Avenida Guayabal Construido & Porcentaje \\
\hline $\begin{array}{l}\text { Centro Logistico de Transporte construido para la operación de Metroplús en el } \\
\text { Sur }\end{array}$ & Porcentaje \\
\hline
\end{tabular}

\subsubsection{PROGRAMA: GESTIÓN INTEGRAL PARA LA MOVILIDAD NO MOTORIZADA}

Es un principio fundamental para la ciudad humanizar la movilidad, por lo tanto la ciudad debe estar pensada y construida para la gente, bajo condiciones de sostenibilidad y equidad, tal como lo establece el actual Plan de Ordenamiento Territorial, priorizando una infraestructura física apropiada para los medios no motorizados.

Indicador de resultado

\begin{tabular}{|l|l|c|c|l|}
\hline \multicolumn{1}{|c|}{ Nombre } & Unidad & Línea de Base & Meta 2019 & Responsable \\
\hline $\begin{array}{l}\text { Intervenciones ejecutadas para } \\
\text { la movilidad no motorizada }\end{array}$ & Número & 0 & 5 & $\begin{array}{l}\text { Gerencia } \\
\text { Movilidad } \\
\text { Humana }\end{array}$ \\
\hline $\begin{array}{l}\text { Usuarios que utilizan el sistema } \\
\text { Encicla }\end{array}$ & Número & 9.000 & 20.000 & $\begin{array}{l}\text { Gerencia de la } \\
\text { Movilidad } \\
\text { Humana }\end{array}$ \\
\hline
\end{tabular}


5.3.3.1. Proyecto: Impulsar y fortalecer el uso de la bicicleta

Son componentes de este proyecto: expandir el sistema de bicicletas pública EnCicla, la integración de las bicicletas al Sistema Masivo de Transporte y la implementación del Plan Metropolitano de la Bicicleta.

Potencializar cultura en bicicleta y transporte no motorizado: como parte de nuestra apuesta por el medio ambiente y la movilidad sostenible cumple un papel fundamental la promoción. Es necesario llevar a cabo campañas e incentivos que potencializarían el uso y la cultura de la bicicleta y el transporte no motorizado.

Responsable: Secretaria de Movilidad

Indicador de producto

\begin{tabular}{|l|c|}
\hline Nombre & Unidad \\
\hline Estaciones implementadas en el sistema EnCicla & Número \\
\hline Bicicletas en funcionamiento dentro del sistema Encicla & Número \\
\hline
\end{tabular}

\subsubsection{Proyecto: Construcción de cicloinfraestructura}

Son componentes de este proyecto construir nuevos kilómetros de ciclorrutas, construir equipamientos públicos de parqueadero de bicicletas.

Lograr una infraestructura que favorezca el desplazamiento de las personas que utilizan modos de transporte no motorizados, especialmente la caminata y la bicicleta, articulando todas las iniciativas sectoriales que contemplen la construcción y/o adecuación de andenes, ciclorrutas, alamedas, corredores de tránsito calmado, corredores peatonales para dar facilidades a personas con movilidad reducida e infraestructura para la intermodalidad.

Responsable: Secretaría de Infraestructura Física

Indicador de producto

\begin{tabular}{|l|c|}
\hline Nombre & Unidad \\
\hline Kilómetros de ciclorutas construidos & Número \\
\hline Cicloparqueaderos instalados en espacio público & Número \\
\hline
\end{tabular}

\subsubsection{Proyecto: Consolidar y desarrollar infraestructura para la movilidad} peatonal

Incluye redes camineras, construcción de corredores de tránsito calmado y corredores peatonales. Construcción del espacio público peatonal a través de un sistema urbano peatonal el cual en su planteamiento urbano cuenta con intervenciones en todas las zonas de la urbe que permitan generar un tejido y una red caminera donde se conecten equipamientos, parques, plazas con el sistema de transporte masivo permitiendo que los ciudadanos puedan recorrer adecuadamente la ciudad garantizando una accesibilidad incluyente 
con andenes adecuados para el tránsito de adultos mayores, niños, personas con limitaciones físicas y/o visuales y público en general.

El proyecto cuenta además con un componente muy fuerte de innovación en materiales y sostenibilidad ambiental donde el paisajismo y arborización son clave para devolverle la vida a los corredores y brindándole al ciudadano un espacio tan atractivo y confortable que lo invite a recorrer la ciudad a pie disfrutando totalmente del entorno circundante y de las dinámicas de la ciudad.

Responsable: Secretaría de Infraestructura Física

Indicador de producto

\begin{tabular}{|l|l|}
\hline Nombre & Unidad \\
\hline Conectividad peatonal intervenida & Número \\
\hline
\end{tabular}




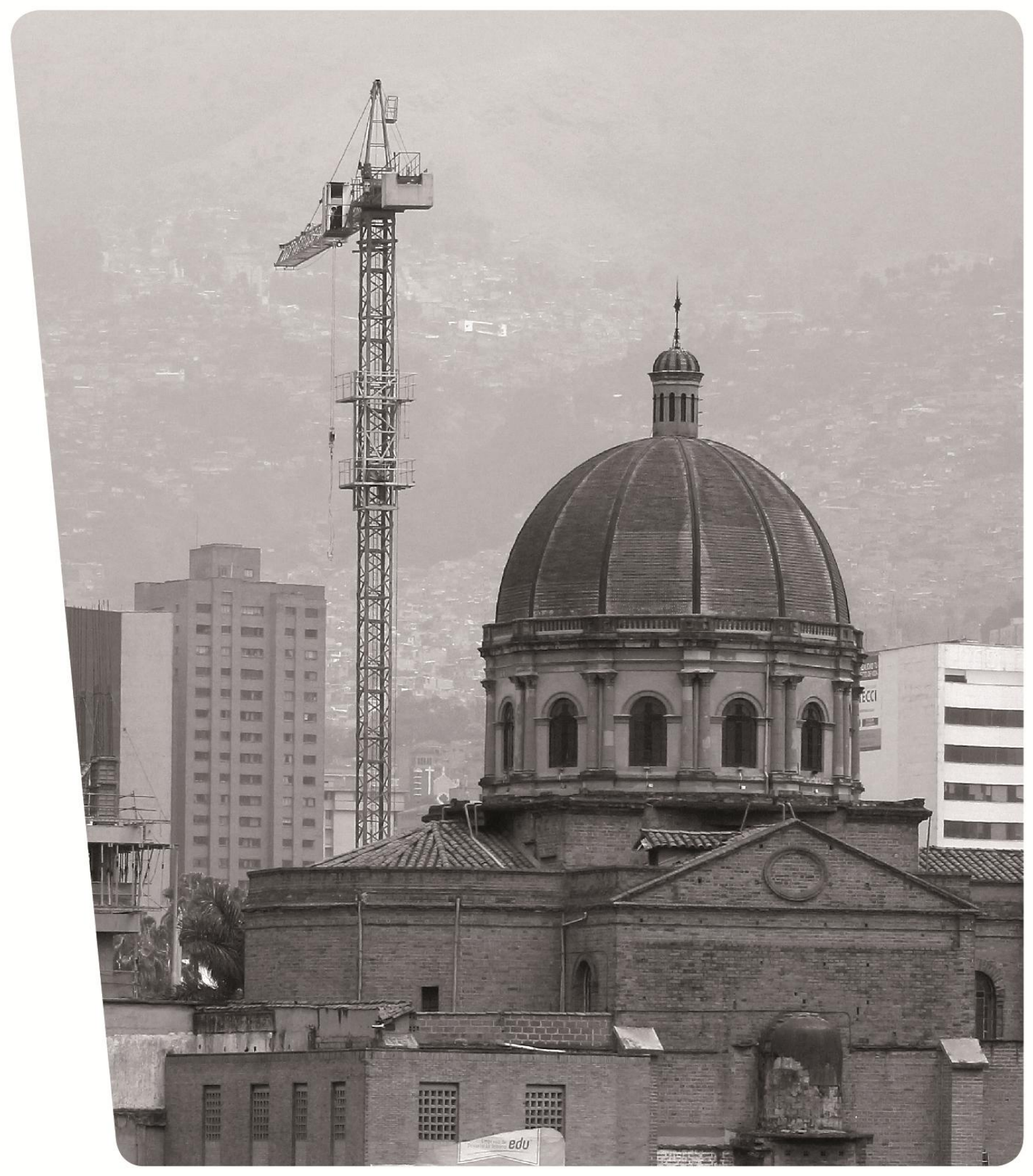

\section{INTERVENCIÓN INTEGRAL DEL TERRITORIO Y RECUPERACIÓN DEL CENTRO}




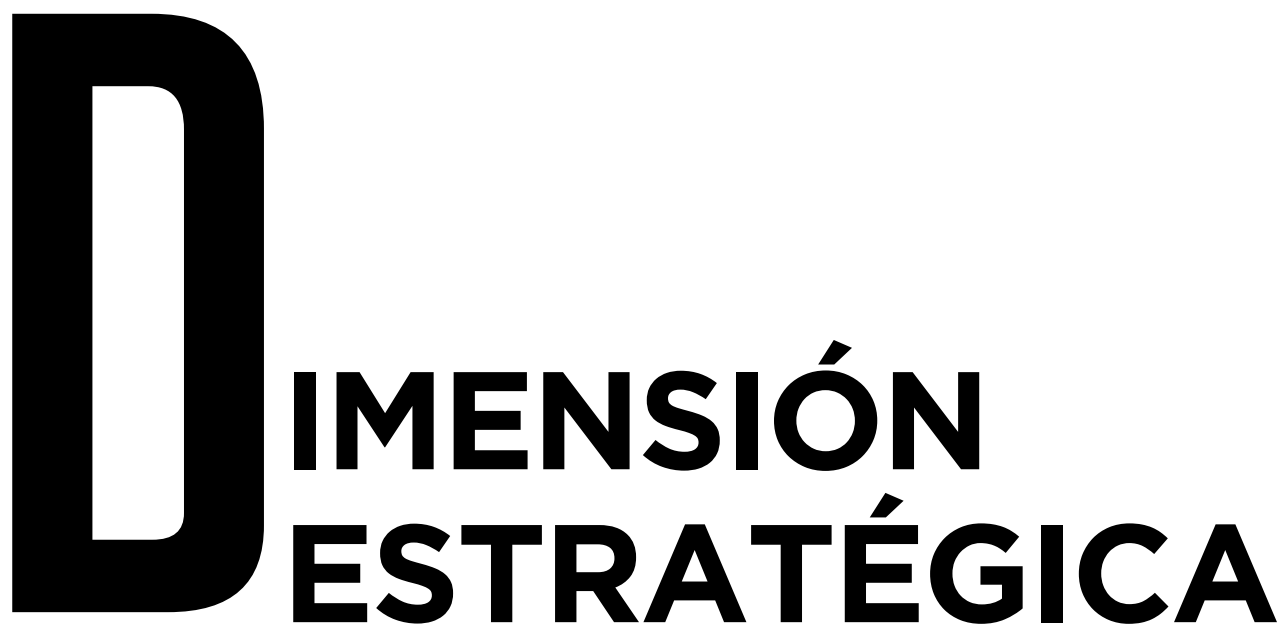

\section{Intervención integral del territorio y recuperación del centro}

Planificar y gestionar los recursos urbanísticos y naturales de Medellín de forma estratégica para brindar a los ciudadanos la posibilidad de habitar plenamente su ciudad y aprovechar toda su potencialidad (patrimonio, espacio público, oferta institucional), especialmente el centro, haciéndolos participes de su cuidado. 


\section{- DIAGNÓSTICO •}

Para establecer una hoja de ruta de renovación urbana en Medellín es inevitable referirse al Plan de Ordenamiento Territorial (POT, Acuerdo 48 de 2014) herramienta que establece los lineamientos de la planeación de la ciudad en cuestiones físicas, urbanas, ambientales y de uso del suelo, el cual define las estrategias, normas y objetivos para la ciudad en un periodo de largo plazo (12 años) además de establecer el marco normativo para la ejecución de grandes proyectos urbanos en la ciudad, la disposición de los suelos y su uso efectivo.

El POT establece un modelo de ocupación inspirado en las directrices propuestas en el Plan BIO 2030, el cual propuso un ejercicio de planificación territorial estratégico para Medellín bajo el modelo de una ciudad compacta, diversa y policéntrica, orientada al crecimiento hacia adentro, respetuosa de la base natural y del medio ambiente, que reduzca los desequilibrios territoriales y la segregación social (Alcaldía de Medellín, 2013). Aunado a ello, esta propuesta de articulación del territorio ubica al Rio Medellín como eje estructurante de la movilidad y gran centro metropolitano de actividades y hábitat, donde también se propende por la contención del crecimiento urbanístico en las laderas a partir de la formulación de proyectos que reorientan la ocupación del espacio público, protegen el paisaje y permiten generar asentamientos seguros y de baja densidad sobre las zonas de mayor pendiente.

Los principales megaproyectos a ejecutarse en la ciudad, que se ajustan al modelo de ocupación del POT, son Parques del Río Medellín y el Cinturón verde. Ambos proyectos han priorizado el desarrollo del espacio público y paisajismo, sin demostrar resultados aún sobre el cumplimiento del modelo de ocupación propuesto. No obstante, representan un reto fundamental para la organización territorial del municipio, pues tal y como lo sugieren los Objetivos de Desarrollo Sostenible (ODS) propuestos por las Naciones Unidas, son muchos los problemas que existen para mantener ciudades de manera que se sigan creando empleos y prosperidad sin ejercer presión sobre la tierra y los recursos.

Los problemas comunes de las ciudades son la congestión, la falta de fondos para prestar servicios básicos, la escasez de vivienda adecuada y el deterioro de la infraestructura. En ese sentido, contrarrestar tales problemáticas requiere de un esfuerzo internacional, interinstitucional y de compromiso ciudadano hacia la garantía de mejores condiciones de hábitat para los habitantes de la ciudad. Por tal razón, esta dimensión incluye los principales aspectos sobre los que se concentra el proceso de la planeación estratégica territorial, apuntando al mejoramiento de la calidad del espacio público y la recuperación de espacios fuertemente golpeados pro al violencia y la criminalidad, apuntando al mejoramiento de las zonas rurales y al fortalecimiento de la presencia institucional 


\section{- PRESENTACIÓN •}

La dimensión territorio Medellín, equitativo e incluyente articula entre otros los procesos para el ordenamiento del territorio, el desarrollo equitativo, ordenado y en armonía con la región. En tal sentido, procura lograr la implementación del Plan de Ordenamiento Territorial - POT privilegiando la densificación y diversificación de usos en las áreas más planas y con mejor capacidad de soporte, al mismo tiempo que se programa un crecimiento moderado y compensado para el área rural en convivencia con sus actividades primarias; ofertando así desde la planificación los más y mejores bienes y servicios para la población tanto de las comunas como de los corregimientos del municipio de Medellín.

El desarrollo del planteamiento de ciudad, se enfatiza en la ejecución e implementación de los escenarios estratégicos para el cumplimiento del modelo de ocupación, en ellos se concentra la localización de los proyectos integrales para el ámbito río, ladera, transversalidades y bordes de ciudad, los cuales aportan a la consolidación de los espacios públicos y colectivos adecuados, suficientes y con garantías de acceso para la población. A su vez, ésta dimensión se ocupa del mantenimiento de los espacios públicos desarrollados a fin de darle continuidad y sostenibilidad a los beneficios y transformaciones positivas desde lo social, ambiental e institucional.

En el marco de lo que significan los proyectos integrales, el centro tradicional y representativo, se constituye el objeto de intervención para ofertar gran vitalidad urbana y recomponer el epicentro del espacio público municipal y metropolitano, bajo la consolidación de gestión armoniosa de la planeación y la participación democrática.

De otro lado, la dimensión reconoce el hábitat adecuado, entendido como la unidad global de interrelaciones entre los elementos bióticos, físico espaciales, socio culturales y socioeconómicos en donde se sitúan la vivienda y el entorno como lugares donde se habita con condiciones para la calidad de vida y el bienestar social y colectivo de los habitantes. En tal sentido, concreta el acceso a una vivienda adecuada, buscando la reducción de los hogares localizados en zonas de alto riesgo no mitigable y la protección de los moradores en proceso de reasentamiento por ejecución de proyectos de utilidad pública o interés social, priorizando el reasentamiento en el entorno próximo, en la medida en que los territorios y el ordenamiento territorial lo permitan.

A continuación se describen los indicadores de impacto asociados a esta dimensión: 


\section{Intervención integral del territorio y recuperación del centro}

Indicadores de impacto

\begin{tabular}{|l|l|l|l|l|}
\hline \multicolumn{1}{|c|}{ Nombre } & \multicolumn{1}{c|}{ Unidad } & Línea de Base & Meta 2019 & \multicolumn{1}{c|}{ Responsable } \\
\hline $\begin{array}{l}\text { Dimensión Medio Ambiente } \\
\text { Encuesta de Calidad de Vida }\end{array}$ & Número & 2,87 & 2,9 & $\begin{array}{l}\text { Departamento } \\
\text { Administrativo de } \\
\text { Planeación }\end{array}$ \\
\hline $\begin{array}{l}\text { Dimensión Entorno y Calidad } \\
\text { de la Vivienda Encuesta de } \\
\text { Calidad de Vida }\end{array}$ & Número & 4,23 & 4,3 & $\begin{array}{l}\text { Departamento } \\
\text { Administrativo de } \\
\text { Planeación }\end{array}$ \\
\hline $\begin{array}{l}\text { Dimensión Acceso a servicios } \\
\text { públicos Encuesta de Calidad } \\
\text { de Vida }\end{array}$ & Número & 3,98 & 4 & $\begin{array}{l}\text { Departamento } \\
\text { Administrativo de } \\
\text { Planeación }\end{array}$ \\
\hline $\begin{array}{l}\text { Índice de Sostenibilidad } \\
\text { Ambiental y cambio climático }\end{array}$ & Número & Nuevo & Nuevo & $\begin{array}{l}\text { Departamento } \\
\text { Planinistrativo de }\end{array}$ \\
\hline
\end{tabular}

En este sentido proponemos para Medellín bajo las condiciones de esta dimensión los siguientes retos: 


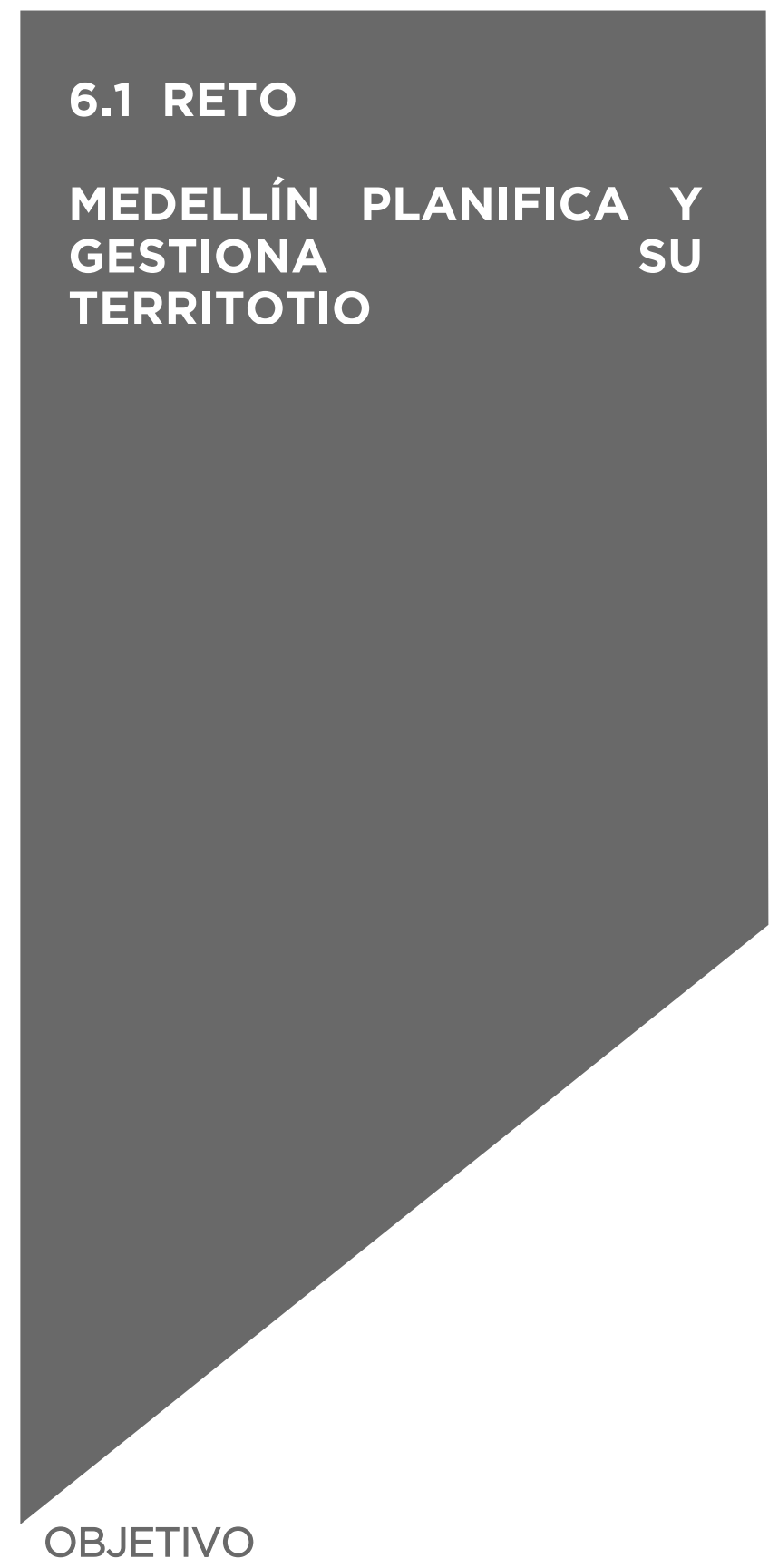

Planificar e implementar las estrategias requeridas para llevar a cabo las apuestas y los lineamientos del Plan de Ordenamiento Territorial.

\section{PROGRAMAS}

4.1.1. Planificación del Ordenamiento Territorial

$\Delta$

4 6.1.2. Planificación del Sistema de Gestión para la Equidad Territorial

$\Delta$

46.1.3. Gestión de la información urbanística y catastral 


\subsection{Medellín planifica y gestiona su territorio}

A partir de los estudios realizados al culminar el plazo del Plan de Ordenamiento Territorial formulado para Medellín en 2006, se pudo determinar que no fue posible fomentar el crecimiento hacia adentro de la ciudad, toda vez que la concentración de viviendas desde 1999 a 2012 fue a través del crecimiento en los bordes Noroccidental y Nororiental. Por tal razón en el ajuste y revisión del POT presentado en el año 2014 se consolidaron instrumentos de planificación para llevar a cabo las transformaciones territoriales necesarias en las áreas de intervención estratégica y cumplir los objetivos del modelo de ocupación propuesto.

En el mapa que aquí se presenta es posible observar la distribución territorial de los proyectos estratégicos de transformación urbana que se contemplan en el POT, según las áreas de intervención estratégica y los macroproyectos de intervención territorial, destacando la posibilidad efectiva de ocupar el territorio y transformarlo según los lineamientos estratégicos del plan.

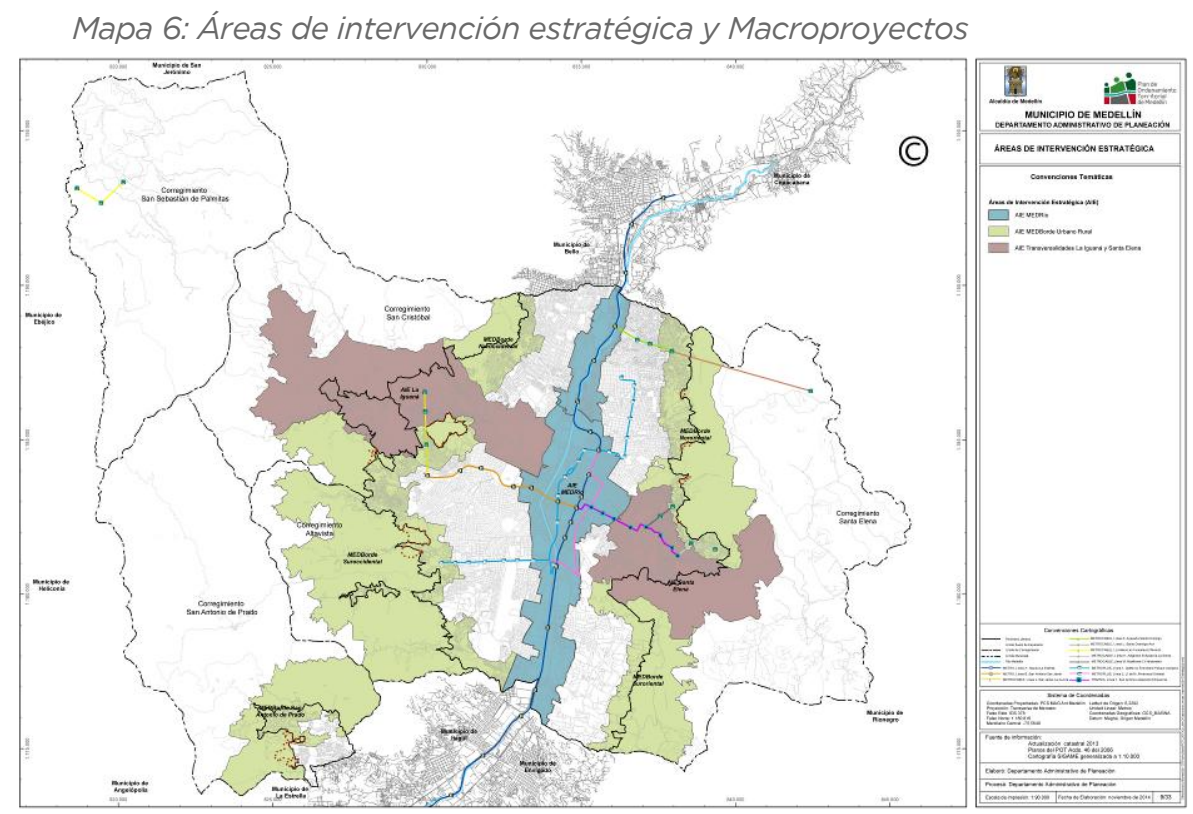

Fuente: Alcaldía de Medellín, POT, Acuerdo 48 de 2014

Por lo anterior, se requiere durante el cuatrienio 2016-2019 tomar las acciones necesarias para que Medellín sea una ciudad que responde al modelo de ocupación establecido en el POT 2014, interviniendo y adelantando lo estipulado en dicho plan para el horizonte de corto plazo que enfrenta.

A continuación se describe el indicador de resultado con el que se evaluará este reto: 


\begin{tabular}{|l|l|l|l|l|}
\hline Nombre & Unidad & $\begin{array}{c}\text { Línea de } \\
\text { Base }\end{array}$ & Meta 2019 & \multicolumn{1}{c|}{ Responsable } \\
\hline $\begin{array}{l}\text { Avance del Plan de } \\
\text { Ordenamiento territorial en } \\
\text { el corto plazo }\end{array}$ & Porcentaje & 0 & 100 & $\begin{array}{l}\text { Departamento } \\
\text { Administrativo } \\
\text { de Planeación }\end{array}$ \\
\hline
\end{tabular}

\subsubsection{PROGRAMA: PLANIFICACIÓN DEL ORDENAMIENTO TERRITORIAL}

La planeación y gestión para el ordenamiento territorial cuenta con el instrumento del Plan de Ordenamiento Territorial -POT-, acuerdo 48 de 2014, eje conductor y articulador de las dinámicas físico espaciales, socioeconómicas, ambientales y culturales, que están presentes en el proceso de uso, ocupación y aprovechamiento del suelo.

En tal sentido, se encuentra la necesidad de articular la gestión de las diferentes dependencias municipales, metropolitanas, de la región y el nivel nacional, buscando la concreción del modelo e imaginario de ciudad a través de la adecuada y armoniosa implementación del POT, para ofertar más y mejores bienes y servicios a la población tanto de las comunas como de los corregimientos del Municipio de Medellín.

La apuesta por concretar un modelo de ocupación territorial, en el cual el Municipio de Medellín como núcleo del Valle de Aburrá y centro de servicios de escala regional trabaja por reducir las desigualdades socio espaciales regionales, y aporta a la consolidación de un territorio regional, funcionalmente integrado, en torno a la estructura ecológica, los sistemas de movilidad, el espacio público de esparcimiento y encuentro, equipamientos, el patrimonio construido y los asentamientos humanos con sus dinámicas singulares, entre otras, y procurando una ocupación del territorio fundamentada en sus atributos y condicionantes garantizando la protección y aprovechamiento sostenible de los recursos naturales, con el afianzamiento y empoderamiento de la ciudadanía como copartícipe de su propio desarrollo.

Es necesario promover en el marco del programa de ejecución del Plan de Ordenamiento Territorial, la formulación e implementación de los planes e instrumentos de planificación complementaria de forma efectiva para alcanzar la sostenibilidad ambiental, la competitividad regional, la solidaridad y el equilibrio funcional del territorio.

Indicador de resultado

\begin{tabular}{|l|l|l|l|l|}
\hline Nombre & Unidad & $\begin{array}{l}\text { Línea de } \\
\text { Base }\end{array}$ & Meta 2019 & Responsable \\
\hline $\begin{array}{l}\text { Compromisos del POT } \\
\text { alcanzados }\end{array}$ & Porcentaje & 0 & 100 & $\begin{array}{l}\text { Departamento } \\
\text { Administrativo } \\
\text { de Planeación }\end{array}$ \\
\hline
\end{tabular}


6.1.1.1.1 Proyecto: Formulación y adopción de los macroproyectos de transversalidades y de borde urbano rural

Articular las dinámicas urbano-rurales que protege valores paisajísticos, buscando la constitución de un límite para el crecimiento urbano con intervenciones de carácter ambiental.

Responsable: Departamento Administrativo de Planeación

Indicador de producto

\begin{tabular}{|c|c|}
\hline Nombre & Unidad \\
\hline Macroproyectos de transversalidades formulados y adoptados & Porcentaje \\
\hline
\end{tabular}

\subsubsection{Proyecto: Formulación del Distrito Rural Campesino}

En el instrumento mediante el cual, se encaminan acciones físico espaciales, económicas, culturales y sociales, que permiten articular y orientar programas y proyectos, en pro del mejoramiento, 1.2. permanencia, promoción, planificación y gestión del territorio rural campesino.

Su objetivo es planificar, gestionar, impulsar y promover mediante programas y proyectos, las economías campesinas y sociales, a escala veredal y corregimental, con una visión regional, que permitan el reconocimiento y el fortalecimiento de la producción agroalimentaria de la ciudad. (Artículo 481, Acuerdo 48 de 2014)

Responsable: Departamento Administrativo de Planeación

Indicador de producto

\begin{tabular}{|c|c|}
\hline Nombre & Unidad \\
\hline Distrito rural campesino formulado y adoptado & Porcentaje \\
\hline
\end{tabular}

\subsubsection{Proyecto: Planes de Manejo y Protección Patrimonial - PEMP}

El Plan Especial de Manejo y Protección PEMP, se enmarca en las estrategias que se establecen desde el Plan de Ordenamiento - POT para el Subsistema de Patrimonio Inmueble de la ciudad, como un instrumento de planificación complementario orientado a definir un conjunto de acciones político administrativas y de planificación con miras a proteger y revitalizar las áreas e inmuebles considerados patrimonio cultural insertos dentro de los sectores definidos como tratamientos urbanísticos de Conservación - C1 (Protección Patrimonial) y C3, (Zonas de influencia de BIC Nacionales), localizados en territorio municipal.

Con los Planes Especiales de Manejo y Protección -PEMP- y la puesta en valor de los bienes inmuebles de valor patrimonial e interés cultural se pretende revitalizar el patrimonio inmueble localizado en la ciudad, como una oportunidad para atender las problemáticas urbanas y contribuir al direccionamiento de la ciudad, como parte estratégica de ella, desde la formulación de medidas y acciones que garanticen la conservación del 
patrimonio articulado con sus entornos y se mejoren las condiciones de sostenibilidad, equidad y la activación de las dinámicas económicas y socio culturales, con el fin de potencializar su valor y conferirles una nueva vida para que se preserven en el tiempo.

A su vez, dentro de este instrumento, se trata de poner en valor estos bienes patrimoniales a través de proyectos urbanos estratégicos para la inclusión de nuevos usos y actividades que permitan rehabitar, resignificar, revitalizar y restituir las dinámicas propias de los sectores de interés patrimonial localizados en el suelo municipal.

Responsable: Departamento Administrativo de Planeación

Indicador de producto

\begin{tabular}{|c|c|}
\hline Nombre & Unidad \\
\hline Planes especiales de manejo y protección patrimonial operando & Porcentaje \\
\hline
\end{tabular}

\subsubsection{Proyecto: Formulación de los protocolos ambientales y urbanísticos -} PAU

Los Protocolos Ambientales y Urbanísticos -PAU- se configuran en el acuerdo 48 de 2014 como un instrumento para viabilizar la localización de algunas actividades económicas que potencialmente generan impactos negativos al uso residencial.

La implementación de los Protocolos Ambientales y Urbanísticos PAU - es el inicio de un ambicioso plan de pedagogía urbana y de cultura ciudadana hacia el respeto del medio ambiente y de los individuos, el cual tendrá que apoyarse en un fortalecimiento de los mecanismos educativos y de control, en las autoridades ambientales, el municipio y demás autoridades en procura del desarrollo del principio de corresponsabilidad ciudadana, como una de las expresiones de la cultura de la legalidad, pilar fundamental del nuevo gobierno municipal.

Responsable: Departamento Administrativo de Planeación

Indicador de producto

\begin{tabular}{|c|c|}
\hline \multicolumn{1}{|c|}{ Nombre } & Unidad \\
\hline Protocolos ambientales y urbanísticos. PAU, formulados & Porcentaje \\
\hline
\end{tabular}

\subsubsection{Proyecto: Desarrollo y actualización de normas y estudios complementarios al POT}

Con la aprobación del acuerdo 48 de 2014, surge la necesidad de desarrollar, actualizar y armonizar la reglamentación complementaria a la luz de los nuevos lineamientos, y las directrices estratégicas y normativas propuestas por el POT para la Ciudad; en este sentido también se hace necesaria la realización de estudios de detalle, tarea que debe abordarse a 
partir de lo definido en el artículo 618 -Reglamentaciones Específicas- del citado Plan, definiendo que la Administración Municipal expedirá la reglamentación específica de las disposiciones previstas en el Acuerdo 48 de 2014.

Responsable: Departamento Administrativo de Planeación

Indicador de producto

\begin{tabular}{|c|c|}
\hline Nombre & Unidad \\
\hline Estudios de la aplicación normativa contenida en el POT, realizados & Porcentaje \\
\hline
\end{tabular}

6.1.1.6 Proyecto: Definición de instrumentos para la gestión articulada del territorio con visión prospectiva estratégica regional

Terminada la vigencia del Plan Estratégico de Medellín y el Área Metropolitana 1997 - 2015 -PEMAM-, y retomando los planteamientos realizados desde la Ley Orgánica de Ordenamiento Territorial 1454 de 2011 y el Plan Nacional de Desarrollo Ley 1753 de 2015, es necesario pensar en la construcción una Visión Compartida de Desarrollo Regional a partir de del análisis de los planes estratégicos subregionales, metropolitano, departamental, nacional y en las nuevas realidades de contexto municipal, regional, nacional e internacional, así como del balance y alcance del PEMAM, que se concrete en nueva Visión Prospectiva Estratégica Regional lo cual permitirá proyectar conjuntamente el desarrollo integral de la región.

Responsable: Departamento Administrativo de Planeación

Indicador de producto

\begin{tabular}{|l|l|}
\hline \multicolumn{1}{|c|}{ Nombre } & \multicolumn{1}{c|}{ Unidad } \\
\hline Acuerdo de voluntades suscrito & Número \\
\hline Mesas regionales y subregionales de formulación participativa realizadas & Número \\
\hline $\begin{array}{l}\text { Lineamientos para la construcción de la visión prospectiva estratégica regional } \\
\text { definidos. }\end{array}$ & Número \\
\hline
\end{tabular}

\subsubsection{PROGRAMA: PLANIFICACIÓN DEL SISTEMA DE GESTIÓN PARA LA EQUIDAD TERRITORIAL}

Lograr el cumplimiento de los compromisos para el corto plazo del POT concernientes al sistema de gestión para la equidad territorial, implica el desarrollo del principio de reparto equitativo de cargas y beneficios, en torno al cual se articularán los instrumentos de planificación, intervención y financiación con criterios de equidad y sostenibilidad. Esto en pro de la superación de los desequilibrios sociales y territoriales, así mismo, promoverá mecanismos de asociación entre propietarios privados o entre éstos y entidades públicas, mediante instrumentos como los macroproyectos, planes parciales, unidades de planificación rural, planes maestros, planes de legalización y regularización urbanística, unidades de actuación urbanística, operadores urbanos, entre otros. 
Con este programa se establecerá la planeación coordinada para el desarrollo de los proyectos e intervenciones estratégicas definidos por el presente plan de desarrollo, adelantando las acciones necesarias para la implementación de los instrumentos ya adoptados y realizando los estudios técnicos requeridos para la consolidación del modelo de ocupación.

Indicadores de resultado

\begin{tabular}{|c|c|c|c|c|}
\hline Nombre & Unidad & $\begin{array}{c}\text { Línea de } \\
\text { Base }\end{array}$ & Meta 2019 & Responsable \\
\hline $\begin{array}{l}\text { Instrumentos } \\
\text { complementarios al POT de } \\
\text { tercer nivel formulados, } \\
\text { adoptados e } \\
\text { implementados }\end{array}$ & Número & 69 & 18 & $\begin{array}{l}\text { Departamento } \\
\text { Administrativo } \\
\text { de Planeación }\end{array}$ \\
\hline $\begin{array}{l}\text { Sistema de Gestión para la } \\
\text { equidad territorial } \\
\text { implementado }\end{array}$ & Porcentaje & 0 & 100 & $\begin{array}{l}\text { Departamento } \\
\text { Administrativo } \\
\text { de Planeación }\end{array}$ \\
\hline
\end{tabular}

\subsubsection{Proyecto: Planificación complementaria para el ordenamiento y desarrollo territorial}

Los instrumentos para la planificación del territorio urbano y rural. bajo el enfoque de equidad social y territorial, los instrumentos complementarios al POT se estructuran en función de promover la igualdad de oportunidades y el acceso a los bienes y servicios del desarrollo territorial para la población del municipio de Medellín, en especial para aquellas personas y hogares con mayor vulnerabilidad social, económica y ambiental.

En tal sentido, la formulación, reglamentación e implementación de los instrumentos de planificación, intervención y financiación para el ordenamiento territorial, buscan además de ordenar el territorio de conformidad al POT, fortalecer el tejido social y el desarrollo integral de la población a partir de mejorar el espacio público, promover la responsable mezcla de usos y actividades económicas, reducir los factores de vulnerabilidad de los asentamientos humanos expuestos a amenazas de origen natural o antrópica, mejorar la cobertura y acceso a los servicios públicos, los equipamientos, la movilidad y el patrimonio construido.

Responsable: Departamento Administrativo de Planeación

Indicador de producto

\begin{tabular}{|l|c|}
\hline \multicolumn{1}{|c|}{ Nombre } & Unidad \\
\hline $\begin{array}{l}\text { Guía metodológica para la formulación de los proyectos urbanos integrales del } \\
\text { ámbito ladera elaborada }\end{array}$ & Porcentaje \\
\hline
\end{tabular}

6.1.2.2. Proyecto: Intervención del suelo en procesos urbanos

Disponer de los diferentes instrumentos que permitirán viabilizar la ejecución de los programas y proyectos del POT, en aplicación del principio equitativo de cargas y beneficios.

Responsable: Departamento Administrativo de Planeación 
Indicador de producto

\begin{tabular}{|c|c|}
\hline \multicolumn{1}{|c|}{ Nombre } & Unidad \\
\hline Intervención del suelo realizadas con los instrumentos definidos & Número \\
\hline
\end{tabular}

6.1.2.3. Proyecto: Instrumentos de financiación del desarrollo físico espacial

Generar el marco normativo local para la obtención de recursos dirigidos a la generación, cualificación y sostenibilidad del sistema físico espacial del POT, mediante el diseño de instrumentos de financiación del PTO.

Responsable: Departamento Administrativo de Planeación

Indicador de producto

\begin{tabular}{|l|c|}
\hline \multicolumn{1}{|c|}{ Nombre } & Unidad \\
\hline Instrumentos de financiación adoptados & Número \\
\hline
\end{tabular}

\subsubsection{PROGRAMA: GESTIÓN DE LA INFORMACIÓN URBANÍSTICA Y CATASTRAL}

Si bien el municipio cuenta con sistema de información georeferenciada para el ordenamiento territorial, entre otras herramientas, es necesario fortalecer lo existente para efectos de poder atender la complejidad sistémica del POT, en términos de su implementación, seguimiento, evaluación y control a la aplicación normativa urbanística.

Lo anterior debido a que la producción y organización de datos responde a intereses o necesidades particulares de cada entidad o dependencia, siendo muy manual el cruce de información digital para generación de datos de varias áreas, a través de programas digitales diferenciales y desarticulados por lo que se requiere generar interfaces para tal fin. Adicionalmente, se requiere incorporar nuevas variables que surgen de la implementación del POT, con miras a la realización de análisis espaciales, entre otros aspectos.

Este programa comprende la construcción de la arquitectura de datos y la respectiva plataforma tecnológica, requerida para la implementación y gestión de los instrumentos, así como el apoyo al seguimiento y evaluación del POT, desde el sistema de gestión para la equidad territorial.

Indicador de resultado

\begin{tabular}{|l|l|l|l|l|}
\hline \multicolumn{1}{|c|}{ Nombre } & \multicolumn{1}{|c|}{ Unidad } & $\begin{array}{c}\text { Línea de } \\
\text { Base }\end{array}$ & \multicolumn{1}{c|}{ Meta 2019 } & \multicolumn{1}{c|}{ Responsable } \\
\hline $\begin{array}{l}\text { Avance de gestión de la } \\
\text { información urbanistica y } \\
\text { catastral }\end{array}$ & Porcentaje & 0 & 100 & $\begin{array}{l}\text { Secretaría de } \\
\text { Gestión y control } \\
\text { territorial }\end{array}$ \\
\hline
\end{tabular}

6.1.3.1. Proyecto: Metodología para el seguimiento de las transformaciones territoriales

Se determinará de manera prioritaria el manejo, almacenamiento de los registros administrativos y demás información que se produce en el marco 
del Sistema de Ordenamiento Territorial y los instrumentos complementarios al POT, para facilitar el monitoreo, seguimiento y evaluación de sus objetivos.

Responsable: Departamento Administrativo de Planeación

Indicador de producto

\begin{tabular}{|l|c|}
\hline \multicolumn{1}{|c|}{ Nombre } & Unidad \\
\hline Plataforma tecnológica diseñada & Porcentaje \\
\hline
\end{tabular}

\subsubsection{Proyecto: Gestión para la información catastral}

Atendiendo a la necesidad de ejercer el seguimiento, monitoreo y control a la implementación del modelo de ocupación del territorio según la norma urbanística vigente, la administración municipal requiere desarrollar mecanismos y soporte tecnológico para cumplir las funciones atribuidas desde el plan de ordenamiento territorial, y el proceso de modernización de la estructura organizacional; lo anterior en materia de inspección, vigilancia y control, liquidación y cumplimiento de las obligaciones urbanísticas.

Responsable: Secretaría de Gestión Territorial

Indicador de producto

\begin{tabular}{|c|c|}
\hline \multicolumn{1}{|c|}{ Nombre } & Unidad \\
\hline Actualización de la Información Catastral & Porcentaje \\
\hline
\end{tabular}

6.1.3.3. Proyecto: Gestión para el control urbanístico y catastral

La gestión del control urbanístico estaría apoyada por diferentes actividades, recursos tecnológicos, logísticos y humanos que cubrirían todos los requerimientos de la comunidad y la administración municipal en el tema del control territorial y las competencias que cada entidad municipal tiene para con el desarrollo del territorio en concordancia con el modelo de ocupación, estrategias y lineamientos de base del Plan de Ordenamiento Territorial.

El control urbanístico estaría enmarcado en el apoyo en el seguimiento a las curadurías urbanas y sus actuaciones, en el otorgamiento de las licencias urbanísticas y los actos de reconocimiento, consecuentes con el respectivo Plan de Ordenamiento Territorial y demás normas complementarias, así como en la verificación del cumplimiento de las obligaciones urbanísticas establecidas en dichas actuaciones y demás gestiones para el efectivo cumplimiento de las mismas.

Fortalecimiento de la capacidad operativa, para la gestión, seguimiento, monitoreo y control a la implementación del modelo de ocupación del territorio, mediante la verificación de la aplicación de las normas urbanísticas por parte de los agentes públicos y privados en la actividad edificadora, para contribuir al desarrollo territorial garante de los derechos individuales y colectivos. 
Así mismo, el generar conciencia en la ciudadanía del control, vigilancia y expansión de la construcción a la luz del POT, promoviendo un crecimiento urbano sostenible con el objetivo de lograr una ciudad compacta y con el máximo aprovechamiento del uso del suelo.

Responsable: Secretaría de Gestión y Control Territorial

Indicador de producto

\begin{tabular}{|l|l|}
\hline \multicolumn{1}{|c|}{ Nombre } & \multicolumn{1}{|c|}{ Unidad } \\
\hline $\begin{array}{l}\text { Quejas atendidas por actuaciones urbanísticas en contravención a lo } \\
\text { establecido en la Ley } 810 \text { de } 2003\end{array}$ & Número \\
\hline Controles urbanísticos realizados & Número \\
\hline
\end{tabular}




\subsection{RETO}

\section{PROYECTOS}

INTEGRALES PARA MEDELLÍN

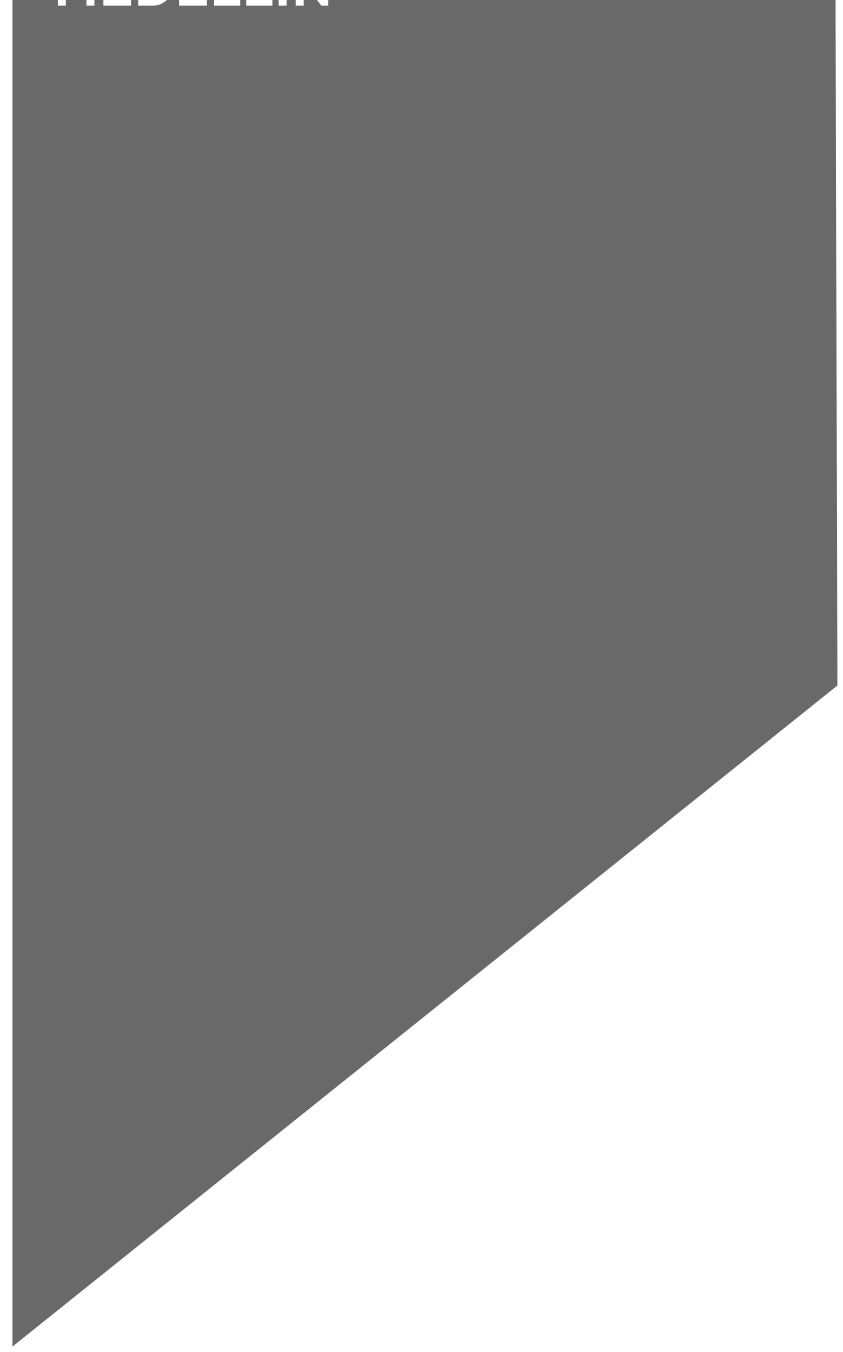

\section{OBJETIVO}

Generar infraestructura necesaria para mejorar la oferta institucional además de mejorar la plataforma urbanística y las condiciones ambientales de la ciudad de manera que impacte positivamente en la comunidad.

\section{PROGRAMAS}

4 6.2.1. Implementación de los instrumentos de planificación adoptados de segundo y tercer nivel del POT

4 6.2.2. Medellín reconoce la importancia de su territorio rural 


\subsection{Proyectos integrales para Medellín}

De acuerdo al POT 2014 los Proyectos Urbanos Integrales (PUI) corresponden al instrumento de planificación complementaria de segundo nivel para el fortalecimiento de los barrios y sus centralidades, que se encuentran por fuera de las Áreas de Intervención Estratégica. Su aplicación busca el direccionamiento de las estrategias e intervenciones dirigidas a fortalecer y mejorar las características de las unidades barriales definidas por la división político-administrativa del Municipio.

No obstante, creemos que la puesta en marcha de tales intervenciones territoriales precisan del fortalecimiento de la infraestructura y la ampliación de la oferta institucional, por lo que este plan se estructura a partir del potenciamiento de la presencia institucional en el territorio, lo que por un lado no solo deba limitarse a la mera presencia de la fuerza pública, y por otro, no solo se reduzca a proyectos asistencialistas o de atención inmediata, sino que realmente pueda constituir una oportunidad de llevar al territorio todo el entramado de apuestas de ciudad que permiten garantizar los derechos fundamentales a la salud, a la educación, al hábitat, a los servicios públicos de calidad, lo que finalmente se complementa con la inversión en infraestructura para la movilidad y la ocupación efectiva del espacio público, llevando a los territorios hacia caminos más eficaces y orientados a una transformación integral de la ciudad

Indicadores de resultado

\begin{tabular}{|l|l|l|l|l|}
\hline \multicolumn{1}{|c|}{ Nombre } & \multicolumn{1}{|c|}{ Unidad } & \multicolumn{1}{c|}{$\begin{array}{c}\text { Línea de } \\
\text { Base }\end{array}$} & \multicolumn{1}{|c|}{ Meta 2019 } & \multicolumn{1}{|c|}{ Responsable } \\
\hline $\begin{array}{l}\text { Satisfacción de los usuarios } \\
\text { de los servicios o la oferta } \\
\text { de los proyectos urbanos } \\
\text { integrales (PUI) }\end{array}$ & Porcentaje & 80 & $\begin{array}{l}\text { Departamento } \\
\text { Administrativo } \\
\text { de Planeación }\end{array}$ \\
\hline $\begin{array}{l}\text { Avance en la ejecución de } \\
\text { Proyectos integrales }\end{array}$ & Porcentaje & 0 & 100 & $\begin{array}{l}\text { Secretaría de } \\
\text { Infraestructura } \\
\text { Física }\end{array}$ \\
\hline
\end{tabular}

\subsubsection{PROGRAMA: IMPLEMENTACIÓN DE LOS INSTRUMENTOS DE PLANIFICACIÓN ADOPTADOS DE SEGUNDO Y TERCER NIVEL DEL POT}

El programa pretende desarrollar el modelo de ocupación previsto desde el Plan de Ordenamiento Territorial mediante una intervención en diferentes componentes como son: movilidad, espacio público, vivienda, equipamientos complementarios e intervención ambiental; así como proporcionar nuevas condiciones urbanas que incentiven la competitividad.

En conclusión, con el fin de acompañar y apoyar el desarrollo, consolidación y estructuración del modelo de ciudad a partir de ejercicios de participación e inclusión de actores sociales, públicos y privados que aporten a un 
desarrollo sostenible, sustentable y equitativo, el DAP debe adelantar estratégicas y acciones encaminadas a acompañar y facilitar la gestión social, ambiental e inmobiliaria de instrumentos como los Macroproyectos, Planes Parciales, Planes Maestros, Planes de legalización y regularización urbanística, Planes Especiales de Manejo y Protección del Patrimonio, entre otros; identificar las tendencias y procesos de cambio en el contexto regional, nacional e internacional que inciden o determinan las condiciones de desarrollo y gestión de dichos instrumentos; desarrollar iniciativas de innovación económica, social, cultural, financieras para la mitigación de los impactos derivados de la ejecución de estos instrumentos de planificación. La implementación de los instrumentos de planificación adoptados se debe realizar a través de un equipo de trabajo especializado y con profesionales calificados y con amplia experiencia en procesos de gestión urbana, inmobiliaria, ambiental y social, quienes acompañaran la implementación de las diferentes dimensiones del desarrollo presentes en cada uno de los instrumentos.

Se basa en el acompañamiento técnico de las acciones orientadas a la ejecución de la operación urbana de gran escala realizar a través de los Macroproyectos de Borde y Transversalidades, garantizando el cumplimiento normativo y los objetivos del Plan de Ordenamiento Territorial de Medellín.

Indicador de resultado

\begin{tabular}{|c|c|c|c|c|}
\hline Nombre & Unidad & $\begin{array}{c}\text { Línea de } \\
\text { Base }\end{array}$ & Meta 2019 & Responsable \\
\hline $\begin{array}{l}\text { Instrumentos de } \\
\text { planificación } \\
\text { complementaria al POT de } \\
\text { segundo nivel formulados y } \\
\text { adoptados }\end{array}$ & Número & 3 & 2 & $\begin{array}{l}\text { Departamento } \\
\text { Administrativo } \\
\text { de Planeación }\end{array}$ \\
\hline $\begin{array}{l}\text { Instrumentos } \\
\text { complementarios al POT de } \\
\text { tercer nivel formulados, } \\
\text { adoptados } \\
\text { implementados }\end{array}$ & Número & 69 & 18 & $\begin{array}{l}\text { Departamento } \\
\text { Administrativo } \\
\text { de Planeación }\end{array}$ \\
\hline
\end{tabular}

6.2.1.1. Proyecto: Viabilidad para la generación del espacio público y el hábitat en las áreas de intervención estratégica

Una vez culminada la formulación de los Macroproyectos y de gestionados los recursos para su ejecución, los proyectos de ciudad planteados por el modelo de ocupación propuesto para las transversalidades, requieren de la viabilización y/o aprobación de los proyectos estratégicos formulados, para lo cual es necesario el apoyo técnico de personal especializado e idóneo que apoyo al equipo técnico del municipio en este proceso, esto teniendo en cuenta que las Áreas de las Transversalidades son zonas con altas complejidades y deficiencias, que requieren de un análisis detallado para su viabilización.

Responsable: Departamento Administrativo de Planeación 
Indicador de producto

\begin{tabular}{|l|c|}
\hline \multicolumn{1}{|c|}{ Nombre } & Unidad \\
\hline $\begin{array}{l}\text { Viabilidad y apoyo a los proyectos del plan de Desarrollo } \\
\text { Proyectos Viabilizados del Plan de desarrollo }\end{array}$ & Porcentaje \\
\hline
\end{tabular}

6.2.1.2. Proyecto: Macroproyectos Río Norte, Centro y Sur; Planes Parciales: Naranjal, Sevilla, Pajarito

Este proyecto busca implementar integralmente los macroproyectos del río, lo anterior con el fin de generar y/o mejorar integralmente los sistemas públicos y colectivos, cualificar los barrios y propiciar la renovación urbana. Cabe anotar que la implementación de los macros implica también la implementación de los Planes Parciales: Naranjal, Sevilla, Pajarito.

Responsable: Departamento Administrativo de Planeación

Indicador de producto

\begin{tabular}{|c|c|}
\hline Nombre & Unidad \\
\hline Macroproyectos MEDRío implementados y ejecutados en el corto plazo del POT & Porcentaje \\
\hline
\end{tabular}

6.2.1.3. Proyecto: Viabilización y/o aprobación de los proyectos urbanos integrales Ámbito Ladera

Los Proyectos Urbanos Integrales tienen como objetivo implementar un modelo de intervención teniendo en cuenta lo social, lo físico y la coordinación interinstitucional para resolver problemáticas específicos sobre un territorio definido, mejorando el espacio público, el medio ambiente, los edificios públicos, la movilidad, fortaleciendo la participación comunitaria y la convivencia.

Responsable: Departamento Administrativo de Planeación Indicador de producto

\begin{tabular}{|c|c|}
\hline \multicolumn{1}{|c|}{ Nombre } & Unidad \\
\hline Viabilidad y apoyo a los proyectos urbanos integrales Ámbito Ladera & Fases \\
\hline
\end{tabular}

\subsubsection{Proyecto: Estrategía de proyectos urbanos integrales}

Intervención de tipo espacial y de mejoramiento y de creación de espacio público de alta calidad y con equipamiento urbano. Intervenciones de tipo social e institucional.

En este proyecto se debe desarrollar los componentes para la definición del PUI: el componente físico, el componente social y el componente institucional; y además implementar las fases de desarrollo del mismo: Fase de Planificación, diagnósticos y formulación, desarrollo del proyecto y entrega del PUI para las comunas de Laureles - La América de las obras modélicas.

Responsable: Secretaría de infraestructura

Indicador de producto

\begin{tabular}{|c|c|}
\hline \multicolumn{1}{|c|}{ Nombre } & Unidad \\
\hline Formulación y ejecución de los proyectos urbanos integrales & Fases \\
\hline
\end{tabular}


6.2.1.5. Proyecto: Terminación de la primera etapa Parques del río, iniciar la construcción primera etapa Parques del río tramo 1,1-B y sus obras complementarias

Terminación de la primera etapa Parques del río tramo 1-A, iniciar la construcción primera etapa parques del rio Tramo 1,1-B y sus obras complementarias. A través de este proyecto se piensa realizar la promoción de Alianza Público Privada para Operación Parques del Río.

Indicador de producto

Responsable: Secretaría de Infraestructura Física

\begin{tabular}{|c|c|}
\hline \multicolumn{1}{|c|}{ Nombre } & Unidad \\
\hline Parques del Río Medellín construido primera Etapa & Porcentaje \\
\hline
\end{tabular}

\subsubsection{PROGRAMA: Medellín reconoce la importancia de su territorio rural}

La ciudad de Medellín tiene cinco corregimientos que constituyen el $71 \%$ del territorio municipal: San Antonio de Prado, San Cristóbal, Santa Elena, Altavista y San Sebastián de Palmitas; la población total de los corregimientos es de 249.126 habitantes (DANE, 2015). Por otro lado, el estudio de calidad de vida para Medellín (2014), muestra que el promedio para las comunas es de $48.79 \%$ y para los corregimientos es de $40.96 \%$, lo cual muestra una intervención desigual entre los territorios rural y urbano.

Los corregimientos, como frontera entre lo urbano y lo rural, representan una zona clave para la seguridad de la ciudad. Son territorios presionados por la ocupación legal e ilegal, tanto para el occidente (San Cristóbal, Altavista y San Antonio de Prado), como para el oriente (Santa Elena). Presentan problemas como la presencia de actores armados, falta de cohesión y conectividad territorial, una alta presión urbana por ocupar los territorios rurales y degradación ambiental (POT, 2014).

Nuestros corregimientos han tenido un alto crecimiento en los últimos años y por ello se plantea la necesidad de crear más espacios que permitan la integración y la convivencia de sus comunidades, a través de instrumentos de intervención urbana que abarquen aspectos físicos, sociales e institucionales de un territorio.

Indicadores de resultados

\begin{tabular}{|l|l|l|l|l|}
\hline Nombre & \multicolumn{1}{|c|}{ Unidad } & \multicolumn{1}{|c|}{$\begin{array}{c}\text { Línea de } \\
\text { Base }\end{array}$} & Meta 2019 & Responsable \\
\hline $\begin{array}{l}\text { Indice de riesgo de la } \\
\text { calidad del agua para } \\
\text { consumo humano - IRCA - } \\
\text { Zona Rural Nucleada }\end{array}$ & Porcentaje & 2,80 & 2,80 & $\begin{array}{l}\text { Secretaría } \\
\text { Salud }\end{array}$ \\
\hline $\begin{array}{l}\text { Indice Multidimensional de } \\
\text { Condiciones de Vida en los } \\
\text { corregimientos }\end{array}$ & Número & 40,92 & 42,1 & $\begin{array}{l}\text { Departamento } \\
\text { Administrativo } \\
\text { de Planeación }\end{array}$ \\
\hline
\end{tabular}


6.2.3.1. Proyecto: Diagnóstico, formulación y ejecución PUI corregimentales

1.1. 6.2.3.2. Proyecto: Asignación y revisión de nomenclatura

6.2.3.3. Proyecto: Fortalecer la presencia institucional en seguridad

6.2.3.4. Proyecto: Equipamientos estratégicos comunitarios

6.2.3.5. Proyecto: Mi corregimiento limpio 


\subsection{RETO:}

GESTIÓN DEL PAISAJE, EL PATRIMONIO Y LOS BIENES INMUEBLES

\section{PROGRAMAS}

4 6.3.1. Recuperemos nuestro patrimonio y paisaje

4 6.3.2. Generando Valor Inmobiliario

\section{OBJETIVO}

Promover el mantenimiento y cuidado colectivo del espacio público y los bienes dispuestos para la comunidad 


\subsection{Gestión del paisaje, el patrimonio y los bienes inmuebles}

De acuerdo a la encuesta de percepción de Medellín Cómo Vamos la ciudad presenta un déficit de espacio público, pues cuenta con 3.5 metros cuadrados de espacio público efectivo por habitante y 1,7metros cuadrados de espacio peatonal, contrastado con los 15 metros cuadrados recomendados por la Política Nacional de Espacio Público y los $10 \mathrm{~m} 2$ sugeridos por la Organización Mundial de la Salud.

Es de resaltar que todo estos presupuestos normativos y orientaciones estratégicas corresponden con los ODS que se señalan líneas arriba, ya que de la intervención y del acompañamiento institucional es posible lograr que las ciudades y sus asentamientos humanos urbanos y rurales contribuyan a reducir las brechas de desigualdad y de pobreza, en la medida en que el ejercicio de planeación del paisaje y del espacio público contribuya efectivamente a la generación de procesos de transformación territorial más inclusivos, seguros y sostenibles.

Sin embargo, una mirada a la realidad más inmediata de nuestra ciudad nos demuestra que el espacio público y su relación directa con el crecimiento poblacional han registrado algunos desniveles que precisan de la intervención estatal y del desarrollo de procesos territoriales dirigidos a la gestión y distribución del espacio por habitante, sobre todo en las áreas peatonales, donde se registra un constante decrecimiento desde el año 2011.

Gráfico 19: Espacio Público efectivo por habitante y peatonal por habitante, 2008 - 2014

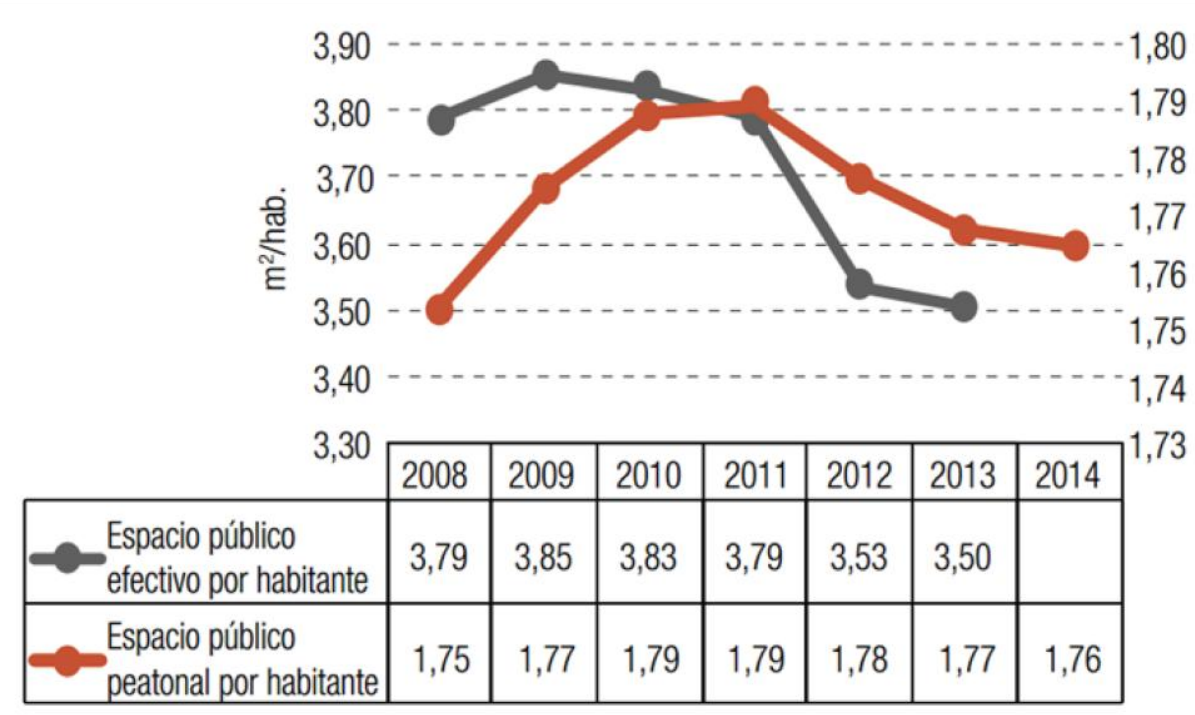

Medellín Cómo Vamos, 2015 
La encuesta incluye también la satisfacción de la ciudadanía con el espacio público, que obtuvo una calificación promedio de 3,3 sobre 5 , inferior a la calificación de 2013 que fue de 3,6 sobre 5. En efecto, desde el 2011 la calificación promedio al espacio público de la ciudad ha venido cayendo gradualmente.

Gráfico 20 Satisfacción con el espacio público en la ciudad, 2009 - 2014

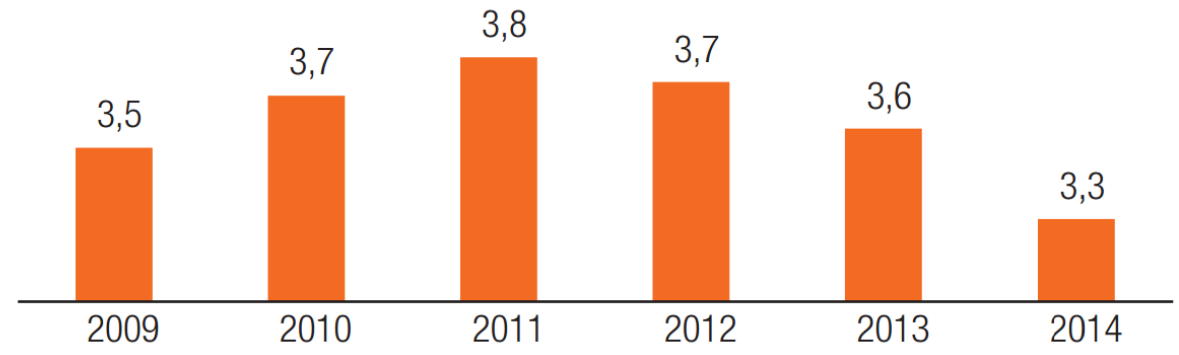

Fuente: Medellín Cómo Vamos, 2015

Una de las estrategias para atender esta situación propuesta por el POT es el diseño y construcción de Ecoparques. Se definió un total de 27 Ecoparques y actualmente hacen parte de este sistema 6 corredores ecológicos de quebrada y 5 parques lineales. Adicionalmente, se cuenta con el diseño y consolidación de redes ecológicas mediante el Acuerdo 41 de 2015; el AMVA ha definido 43 redes ecológicas para Medellín asociadas a diferentes sistemas urbanos: quebradas, parques, andenes, separadores viales, etc. Estos sistemas han sido históricamente degradados, debido especialmente a la conurbación del Valle de Aburrá. Desde el año 2012, la Secretaría de Medio Ambiente ha intervenido 12 redes ecológicas con acciones de mantenimiento y resiembra pero no se ha realizado ampliación de áreas verdes. Mediante el Acuerdo 47 de 2015 se definió la caracterización y fortalecimiento de la estructura ecológica urbana. Sin embargo, actualmente no existe un diagnóstico del estado real de las zonas verdes de la ciudad que incluya un inventario real y detallado.

Por otra parte, y en lo referente a bienes inmuebles, a continuación se relaciona la cantidad existente en la administración:

Tabla 2: Bienes inmuebles

\begin{tabular}{|l|l|}
\hline Bienes Fiscales & 4.000 \\
\hline Bienes de Uso Público & 33.000 \\
\hline Total & 37.000 \\
\hline
\end{tabular}

Fuente: Documento diagnóstico de la Subdirección Administración de Bienes - Subsecretaría de Logística y Administración de bienes - Secretaría de Servicios Administrativos. Año 2013

Existe una problemática en la administración de los bienes inmuebles basada en los siguientes aspectos: 
Deficiencia de recursos financieros y logísticos para desempeñar todas las acciones administrativas, técnicas, jurídicas y contables que competen a la administración, conservación, inventario, aseguramiento, mantenimiento y operación de los todos los bienes inmuebles.

No se han generado recursos económicos con los bienes inmuebles que sean suficientes para el mantenimiento y sostenibilidad de los mismos; por esto se ha presentado un déficit económico.

Adicionalmente, todavía no se han reglamentado e implementado en su totalidad los instrumentos de financiación del POT que permitan administrar, operar y mantener los bienes inmuebles.

Estos temas han comenzado a ser abordados por la recientemente creada Agencia para la Gestión del Paisaje, el Patrimonio y las Alianzas Público Privadas, la cual está en proceso de consolidación en su esquema organizacional y definición de funciones, objetivos, programas y proyectos.

A continuación se describe el indicador de resultado que evaluará este reto: Indicador de resultado

\begin{tabular}{|l|l|l|l|l|}
\hline \multicolumn{1}{|c|}{ Nombre } & \multicolumn{1}{|c|}{ Unidad } & \multicolumn{1}{c|}{$\begin{array}{c}\text { Línea de } \\
\text { Base }\end{array}$} & \multicolumn{1}{c|}{ Meta 2019 } & \multicolumn{1}{c|}{ Responsable } \\
\hline $\begin{array}{l}\text { Espacio público efectivo } \\
\text { por habitante }\end{array}$ & $\begin{array}{l}\text { Metros Cuadrados por } \\
\text { habitante }\end{array}$ & 3,57 & 3,6 & $\begin{array}{l}\text { Secretaría de } \\
\text { Infraestructura } \\
\text { Física }\end{array}$ \\
\hline
\end{tabular}

\subsubsection{PROGRAMA: RECUPEREMOS NUESTRO PATRIMONIO Y PAISAJE}

Busca la revitalización socioeconómica y cultural de las áreas urbanas de la ciudad, a través de la gestión, la administración, la cualificación e implementación de estrategias de sostenibilidad del espacio público, el paisaje y el patrimonio.

Indicador de resultado

\begin{tabular}{|l|l|l|l|l|}
\hline \multicolumn{1}{|c|}{ Nombre } & Unidad & $\begin{array}{c}\text { Línea de } \\
\text { Base }\end{array}$ & Meta 2019 & \multicolumn{1}{c|}{ Responsable } \\
\hline $\begin{array}{l}\text { Áreas de espacio público } \\
\text { patrimoniales } \\
\begin{array}{l}\text { intervenidas } \\
\text { restauradas }\end{array}\end{array}$ & Metros Cuadrados & N/D & 222871 & $\begin{array}{l}\text { Agencia para la } \\
\text { gestión paisaje, del } \\
\text { patrimonio, y } \\
\text { papP }\end{array}$ \\
\hline
\end{tabular}

\subsubsection{Proyecto: Proyectos de borde}

Se busca garantizar el fortalecimiento institucional para la administración, cualificación y sostenibilidad del paisaje urbano y el patrimonio de la ciudad; áreas y corredores de revitalización estratégica y económica; revitalización estratégica de nuestro patrimonio; gestión de la publicidad en espacio 
público; paisajismo y silvicultura, espacios públicos verdes y mantenimiento de zonas verdes.

Responsable: Secretaría de Infraestructura Física

Indicador de producto

\begin{tabular}{|c|c|}
\hline 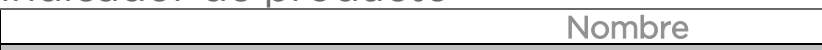 & Unidad \\
\hline Espacio público nuevo generado en el cinturón verde & $\begin{array}{l}\text { Metros } \\
\text { Cuadra }\end{array}$ \\
\hline
\end{tabular}

6.3.1.2 Proyecto: Fortalecimiento institucional para la administración, cualificación y sostenibilidad del paisaje urbano y el patrimonio de la ciudad

Creación de instrumentos normativos e insumos complementarios para la administración, cualificación y sostenibilidad del paisaje urbano y el patrimonio.

Creación y actualización de la plataforma tecnológica y de la respectiva Geo Data base, para la gestión y administración del aprovechamiento económico del espacio público del Municipio de Medellín. Creación de instrumentos normativos e insumos complementarios para la administración, cualificación y sostenibilidad del paisaje urbano y el patrimonio.

Incluye el subproyecto 'Ciudad y campo a la vez' como la estrategia de Fortalecimiento institucional para la administración, cualificación y sostenibilidad del paisaje urbano y el patrimonio de la ciudad para los corregimientos.

Responsable: Agencia para la gestión del paisaje

Indicador de producto

$$
\text { y patrimonio y APP }
$$

\begin{tabular}{|l|l|}
\hline \multicolumn{1}{|c|}{ Nombre } & \multicolumn{1}{|c|}{ Unidad } \\
\hline $\begin{array}{l}\text { Instrumento financiero Aprovechamiento Económico del Espacio Público } \\
\text { implementado }\end{array}$ & Porcentaje \\
\hline
\end{tabular}

6.3.1.3 Proyecto: Áreas y corredores de revitalización estratégica y
económica Estrategia para la revitalización socioeconómica y cultural de una determinada área urbana, a través de la creación y coordinación de alianzas generadas entre privados y dinamizadas por comerciantes del sector, con recaudados destinados a servicios suplementarios que mejoren la zona.

Responsable: Agencia para la gestión del paisaje

Indicador de producto y patrimonio y APP

\begin{tabular}{|l|l|}
\hline \multicolumn{1}{|c|}{ Nombre } & \multicolumn{1}{|c|}{ Unidad } \\
\hline Áreas de fachadas de paisaje urbano intervenidas & $\begin{array}{l}\text { Metros } \\
\text { Cuadrados }\end{array}$ \\
\hline $\begin{array}{l}\text { Espacios públicos intervenidos en Áreas y Corredores de Revitalización } \\
\text { Estratégica y Económica }\end{array}$ & $\begin{array}{l}\text { Metros } \\
\text { Cuadrados }\end{array}$ \\
\hline
\end{tabular}


6.3.1.4Proyecto: Revitalización estratégica de nuestro patrimonio Modelo de gestión socioeconómica, cultural y financiera como estrategia para obtener y gestionar recursos económicos aprovechando los instrumentos de financiación establecidos por el POT y generando nuevos modelos de revitalización, inversión de capital y demás esquemas que permitan la activación económica de los sectores y por ende se garantice la conservación del patrimonio cultural.

Incluye el subproyecto de rehabilitar nuestros corregimientos con la intervención, recuperación, señalización y promoción del patrimonio corregimental.

Responsable: Agencia para la gestión del paisaje y patrimonio y APP

Indicador de producto

\begin{tabular}{|l|l|}
\hline \multicolumn{1}{|c|}{ Nombre } & \multicolumn{1}{|c|}{ Unidad } \\
\hline Áreas de interés patrimonial restauradas & Metros \\
Cuadrados
\end{tabular}

6.3.1.5 Proyecto: Gestión de la publicidad

Dimensionar y potencializar equilibradamente la publicidad en el espacio público y los bienes inmuebles fiscales como parte del instrumento del aprovechamiento económico que permitirá incorporar recursos para la cualificación, sostenibilidad y mantenimiento de los mismos.

Responsable: Agencia para la gestión del paisaje y patrimonio y APP

Indicador de producto

\begin{tabular}{|c|c|}
\hline Nombre & Unidad \\
\hline Aprovechamiento Económico de la Publicidad implementado & Porcentaje \\
\hline
\end{tabular}

\subsubsection{Proyecto: Paisajismo y silvicultura espacios públicos verdes}

Pretende fortalecer los elementos de la estructura ecológica principal 1. urbana y rural mediante el mantenimiento y el incremento de acciones de manejo forestal que provean el mejor diseño paisajístico en concordancia con la función ambiental de estos espacios.

Responsable: Secretaría de Infraestructura Física

Indicador de producto

\begin{tabular}{|c|c|}
\hline \multicolumn{1}{|c|}{ Nombre } & \multicolumn{1}{c|}{ Unidad } \\
\hline Paisajismo y silvicultura espacios públicos verdes intervenidos & $\begin{array}{l}\text { Metros } \\
\text { Cuadrados }\end{array}$ \\
\hline
\end{tabular}




\subsubsection{PROGRAMA: GENERANDO VALOR INMOBILIARIO}

Gestionar eficientemente los bienes inmuebles propiedad del Municipio de Medellín como elementos fundamentales del sistema público y colectivo, para obtener valor económico y social que permita la generación de recursos destinados a la cualificación, sostenibilidad y mantenimiento de los mismos, a través de la formulación, dirección, ejecución y control de planes, programas y proyectos de tipo inmobiliario.

Indicador de resultado

\begin{tabular}{|c|c|c|c|c|}
\hline Nombre & Unidad & $\begin{array}{c}\text { Línea de } \\
\text { Base }\end{array}$ & Meta 2019 & Responsable \\
\hline $\begin{array}{l}\text { Áreas de espacio público } \\
\text { y patrimoniales } \\
\text { intervenidas } \\
\text { restauradas }\end{array}$ & Metros Cuadrados & N/D & 222871 & $\begin{array}{ll}\text { Agencia para la } \\
\text { gestión, } & \text { e } \\
\text { paisaje } & \text { y } \\
\text { patrimonio } & \text { y } \\
\text { APP } & \end{array}$ \\
\hline
\end{tabular}

6.3.2.1 Proyecto: Fortalecimiento institucional para la administración, aprovechamiento, cualificación y sostenibilidad de los bienes inmuebles

Gestión y administración para el aprovechamiento económico del espacio público del Municipio de Medellín. Creación de instrumentos normativos e insumos complementarios para la Administración, cualificación y sostenibilidad del paisaje urbano y el patrimonio.

Responsable: Agencia para la gestión del paisaje y patrimonio y APP

Indicador de producto

\begin{tabular}{|l|l|}
\hline \multicolumn{1}{|c|}{ Nombre } & Unidad \\
\hline $\begin{array}{l}\text { Bienes Inmuebles del Municipio de Medellín Aprovechados Económicamente por } \\
\text { venta O arriendo }\end{array}$ & Número \\
\hline
\end{tabular}

6.3.2.2 Impulsando el desarrollo a través de estrategias inmobiliarias Estrategia para la revitalización socioeconómica y cultural de una determinada área urbana, a través de la creación y coordinación de alianzas generadas entre privados y dinamizadas por comerciantes del sector, con recaudados destinados a servicios suplementarios que mejoren la zona.

Indicador de producto

Responsable: Agencia para la gestión del paisaje y patrimonio y APP

\begin{tabular}{|l|c|}
\hline \multicolumn{1}{|c|}{ Nombre } & Unidad \\
\hline Proyectos Inmobiliario Promovido en complejos barriales & Número \\
\hline Proyectos Inmobiliario Promovido en lotes remanentes & Número \\
\hline
\end{tabular}




\subsection{RETO}

MEDELLIIN VUELVE A SU CENTRO

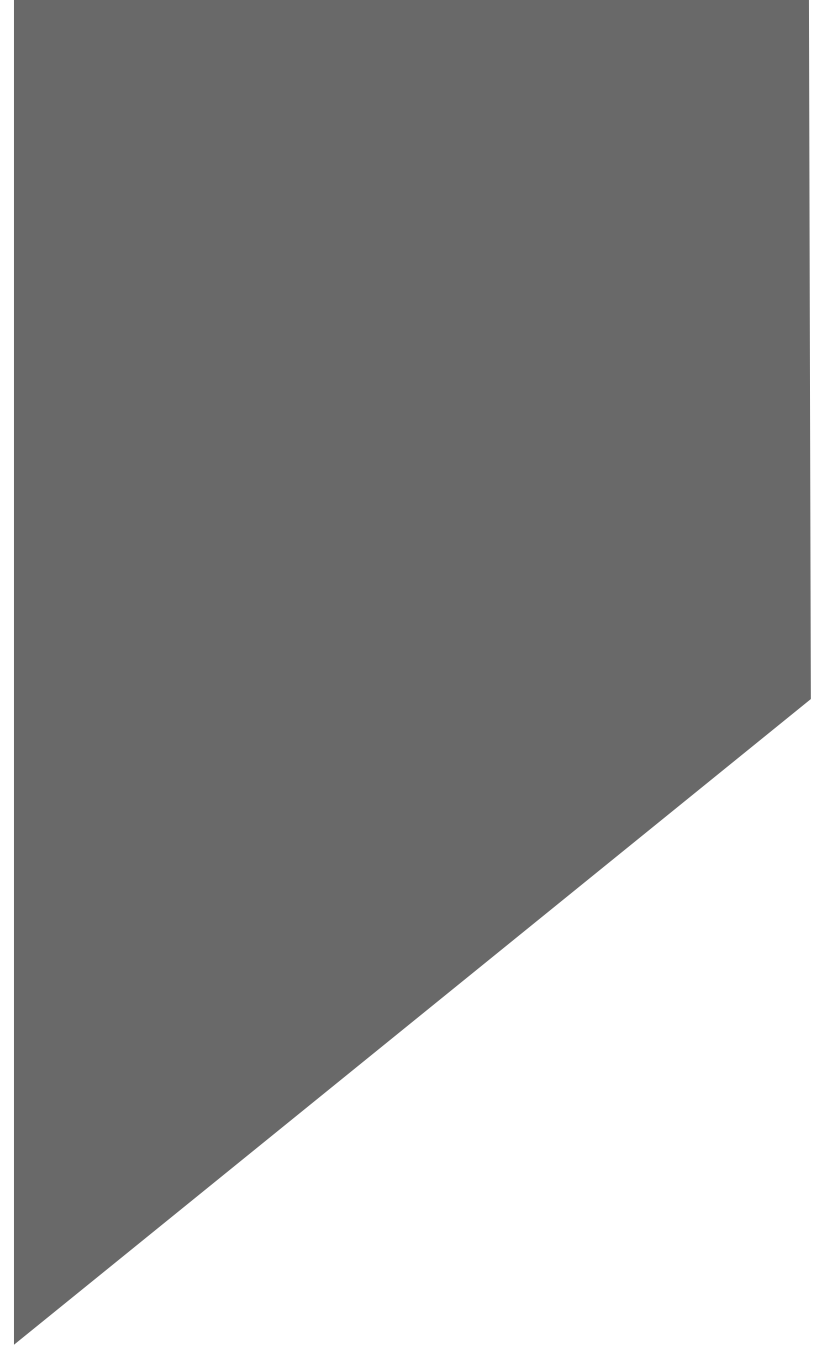

OBJETIVO

Rehabilitar las condiciones del centro de la ciudad para que las personas lo rehabiten y hagan un uso sano de los espacios de los que dispone.

\section{PROGRAMAS}

6.4.1. Rehabitar el centro

4

4 6.4.2. Conectividad y nueva movilidad

4 6.4.3. Aprovechamiento del espacio público y patrimonio cultural

4 6.4.4.Presencia institucional y gobernabilidad

\section{y}




\subsection{Medellín vuelve a su centro}

Según proyecciones del Departamento Administrativo Nacional de Estadística (DANE, 2015)) en el Centro Metropolitano o centro ampliado habita el $6 \%$ del total de la población de Medellín, es decir 149.227 habitantes y en el centro tradicional la población residente es de 85.221 habitantes. No obstante, aproximadamente 1.200 .000 personas transitan a diario por el centro (población flotante); de 3.250 habitantes de calle de la ciudad de Medellín, alrededor de 2.000 realizan sus actividades en el centro. En la ciudad existen 11.000 venteros informales regulados, de los cuales 5.500 se encuentran en el centro; de estos, 2.000 están ubicados en los centros comerciales populares (Subsecretaría de Espacio Público, 2015).

Queremos recuperar de manera integral el Centro, en tanto esta zona de la ciudad lidera los índices de criminalidad. Durante el 2015 la tasa de homicidios alcanzó una cifra de 106 muertes por cada 100 mil habitantes, frente a la tasa registrada para toda la ciudad que fue de 20 por cada 100 mil, es decir, 5 veces el valor total de la ciudad; situación similar se evidencia en otros delitos como el hurto y el número de extorsiones los cuales alcanzaron las cifras más altas de la ciudad. El hurto a personas registró un total de 3.224 casos, casi la mitad del total de la ciudad que fue de 7.530 casos. En este contexto es posible evidenciar por qué solo el $37 \%$ de los habitantes de esta comuna manifestaron sentirse seguros en la última Encuesta de Seguridad, Victimización y Convivencia realizada en 2015

En el centro de Medellín se ubican diversas instituciones públicas y privadas, además cuenta con 29 parques y plazoletas y otros equipamientos urbanos como el edificio de la Plaza de la Libertad, Plaza Mayor e infraestructuras públicas como Ruta N. No obstante, se presenta una ocupación indebida del espacio público por ventas informales (regulados y no regulados), comercio formal con extensión de negocio, carretillas y perifoneo, contaminación por publicidad exterior y altos índices de indigencia. Así mismo es evidente el deterioro del espacio público, la infraestructura, el mobiliario e iluminación de parques y espacios públicos, así como la inadecuada disposición de residuos. Por eso propendemos por una reactivación del espacio público a partir de una adecuación de sus parques y el patrimonio que allí coexiste

Recuperar el centro constituye una de las prioridades de este plan, en tanto la alta circulación de personas y el crecimiento clima de inseguridad requieren acciones interinstitucionales que permitan una reocupación del espacio público y una alternativa para la incidencia de la oferta institucional dirigidas a contrarrestar los fenómenos de delincuencia, drogadicción y la indebida ocupación del espacio, además de brindar a la ciudadanía un lugar de encuentro para el goce y el disfrute de las actividades que desde allí se deben generar, pues creemos que la transformación del centro de la ciudad requiere de importantes esfuerzos en materia de seguridad, cultura, infraestructura y fomento de la cultura ciudadana y del compromiso de 
todos los habitantes para su apropiación y empoderamiento ciudadano de este complejo territorio

A continuación se describe el indicador de resultado que se evaluará en este reto:

Indicador de resultado

\begin{tabular}{|l|l|l|l|l|}
\hline Nombre & Unidad & $\begin{array}{l}\text { Línea de } \\
\text { Base }\end{array}$ & Meta 2019 & Responsable \\
\hline $\begin{array}{l}\text { Percepción ciudadana de } \\
\text { recuperación del centro }\end{array}$ & Porcentaje & 0 & 60 & Seguridad \\
\hline
\end{tabular}

\subsubsection{PROGRAMA: REHABITAR EL CENTRO}

Como una de las estrategias establecidas en el Plan del Centro, se establece la recuperación, cualificación y sostenibilidad de los diferentes elementos que componen el paisaje y el patrimonio, en una de las Áreas de Intervención Estratégicas de MEDRIO Macroproyecto Rio Centro sub zona Centro Tradicional.

Desarrollar el Plan de Intervención del Centro de Medellín como Proyecto Urbano Integral Especial para el Centro de la ciudad., como plan de recuperación del centro de la ciudad. Es un instrumento de gestión pública que debe hacer efectiva e integral la acción y presencia institucional de la administración en el centro de Medellín.

Indicador de resultado

\begin{tabular}{|l|l|l|l|l|}
\hline \multicolumn{1}{|c|}{ Nombre } & \multicolumn{1}{c|}{ Unidad } & $\begin{array}{c}\text { Línea de } \\
\text { Base }\end{array}$ & Meta 2019 & \multicolumn{1}{c|}{ Responsable } \\
\hline $\begin{array}{l}\text { Espacio público } \\
\text { generado en el centro }\end{array}$ & Metros cuadrados & PD & PD & $\begin{array}{l}\text { GERENCIA } \\
\text { CENTRO }\end{array}$ \\
\hline
\end{tabular}

6.4.1.1. Proyecto: Ocupación de inmuebles públicos y privados para llevar la institucionalidad 6.4.1.2 Proyecto: Plan de cultural en el centro

\subsubsection{PROGRAMA: CONECTIVIDAD Y NUEVA MOVILIDAD}

El centro es el corazón de Medellín, un sitio tradicional y emblemático con una gran historia. El desarrollo de la ciudad hacia nuevos espacios, la falta de mantenimiento y la falta de directrices clara para conservar y mantener el centro tradicional durante el pasado, han llevado a este hermoso sitio a un avanzado estado de deterioro de sus espacios públicos y lugares de encuentro. Es un compromiso de esta administración la recuperación integral del centro, rehabilitando y recuperando los espacios públicos existentes y con la generación de muchos más, en la búsqueda de un centro seguro, agradable y atractivo para sus habitantes. 
Indicador de resultado

\begin{tabular}{|l|l|l|l|l|}
\hline \multicolumn{1}{|c|}{ Nombre } & \multicolumn{1}{|c|}{ Unidad } & $\begin{array}{c}\text { Línea de } \\
\text { Base }\end{array}$ & Meta 2019 & Responsable \\
\hline $\begin{array}{l}\text { Espacio público } \\
\text { recuperados y } \\
\text { rehabilitados }\end{array}$ & Metros cuadrados & PD & PD & $\begin{array}{l}\text { GERENCIA } \\
\text { CENTRO }\end{array}$ \\
\hline $\begin{array}{l}\text { Percepción aceptable } \\
\text { del estado de andenes } \\
\text { y separadores de calle } \\
\text { en la Comuna 10 }\end{array}$ & Porcentaje & 88,78 & 90,38 & $\begin{array}{l}\text { Departamento } \\
\text { Administrativo } \\
\text { de Planeación }\end{array}$ \\
\hline
\end{tabular}

6.4.1.2 Proyecto: Estructuración y formulación para recuperar corredores importantes

6.4.1.3 Proyecto: Estructuración y formulación del centro tradicional con el barrio Prado

6.4.1.4 Proyecto: Recuperación integral de andenes y espacio público

6.4.1.5 Proyecto: Galería Bolívar

6.4.1.6 Proyecto: Corredor Córdoba

6.4.1.7 Proyecto: Ruta para vos - Conectividad corredores en el centro tradicional - Peatonalización de vías

\subsubsection{PROGRAMA: Aprovechamiento del espacio público y patrimonio cultural}

Mejoramiento y recuperación de las condiciones peatonales y de espacios públicos del centro de la ciudad y de su patrimonio cultural, buscando el mejoramiento de la calidad de vida de sus habitantes, del espacio público, de las condiciones físicas en las edificaciones existentes, de la movilidad urbana, de las actividades culturales, sociales y comerciales, y de las condiciones de habitación.

Indicador de resultado

\begin{tabular}{|l|l|l|l|l|}
\hline \multicolumn{1}{|c|}{ Nombre } & \multicolumn{1}{|c|}{ Unidad } & $\begin{array}{c}\text { Línea de } \\
\text { Base }\end{array}$ & Meta 2019 & \multicolumn{1}{c|}{ Responsable } \\
\hline $\begin{array}{l}\text { Espacios públicos } \\
\text { intervenidos y } \\
\text { recuperados }\end{array}$ & Porcentaje & 0 & 100 & $\begin{array}{l}\text { GERENCIA } \\
\text { CENTRO }\end{array}$ \\
\hline
\end{tabular}

6.4.3.1Proyecto: Intervenciones en espacio público y fachadas corredores importantes

6.4.3.2 6.4.3.2 Proyecto: Consolidación Junín

6.4.3.3 Proyecto: Unidades productivas para los venteros informales Recuperación del espacio público

6.4.3.4 Proyecto: Remodelación y activación del parque en el centro

6.4.3.5 Proyecto: Plan Maestro de San Antonio 


\section{Intervención integral del territorio y recuperación del centro}

\subsubsection{PROGRAMA: PRESENCIA INSTITUCIONAL Y GOBERNABILIDAD}

La permanente presencia en los diferentes territorios de Medellín, permite acercar a todos los ciudadanos la oferta que como Alcaldía se dispone para garantizar el goce efectivo de derechos. Por ello, una de las tareas prioritarias será la de fortalecer la presencia institucional en seguridad en los territorios rurales de Medellín, todo ello, a través no sólo de la adecuación de infraestructura coherente con el territorio y capaz de atender la demanda ciudadana, si no del fortalecimiento del conocimiento técnico de los equipos de las secretarías y dependencias con competencias funcionales en materia de seguridad y convivencia.

Indicador de resultado

\begin{tabular}{|c|l|l|l|l|}
\hline Nombre & \multicolumn{1}{|c|}{ Unidad } & Línea de Base & Meta 2019 & Responsable \\
\hline $\begin{array}{l}\text { Actividades y eventos } \\
\text { realizados }\end{array}$ & Número & PD & PD & $\begin{array}{l}\text { GERENCIA } \\
\text { CENTRO }\end{array}$ \\
\hline
\end{tabular}

6.4.4.1Proyecto: Fortalecimiento de la seguridad y la gobernabilidad en el centro

6.4.4.2 Proyecto: Utilización de los espacios públicos para los eventos de ciudad

6.4.4.3 Proyecto: Consolidación Plan Maestro del Centro

6.4.4.4 Proyecto: Todos podemos conocer y volver al centro 


\subsection{RETO}

\section{HÁBITAT ADECUADO PARA MEDELLIIN}

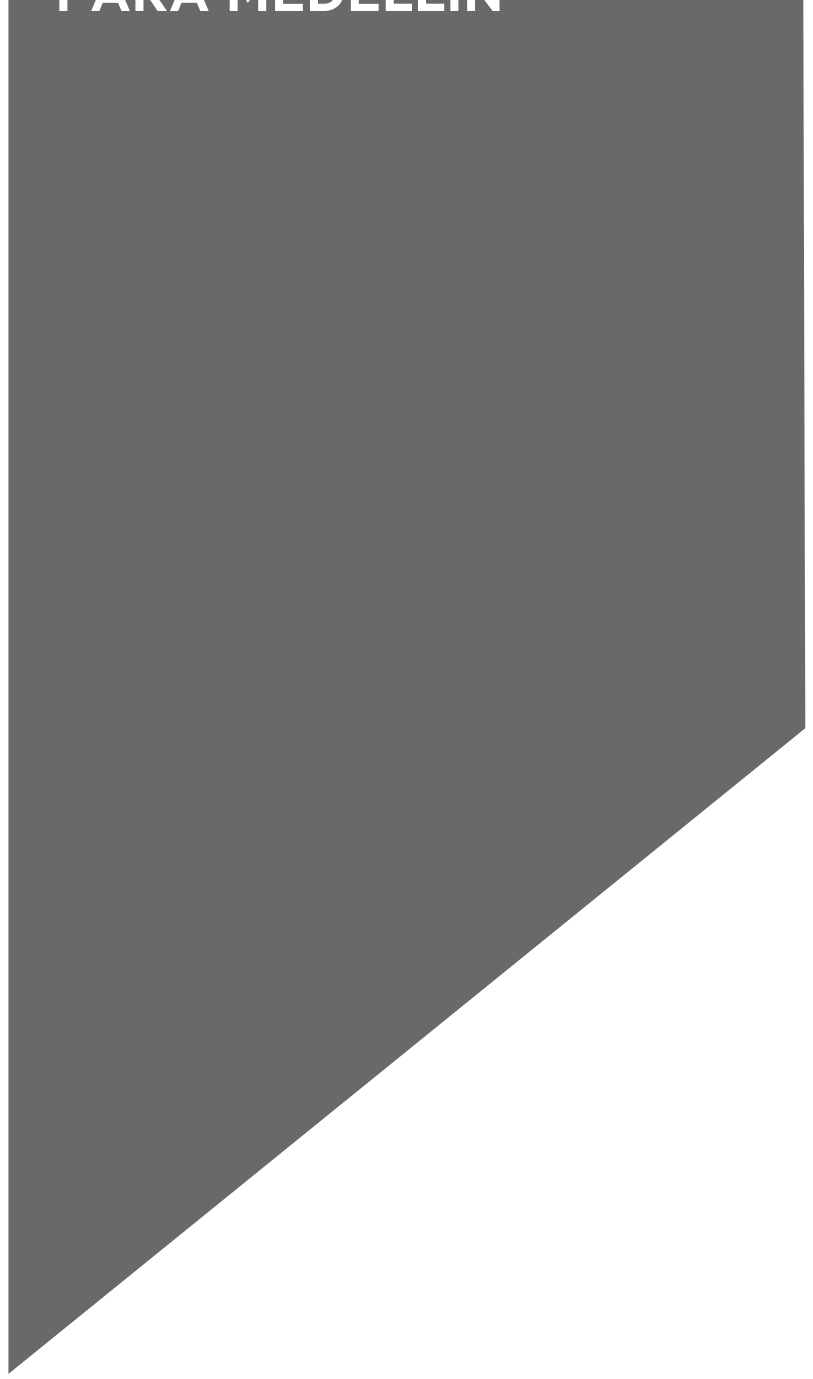

OBJETIVO

Promover un ambiente sano para la población con conciencia ambiental y espacios adecuados y aptos para ser habitados.

\section{PROGRAMAS}

4 6.5.1. Fortalecimiento al Sistema Municipal Habitacional

4 6.5.2. Reasentamiento integral de población

4 6.5.3. Gestión de nuevos desarrollos habitacionales de vivienda social

4 6.5.4. Mejoramiento integral de barrios 


\subsection{Hábitat adecuado para Medellín}

En el municipio de Medellín a 2014 se presenta un stock habitacional de 775.683 viviendas, de estas el $97,1 \%$ son urbanas y el $2,9 \%$ rurales, se concentran principalmente en las comunas de Belén y Robledo (9,2\% y 7,4\% respectivamente). Entre 2008 y 2014 se incrementó el número de viviendas en 113.656 con un crecimiento anual alrededor de 2,7\%, estas viviendas se concentran en un $76,3 \%$ en los estratos bajos y medio bajos principalmente en el estrato 2 con un 34,5\%. (DAP, 2014)

Gráfico 21: Viviendas según estrato socioeconómico, 2014

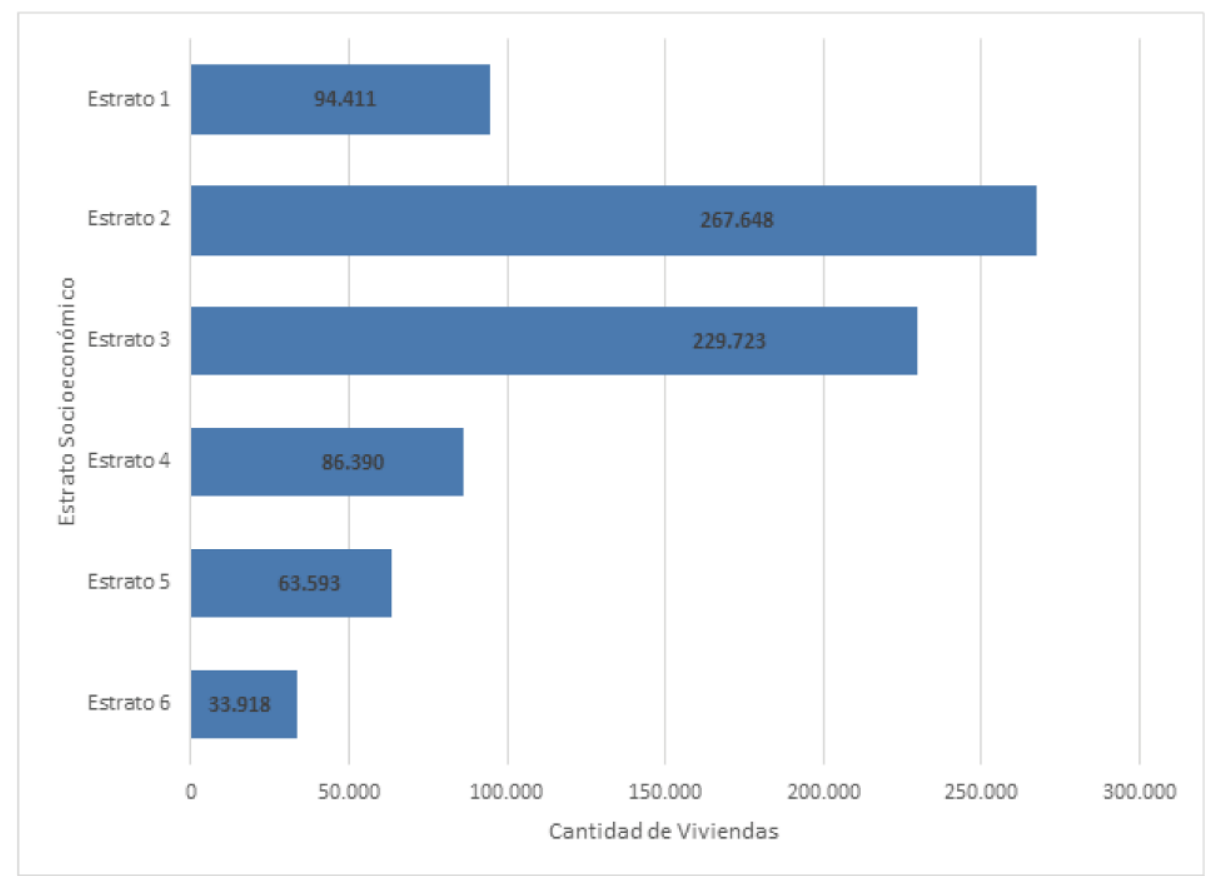

Fuente: Departamento Administrativo de Planeación 2014. Alcaldía de Medellín.

El predominio de estratos 1, 2 y 3 se concentra en las zonas norte (oriental y occidental) y centro (oriental y occidental) de la ciudad; el estrato 6, es predominante en la zona suroriental, mientras que los estratos 4 y 5 predominan en las zonas centro (oriental y occidental); la mayor mezcla de estratos socioeconómicos se presenta en las zonas centro occidental y suroccidental (DAP, 2014).

Para el año 2014 el 56.5\% de los hogares en Medellín habitaban en una vivienda propia, el $35.3 \%$ habitaba en una vivienda arrendada y el $8.2 \%$ habitaba en otro tipo de vivienda. 


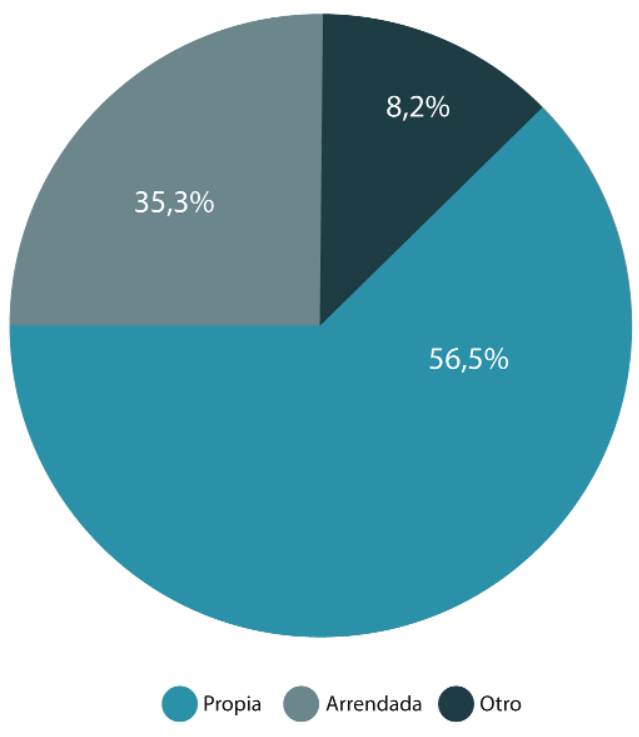

Fuente: Encuesta de Calidad de Vida 2014

El déficit cuantitativo para el año 2014 es de 23.470 hogares sin vivienda los cuales se concentran en un $45,3 \%$ en estrato 1 y cuya causa principal de déficit es el hacinamiento no mitigable (44,7\%); en cuanto su ubicación, la zona nororiental concentra el $47,4 \%$ de este fenómeno, y en la cual se presenta la comuna El Popular como aquella con mayor concentración de la ciudad $(14,3 \%)$.

Ahora bien, para el 2014 el número de viviendas en zonas de alto riesgo no mitigable fueron 5.544, de las cuales el 27,0\% (1.499) se ubican en la comuna del Popular; el 17,9\% (990) en Manrique; el 17,0\% (943) en Manrique; el 16,5\% (917) en Villa Hermosa y el 7,7\% (428) en Robledo, con lo que estas cinco comunas concentran el 86,2\% del fenómeno. (DAP, 2014).

Así las cosas, este plan reorienta sus esfuerzos institucionales hacia una transformación integral del territorio, que contribuya de manera significativa al aumento de la calidad de sus habitantes y a la calidad del espacio público que pretendemos consolidar, toda vez que las intervenciones en proyectos y megaproyectos apuntan a cumplir el sueño de una Medellín equitativa y sostenible para el disfrute de la ciudadanía, a partir del cuidado de sus paisajes y del control de la explosión urbanística que implica profundas problemáticas para la comunidad, apuntando a consolidar apuestas de fortalecimiento en infraestructura para la movilidad y el desarrollo urbano y rural, garantizando la presencia institucional y la seguridad en lo largo y ancho de la ciudad de Medellín. 
A continuación describimos los indicadores de resultado que se evaluarán en este reto:

Indicadores de resultado

\begin{tabular}{|c|c|c|c|c|}
\hline Nombre & Unidad & Línea de Base & Meta 2019 & Responsable \\
\hline $\begin{array}{l}\text { Hogares que superan } \\
\text { el déficit cuantitativo } \\
\text { de vivienda en el } \\
\text { cuatrienio }\end{array}$ & Número & 0 & 8773 & $\begin{array}{l}\text { Instituto Social } \\
\text { de Vivienda y } \\
\text { Hábitat de } \\
\text { Medellín }\end{array}$ \\
\hline $\begin{array}{l}\text { Hogares que superan } \\
\text { el déficit cualitativo de } \\
\text { vivienda en } \\
\text { cuatrienio }\end{array}$ & Número & 0 & 2580 & $\begin{array}{l}\text { Instituto Social } \\
\text { de Vivienda y } \\
\text { Hábitat de } \\
\text { Medellín } \\
\end{array}$ \\
\hline $\begin{array}{l}\text { Hogares que superan } \\
\text { el déficit habitacional } \\
\text { en el cuatrienio }\end{array}$ & Número & 0 & 10445 & $\begin{array}{l}\text { Instituto Social } \\
\text { de Vivienda y } \\
\text { Hábitat de } \\
\text { Medellín }\end{array}$ \\
\hline $\begin{array}{l}\text { Subsidios de vivienda } \\
\text { asignados }\end{array}$ & Porcentaje & $\mathrm{O}$ & 80 & $\begin{array}{c}\text { Instituto Social } \\
\text { de Vivienda y } \\
\text { Hábitat de } \\
\text { Medellín }\end{array}$ \\
\hline
\end{tabular}

\subsubsection{PROGRAMA: FORTALECIMIENTO AL SISTEMA MUNICIPAL HABITACIONAL}

Fortalecer las capacidades institucionales de los diversos actores del sistema habitacional para garantizar el acceso equitativo, solidario y sostenible a los bienes y servicios habitacionales.

Indicador de resultado

\begin{tabular}{|l|l|l|l|l|}
\hline \multicolumn{1}{|c|}{ Nombre } & Unidad & Línea de Base & Meta 2019 & Responsable \\
\hline $\begin{array}{l}\text { Sistema Municipal } \\
\text { Habitacional } \\
\text { fortalecido }\end{array}$ & Porcentaje & 0 & 100 & $\begin{array}{l}\text { Instituto Social } \\
\text { de Vivienda y } \\
\text { Hábitat de } \\
\text { Medellín }\end{array}$ \\
\hline
\end{tabular}

6.5.1.1 Proyecto: Creación e implementación del Comité de Política Habitacional

Creación mediante Decreto Municipal e implementación del Comité de Política Habitacional, órgano consultivo y asesor de la Administración que hace parte de la estructura organizacional que da soporte al PEHMED 2020. Es una instancia de participación ciudadana, articulación, concertación y coordinación de agendas entre los diversos actores del sistema, en función del fortalecimiento de redes colaborativas en la gestión integral de la política pública habitacional. La estructura comprende de un comité técnico de coordinación, comisiones técnicas, mesas zonales y corregimentales de vivienda y hábitat, su implementación será progresiva.

Responsable: Instituto Social de Vivienda y Hábitat de Medellín - ISVIMED 
Indicador de producto

\begin{tabular}{|c|c|}
\hline Nombre & Unidad \\
\hline Comité de Política habitacional implementado & Porcentaje \\
\hline
\end{tabular}

6.5.1.2 Proyecto: Revisión y Ajuste del Plan Estratégico habitacional de Medellín - PEHMED

En razón de las modificaciones de los datos estadísticos, normativas,

"粗国田 cambios poblacionales y territoriales, entre otros, el Plan debe ser revisado y actualizado de modo que responda a las realidades actuales, además el POT en el artículo 215 parágrafo, establece que será revisado y ajustado cada cuatro años.

Responsable: Instituto Social de Vivienda y Hábitat de Medellín - ISVIMED Indicador de producto

\begin{tabular}{|l|c|}
\hline \multicolumn{1}{|c|}{ Nombre } & Unidad \\
\hline Plan estratégico habitacional actualizado & Porcentaje \\
\hline
\end{tabular}

\subsubsection{PROGRAMA: REASENTAMIENTO INTEGRAL DE POBLACIÓN}

Restablecimiento de las condiciones habitacionales de los hogares intervenidos por obras públicas, eventos naturales y prevención del riesgo.

Indicador de resultado

\begin{tabular}{|c|l|l|l|l|}
\hline Nombre & Unidad & Línea de Base & Meta 2019 & Responsable \\
\hline $\begin{array}{l}\text { Reasentamiento } \\
\text { integral de población }\end{array}$ & Porcentaje & 0 & 100 & $\begin{array}{l}\text { Instituto Social } \\
\text { de Vivienda y } \\
\text { Hábitat de } \\
\text { Medellin }\end{array}$ \\
\hline
\end{tabular}

6.5.2.1 Proyecto: Reasentamiento de población por obras de utilidad pública Oferta de soluciones de vivienda (nueva, usada, arrendamiento temporal) a grupos familiares que han debido entregar su vivienda al Municipio por ser propietarios o poseedores de viviendas de comprometidas con proyectos de interés general.

Responsable: Instituto Social de Vivienda y Hábitat de Medellín - ISVIMED Indicador de producto

\begin{tabular}{|c|c|}
\hline \multicolumn{1}{|c|}{ Nombre } & Unidad \\
\hline Hogares sujetos de reasentamiento por obras de utilidad pública atendidos & Porcentaje \\
\hline
\end{tabular}

6.5.2.2. Proyecto: Reasentamiento de población por eventos naturales y desastres

Oferta de soluciones de vivienda (nueva, usada, arrendamiento temporal) a grupos familiares que han debido entregar su vivienda al Municipio por ser propietarios o poseedores de viviendas de interés prioritario ubicadas en áreas afectadas por eventos naturales o desastres. 
Responsable: Instituto Social de Vivienda y Hábitat de Medellín - ISVIMED Indicador de producto

\begin{tabular}{|c|c|}
\hline \multicolumn{1}{|c|}{ Nombre } & Unidad \\
\hline Hogares sujetos de reasentamiento por eventos naturales y desastres atendidos & Porcentaje \\
\hline
\end{tabular}

6.5.2.3. Proyecto: Piloto de reasentamiento preventivo en suelo de riesgo no mitigable

EI POT establece el reasentamiento de poblaciones que se encuentran en zonas de riesgo no mitigable por movimientos en masa o riesgo de inundación. Con este proyecto se pretende reducir progresivamente las condiciones de amenaza y riesgo, mejorar condiciones habitacionales e intervenir uno de los territorios priorizados en el POT, desarrollando una metodología integral que involucre criterios de protección a moradores y sostenibilidad.

Responsable: Instituto Social de Vivienda y Hábitat de Medellín -ISVIMED Indicador de producto

\begin{tabular}{|c|c|}
\hline \multicolumn{1}{|c|}{ Nombre } & Unidad \\
\hline Hogares sujetos de reasentamiento por riesgo no mitigable atendidos & Porcentaje \\
\hline
\end{tabular}

\subsubsection{Proyecto: Arrendamiento temporal}

Comprende el acompañamiento y la asignación de subsidios temporales a hogares que deben evacuar sus viviendas debido a desastres, por estar ubicados en zonas de alto riesgo, la ejecución de obras públicas u otros eventos, para que puedan continuar con su desarrollo familiar mientras acceden a soluciones habitacionales definitivas o regresan a sus hogares.

En este proyecto se pretende enmarcar el proyecto APP para arrendamientos temporales. Los recursos para estructuración y/o evaluación se enmarcan en la dimensión 1 en un proyecto de gestión de Alianzas Público Privadas.

Responsable: Instituto Social de Vivienda y Hábitat de Medellín Indicador de producto

\begin{tabular}{|c|c|}
\hline \multicolumn{1}{|c|}{ Nombre } & Unidad \\
\hline Hogares con subsidio de arrendamiento temporal atendidos & Porcentaje \\
\hline
\end{tabular}

\subsubsection{PROGRAMA: GESTIÓN DE NUEVOS DESARROLLOS HABITACIONALES DE VIVIENDA SOCIAL}

Se pretende cambiar el modelo generando vivienda con calidad humana, una vivienda que trasciende de la funcionalidad hacia parámetros arquitectónicos y urbanísticos, combinando la ingeniería con diseño. La vivienda con calidad humana es aquella que genera sentido de pertenencia y permite ser apropiada y apersonada por parte de sus moradores, son 
viviendas accesibles, de calidad y equitativas que atienden los parámetros de accesibilidad, urbanismo, sostenibilidad e integralidad.

El modelo priorizará la construcción de proyectos más pequeños pero que abarquen toda la ciudad y que podrán estar acompañados de mejoramientos barriales integrales. La generación de vivienda a gran escala estará acompañada de movilidad, educación, salud, seguridad, comercio, entre otros servicios.

La vivienda nueva se orienta a atender la demanda libre y un stock de hogares vulnerables que se encuentran en el programa de arrendamiento temporal.

Indicador de resultado

\begin{tabular}{|l|l|l|l|l|}
\hline \multicolumn{1}{|c|}{ Nombre } & Unidad & Línea de Base & Meta 2019 & Responsable \\
\hline $\begin{array}{l}\text { Nuevos desarrollos } \\
\text { habitacionales de } \\
\begin{array}{l}\text { Vivienda Social } \\
\text { gestionados }\end{array}\end{array}$ & Porcentaje & 0 & 100 & $\begin{array}{l}\text { Instituto Social } \\
\text { de Vivienda y } \\
\text { Hábitat de } \\
\text { Medellín }\end{array}$ \\
\hline
\end{tabular}

\subsubsection{Proyecto Nueva vivienda social urbano y rural}

Proyectos de vivienda social para atender la población en déficit cuantitativo de vivienda y proyectos generados como impulso a la clase media, donde la diferenciación del subsidio es la posibilidad de acceso y no la calidad de la vivienda. Los proyectos podrán ser generados a través de alianzas estratégicas.

Así mismo se priorizará la población vulnerable que se encuentra en el programa de arrendamiento temporal debido a desastres, evacuaciones, por estar ubicadas en zonas de alto riesgo o por el requerimiento de sus viviendas para la ejecución de obras municipales.

Responsable: Instituto Social de Vivienda y Hábitat de Medellín- ISVIMED Indicador de producto

\begin{tabular}{|l|c|}
\hline \multicolumn{1}{|c|}{ Nombre } & Unidad \\
\hline Viviendas construidas & Número \\
\hline Unidades de vivienda iniciadas & Número \\
\hline
\end{tabular}

\subsubsection{Proyecto: Gestión del suelo para vivienda social}

Consiste en el análisis, revisión y diagnóstico de los suelos aptos para el desarrollo de proyectos y programas de vivienda de interés social, considerando la renovación urbana en el escenario río, la consolidación de la ladera en el escenario de ladera y la mitigación de los riesgos ambientales a través del reasentamiento de vivienda en el escenario de borde. Todo esto encaminado a las actividades necesarias para la viabilidad de los proyectos de vivienda. 
Responsable: Instituto Social de Vivienda y Hábitat de Medellín- ISVIMED Indicador de producto

\begin{tabular}{|l|c|}
\hline \multicolumn{1}{|c|}{ Nombre } & Unidad \\
\hline Suelo de vivienda social gestionado & Porcentaje \\
\hline
\end{tabular}

\subsubsection{Proyecto: Fomento a la autoconstruccón e iniciativas} comunitarias

Valoración de las experiencias organizativas como las organizaciones populares de vivienda y las prácticas de los sectores populares, estimulando los procesos de autogestión del hábitat a través de formas asociativas, experimentación y desarrollo de tecnologías apropiadas a dichos procesos.

Responsable: Instituto Social de Vivienda y Hábitat de Medellín- ISVIMED Indicador de producto

\begin{tabular}{|c|c|}
\hline \multicolumn{1}{|c|}{ Nombre } & Unidad \\
\hline Subsidios en proyectos de iniciativas comunitarias asignados & Número \\
\hline
\end{tabular}

\subsubsection{PROGRAMA: Mejoramiento integral de barrios}

Es una estrategia que opera con integralidad desde la intervención en los territorios a mejorar, tiene la capacidad de transformar positivamente los desequilibrios en sus manifestaciones ambientales, socioculturales, socioeconómicas y de incrementar la integración socioespacial, la sostenibilidad ambiental y el mejoramiento de la calidad de vida de la población objetivo del programa. Comprende un conjunto de proyectos dirigidos a la regularización urbanística, el mejoramiento de la vivienda y el mejoramiento del entorno ejecutados en forma complementaria y coordinada. Más allá de intervenciones puntuales y aisladas, el mejoramiento integral de barrios impacta de forma directa la sostenibilidad de los barrios.

\begin{tabular}{|l|l|l|l|l|}
\hline \multicolumn{1}{|c|}{ Nombre } & Unidad & Línea de Base & Meta 2019 & Responsable \\
\hline $\begin{array}{l}\text { Mejoramiento Integral } \\
\text { de Barrios }\end{array}$ & Porcentaje & 0 & 100 & $\begin{array}{l}\text { Instituto Social } \\
\text { de Vivienda y } \\
\text { Hábitat de } \\
\text { Medellín }\end{array}$ \\
\hline
\end{tabular}

\subsubsection{Proyecto: Titulación de predios}

Consiste en ceder a título gratuito la propiedad a hogares poseedores o tenedores de viviendas de interés social ubicadas en predios fiscales del Municipio de Medellín, vinculándolos al proceso en forma organizada, por sectores y en cumplimiento de los lineamientos del Plan de Ordenamiento Territorial, para elevar sus estándares de calidad habitacional y disminuir la informalidad.

Responsable: Instituto Social de Vivienda y Hábitat de Medellín- ISVIMED 
Indicador de producto

\begin{tabular}{|c|c|}
\hline Nombre & Unidad \\
\hline Resoluciones de cesión de título gratuito expedida & Número \\
\hline
\end{tabular}

6.5.4.2 . Proyecto: Mejoramientos de vivienda urbano y rural Acompañar técnicamente el mejoramiento de las condiciones físicas de las viviendas de los grupos familiares en condiciones de vulnerabilidad social y económica con el fin de cualificar sus condiciones de habitabilidad y contribuir a la disminución del déficit cualitativo de vivienda en Medellín.

Responsable: Instituto Social de Vivienda y Hábitat de Medellín- ISVIMED Indicador de producto

\begin{tabular}{|l|l|}
\hline \multicolumn{1}{|c|}{ Nombre } & Unidad \\
\hline Subsidios para mejoramiento de vivienda asignados & Número \\
\hline Mejoramientos de vivienda ejecutados & Número \\
\hline
\end{tabular}

\subsubsection{Proyecto: Reconocimiento de edificaciones}

Dirigido a las viviendas que se han levantado o mejorado sin licencia de construcción, tiene como objeto declarar la existencia de los desarrollos arquitectónicos que se ejecutaron sin obtener las licencias siempre y cuando cumplan con el uso previsto por las normas urbanísticas vigentes y que la edificación se haya concluido como mínimo cinco años antes de la solicitud de reconocimiento.

Responsable: Instituto Social de Vivienda y Hábitat de Medellín - ISVIMED Indicador de producto

\begin{tabular}{|c|c|}
\hline Nombre & Unidad \\
\hline Reconocimiento de edificaciones radicadas en curaduría & Porcentaje \\
\hline
\end{tabular}

6.5.4.4 Proyecto: Adopción, reglamentación e implementación de la política pública de inquilinatos

En Medellín, un número considerable y creciente de hogares encuentra una solución de vivienda en el inquilinato que el POT define como "una vivienda administrada por una persona que, para ella misma o para el propietario del inmueble, alquila cuartos a hogares (personas o familias) que pagan diaria, semanal o mensualmente. Los habitantes de inquilinatos son cada vez más numerosos por razones como la informalidad, el desplazamiento y la transformación de las relaciones familiares.

Una vez se encuentre adoptada la política pública, instrumento de orientación, planificación y ejecución de programas y proyectos que conllevan al mejoramiento de la calidad de vida de los habitantes de los inquilinatos de la ciudad, se reglamentará identificando los responsables, tiempos, recursos y resultados esperados. 
Se requiere conformar mesas de trabajo interinstitucionales para formular e implementar proyectos que permitan mejorar de forma integral la habitabilidad de los inquilinatos de Medellín.

Responsable: Instituto Social de Vivienda y Hábitat de Medellín - ISVIMED Indicador de producto

\begin{tabular}{|c|c|}
\hline \multicolumn{1}{|c|}{ Nombre } & Unidad \\
\hline Política pública de inquilinatos implementada & Porcentaje \\
\hline
\end{tabular}

6.5.4.5 Proyecto: Construcción, adecuación y mantenimiento de escenarios deportivos y recreativos

(Subproyectos: Construcción, adecuación y mantenimiento de escenarios deportivos y recreativos - INDER. Estructuración y/o evaluación de renovación del Estadio Atanasio Girardot / Renovación Sede Movilidad Caribe - APP.

Se construirán unidades deportivas como estrategia de intervención barrial según las necesidades y la pertinencia que se encuentren en los barrios y los corregimientos de San Antonio de Prado, Altavista y San Cristóbal. Estas unidades deportivas son escenarios que sirven de apropiación, empoderamiento y esparcimiento para la ciudadanía y el desarrollo de las comunidades.

Como estrategia de intervención barrial según las necesidades y la pertinencia que se encuentren en el territorio. Estos equipamientos posibilitan la apropiación, empoderamiento y esparcimiento de la ciudadanía y el desarrollo de las comunidades.

En este proyecto se pretende enmarcar el proyecto APP para renovar la sede de Movilidad. Los recursos para estructuración y/o evaluación se enmarcan en la dimensión 1 en un proyecto de gestión de Alianzas Público Privadas. Se debe enmarcar de importancia estratégica. Así como promover Alianza Público Privada para diseñar, construir, adecuar, operar, mantener el Estadio Atanasio Girardot e instalaciones comunitarias y recreativas aledañas a la Unidad Deportiva Atanasio Girardot.

Responsable: INDER

Indicadores de producto:

\begin{tabular}{|l|l|}
\hline \multicolumn{1}{|c|}{ Nombre } & Unidad \\
\hline $\begin{array}{l}\text { Adecuación de escenarios deportivos, recreativos y de actividad física durante el } \\
\text { cuatrienio }\end{array}$ & Número \\
\hline $\begin{array}{l}\text { Construcción de escenarios deportivos, recreativos y de actividad física durante el } \\
\text { cuatrienio }\end{array}$ & Número \\
\hline $\begin{array}{l}\text { Unidades de Vida Articulada construidas y puestas en funcionamiento } \\
\text { Adecuación y mantenimiento de la infraestructura física de las unidades de vida } \\
\text { articulada -UVA }\end{array}$ & Número \\
\hline
\end{tabular}




\subsubsection{Proyecto: Mantenimiento y conservación espacios públicos de encuentro y esparcimiento}

Con el mejoramiento de cada uno de los parques de la ciudad, se facilita la recreación en estos espacios de encuentro y esparcimiento, con la dotación y reposición de amueblamiento urbano tales como bancas, basureras, luminarias; construcción de pisos duros y espacios de recreación pasiva, y el mantenimiento de los espacios verdes al interior de los parques, entre otros. También se busca generar mejores espacios para nuestros corregimientos.

Responsable: INDER

Indicador de producto

\begin{tabular}{|l|l|}
\hline \multicolumn{1}{|c|}{ Nombre } & \multicolumn{1}{|c|}{ Unidad } \\
\hline Espacios públicos de encuentro y esparcimiento, mantenidos y conservados & $\begin{array}{l}\text { Metros } \\
\text { Cuadrados }\end{array}$ \\
\hline Espacios públicos de encuentro y esparcimiento intervenidos Urbanos y Rurales & $\begin{array}{l}\text { Metros } \\
\text { Cuadrados }\end{array}$ \\
\hline
\end{tabular}

\subsubsection{Proyecto: Pilas Públicas}

Es el suministro de agua para el abastecimiento colectivo y evacuación de las aguas residuales de manera provisional, a través de una JAC O Entidad Asociativa. Esta iniciativa pretende facilitar el acceso a los servicios de acueducto y alcantarillado en asentamientos subnormales o zonas que no cuentan con redes porque las condiciones técnicas, económicas y jurídicas impiden la instalación de redes domiciliarias por parte de EPM.

En este proyecto se define un modelo económico acorde a la capacidad de pago de estas comunidades con la participación del municipio para el aporte de subsidios.

Responsable: Empresas Públicas de Medellín

Indicador de producto

\begin{tabular}{|c|c|}
\hline \multicolumn{1}{|c|}{ Nombre } & Unidad \\
\hline $\begin{array}{l}\text { Viviendas con servicio de agua potable por pila pública que se ubican en } \\
\text { asentamientos informales }\end{array}$ & Número \\
\hline
\end{tabular}

6.5.4.8 . Proyecto: Proyectos de infraestructura en zonas de no cobertura

El nuevo POT definió algunas zonas de expansión urbana donde actualmente no cuentan con los servicios públicos que pueden ser susceptibles de intervenir con proyectos de infraestructura, el cual se planea y ejecuta conjuntamente con la alcaldía. Estas zonas se intervienen de acuerdo con los planes de intervención del municipio para dimensionar los plazos y la inversión en cada una de ellas. Las zonas identificadas y que serán analizadas son: La Honda, La Cruz, María Cano Carambolas, Versalles 2, Llanaditas y 13 de Noviembre. 
Responsable: Empresas Públicas de Medellín

Indicador de producto

\begin{tabular}{|c|c|}
\hline \multicolumn{1}{|c|}{ Nombre } & Unidad \\
\hline Viviendas que acceden a agua potable en desarrollo de obras de mitigación & Número \\
\hline
\end{tabular}

6.5.4.9 Proyecto: Regularización de requisitos oferta especial

Iniciativa que busca la flexibilización de los requisitos urbanísticos - para la vinculación en acuerdo con el Municipio de Medellín para Legalizar o formalizar el servicio de acueducto y alcantarillado a los hogares que actualmente se encuentran en zona de cobertura a través de una oferta especial de financiación y por tiempo limitado

Responsable: Empresas Públicas de Medellín

Indicador de producto

\begin{tabular}{|c|c|}
\hline \multicolumn{1}{|c|}{ Nombre } & Unidad \\
\hline Viviendas habilitadas para conexión de los servicios de acueducto y alcantarillado & Número \\
\hline
\end{tabular}

\subsubsection{Proyecto: Proteger el patrimonio cultural}

Busca a través de diferentes 'lineamientos, estrategias, programas y proyectos la protección, recuperación, conservación y sostenibilidad del patrimonio cultural que constituye el fundamento de la identidad de la Ciudad, acorde con la Ley General de Cultura y la Ley de Patrimonio Cultural.

Responsable: Secretaría de Cultura Ciudadana Indicador de producto

\begin{tabular}{|l|l|}
\hline \multicolumn{1}{|c|}{ Nombre } & Unidad \\
\hline Programas para la salvaguardia, protección, recuperación, conservación y & Número \\
sostenibilidad del patrimonio cultural realizados
\end{tabular}




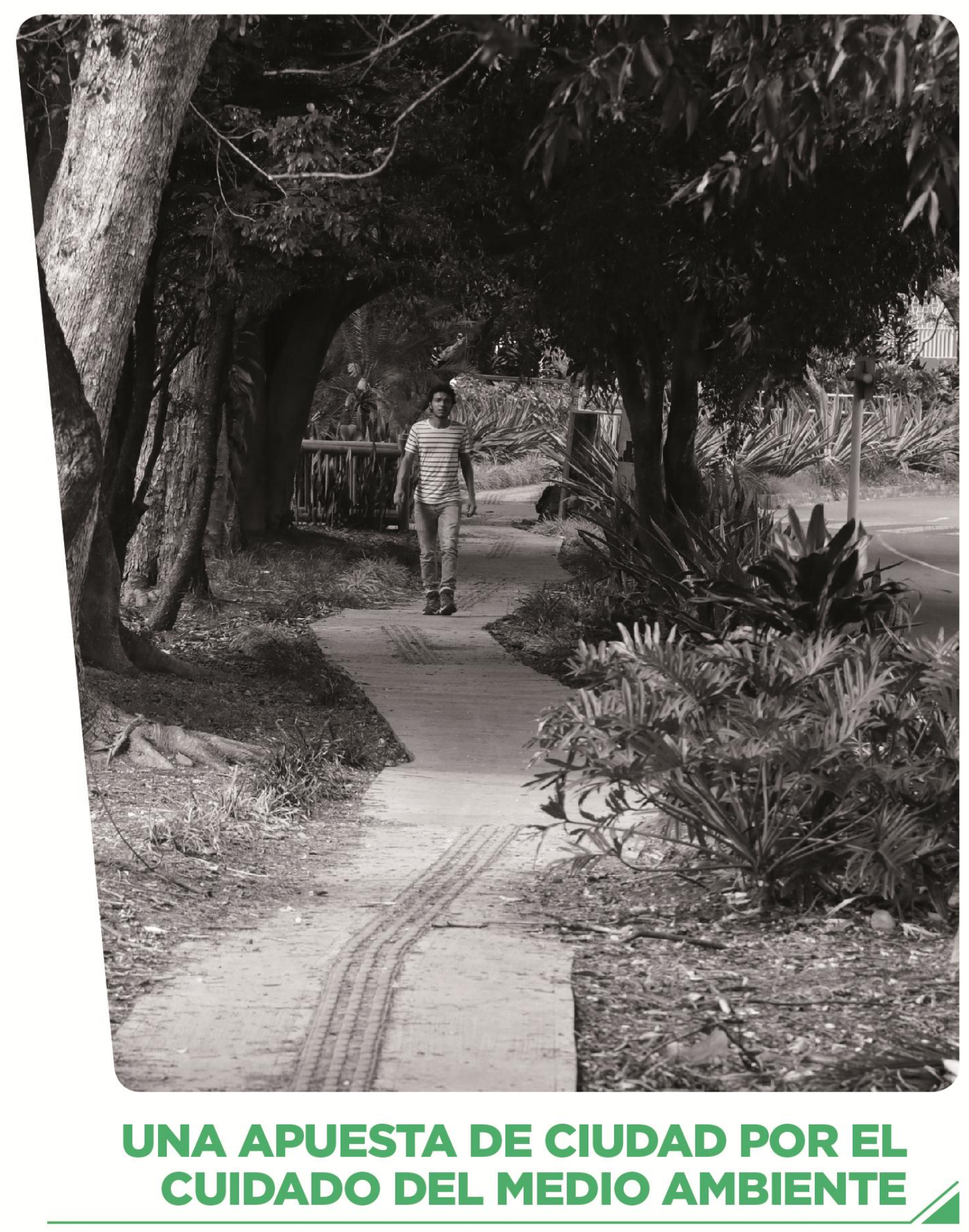




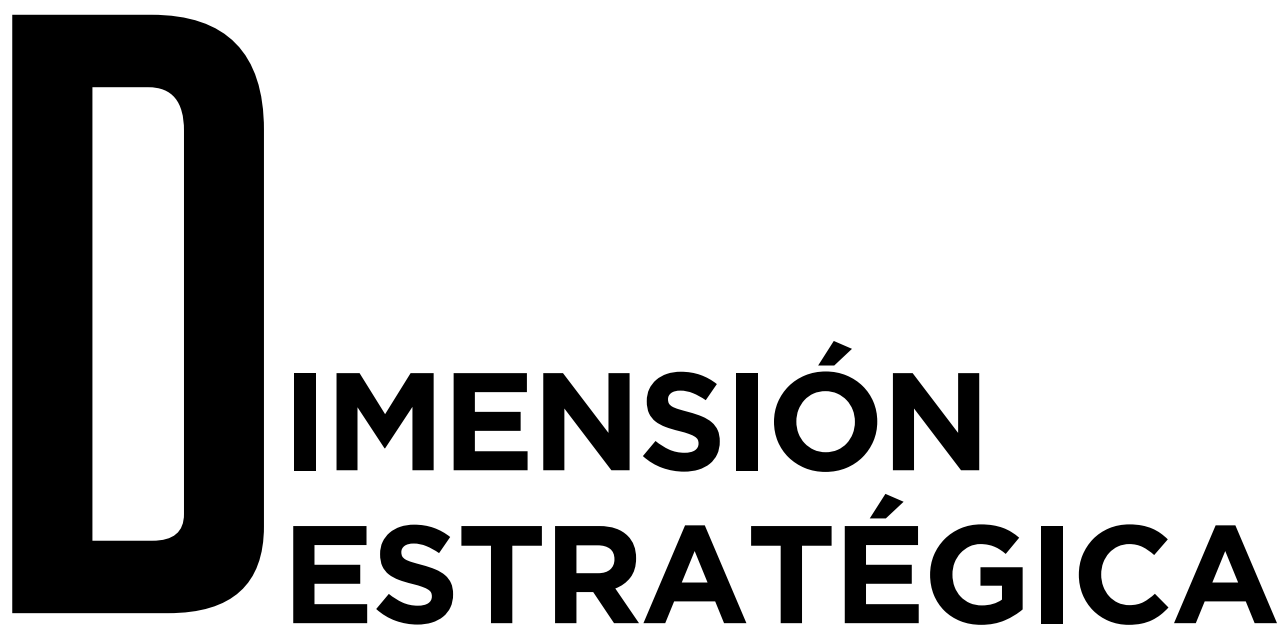

\section{Una apuesta de ciudad por el cuidado del medio ambiente}

Promover el acceso y mejoramiento de la prestación de servicios públicos de calidad, fortalecer la prevención y gestión de los factores de amenaza y riesgo e incrementar los esfuerzos en la construcción de una conciencia ambiental que conlleve al uso responsable y conservación de los recursos y en general a la sostenibilidad de la ciudad. 


\section{- DIAGNÓSTICO •}

Creemos que el medio ambiente constituye un elemento estructurante de la planificación urbana y rural de la ciudad; por ello, preservar los ecosistemas naturales, propiciar el cuidado de los espacios verdes y crear las condiciones para un desarrollo económico sostenible son nuestras prioridades hacia al mejoramiento de la calidad de vida de los habitantes de Medellín.

La expansión demográfica y la urbanización desmedida se han convertido en complejas problemáticas que afectan significativamente la conservación de las áreas verdes, la fauna, la flora y las fuentes hídricas del territorio. Así mismo, la contaminación derivada de la producción industrial y de los sistemas de movilidad precisa de la acción institucional y del compromiso ciudadano hacia la superación de tales problemáticas.

Por otro lado, los problemas ecológicos y medioambientales asociados al cambio climático se han convertido en un reto generalizado tanto a nivel local como internacional. Por tal razón, las directrices propuestas por los Objetivos de Desarrollo Sostenible (ODS) indican que las ciudades deben generar una infraestructura institucional y un entramado de programas y proyectos que busquen, por un lado, la consolidación de ciudades sostenibles y responsables con el medio ambiente, y por otro mejorar los procesos de generación de energía no contaminante que permita conservar los ecosistemas terrestres (ODS, 2015).

Sin embargo, existe una deficiencia en los instrumentos de medición para el cuidado y sostenimiento del medio ambiente, pues uno de los pocos esfuerzos por abordar esta temática lo constituyó la Encuesta de Calidad de Vida (ECV, 2014) la cual en uno de sus componentes se hizo mención explícita al medio ambiente, cuya medición se realizó a partir de nueve variables, a saber: El estado de contaminación de aire; contaminación de ríos y quebradas; nivel del ruido; basuras y escombros en las calles; la contaminación visual,; arborización; pavimentación y señalización de vías; estado de andenes y separadores de calles y; cumplimiento de normas de tránsito. A través de este instrumento que se cuantificó desde la percepción ciudadana es posible reconocer niveles de estimación comparables entre lo urbano y lo rural, en la medida en que las cifras arrojadas en los corregimientos muestran que sólo el 52\%, 47\%, 44\%, 44\% y $57 \%$ de los habitantes de Palmitas, San Cristobal, Altavista, San Antonio de Prado y Santa Elena, respectivamente, tienen una percepción positiva sobre el cuidado y la calidad del medio ambiente, lo que precisa de una acción interinstitucional dirigida al fortalecimiento y conservación de los espacios y a promover la educación ambiental en la ciudadanía.

Ahora bien, si los resultados arrojados para las áreas rurales se presentan relativamente bajos, las cifras son aún más preocupantes para la zona 
urbana, en tanto el resultado de la percepción de los habitantes todas las comunas permite ver que ninguna de ellas alcanza el $50 \%$, pues el resultado más alto lo registra el Poblado con el 49\%, mientras que comunas como Villa Hermosa, Santa Cruz y el Popular se encuentran por debajo del $34 \%$ de percepción positiva de sus habitantes sobre el estado del medio ambiente en sus territorios. Estos problemáticos resultados, por una parte, evidencian la necesidad de emprender proyectos estratégicos educativos para la preservación del medio ambiente y de impulsar el control a la contaminación ambiental, y por otra, requieren del diseño de un nuevo instrumento que permita focalizar los aspectos medioambientales y climáticos hacia la identificación de aquellos elementos que inciden directamente en la calidad, preservación y conservación del ecosistema.

En ese sentido, desde este Plan de Desarrollo planteamos un nuevo indicador denominado Índice de Sostenibilidad Ambiental y Cambio Climático el cual deja por fuera asuntos como el estado de las vías y las normas del tránsito, que funcionaron como variables para la ECV, y propone el siguiente conjunto de elementos: Agua, saneamiento y drenaje; gestión de residuos sólidos; energía; calidad del aire; mitigación del cambio climático; ruido; y vulnerabilidad ante desastres productos del cambio climático. Además, esta apuesta por el cuidado del ecosistema natural y el mejoramiento de la calidad de vida de los habitantes de las zonas urbanas y rurales de la ciudad, se complementa con esfuerzos institucionales y generación de infraestructura para el acceso a servicios públicos y contribuir a mejorar su calidad, ya que este aspecto incide positivamente en brindar condiciones dignas para sus habitantes, siempre y cuando se rijan bajo los principios de sostenibilidad y armonía con la naturaleza y disminuyan el impacto ambiental en los territorios.

\section{- PRESENTACIÓN •}

El equilibrio ambiental de nuestro territorio se fundamenta en una relación armónica y sinérgica de las condiciones naturales con los desarrollos humanos. Es así como las necesidades de desarrollo de las ciudades se sustentan a partir de los recursos naturales, los servicios, los productos, las materias primas, las relaciones humanas entre otros; con la satisfacción de las mismas y con la generación de bienes y servicios.

Medellín ha liderado una relación de sano equilibrio con los componentes ambientales que sustentan su desarrollo. Es por ello, que debemos continuar fortaleciendo la planeación para la conservación y preservación del medio ambiente, el uso racional y adecuado del suelo, del agua, del aire, la prevención del riesgo como la herramienta del desarrollo armónico y la prestación de servicios públicos de calidad y con cobertura social. 
Creemos y queremos que este municipio y sus habitantes continúen su apuesta por una ciudad que aprende de su pasado, que respeta las condiciones ambientales del presente y permite que las generaciones futuras disfruten de éstas. Este compromiso implica que nuestra responsabilidad y trabajo debe ser consecuente con los desarrollos integrales locales, regionales y nacionales e internacionales, encaminadas hacia la mitigación y adaptación al cambio climático.

Porque el medio ambiente está vinculado con vos, esta dimensión pretende lograr un desarrollo integral sustentado en su conservación, su defensa y el uso racional de los recursos naturales.

A continuación se describen los indicadores de impacto asociados a esta dimensión:

Indicadores de impacto

\begin{tabular}{|c|c|c|c|c|c|}
\hline Nombre & $\begin{array}{c}\text { Descripción } \\
\text { variables }\end{array}$ & Unidad & $\begin{array}{c}\text { Línea de } \\
\text { Base }\end{array}$ & Meta 2019 & Responsable \\
\hline $\begin{array}{l}\text { Dimensión } \\
\text { Medio } \\
\text { Ambiente } \\
\text { Encuesta de } \\
\text { Calidad de } \\
\text { Vida }\end{array}$ & $\begin{array}{l}\text { Arborización, } \\
\text { contaminación } \\
\text { de aire, } \\
\text { quebradas, } \\
\text { basura y ruido }\end{array}$ & Número & 2,87 & 2,9 & DAP \\
\hline $\begin{array}{l}\text { Dimensión } \\
\text { Entorno y } \\
\text { Calidad de la } \\
\text { Vivienda } \\
\text { Encuesta de } \\
\text { Calidad de } \\
\text { Vida }\end{array}$ & $\begin{array}{l}\text { Estrato, } \\
\text { viviendas con } \\
\text { materiales } \\
\text { inadecuados }\end{array}$ & Número & 4,23 & 4,3 & DAP \\
\hline $\begin{array}{l}\text { Dimensión } \\
\text { Acceso a } \\
\text { servicios } \\
\text { públicos } \\
\text { Encuesta de } \\
\text { Calidad de } \\
\text { Vida }\end{array}$ & $\begin{array}{l}\text { Número de } \\
\text { servicios } \\
\text { públicos y } \\
\text { número de } \\
\text { servicios } \\
\text { suspendidos }\end{array}$ & Número & 3,98 & 4 & DAP \\
\hline
\end{tabular}

En este sentido proponemos para Medellín bajo esta dimensión, los siguientes retos: 


\subsection{RETO}

\section{MEDELLÍN CIUDAD} VERDE Y SOSTENIBLE

\section{PROGRAMAS}

4 7.1.1 Infraestructura verde: generación, conservación y mantenimiento de espacios verdes

4 7.1.2 Estructura ecológica y sus servicios ecosistémicos

$\Delta$ 7.1.3. Nuestro rio y sus quebradas

4 7.1.4. Gestión Integral de residuos sólidos

$\Delta$ 7.1.5. Protección animal

4 7.1.6. Sistema de gestión Ambiental Integral de Medellín para el cambio climático

$\Delta$ 7.1.7. Salud ambiental

4 7.1.8. Por la calidad del aire que respiramos

\section{OBJETIVO}

Proteger, restaurar y promover el uso sostenible de los recursos naturales, así como los espacios verdes y arborizados de la ciudad para beneficio de todos 


\subsection{Medellín ciudad verde y sostenible}

Desde hace varios años, Medellín se ha interesado en incluir conceptos y prácticas de sostenibilidad ambiental en sus procesos de planeación y gestión. Por esto, en la ciudad se han promovido políticas con el fin de implementar estrategias para gestionar de manera integral los recursos naturales y los problemas ambientales de la ciudad e incorporar la conservación, restauración y uso sostenible de la biodiversidad y los servicios ecosistémicos como parte fundamental del desarrollo territorial para una ciudad sostenible y resiliente.

Adicionalmente, el plan de ordenamiento territorial -POT- de Medellín, define los lineamientos para la incorporación de los elementos naturales como parte fundamental del proceso de planeación, construcción y transformación de la ciudad. Por ejemplo, la definición de la estructura ecológica como el principal elemento estructurante de la ciudad, pretende, además de proteger y mejorar los servicios de los ecosistemas que dan soporte a la vida en el municipio, generar un marco de acción que sea transversal a los ámbitos urbano y rural que pueda trascender los límites administrativos de Medellín y del Área Metropolitana.

Actualmente, Medellín cuenta con 5 áreas naturales protegidas: 2 áreas rurales (reserva forestal nacional Nare y distrito de manejo integrado de los recursos naturales de la divisoria Aburrá-Cauca) y 3 áreas urbanas (parque natural regional Cerro el Volador, y las áreas de recreación Cerro Nutibara y Cerro la Asomadera).

Mapa 7: Estructura ecológica de Medellín.

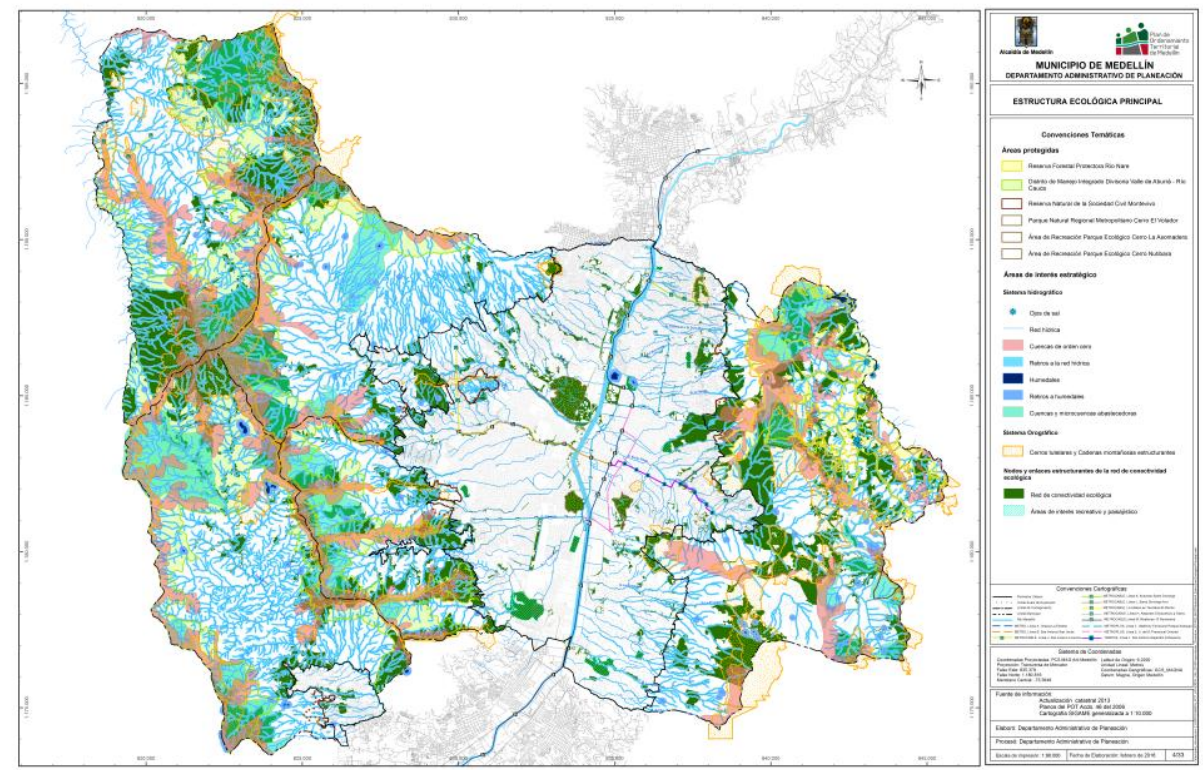

Fuente POT 2014. 
En adición, en temas de reforestación y restauración ecológica de ecosistemas se han recuperado alrededor de 569.95 hectáreas, con más de 800.000 árboles; acciones que aportan al proceso de adaptación al cambio climático, para el cual se cuenta con un inventario de emisiones de gases de efecto invernadero para el Valle de Aburrá, que incluye los sectores de energía, procesos industriales y uso de productos (IPPU), agricultura, silvicultura y otros usos del suelo (AFOLU) y residuos.

Medellín tiene enormes retos en cuanto al manejo de residuos sólidos y líquidos. Hasta el momento se han desarrollado estrategias para fomentar la cultura ambiental en el manejo integral de residuos sólidos, pero este proceso es aún muy débil y persiste la inadecuada separación en la fuente, el bajo reconocimiento de los recuperadores en la cadena de aprovechamiento y las pocas acciones de producción y consumo sostenible. De igual manera se encuentran dificultades en el aprovechamiento eficiente de residuos sólidos, debido a la falta generalizada de visión sobre su potencial económico y la baja implementación de tecnologías en economía de escala para la ciudad.

Actualmente se producen más de 8.000 toneladas diarias de escombros, esta cifra excede incluso la de residuos ordinarios (2.250 ton/día). Una alta cantidad de estos residuos se podría aprovechar para reutilizar, reciclar o convertir en nuevos productos; sin embargo el porcentaje de recuperación aún sigue siendo muy bajo (menor al 15\%) (SMA, 2015).

En cuanto a los residuos líquidos, las acciones relacionadas con la gestión de las aguas residuales para la descontaminación del río Medellín (Río Aburrá) y sus quebradas afluentes, se encuentran consolidadas en el Plan de Saneamiento y Manejo de Vertimientos. El proceso de descontaminación se realiza mediante la recolección, transporte, tratamiento y disposición final de las aguas residuales descargadas al sistema público de alcantarillado, el cual se espera que incremente la capacidad de recolección y transporte hacia las plantas de tratamiento de aguas residuales de San Fernando y Bello.

A continuación se describe el indicador con el que se evaluará este reto:

\begin{tabular}{|c|c|c|c|c|c|}
\hline Nombre & Descripción variables & Unidad & $\begin{array}{c}\text { Línea de } \\
\text { Base }\end{array}$ & Meta 2019 & $\begin{array}{c}\text { Respon } \\
\text { sable }\end{array}$ \\
\hline $\begin{array}{c}\text { Estrategias } \\
\text { implementadas } \\
\text { para fortalecer } \\
\text { la gestión } \\
\text { integral de } \\
\text { Medio } \\
\text { Ambiente }\end{array}$ & $\begin{array}{l}\text { Estrategias } \\
\text { implementadas para el } \\
\text { fortalecimiento y la } \\
\text { sostenibilidad de los } \\
\text { recursos naturales }\end{array}$ & Número & $\mathrm{O}$ & 25 & $\begin{array}{c}\text { Grupo } \\
\text { de } \\
\text { líderes } \\
\text { de la } \\
\text { Secreta } \\
\text { ría de } \\
\text { Medio } \\
\text { Ambien } \\
\text { te }\end{array}$ \\
\hline
\end{tabular}




\subsubsection{PROGRAMA: INFRAESTRUCTURA VERDE: GENERACIÓN, CONSERVACIÓN Y MANTENIMIENTO DE ESPACIOS VERDES}

Programa que busca la generación, conservación y mantenimiento de espacios verdes. Estos proyectos a su vez buscan fortalecer el componente $\begin{array}{lllll}\text { arbóreo } & \mathrm{y} & \text { paisajístico le ciudad. }\end{array}$

Indicador de resultado

\begin{tabular}{|c|c|c|c|c|c|}
\hline Nombre & $\begin{array}{c}\text { Descripción } \\
\text { variables }\end{array}$ & Unidad & $\begin{array}{l}\text { Línea de } \\
\text { Base }\end{array}$ & Meta 2019 & Responsable \\
\hline $\begin{array}{l}\text { Zonas Verdes } \\
\text { Recuperadas }\end{array}$ & $\begin{array}{l}\text { Metros } \\
\text { cuadrados de } \\
\text { zonas públicas en } \\
\text { piso duro } \\
\text { convertidas en } \\
\text { zonas verdes }\end{array}$ & $\begin{array}{l}\text { Metros } \\
\text { cuadrados }\end{array}$ & 0 & 10000 & $\begin{array}{l}\text { Equipo de } \\
\text { Silvicultura } \\
\text { JAIME } \\
\text { GÓMEZ G. }\end{array}$ \\
\hline
\end{tabular}

7.1.1.1 Proyecto: Ecoparques en borde y ladera de ciudad

Espacios verdes asociados a retiros de quebradas diseñados y construidos con base en siembra de árboles, establecimiento de paisajismo y pequeño mobiliario para su aprovechamiento y apropiación de la comunidad en forma activa y pasiva.

Indicador de producto

Responsable: Secretaría de Medio Ambiente

\begin{tabular}{|c|c|}
\hline Nombre & Unidad \\
\hline Ecoparques Construidos & Número \\
\hline
\end{tabular}

7.1.1.2 Proyecto: Consolidación de redes ecológicas para la protección de la fauna y la flora

$\stackrel{15}{\underline{\underline{1}}}$

Las redes ecológicas se consolidan como la infraestructura verde urbana necesaria para conformar adecuados corredores biológicos que permitan el tránsito y asentamiento de fauna silvestre, especialmente avifauna, con conectividad desde el borde de la zona rural hasta el cauce del rio Medellín.

Indicador de producto

Responsable: Secretaría de Medio Ambiente.

\begin{tabular}{|c|c|} 
Nombre & Unidad \\
\hline Redes Ecológicas Fortalecidas & Número \\
\hline
\end{tabular}

7.1.1.3 Proyecto: Declaratoria de árboles patrimoniales para Medellín Existen árboles en la ciudad que, por su singularidad, técnicamente demostrada, deben conservarse, protegerse y preservarse, por lo tanto se deben emprender acciones de declarativa para cumplir con su cuidado.

Responsable: Departamento Administrativo de Planeación 
Indicador de producto

Nombre

Unidad

Número

7.1.1.4 Proyecto: Valoración estructura ecológica urbana e instrumentos económicos y financieros para garantizar la sostenibilidad de las zonas verdes.

La valoración de los servicios ambientales que prestan las áreas verdes urbanas, nos permitirán dimensionar la importancia de estos espacios para la ciudad y contar con herramientas para el trámite de recursos de fuentes externas para su protección.

Indicador de producto

Responsable: Secretaría de Medio Ambiente

\begin{tabular}{|c|c|}
\hline Nombre & Unidad \\
\hline Arboles Urbanos Sembrados & Número \\
\hline Árboles Producidos para Restauración & Número \\
\hline
\end{tabular}

7.1.1.5 Proyecto: Formulación y ejecución de la estrategia de generación, conservación y recuperación de las áreas verdes urbanas

Este proyecto busca poner en marcha el Acuerdo en 47 que se encuentra en reglamentación, a partir de una Estrategia integral la cual consiste en establecer una metodología para la valoración multidimensional de los espacios verdes de la ciudad, y propender por las acciones de: generación, recuperación y mantenimiento de las zonas verdes.

Indicador de producto

Responsable: Secretaría de Medio Ambiente

\begin{tabular}{|c|c|}
\hline Nombre & Unidad \\
\hline Zonas Verdes intervenidas en retiros de quebradas & $\begin{array}{c}\text { Metro } \\
\text { lineal }\end{array}$ \\
\hline
\end{tabular}

\subsubsection{PROGRAMA: ESTRUCTURA ECOLÓGICA Y SUS SERVICIOS ECOSISTÉMICOS}

Todos los proyectos de este programa están dirigidos a proteger y mejorar los ecosistemas que dan soporte a la vida en el Municipio de Medellín. Pretende reconocer y mejorar las condiciones de los recursos naturales; se constituye en un tema transversal al territorio urbano - rural y que trasciende los límites administrativos de Medellín y del Área Metropolitana. 
Indicador de resultado

\begin{tabular}{|c|c|c|c|c|c|}
\hline Nombre & $\begin{array}{c}\text { Descripción } \\
\text { variables }\end{array}$ & Unidad & $\begin{array}{c}\text { Línea de } \\
\text { Base }\end{array}$ & Meta 2019 & Responsable \\
\hline $\begin{array}{l}\text { Elementos de la } \\
\text { estructura } \\
\text { ecológica } \\
\text { intervenidos para } \\
\text { el mejoramiento } \\
\text { de la oferta de } \\
\text { servicios } \\
\text { ecosistémicos }\end{array}$ & $\begin{array}{lr}\begin{array}{l}\text { Areas } \\
\text { conforman }\end{array} & \begin{array}{r}\text { que } \\
\text { estructura }\end{array} \\
\text { ecológica } & \text { del } \\
\text { municipio, con } \\
\text { intervenciones } \\
\text { para } & \text { su } \\
\text { recuperación, } & \\
\text { protección } & \text { y } \\
\text { conservación } & \end{array}$ & Número & 22 & 30 & $\begin{array}{l}\text { Secretaría } \\
\text { Medio } \\
\text { Ambiente }\end{array}$ \\
\hline
\end{tabular}

7.1.2.1 Proyecto: Restauración y aumento de la cobertura boscosa de Medellín

Reúne las acciones necesarias para garantizar una restauración y aumento de la cobertura boscosa del territorio municipal, a través de producción de materia vegetal y fortalecimiento del vivero municipal, y la implementación de sistemas agroforestales como medida de protección de los suelos rurales y de protección.

Indicador de producto

Responsable: Secretaría de Medio Ambiente

\begin{tabular}{|c|c|} 
Nombre & Unidad \\
\hline Arboles sembrados en la zona rural & Número \\
\hline
\end{tabular}

\subsubsection{Proyecto: Gestión para la protección del recurso hídrico}

Busca mejorar la oferta de los servicios eco sistémicos asociados al recurso hídrico, e incluye las siguientes acciones: Restauración y 13 protección de las Cuencas Externas de importancia para Medellín Q (Fondo del Agua), identificación, caracterización y planes de manejo de cuencas de orden cero, ojos de agua y salados y ompra y administración de predios e implementación de esquemas de pagos por servicios ambientales en microcuencas abastecedoras de acueductos veredales (Ley 99 del 93)

Indicador de producto

Responsable: Secretaría de Medio Ambiente

Cuencas externas restauradas en zonas fuera de Medellín (Fondo del Agua) Unidad

7.1.2.3 Proyecto: Gestión de áreas protegidas y áreas estratégicas para la sostenibilidad ambiental

Se refiere al apoyo de la ejecución de los planes de manejo de las áreas protegidas, cerros tutelares y otras áreas de interés estratégico ambiental, en coordinación con las autoridades ambientales.

Responsable: Secretaría de Medio Ambiente 


\section{Una apuesta de ciudad por el cuidado del medio ambiente}

Indicador de producto

\begin{tabular}{|c|c|}
\hline Nombre & Unidad \\
\hline Áreas protegidas con plan de manejo adoptado y que están siendo administradas & Número \\
\hline Estructura ecológica restaurada & Hectáreas \\
\hline
\end{tabular}

\subsubsection{Proyecto: Conocimiento, valoración y gestión de la biodiversidad y los servicios ecosistémicos}

Este proyecto se refiere a la implementación de la política de biodiversidad. Acuerdo 10 de 2014, a través de la cual se busca continuar con la implementación del Centro de investigaciones para la Biodiversidad y los servicios ecosistémicos.

Se incluye además la conservación y fortalecimiento de El Refugio de Vida Silvestre Alto de San Miguel, donde se está implementando el Centro de investigaciones para la Biodiversidad y los servicios ecosistémicos.

Indicador de producto

Responsable: Secretaría de Medio Ambiente

\begin{tabular}{|c|c|}
\hline Nombre & Unidad \\
\hline Investigaciones en biodiversidad realizadas & Número \\
\hline
\end{tabular}

\subsubsection{Proyecto: Recuperación de suelos degradados}

"周灌田 Este proyecto busca la recuperación de áreas degradadas por inadecuadas prácticas agrícolas y de actividad minera.

Responsable: Secretaría de Medio Ambiente

Indicador de producto Áreas de suelos degradados intervenidas

\subsubsection{PROGRAMA: NUESTRO RIO Y SUS QUEBRADAS}

Lo estipulado por la subcomisión técnica del Convenio Nuestro Río estableció como objetivo generar un equipo de trabajo que materialice las iniciativas del plan operativo formulado por esta subcomisión, lo cual puede asociarse con el objetivo de revivir el instituto Mi Río con un nuevo énfasis actualizado a las necesidades de la adaptación al cambio climático.

Indicador de resultado

\begin{tabular}{|c|c|c|c|c|c|}
\hline Nombre & $\begin{array}{c}\text { Descripción } \\
\text { variables }\end{array}$ & Unidad & $\begin{array}{c}\text { Línea de } \\
\text { Base }\end{array}$ & Meta 2019 & Responsable \\
\hline $\begin{array}{c}\text { Quebradas } \\
\text { intervenidas, } \\
\text { mantenidas y } \\
\text { recuperadas } \\
\text { metros lineales } \\
\text { de quebradas } \\
\text { con intervención, } \\
\text { recupenimiento y }\end{array}$ & Metro lineal & NA & 5000 & $\begin{array}{c}\text { Unidad } \\
\text { del Renamiento } \\
\text { Hidrico }\end{array}$ \\
\hline
\end{tabular}




\subsubsection{Proyecto: Nuestro Río}

El convenio "Nuestro Río", suscrito entre el Municipio de Medellín Secretaría del Medio Ambient e, el AMVA, Corantioquia, Cornare, EPM, y el Metro de Medellín, se ha trazado un importante reto como lo es la recuperación del río Medellín-Aburrá y sus afluentes, como una apuesta de ciudad que tiene como fin la articulación institucional en pro de la recuperación y mejoramiento ambiental, ecológica y paisajística del sistema hídrico de la ciudad y el territorio metropolitano así como la infraestructura asociada a este sistema, en la búsqueda de una ciudad sostenible en un horizonte de planificación de 10 años.

En este sentido, se establece en el Convenio grandes momentos o etapas: Un primer momento o etapa Planeación que se lleva a cabo desde la firma del convenio hasta diciembre de 2015, y un segundo momento o etapa de Ejecución, donde se llevarán a cabo las obras priorizadas, pero también se definirán los mecanismos y herramientas administrativas, jurídicas y financieras que permitan la ejecución del convenio (planes, programas y proyectos) en el plazo de 10 años.

Indicador de producto

Responsable: Secretaría de Medio Ambiente

\begin{tabular}{|c|c|}
\hline Nombre & Unidad \\
\hline Estrategias de mitigación, prevención del riesgo, recuperación y conservación del Río y & Número \\
todos sus afluentes, formuladas y evaluadas
\end{tabular}

\subsubsection{Proyecto: Las quebradas recuperan su cauce}

El objetivo básico es identificar, planear y atender las diferentes

${ }^{6}$ solicitudes asociadas a eventos en quebradas con el fin de apoyar, definir, priorizar y coordinar la ejecución de actividades para el mantenimiento de los cauces de quebradas contribuyendo al mejoramiento hidráulico de las corrientes.

Indicador de producto

Responsable: Secretaría de Medio Ambiente

\begin{tabular}{|c|c|}
\hline Nombre & Unidad \\
\hline Tramos de quebradas recuperados integralmente & Metro \\
\hline
\end{tabular}

7.1.3.3 Proyecto: Ejecución de Estudios para optimizar el manejo del recurso hídrico en atención a requerimientos del Plan de Ordenamiento Territorial

EI POT dejó como tarea el desarrollo de diferentes planes de manejo para diferentes tipos de elementos de la estructura ecológica principal, como lo son los ojos de sal y el acuífero, entre otros. Son proyectos estipulados para cumplirse en el corto y mediano plazo.

Indicador de producto

Responsable: Secretaría de Medio Ambiente

\begin{tabular}{|c|c|}
\hline Nombre & Unidad \\
\hline Recurso hídrico con políticas de Intervención, de acuerdo con el POT & Número \\
\hline
\end{tabular}




\subsubsection{PROGRAMA: GESTIÓN INTEGRAL DE RESIDUOS SÓLIDOS}

La dinámica de ciudad incluye entre sus componentes ambientales la generación de residuos sólidos, hoy Medellín cuenta con estrategias que han permitido fomentar avances positivos en la cultura ambiental de sus habitantes para el manejo integral de los mismos, sin embargo aún persiste la inadecuada separación en la fuente, la presencia de puntos críticos, el débil reconocimiento del reciclador en la cadena de aprovechamiento y las pocas acciones de producción y consumo sostenible. Así mismo se encuentran dificultades para desarrollar la actividad de aprovechamiento eficiente de residuos sólidos, unido a la falta de implementación de tecnologías en economía de escala para la ciudad.

Indicador de resultado

\begin{tabular}{|c|c|c|c|c|c|}
\hline Nombre & $\begin{array}{c}\text { Descripción } \\
\text { variables } \\
\end{array}$ & Unidad & $\begin{array}{c}\text { Línea de } \\
\text { Base }\end{array}$ & Meta 2019 & Responsable \\
\hline $\begin{array}{l}\text { Residuos sólidos } \\
\text { generados } \\
\text { dispuestos en sitio } \\
\text { de disposición } \\
\text { final }\end{array}$ & $\begin{array}{l}\text { Toneladas de } \\
\text { residuos sólidos } \\
\text { dispuestas en un } \\
\text { sitio adecuado de } \\
\text { disposición final/ } \\
\text { toneladas de } \\
\text { residuos sólidos } \\
\text { totales } \\
\text { generadas. }\end{array}$ & Porcentaje & 87 & 87 & $\begin{array}{l}\text { Secretaría de } \\
\text { Gestión y } \\
\text { Control } \\
\text { Territorial }\end{array}$ \\
\hline $\begin{array}{l}\text { Puntos críticos } \\
\text { recuperados }\end{array}$ & $\begin{array}{l}\text { Son los puntos } \\
\text { críticos de } \\
\text { residuos sólidos } \\
\text { intervenidos de } \\
\text { manera integral } \\
\text { para su } \\
\text { recuperación }\end{array}$ & Número & 205 & 62 & $\begin{array}{c}\text { Secretaría de } \\
\text { Medio } \\
\text { Ambiente }\end{array}$ \\
\hline $\begin{array}{c}\text { Cobertura de la } \\
\text { actividad de } \\
\text { Barrido }\end{array}$ & $\begin{array}{c}\text { Total kilómetros } \\
\text { efectivamente } \\
\text { barridas/ total } \\
\text { km vías y áreas } \\
\text { públicas }\end{array}$ & Porcentaje & 86 & 90 & $\begin{array}{c}\text { Secretaría de } \\
\text { Gestión y } \\
\text { Control } \\
\text { Territorial }\end{array}$ \\
\hline
\end{tabular}

7.1.4.1 Proyecto: Implementación, seguimiento, revisión y actualización de los PGIRS para el cuidado de los recursos naturales

Este proyecto comprende todas las acciones encaminadas a cumplir con los PGIRs para el cuidado de los recursos naturales, haciendo acuerdos de desarrollo estratégicos para la innovación y tecnología

13 en la gestión de los residuos sólidos (valorización de residuos), apoyados con la gestión institucional para la reconversión de puntos críticos, con el propósito de reconvertir los puntos críticos que actualmente existen en el área urbana del Municipio de Medellín y disminuir la posibilidad en la reaparición de nuevos puntos.

Además de tener estrategias para la gestión de las zonas verdes objeto de corte y de los individuos arbóreos ubicados en vías y áreas 
públicas, promover e incentivar el aprovechamiento de los residuos sólidos y posicionamiento de la labor de los recicladores en el municipio, implementar un modelo operativo y tecnológico que garantice la gestión de los residuos especiales: los peligrosos, los residuos de construcción y demolición, entre otros.

Indicador de producto

Responsable: Secretaría de Medio Ambiente

\begin{tabular}{|c|c|}
\hline Nombre & Unidad \\
\hline Material Reciclable Aprovechado & Toneladas \\
\hline
\end{tabular}

7.1.4.2Proyecto: Ubicación de sitios para la gestión de RCD, RESPEL y aprovechamiento

Se desarrollarán estudios que permitan determina la ubicación de sitios estratégicos para la Gestión integral de los residuos sólidos ordinarios, ya que en la actualidad no se cuenta con un lugar que pueda hacer las veces de disposición final, cuando el relleno sanitario actual (La Pradera) cumpla con su vida útil o cuando por diferentes situaciones de calamidad o dificultades temporales no se puedan disponer allí los residuos. El proyecto además determinará los sitios que para la gestión de residuos sólidos aprovechables como las Estaciones de Clasificación y aprovechamiento, Gestión de Residuos peligrosos y la transformación de Residuos de la Construcción y Demolición como CATES y Escombreras; además sitios para aprovechamiento de orgánicos entre otros, según lo establecido en el PGIRS municipal que se requieran en el municipio.

Responsable: Secretaría de Gestión Territorial y Departamento Administrativo de Planeación

Indicador de producto

\begin{tabular}{|c|c|}
\hline Nombre & Unidad \\
\hline Sitios evaluados para gestión de RCD, RESPEL y aprovechamiento & Número \\
\hline
\end{tabular}

7.1.4.3Proyecto: Optimización de estrategias para la gestión de residuos sólidos

13 Realizar un mejoramiento continuo de acciones encaminadas a la gestión integral de los residuos sólidos, mediante la implementación de acuerdos y políticas locales que fortalezcan el desarrollo sostenible de la ciudad de una manera innovadora.

Indicador de producto

Responsable: Secretaría de Medio Ambiente

\begin{tabular}{|c|c|}
\hline Nombre & Unidad \\
\hline Acuerdos y políticas de ciudad implementados y con seguimiento & Número \\
\hline
\end{tabular}

\subsubsection{PROGRAMA: PROTECCIÓN ANIMAL}

Dentro las acciones encaminadas al cuidado y bienestar animal se tienen las siguientes acciones: Operación del centro de bienestar animal La Perla, el cual incluye acciones como el Rescate, la Atención 
Médica Veterinaria Integral, la Atención a la comunidad; Educación en tenencia responsable; Atención animal de compañía comunal y animal de compañía escolar; Adopción; entre otros proyectos.

Indicador de resultado

\begin{tabular}{|c|c|c|c|c|c|}
\hline Nombre & $\begin{array}{c}\text { Descripción } \\
\text { variables }\end{array}$ & Unidad & $\begin{array}{c}\text { Línea de } \\
\text { Base }\end{array}$ & Meta 2019 & Responsable \\
\hline $\begin{array}{l}\text { Animales atendidos } \\
\text { a través del } \\
\text { programa de } \\
\text { Bienestar Animal }\end{array}$ & $\begin{array}{l}\text { Corresponde a } \\
\text { los nuevos } \\
\text { animales caninos, } \\
\text { felinos y } \\
\text { semovientes } \\
\text { alojados y } \\
\text { esterilizados y } \\
\text { devueltos } \\
\text { (caninos y } \\
\text { felinos) }\end{array}$ & Número & 14326 & 12000 & $\begin{array}{l}\text { Equipo } \\
\text { Bienestar } \\
\text { Animal }\end{array}$ \\
\hline
\end{tabular}

\subsubsection{Proyecto: Fortalecer MICHIP}

Este sistema de identificación se basa en la tecnología del $\mathbf{5} \mathbf{2}$ - Microchip, que ofrece una alternativa de seguridad de la I información y permite tener un mejor control de los animales, extraviados. además es de gran utilidad en la identificación de perros y gatos

Indicador de producto

Responsable: Secretaría de Medio Ambiente Animales identificados con microchip Unidad

\subsubsection{Proyecto: Fortalecimiento del Centro de Bienestar Animal La Perla y puntos móviles para la promoción de la adopción}

El Centro de Bienestar Animal La Perla, se ha constituido como un proyecto de gran importancia para la ciudad, puesto que a través de este se ha reducido considerablemente la presencia de perros y gatos callejeros, aumentando su calidad de vida y velando por el respeto hacia los animales de nuestra ciudad, dándoles la oportunidad de ser atendidos en sus condiciones de salud y de ser adoptados y tener un hogar y amor, cuando en la calle no lo tenían. Adicionalmente, el Centro de Bienestar Animal La Perla también brinda atención a semovientes (ganado vacuno, equinos, etc.), que también se ven desamparados, abandonados $\mathrm{y} / \mathrm{o}$ maltratados, encontrando aquí un bienestar único frente a las inadecuadas condiciones en las que se encuentran lamentablemente en algunos casos.

Responsable: Secretaría de Medio Ambiente Indicador de producto

\begin{tabular}{|c|c|}
\hline Nombre & Unidad \\
\hline Personas sensibilizadas en tenencia responsable & Número \\
\hline
\end{tabular}




\subsubsection{Proyecto: Plan Padrino}

15 Este programa busca garantizar la educación para una tenencia responsable de mascotas, además de generar programas de voluntariado que persigan el mismo ideal.

Indicador de producto

Responsable: Secretaría de Medio Ambiente Animales entregados en adopción

\subsubsection{PROGRAMA: SISTEMA DE GESTIÓN AMBIENTAL INTEGRAL DE MEDELLÍN PARA EL CAMBIO CLIMÁTICO}

Se considera la elaboración del Plan de Mitigación y Adaptación al Cambio Climático, así como la priorización de algunas acciones para enfrentar en cambio climático, identificadas durante la elaboración de dicho plan. Se busca el cumplimiento de las obligaciones consignadas en el acuerdo 48 de 2014 y el acuerdo 46 de 2015. Todas las acciones deben estar articuladas con las directrices nacionales y los compromisos adquiridos por Colombia en la Conferencia de las Partes, en su versión 21, llevada a cabo en París.

Indicador de resultado

\begin{tabular}{|l|c|c|c|c|}
\hline \multicolumn{1}{|c|}{ Nombre } & Unidad & $\begin{array}{c}\text { Línea de } \\
\text { Base }\end{array}$ & Meta 2019 & Responsable \\
\hline $\begin{array}{l}\text { Medidas para enfrentar el cambio } \\
\text { climático implementadas }\end{array}$ & Número & NA & 3 & $\begin{array}{c}\text { Secretaría de } \\
\text { Medio Ambiente }\end{array}$ \\
\hline $\begin{array}{l}\text { Instancias de Coordinación Institucional } \\
\text { Fortalecidas }\end{array}$ & Número & 13 & 14 & $\begin{array}{c}\text { Secretaría de } \\
\text { Medio Ambiente }\end{array}$ \\
\hline
\end{tabular}

7.1.6.1 Proyecto: Estructura para la Gestión Ambiental Integral de Medellín

Se trata de todas las herramientas para la gestión ambiental articulado en el municipio de Medellín así como las intervenciones integrales según temática o territorio. Se incluyen herramientas tecnológicas y operativas como el sistema de información ambiental y el plan ambiental de Medellín

Indicador de producto

Responsable: Secretaría de Medio Ambiente

\begin{tabular}{|c|c|}
\hline Nombre & Unidad \\
\hline Componentes del SIAMED actualizados y mantenidos & Fases \\
\hline
\end{tabular}

7.1.6.2 Proyecto: Habilitación Ambiental del Morro de Basuras de Moravia Las acciones de habilitación ambiental incluyen tecnologías amigables con el ambiente, el monitoreo permanente de las condiciones en el morro, la expansión del mejoramiento del hábitat para los habitantes de Moravia y el mantenimiento de las estructuras para la 
fitoremediación, bioremediación y tratamiento de lixiviados. Finalmente, se incorporan acciones de tipo social y productivo, que vinculan madres cabeza de familia y otros grupos sociales de Moravia.

Responsable: Secretaría de Medio Ambiente

Indicador de producto

\begin{tabular}{|l|c|}
\hline Nombre & Unidad \\
\hline Metros sostenidos y adecuados de parcelas & Metros \\
cuadrados
\end{tabular}

\subsubsection{Proyecto: Intervenciones sociales y ambientales integrales}

La articulación interinstitucional, permite realizar intervenciones ambientales integrales, que mejoran las condiciones de hábitat y aportan a la sostenibilidad mediante la apropiación por parte de la comunidad, con acciones de educación ambiental in situ. Se realizan diagnósticos permanentes para identificar los puntos más críticos en la ciudad y se vinculan todas las dependencias de la administración municipal, para que desde su misión mitiguen y prevengan posibles impactos ambientales para la ciudadanía.

Responsable: Secretaría de Medio Ambiente

Indicador de producto

\begin{tabular}{|l|l|}
\hline \multicolumn{1}{|c|}{ Nombre } & Unidad \\
\hline $\begin{array}{l}\text { Alianzas interinstitucionales para el mejoramiento de las condiciones ambientales } \\
\text { realizadas }\end{array}$ & Número \\
\hline
\end{tabular}

\subsubsection{Proyecto: Plan de mitigación y adaptación al cambio climático} En el marco del cumplimiento del Plan de Ordenamiento Territorial, y el acuerdo 46 de 2015, "por medio del cual se adopta la estrategia integral para la gestión del cambio climático y la variabilidad climática en el municipio de Medellín", con este proyecto se busca la elaboración de una herramienta de gestión, en la cual se ordenen las acciones asociadas a cambio climático, en la ciudad de Medellín.

Indicador de producto

Responsable: Secretaría de Medio Ambiente

\begin{tabular}{|c|c|}
\hline \multicolumn{1}{|c|}{ Nombre } & Unidad \\
\hline Plan de gestión integral para el cambio climático formulado & Número \\
\hline
\end{tabular}

\subsubsection{Proyecto: Acciones de Mitigación y Adaptación al Cambio} Climático

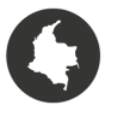
A partir de lo identificado en el Plan de Mitigación y Adaptación al Cambio Climático, se propone priorizar algunas acciones integrales que se consideren prioritarias y que no estén siendo ejecutadas dentro de las acciones misionales priorizadas por las dependencias del municipio. 
Indicador de producto

\begin{tabular}{|c|c|}
\hline \multicolumn{1}{|c|}{ Nombre } & Unidad \\
\hline Acciones integrales en cambio climático ejecutadas & Número \\
\hline
\end{tabular}

\subsubsection{PROGRAMA: SALUD AMBIENTAL}

De acuerdo con el Plan Decenal de Salud Pública 2012-2021, la salud ambiental es una dimensión prioritaria y la define como el "Conjunto de políticas, planificado y desarrollado de manera transectorial, con la participación de los diferentes actores sociales, que busca favorecer y promover la calidad de vida y salud de la población, de las presentes y futuras generaciones, y materializar el derecho a un ambiente sano, a través de la transformación positiva de los determinantes sociales, sanitarios y ambientales.

Indicador de resultado

\begin{tabular}{|c|c|c|c|c|c|}
\hline Nombre & $\begin{array}{c}\text { Descripción } \\
\text { variables }\end{array}$ & Unidad & $\begin{array}{c}\text { Línea de } \\
\text { Base }\end{array}$ & Meta 2019 & Responsable \\
\hline $\begin{array}{l}\text { Construcción, } \\
\text { implementación y } \\
\text { evaluación del } \\
\text { índice de salud } \\
\text { ambiental } \\
\text { (CEPAL) }\end{array}$ & $\begin{array}{c}\text { Porcentaje de } \\
\text { avance de la } \\
\text { construcción, } \\
\text { implementación } \\
\text { y evaluación del } \\
\text { indice de salud } \\
\text { ambiental } \\
\text { (CEPAL) }\end{array}$ & Porcentaje & N.D & 100 & Sec. Salud \\
\hline
\end{tabular}

7.1.7.1 Proyecto: Establecimientos y servicios sanos, seguros y saludables Desde el cual se realizan acciones de inspección, vigilancia y control de los factores de riesgo asociados al consumo de bienes y servicios, necesarias para proteger la salud humana individual y colectiva, bajo el marco de la seguridad sanitaria, la gestión del riesgo, desde su detección temprana hasta su intervención oportuna.

Indicador de producto

Responsable: Secretaría de Salud

\begin{tabular}{|c|c|}
\hline Nombre & Unidad \\
\hline Cobertura de establecimientos de alto riesgo priorizados con auditoria sanitaria & Porcentaje \\
\hline
\end{tabular}

7.1.7.2 Proyecto: Gestión integral para la prevención y control de enfermedades transmitidas por vectores y zoonosis

Las enfermedades trasmitidas por vectores y zoonosis representan una seria problemática en la salud de la población mundial, nacional y local, lo que ha generado el alistamiento de los países para enfrentar grandes retos en materia de prevención y control. Medellín no es ajena a estas problemáticas y debe alinearse a este proceso basado en estrategias de gestión integral, donde se articulen los diferentes actores que deben hacen parte de las intervenciones de a los factores de riesgo y dinámicas de trasmisión de estas enfermedades. 
Con los resultados se espera la disminución de la morbilidad y mortalidad por enfermedades endémicas y epidémicas como el Dengue, Chicungunya, y Zika, entre otras. Así como también a mantener en cero la incidencia de enfermedades zoonóticas como la rabia y a establecer líneas de base en otras zoonosis para orientar acciones. Además, de impactar positivamente en los costos para el sistema de salud, y los que recaen sobre el sector productivo por los gastos los costos generados por incapacidades médicas.

Indicador de producto

Responsable: Secretaría de Salud

\begin{tabular}{|c|c|}
\hline Nombre & Unidad \\
\hline Vigilancia entomológica de vectores de dengue chikunguña y zika & Porcentaje \\
\hline Coberturas del programa de control de natalidad en caninos y felinos & Número \\
\hline
\end{tabular}

7.1.7.3 Proyecto: Gestión integral de riesgos sanitarios del ambiente Conformado por un conjunto de acciones de promoción, prevención, gestión interinstitucional e intersectorial, vigilancia y control de riesgos sanitarios y ambientales para la salud, asociados a la calidad del agua para consumo humano, de uso terapéutico, recreacional; residuos líquidos, la calidad del aire, el ruido, radiaciones, residuos sólidos y cambio climático que permitan modificar la carga ambiental de la enfermedad.

Indicador de producto

Responsable: Secretaría de Salud

\begin{tabular}{|c|c|}
\hline Nombre & Unidad \\
\hline Formulación, aprobación y divulgación de la política de salud ambiental & Porcentaje \\
\hline
\end{tabular}

\subsubsection{PROGRAMA: POR LA CALIDAD DEL AIRE QUE RESPIRAMOS}

Con este programa se busca fortalecer los instrumentos, mecanismos y medios de pedagogía y educación ambiental, así como el fortalecimiento de las buenas prácticas ambientales en diferentes ámbitos para que se genere conciencia social sobre el cuidado del aire y se contribuya a través de estas estrategias con el mejoramiento de la calidad del mismo.

Indicador de resultado

\begin{tabular}{|c|c|c|c|c|c|}
\hline Nombre & $\begin{array}{c}\text { Descripción } \\
\text { variables }\end{array}$ & Unidad & $\begin{array}{c}\text { Línea de } \\
\text { Base }\end{array}$ & Meta 2019 & Responsable \\
\hline $\begin{array}{c}\text { Concentración de } \\
\text { material articulado } \\
\text { (PM }\end{array}$ & $\begin{array}{c}\text { VO: Nivel máximo } \\
\text { permisible en un } \\
\text { metro cúbico de } \\
\text { aire. }\end{array}$ & $\mathrm{mg} / \mathrm{m3}$ & 21 & 19 & $\begin{array}{c}\text { Medio } \\
\text { Ambiente }\end{array}$ \\
\hline
\end{tabular}


7.1.8.1 Proyecto: Impulsar desde la institucionalidad la movilidad amigable con el medio ambiente

Tiene como origen las iniciativas que ha venido teniendo EPM en términos de la innovación en el fomento del uso de energías alternativas en diferentes escenarios, como en la movilidad, con la introducción de vehículos y bicicletas eléctricas como opción amigable con el medio ambiente y específicamente con la calidad del aire que respiramos en el valle de Aburrá.

Indicador de producto

Responsable: Secretaria de Medio Ambiente

\begin{tabular}{|c|c|}
\hline Nombre & Unidad \\
\hline Campañas de educación sobre movilidad amigable realizadas & Número \\
\hline
\end{tabular}

7.1.8.2 Proyecto: Adelantar campañas masivas de calidad de combustibles y del buen manejo de gases móviles e industriales

"11. Con este proyecto se pretende dar continuidad al trabajo

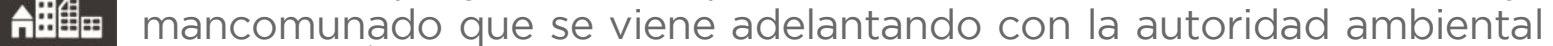
urbana, el Área Metropolitana del Valle de Aburrá, en torno a mejorar cada vez más la calidad de los combustibles utilizados en el territorio municipal, tanto en vehículos como en sectores industriales.

Indicador de producto

Responsable: Secretaria de Medio Ambiente

\begin{tabular}{|c|c|}
\hline Nombre & Unidad \\
\hline $\begin{array}{c}\text { Campañas de educación sobre calidad de combustibles y del buen manejo } \\
\text { móviles e industriales realizadas }\end{array}$ & \\
\hline
\end{tabular}




\subsection{RETO}

ACCESO DE CALIDAD A LOS SERVICIOS PÚBLICOS

\section{PROGRAMAS}

$\Delta$ 7.2.1. Medellín con acceso de calidad al acueducto y al alcantarillado

4 7.2.2. Gestión integral de los servicios públicos

\section{OBJETIVO}

Facilitar y promover el acceso de todas las personas a viviendas $y$ servicios básicos adecuados y de calidad. 
Una apuesta de ciudad por el cuidado del medio ambiente

\subsection{Acceso de calidad a los servicios públicos}

Garantizar la prestación eficiente y efectiva de los servicios públicos básicos es un derecho esencial y condición fundamental para una vida digna y saludable. En el contexto colombiano, Medellín ha sido líder en este tema, al presentar coberturas de $99,95 \%$ en el servicio de energía, $95,8 \%$ en acueducto, $88,6 \%$ en alcantarillado y $89,5 \%$ en aseo; se destaca también la operación de 27 sistemas de acueducto y/o alcantarillado en los corregimientos y la certificación de calidad de agua apta para consumo humano por varios años (Subsecretaría de servicios públicos, 2014).

Dicho liderazgo ha estado permeado por elementos como la implementación del programa Mínimo Vital de Agua Potable (MVAP), pionero en Colombia, que desde el año 2009 ha beneficiado a más de 41.000 hogares (Subsecretaría de servicios públicos, 2015). Adicionalmente, es la única ciudad de Suramérica que pertenece a la Asociación Internacional de Ciudades Mejor Iluminadas del Mundo ( $\mathrm{LUCl}$ ).

Sin embargo, aún existen dificultades en el acceso a los servicios públicos esenciales en algunos sectores de la ciudad. Las cifras de pobreza y desigualdad para Medellín, indican que para el año 2014, la población en situación de pobreza era de 291.115 habitantes (DAP, 2014); debido a condiciones de vulnerabilidad socioeconómica, 11.848 viviendas presentan corte del servicio de energía por mora, 19.101 viviendas en el servicio de acueducto y 13.146 en el servicio de gas domiciliario (EPM, 2015). Estas cifras corresponden a menos del $2 \%$ del total de instalaciones del municipio.

Para el año 2014, 27.581 viviendas presentaban situación de carencia (déficit cualitativo) en temas de servicios públicos domiciliarios (acueducto o alcantarillado); esta cifra representa un aumento del $2 \%$ con respecto al año 2013. (Encuesta SISBEN, 2013) 


\section{Una apuesta de ciudad por el cuidado del medio ambiente}

\section{Gráfico 23: Servicios públicos en viviendas2014}

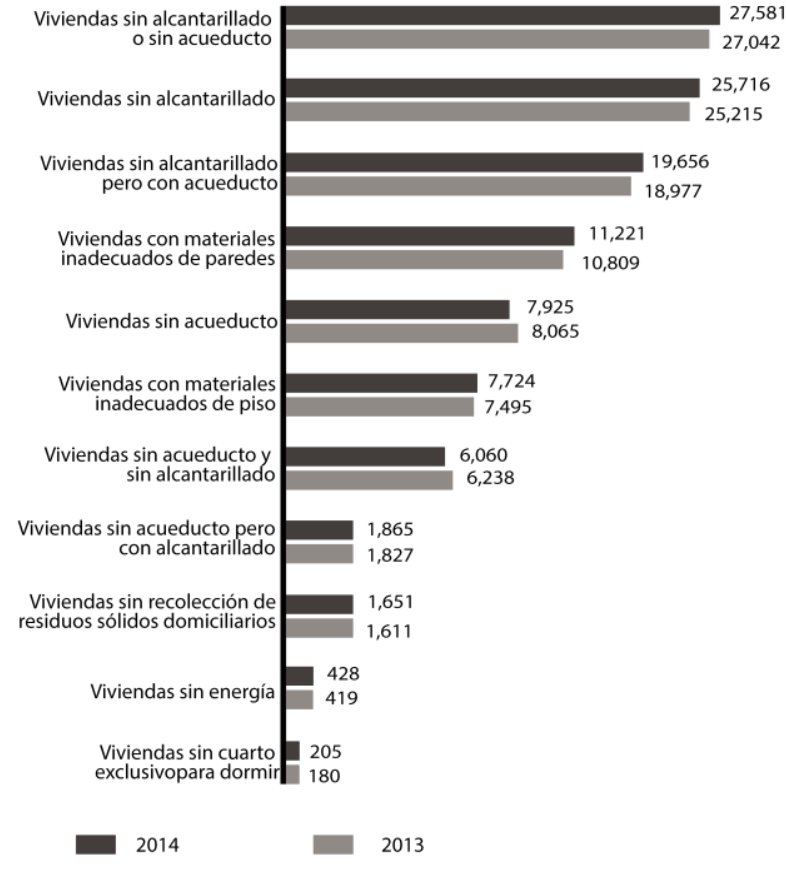

Fuente: Bases de datos Certificadas SISBEN Verción III, 2013-2014 Subdirección de Información, Seguimiento y Evaluación Estratégica.

A continuación se muestran los indicadores de resultado que se evaluarán en este reto:

\begin{tabular}{|c|c|c|c|c|c|}
\hline Nombre & Descripción variables & Unidad & $\begin{array}{c}\text { Línea de } \\
\text { Base }\end{array}$ & Meta 2019 & Responsable \\
\hline $\begin{array}{l}\text { Cobertura de } \\
\text { Acueducto } \\
\text { Zona Urbana }\end{array}$ & $\begin{array}{l}\text { \# de predios } \\
\text { residenciales con } \\
\text { acceso al servicio de } \\
\text { acueducto comunas / } \\
\text { Total de predios } \\
\text { residenciales } \\
\text { comunas } \\
\end{array}$ & Porcentaje & 96,72 & 96,72 & $\begin{array}{l}\text { Secretaría de } \\
\text { Gestión y } \\
\text { Control } \\
\text { Territorial }\end{array}$ \\
\hline $\begin{array}{l}\text { Cobertura de } \\
\text { Acueducto } \\
\text { Zona Rural } \\
\text { Nucleada }\end{array}$ & $\begin{array}{l}\text { \# de predios } \\
\text { residenciales con } \\
\text { acceso al servicio de } \\
\text { acueducto } \\
\text { corregimientos/ Total } \\
\text { de predios } \\
\text { residenciales } \\
\text { corregimientos } \\
\end{array}$ & Porcentaje & 88,09 & 88,09 & $\begin{array}{l}\text { Secretaría de } \\
\text { Gestión y } \\
\text { Control } \\
\text { Territorial }\end{array}$ \\
\hline $\begin{array}{l}\text { Cobertura de } \\
\text { Alcantarillado } \\
\text { Zona Urbana }\end{array}$ & $\begin{array}{l}\text { \# de predios } \\
\text { residenciales con } \\
\text { acceso al servicio de } \\
\text { alcantarillado } \\
\text { comunas / Total de } \\
\text { predios residenciales } \\
\text { comunas }\end{array}$ & Porcentaje & 91,28 & 91,28 & $\begin{array}{l}\text { Secretaría de } \\
\text { Gestión y } \\
\text { Control } \\
\text { Territorial }\end{array}$ \\
\hline
\end{tabular}




\begin{tabular}{|c|c|c|c|c|c|}
\hline Nombre & Descripción variables & Unidad & $\begin{array}{c}\text { Línea de } \\
\text { Base }\end{array}$ & Meta 2019 & Responsable \\
\hline $\begin{array}{l}\text { Cobertura de } \\
\text { Alcantarillado } \\
\text { Zona Rural } \\
\text { Nucleada }\end{array}$ & $\begin{array}{l}\text { \# de predios } \\
\text { residenciales con } \\
\text { acceso al servicio de } \\
\text { alcantarillado } \\
\text { corregimientos/ Total } \\
\text { de predios } \\
\text { residenciales } \\
\text { corregimientos }\end{array}$ & Porcentaje & 65,91 & 65,91 & $\begin{array}{l}\text { Secretaría de } \\
\text { Gestión y } \\
\text { Control } \\
\text { Territorial }\end{array}$ \\
\hline $\begin{array}{l}\text { Cobertura de } \\
\text { Aseo }\end{array}$ & $\begin{array}{l}\text { \# de predios } \\
\text { residenciales con } \\
\text { acceso al servicio de } \\
\text { aseo/Total de } \\
\text { predios residenciales }\end{array}$ & Porcentaje & 89,50 & 91,00 & $\begin{array}{l}\text { Secretaría de } \\
\text { Gestión y } \\
\text { Control } \\
\text { Territorial }\end{array}$ \\
\hline $\begin{array}{l}\text { Índice de } \\
\text { riesgo de la } \\
\text { calidad del } \\
\text { agua para } \\
\text { consumo } \\
\text { humano - } \\
\text { IRCA - Zona } \\
\text { Urbana }\end{array}$ & $\begin{array}{l}\text { \% IRCA anual } \\
\text { comunas }\end{array}$ & Porcentaje & 1,40 & 1,40 & $\begin{array}{l}\text { Secretaría de } \\
\text { Gestión y } \\
\text { Control } \\
\text { Territorial }\end{array}$ \\
\hline
\end{tabular}

\subsubsection{PROGRAMA: MEDELLÍN CON ACCESO DE CALIDAD AL ACUEDUCTO Y AL ALCANTARILLADO}

La garantía de la prestación de los servicios públicos de acueducto y alcantarillado son de vital importancia para el territorio municipal. Este programa contiene los proyectos necesarios para garantizar un Mínimo vital de agua potable, se propenderá por el fortalecimiento del Fondo de solidaridad y redistribución de Ingresos, se hará un trabajo intensivo en el mejoramiento, mediante inversiones estratégicas en el sector, el acceso a Agua potable y saneamiento básico especialmente para los corregimientos del Municipio, y se implementará el suministro de "Pilas públicas" para el abastecimiento colectivo y evacuación de las aguas residuales de manera provisional.

Indicador de resultado

\begin{tabular}{|c|c|c|c|c|c|}
\hline Nombre & $\begin{array}{c}\text { Descripción } \\
\text { variables }\end{array}$ & Unidad & $\begin{array}{c}\text { Línea de } \\
\text { Base }\end{array}$ & Meta 2019 & Responsable \\
\hline $\begin{array}{l}\text { Continuidad del } \\
\text { servicio de } \\
\text { acueducto en la } \\
\text { Zona Urbana }\end{array}$ & $\begin{array}{c}\text { \# horas de } \\
\text { prestación de } \\
\text { servicio al mes } \\
\text { acueducto } \\
\text { comunas * } \\
\text { Población } \\
\text { Servida } \\
\text { comunas*24/ } \\
\text { (730* Población } \\
\text { Urbana Total) } \\
\end{array}$ & Horas/día & Nuevo & 20 & $\begin{array}{l}\text { Secretaría de } \\
\text { Gestión y } \\
\text { Control } \\
\text { Territorial }\end{array}$ \\
\hline $\begin{array}{l}\text { Porcentaje de } \\
\text { micromedición } \\
\text { en la Zona } \\
\text { Urbana }\end{array}$ & $\begin{array}{c}\text { Total de } \\
\text { micromedidores } \\
\text { funcionando } \\
\text { comunas/Total } \\
\text { de predios } \\
\text { residenciales } \\
\text { comunas }\end{array}$ & Porcentaje & Nuevo & 95,00 & $\begin{array}{l}\text { Secretaría de } \\
\text { Gestión y } \\
\text { Control } \\
\text { Territorial }\end{array}$ \\
\hline Indice de Aguas & Volumen de agua & Porcentaje & Nuevo & 30,00 & Secretaría de \\
\hline
\end{tabular}




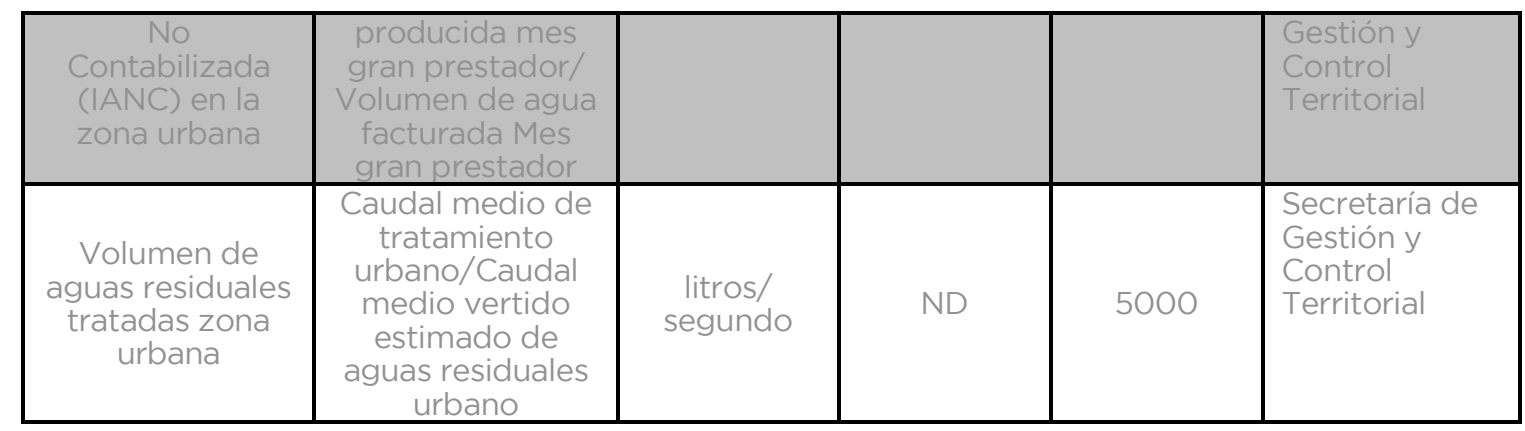

\subsubsection{Proyecto: Mínimo vital de agua potable}

En principio, el agua constituye fuente de vida, la falta del servicio atenta directamente con el derecho fundamental a la vida de las personas, por tanto, el servicio público domiciliario de acueducto y alcantarillado en tanto que afecte la vida de las personas, la salubridad pública y la salud es un derecho constitucional fundamental y como tal debe ser objeto de protección, por lo cual este proyecto se encargará de fortalecer los instrumentos que posee el Municipio de Medellín para que todos los habitantes menos favorecidos de Medellín tengan garantía del mínimo vital de agua potable y saneamiento básico De igual forma se promoverá una cultura de buen uso del agua en la ciudad y su entorno, reconociendo en el agua un bien común que involucra el acceso sin ningún tipo de discriminación, la disponibilidad física y la capacidad de democratizarla, intentando recuperar el sentido de elemento dador de vida que proporciona equilibrio al territorio y a cada ser que lo habita. Incluye el MVAP Rural para los Corregimientos.

Responsable: Secretaría de Gestión Territorial

Indicador de producto

\begin{tabular}{|c|c|}
\hline Nombre & Unidad \\
\hline Personas que reciben el auspicio del Mínimo Vital de Agua Potable & Número \\
\hline
\end{tabular}

\subsubsection{Proyecto: Fondo de solidaridad y redistribución de Ingresos}

Especialmente, se dará prioridad al fortalecimiento del funcionamiento del Fondo de Solidaridad del Municipio de Medellín y mediante un acuerdo con el Concejo Municipal se construirán estrategias para incrementar la cobertura y los impactos de los subsidios que entrega el fondo a las viviendas de los estratos 1, 2 y 3 para los servicios públicos de acueducto, alcantarillado y aseo en el Municipio.

Indicador de producto

Responsable: Secretaría de Gestión Territorial

\begin{tabular}{|c|c|}
\hline Nombre & Unidad \\
\hline $\begin{array}{r}\text { Subsidios mensuales de acueducto entregados en el marco del Fondo de } \\
\text { Solidaridad y Redistribución de Ingresos }\end{array}$ & Número \\
\hline $\begin{array}{r}\text { Subsidios mensuale alcantarillado entregados en el marco del Fondo de } \\
\text { Solidad Redistribución de Ingresos }\end{array}$ & Número \\
\hline $\begin{array}{r}\text { Subsidios mensuales de aseo entregados en el marco del Fondo de Solidaridad y } \\
\text { Redistribución de Ingresos }\end{array}$ & Número \\
\hline
\end{tabular}




\subsubsection{Proyecto: Agua potable y saneamiento básico (Subsanación de déficit)}

Mediante inversiones estratégicas en el sector, se fortalecerán las estructuras empresariales que operen los sistemas de acueducto y alcantarillado en los corregimientos y sectores urbanos y suburbanos, además se construirán nuevos sistemas y se mejorarán los existentes de manera que se incremente la cobertura de servicios públicos en el Municipio, promoviendo conjuntamente estrategias de investigación y desarrollo que permitan el acceso al agua potable y el saneamiento básico mediante soluciones alternativas, no convencionales o soluciones individuales especialmente en las áreas rurales dispersas del Municipio, en donde por condiciones técnicas o geográficas no es posible conectar a las viviendas a los sistemas convencionales de prestación de los servicios públicos de acueducto y alcantarillado.

Indicador de producto

Responsable: Secretaría de Gestión Territorial

\begin{tabular}{|c|c|}
\hline Nombre & Unidad \\
\hline Sistemas comunitarios que ofrecen agua apta para el consumo humano & Número \\
\hline $\begin{array}{c}\text { Prestadores comunitarios de agua potable y saneamiento básico que mejoran sus } \\
\text { indicadores de sostenibilidad }\end{array}$ & Número \\
\hline
\end{tabular}

\subsubsection{PROGRAMA: GESTIÓN INTEGRAL DE LOS SERVICIOS PÚBLICOS}

Para garantizar la optimización en la prestación de los servicios públicos resulta indispensable realizar diferentes labores de gestión y educación que acompañen la instalación de la infraestructura necesaria. En este sentido, el programa de Gestión Integral de los Servicios Públicos busca fortalecer la Gestión para los sistemas de aguas crudas en cuanto a la Subsanación de déficits, realizar jornadas que involucren ejercicios de Pedagogía ciudadana en servicios públicos. Un gran énfasis en la Formulación e implementación de políticas para los servicios públicos, así como en la Formalización de servicios públicos (flexibilización de requisitos) y finalmente la inversión en Proyectos de infraestructura en zonas de no cobertura

Indicador de resultado

\begin{tabular}{|c|c|c|c|c|c|}
\hline Nombre & $\begin{array}{c}\text { Descripción } \\
\text { variables }\end{array}$ & Unidad & $\begin{array}{c}\text { Línea de } \\
\text { Base }\end{array}$ & Meta 2019 & Responsable \\
\hline $\begin{array}{l}\text { Recursos de } \\
\text { cofinanciación } \\
\text { gestionados }\end{array}$ & $\begin{array}{c}\text { Total recursos de } \\
\text { cofinanciación } \\
\text { comprometidos } \\
\text { en proyectos de } \\
\text { la Administración } \\
\text { Municipal, para la } \\
\text { gestión de } \\
\text { servicios públicos } \\
\text { domiciliarios, no } \\
\text { domiciliarios y } \\
\text { TICS }\end{array}$ & $\begin{array}{c}\text { Millones de } \\
\text { pesos }\end{array}$ & 0 & 10000 & $\begin{array}{c}\text { Subsecretaría } \\
\text { de Servicios } \\
\text { Públicos }\end{array}$ \\
\hline
\end{tabular}




\subsubsection{Proyecto : Gestión para los sistemas de aguas crudas (Subsanación de déficit)}

Mediante alianzas estratégicas con prestadores legales de servicios públicos, se implementarán acciones para que los habitantes que se abastecen de sistemas de aguas crudas para su consumo, accedan a servicios públicos de acueducto y alcantarillado de calidad mediante sistemas que les garanticen agua apta para consumo humano.

Adicionalmente, se pretende promover la Alianza Público Privada para el diseño, ampliación, optimización, adecuación, reparación, reposición, construcción, operación y mantenimiento de la infraestructura de acueducto y plantas de tratamiento y sistemas de saneamiento de las zonas rurales y sub-urbanas del Municipio de Medellín.

Indicador de producto

Responsable: Secretaría de Gestión Territorial

\begin{tabular}{|c|c|}
\hline Nombre & Unidad \\
\hline Iniciativa para la gestión de aguas crudas en el Municipio ejecutadas & Fases \\
\hline
\end{tabular}

\subsubsection{Proyecto: Pedagogía ciudadana en servicios públicos}

狽隹田 Se desarrollarán estrategias de educación y pedagogía para dotar a la comunidad de conocimiento e información del sector de los servicios públicos domiciliarios, el alumbrado público y las TICS que les permita no solo ejercer el control social de la prestación de dichos servicios, sino que aporten efectivamente a la construcción de la política pública que permita el mejoramiento permanente de la prestación de los servicios públicos y, de esta manera, de la calidad de vida de todos los habitantes del Municipio.

De igual manera se fortalecerá la pedagogía al ciudadano para que haga uso racional y eficiente de los servicios públicos, disminuya sus consumos especialmente de energía y agua, no solo mostrando los beneficios económicos de estas buenas prácticas, sino también los grandes beneficios en el ambiente y como aporte a disminuir los impactos del cambio climático.

También se fortalecerá la defensa de los derechos de los usuarios TICS, mediante la puesta en funcionamiento de la Oficina de atención a dichos usuarios y la ejecución de campañas que propendan porque todos los medellinenses conozcan sus deberes, derechos y los mecanismos de participación y de defensa, como usuarios de los servicios asociados a las tecnologías de la información y las comunicaciones.

Indicador de producto

Responsable: Secretaría de Gestión Territorial

\begin{tabular}{|c|c|}
\hline Nombre & Unidad \\
\hline Eventos de capacitación realizados a la ciudadanía & Número \\
\hline Total de atenciones mensuales en la oficina de atención al usuario TICS & Número \\
\hline
\end{tabular}


7.3.2.3 Proyecto: Formulación e implementación de políticas para los servicios públicos

1.n Iniciativa que busca la flexibilización de los requisitos urbanísticos - para la vinculación en acuerdo con el Municipio de Medellín para "If Legalizar o formalizar el servicio de acueducto y alcantarillado a los hogares que actualmente se encuentran en zona de cobertura a través de una oferta especial de financiación y por tiempo limitado.

Indicador de producto

Responsable: Secretaría de Gestión Territorial

\begin{tabular}{|c|c|}
\hline Nombre & Unidad \\
\hline Políticas para los servicios públicos formuladas y gestionadas & Número \\
\hline
\end{tabular}

7.3.2.4 Proyecto: Mínimo vital de energía

Este proyecto se encargará de fortalecer los instrumentos que posee el Municipio de Medellín para que la población menos favorecida tenga acceso al mínimo vital de energía, en garantía de los derechos fundamentales a la vida, a la salud y la seguridad.

Indicador de producto

Responsable: Secretaría de Gestión Territorial

\begin{tabular}{|c|c|}
\hline Nombre & Unidad \\
\hline Personas que reciben el auspicio del Mínimo Vital de Energía & Número \\
\hline
\end{tabular}




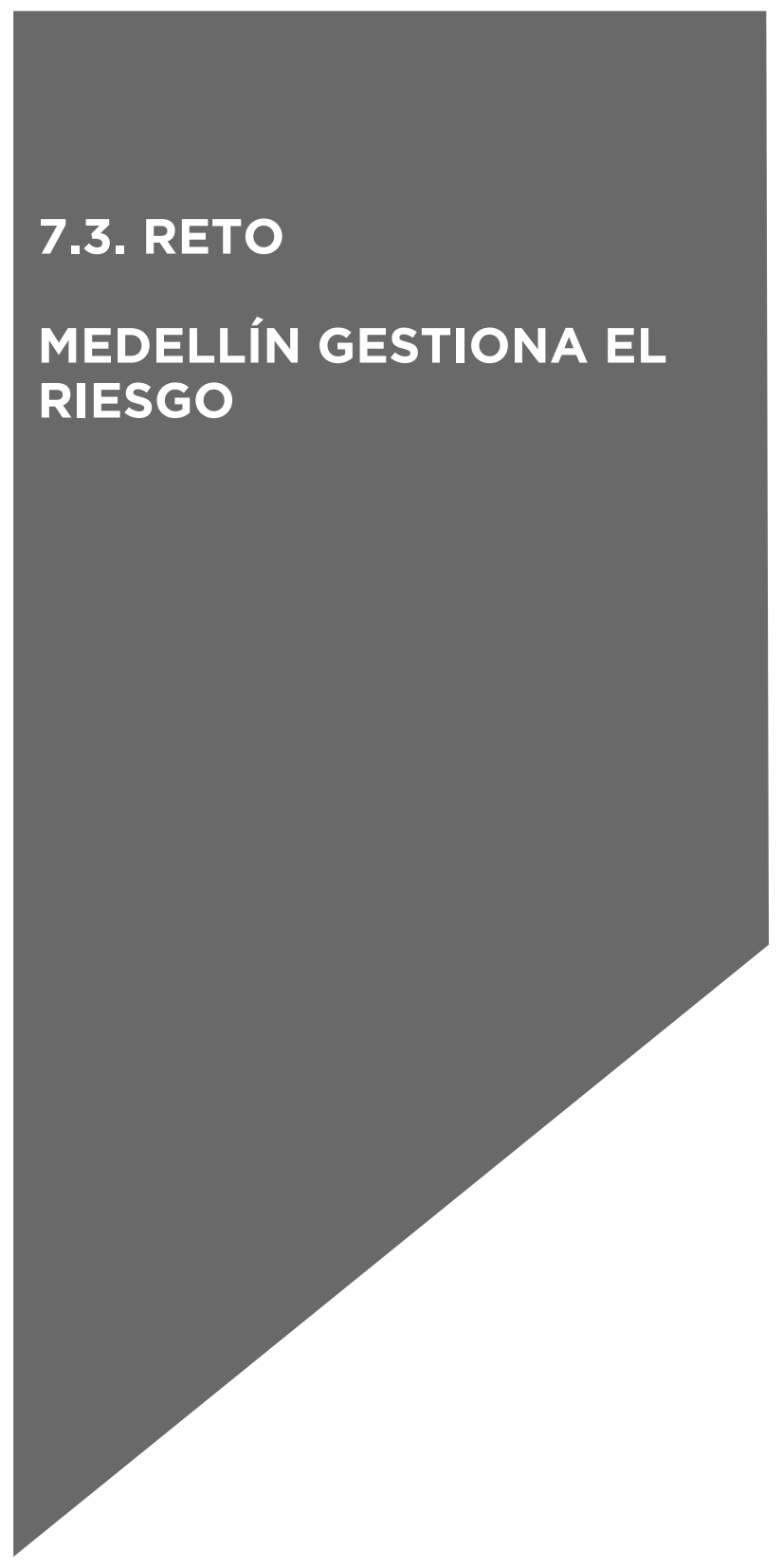

\section{PROGRAMAS}

4 7.3.1. Conocimiento del riesgo

4 7.3.2. Reducción y mitigación del riesgo

rć 4 7.3.3. Manejo eficaz de desastres

\section{OBJETIVO}

Reducir de manera significativa el número de personas afectadas y pérdidas materiales causadas por cualquier tipo de desastre a través de la promoción del autocuidado y prevención del riesgo. 


\subsection{Medellín gestiona el riesgo}

La entidad encargada de la gestión del riesgo en Medellín es el Departamento Administrativo de Gestión del Riesgo de Desastres DAGRD-, el cual aporta los elementos necesarios para promover las medidas eficientes en el tema y tiene como propósito contribuir a la seguridad, el bienestar y la calidad de vida de los habitantes.

En el período comprendido entre 1950 y 2015, los eventos ocurridos con mayor frecuencia fueron las inundaciones, los deslizamientos y las avenidas torrenciales, asociadas en gran parte a fenómenos hidrometeorológicos; la frecuencia e intensidad de estas situaciones tienden a incrementarse con el avance del cambio climático global. Para el año 2013 se reportaron 992 viviendas afectadas por evacuaciones, de las cuales 656 fueron definitivas (Medellín cómo vamos, 2014).

Existe amplia evidencia sobre la relación directa que existe entre la consolidación urbana y el aumento de los riesgos en el largo plazo, debido principalmente a la ineficiencia de las políticas públicas de control y desarrollo; como consecuencia, se genera una aceleración de la degradación ambiental y el incremento en las condiciones de vulnerabilidad de la población, los ecosistemas y la infraestructura frente a los eventos naturales y antrópicos.

Mapa 8: Zonificación de áreas de amenaza por movimientos en masa.

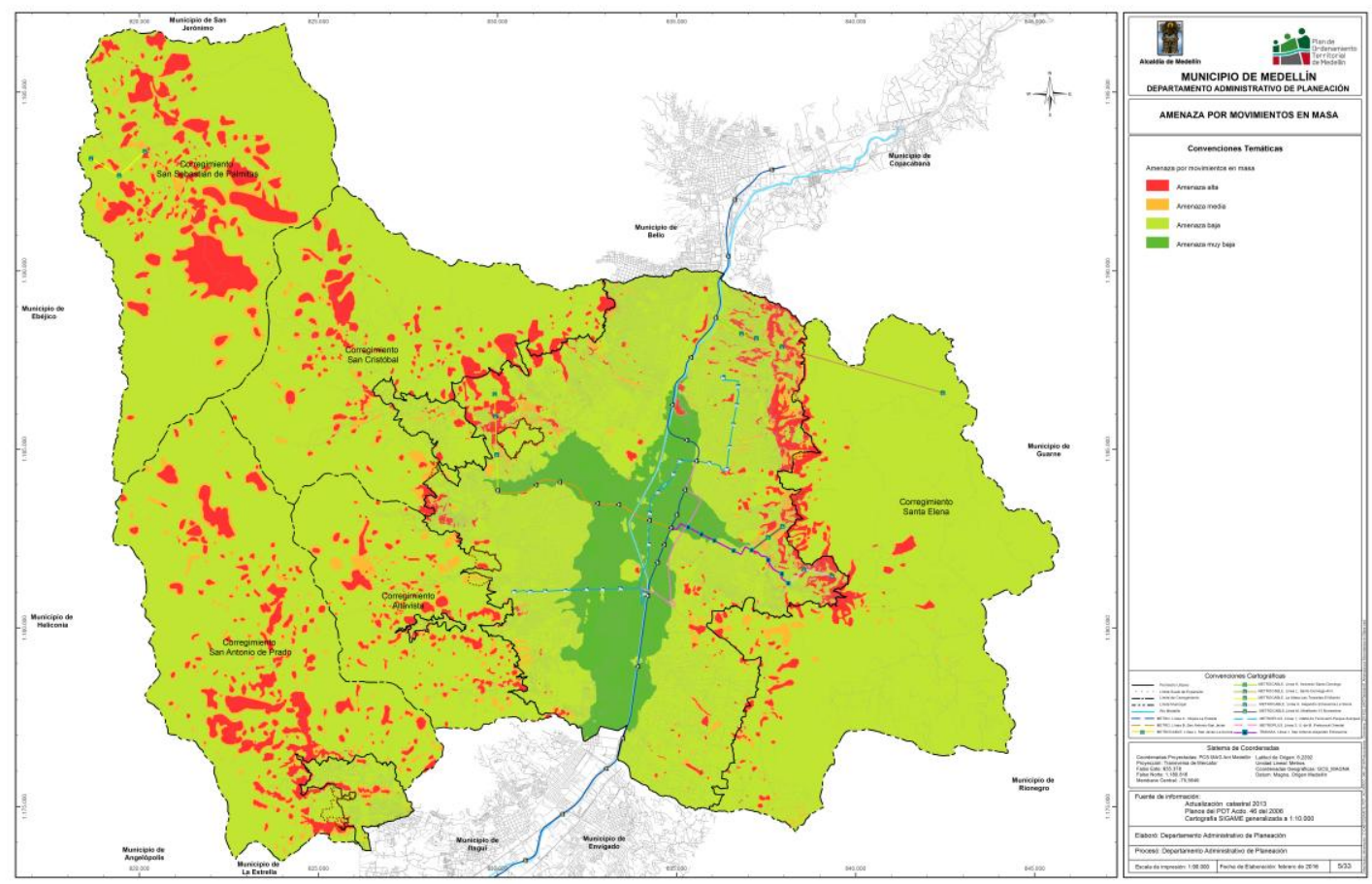

Fuente: POT 2014 
Desde la década de 1980, la ciudad ha desarrollado una serie de instrumentos y estrategias enfocados en la reducción de las condiciones de riesgo mediante normas, sistemas interinstitucionales de gestión, estudios de amenaza y riesgo, instrumentos de monitoreo, proyectos de mejoramiento integral de barrios, planes ambientales y protección de microcuencas. Estos adelantos se enmarcan en los avances de las políticas nacionales de gestión y en la evolución de los sistemas normativos e institucionales.

Adicionalmente, Medellín ha sido pionera en innovación para la gestión del riesgo, entre otras por la creación del Sistema de Alerta Temprana SIATA-; este proyecto involucra a entidades como el Área Metropolitana del Valle de Aburrá -AMVA-, el DAGRED, EPM e ISAGEN y constituye una de las principales estrategias de gestión del riesgo para los diferentes municipios de la región. Su objetivo principal es "alertar de manera oportuna a la comunidad sobre la probabilidad de ocurrencia de un evento hidrometeorológico extremo que pueda generar una situación de emergencia y así reducir los impactos de los fenómenos mediante la implementación de medidas de respuesta ante una amenaza inminente"; el SIATA también se encarga del monitoreo de cuencas y microcuencas hidrográficas y la modelación hidrológica y meteorológica, con el fin de generar información de alta relevancia para la gestión ambiental y de riesgo a nivel regional (SIATA, 2016).

A continuación se describe el indicador de resultado con el que se evaluará:

\begin{tabular}{|c|c|c|c|c|c|}
\hline Nombre & Descripción variables & Unidad & $\begin{array}{c}\text { Línea de } \\
\text { Base }\end{array}$ & Meta 2019 & $\begin{array}{c}\text { Responsabl } \\
\text { e }\end{array}$ \\
\hline $\begin{array}{l}\text { Efectividad en } \\
\text { la atención de } \\
\text { emergencias }\end{array}$ & $\begin{array}{l}\text { Este indicador da } \\
\text { cuenta de la atención } \\
\text { oportuna y efectiva de } \\
\text { las emergencias que se } \\
\text { presentan en la ciudad } \\
7 / 24\end{array}$ & Porcentaje & 0 & 100 & DAGRED \\
\hline
\end{tabular}




\subsubsection{PROGRAMA: CONOCIMIENTO DEL RIESGO}

Es el proceso de la gestión del riesgo compuesto por la identificación de escenarios de riesgo, el análisis y evaluación del riesgo, el monitoreo y seguimiento del riesgo con sus componentes, y la comunicación para promover una mayor conciencia del mismo que alimenta los procesos de reducción del riesgo y de manejo de desastre.

Indicador de resultado

\begin{tabular}{|c|c|c|c|c|c|}
\hline Nombre & $\begin{array}{l}\text { Descripción } \\
\text { variables }\end{array}$ & Unidad & $\begin{array}{l}\text { Línea de } \\
\text { Base }\end{array}$ & Meta 2019 & Responsable \\
\hline $\begin{array}{l}\text { Capacidad } \\
\text { organizativa } \\
\text { mejorada }\end{array}$ & $\begin{array}{l}N^{\circ} \text { de estudios } \\
\text { técnico y actos } \\
\text { administrativos } \\
\text { para el aumento } \\
\text { de la capacidad } \\
\text { organizativa en el } \\
\text { año/Total de } \\
\text { estudios técnico } \\
\text { y actos } \\
\text { administrativos } \\
\text { para el aumento } \\
\text { de la capacidad } \\
\text { organizativa en el } \\
\text { año }{ }^{*} 100\end{array}$ & Porcentaje & 0 & 30 & $\begin{array}{l}\text { Sec. Gestión } \\
\text { del Riesgo de } \\
\text { Desastres }\end{array}$ \\
\hline
\end{tabular}

7.4.2.1 Proyecto: Formación y capacitación en gestión del riesgo

Potencializar y optimizar recursos a través del desarrollo de acciones efectivas, oportunas y eficientes de acuerdo a protocolos y tendencias probadas en diferentes escenarios nacionales e internacionales, en gestión del riesgo de desastres en procura de una mayor cobertura en capacitación a las personas del DAGRD en gestión del riesgo de desastres, definiendo el esquema de capacitación según las necesidades evidenciadas, para priorizar las temáticas y el perfil del personal que las recibirá.

Responsable: Departamento Administrativo de Gestión del Riesgo y Desastres

Indicador de producto

\begin{tabular}{|c|c|}
\hline Nombre & Unidad \\
\hline Capacitación y educación en gestión de riesgos & Número \\
\hline
\end{tabular}

\subsubsection{Proyecto: Fortalecimiento de SIATA e innovación para la} gestión del riesgo.

La operación del Sistema de Alerta Temprana Ambiental del Municipio de Medellín y de las redes que lo conforman. RED ACELEROGRÁFICA Operación y mantenimiento de la red acelerográfica de Medellín (RAM) La metodología empleada se 
desarrollaría así: Recolección periódica de la información almacenada en cada acelerógrafo. Procesamiento de la información recolectada con el fin de obtener las herramientas útiles para el análisis y diseño sismo resistentes de estructuras, tales como espectros, etc. Mantenimiento de los equipos. Divulgación de la información a través de Internet y de forma impresa en material de distribución de edición semestral para un público técnico. Priorización y cuantificación de la inversión requerida para la actualización y reemplazo de equipos. Remplazo de equipos fuera de operación. RED HIDROMETEOROLÓGICA Consiste en el procesamiento y recolección de la información hidrometeorológica de la red instalada. La metodología empleada se desarrollaría así: Recolección periódica de la información almacenada en cada pluviografo. Procesamiento de la información recolectada con el fin de obtener las herramientas útiles para el análisis de los eventos de precipitación. Mantenimiento de los equipos. Divulgación de la información a través de internet y de forma impresa en material de distribución de edición semestral para un público técnico. Reemplazo de equipos con tecnología que permita la obtención de información.

Responsable: Departamento Administrativo de Gestión del Riesgo y Desastres Indicador de producto

\begin{tabular}{|c|c|}
\hline Nombre & Unidad \\
\hline Sistema de Información de Alertas Tempranas -SIATA fortalecido. & $\begin{array}{c}\text { Millones } \\
\text { de Pesos }\end{array}$ \\
\hline
\end{tabular}

7.4.2.3 Proyecto: Divulgación del Plan Municipal de Gestión del Riesgo Generar una estrategia de comunicación masiva sobre la gestión del riesgo y la responsabilidad de la ciudadanía con respecto al autocuidado y a que la ocurrencia de los desastres de orinen natural obedece a un proceso de construcción social del que todos somos responsables.

Responsable: Departamento Administrativo de Gestión del Riesgo y Desastres Indicador de producto

\begin{tabular}{|c|c|}
\hline Nombre & Unidad \\
\hline Acciones realizadas para la divulgación del Plan Municipal de Gestión del Riesgo & Número \\
\hline
\end{tabular}

\subsubsection{Proyecto: Estudios de riesgo}

Las áreas identificadas y clasificadas como zonas con condiciones de riesgo por movimientos en masa, inundaciones y/o avenidas torrenciales en el Acuerdo 48 de 2014 - Plan de Ordenamiento Territorial - POT - deben ser objeto de estudios de riesgo de detalle, acorde con la priorización establecida en el Articulo 572 del Acuerdo 48 de 2014.

Los estudios de riesgo de detalle para las zonas con condiciones de riesgo están orientados a categorizar la amenaza, la vulnerabilidad y el riesgo, y definir si este último es mitigable o no mitigable, en función del nivel de 
afectación esperada. Adicionalmente, deben establecer las medidas estructurales de intervención (obras de estabilización y/o mitigación) requeridas, con sus respectivos diseños y presupuestos para prevenir la ocurrencia de daños ocasionados por este tipo de fenómenos amenazantes; complementados con el seguimiento y monitoreo de las mismas, y las medidas no estructurales relacionadas con los usos que se deben promover para las zonas que se clasifiquen como de alto riesgo no mitigables

Indicador de producto

Responsable: Secretaría de Gestión Territorial

\begin{tabular}{|c|c|}
\hline Nombre & Unidad \\
\hline Estudios técnicos de vulnerabilidad, amenaza y riesgo realizados & Número \\
\hline
\end{tabular}

\subsubsection{PROGRAMA: Reducción y mitigación del riesgo}

Es el proceso de la gestión del riesgo, está compuesto por la intervención dirigida a modificar o disminuir las condiciones de riesgo existentes, entiéndase: mitigación del riesgo y a evitar nuevo riesgo en el territorio, entiéndase: prevención del riesgo. Son medidas de mitigación y prevención que se adoptan con antelación para reducir la amenaza, la exposición y disminuir la vulnerabilidad de las personas, los medios de subsistencia, los bienes, la infraestructura y los recursos ambientales, para evitar o minimizar los daños y pérdidas en caso de producirse los eventos físicos peligrosos. La reducción del riesgo la componen la intervención correctiva del riesgo existente, la intervención prospectiva de nuevo riesgo y la protección financiera.

Indicador de resultado

\begin{tabular}{|c|c|c|c|c|c|}
\hline Nombre & $\begin{array}{l}\text { Descripción } \\
\text { variables }\end{array}$ & Unidad & \begin{tabular}{ll|} 
Línea de \\
Base
\end{tabular} & Meta 2019 & Responsable \\
\hline $\begin{array}{l}\text { Implementación } \\
\text { de medidas de } \\
\text { protección y } \\
\text { mitigación de } \\
\text { eventos } \\
\text { desastrosos }\end{array}$ & $\begin{array}{lr}\text { Total } & \text { de } \\
\text { proyectos que } \\
\text { contribuyen a la } \\
\text { reducción del } \\
\text { riesgo en el año } / \\
\text { total } \\
\text { proyectos } \\
\text { apoyados por el } \\
\text { programa en el } \\
\text { año*100 }\end{array}$ & Porcentaje & 0 & 80 & DAGRD \\
\hline
\end{tabular}

\subsubsection{Proyecto: Fortalecimiento de instancias sociales del DAGRD}

Diseñar un mecanismo de coordinación, articulación e intercambio que permita la apropiación y divulgación de conocimientos, experiencias y metodologías para la formulación y operación de planes de gestión del riesgo.

Potenciar y optimizar recursos integrando la comunidad, las organizaciones y la municipalidad en torno al tema, procurar una 
Una apuesta de ciudad por el cuidado del medio ambiente

rápida y eficiente atención de las emergencias a partir dela activación del primer eslabón, en el cual se constituye la comunidad afectada.

Desarrollar habilidades y actitudes en la población escolar y en las instituciones que permiten generar conciencia frente a la gestión del riesgo.

Procurar a partir del conocimiento la gestión del riesgo asociado a la práctica de actividades comerciales o industriales.

Mejorar la capacidad de respuesta a través de la capacitación y la dotación

Promover la seguridad de la población escolar a partir de la identificación y mitigación de riesgos.

Responsable: Departamento Administrativo de Gestión del Riesgo y Desastres

Indicador de producto

\begin{tabular}{|c|c|}
\hline Nombre & Unidad \\
\hline Comunidad preparada y capacitada en gestión del riesgo & Porcentaje \\
\hline
\end{tabular}

\subsubsection{Intervención en zonas de riesgo}

Disminuir el riesgo de la población expuesta ante amenazas de tipo físico, antrópico y tecnológico, a través de la ejecución de actividades de prevención - mitigación (Obras civiles de Mitigación) y una recuperación integral, equitativa y eficaz, de las zonas afectadas por fenómenos de inestabilidad y amenazas de tipo natural y antrópico.

Mediante estas acciones se busca mitigar en un $100 \%$ el riesgo al que están expuesta la población, y que ha sido identificado mediante estudios geotécnicos y de patología estructural realizados con anterioridad.

Responsable: Departamento Administrativo de Gestión del Riesgo y

Desastres

Indicador de producto

\begin{tabular}{|c|c|}
\hline Nombre & Unidad \\
\hline Áreas o sitios en situaciones de riesgo intervenidas & Número \\
\hline
\end{tabular}

\subsubsection{Proyecto: Adecuación, mantenimiento y dotación de estaciones de bomberos}

Realizar el mantenimiento locativo, de carácter correctivo y preventivo, a todas las estaciones de bomberos; adecuar los espacios requeridos debido a los nuevos requerimientos institucionales, de igual forma hacer la adquisición de muebles y elementos mobiliarios complementarios de todas las estaciones de bomberos. Fortalecer el Cuerpo Oficial de Bomberos de Medellín, mediante la renovación y mejoramiento tecnológico de su maquinaria, equipos de protección personal, equipos y herramientas especializadas para la atención de desastres, buscando también el logro de los siguientes objetivos: a) garantizar la seguridad del personal durante la 
atención de las diferentes emergencias y desastres que se puedan presentar en la ciudad; b) dotar al COBM de los equipos y herramientas.

Responsable: Departamento Administrativo de Gestión del Riesgo y Indicador de producto

Desastres

\begin{tabular}{|c|c|}
\hline Nombre & Unidad \\
\hline Instalaciones de bomberos adecuadas óptimamente & Número \\
\hline
\end{tabular}

7.4.3.4 Proyecto: Construcción de la política para la gestión del riesgo de desastres

Con el fin de vincular todas las entidades del nivel central y las descentralizadas, además de las mixtas con participación de la Administración Municipal para la protección de la comunidad, de lo público y la integración real y perceptible de la gestión del riesgo como parte fundamental del concepto de Seguridad Pública, este proyecto busca fortalecer la política pública para la gestión del riesgo. El alcance de este propósito no solo se da desde lo jurídico legal, con una articulación efectiva entre la Administración y el Concejo Municipal, sino desde la directriz pragmática de conjugación de recursos y capacidades alrededor de la consolidación de un Sistema Integral de Gestión del Riesgo de Desastres.

Responsable: Departamento Administrativo de Gestión del Riesgo y Desastres Indicador de producto

\begin{tabular}{|c|c|}
\hline Nombre & Unidad \\
\hline Iniciativas de política pública para la gestión del riesgo radicadas & Fases \\
\hline
\end{tabular}

7.4.3.5 Proyecto: Aseguramiento y transferencia del riesgo Mediante este proyecto se pretende crear una estrategia que permita transferirle a las compañías de seguros mediante pólizas los costos por la pérdida en infraestructura y bienes ocasionada por la ocurrencia de desastres de origen natural o antrópico.

Responsable: Departamento Administrativo de Gestión del Riesgo y Desastres

Indicador de producto

Nombre

\subsubsection{Proyecto: Realización del inventario municipal de asentamientos humanos localizados en zonas de alto riesgo no mitigable.}

Las áreas identificadas y clasificadas de alto riesgo no mitigables deben ser inventariadas (censadas), de acuerdo con lo establecido en la Resolución O448 del 17 de julio de 2.014 del Ministerio de Vivienda, Ciudad y Territorio, 
por medio de la cual se establecen los lineamientos para conformar el inventario nacional de asentamientos en alto riesgo de desastres.

El municipio de Medellín en cumplimiento de la Resolución 0448 de 17 de julio de 2014, expedida por el Ministerio de Vivienda, Ciudad y Territorio, a través de la cual se establecen los lineamientos para la recolección y suministro de información, para conformar el inventario nacional de asentamientos en alto riesgo de desastres, debe disponer los recursos y acometer las acciones necesarias que permitan dar cumplir con tal directriz, la cual había establecido como fecha perentoria el día 1 de marzo de 2015.

Responsable: Departamento Administrativo de Planeación

Indicador de producto

\begin{tabular}{|l|c|}
\hline \multicolumn{1}{|c|}{ Nombre } & Unidad \\
\hline $\begin{array}{l}\text { Realización del inventario municipal de asentamientos humanos localizados en zonas } \\
\text { de alto riesgo no mitigable. }\end{array}$ & Porcentaje \\
\hline $\begin{array}{l}\text { Revisión anual del inventario municipal de asentamientos humanos localizados en } \\
\text { zonas de alto riesgo no mitigable. }\end{array}$ & Número \\
\hline
\end{tabular}

\subsubsection{PROGRAMA: MANEJO EFICAZ DE DESASTRES}

Es el proceso de la gestión del riesgo compuesto por la preparación para la respuesta a emergencias, la preparación para la recuperación post-desastre, la ejecución de dicha respuesta y la ejecución de la respectiva recuperación, entiéndase: rehabilitación y recuperación.

Indicador de resultado

\begin{tabular}{|l|l|l|l|l|l|}
\hline Nombre & $\begin{array}{l}\text { Descripción } \\
\text { variables }\end{array}$ & Unidad & $\begin{array}{l}\text { Línea de } \\
\text { Base }\end{array}$ & Meta 2019 & Responsable \\
\hline Eficacia en la & $\begin{array}{l}\text { Total } \\
\text { proyectos que } \\
\text { contribuyen al } \\
\text { atención dejo eficaz de } \\
\text { situaciones de } \\
\text { emergencia desastres en el } \\
\text { año/total desastres } \\
\text { proyectos de } \\
\text { apoyados por el } \\
\text { programa en el } \\
\text { año*100 }\end{array}$ & & & & \\
\hline
\end{tabular}

\subsubsection{Proyecto: Gestión integral de emergencias y desastres}

Atender de manera efectiva las emergencias y desastres en la ciudad, a partir de la integración del componente logístico, administrativo y operativo del DAGRD, con el fin de garantizar el derecho a la vida de los habitantes del municipio de Medellín y desarrollar mecanismos con sus estrategias que permitan la protección de los bienes y servicios que contribuyan al mejoramiento de la calidad de vida y al equilibrio medioambiental. 
Una apuesta de ciudad por el cuidado del medio ambiente

Responsable: Departamento Administrativo de Gestión del Riesgo y

Desastres

Indicador de producto

\begin{tabular}{|l|c|}
\hline \multicolumn{1}{|c|}{ Nombre } & Unidad \\
\hline $\begin{array}{l}\text { Es la atención integral de las emergencias que se presentan en la ciudad reportadas } \\
\text { por la línea de atención } 123\end{array}$ & Porcentaje \\
\hline
\end{tabular}

7.3.3.2. Proyecto: Atención social de emergencias naturales y antrópicas En este proyecto brinda atención psicosocial y/o ayuda humanitaria a personas en situación de riesgo y a las personas víctimas de emergencias sociales, naturales y/o causadas por el hombre, a través de información, orientación o asesoría, intervención en crisis, y la remisión y/o coordinación para el traslado de la población afectada a los diferentes programas de la Secretaria de Inclusión social y familia u otros servicios de la ciudad de Medellín.

Responsable: Secretaría de Inclusión Social, Familia y Derechos Humanos. Indicador de producto

\begin{tabular}{|c|c|}
\hline \multicolumn{1}{|c|}{ Nombre } & Unidad \\
\hline Eventos calamitosos atendidos con acompañamiento sicosocial & Porcentaje \\
\hline
\end{tabular}




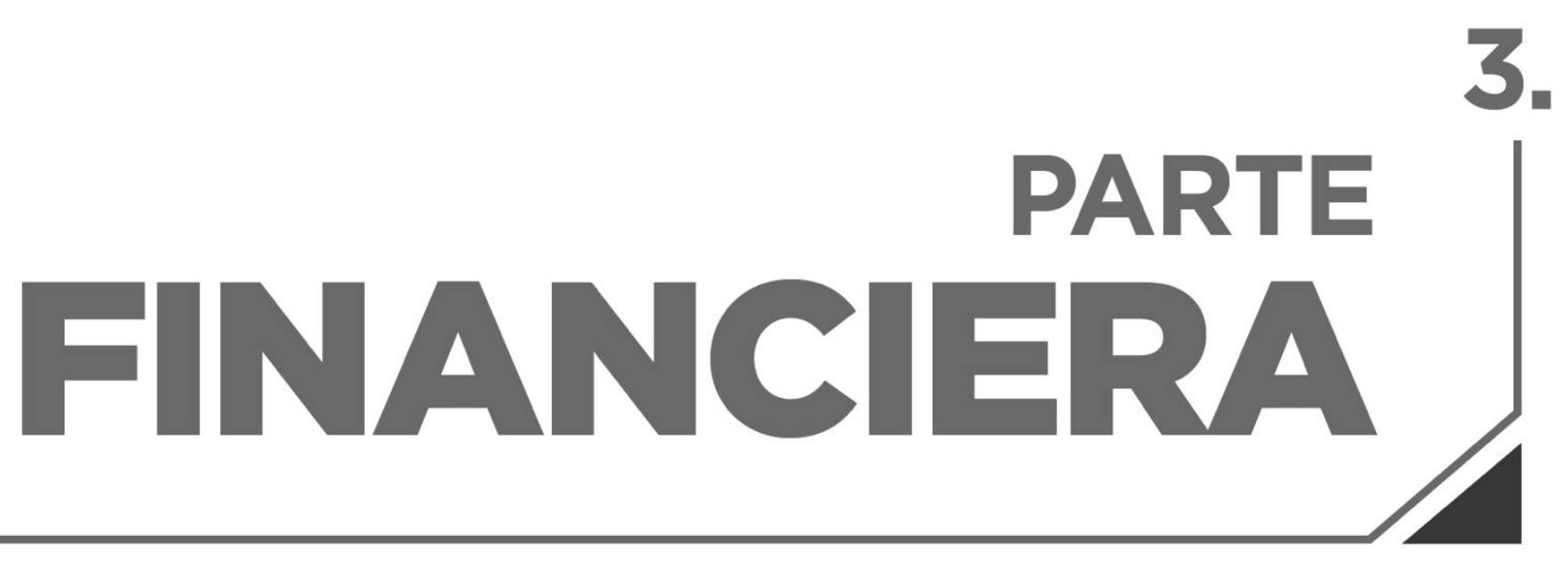




\section{- PLAN FINANCIERO •}

En términos legales, el Plan Financiero es un instrumento de planificación y gestión financiera del sector público, el cual, a partir de la situación económica y financiera del ente territorial, permite vislumbrar el escenario de mediano plazo de sus finanzas, en cumplimiento al Plan Nacional de Desarrollo y en concordancia con la política monetaria y cambiaria del país. (Ley 38/89, artículo 4‥ Ley 179/94, artículo 55, inciso 5‥).

Trasladado al ámbito de las entidades territoriales, el Plan Financiero permite visualizar el escenario de mediano plazo de las finanzas en cumplimiento al Plan de Desarrollo; para nuestra ciudad, el Plan Financiero es la carta de navegación financiera, porque a través de la estimación de los ingresos que la Administración percibirá en el mediano plazo, se establece la distribución del gasto y se fijan los límites de éste, asignando así los montos que garanticen el funcionamiento y operatividad de la Administración, el cumplimiento de las obligaciones financieras y de las metas y programas trazados en el Plan de Desarrollo.

Debido a que en la proyección de los ingresos se soporta la distribución del gasto, la elaboración del Plan Financiero comprende un riguroso ejercicio de análisis; en este proceso se tienen en cuenta factores económicos como la inflación, la Tasa Representativa del mercado -TRM-, el Producto Interno Bruto -PIB- Nacional, el Índice de Precios al Consumidor -IPC- y otras variables macroeconómicas, se analiza su asociación con el comportamiento de los ingresos municipales, sus perspectivas en el mediano y largo plazo y su posible incidencia en los rubros municipales. Esta etapa contempla el uso de diversas metodologías estadísticas y econométricas, así como la revisión de los datos históricos, buscando con ello disminuir el margen de error e incrementar la precisión de los datos proyectados.

El análisis incluye igualmente una revisión en materia normativa, desde leyes promulgadas por el Gobierno Nacional hasta decretos de orden Municipal, y las consecuencias que tales actos puedan tener sobre las finanzas de la Administración Municipal, así como el criterio de expertos al interior de la Administración Municipal.

Por otra parte, la distribución del Gasto se hace priorizando el componente de inversión social como eje del Plan de Desarrollo, el uso eficiente de los recursos sin afectación de las condiciones normales de operación, y el cumplimiento oportuno de las obligaciones financieras y aunque ello represente un el buen flujo de recursos de Medellín, no por ello se puede caer en el síndorme de la abundancia. Todas las inversiones y proyecciones presupuestales están rigurosamente planeadas y pueden ser conocidas por la ciudadanía.

Presentamos a continuación el Plan Financiero Municipal para el periodo 2016 - 2019, mediante el cual pretendemos materializar nuestro Plan de 
Desarrollo, donde trazamos metas exigentes, que nos sentimos seguros de poder realizar porque sabemos que para alcanzarlas, Medellín cuenta con el compromiso de todos y cada uno de nosotros.

Tabla 1. Plan Financiero 2016 - 2019. Cifras en Millones.

\begin{tabular}{|c|c|c|c|c|c|}
\hline Concepto & 2016 & 2017 & 2018 & 2019 & $\begin{array}{l}\text { Total periodo } \\
2016-2019\end{array}$ \\
\hline Ingresos Corrientes & 2.322 .280 & 2.373 .604 & 2.424 .594 & 2.482 .022 & 9.602 .500 \\
\hline Ingresos Tributarios & 1.253 .256 & 1.284 .679 & 1.315 .307 & 1.351 .933 & 5.205 .175 \\
\hline Ingresos No Tributarios & 1.069 .023 & 1.088 .924 & 1.109 .287 & 1.130 .090 & 4.397 .325 \\
\hline Transferencias & 748.616 & 760.851 & 773.338 & 786.048 & 3.068 .853 \\
\hline Resto de Ingresos No Tributarios & 320.407 & 328.073 & 335.949 & 344.042 & 1.328 .471 \\
\hline Fondo Local de Salud & 417.228 & 423.815 & 430.511 & 437.317 & 1.708 .871 \\
\hline Fondo De Emergencias y Desastres & & & & & 0 \\
\hline Recursos de Capital & 1.080 .956 & 1.081 .814 & 1.246 .604 & 1.481 .931 & 4.891 .305 \\
\hline Recursos del Balance & 11.819 & 12.239 & 12.530 & 12.973 & 49.562 \\
\hline Venta de Activos & 848 & 939 & 891 & 984 & 3.662 \\
\hline Recuperaciones & 10.971 & 11.300 & 11.639 & 11.989 & 45.900 \\
\hline Superávit ejecución Presupuestal & 0 & 0 & 0 & 0 & 0 \\
\hline Recuperación cartera tributarios & 0 & 0 & 0 & 0 & 0 \\
\hline Recursos del Crédito & 168.900 & 55.000 & 54.900 & 107.500 & 386.300 \\
\hline Interno & 168.900 & 55.000 & 54.900 & 107.500 & 386.300 \\
\hline Externo & 0 & 0 & 0 & 0 & 0 \\
\hline Otros Recursos de Capital & 900.236 & 1.014 .575 & 1.179 .174 & 1.361 .458 & 4.455 .444 \\
\hline Ingresos Financieros & 72.666 & 70.379 & 69.052 & 67.332 & 279.429 \\
\hline Excedentes Financieros & 826.872 & 943.008 & 1.109 .403 & 1.292 .901 & 4.172 .184 \\
\hline Otros Ingresos Extraordinarios & 698 & 1.189 & 719 & 1.224 & 3.831 \\
\hline Ingresos Totales & 3.820 .464 & 3.879 .233 & 4.101 .709 & 4.401 .269 & 16.202 .676 \\
\hline Gastos de Funcionamiento & 616.284 & 632.815 & 653.348 & 672.793 & 2.575 .240 \\
\hline Nivel Central & 546.691 & 561.171 & 579.636 & 596.969 & 2.284 .466 \\
\hline Gastos de Personal & 307.632 & 323.510 & 338.611 & 352.425 & 1.322 .179 \\
\hline Gastos Generales & 76.190 & 78.928 & 81.393 & 83.903 & 320.414 \\
\hline Transferencias & 162.869 & 158.732 & 159.631 & 160.640 & 641.873 \\
\hline Organismos de Control $^{\star}$ & 69.593 & 71.645 & 73.713 & 75.824 & 290.774 \\
\hline Deuda Pública & 309.088 & 205.217 & 210.776 & 266.313 & 991.393 \\
\hline $\begin{array}{l}\text { Servicio de la Deuda Pública } \\
\text { Financiera }\end{array}$ & 261.681 & 157.810 & 163.369 & 218.906 & 801.766 \\
\hline Interna & 178.680 & 48.348 & 56.611 & 117.978 & 401.616 \\
\hline Amortización & 141.000 & 0 & 0 & 56.300 & 197.300 \\
\hline Títulos Emitidos & 141.000 & 0 & 0 & 0 & 141.000 \\
\hline Entidades Financieras & 0 & 0 & 0 & 56.300 & 56.300 \\
\hline Créditos de proveedores & 0 & 0 & 0 & 0 & 0 \\
\hline Intereses, Comisiones y Gastos & 37.680 & 48.348 & 56.611 & 61.678 & 204.316 \\
\hline Intereses Títulos Emitidos & 37.680 & 22.974 & 22.974 & 22.974 & 106.603 \\
\hline Comisiones Títulos Emitidos & 0 & 0 & 0 & 0 & 0 \\
\hline $\begin{array}{l}\text { Intereses Entidades } \\
\text { Financieras }\end{array}$ & 0 & 25.374 & 33.636 & 38.703 & 97.713 \\
\hline $\begin{array}{l}\text { Comisiones Entidades } \\
\text { Financieras }\end{array}$ & 0 & 0 & 0 & 0 & 0 \\
\hline
\end{tabular}




\begin{tabular}{|c|c|c|c|c|c|}
\hline Concepto & 2016 & 2017 & 2018 & 2019 & $\begin{array}{l}\text { Total periodo } \\
2016-2019\end{array}$ \\
\hline $\begin{array}{l}\text { Intereses Créditos de } \\
\text { proveedores }\end{array}$ & 0 & 0 & 0 & 0 & 0 \\
\hline $\begin{array}{l}\text { Comisiones Créditos de } \\
\text { proveedores }\end{array}$ & 0 & 0 & 0 & 0 & 0 \\
\hline Externa & 82.436 & 108.882 & 106.148 & 100.443 & 397.910 \\
\hline Amortización & 35.851 & 63.972 & 64.318 & 61.611 & 225.752 \\
\hline Banca Multilateral & 3.351 & 3.136 & 3.153 & 0 & 9.640 \\
\hline AFD & 32.500 & 60.836 & 61.165 & 61.611 & 216.112 \\
\hline Intereses, Comisiones y Gastos & 46.586 & 44.910 & 41.830 & 38.832 & 172.158 \\
\hline Intereses Banca Multilateral & 515 & 305 & 132 & 0 & 952 \\
\hline Intereses AFD & 46.071 & 44.604 & 41.698 & 38.832 & 171.206 \\
\hline Comisiones AFD & 0 & 0 & 0 & 0 & 0 \\
\hline $\begin{array}{l}\text { Operaciones Conexas de la } \\
\text { deuda }\end{array}$ & 565 & 580 & 610 & 485 & 2.240 \\
\hline Deuda Interna & 374 & 393 & 413 & 276 & 1.457 \\
\hline Deuda Externa & 190 & 187 & 197 & 209 & 783 \\
\hline $\begin{array}{l}\text { Bonos Pensionales Tipo A y B según } \\
\text { Ley } 617 \text { de } 2000\end{array}$ & 47.407 & 47.407 & 47.407 & 47.407 & 189.627 \\
\hline Plan Operativo Anual de Inversiones & 2.895 .092 & 3.041 .201 & 3.237 .586 & 3.462 .164 & 12.636 .043 \\
\hline Cobertura Déficit Acumulado & 0 & 0 & 0 & 0 & 0 \\
\hline Cobertura Déficit & 0 & 0 & 0 & 0 & 0 \\
\hline Gastos Totales & 3.820 .464 & 3.879 .233 & 4.101 .709 & 4.401 .269 & 16.202 .676 \\
\hline
\end{tabular}


Para el periodo 2016 - 2019 hemos presupuestado ingresos que ascienden a más de $\$ 16.2$ billones, de los cuales el $59.3 \%$ corresponden a Ingresos Corrientes, $10.5 \%$ al Fondo Local de Salud mientras que el $30.2 \%$ restante a Recursos de Capital; destacamos en los Ingresos Corrientes la importancia de los recursos provenientes de los impuestos Predial e Industria y Comercio, consecuencia de un proceso de fortalecimiento de cultura tributaria, que esperamos se consolide aún más durante nuestra Administración.

Creemos en el manejo pulcro, técnico y eficiente de los recursos, de manera tal que se le genere confianza a la ciudadanía y así incentivar la cultura del pago de impuestos, al poderse constatar que los dineros públicos están siendo cuidadosamente administrados para el bien mismo de la ciudadanía.

Por otro lado, el uso apropiado de los recursos transferidos por la Nación nos permite contar con recursos para el Fondo Local de Salud, impulsadores de diferentes proyectos en materia de mejoramiento de condiciones y calidad de vida; así mismo, en el rubro de Recursos de Capital se destaca el aporte de los excedentes financieros que anualmente son transferidos desde Empresas Públicas de Medellín, y que financian importantes iniciativas en materia de educación, bienestar e infraestructura.

En materia de gasto, la inversión social representa el componente más importante: de los recursos programados para el cuatrienio, 78\% tendrá como destino la inversión, lo que significa que por cada 100 pesos ejecutados en el gasto, 78 serán en el rubro de inversión. El componente de funcionamiento se regirá por el principio de eficiencia y representa un 15.9\% del total del gasto, mientras que el 6.1\% restante está destinado a garantizar el cumplimiento de las obligaciones financieras.

\section{Origen de los recursos}

\subsection{Composición de Ingresos}

Ingresos totales 


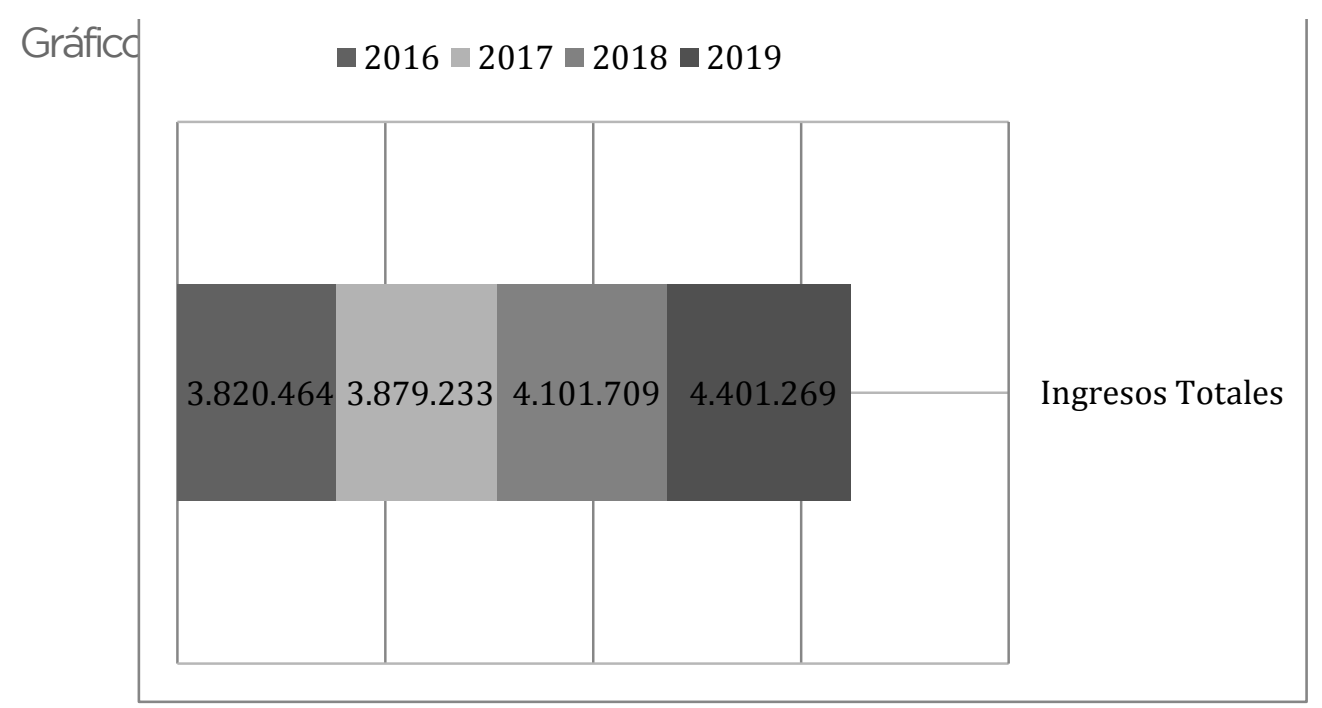

Millones.

Hemos presupuestado para el cuatrienio recursos por un valor superior a $\$ 16.2$ billones de pesos, y en concordancia con los análisis de perspectiva económica y tendencia histórica observada, la tasa de crecimiento anual promedio está alrededor de 5.4\%; el mayor crecimiento proyectado para la vigencia 2019 obedece principalmente a la proyección de recursos del crédito y los excedentes financieros de epm para dicha vigencia.

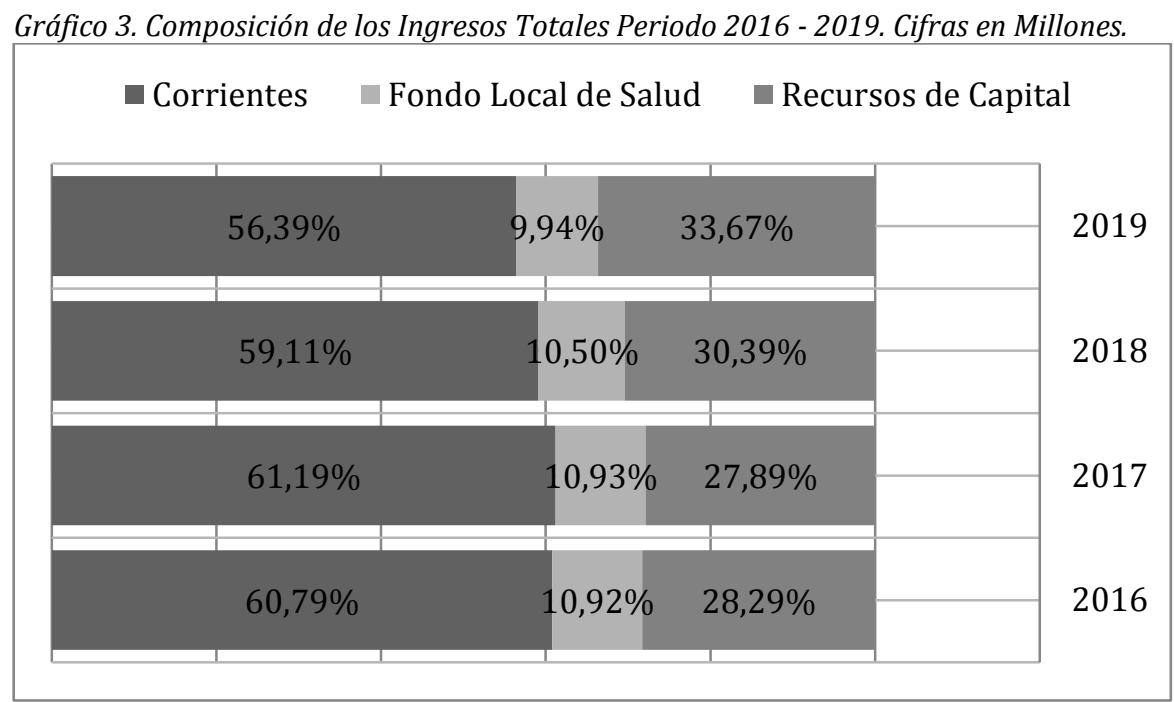

Los Ingresos Corrientes representan para la Administración Municipal en promedio el $60 \%$ del total, mientras que el promedio de participación del Fondo Local de Salud asciende aproximadamente a 10\%, y el 30\% restante corresponde a los Recursos de Capital; el mayor porcentaje de participación para este agregado en el 2019 obedece a los excedentes financieros de epm proyectados para esta vigencia. 
Ingresos tributarios

Gráfico 4. Distribución de los Ingresos Tributarios Periodo 2016 - 2019. Cifras en Millones

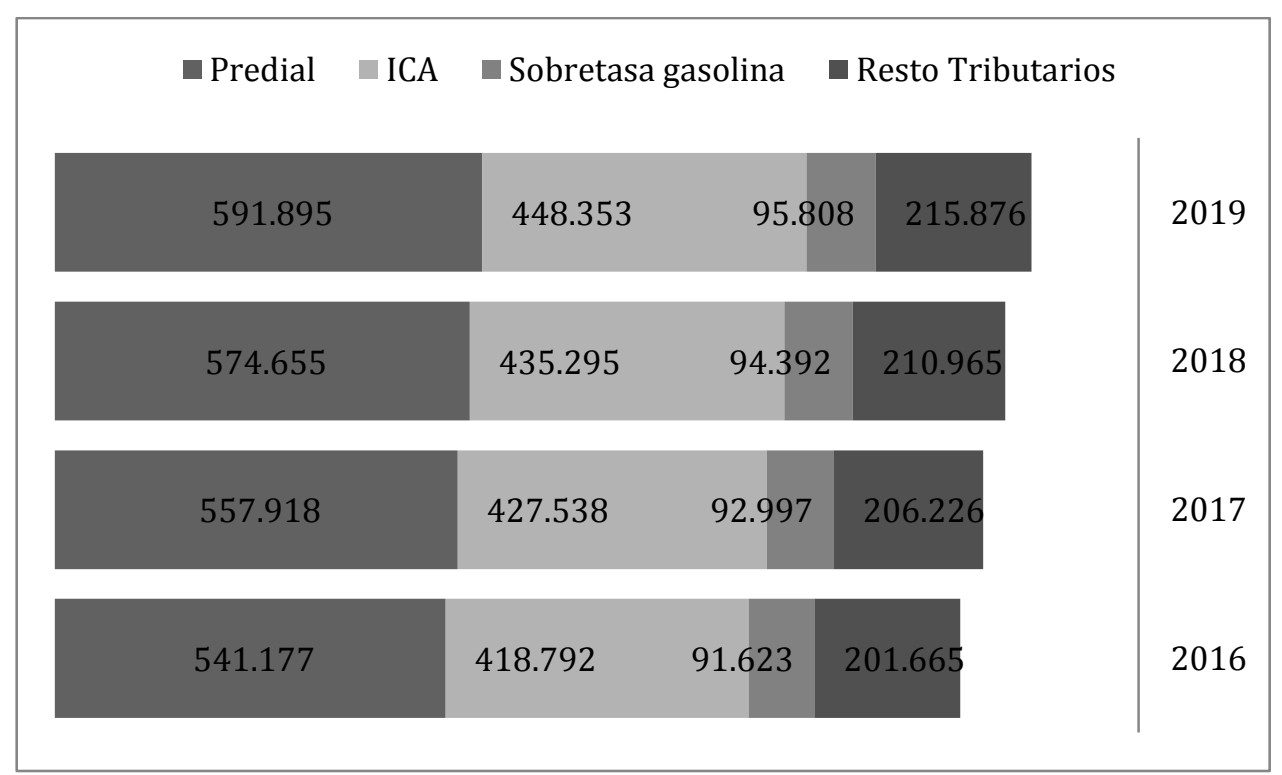

La proyección de los ingresos tributarios para el cuatrienio 2016 - 2019 obedece a un criterio conservador, atendiendo al principio de coherencia macroeconómica y minimizando los riesgos asociados a una sobrevaloración de los recursos, que podrían traer como consecuencia una desfinanciación de proyectos; así, la tasa de crecimiento promedio del impuesto predial es levemente superior a 3\%, considerando los incrementos autorizados por el Gobierno Nacional al inicio de cada año, así como la gestión en materia de conservación catastral que periódicamente realiza la Administración Municipal; por otro lado, la tasa de crecimiento promedio del impuesto de industria y comercio es del orden de $2.3 \%$, mientras que la sobretasa a la gasolina presenta un crecimiento promedio de $1.5 \%$ a pesar de la recuperación presentada por este rubro durante las dos últimas vigencias, ya que por estar altamente asociado al precio internacional del crudo y la dinámica del mercado automotriz, este concepto está expuesto a una alta variabilidad, y en vigencias anteriores presentó tasas de crecimiento negativas.

Dentro de los ingresos tributarios se destaca la participación que tienen el impuesto predial e industria y comercio, pues representan conjuntamente más del $76 \%$ del total de éstos. 
Ingresos no tributarios

Gráfico 5. Composición de los Ingresos No Tributarios Periodo 2016 - 2019. Cifras en Millones.

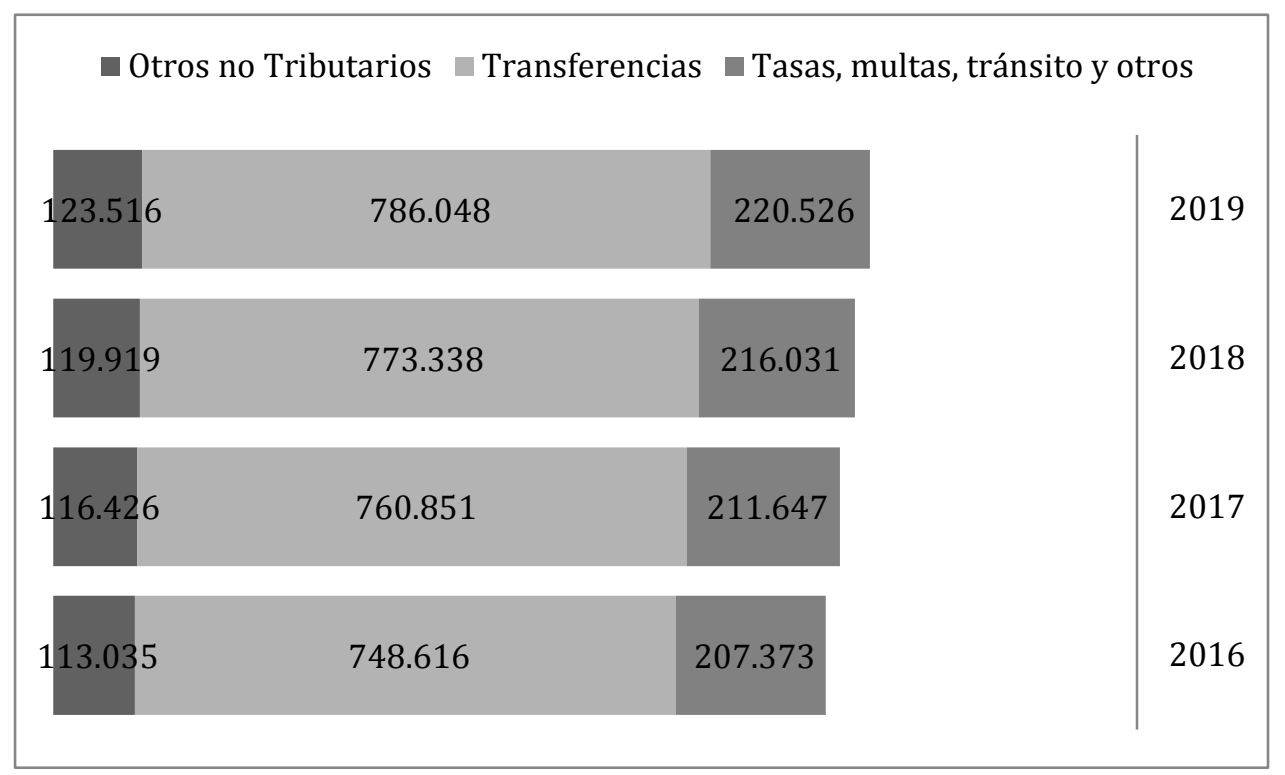

El agregado de otros ingresos no tributarios está compuesto fundamentalmente de los conceptos asociados a obligaciones urbanísticas y contribuciones para servicios públicos de aseo y alcantarillado; representa en promedio un $10.7 \%$ del total de los ingresos no tributarios y la tasa promedio de crecimiento para el cuatrienio es de 3.0\%; por otro lado, las transferencias, rubro que incluye fundamentalmente el Sistema General de Participación -SGP- y transferencias departamentales (como la de impuesto vehicular) representan en promedio el $70 \%$ de los ingresos no tributarios y la tasa de crecimiento promedio para el periodo es de aproximadamente $1.6 \%$, pues más que debido a factores macroeconómicos, el valor de los giros que efectúa la Nación a las entidades territoriales se establece mediante las disposiciones que para tal efecto establece periódicamente el CONPES.

El resto de ingresos no tributarios, donde se encuentran las tasas, multas, intereses sanciones, servicios de tránsito y rentas contractuales entre otros, comprende aproximadamente el $20 \%$ de los ingresos no tributarios y presenta una tasa de crecimiento promedio de $2 \%$ durante el cuatrienio 2016 - 2019. 


\section{Fondo local de salud}

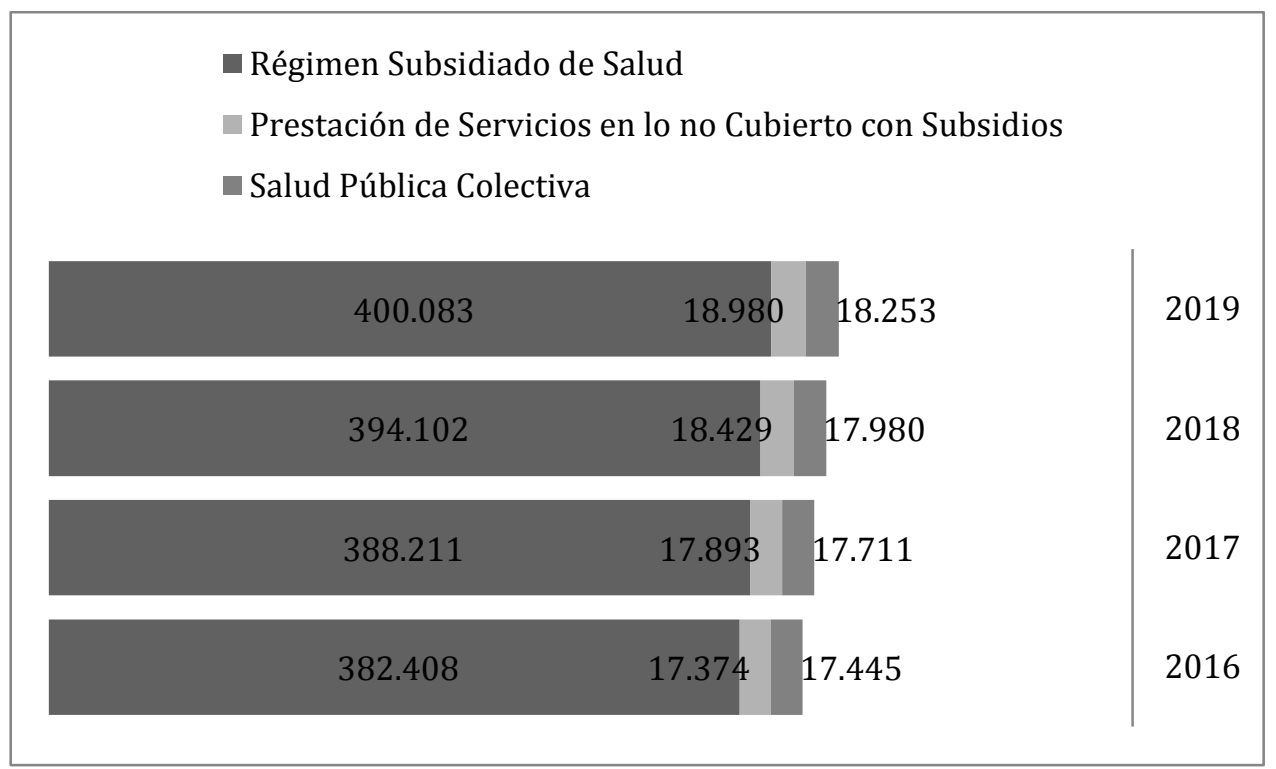

Al interior del Fondo Local de Salud, el agregado de "Régimen Subsidiado" representa en promedio más de $91 \%$ del total del Fondo, mientras que la tasa de crecimiento promedio durante el periodo es del orden de $1.5 \%$, pues el valor de los giros que efectúa la Nación a las entidades territoriales se establece mediante las disposiciones que para tal efecto establece periódicamente el CONPES. Este agregado incluye las transferencias por concepto de FOSYGA y SGP Régimen Subsidiado.

\section{Recursos de capital}

Gráfico 6. Composición de los Recursos de Capital Periodo 2016 - 2019. Cifras en Millones.

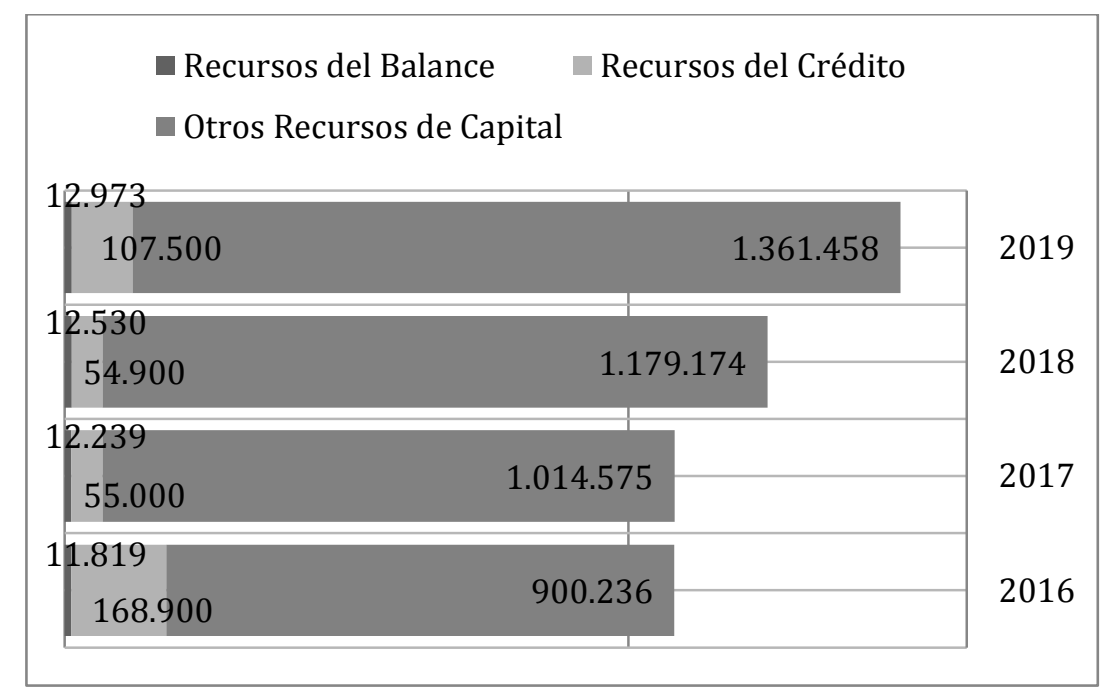

El componente de menor proporción, que representa en promedio un $1 \%$ del total de recursos de capital, corresponde al agregado "Recursos del 
Balance" y que incluye conceptos como venta de activos y recuperaciones; por otro lado, el agregado correspondiente a Recursos del Crédito presenta variaciones entre los diferentes periodos, pues la proyección de créditos obedece a necesidades específicas de financiación; así por ejemplo, para la vigencia 2016, la Administración Municipal proyecta contratar recursos por valor de $\$ 168.900$ millones.

El rubro de "Otros Recursos de Capital" incluye los excedentes financieros transferidos a la Administración Municipal por Empresas Públicas de Medellín, y que constituyen una fuente de financiación que apalanca importantes iniciativas de inversión social.

\subsection{Composición de Gastos}

\section{Gastos totales}

Gráfico 7. Composición de los Gastos Totales Periodo 2016 - 2019. Cifras en Millones.

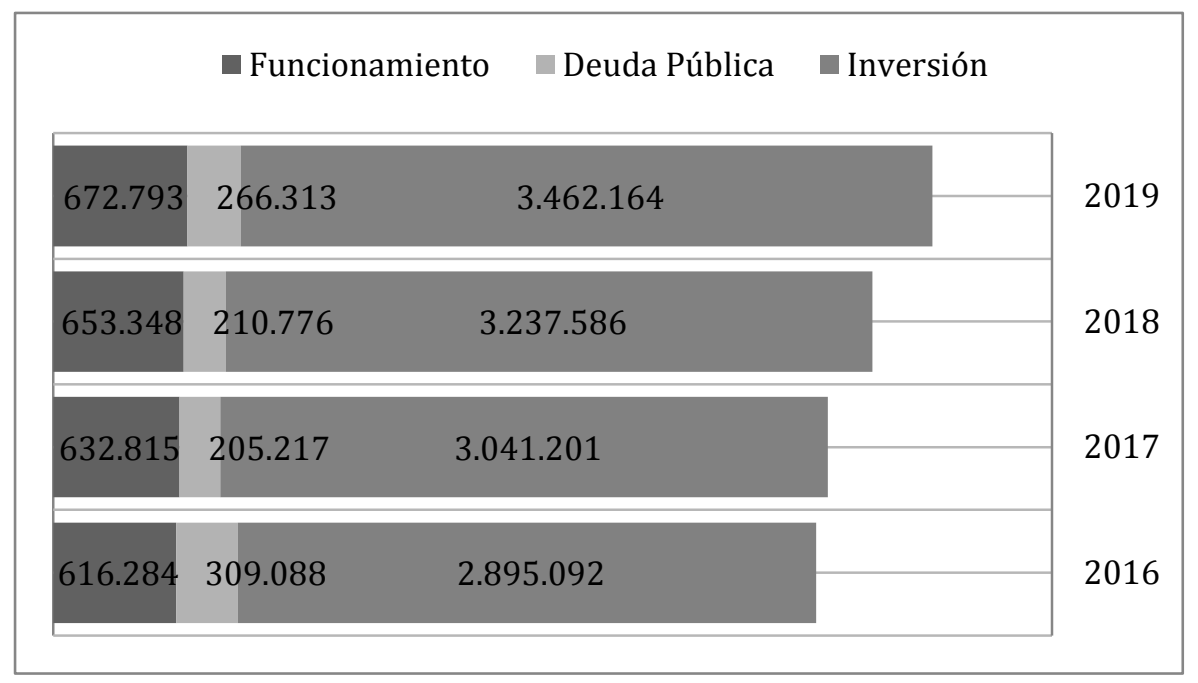

En promedio, durante el cuatrienio 2016 - 2019, los gastos de funcionamiento representan el $16 \%$ del total, destacando de este rubro una tasa de crecimiento moderado de $3 \%$ en promedio, lo que refleja nuestro esfuerzo por incrementar los niveles de eficiencia y austeridad en el uso de recursos y brinda la posibilidad de destinar una mayor proporción al componente de inversión, el cual representa en promedio el $78 \%$ del total de los gastos y una tasa de crecimiento anual promedio cercana al 7\%; es a través del rubro de inversión como materializamos las iniciativas del Plan de Desarrollo.

Por otro lado, el agregado correspondiente a la Deuda Pública presenta su mayor valor en el 2016, año durante el cual tiene lugar el vencimiento de los bonos emitidos en el 2007, lo que aumenta el servicio de la deuda, sumado al inicio de la amortización del crédito contratado con la Agencia Francesa para el Desarrollo - AFD-. 


\section{Gastos de funcionamiento}

Gráfico 8. Composición de los Gastos de Funcionamiento Periodo 2016 - 2019. Cifras en Millones.

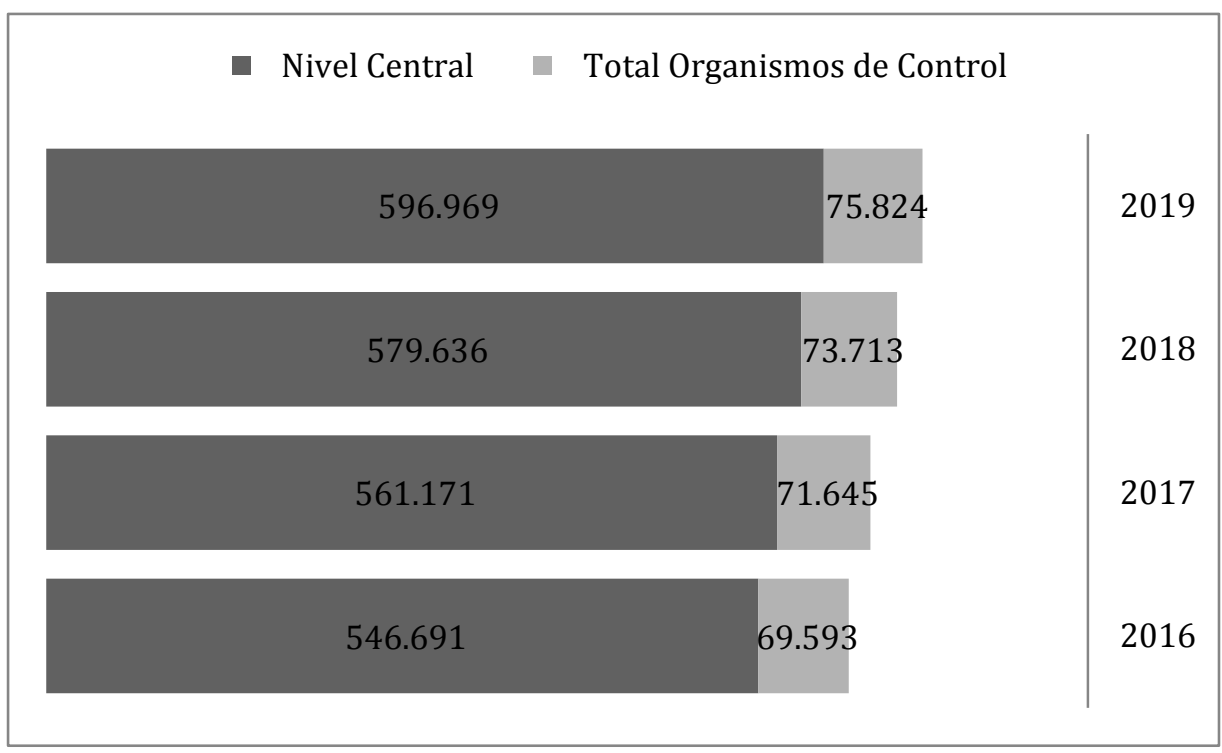

Los gastos de funcionamiento mantienen una tasa de crecimiento alrededor de $3 \%$ en concordancia con la estrategia de eficiencia en el uso de recursos y austeridad en el gasto; los recursos de funcionamiento asignados a los órganos de control se asignan con base en las directrices que para ello establece la Ley.

Deuda pública 
Gráfico 9. Composición de la Deuda Pública Periodo 2016 - 2019. Cifras en Millones.

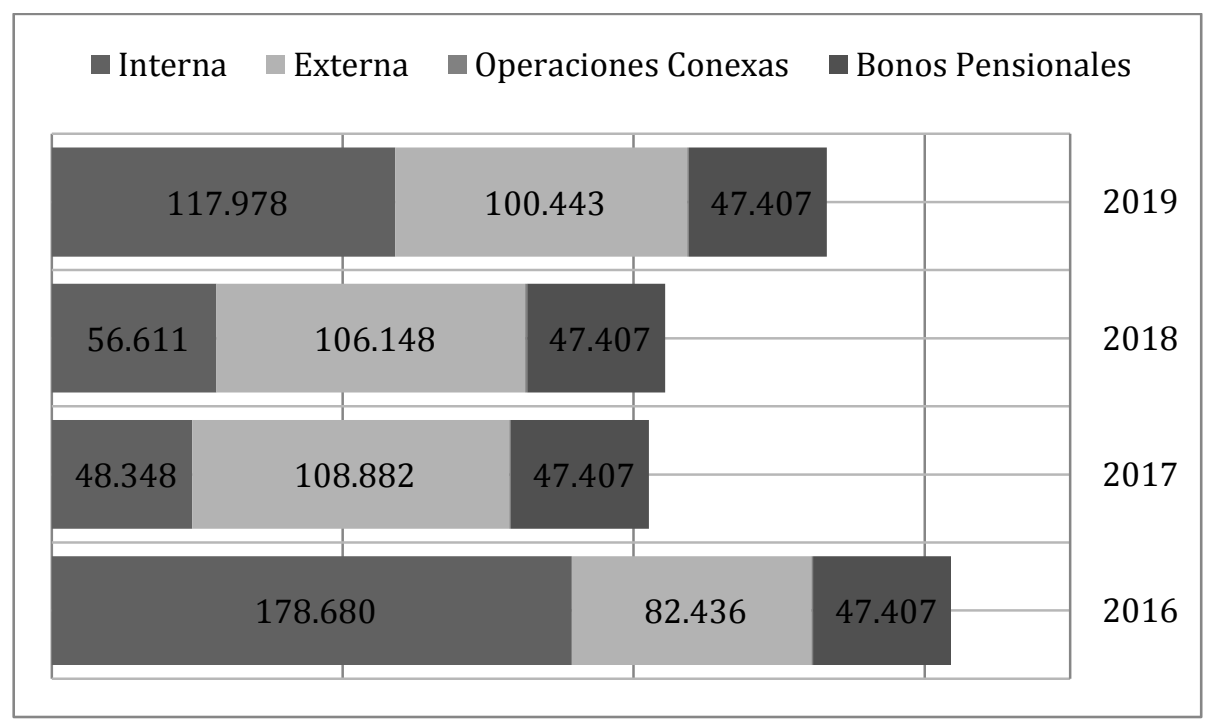

La composición de la deuda pública varía significativamente entre periodos, debido en mayor medida al Servicio de la Deuda Pública, pues durante la vigencia 2016 por ejemplo tiene lugar el vencimiento de los títulos emitidos en 2007 por valor de $\$ 141.000$ millones, así como el comienzo de la amortización al crédito contratado con la AFD para la ejecución del Tranvía de Ayacucho y los dos cables complementarios; la cuota fija de \$47.407 millones corresponden a recursos proyectados a apropiar en cada vigencia por parte de la Administración Municipal para garantizar el cumplimiento del pasivo pensional con base en lo establecido en la Ley 549 de 1999. 


\section{-PLAN DE INVERSIONES Y FUENTES DE FINANCIACIÓN•}

Gráfico 10. Gasto de Inversión Periodo 2016 - 2019. Cifras en Millones.

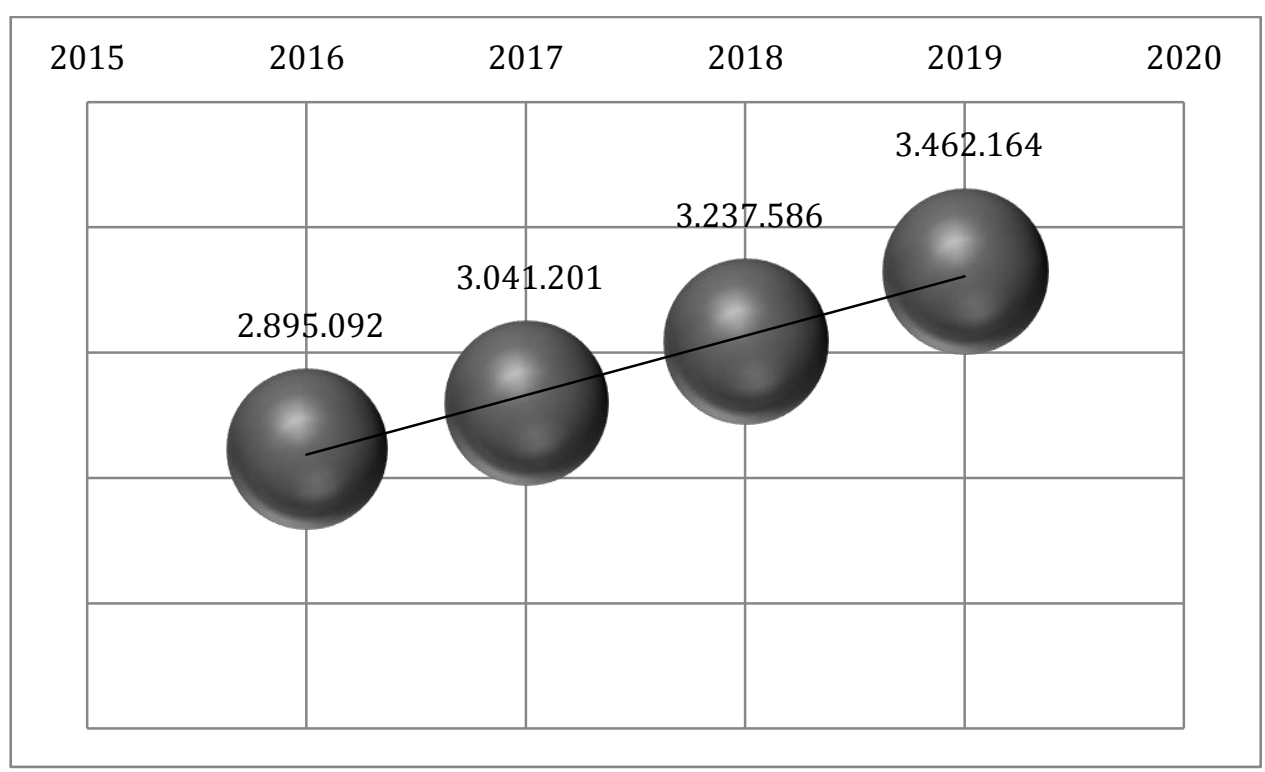

El monto total de inversión proyectado para el periodo 2016 - 2019 es superior a $\$ 12.5$ billones de pesos, con una tasa promedio de crecimiento anual cercana a 7.0\%; es a través de este rubro que se financian las iniciativas y se ejecutan los proyectos y obras contemplados en el Plan de Desarrollo; la tasa de crecimiento proyectada para este componente y el control sobre el agregado de funcionamiento evidencian nuestro compromiso con la ciudad a través del logro de los objetivos trazados y los recursos destinados para ello.

Indicadores de ley

Los datos financieros incluidos en el Plan de Desarrollo 2016 - 2019 son el resultado de un ejercicio riguroso de planificación financiera, mediante el cual no solo se busca garantizar los recursos necesarios para la ejecución de las iniciativas del Plan, sino procurar el cumplimiento de los indicadores establecidos por las Leyes 358 de 1997, 617 de 2000 y 819 de 2003 y consolidar un horizonte financieramente sostenible por parte del Municipio de Medellín.

Los indicadores son objeto de seguimiento y monitoreo permanente, de modo que cualquier desviación del comportamiento normal pueda evitarse oportunamente a través de las medidas preventivas necesarias. 
Tabla 2. Indicadores de ley. Proyección 2016 - 2019.

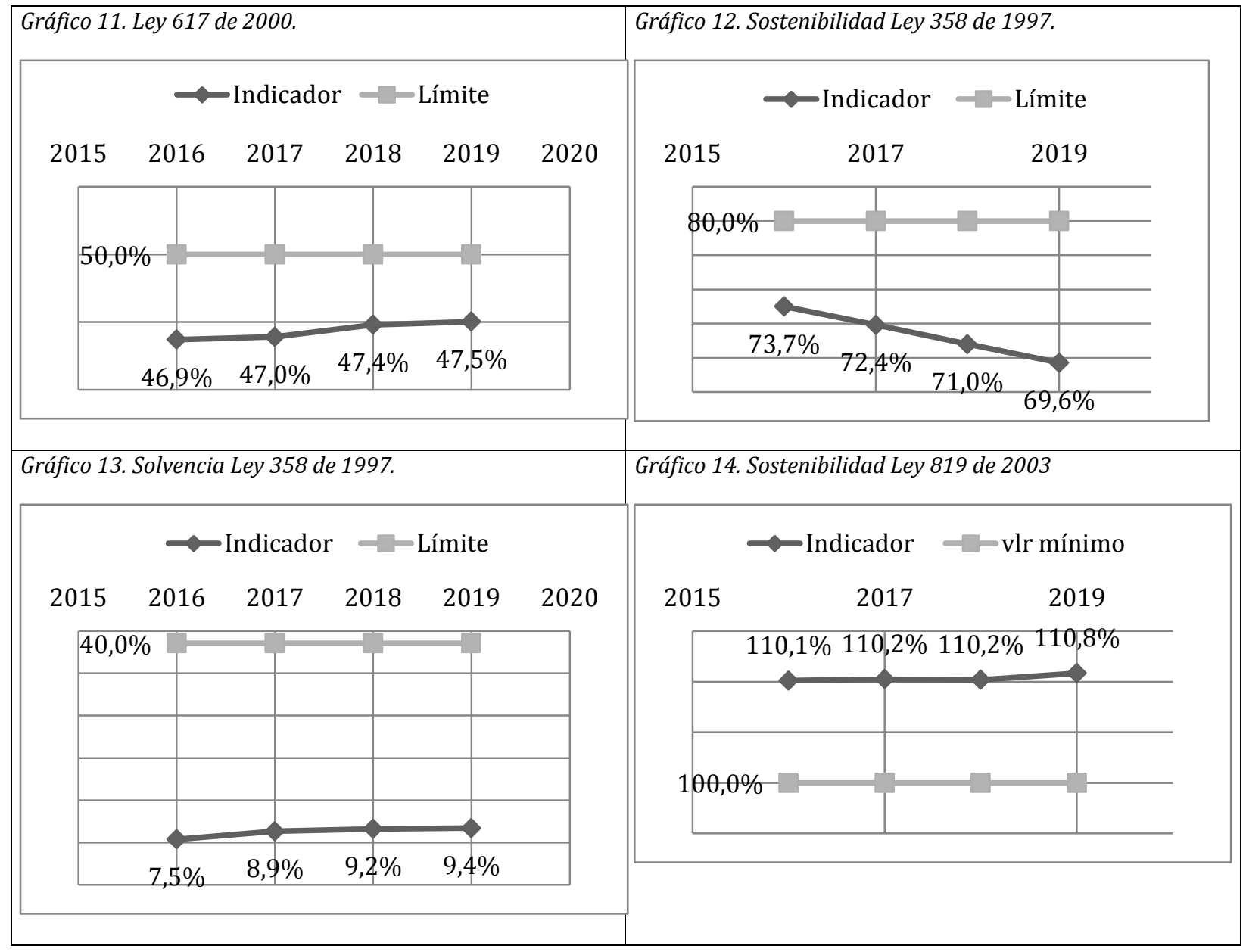

El margen existente entre el indicador proyectado y los límites legales permite a la Administración Municipal garantizar la sostenibilidad financiera de la entidad y el cumplimiento de las obligaciones financieras (sostenibilidad y solvencia Ley 358; sostenibilidad Ley 819); igualmente, el manejo y planificación detallada de las finanzas representan resultados positivos en materia de valoración de riesgos y la posibilidad de acceder a contratos de crédito bajo condiciones financieras favorables. 


\section{Plan cuatrienal de inversiones}

A continuación se presenta en plan plurianual de inversiones 2016-2019, en el cual se relaciona cada una de las dimensiones con sus respectivos retos y programas con la inversión estimada para los próximos cuatro años. Vale la pena mencionar que si bien se cuenta con una cifra estimada de inversión según el Plan Financiero expuesto anteriormente, se consideran, además, fuentes alternativas de financiación para los proyectos de inversión del plan como recursos de regalías, proyectos financiados con los recursos del Fondo Medellín Ciudad para la Vida y recursos del superávit de la vigencia 2016, entre otros.

\begin{tabular}{|c|c|c|c|}
\hline \multicolumn{4}{|c|}{ Plan Plurianual de Inversiones 2016 - 2019} \\
\hline Dimensión / Reto / Programa & $\begin{array}{c}\text { Plan } \\
\text { financiero }\end{array}$ & $\begin{array}{l}\text { Fuentes } \\
\text { alternativas }\end{array}$ & $\begin{array}{l}\text { Inversión } \\
\text { total }\end{array}$ \\
\hline Creemos en la cultura ciudadana & 680.123 & - & 680.123 \\
\hline Cultura Medellín & 157.236 & - & 157.236 \\
\hline Recuperando la confianza & 20.275 & - & 20.275 \\
\hline Formación ciudadana & 28.761 & - & 28.761 \\
\hline Cultura de la legalidad & 3.100 & - & 3.100 \\
\hline Cultura del cuidado para una Medellín saludable & 30.000 & - & 30.000 \\
\hline Educación y Buenas Prácticas Ambientales & 4.360 & - & 4.360 \\
\hline Cultura D & 70.740 & - & 70.740 \\
\hline Medellín participativa & 63.637 & - & 63.637 \\
\hline $\begin{array}{l}\text { Promoción de la organización, la movilización y la formación } \\
\text { para la participación }\end{array}$ & 45.463 & - & 45.463 \\
\hline Presupuesto participativo & 7.000 & - & 7.000 \\
\hline Fortalecimiento estratégico de la planeación social y económica & 11.174 & - & 11.174 \\
\hline Medellín bien administrado & 459.250 & - & 459.250 \\
\hline Gobierno visible & 37.720 & - & 37.720 \\
\hline Transparencia como modelo de gestión & 25.192 & - & 25.192 \\
\hline Excelente manejo de las finanzas y los recursos públicos & 33.500 & - & 33.500 \\
\hline Gestión eficiente & 53.500 & - & 53.500 \\
\hline Gestión eficaz & 273.338 & - & 273.338 \\
\hline Innovación pública - laboratorio de gobierno & 36.000 & - & 36.000 \\
\hline Recuperando la seguridad y la convivencia ciudadana & 690.538 & 10.000 & 700.538 \\
\hline Medellín segura & 494.004 & - & 494.004 \\
\hline Planeación para la seguridad integral & 209.377 & - & 209.377 \\
\hline Infraestructura y tecnología para la seguridad y la convivencia & 238.734 & - & 238.734 \\
\hline Justicia y política criminal & 32.307 & - & 32.307 \\
\hline Medellín segura para las mujeres y las niñas & 13.586 & - & 13.586 \\
\hline En Medellín convivimos todos & 75.968 & - & 75.968 \\
\hline
\end{tabular}




\begin{tabular}{|c|c|c|c|}
\hline \multicolumn{4}{|c|}{ Plan Plurianual de Inversiones 2016 - 2019} \\
\hline Dimensión / Reto / Programa & $\begin{array}{c}\text { Plan } \\
\text { financiero }\end{array}$ & $\begin{array}{c}\text { Fuentes } \\
\text { alternativas }\end{array}$ & $\begin{array}{c}\text { Inversión } \\
\text { total }\end{array}$ \\
\hline Justicia cercana al ciudadano & 31.428 & - & 31.428 \\
\hline Promoción de la Convivencia & 19.369 & - & 19.369 \\
\hline Todos convivimos en el espacio público & 17.570 & - & 17.570 \\
\hline Prevención de las violencias & 7.602 & - & 7.602 \\
\hline Medellín cuenta con vos para construir la paz en el territorio & 120.565 & 10.000 & 130.565 \\
\hline Promoción de los Derechos humanos & 14.597 & - & 14.597 \\
\hline Postacuerdo y garantías de no repetición & 22.330 & - & 22.330 \\
\hline Memoria y participación para la construcción de paz & 32.923 & - & 32.923 \\
\hline Atención a víctimas del conflicto armado & 50.716 & 10.000 & 60.716 \\
\hline Un nuevo modelo de equidad social & 2.506 .474 & - & 2.506.474 \\
\hline Medellín para vivir más y mejor & 1.873 .215 & - & 1.873 .215 \\
\hline Fortalecimiento del acceso a los servicios de salud & 1.846 .476 & - & 1.846 .476 \\
\hline Gestión de estrategias en salud & 8.367 & - & 8.367 \\
\hline Articulación sistema de la salud & 10.000 & - & 10.000 \\
\hline Vigilancia integral en salud & 8.372 & - & 8.372 \\
\hline Medellín Digna & 633.259 & - & 633.259 \\
\hline Por el sueño de ciudad de la Infancia y la adolescencia & 35.715 & - & 35.715 \\
\hline Por un envejecimiento digno & 21.539 & - & 21.539 \\
\hline Empoderameinto y transversalización de la equidad de género & 6.255 & - & 6.255 \\
\hline Promoción del desarrollo humano integral de la juventud & 5.104 & - & 5.104 \\
\hline Atención e inclusión social para el habitante de calle & 28.817 & - & 28.817 \\
\hline Seguridad alimentaria y nutricional & 467.158 & - & 467.158 \\
\hline Ser Capaz: personas con discapacidad, familiares y cuidadores & 23.157 & - & 23.157 \\
\hline Diversidad sexual e identidades de género & 821 & - & 821 \\
\hline Diversidad étnica y cultural & 3.497 & - & 3.497 \\
\hline Familia & 41.195 & - & 41.195 \\
\hline Educación con calidad para el desarrollo y la competitividad & 3.901 .636 & 394.600 & 4.296.236 \\
\hline Medellín, camino a la excelencia y la calidad & 95.288 & 315.000 & 410.288 \\
\hline Maestros y maestras sujetos de saber & 22.000 & - & 22.000 \\
\hline Infraestructura para la calidad de la educación & 44.001 & $315.000 *$ & 359.001 \\
\hline Medellín multilingüe & 11.287 & - & 11.287 \\
\hline Promoción de las capacidades y talentos de los ciudadanos & 16.000 & - & 16.000 \\
\hline Comunidad educativa como escenario de desarrollo & 2.000 & - & 2.000 \\
\hline Medellín gestiona su oferta educativa & 3.370 .884 & - & 3.370 .884 \\
\hline
\end{tabular}




\begin{tabular}{|c|c|c|c|}
\hline \multicolumn{4}{|c|}{ Plan Plurianual de Inversiones 2016 - 2019} \\
\hline Dimensión / Reto / Programa & $\begin{array}{c}\text { Plan } \\
\text { financiero }\end{array}$ & $\begin{array}{c}\text { Fuentes } \\
\text { alternativas }\end{array}$ & $\begin{array}{c}\text { Inversión } \\
\text { total }\end{array}$ \\
\hline Educación inicial, preescolar, básica y media & 3.275 .884 & - & 3.275 .884 \\
\hline Fortalecer el sistema de educación técnica y superior & 95.000 & - & 95.000 \\
\hline Medellín se construye desde la cultura & 150.764 & 38.000 & 188.764 \\
\hline Bibliotecas para una sociedad del conocimiento & 77.667 & - & 77.667 \\
\hline Movilización por la cultura & 18.997 & - & 18.997 \\
\hline Creación, Formación, Fomento y Circulación & 54.100 & $38.000 *$ & 92.100 \\
\hline Medellín con acceso al empleo & 165.631 & - & 165.631 \\
\hline Desarrollo empresarial & 22.288 & - & 22.288 \\
\hline Educación pertinente a la dinámica laboral & 35.000 & - & 35.000 \\
\hline Generación de empleo & 10.000 & - & 10.000 \\
\hline Medellín Emprendedora & 66.668 & - & 66.668 \\
\hline Desarrollo empresarial rural & 18.475 & - & 18.475 \\
\hline En búsqueda de la competitividad & 13.200 & - & 13.200 \\
\hline Medellín Innovadora & 119.069 & 41.600 & 160.669 \\
\hline Ciencia, innovación y tecnología para la sociedad & 50.000 & 40.000 & 90.000 \\
\hline Turismo & 27.700 & - & 27.700 \\
\hline Internacionalización & 36.930 & - & 36.930 \\
\hline Investigación científica y desarrollo tecnológico & 4.439 & 1.600 & 6.039 \\
\hline Movilidad sostenible & 1.792 .000 & 1.089 .444 & 2.881 .444 \\
\hline Medellín se integra con la región y el Área Metropolitana & 311.441 & 28.870 & 340.311 \\
\hline Gestión de planes regionales y metropolitanos & 311.441 & 28.870 & 340.311 \\
\hline Movilidad para la ciudad & 820.150 & 242.574 & 1.062 .724 \\
\hline Planificación del Sistema de Movilidad de la ciudad & 70.150 & - & 70.150 \\
\hline Proyectos de infraestructura para la movilidad de la ciudad & 750.000 & 242.574 & 992.574 \\
\hline Gestión de la Movilidad Accesible, Sostenible y Segura & 660.409 & 818.000 & 1.478.409 \\
\hline $\begin{array}{l}\text { Fortalecimiento a la integración multimodal del Transporte } \\
\text { público }\end{array}$ & 262.409 & 600.000 & 862.409 \\
\hline Intervenciones movilidad para transporte público multimodal & 323.000 & $218.000 *$ & 541.000 \\
\hline Gestión integral para la movilidad no motorizada & 75.000 & - & 75.000 \\
\hline Intervención integral del territortio y recurperacion del centro & 899.803 & 477.877 & 1.377 .681 \\
\hline Medellín planifica y gestiona su territorio & 95.764 & - & 95.764 \\
\hline Planificación del Ordenamiento Territorial & 13.550 & - & 13.550 \\
\hline Planificación del Sistema de Gestión para la Equidad Territorial & 12.102 & - & 12.102 \\
\hline Gestión de la información urbanística y catastral & 70.112 & - & 70.112 \\
\hline
\end{tabular}




\begin{tabular}{|c|c|c|c|}
\hline \multicolumn{4}{|c|}{ Plan Plurianual de Inversiones 2016 - 2019} \\
\hline Dimensión / Reto / Programa & $\begin{array}{c}\text { Plan } \\
\text { financiero }\end{array}$ & $\begin{array}{c}\text { Fuentes } \\
\text { alternativas }\end{array}$ & $\begin{array}{c}\text { Inversión } \\
\text { total }\end{array}$ \\
\hline Proyectos Integrales para Medellín & 100.920 & 174.877 & 275.797 \\
\hline $\begin{array}{l}\text { Implementación de los instrumentos de planificación adoptados } \\
\text { de segundo nivel del POT }\end{array}$ & 460 & - & 460 \\
\hline $\begin{array}{l}\text { Implementación de los instrumentos de planificación adoptados } \\
\text { de tercer nivel del POT }\end{array}$ & 50.460 & $174.877^{*}$ & 225.337 \\
\hline Medellin reconoce la importancia de su territorio rural & 50.000 & - & 50.000 \\
\hline Gestión del paisaje, el patrimonio y los bienes inmuebles & 141.346 & - & 141.346 \\
\hline Recuperemos nuestro patrimonio y paisaje & 111.846 & - & 111.846 \\
\hline Generando valor inmobiliario & 29.500 & -1 & 29.500 \\
\hline Medellín vuelve a su centro & 282.698 & 50.000 & 332.698 \\
\hline Rehabitar el centro & 95 & - & 95 \\
\hline Conectividad y nueva movilidad & 35.303 & $50.000 *$ & 85.303 \\
\hline Aprovechamiento del espacio público y patrimonio cultural & 80.000 & - & 80.000 \\
\hline Presencia institucional y gobernabilidad & 167.300 & - & 167.300 \\
\hline Hábitat adecuado para Medellín & 279.076 & 253.000 & 532.076 \\
\hline Fortalecimiento al Sistema Municipal Habitacional & 3.041 & - & 3.041 \\
\hline Reasentamiento integral de población & 110.000 & 40.000 & 150.000 \\
\hline $\begin{array}{l}\text { Gestión de nuevos desarrrollos habitacionales de Vivienda } \\
\text { Social }\end{array}$ & 15.000 & 80.000 & 95.000 \\
\hline Mejoramiento Integral de Barrios & 151.035 & 133.000 & 284.035 \\
\hline Una apuesta de ciudad por el ciudado del medio ambiente & 767.138 & 17.000 & 784.138 \\
\hline Medellín ciudad verde y sostenible & 207.413 & 4.000 & 211.413 \\
\hline $\begin{array}{l}\text { Infraestructura Verde: Generacion, conservación y } \\
\text { mantenimiento de espacios verdes }\end{array}$ & 7.866 & - & 7.866 \\
\hline Estructura ecologica y sus servicios ecosistemicos & 51.096 & 4.000 & 55.096 \\
\hline Nuestro río y sus quebradas & 99.928 & - & 99.928 \\
\hline Gestión Integral de Residuos Sólidos & 11.673 & - & 11.673 \\
\hline Protección animal & 15.557 & - & 15.557 \\
\hline $\begin{array}{l}\text { Sistema de gestión Ambiental Integral de Medellín para el } \\
\text { cambio climático }\end{array}$ & 6.114 & - & 6.114 \\
\hline Salud ambiental & 12.180 & - & 12.180 \\
\hline Por la calidad del aire que respiramos & 3.000 & - & 3.000 \\
\hline Acceso de calidad a los Servicios Públicos & 507.704 & 13.000 & 520.704 \\
\hline Medellín con acceso de calidad al acueducto y al alcantarillado & 486.104 & -1 & 486.104 \\
\hline
\end{tabular}




\begin{tabular}{|c|c|c|c|}
\hline \multicolumn{4}{|c|}{ Plan Plurianual de Inversiones 2016 - 2019} \\
\hline Dimensión / Reto / Programa & $\begin{array}{c}\text { Plan } \\
\text { financiero }\end{array}$ & $\begin{array}{c}\text { Fuentes } \\
\text { alternativas }\end{array}$ & $\begin{array}{c}\text { Inversión } \\
\text { total }\end{array}$ \\
\hline Gestión integral de los servicios públicos & 21.600 & 13.000 & 34.600 \\
\hline Medellín gestiona el riesgo & 52.022 & - & 52.022 \\
\hline Conocimiento del riesgo & 25.895 & - & 25.895 \\
\hline Reducción y mitigación del riesgo & 17.104 & - & 17.104 \\
\hline Manejo eficaz de desastres & 9.022 & - & 9.022 \\
\hline \multicolumn{4}{|l|}{ Inversión interinstitucional y obligaciones presupuestales } \\
\hline Presupuesto Participativo & 631.802 & - & 631.802 \\
\hline Transferencias al Área Metropolitana & 281.620 & - & 281.620 \\
\hline Acuerdo de pago Metro & 202.605 & - & 202.605 \\
\hline $\begin{array}{l}\text { Alumbrado público e iluminación para la seguridad y el } \\
\text { disfrute de los espacios públicos }\end{array}$ & 267.587 & - & 267.587 \\
\hline Compromiso Socios Junta Metroplus & 14.716 & - & 14.716 \\
\hline Total cuatrienio & 12.636 .043 & 1.988 .921 & 14.624.964 \\
\hline
\end{tabular}

*Recursos del Fondo Medellín Ciudad para la Vida

Fuentes alternativas:

Tal como lo dijimos anteriormente es muy importante para poder llevar a cabo este sueño de ciudad encontrar otro tipo de fuentes de financiación para cada uno de los proyectos que se están considerando. A continuación describimos posibles fuentes alternativas que contribuyen en gran parte a poder estructurar financieramente los proyectos y llevarlos a cabo.

Sistema General de Regalías: Nace en el año 2012 y para los entes territoriales se convierte desde ese momento en una de las fuentes de financiación de más fácil acceso para financiar los diferentes proyectos de inversión. Entendiendo que hay diferentes fondos con objetos específicos a los cuales podemos acceder como municipio, refiriéndonos específicamente a los fondos regionales y el de ciencia y tecnología. Encontramos que esta podría ser una fuente de financiación importante para aquellos proyectos que cumplan con la normativa y con los requisitos de cada fondo. Medellín el cuatrienio anterior accedió a recursos de ciencia, tecnología e innovación a través de Ruta $\mathrm{N}$, distinguiéndose por ser uno de los municipios ejemplo en la estructuración y ejecución de este tipo de proyectos.

Nuestro compromiso es entonces fortalecer las capacidades institucionales en el marco del aprendizaje normativo y procedimental para poder acceder a estos recursos. 
Recursos provenientes del Gobierno Nacional: Medellín como la segunda ciudad más importante del país se ha constituido como uno de los grandes aliados del gobierno nacional en materia de proyectos estratégicos para éste, tal es el ejemplo del trabajo que se ha adelantado con la apuesta integral a víctimas, y al programa de retorno de las víctimas que están en Medellín a los municipios de los cuales han sido desplazados; no siendo en vano el gobierno nacional en el cuatrienio anterior aportó alrededor de 20 mil millones de pesos para este proyecto.

Es entonces como esta otra fuente de financiación también es una puerta para financiar grandes proyectos de ciudad y de carácter nacional

Superávit 2016: Con el cierre contable de la vigencia 2015 se tiene un estimado de superávit que aún no es oficial ya que se están haciendo los procedimientos internos respectivos para que contabilidad del municipio de Medellín pueda certificar dicho monto. Pero con la cifra que se tiene hasta hoy estimada se ha considerado como una posible fuente de financiación de algunos proyectos. Cabe resaltar que el superávit debe cumplir todos los procesos correspondientes ante el Honorable Concejo Municipal y hasta ese momento no se tendría la decisión del direccionamiento de estos recursos a unos proyectos específicos.

Fondo Medellín ciudad para la vida: Este fondo creado por la administración anterior con algunos proyectos en ejecución y otros proyectos en estado priorizados se convierte también en una fuente de recursos que debemos estudiar, analizar y definir para la financiación de los proyectos con un énfasis claro de poder terminar las obras en ejecución del mismo y poder encaminar el resto de los recursos a diferentes proyectos de inversión priorizados. Adicional a esto, es importante tener en cuenta que así los recursos estén en una fiducia y contablemente ya se encuentren ejecutados, la actual administración está manejando dicho fondo y está llevando a cabo toda la gestión de los proyectos correspondientes, por lo tanto por responsabilidad con la ciudadanía, es importante que hagan parte estructural del Plan de Desarrollo.

Recursos provenientes de un ente descentralizado: Un ejemplo de los recursos que pueden aportar al Plan de Desarrollo los entes descentralizados es El Metro. Dentro del plan de expansión del Metro, con recursos propios de esta entidad, y con algunos de la Alcaldía se llevarán a cabo diferentes obras para el mejoramiento del servicio del sistema de transporte público. Es entonces como un proyecto tan importante de ciudad en el marco de unos objetivos comunes, el proyecto es un proyecto de Plan de Desarrollo cuya financiación proviene de un ente como este.

Recursos de cooperación internacional: Una ciudad como Medellín donde ha sabido resurgir de un tema de violencia complejo catalogándola como una de las ciudades más peligrosas del mundo y siendo hoy un ejemplo de transformación social e institucional gracias a intervención pública, los recursos de cooperación internacional son recursos que se pueden captar no sólo para continuar con estos proyectos de transformación social sino 
para traer inversión extranjera y eventos internacionales que redunden en empleo y en mejorar la economía de una ciudad que lo necesita.

Alianzas público - privadas (APP): Con la creación de la Agencia para la gestión del paisaje y patrimonio y APP, Medellín le apuesta desde hace unos años a incentivar la vinculación del capital privado en alianza con el gobierno para llevar a cabo proyectos que den beneficios a las dos partes, al primero una rentabilidad económica, y al segundo una rentabilidad social. Hoy el mundo y el gobierno nacional han logrado identificar que esta es una fuente valida de financiación de proyectos de inversión y que con los recursos escasos del estado el sector privado y empresarial se convierten en unos aliados estratégicos para llevar desarrollo a las ciudades como lo es el ejemplo de todos los proyectos de infraestructura vial del gobierno nacional que se han hecho mediante APP.

Es claro que en este camino hay muchas cosas por aprender, pero hoy no sólo Medellín le apostando al tema, sino que contamos con el apoyo técnico del Gobierno Nacional, y es así como varios de los proyectos del Plan de Desarrollo serán financiados con este modelo.

\section{Políticas y Estrategias de Financiación}

Nuestro Plan de Desarrollo es exigente; desde el Programa de Gobierno hemos definido 11 ejes estratégicos, concebidos a partir de nuestro recorrido por la ciudad, nuestra caminata por las calles, el intercambio de experiencias con las personas que la habitan, y los comités de estudio conformados.

El conocer de primera mano las necesidades de la ciudad nos ha permitido elaborar un Plan de Desarrollo diseñado para construir la ciudad que soñamos, y por eso nuestros esfuerzos se centrarán en abordar el fortalecimiento de la legalidad y la cultura ciudadana, la recuperación de la seguridad y la convivencia, el fortalecimiento y mejoramiento de los sistemas de educación, cultura y deporte, el desarrollo de un sistema de movilidad sostenible, las condiciones para un ambiente de desarrollo económico, la recuperación del centro de la ciudad, el funcionamiento de un sistema de salud adecuado, el respeto por la diversidad y la integración con la región y el departamento.

Pero alcanzar esas metas se requiere n esfuerzo conjunto, y la ejecución de los proyectos que componen esas metas necesitan recursos económicos; de ahí que nuestra primera tarea ha sido la de garantizar, mediante un trabajo estructurado de planificación financiera, la construcción del escenario económico idóneo, prudente en la proyección de ingresos, coherente con la realidad económica del país, eficiente en el funcionamiento de la entidad, responsable con el cumplimiento de las obligaciones financieras, concebido para garantizar la sostenibilidad de la entidad en el mediano y largo plazo, y enfocado en el uso de más recursos a destinar para el componente de inversión y la construcción de nuestro sueño de ciudad, ese que recoge las ideas de todos sus habitantes. 
La construcción del Plan Financiero inicia entonces con la proyección de los ingresos de la Administración Municipal para el periodo 2016 - 2019, tarea que involucra el análisis de datos históricos, tendencias, cambios y efectos de leyes sobre los ingresos, la revisión de la coyuntura económica del momento, sus perspectivas y posibles efectos sobre el recaudo de los diferentes rubros, y la proyección de cifras mediante el uso de modelos estadísticos y econométricos, así como la revisión, validación y ajuste de las cifras finales.

Con la consolidación de los ingresos esperados a recibir en el periodo, se determinan los usos que se darán a dichos recursos; el valor total de los ingresos actúa entonces como el límite de gasto durante el mismo periodo. Se destinan los recursos necesarios para garantizar el normal funcionamiento de la entidad bajo criterios de austeridad y eficiencia, y los necesarios para el cumplimiento de las obligaciones financieras, atendiendo las directrices en materia de cobertura de riesgos para mitigar los riesgos asociados a la volatilidad del mercado financiero y cambiario.

Una vez distribuidos los componentes de funcionamiento y deuda pública, se establece el monto correspondiente al agregado de inversión, siendo éste el principal rubro del gasto de la Administración Municipal, privilegiado por la Constitución a través del Gasto Público Social.

Como resultado de este ejercicio responsable, y la interacción entre los recursos proyectados, la distribución del gasto, el estudio de las necesidades de endeudamiento y el cumplimiento de los indicadores de Ley, la ciudad de Medellín ha venido obteniendo la mejor calificación de riesgo crediticio interno -AAA- y calificación en grado de inversión a nivel externo (BBB- y Baa3) por parte de firmas como Fitch Ratings y Moody's, así como regularidad en los resultados de desempeño fiscal e integral en el ranking elaborado por el Departamento Nacional de Planeación, en el cual actualmente Medellín es la mejor ciudad capital y la segunda a nivel departamental.

\section{Estrategias}

- Fortalecimiento de procesos de fiscalización, para reducir los niveles de evasión y de elusión; queremos demostrarle a la ciudad que el cumplimiento de las obligaciones sí contribuye a la construcción de ciudad.

- La cultura tributaria como aporte al logro del Plan y mejoramiento de procesos para la recuperación del debido cobrar, a través del cobro persuasivo y coactivo, los acuerdos de pago, los cruces de cuentas y la selección de cartera. Desde la legalidad sí se contribuye al cumplimiento de los objetivos.

- Análisis minucioso de necesidades de endeudamiento, garantizando en todo momento el cumplimiento de los indicadores de Ley; la sostenibilidad financiera de la entidad también es uno de nuestros propósitos.

- Eficiencia y austeridad en gastos de funcionamiento sin el deterioro de las condiciones de operación. 
- Análisis de venta de bienes muebles o inmuebles o participación en sociedades o empresas.

- Continuidad a los procesos de actualización tecnológica que faciliten a los ciudadanos y contribuyentes el pago oportuno de las obligaciones. 


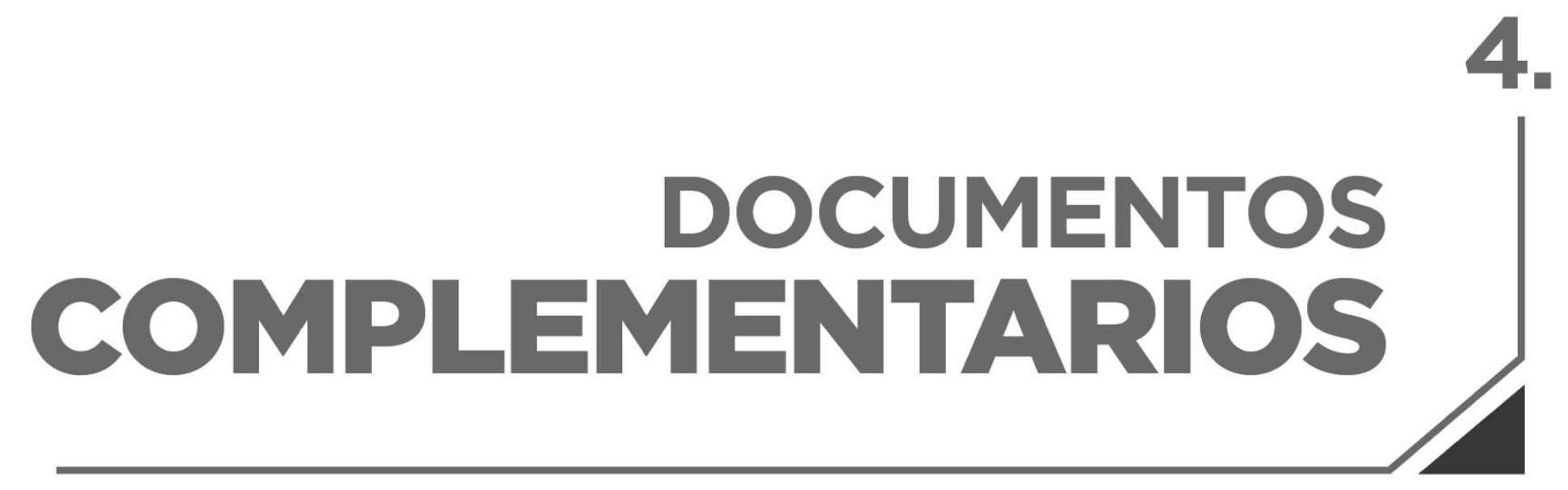




\section{- DIAGNÓSTICO DE PRIMERA INFANCIA, Y ADOLESCENCIA DE MEDELLÍN 2016 - $2019 \cdot$}

Este texto constituye un contexto para la construcción del Diagnóstico de primera infancia, infancia y adolescencia del Municipio de Medellín, contemplado artículo 204 de la Ley 1098 de 2006 Código de Infancia y Adolescencia y que debe ser presentado dentro de los primeros cuatro (4) meses del inicio del mandato.

Es por esto que en la elaboración del Plan de Desarrollo de Medellín 2016 - 2019, se ha venido recopilando suficientes insumos para entregar el texto final junto con el anteproyecto del Plan al Consejo municipal. Se cuenta con diferentes políticas públicas para la primera infancia, infancia, adolescencia y juventud, las cuales contemplan unos escenarios de participación mediante los cuales se genera la participación y confluencia de múltiples actores para el beneficio de la población y de la solución de las diferentes problemáticas. Estas son:

- Acuerdo 84 de 2006. Por el cual se adopta una política pública de Protección y Atención integral a la infancia y la adolescencia y se crea el Consejo de Política de Infancia y Adolescencia en la ciudad de Medellín.

- Acuerdo 09 de 2006. "Por el cual se establece una Política Pública para prevenir y atender las violencias sexuales que afectan a la ciudadanía, principalmente a mujeres, niños y niñas en la ciudad de Medellín".

- Acuerdo 20 de 2011. "Por medio del cual se modifica el Acuerdo 09 de 2006 y se hacen ajustes a la Política Pública para la Prevención y Atención de las violencias sexuales que afectan a la ciudadanía, principalmente a mujeres, niñas, niños y adolescentes en el Municipio de Medellín."

- Acuerdo 58 de 2011. "Por el cual se adopta una política pública de Atención Integral a la Primera Infancia Buen Comienzo, se desarrolla un Sistema de Atención Integral y se modifica el acuerdo 14 de 2004".

- Acuerdo 30 de 2013. Por medio del cual se adiciona el Acuerdo Municipal 85 de 2006, se acoge la estrategia nacional para prevenir y erradicar las peores formas de trabaja infantil y proteger al joven trabajador 2008 - 2015 o la que haga sus veces".

- Acuerdo 19 de 2014. "Por el cual se actualiza y adopta la política pública de juventud".

- Acuerdo 54 de 2015. "Por medio del cual se redefine la regulación municipal sobre la política pública de primera infancia, el programa Buen comienzo y se dictan otras disposiciones. 
De igual manera, desde el año 2012, se inició el proceso de elaboración de un Plan Docenal: "Medellín, ciudad y ruralidad de niños, niñas y adolescentes 2016-2028", que servirá de insumo fundamental para la elaboración del Diagnóstico de infancia y estrategias para el Plan de Desarrollo 2016 - 2019, a partir de una "planificación prospectiva, que consiste en situarse en un futuro posible y deseable, y desde este futuro anticipado, reflexionar sobre el presente para actuar sobre él, organizando y acelerando procesos de transformación y movilización”. 16

Este Plan Docenal, contempla al análisis situacional de infancias y adolescencias desde el enfoque de derechos con perspectiva territorial en Medellín 2015. En este se realiza una aproximación sociodemográfica y desde las categorías de derechos: Existencia, desarrollo integral, ciudadanía, protección. También contempla un componente estratégico programático con el cual gestionar las problemáticas identificadas, a corto, mediano y largo plazo.

A su vez, sobre el diagnóstico de la situación de la niñez y la adolescencia la Procuraduría General de la Nación expidió la Circular 002 de febrero 6 de 2016, en donde establece unas directrices a tener en cuenta como: la información entregada para la Rendición Pública de Cuentas del año 2012 - 2015 mediante el aplicativo diseñado para la vigilancia superior a la gestión pública territorial definido por ese Ministerio público; el enfoque del ciclo de vida y el enfoque de garantía y restablecimiento de derechos; y los Objetivos de Desarrollo Sostenible con los cuales se va a comprometer, entre otros.

El Instituto Colombiano de Bienestar Familiar ICBF, como entidad coordinadora del Sistema Nacional de Bienestar Familiar, preparó los "Lineamientos para la inclusión de la primera infancia, la infancia y la adolescencia en los planes territoriales de desarrollo" (enero 29 de 2016), e inició la preparación técnica de los equipos responsables en los municipios. Estos definen una serie de pasos para lograr una descripción de la situación actual de la entidad territorial y el diagnóstico es la base para construir la situación deseada.

Es así que, acogiendo las comunicaciones, directrices y circulares de la Procuraduría General de la Nación y la Procuraduría delegada para la niñez, la infancia y la familia, expedidas para la elaboración del diagnóstico y contemplando lo realizado para el proceso de rendición pública de cuentas 2015, se pretende contemplar en el texto:

PRIMERA INFANCIA, INFANCIA Y ADOLESCENCIA EN EL MUNICIPIO DE MEDELLÍN: Análisis demográfico: distribución de la población por edad, sexo, etnia, discapacidad, desplazamiento forzado, comunas y corregimientos.

${ }^{16}$ Plan docenal: Medellín, ciudad y ruralidad de niños, niñas y adolescentes 2016 - 2028. Pág. 58 
ANÁLISIS POR CATEGORÍA DE DERECHO: Análisis de cada uno de los principales problemas por derecho, sustentado en datos cuantitativos y utilizando los indicadores propuestos por la estrategia de Hechos y Derechos. Estos indicadores deben estar desagregados por sexo, edad, etnia, comunas y corregimientos. Se debe realizar el análisis de los últimos 4 años: derechos a la Existencia, derechos al Desarrollo, derechos a la Ciudadanía y derechos a la protección

RETOS PARA EL CUATRIENIO 2016 - 2019: De acuerdo a los problemas analizados de en cada uno de los derechos, plantear cuales son los retos para el cuatrienio, que se debe priorizar, qué situaciones urgentes se presentan en la ciudad y los programas y proyectos que se deben generar para ser atendidas.

Los niños, niñas y adolescentes de Medellín, sin importar sus condiciones socioeconómicas, necesitan acciones y atenciones sociales, políticas, económicas y culturales contundentes que generen ambientes y entornos protectores para su adecuado desarrollo. El Plan Docenal: Medellín ciudad y ruralidad de niños, niñas y adolescentes 2016-2028, pretende generar procesos de transformación en imaginarios, discursividades y prácticas para el reconocimiento de niños, niñas y adolescentes como sujetos políticos, en aras de crear las condiciones con las que ellos, ellas y sus familias, gocen de una vida digna que les permita la potenciación de sus capacidades humanas y en armonía con su entorno natural, familiar y social. El Análisis Situacional se construyó a partir de voces ciudadanas, revisión documental y el seguimiento a indicadores identificando el estado actual de las áreas de derechos de niños, niñas y adolescentes de las 16 comunas y 5 corregimientos desde una perspectiva territorial.

Con el fin de cumplir oportunamente con lo encomendado a través de la Constitución y la Ley, se presentan las siguientes cifras, incluidas en el Analisis Situacional Del Plan Docenal17, elaborado por la Secretaría de Inclusion Social y Familia que expone los principales elementos encontrados para ser incluidos en el Diagnóstico (versión final) que se entregará con el Anteproyecto del Plan de Desarrollo en el mes de mayo de 2016, al Concejo Municipal:

En Medellín, según proyecciones del DANE, en el año 2015 existe una población total de 587.836 niños, niñas y adolescentes entre los 0 y los 18 años de edad, que representan el $24 \%$ del total de habitantes.

De este total 300.188 son hombres (51\%) y 287.648 son mujeres (49\%).

En primera infancia ( $0-5$ años) son 175.854 (30\% del total de población de niños, niñas y adolescentes); infancia (6-12 años) 211.360 (36\%), y adolescencia (13 a 18 años) 200.622, (34\%).

17 Convenio CINDE - Unidad de Niñez 2015. 
En el año 2013 el 69\% de la población de niños, niñas y adolescentes encuestada y sisbenizada obtuvo menos de 50 puntos en una escala de 0 a 100 y el $38.25 \%$ están clasificados con los puntajes más bajos (0.01 - 36, 32).

El Sistema General de Seguridad Social en Salud acoge en sus regímenes el 2014, el $98.6 \%$ de las personas menores de 18 años de Medellín. Aún hay niños, niñas y adolescentes en la ciudad y la ruralidad que se encuentran por fuera del sistema.

En el año 2014 la tasa de mortalidad en niños y niñas menores de 5 años representó el $8.1 \%$, lo que indica que en Medellín aún se registran muertes evitables.

Según el registro para la localización y caracterización de personas en situación de discapacidad 2010-2011 de la Secretaría de Salud, existen en la ciudad 47.252 personas con algún tipo de discapacidad, de éstos, 6.552 son niños, niñas y adolescentes ( $14.5 \%$ de la población identificada).

El Perfil Alimentario y Nutricional de Medellín, realizado en el 2010, mostró para la ciudad un $41,4 \%$ de hogares con seguridad alimentaria y el $58.6 \%$ con inseguridad alimentaria.

La Personería de Medellín, encontró que 34 instituciones educativas (52,3 $\%$ ) se ubican en zonas afectadas por fronteras invisibles y zonas controladas por bandas u organizaciones delincuenciales, siendo esta una de las mayores causas de deserción escolar.

El 99\% de los niños atendidos por el programa Buen Comienzo en el 2013 se insertaron exitosamente en la educación regular en el 2014.

La Violencia intrafamiliar (toda forma de abuso, discriminación y agresión física, verbal, psicológica y sexual) ocurrida en el núcleo familiar, según el Informe Forensis (Instituto Nacional de Medicina Legal y Ciencias Forenses, 2014) presentó una tasa de 37,4 para Medellín. Este indicador sobre niños, niñas y adolescentes ha registrado una reducción de 17,4 casos por cada 100.000 niños, niñas y adolescentes, debido a que pasó de 53,8 en 2011 a 37,4 en 2014.

Según el mapeo de escenarios de explotación sexual comercial de niños, niñas y adolescentes (ESCNNA) realizado en el 2012 en las comunas 4 y 10 existen 11 sectores con presencia de ESCNNA y, en promedio, 12 niñas, niños y adolescentes explotados sexual y comercialmente por sector.

La Personería de Medellín en 2014 recibió 1.774 declaraciones en el Formato Único de Declaración -FUD- por desplazamiento forzado intraurbano; y reporta para el año 2013 las comunas 13 (San Javier), 8 (Villa Hermosa), 1 (Popular), 3 (Manrique) y 7 (Robledo) como las principales comunas expulsoras. 
En Medellín aún no se tienen cifras actualizadas sobre el fenómeno del trabajo infantil, según el DANE (2014) 9.800 niñas, niños y adolescentes entre 5 y 17 años en Medellín participaron en una actividad remunerada o no. En comparación con la investigación "Una Generación Libre y con Derechos" que señaló que "en Medellín y su Área Metropolitana el 6.3\% de niños y niñas se encontraba trabajando, esto es 43.160 ; el 1.4\% buscaba trabajo y el $54 \%$ dedicó tiempo a oficios del hogar.

De acuerdo a la caracterización de niños, niñas y adolescentes habitantes de calle realizada durante el 2014 en Medellín se registraron 71 menores de 17 años y no se registró ninguno por debajo de los 10 años.

Según los Informes de la Secretaría de Seguridad de Medellín -SISC- las denuncias por abuso sexual han aumentado paulatinamente entre 2011 y 2014. Del total de denuncias por abuso sexual, el $86 \%$ de los casos corresponde a niñas y adolescentes mujeres. (En este flagelo, se habla de denuncias, porque resulta complejo hacer afirmaciones sobre aumento o disminución de casos, considerando el alto porcentaje de sub-registro que existe a nivel nacional).

En Medellín para el año 2014, según el informe de la Personería, el 34\% del total de personas desaparecidas en la ciudad (644) corresponde a niños, niñas o adolescentes (243); el $66 \%$ son niñas y adolescentes mujeres (161) y $34 \%$ son niños y adolescentes hombres (82).

La tasa de homicidios de los niños y las niñas de $\mathrm{O}$ a 5 años que se registra desde el año 2011 no ha superado los 1,7 homicidios por cada 100.000 niños y niñas de esta edad; para los niños y las niñas de 6 a 11 años en el año 2014 se redujo a una tasa de 1,1 homicidios por cada 100.000 niños y niñas. Para los y las adolescentes de 12 a 17 años ha mostrado una tendencia a la disminución entre los años 2012 y 2014.

Los casos de lesiones personales, analizadas por el Informe Forensis 2014, reportó en Medellín la denuncia de 6.898 víctimas de lesiones personales (no se especifica por grupo de edad) y 1.379 casos adicionales por maltrato en niños y niñas de la primera infancia.

Con base en el informe de garantía de derechos de primera infancia, infancia, adolescencia y juventud 2012-2015, en el marco de la rendición pública de cuentas, durante los años 2013 y 2014, 5.004 adolescentes entre 14 y 17 años, infractores de la Ley Penal, fueron vinculados a procesos judiciales en Medellín. 


\section{- BIBLIOgRAFÍA •}

Federico Guitierrez Zuluaga. (2015). Programa de Gobierno: Porque creemos en Medellín.

Corporvisionarios y Alcaldía de Medellín. (2015). Encuesta de Cultura Ciudadana.

Mockus, A. (2002). La educación para aprender a vivir juntos. Convivencia como armonización de ley, moral y cultura. Recuperado de: Perspectivas, XXXII (1).

García Villegas, M. (2009). Caracterización del régimen político colombiano (1956- 2008). En M. García Villegas, \& J. Revelo Rebolledo, Mayorías sin democracia. Desequilibrio de poderes y Estado de derecho en Colombia, 2002-2009 (p. 17-75). Bogotá: Centro de estudios de Derecho Justicia y Sociedad De Justicia.

Secretaría de la Juventud, Alcaldía de Medellín. (2015). Informe de Gestión Secretaría de la Juventud. Medellín.

Secretaría de Seguridad y Invamer y Universidad Eafit. (2015). Encuesta de Percepción y Victimización de Medellín. Medellín

Barranquilla Cómo Vamos. (2015). Encuesta de Percepción Ciudadana. Recuperado de: http://www.barranquillacomovamos.org/

Bogotá Cómo Vamos. (2015). Encuesta de Percepción Ciudadana. Recuperado de: http://www.bogotacomovamos.org/

Cali Cómo Vamos. (2015). Encuesta de Percepción Ciudadana. Recuperado de: http://www.calicomovamos.org/ 
Periódico El Tiempo. (2016). Homicidios en el 2015 en Colombia. Recuperado de: http://www.eltiempo.com/politica/justicia/homicidios-en-el-2015en-colombia/16471335

Alcaldía de Medellín (2015). Índice Multidimensional de Condiciones de Vida IMCV de 2014. Medellín.

Departamento Administrativo Nacional de Estadística - DANE. (2015) Proyecciones en el Centro Metropolitano. Medellín.

Secretaría de Salud de Medellín \& DANE. (2015). Certificados de Estadísticas Vitales. Medellín

Alcaldía de Medellín. (2015). Informe de Gestión 2012 - 2015. Medellín

Alcaldía de Medellín. (2015). Plan de Seguridad Alimentaria 2016-2028. Medellín

Secretaría de Salud de Medellín. (2012). Diagnóstico de la demanda, oferta y déficit de servicios de salud 2011. Medellín.

Alcaldía de Medellín (2015). Análisis de la Situación de Salud de Medellín 2014.

Acemoglu, D., \& Robinson, J. A. (2014). Por qué fracasan los países. Mexico: Editorial Planeta.

Alcaldía de Medellín. (2011). Plan de Desarrollo Cultural de Medellín 20112020. Medellín una ciudad que se piensa y se construye desde la cultura. Medellín: Alcaldía de Medellín.

Alcaldía de Medellín. (2014). Documento Técnico de Soporte (DTS). Formulación Plan de Ordenamiento Territorial de Medellín (Vol. Tomo IVa). Medellín, Colombia: Alcaldía de Medellín.

Piketty, T. (2013). El capital en el siglo XXI. México: Fondo de Cultura Económica. 
Sanchez, R. (2013). Enfoques, conceptos y metodologías de medición de la informalidad laboral en Colombia. Lecturas de Economía(79), 943.

Revista América Economía. (2015) Ranking de la mejores ciudades para hacer negocios para la ciudad de Medellín.

Secretaría de Educación. (2015). Cobertura por niveles educativos 20042014

Alcaldía de Medellín. (2014). Plan de Ordenamiento Territorial (POT, Acuerdo 48 de 2014).

Departamento Administrativo de Planeación, Área Metropolitana del Valle de Aburrá \& Universidad EAFIT. (2011) Plan BIO 2030.

Medellín Cómo Vamos. (2015). Encuesta de Percepción Ciudadana.

Alcaldía de Medellín. (2015). Encuesta de Calidad de Vida 2014. Medellín.

Subdirección de Información y Evaluación estratégica. DAP. (2015). Base de datos certificadas SISBEN 2013 -2014. (Versión III). Medellín. 


\section{- LISTADO DE GRÁFICOS•}

Gráfica 1: Estructura anteproyecto Plan de Desarrollo 2016 - 2019

Distribución por comunas y corregimientos en la ciudad de Medellín, 2014

Gráfico 2: Casos reportados de desplazamiento forzado intraurbano en Medellín. Periodo 20072014

Distribución por comunas y corregimientos, 2015

Gráfico 3. Índice Multidimensional de Condiciones de Vida, 2010-2014

Gráfico 4. Coeficiente de Gini, Medellín-AM, 2002-2005 y 2008-2014

Gráfico 5. Indicadores de Pobreza monetaria extrema y moderada para Medellín-AM (2002-2005

y 2008-2014), e Índice de Pobreza Multidimensional (IPM) de Medellín, 2012-2014

Gráfica 6. Participación en espacios públicos durante el último año.

Grafica 7. Ley, moral y cultura. ECC Medellín 2015

Gráfico 8. Percepción de seguridad y convivencia ciudadana, por niveles y según barrio, comunacorregimiento y total ciudad, 2015

Gráfico 9. Nivel de Victimización de la población en Medellín, 2015

Gráfico 10. Tasa y casos de homicidio en Medellín, 1975 - 2015

Gráfico 11. Hurtos

Gráfico 12. Goce de derechos en las víctimas del conflicto armado en Colombia, homologable para

la lectura de derechos en Medellín

Gráfico 13. Tasa de Mortalidad en menores de cinco años

Gráfico 154. Tasa neta de cobertura por niveles educativos, 2004-2014

Gráfico 15. Evolución de Medellín, Bogotá y Cali en el ranking de las mejores ciudades para hacer negocios en América Latina 2001-2015

Gráfico 16. Estado de los diferentes indicadores del ranking de la mejores ciudades para hacer negocios para la ciudad de Medellín, 2015

Gráfico 17. Evolución del PIB de Medellín a precios constantes de 2005 (2006-2013p) y

comparativo del crecimiento de Medellín, Antioquia y Nacional

Gráfico 18. Participación del PIB por ramas de actividad económica, 2013

Gráfico 19: Espacio Público efectivo por habitante y peatonal por habitante, 2008 - 2014

Gráfico 20 Satisfacción con el espacio público en la ciudad, 2009 - 2014

Gráfico 21: Viviendas según estrato socioeconómico, 2014

Gráfico 22: Propiedad sobre la vivienda que se habita, 2014

Gráfico 23: Servicios públicos en viviendas2014

\section{- LISTADO DE MAPAS•}

Mapa 1: Coeficiente de GINI para la ciudad de Medellín

Mapa 2: Índice Multidimensional de condiciones de Vida.

Mapa 3: Percepción ciudadana de seguridad en Medellín.

Mapa 4. Percepción de confianza en las instituciones por comuna y corregimiento 2014

Mapa 5. Tasa de homicidios por cien mil millones de habitantes por comuna y corregimiento 2015

Mapa 6: Áreas de intervención estratégica y Macroproyectos

Mapa 7: Estructura ecológica de Medellín

Mapa 8: Zonificación de áreas de amenaza por movimientos en masa.

\section{- LISTADO DE TABLAS•}

Tabla 1. Comparación de indicadores de cultura ciudadana en Medellín 2007 a 2015

Tabla 2: Bienes inmuebles 


\section{- CRÉDITOS•}

Las fotografías utilizadas en este documento corresponden al registro visual de las actividades de participación para la construcción del anteproyecto del Plan de Desarrollo 2016 - 2019, Medellín cuenta con vos.

Fotos: Andrés Zapata - Alcaldía de Medellín / Andrés Henao - RutaN 